\title{
Geochemical and Rheological Constraints on the Dynamics of the Oceanic Upper Mantle
}

\author{
by \\ Jessica Mendelsohn Warren
}

M.Sci., Earth Sciences, University of Cambridge, 2000

B.A., Natural Sciences, University of Cambridge, 1999

Submitted to the MIT/WHOI Joint Program in Marine Geology and Geophysics in partial fulfillment of the requirements for the degree of

Doctor of Philosophy

at the

\section{MASSACHUSETTS INSTITUTE OF TECHNOLOGY}

and the

WOODS HOLE OCEANOGRAPHIC INSTITUTION

September 2007

(c) Jessica Mendelsohn Warren, MMVII. All rights reserved.

The author hereby grants to MIT and WHOI permission to reproduce and distribute publicly paper and electronic copies of this thesis document in whole or in part in any medium now known or hereafter created.

Author .

MIT/WHOI Joint-Rrogram in Marine Geology and Geophysics

August 30, 2007

Certified by ....

Cro

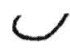

Nobumichi Shimizu

Senior Scientist, Woods Hole Oceanographic Institution

Thesis Supervisor

Certified by

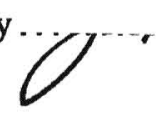

$\checkmark$

Gregory Hirth

Associate Scientist, Woods Hole Oceanographic Institution

Thesis Supervisor

Certified by

Henry J. B. Dick

Senior Scientist, Woods Hole Oceanographic Institution

Thesis Supervisor

Accepted by

Gregory Hirth

Chairman, Joint Committee for Marine Geology and Geophysics MIT/WHOI Joint Program 


\title{
Geochemical and Rheological Constraints on the Dynamics of the Oceanic Upper Mantle
}

\author{
by \\ Jessica Mendelsohn Warren
Submitted to the MIT/WHOI Joint Program in Marine Geology and Geophysics on August 30, 2007, in partial fulfillment of the requirements for the degree of
Doctor of Philosophy

\begin{abstract}
I provide constraints on mantle convection through observations of the rheology and composition of the oceanic upper mantle. Convection cannot be directly observed, yet is a fundamental part of the plate tectonic cycle. Relative motion among plates is accommodated by localized deformation at their boundaries. I demonstrate that in the ductile regime, strain localization occurs when different mineral phases are mixed together, limiting grain annealing. Upper mantle flow is by dislocation creep, resulting in seismic anisotropy due to mineral alignment. I use a shear zone in the Josephine Peridotite to quantify the relationship between mineral orientation and shear strain, providing an improved framework for the interpretation of seismic anisotropy. The upper mantle is generally assumed to be homogeneous in composition. From detailed isotopic and chemical analyses of abyssal peridotites from the Southwest Indian Ridge, I show that the mantle is heterogeneous at a range of length-scales. Abyssal peridotites recovered at ocean ridges are generally interpreted as the depleted residues of melt extraction. I find that melt-rock reaction is a significant part of the melt extraction process, modifying the composition of the lithospheric mantle. The generation of heterogeneous lithosphere provides a source for asthenospheric heterogeneity, via subduction and mantle convection.
\end{abstract}

Thesis Supervisors:

Nobumichi Shimizu, Senior Scientist, Woods Hole Oceanographic Institution

Gregory Hirth, Associate Scientist, Woods Hole Oceanographic Institution

Henry J. B. Dick, Senior Scientist, Woods Hole Oceanographic Institution 


\section{Acknowledgments}

I have been fortunate at WHOI to have three wonderful advisors: Nobu Shimizu, Greg Hirth, and Henry Dick. They have each provided unique insights into the upper mantle while demonstrating unique styles of advising. Henry introduced me to abyssal peridotites, took me out on three research cruises and spent hours expounding on ultra-slow spreading, dredging techniques and right-wing politics. Nobu gave me free reign on the ion probe, a solid background in geochemistry, 26 hand-picked mineral separates and much-needed left-wing literature. Greg successfully diverted my attention towards rheology and rock mechanics, though not the Red Sox, explaining everything from collecting oriented samples to the intricacies of deformation mechanisms to the broader contexts of mantle rheology. All three have been extremely supportive and generous in their time and funding.

My committee has been an invaluable source of knowledge and patience, particularly during the last 6 months of writing. Wenlu Zhu, as committee chair, has provided guidance throughout. As a committee and as individuals, Fred Frey, Glenn Gaetani, Stan Hart and Peter Kelemen have always made themselves available to answer questions, provide ideas and strengthen my understanding of mantle processes. Fred kept me on track with trace elements, Glenn gave clear explanations of thermodynamics, Stan combed through my isotope data and Peter expanded my view of the physical mantle.

I have benefited from interactions with a variety of scientists and professors at WHOI and MIT. Marc Kurz improved my education in helium isotopes. Jurek Blusztajn attempted to improve my understanding of osmium while actually improving my knowledge of general isotope analytical techniques. Tim Grove has always been willing to discuss thermodynamics and obscure minerals. Jeff McGuire pushed me to place rock deformation in a context relevant to seismologists. Mark Behn and Laurent Montési patiently explained mantle flow modeling while making available their own model results. Susan Humphris chaired my generals committee and has not stopped providing advice and support since then. Karen Hanghøj, Jian Lin, Jerry McManus, Brian Tucholke, Ken Sims, Adam Soule, and Jack Whitehead have always been willing to answer questions and share their research.

The isotope and trace element work in Chapter 4 of this thesis would not have been completed without the generosity of Eizo Nakamura, who invited me to spend over 4 months in his lab at the Institute for Study of the Earth's Interior in Misasa, Japan. I am indebted to Chie Sakaguchi, who trained me in the clean room, shared her extensive knowledge of isotope separation techniques and was both a patient teacher and a friend. Yoshiko Nakano facilitated the coordination of my visits and made sure that I learnt to play badminton. The members of the Pheasant Memorial Lab were all extremely helpful and hospitable. In particular, my visits would have been much less fun without Maria Marin, Lucy Lu and Masako Uyama.

Three chapters of this thesis relied on samples collected by the hard work of the captain 
and crew of eight research cruises. In addition, I have benefitted from free access to the WHOI rock archive, which, with samples collected over the past 40 years, represents the work of innumerable captains, crews and scientists on many ships and expeditions. The analytical work in Chapters 2 and 3 of my thesis would not have been completed without Louie Kerr at MBL, who kept the SEM running and replaced numerous filaments. Chapter 5 of my thesis required the WHOI $3 \mathrm{f}$ ion probe to run smoothly, which in turn required the collective expertise of Nobu, Graham Layne and Pete Landry. Finally, collection of the microprobe data in Chapters 4 and 5 was aided by Nilanjan Chatterjee at MIT.

The MIT/WHOI Joint Program provides fabulous support for its graduate students in the form of the Academic Programs Office. Julia Westwater and Marsha Gomes solved any problem I encountered, always while making me laugh. I was fortunate to interact with two deans while at WHOI, Jim Yoder and John Farrington. In addition, the Joint Program experience would not have been complete without Ronni Schwartz at MIT. Finally, the Geology and Geophysics administrative staff - in particular Fran Halbrooks, Pam Foster, Lynn Stellrecht and Maryanne F. Ferreira - are always willing to help students.

Outside of the Joint Program, I have been fortunate to interact with a variety of scientists. I met Ian MacGregor before I understood the meaning of the word geology. He has been a source of encouragement, advice and mentoring over the past 13 years. My early science training was the result of four teachers, Mrs. Goshko, Mrs. Katbab, Mr. Hoare and Mr. Buck. I have a deep respect and appreciation for their skills at and commitment to teaching. As an undergraduate at the Department of Earth Sciences at Cambridge University, I benefited from supervision by David Pyle and Marion Holness. My first experience of research was an undergraduate summer spent at the Smithsonian Department of Mineral Sciences, working with Tom Simkin and Sorena Sorensen. During my first research cruise, I met Bobbie John and Mike Cheadle from the University of Wyoming and ever since they have been a counterbalance to my WHOI view of life-as-a-scientist.

The students who have been with me in graduate school have been a continual source of knowledge, ideas, support, laughter, and good food. Clare Williams has been a great friend, classmate, flat-mate, and true Brit. Jeff Standish and Margaret Boettcher, as elder students who shared their advisors with me, have always been willing to share their own knowledge and time. Matt Jackson is forgiven for never not talking about geochemistry because of all the insight he shares. Rachel Stanley, Anna Michel, Greg Gerbi, Elke Hodson, Mea Cook, Cara Santelli, Linda Kalnejais, Luc Mehl, Nick Austin, Emily Van Ark, Brian deMartin, Melanie Fewings, Andrew Mosedale, Carolyn Walker, Petra Klepac, Rhea Workman, Amy Draut, Seth John, Stephen Licht, Trish Gregg, Janelle Homburg, Kay Achenbach, Elena Miranda, and Graham Baines have all provided cheerful camaraderie over the years. Finally, the support of the WGals has been invaluable this past year and I hope it continues for years to come.

I thank my parents, Margaret and Colin, who have supported me in whatever I have 
endeavored to do. Education is important to them and in giving me the best education they could provide, they made it important to me too. My brothers, Jolin and Nigel, and my sister-in-law, Susan, have also supported me, even if their excitement for what I do is more for the amusement of watching someone look at rocks than from a direct interest in rocks. My grandmother, aunts and the rest of my extended family have cheered me on for many years.

The last, but most important, person I would like to acknowledge is Carlos Moffat Varas, who showed up on my porch during my first summer in Woods Hole and hasn't left since. I don't know what the last 6 years would have been like without him. He has counseled me in everything from Matlab to negotiation tactics to politics and has provided unswerving encouragement when I have most needed it. He made me laugh from the beginning and kept me smiling at the end.

This work has been supported financially by a variety of sources, including a Hollister Fellowship from WHOI, the Richard Vanstone Fund at WHOI and student travel assistance funds at both WHOI and MIT. Funding from the National Science Foundation was provided by grants OCE-0526905 and OCE-0624408 to H.J.B.D., EAR-0230267, EAR0405709 and EAR-0409609 to G.H., and EAR-0115433 and EAR-0106578 to N.S. Research at ISEI, Japan, was supported by COE-21 funding to E.N. 


\section{Contents}

1 Introduction 15

1.1 Rheological Constraints . . . . . . . . . . . . . . . . . . . . 15

1.2 Geochemical Constraints . . . . . . . . . . . . . . . . 17

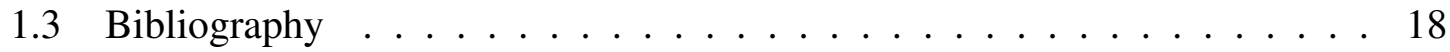

2 Grain Size Sensitive Deformation Mechanisms in Naturally Deformed Peridotites 21

2.1 Introduction . . . . . . . . . . . . . . . . . 22

2.2 Methods . . . . . . . . . . . . . . . . . . . . . . . . . 23

2.3 Results. . . . . . . . . . . . . . . . . . . . . 25

2.4 Discussion. . . . . . . . . . . . . . . . . . . . . . . . . . . 27

2.4 .1 Fabric variations with grain size $\ldots \ldots \ldots \ldots . \ldots . \ldots 27$

2.4 .2 Deformation mechanism maps . . . . . . . . . . . . . . . . . . . 29

2.4 .3 Recrystallization and grain boundary pinning . . . . . . . . . 31

2.4 .4 Strain localization . . . . . . . . . . . . . . . . . . . . . 32

2.4 .5 Relationship of mylonites to earthquake processes $\ldots \ldots \ldots$. . . 34

2.4 .6 Mantle anisotropy $\ldots \ldots \ldots \ldots \ldots \ldots \ldots$

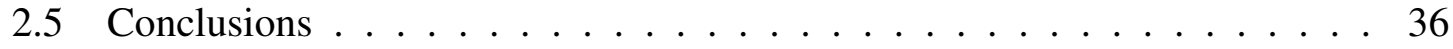

2.6 Bibliography $\ldots \ldots \ldots \ldots \ldots \ldots \ldots \ldots$

3 A Natural Example of Olivine LPO Variation With Shear Strain 49

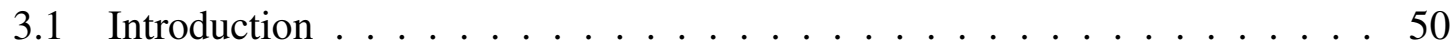

3.2 Methods . . . . . . . . . . . . . . . . . . . . . . . . . 53

3.3 Results . . . . . . . . . . . . . . . . . . . 55

3.4 Discussion . . . . . . . . . . . . . . . . . . . . . . . 58

3.4 .1 Comparison to LPO evolution models . . . . . . . . . . . . . . 59

3.4 .2 Active slip systems and the pre-existing LPO . . . . . . . . 61

3.4 .3 LPO Strength . . . . . . . . . . . . . . . . . . 63

3.4 .4 Grain size variation and recrystallization. . . . . . . . . . . . 65

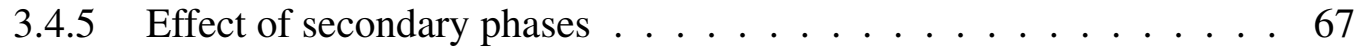

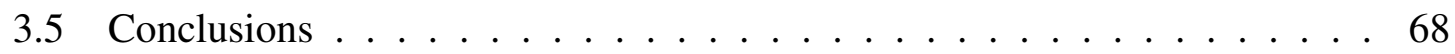

3.6 Bibliography $\ldots \ldots \ldots \ldots \ldots \ldots \ldots$ 
4 An Assessment of Mantle Heterogeneity and Depletion Based on Abyssal Peridotite Isotope and Trace Element Compositions 85

4.1 Introduction . . . . . . . . . . . . . . . . 86

4.2 Methods . . . . . . . . . . . . . . . . . . . . . . . . . . . 89

4.2 .1 Sample selection and characteristics . . . . . . . . . . . . . 89

$4.2 .2 \quad$ Modal analyses . . . . . . . . . . . . . . . . . 91

$4.2 .3 \quad$ Chemical analyses . . . . . . . . . . . . . . . . . . 91

4.3 Results . . . . . . . . . . . . . . . . . . . 96

4.3 .1 Data quality . . . . . . . . . . . . . . . . . . . . . . 96

4.3 .2 Modes and petrography . . . . . . . . . . . . . . . . . . . . . . . . . . . . . . . . . 98

4.3 .3 Trace elements . . . . . . . . . . . . . . . . . . . . . . . . . 99

4.3 .4 Isotopes . . . . . . . . . . . . . . . . . . . 100

4.4 Discussion . . . . . . . . . . . . . . . . . . . . . 103

4.4 .1 Partition coefficients . . . . . . . . . . . . . 103

$4.4 .2 \quad$ Isotopic disequilibrium between Cpx and Opx . . . . . . . . . . . . 105

4.4 .3 Radiogenic ingrowth . . . . . . . . . . . . . . . . . . . . . . . . . . . . 107

4.4 .4 Origin of the pyroxenite veins . . . . . . . . . . . . . . . . . 110

$4.4 .5 \quad$ Relationship between peridotites and basalts . . . . . . . . . 113

4.4.6 Variation of isotopic composition with peridotite melt depletion . . 116

4.4 .7 Implications for mantle composition . . . . . . . . . . . . . . 119

4.5 Conclusions . . . . . . . . . . . . . . . . . . . . 123

Appendix 4.A Major elements . . . . . . . . . . . . . . . . . . . . . . . . . . . . . . . . . . . . . . . . . . . .

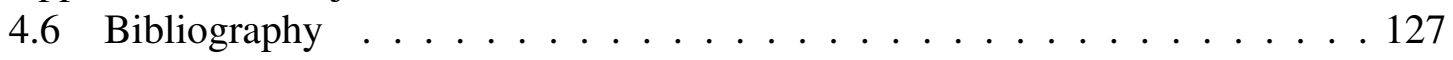

5 Variations in Abyssal Peridotite Composition: Implications for Oceanic Upper

Mantle Composition and Processes 165

5.1 Introduction . . . . . . . . . . . . . . . . 166

5.2 Methods . . . . . . . . . . . . . . . . . . . . . . . . . 169

5.3 Ion probe data quality . . . . . . . . . . . . . . . . 171

5.4 Results . . . . . . . . . . . . . . . . . . . . 173

5.5 Discussion . . . . . . . . . . . . . . . . 176

5.5.1 Justification for the use of Cpx to interpret whole-rock processes . . 176

5.5 .2 Mechanisms of melt-rock reaction . . . . . . . . . . . . . 177

5.5.3 Length-scales of peridotite variations and their origins . . . . . . . 180

$5.5 .4 \quad$ Estimates of degree of melting . . . . . . . . . . . . . . . . 189

5.5.5 Towards an understanding of mantle initial composition and regional variability . . . . . . . . . . . . . . . . 193

5.6 Conclusions . . . . . . . . . . . . . . . . . . . . . . . . . . . 194

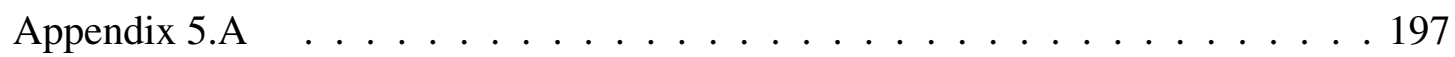

Appendix 5.B . . . . . . . . . . . . . . . . . . . 197

Appendix 5.C . . . . . . . . . . . . . . . . . . . . . . 198

Appendix 5.D . . . . . . . . . . . . . . . . . . . . . . . 199

5.7 Bibliography . . . . . . . . . . . . . . . . 200 


\section{List of Figures}

2.1 Photomicrographs of an ultra-mylonite peridotite . . . . . . . . . . . 41

2.2 EBSD orientation maps and pole figures . . . . . . . . . . . . . . . . 42

2.3 Olivine orientations in coarser grained areas . . . . . . . . . . . . . . 44

$2.4 \quad$ Olivine orientations in finer grained areas . . . . . . . . . . . . . . 45

2.5 Olivine deformation mechanism map and strain rate variation with grain size 46

$2.6 \quad$ Variation of shear zone viscosity with temperature . . . . . . . . . . . . 47

2.7 Comparison of mylonite strain rates to tectonic processes . . . . . . . . . . 48

3.1 Photo of a Josephine shear zone . . . . . . . . . . . . . . . . 74

3.2 Shear zone cross-section, stereonet and strain calculation . . . . . . . . . 75

3.3 Photomicrographs and grain size distributions at low and high strain . . . . 76

$3.4 \quad$ EBSD maps and inverse pole figures at low and high strain . . . . . . . . 77

3.5 Olivine pole figures and misorientation distributions for the harzburgites . . 78

$3.6 \quad$ Olivine pole figure and misorientation distribution for the dunite . . . . . . 79

3.7 Variation of the olivine [100] maxima as a function of shear strain . . . . . 80

3.8 Variation of fabric strength with shear strain . . . . . . . . . . . . 81

3.9 Comparison of the $\mathrm{J}$ - and $\mathrm{M}$ - fabric strength indices . . . . . . . . . . . . . 82

3.10 The olivine piezometer . . . . . . . . . . . . . . 82

4.1 Location maps . . . . . . . . . . . . . . . . . . . . . . . 136

$4.2 \quad$ Sample photos . . . . . . . . . . . . . . . . . . . . . . 137

4.3 Sample modal maps . . . . . . . . . . . . . . . . . . . . . . . 138

4.4 Comparison of ICPMS and TIMS data . . . . . . . . . . . . . . . . . . 139

4.5 Peridotite REE variations . . . . . . . . . . . . . . . . . . . . . . . . . 140

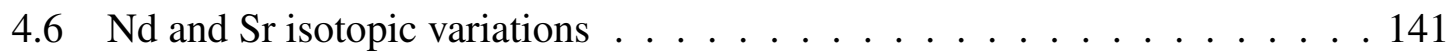

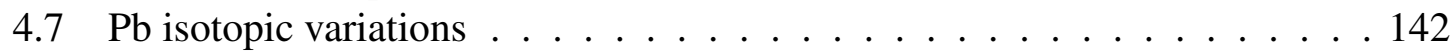

4.8 Cpx/Opx partition coefficients . . . . . . . . . . . . . . . . . . . . . 143

4.9 Isochrons . . . . . . . . . . . . . . . . . . . . . . . . . . . 144

4.10 Radiogenic ingrowth . . . . . . . . . . . . . . . . . . . . 145

4.11 Oblique Segment isotopic variations . . . . . . . . . . . . . . . . 146

4.12 Atlantis II Fracture Zone isotopic variations . . . . . . . . . . . . . . . . 147

4.13 Histograms of peridotite and basalt Nd isotopes . . . . . . . . . . . . . . 148

4.14 Variation of Nd isotopes with indices of peridotite melt depletion . . . . . . 149

$4.15 \mathrm{Nd}$ isotope and concentration variations . . . . . . . . . . . . . 150

4.16 Mantle depletion models . . . . . . . . . . . . . . . . 151 
4.17 Mantle depletion models . . . . . . . . . . . . . . . . . . . . 152

4.All Spinel major element variations . . . . . . . . . . . . . . . . . . 153

$4 . \mathrm{A} 2$ Cpx major element variations . . . . . . . . . . . . . . . . . . . . 154

5.1 Global distribution of depleted and veined abyssal peridotites . . . . . . . . 210

5.2 Peridotite spreading rate variations . . . . . . . . . . . . . 211

5.3 Maps of the Oblique/Orthogonal Segments and Atlantis II Fracture Zone. . 212

5.4 Comparison of duplicate sample ion probe analyses . . . . . . . . . . 213

5.5 Comparison of ion probe, ICP-MS, and TIMS data . . . . . . . . . . . . 214

5.6 Comparison ion probe and electron microprobe data . . . . . . . . . . . . . 215

5.7 Variation of Spinel Cr\# with Mg\# . . . . . . . . . . . . . . . . . . . 216

5.8 Variation of Spinel $\mathrm{TiO}_{2}$ with $\mathrm{Cr} \# \ldots \ldots$. . . . . . . . . . . . . . . . . . . . . . . . . . . . . .

5.9 Major element variations in $\mathrm{Cpx}$. . . . . . . . . . . . . . . . . . . 217

5.10 REE variations in individual peridotite $\mathrm{Cpx}$. . . . . . . . . . . . . 218

5.11 Ti-Zr variations in individual peridotite $\mathrm{Cpx}$. . . . . . . . . . . . . . . 219

5.12 REE variations in chromatographic peridotites . . . . . . . . . . . . . . . 220

5.13 Histograms of $\mathrm{Ce} / \mathrm{Yb}$ in peridotite $\mathrm{Cpx}$. . . . . . . . . . . . . . 221

5.14 Core, rim and interstitial Cpx trace element variations . . . . . . . . . . . . 222

5.15 Photomicrograph of a compositionally zoned $\mathrm{Cpx}$. . . . . . . . . . . . . 223

5.16 REE variations along the Atlantis II Fracture Zone . . . . . . . . . . . . . 224

5.17 REE variations in Oblique/Orthogonal Segment dredges . . . . . . . . . . . 225

5.18 Spinel compositions . . . . . . . . . . . . . . . . 226

5.19 Variations along the Oblique Segment . . . . . . . . . . . . . . . . 227

5.20 Length-scales of residual peridotite variability . . . . . . . . . . . . . . . . 228

5.All REE plots of each analysis by sample . . . . . . . . . . . . . . . . . . 229

5.B $1 \mathrm{Co}$-variation of spinel $\mathrm{Cr} \#, \mathrm{Yb}_{N}$ in $\mathrm{Cpx}$ and modal $\mathrm{Cpx}$. . . . . . . . . 233

5.C1 Armalcolite in sample Van7-96-14 . . . . . . . . . . . . . . . . 234

5.D1 Kaersutite vein in sample 6K-465-3 . . . . . . . . . . . . . . . . . 235

5.D2 Unusual Cpx exsolution in sample 6K-465-3 . . . . . . . . . . . . . . 236 


\section{List of Tables}

3.1 Josephine shear zone sample data. . . . . . . . . . . . . . . 83

$4.1 \quad$ Dredge locations $\ldots \ldots \ldots \ldots$

4.2 Peridotite modal compositions . . . . . . . . . . . . . . . . . 156

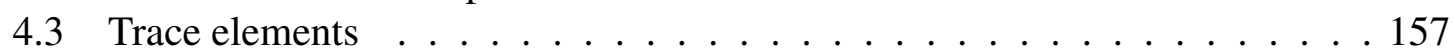

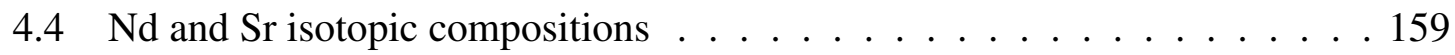

4.5 Pb isotopic compositions . . . . . . . . . . . . . . . . . . . 160

4.6 Partition Coefficients . . . . . . . . . . . . . . . . . . . . 161

4. Al Olivine major element compositions . . . . . . . . . . . . . . . . . 162

4. A2 Pyroxene major element compositions . . . . . . . . . . . . . . . . . . . . . . . . . . . . . . . . . . .

$4 . \mathrm{A} 3$ Spinel major element compositions . . . . . . . . . . . . . . . . . . . . 164

4. A4 Plagioclase major element compositions . . . . . . . . . . . . . . . . . 164

5.1 Summary of global peridotite compilation . . . . . . . . . . . . . 237

5.2 Dredge locations . . . . . . . . . . . . . . . . . . . . 239

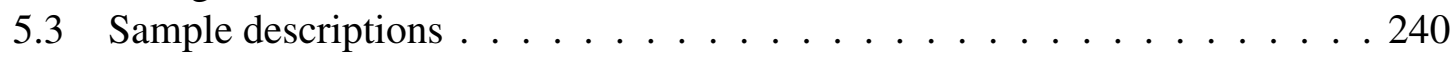

5.4 Olivine major element compositions . . . . . . . . . . . . . . . . . . . . . 242

5.5 Opx major element compositions . . . . . . . . . . . . . . . . . . . . . . . . . . . . . . . . . . . . . . . . . .

5.6 Cpx major element compositions . . . . . . . . . . . . . . . . . . . . . . . . . . . . . . . . . . . . . . . . .

5.7 Spinel major element compositions . . . . . . . . . . . . . . . . . 258

5.8 Plagioclase major element compositions . . . . . . . . . . . . . . . 261

5.9 Amphibole major element compositions . . . . . . . . . . . . . . . . 262

5.10 Clinopyroxene trace element concentrations . . . . . . . . . . . 263

5.11 Plagioclase trace element concentrations . . . . . . . . . . . . . . . 275

5.12 Orthopyroxene trace element concentrations . . . . . . . . . . . . . . 277

5.13 Alteration phase trace element concentrations . . . . . . . . . . . . . 278

5.14 Percent deviation among repeat measurements of the KH1 standard . . . 279

5.15 Percent deviation among repeat measurements of the KL2G standard . . . . 280

5.D 1 Compositions of unusual phases in Sample 6K-465-3 . . . . . . . . . . . . 281 


\section{Chapter 1}

\section{Introduction}

This thesis provides constraints on mantle convection through observations of the rheology and composition of the oceanic upper mantle. Mantle convection is a fundamental part of the plate tectonic cycle, but cannot be directly observed. Instead, it must be studied by indirect methods, such as seismic observations, modeling, and sampling of peridotites, the depleted residue of mantle melting that produces oceanic crust. In this thesis, I present two investigations into the rheology of peridotites (Chapters 2 and 3) and two investigations into the geochemistry of peridotites (Chapters 4 and 5). From analysis of olivine microstructures, I address the origins of localized ductile deformation in the lithosphere and the response of olivine orientation to flow in the upper mantle. I then present datasets of peridotite chemical and isotopic compositions and use these to constrain mantle composition - both lithospheric and asthenospheric - and ridge melting processes.

\subsection{Rheological Constraints}

The oceanic crust and upper mantle, collectively known as the oceanic lithosphere, form two-thirds of the rigid plates that make up the outer layer of the Earth. Relative motion among plates is accommodated at their boundaries, resulting in zones of localized defor- 
mation, such as transform faults. At the surface, strain accumulation results in brittle failure on these faults, producing earthquakes. At depth below a fault, increasing pressure and temperature result in a transition from brittle to ductile accommodation of strain. In Chapter 2 , I present observations from peridotite mylonites - ultra-fine grained rocks collected at oceanic fracture zones - for the mechanisms involved in ductile shear localization.

Strain localization in the ductile regime is promoted by the transition from grain-size insensitive to grain-size sensitive creep, which at small grain size results in a lower viscosity and thus higher strain rate. This transition requires grain size reduction, which must be permanent for strain localization to be permanent. In Chapter 2, I use electron backscatter diffraction (EBSD) analysis of a peridotite mylonite to examine olivine grain orientation and size, and the distribution of secondary phases. The observations place constraints on the dominant creep mechanisms in peridotites during strain localization and the process by which grain size is limited. In addition, the conditions of mylonite deformation are estimated by comparison to laboratory data for olivine, to provide quantitative constraints on conditions at the base of the seismogenic zone.

In the convecting mantle, movement is accommodated by creep mechanisms. In the upper mantle, the observation of seismic anisotropy indicates that creep has produced mineral alignment, leading to the conclusion that olivine is deforming by dislocation creep (Hess, 1964). In Chapter 3, I provide quantitative constraints on the relationship between olivine orientation and shear strain. These observations are critical for quantifying the relationship between the kinetics of deformation and the direction and magnitude of seismic anisotropy. Experimental investigations (e.g., Nicolas et al., 1973) into the relationship between olivine LPO and shear strain have provided a framework for LPO evolution models. However, experiments are conducted on pure olivine aggregates at higher stresses and faster strain rates than occur within the Earth. Using EBSD, I determine the evolution of olivine lattice preferred orientation as a function of shear strain in naturally deformed peridotites from the 
Josephine Peridotite in southwest Oregon. Our observations from natural samples provide an improved framework for the interpretation of seismic anisotropy.

\subsection{Geochemical Constraints}

The oceanic lithosphere is produced by pressure-release melting of the convecting asthenospheric mantle when it upwells beneath ocean ridges. This lithosphere eventually cools and becomes negatively buoyant, sinking back into the asthenosphere at subduction zones. The extent to which subducted slabs are re-mixed into the convecting mantle and eventually exposed again at ridges is the subject of much debate. In general, the upper mantle is treated as compositionally homogeneous, due to the relative homogeneity of MORBs (mid-ocean ridge basalts) with respect to ocean island basalts (Zindler and Hart, 1986). The composition of the upper mantle is constrained from (1) the average MORB isotopic composition, which reflects continental crust extraction over the past $3 \mathrm{~Gy}$, and (2) the composition of residual abyssal peridotites. Workman and Hart (2005) used these constraints to construct a model average composition for the upper mantle, referred to as DMM (Depleted MORB Mantle). I use abyssal peridotites in Chapters 4 and 5 to assess the extent to which the upper mantle deviates from this average composition.

In Chapter 4, I present detailed isotopic and trace element analyses of clinopyroxenes and orthopyroxenes from abyssal peridotites, to constrain isotopic heterogeneity in the asthenospheric mantle. MORBs, as mixtures of melts sourced over relatively large areas, cannot preserve heterogeneities at the shortest length-scales. In addition, by mass balance, the isotopic composition of MORBs are dominated by the least chemically depleted component in the melt. However, despite these constraints, significant variations in MORB composition have been observed (e.g., Dupré and Allègre, 1983). In addition, while a general consensus exists as to the presence of recycled crustal components in the mantle, the debate in recent years has centered around the "veined mantle hypothesis" (e.g., 
Allègre and Turcotte, 1986). In this model, the upper mantle contains eclogite and pyroxenite veins that are direct remnants of stretched and thinned subducted oceanic crust. I test this hypothesis in Chapter 4 by examining the isotopic and trace element compositions of pyroxenite-veined abyssal peridotites.

The composition of peridotites collected at ocean ridges reflects the processes of melting and melt extraction, in addition to initial source composition. In Chapter 5, I assess the role of melt-rock reaction in modifying the composition of the lithospheric mantle at ridges. Abyssal peridotites, collected at all major ocean ridges, are generally interpreted as the depleted residues of near-fractional melting (Johnson et al. 1990$)$. Melt is extracted from peridotites by focused flow in dunite channels, which produces the observed chemical disequilibrium between peridotites and MORBs (e.g., Kelemen et al., 1995). This interpretation minimizes the role of other melt-rock reaction processes in modifying peridotite composition. In Chapter 5, I demonstrate that abyssal peridotites encompass a larger compositional range than previously recognized and that much of this variation is the result of a variety of melt-rock reaction mechanisms. Heterogeneity of the lithospheric mantle is an important component of the convection cycle, as the lithosphere is eventually recycled back into the convecting mantle at subduction zones. The time-integrated effect of recycling heterogeneous lithospheric mantle into the asthenosphere will be increased heterogeneity within the Earth.

\subsection{Bibliography}

Allègre, C. J., Turcotte, D. L., 1986. Implications of a two-component marble-cake mantle. Nature 323, 123-127.

Dupré, B., Allègre, C. J., 1983. Pb-Sr isotope variation in Indian Ocean basalts and mixing phenomena. Nature 303, 142-146.

Hess, H. H., 1964. Seismic anisotropy of the uppermost mantle under oceans. Nature 203 (4945), 629-631. 
Johnson, K. T. M., Dick, H. J. B., Shimizu, N., 1990. Melting in the oceanic upper mantle: An ion microprobe study of diopsides in abyssal peridotites. Journal of Geophysical Research 95, 2661-2678.

Kelemen, P. B., Shimizu, N., Salters, V. J. M., 1995. Extraction of mid-ocean-ridge basalt from the upwelling mantle by focused flow of melt in dunite channels. Nature 375, 747753.

Nicolas, A., Boudier, F., Boullier, A. M., 1973. Mechanisms of flow in naturally and experimentally deformed peridotites. American Journal of Science 273, 853-876.

Workman, R. K., Hart, S. R., 2005. Major and trace element composition of the depleted MORB mantle (DMM). Earth and Planetary Science Letters 231, 53-72.

Zindler, A., Hart, S., 1986. Chemical geodynamics. Annual Review of Earth and Planetary Sciences 14, 493-571. 


\title{
Chapter 2
}

\section{Grain Size Sensitive Deformation Mechanisms in Naturally Deformed Peridotites*}

\begin{abstract}
Microstructural analyses of peridotite mylonites from the oceanic lithosphere indicate that shear localization results from the combined effects of grain size reduction, grain boundary sliding and second phase pinning during deformation. The pinning effect, combined with experimental flow laws for olivine, suggests that a permanent transition from dislocation creep processes to diffusion creep occurs. This rheological transition provides a mechanism for long term weakening of the lithosphere for rocks deforming in the brittleductile regime. In addition, our results support the hypothesis that a transition to diffusion creep promotes the randomization of pre-existing lattice preferred orientations, which would reduce seismic anisotropy.
\end{abstract}

${ }^{*}$ Reprinted from Earth and Planetary Science Letters, Vol. 248, J. M. Warren and G. Hirth, Grain Size Sensitive Deformation Mechanisms in Naturally Deformed Peridotites, 423-435, (c)2006, with permission from Elsevier. 


\subsection{Introduction}

The observation of fine grained mylonites in shear zones indicates that grain size sensitive creep processes promote strain localization (e.g., Kirby, 1985; Tullis et al., 1990; Drury et al., 1991; Jaroslow et al., 1996; Jin et al., 1998; Newman et al., 1999; Jiang et al., 2000).

For the sample in Fig. 2.1, microstructural observations show that ductile deformation resulted in three orders of magnitude grain size reduction. Peridotite mylonites are commonly sampled from oceanic fracture zones (Jaroslow et al., 1996). The geologic provenance of these mylonites suggests that they formed in the ductile region of the lithosphere along the down-dip extension of transform faults. We describe fabrics in a peridotite mylonite from the Shaka Fracture Zone that support extrapolation of experimentally determined rheological data (Hirth and Kohlstedt, 2003) to geologic conditions appropriate for the oceanic lithosphere. We conclude that grain boundary sliding and grain boundary pinning lead to permanent grain size reduction and strain localization.

Previous studies of peridotite mylonites in orogenic massifs and ophiolites have interpreted grain size reduction in mylonites as the result of (i) fluid addition (e.g., Vissers et al., 1995), (ii) reaction with melt (e.g., Dijkstra et al., 2002), and (iii) the breakdown reaction of spinel to plagioclase with decreasing pressure (e.g., Furusho and Kyuichi, 1999, Newman et al., 1999); see Drury et al. (1991) for a review of earlier literature. Vissers et al. (1995) interpreted the microstructures in Erro-Tobbio lherzolite mylonites as resulting from a wet olivine rheology with reaction-related grain size reduction. Dijkstra et al.(2002) concluded that a melt-present reaction promoted grain size sensitive deformation in shear zone mylonites from the Othris peridotite massif. In the Turon de Técouére peridotite shear zone, Newman et al. (1999) suggested that grain size reduction resulted from the spinel to plagioclase phase transition reaction.

Several lines of evidence indicate that the Shaka Fracture Zone mylonites deformed in the absence of water and melt, and that breakdown reactions were not involved. We find 
no syn-deformational hydrous phases such as amphibole, talc or serpentine. The mantle at fracture zones is expected to be dehydrated and depleted due to earlier on-axis melting and melt extraction (Hirth and Kohlstedt, 1996). In addition to the lack of evidence for melt or water involvement in the mylonite deformation, we find no indication of reaction enhancement via the breakdown of spinel to plagioclase. The rare earth element concentrations measured by ion microprobe in a clinopyroxene porphyroclast have the typical depleted compositions found in other abyssal peridotites (Johnson et al., 1990), with no Eu anomaly, which is a sensitive indicator of plagioclase formation (Warren et al., 2003).

\subsection{Methods}

To study deformation mechanisms in mylonites, we used electron backscatter diffraction (EBSD) to analyze olivine and orthopyroxene crystal orientations in thin sections of mylonitized peridotites cut parallel to lineation and perpendicular to foliation. We made orientation measurements down to a $1 \mu \mathrm{m}$ grain size, an order of magnitude smaller size than that accessible with a U-stage. In addition, EBSD permits identification and quantification of the distribution of secondary phases. Data were gathered using an electron backscatter detector attached to a JEOL 840 SEM. Portions of thin sections were mapped for lattice orientation in 1,2, or 4 micron steps (depending on the average grain size of the region being mapped), using a rasterized beam across the sample surface. EBSD patterns were processed and analyzed using HKL Technology's Channel 5 software package.

Orientation maps in Figs. 2.2. 2.4 contain from 52\% to $72 \%$ indexed data. Non-indexed (white) pixels represent points with a mean angular deviation (MAD) number $\geq 1^{\circ}$, which result from surface roughness and computer mis-indexing. The MAD number quantifies the mismatch between lattice planes in the calculated orientation and those quantified from the digitized bands of the diffraction pattern. Raw data, consisting of all indexed points with a MAD number $<1^{\circ}$, are shown as maps and pole figures for coarser and finer grained regions 
in Fig. 2.2. Processed data, for which wild spikes have been removed and all pixels with zero solutions have been extrapolated, are also shown in Fig. 2.2. Wild spikes are single pixels (i) which are misoriented by $>10^{\circ}$ from the average orientation of the surrounding eight pixels and (ii) for which the maximum misorientation between any two of the surrounding pixels is $<10^{\circ}$. All pixels which are wild spikes or have a MAD number $>1^{\circ}$ are replaced with zero, or null, solutions. In the processed data, pixels with zero solutions were replaced with the most common neighbor orientation. This method of processing the data minimizes the overcounting of individual grains when extracting one orientation point per grain for the construction of pole figures. However, it under-represents the smallest grains, which are close to the sampling step size and are filtered out with noise in the data.

Pole figures, shown in Figs. 2.2,2.4, were calculated using one point per grain, with all data sets containing $\geq 180$ grains, which has been demonstrated to provide statistically robust results (Ben Ismaïl and Mainprice, 1998). Grain boundaries were defined by misorientations $\geq 10^{\circ}$ between adjacent points and subgrains by $2^{\circ}-10^{\circ}$ misorientations. Pole figures of raw and processed data in Fig. 2.2 demonstrate that in both the finer and coarser grained areas, the processing affects the strength of the lattice preferred orientation (LPO), but does not alter the overall LPO pattern. There are two main differences between the raw and processed data: (1) the removal of small grains, points with no solutions and wild spikes, which decreases the randomness of the data, leading to a stronger LPO and (2) extrapolation of the data, which further reduces the number of small grains but increases the randomness of the data, as groups of adjacent small grains with the same orientation are replaced by individual large grains.

Using an alternative processing method, shown in Fig. 2.2[-J, data are extrapolated prior to the removal of wild spikes. This provides a better representation of the distribution of the pyroxene and spinel grains in the finest grained areas of the sample. However, as we wish to minimize potential bias in the olivine fabrics, we show data processed by the first 
method only in Figs. 2.3 and 2.4. These issues are inherent in analyzing such fine grained material, which has a grain size close to the minimum step size.

\subsection{Results}

Microstructural observations of the mylonites indicate that grain size reduction leads to progressive localization of deformation into fine-grained bands. The influence of grain size on rheology can be seen in the optical-scale microstructures in Fig. 2.1. The mylonite consists of anastomosing bands of coarser $(\leq 100 \mu \mathrm{m})$ and finer $(\leq 10 \mu \mathrm{m})$ grained olivine, with distributed grains of orthopyroxene, clinopyroxene and spinel. Large, round to elongate porphyroclasts of olivine, orthopyroxene, clinopyroxene and spinel, ranging in size from $0.1 \mathrm{~mm}$ to $5 \mathrm{~mm}$, are preserved in the fine grained matrix. These microstructures indicate that the large porphyroclast grains behaved as hard inclusions during deformation. In some cases, these inclusions are relatively coarse-grained aggregates of olivine (Fig. 2.1. Kinematic indicators, such as vergence of small folds and asymmetric recrystallization trails around porphyroclasts, indicate the relative sense of shear for the mylonite.

Olivine orientations in coarser and finer grained regions of the mylonite are shown in maps and pole figures in Figs. 2.3 and 2.4. The data are plotted with respect to the banding and lineation orientations, which we assume are equivalent to the shear plane for this high strain rock. Data are presented for two coarser grained regions of the mylonite in Fig. 2.3, with the pole figures divided into $1-10 \mu \mathrm{m}$ and 10-100 $\mu \mathrm{m}$ size grains for each dataset. In the first region (Fig. 2.3A-C), a [100] maximum is observed in the plane of the banding and sub-parallel to the lineation, while a [001] maximum is observed perpendicular to the banding. In some areas, the LPO is significantly stronger among 10-100 $\mu \mathrm{m}$ grains than among 1-10 $\mu \mathrm{m}$ grains. In the other coarse grained region, a pole figure is only shown for the $10-100 \mu \mathrm{m}$ size grains (Fig. $2.3 \mathrm{E}$ ), due to the large step size at which this dataset was collected. The [100] maximum is not oriented parallel to the banding. A variable LPO 
was also found by limited universal stage work on coarser grained regions in this sample (Jaroslow et al., 1996).

In the finer grained regions, shown in Fig. 2.4, a decrease in LPO strength is observed in all three areas measured. Almost no LPO is observed in some regions of the fine-grained bands (Fig. 2.4A-F). Locally, in the fine grained region shown in Fig. 2.4E-F, we find a weak and dispersed "ghost" of the LPO observed in the coarser-grained region in Fig. 2.3A-C.

The variation of LPO and grain size correlates with the secondary phase distribution. Pyroxenes and spinel are inhomogeneously distributed in the mylonite, with small grains of these phases predominant in regions with a smaller olivine grain size. Based on the very fine grain size, the raw data (Fig. 2.2A,E), and the alternative method of processing the data (Fig. 2.21), the number of small orthopyroxene grains is greater than that shown in Figs. 2.3 and 2.4. The EBSD orientation maps highlight the larger number of secondary phases in finer grained areas relative to coarser grained areas (compare Fig. 2.2B to Fig. 2.2F). The finer grained areas have a smaller range of grain sizes and a more random distribution of secondary phases. In contrast, the coarser grained regions have a larger range of olivine grain sizes. Locally, small grains of secondary phases are mixed with small grains of olivine at the edges of larger olivine grains.

Figs. 2.2F and 2.2I provide lower and upper bounds on the amount of secondary phases pinning the grain boundaries in the finest grained areas. We have also examined backscattered electron images and X-ray maps of coarse and fine grained areas. These confirm our observation of a greater concentration of secondary phases in the finest grained areas. Similarly, high resolution EBSD and X-ray maps of Michibayashi and Mainprice 2003, 2004) show a greater accumulation of secondary phases in finer grained regions of the peridotite mylonite in their study. 


\subsection{Discussion}

\subsubsection{Fabric variations with grain size}

The variation in olivine fabric with grain size in the mylonite provides an opportunity to constrain grain size sensitive deformation mechanisms in the lithosphere. Three observations in particular can be exploited to constrain the deformation mechanisms: (i) randomization of a pre-existing LPO in the finest grained regions of the mylonite; (ii) observation of an LPO in coarser grained regions; (iii) the preservation of porphyroclasts.

The randomization of olivine LPO in the finest grained regions of the mylonite indicates a change in deformation mechanism to diffusion creep. Two observations suggest that the randomization of LPO occurred as deformation localized into fine grained regions. First, a weak LPO is observed in one fine grained area (Fig. 2.4F) which is similar to the LPO in a coarser grained area (Fig. 2.3B-C). Second, the LPO among 1-10 $\mu \mathrm{m}$ grains in a coarser grained area is similar, but weaker, than that in the 10-100 $\mu \mathrm{m}$ size fraction (Fig. 2.3B-C). We conclude that the randomization of LPO is related to grain rotations that occur during the grain boundary switching process, which is required during diffusion creep (e.g., Raj and Ashby, 1971).

The LPO in the coarser grained regions indicates that a dislocation process accommodated deformation during the early stages of mylonitization. At the same time, the preservation of large, sometimes equant, porphyroclasts implies that the rheology is grain size sensitive. If the rheology was not grain size sensitive, then all grains should be deformed to the same degree and large, relatively undeformed porphyroclasts would not be preserved. Based on comparison to experimental studies, we suggest that deformation in the coarser grained bands occurred by dislocation accommodated grain boundary sliding (DisGBS). DisGBS is a grain size sensitive creep mechanism that was identified experimentally on the basis of rheologic data on olivine aggregates deformed near the transition between disloca- 
tion creep and diffusion creep (Hirth and Kohlstedt, 1995, 2003). Of particular significance for our analysis is that deformation by DisGBS has been shown to produce LPOs in calcite (Schmid et al., 1987; Rutter et al., 1994) and ice (Durham et al., 2001; Goldsby and Kohlstedt, 2002).

During DisGBS, strain is dominantly accommodated by the relative movement of grains (i.e. grain boundary sliding) and is limited by either this process or the movement of dislocations within grains on the easy slip system (Goldsby and Kohlstedt, 2001; Hirth and Kohlstedt, 2003). These two processes act in series, as deformation is not accommodated independently by either grain boundary sliding or easy slip. Thus the strain rate for DisGBS $\left(\dot{\epsilon}_{D i s G B S}\right)$ is limited by the slowest of the two mechanisms through the relationship:

$$
\dot{\epsilon}_{D i s G B S}=\left(\frac{1}{\dot{\epsilon}_{G B S}}+\frac{1}{\dot{\epsilon}_{E a s y}}\right)^{-1}
$$

where $\dot{\epsilon}_{G B S}$ is the strain rate for grain boundary sliding (GBS) and $\dot{\epsilon}_{E a s y}$ is the strain rate for easy slip. The grain size sensitivity of DisGBS results from the influence of grain size on the GBS component of the flow law.

There is considerable confusion regarding the terminology used for grain size dependent deformation mechanisms. For example, deformation in both the diffusion creep and DisGBS regimes involves grain boundary sliding, with relative grain movement accommodated either by diffusion or dislocation processes, respectively. Furthermore, the term superplasticity is often used when referring to deformation accommodated by GBS (see discussion in Goldsby and Kohlstedt, 2001)). To clarify our terminology, we refer to the serial deformation process (Eq. 2.1) as DisGBS and the grain boundary sliding component of the process as GBS. 


\subsubsection{Deformation mechanism maps}

We use olivine deformation mechanism maps to constrain the deformation conditions of the mylonites (Fig. 2.5A). The total strain rate $\left(\dot{\epsilon}_{\text {Total }}\right)$ during deformation is contoured in stress versus grain size space, using the constitutive law (Hirth and Kohlstedt, 2003):

$$
\dot{\epsilon}_{T o t a l}=\dot{\epsilon}_{D i f}+\dot{\epsilon}_{D i s}+\dot{\epsilon}_{L T P}+\dot{\epsilon}_{D i s G B S}
$$

where $\dot{\epsilon}_{D i f}$ is the strain rate for diffusion creep, $\dot{\epsilon}_{D i s}$ for dislocation creep, and $\dot{\epsilon}_{L T P}$ for low-temperature plasticity (LTP). The flow law formulation and experimental data for LTP are from Goetze (1978) and Evans and Goetze (1979). These four deformation mechanisms are independent, so the mechanism with the fastest strain rate controls the rheology.

The boundaries for the fields of diffusion creep, dislocation creep, and DisGBS are calculated using a compilation of olivine experimental data from Hirth and Kohlstedt (2003). The flow laws for melt- and water-free aggregates in these regimes have the form:

$$
\dot{\epsilon}=A \sigma^{n} d^{-m} \exp \left(-\frac{E+P V}{R T}\right)
$$

where $A$ is a constant, $\sigma$ is the differential stress, $n$ is the stress exponent, $d$ is the grain size, $p$ is the grain size exponent, $E$ is the activation energy, $P$ is the pressure, $V$ is the activation volume, $R$ is the gas constant, and $T$ is the absolute temperature. For the mylonite, $d$ is in the range of $1-100 \mu \mathrm{m}$. The deformation temperature is constrained from thermometry to lie in the range $600-750^{\circ} \mathrm{C}$ (Jaroslow et al., 1996). We use a nominal pressure of $400 \mathrm{MPa}$ for these calculations. The pressure of deformation is not well constrained, however the $P V$ term in Eq. 2.3 is negligible for deformation in the shallow oceanic lithosphere.

Application of the experimental olivine data to the conditions of mylonite formation involves a significant extrapolation of temperature, but not of grain size or stress. Therefore, the greatest uncertainty in the map in Fig. $2.5 \mathrm{~A}$ is in the activation energies for the defor- 
mation mechanisms. We calculated the error range for the field boundaries due to error in these activation energies. The activation energies for DisGBS are the most uncertain. For the grain boundary sliding component, the activation energy is assumed to be the same as that for the easy slip system, which is constrained experimentally at high temperature (Bai et al., 1991). However, results from Carter and Ave'Lallemant (1970) on the experimental deformation of dunites indicate that the easy slip system in olivine changes at low temperature. Despite uncertainty in the extrapolation to low temperature, the range of estimated mylonite deformation conditions lies within the DisGBS field, as shown in Fig. 2.5.A.

To emphasize the conditions where DisGBS is a significant deformation mechanism, and its significance for LPO development, we plot strain rate versus grain size for a stress of $300 \mathrm{MPa}$ in Fig. 2.5B. This plot represents a constant stress section through Fig. 2.5A. The total strain rate is dominated by DisGBS at grain sizes in the range $\sim 15-700 \mu \mathrm{m}$. Furthermore, the strain rate for DisGBS is at least an order of magnitude greater than that for dislocation creep at grain sizes $<\sim 300 \mu \mathrm{m}$. The strain rate for diffusion creep becomes greater than that for DisGBS at grain sizes $<\sim 15 \mu \mathrm{m}$. For comparison, at a grain size of $\sim 15 \mu \mathrm{m}$, the strain rate for diffusion creep is approximately three orders of magnitude greater than that for dislocation creep. Assuming that LPOs form when a dislocation process accommodates a significant component of the total strain - and recalling that our microstructural observations indicate a randomization of LPO when grain size decreases below $\sim 10 \mu \mathrm{m}$ - we conclude that the LPOs observed in coarser grained regions of the mylonite resulted from DisGBS.

Our results suggest that an LPO is maintained during DisGBS when the easy slip component is dominant during deformation, though rate limited by the GBS component. Grain boundary sliding, whether diffusion or dislocation accommodated, tends to randomize LPOs. Prior and co-workers have demonstrated that a grain boundary sliding process leads to an increased dispersion in the misorientation between grains, which weakens an initial 
single crystal LPO (Jiang et al., 2000; Bestmann and Prior, 2003; Storey and Prior, 2005).

Our observation of a randomized LPO during diffusion creep supports the suggestion by Bestmann and Prior (2003) that a grain boundary sliding process weakens LPOs.

\subsubsection{Recrystallization and grain boundary pinning}

To understand how grain size sensitive creep promotes strain localization, we consider the processes that control the evolution of grain size during mylonite deformation. As deformation continues to lower temperature, and therefore higher stress, grain size decreases as a result of dynamic recrystallization. Empirical relationships between stress and grain size have been determined for olivine and this recrystallization piezometer (Karato et al., 1980, Van der Wal et al., 1993) is shown in Fig. 2.5A. Dynamic recrystallization is driven by gradients in dislocation density, which promote subgrain rotation and grain boundary migration. In the diffusion creep field, the applicability of the empirical piezometer is problematic owing to a potential lack of driving force for recrystallization. This insight motivated the field boundary hypothesis (De Bresser et al., 1998, 2001), in which the piezometer is defined by the boundary between the dislocation creep and diffusion creep fields. Thus, the piezometric relationship may be temperature dependent due to differences in the activation energy for the creep processes. However, Drury (2005) emphasized the lack of evidence for temperature dependence in the empirical relationships for olivine, based on the observation of statistically equivalent piezometric relationships for samples deformed at $1100-1300^{\circ} \mathrm{C}$ (Van der Wal et al., 1993) and at $1500^{\circ} \mathrm{C}$ (Karato et al., 1980). Thus, while the field boundary hypothesis has merit, the higher temperature experimental data indicate that a recrystallization piezometer applies within the dislocation creep regime.

The magnitude of grain size reduction in the mylonite can be explained by either the empirical piezometric relationship or a modified field boundary hypothesis. As illustrated in Fig. 2.5 A, the grain size at which we see evidence for LPO randomization (i.e., $\sim 10$ 
$\mu \mathrm{m})$ falls near the boundary between diffusion creep and DisGBS at geologic strain rates, consistent with a modified field boundary hypothesis in which the piezometer is defined by the diffusion creep/DisGBS field boundary, rather than the diffusion creep/dislocation creep field boundary. At the same time, the empirical piezometric relationship falls in the DisGBS field (within uncertainty), indicating that the driving force for recrystallization arises from the easy slip component of the DisGBS mechanism. In either case, we emphasize that the extreme grain size reduction observed in the mylonites is difficult to explain without the DisGBS mechanism.

Grain boundary pinning can lead to permanent grain size reduction and a transition to diffusion creep. Without a mechanism to limit grain growth, grain size reduction may not promote a transition to diffusion creep in single phase materials, due to a dynamic balance between grain growth and recrystallization (De Bresser et al., 1998, 2001). However, we suggest that the translation of grains during DisGBS by grain boundary sliding (and phase boundary sliding) results in the mixing of different mineral phases, which eventually inhibits grain growth. In the mylonite, the randomization of LPO in the fine grained regions indicates that the presence of pyroxenes and spinel results in the pinning of olivine grain boundaries, leading to a transition to diffusion creep. Previous studies have emphasized the role of grain size pinning, resulting from fluid addition, melt crystallization or metamorphic reactions, in promoting grain size sensitive creep processes (Vissers et al., 1995; Furusho and Kyuichi, 1999; Newman et al., 1999; Dijkstra et al., 2002).

\subsubsection{Strain localization}

To explore the implications of grain size sensitive creep mechanisms for strain localization in the oceanic lithosphere, in Fig. 2.6 we compare the viscosities of a fine grained shear zone and the surrounding coarse grained mantle. Based on our analysis of microstructural data and experimental flow laws, we assume that deformation in the shear zone occurs at 
a stress and grain size on the boundary between the DisGBS and diffusion creep fields on the deformation mechanism map, which leads to the relationships:

$$
\begin{gathered}
\dot{\epsilon}_{D i s G B S}=\dot{\epsilon}_{D i f} \\
\dot{\epsilon}_{S Z}=\dot{\epsilon}_{D i s G B S}+\dot{\epsilon}_{D i f}=2 \dot{\epsilon}_{D i s G B S}=2 \dot{\epsilon}_{D i f}
\end{gathered}
$$

where $\dot{\epsilon}_{S Z}$ is the shear zone strain rate.

The effective viscosity $(\eta)$ of the shear zone in Fig. 2.6 is calculated using Eqs. 2.3 and 2.5, the relationship $\eta=\sigma / \dot{\epsilon}_{S Z}$ and assuming $\dot{\epsilon}_{S Z}=10^{-12} \mathrm{~s}^{-1}$. The calculations are made for both the GBS and the easy slip components of DisGBS, as shown in Fig. 2.6. At temperatures greater than $\sim 700^{\circ} \mathrm{C}$, viscosity in the shear zone is controlled by the GBS component of the DisGBS flow law and this component may dominate, within error, at lower temperatures as well.

The shear zone viscosity at $700^{\circ} \mathrm{C}$ is approximately four orders of magnitude lower than outside the shear zone (Fig. 2.6). Outside the shear zone, we assume (i) that dislocation creep accommodates deformation of the coarse-grained mantle and (ii) that stress is limited by the strength of the shear zone. The effective viscosity for the shear zone remains lower than the coarse grained mantle until a temperature of $\sim 950^{\circ} \mathrm{C}$, at which point deformation is no longer localized. Where grain size pinning results in a transition to diffusion creep, the viscosity contrast would be even larger than that illustrated in Fig. 2.6.

A convenient flow law for deformation in mantle shear zones - which accounts for grain size dependence - can be derived by solving Eq. 2.4 for grain size and substituting into Eq. 2.5 .

$$
\dot{\epsilon}_{S Z}=2 \frac{A_{D i s G B S}^{3}}{A_{D i f}^{2}} \sigma^{8.5} \exp \left(\frac{2 H_{D i f}-3 H_{D i s G B S}}{R T}\right)
$$

where $H=E+P V$. Using the values for these parameters from Hirth and Kohlstedt 
(2003), Eq. 2.6 can then be written as:

$$
\dot{\epsilon}_{S Z}=2.4 \times 10^{-7} \sigma^{8.5} \exp \left(\frac{-4.7 \times 10^{5}}{R T}\right)
$$

for $\sigma$ in MPa. This relationship is applicable for shear zone deformation at temperatures $<950^{\circ} \mathrm{C}$ and lithospheric depths, where the $P V$ term is negligible. We reiterate that the largest uncertainty is related to the activation energy, as shown in Fig. 2.5 A. At higher temperature, and therefore lower stress, errors associated with extrapolation in stress and grain size should also be considered.

\subsubsection{Relationship of mylonites to earthquake processes}

A combination of geophysical, experimental and geochemical observations indicate that the transition from brittle to ductile processes occurs at a temperature of $\sim 600^{\circ} \mathrm{C}$ in the oceanic lithosphere. Seismological studies of the depth of earthquakes along transform faults indicate that seismicity is confined to depths in the oceanic lithosphere with temperatures $<600^{\circ} \mathrm{C}$ (e.g., Engeln et al., 1986; Abercrombie and Ekström, 2001). Extrapolation of experimental data for olivine aggregates indicates that the $600^{\circ} \mathrm{C}$ isotherm also marks the transition from stable to unstable frictional sliding (Boettcher et al., 2007). Finally,Jaroslow et al. (1996) estimated that the minimum temperature for mylonite deformation is $\sim 600^{\circ} \mathrm{C}$, based on olivine-spinel geothermometry.

In Fig. 2.7, we compare the estimated strain rate for mylonite deformation to the strain rates for different geologic processes. The stress and strain rate of mylonite deformation are estimated using the microstructural observations combined with the olivine flow laws. From the recrystallization piezometer (Karato et al., 1980; Van der Wal et al., 1993), the estimated differential stress for a recrystallized grain size of $10 \mu \mathrm{m}$ is $240 \mathrm{MPa}$ and of $3 \mu \mathrm{m}$ is $580 \mathrm{MPa}$. At $600-700^{\circ} \mathrm{C}$ and these stress and grain size conditions, the estimated strain 
rate for mylonite deformation is $10^{-14}-10^{-10} \mathrm{~s}^{-1}$. The strain rate for post-seismic slip in Fig. 2.7 is calculated as:

$$
\dot{\epsilon}=\left(\frac{\operatorname{slip}}{w i d t h}\right) \times\left(\frac{1}{\Delta t}\right)
$$

where $\Delta t$ is the duration of post-seismic slip. The estimated strain rate for post-seismic slip is $10^{-10}-10^{-5} \mathrm{~s}^{-1}$, for slip $<1 \mathrm{~m}$, width $\sim 1 \mathrm{~m}$ to $<1 \mathrm{~km}$, and $\Delta t \approx 1-100$ days. Therefore, the estimated strain rate for mylonites overlaps the low end of post-seismic slip and the high end of tectonic strain rates (i.e., $10^{-15}-10^{-12} \mathrm{~s}^{-1}$ ). Our results place constraints on the conditions of deformation at the base of the seismogenic zone in the oceanic lithosphere, which may be used to interpret geodetic data for post-seismic slip (e.g., Montési and Hirth, 2003).

\subsubsection{Mantle anisotropy}

The microstructural observations of the mylonite demonstrate that the transition to diffusion creep results in a randomization of pre-existing LPOs. Evidence that pre-existing anisotropy may be destroyed by the transition to diffusion creep is important for understanding mantle anisotropy. In the upper mantle, seismic anisotropy reflects high temperature flow by dislocation creep (Nicolas and Christensen, 1987; Nishimura and Forsyth, 1989; Mainprice and Silver, 1993; Jung and Karato, 2001). However, with increasing depth and temperature in the mantle, the dominant mechanism of olivine deformation may change from dislocation creep to diffusion creep (Karato and Wu, 1993). Our results indicate that such a change can lead to a decrease in mantle anisotropy, if enough strain is accumulated to randomize the fabric. We emphasize that in the case of shear zones, we do not expect fabric randomization to have a detectable effect on regional mantle anisotropy. However, following the suggestion of Karato and $\mathrm{Wu}(1993)$ that a transition to diffusion creep may occur at depth in the upper mantle, our results imply that this would lead to an isotropic layer in the lower portion of the upper mantle. 


\subsection{Conclusions}

Peridotite mylonites demonstrate that three orders of magnitude grain size reduction occurs during localized deformation in the oceanic lithosphere. Microstructural analyses of the mylonite fabric suggest that deformation of aggregates with a grain size of 10-100 $\mu \mathrm{m}$ occurred by DisGBS and produces an LPO. Grain boundary pinning, due to the mixing of pyroxenes and spinel among olivine grains during DisGBS, resulted in permanent grain size reduction. Reduction in grain size down to $1-10 \mu \mathrm{m}$, combined with second phase pinning, led to a transition to diffusion creep and resulted in a randomization of the preexisting LPO.

Our microstructural observations are consistent with extrapolation of experimental olivine flow laws to temperatures of $600-800^{\circ} \mathrm{C}$ during mylonite deformation. The empirical recrystallization piezometer plots within the field of DisGBS, providing a driving force for grain size reduction. Alternatively, grain size reduction may have followed a modified version of the field boundary hypothesis (De Bresser et al., 1998, 2001). At temperatures below $\sim 950^{\circ} \mathrm{C}$, deformation in the DisGBS and diffusion creep fields occurs at lower stress and viscosity than in the dislocation creep field, providing a mechanism for weakening and strain localization in the oceanic lithosphere at transform faults.

\section{Acknowledgements}

We thank Henry Dick for bringing our attention to the peridotite mylonites. Louie Kerr provided invaluable assistance with the SEM at the Marine Biological Laboratory. In addition we would like to thank Margaret Boettcher, Mike Braun, Peter Kelemen, Jeff McGuire, and Laurent Montèsi for helpful discussions. Reviews by David Prior and an anonymous reviewer helped improve our manuscript. This work was supported by NSF grant EAR0230267 and a Hollister Fellowship from the WHOI Academic Programs Office. 


\subsection{Bibliography}

Abercrombie, R. E., Ekström, G., 2001. Earthquake slip on oceanic transform faults. Nature 410, 74-77.

Bai, Q., Mackwell, S. J., Kohlstedt, D. L., 1991. High-temperature creep of olivine single crystals 1. Mechanical results for buffered samples. Journal of Geophysical Research 96 (B2), 2411-2463.

Ben Ismaïl, W., Mainprice, D., 1998. An olivine fabric database: an overview of upper mantle fabrics and seismic anisotropy. Tectonophysics 296, 145-157.

Bestmann, M., Prior, D. J., 2003. Intragranular dynamic recrystallization in naturally deformed calcite marble: diffusion accommodated grain boundary sliding as a result of subgrain rotation recrystallization. Journal of Structural Geology 25, 1597-1613.

Boettcher, M. S., Hirth, G., Evans, B., 2007. Olivine friction at the base of oceanic seismogenic zones. Journal of Geophysical Research 112, 10.1029/2006JB004301.

Carter, N. L., Ave'Lallemant, H. G., 1970. High temperature flow of dunite and peridotite. Geological Society of America Bulletin 81, 2181-2202.

De Bresser, J. H. P., Peach, C. J., Reijs, J. P. J., Spiers, C. J., 1998. On dynamic recrystallization during solid state flow: Effects of stress and temperature. Geophysical Research Letters 25 (18), 3457-3460.

De Bresser, J. H. P., Ter Heege, J. H., Spiers, C. J., 2001. Grain size reduction by dynamic recrystallization: Can it result in major rheological weakening? International Journal of Earth Sciences 90 (28-45).

Dijkstra, A. H., Drury, M. R., Vissers, R. L. M., Newman, J., 2002. On the role of melt-rock reaction in mantle shear zone formation in the Othris Peridotite Massif (Geece). Journal of Structural Geology 24, 1431-1450.

Drury, M. R., 2005. Dynamic recrystallization and strain softening of olivine aggregates in the laboratory and the lithosphere. In: Gapais, D., Brun, J. P., Cobbold, P. R. (Eds.), Deformation Mechanisms, Rheology and Tectonics: from Minerals to the Lithosphere. No. 243 in Special Publication. Geological Society of London, pp. 143-158.

Drury, M. R., Vissers, R. L. M., Van der Wal, D., Hoogerduijn Strating, E. H., 1991. Shear localisation in upper mantle peridotites. Pure and Applied Geophysics 137 (4), 439-460.

Durham, W. B., Stern, L. A., Kirby, S. H., 2001. Rheology of ice I at low stress and elevated confining pressure. Journal of Geophysical Research 106 (6), 11031-11042.

Engeln, J. F., Wiens, D. A., Stein, S., 1986. Mechanisms and depths of Atlantic transform earthquakes. Journal of Geophysical Research 91 (B1), 548-577. 
Evans, B., Goetze, C., 1979. The temperature variation of hardness of olivine and its implication for polycrystalline yield stress. Journal of Geophysical Research 84, 5505-5524.

Furusho, M., Kyuichi, K., 1999. Transformation-induced strain localization in a lherzolite mylonite from the Hidaka metamorphic belt of central Hokkaido, Japan. Tectonophysics $313,411-432$.

Goetze, C., 1978. The mechanisms of creep in olivine. Philosophical Transactions of the Royal Society of London A 288, 99-119.

Goldsby, D. L., Kohlstedt, D. L., 2001. Superplastic deformation of ice: Experimental observations. Journal of Geophysical Research 106 (B6), 11017-11030.

Goldsby, D. L., Kohlstedt, D. L., 2002. Reply to comment by P. Duval and M. Montagnat on "Superplastic deformation of ice: Experimental observations". Journal of Geophysical Research 107 (B11), 2313.

Hirth, G., Kohlstedt, D. L., 1995. Experimental constraints on the dynamics of the partially molten upper mantle 2. Deformation in the dislocation creep regime. Journal of Geophysical Research 100, 15441-15449.

Hirth, G., Kohlstedt, D. L., 1996. Water in the oceanic upper mantle: implications for rheology, melt extraction and the evolution of the lithosphere. Earth and Planetary Science Letters 144, 93-108.

Hirth, G., Kohlstedt, D. L., 2003. Rheology of the upper mantle and the mantle wedge: A view from the experimentalists. In: Eiler, J. (Ed.), The Subduction Factory. Vol. 138 of Geophysical Monograph. American Geophysical Union, pp. 83-105.

Jaroslow, G. E., Hirth, G., Dick, H. J. B., 1996. Abyssal peridotite mylonites: implications for grain-size sensitive flow and strain localization in the oceanic lithosphere. Tectonophysics 256, 17-37.

Jiang, Z., Prior, D. J., Wheeler, J., 2000. Albite crystallographic preferred orientation and grain misorientation distribution in a low-grade mylonite: implications for granular flow. Journal of Structural Geology 22, 1663-1674.

Jin, D., Karato, S.-I., Obata, M., 1998. Mechanisms of shear localization in the continental lithosphere: Inference from the deformation microstructures of peridotites from the Ivrea zone, northwestern Italy. Journal of Structural Geology 20 (2/3), 195-209.

Johnson, K. T. M., Dick, H. J. B., Shimizu, N., 1990. Melting in the oceanic upper mantle: An ion microprobe study of diopsides in abyssal peridotites. Journal of Geophysical Research 95, 2661-2678.

Jung, H., Karato, S.-I., 2001. Water-induced fabric transitions in olivine. Science 293, 1460-1463. 
Karato, S.-I., Toriumi, M., Fujii, T., 1980. Dynamic recrystallization of olivine single crystals during high-temperature creep. Geophysical Research Letters 7 (9), 649-652.

Karato, S.-I., Wu, P., 1993. Rheology of the upper mantle: A synthesis. Science 260, 771778.

Kirby, S. H., 1985. Rock mechanics observations pertinent to the rheology of the continental lithosphere and the localization of strain along shear zones. Tectonophysics 119 , $1-27$.

Mainprice, D., Silver, P. G., 1993. Interpretation of SKS-waves using samples from the subcontinental lithosphere. Physics of the Earth and Planetary Interiors 78, 257-280.

Michibayashi, K., Mainprice, D., 2003. Understanding the deformation of rocks from the Earth's mantle using simultaneous EBSD and EDS. www.hkltechnology.com/data/0mantle.pdf.

Michibayashi, K., Mainprice, D., 2004. The role of pre-existing mechanical anisotropy on shear zone development within oceanic mantle lithosphere: an example from the Oman Ophiolite. Journal of Petrology 45 (2), 405-414.

Montési, L. G. J., Hirth, G., 2003. Grain size evolution and the rheology of ductile shear zones: from laboratory experiments to postseismic creep. Earth and Planetary Science Letters 211, 97-110.

Newman, J., Lamb, W. M., Drury, M. R., Vissers, R. L. M., 1999. Deformation processes in a peridotite shear zone: reaction-softening by an $\mathrm{H}_{2} \mathrm{O}$-deficient, continuous net transfer reaction. Tectonophysics 303, 193-222.

Nicolas, A., Christensen, N. I., 1987. Formation of anisotropy in upper mantle peridotites - A review. In: Fuchs, K., Froidevaux, C. (Eds.), Composition, Structure and Dynamics of the Lithosphere-Asthenosphere System. Vol. 16 of Geodynamics Series. American Geophysical Union, pp. 111-123.

Nishimura, C. E., Forsyth, D. W., 1989. The anisotropic structure of the upper mantle in the Pacific. Geophysical Journal 96, 203-229.

Raj, R., Ashby, M. F., 1971. On grain boundary sliding and diffusional creep. Metallurgical Transactions 2, 1113-1127.

Rutter, E. H., Casey, M., Burlini, L., 1994. Preferred crystallographic orientation development during the plastic and superplastic flow of calcite rocks. Journal of Structural Geology 16 (10), 1431-1446.

Schmid, S. M., Panozzo, R., Bauer, S., 1987. Simple shear experiments on calcite rocks: Rheology and microfabric. Journal of Structural Geology 9 (5/6), 747-778. 
Storey, C. D., Prior, D. J., 2005. Plastic deformation and recrystallization of garnet: A mechanism to facilitate diffusion creep. Journal of Petrology 46 (12), 2593-2613.

Tullis, J., Dell' Angelo, L., Yund, R. A., 1990. Ductile shear zones from brittle precursors in feldspathic rocks: the role of dynamic recrystallization. In: Duba, A. G., Durham, W. B., Handin, J. W., Wang, H. F. (Eds.), The brittle-ductile transition in rocks. Vol. 56 of Geophysical Monograph. American Geophysical Union, pp. 67-82.

Van der Wal, D., Chopra, P., Drury, M., Fitz Gerald, J., 1993. Relationships between dynamically recrystallized grain size and deformation conditions in experimentally deformed olivine rocks. Geophysical Research Letters 20 (14), 1479-1482.

Vissers, R. L. M., Drury, M. R., Hoogerduijn Strating, E. H., Spiers, C. J., van der Wal, D., 1995. Mantle shear zones and their effect on lithosphere strength during continental breakup. Tectonophysics 249, 155-171.

Warren, J. M., Shimizu, N., Dick, H. J. B., 2003. Melt impregnation revealed by clinopyroxene geochemistry in abyssal peridotites. Geochimica et Cosmochimica Acta 67, A526. 

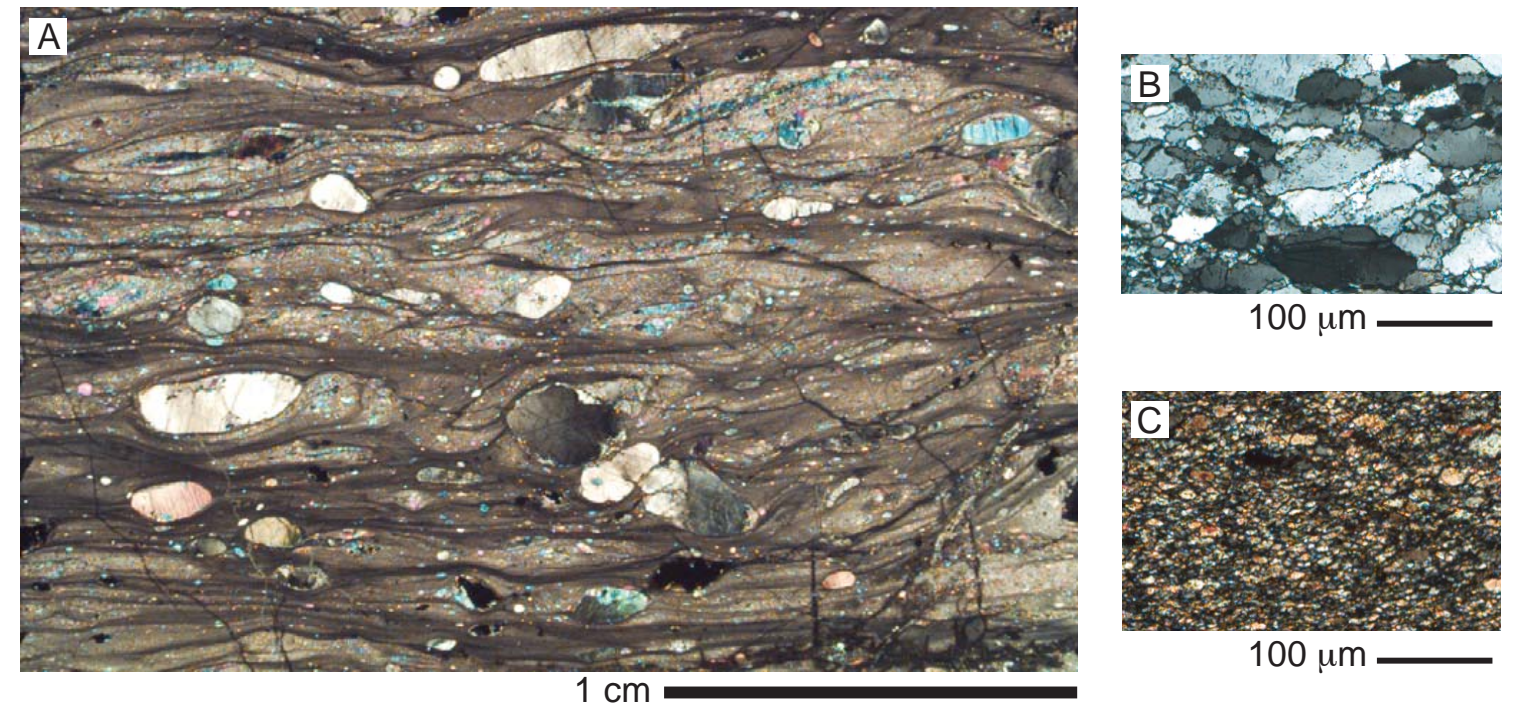

Figure 2.1: (A) Photomicrograph of ultra-mylonite peridotite sample AII-107-61-83 from the Shaka Fracture Zone on the Southwest Indian Ridge. Grain size sensitive deformation has resulted in the formation of anastomosing bands of coarser $(<100 \mu \mathrm{m})$ and finer $(<10$ $\mu \mathrm{m})$ grained olivine, with distributed grains of orthopyroxene, clinopyroxene and spinel. Large porphyroclasts of olivine, orthopyroxene, clinopyroxene, spinel and coarser grained olivine aggregates remain and appear to have behaved as hard inclusions during deformation. (B) Photomicrograph of a coarser grained area of the ultra-mylonite, with a grain size range of 1-100 $\mu \mathrm{m}$. (C) Photomicrograph of a finer grained area, with an olivine grain size of $1-10 \mu \mathrm{m}$. 

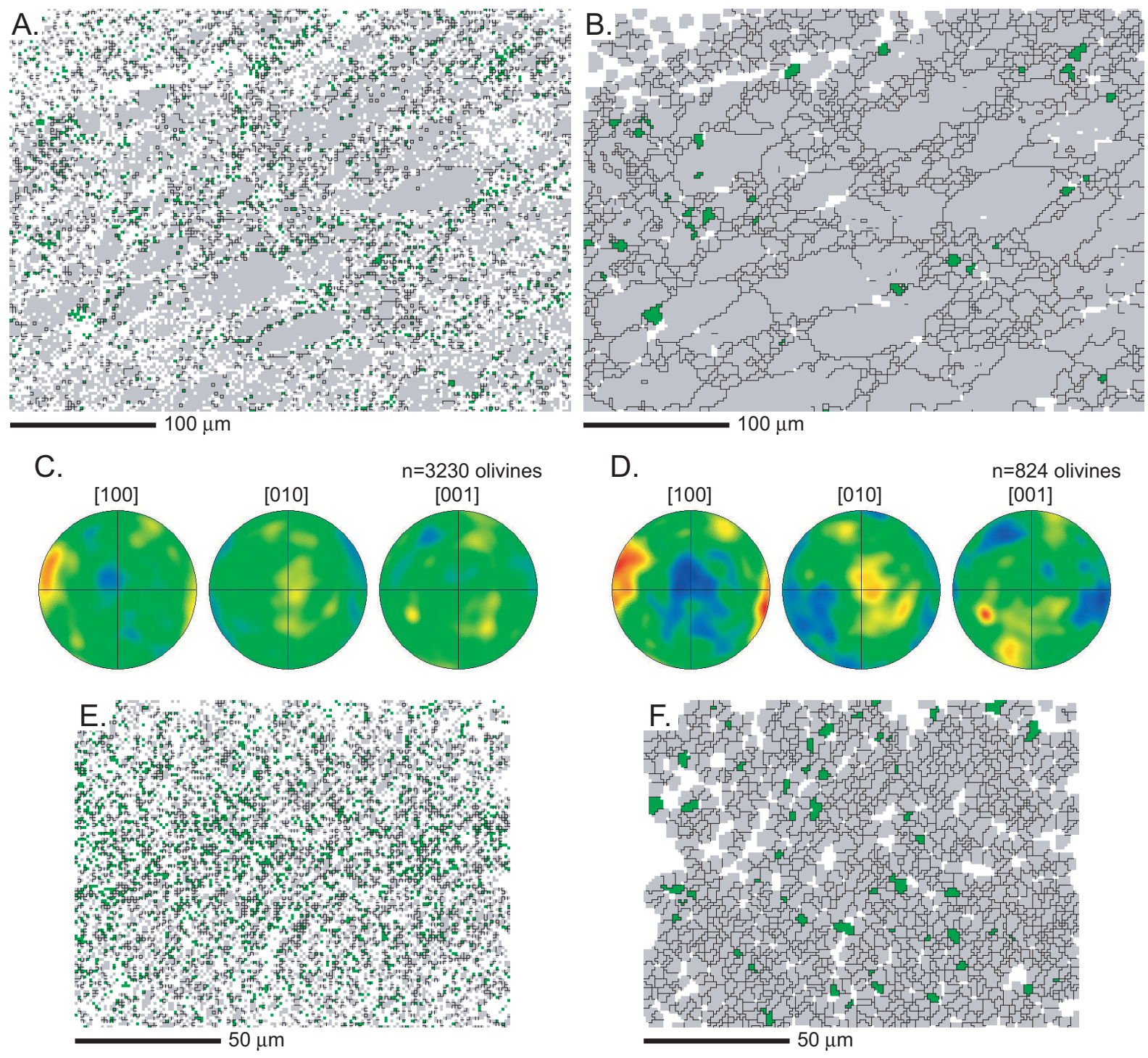

G.
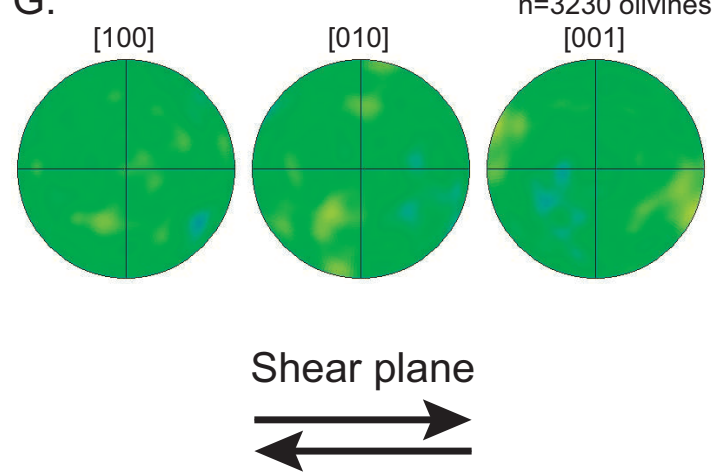

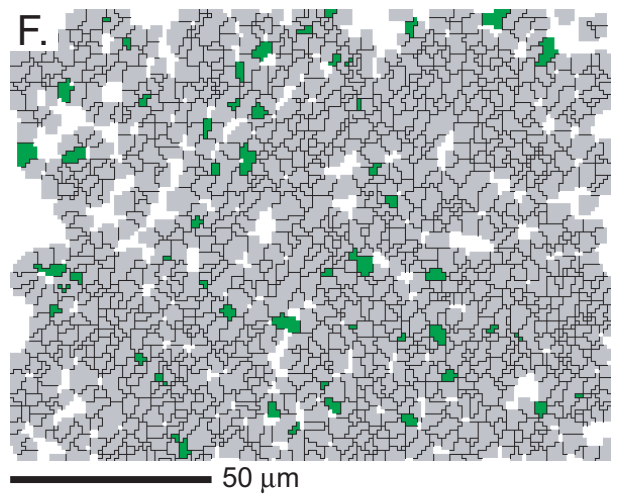

$\mathrm{H}$.
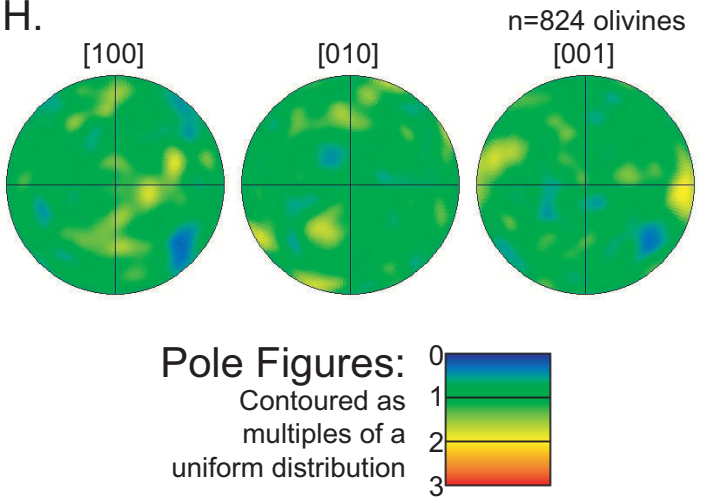

Figure 2.2: Maps of raw data collected in a coarser grained area (A) and a finer grained area (E) of the ultra-mylonite. (Continued on next page.) 


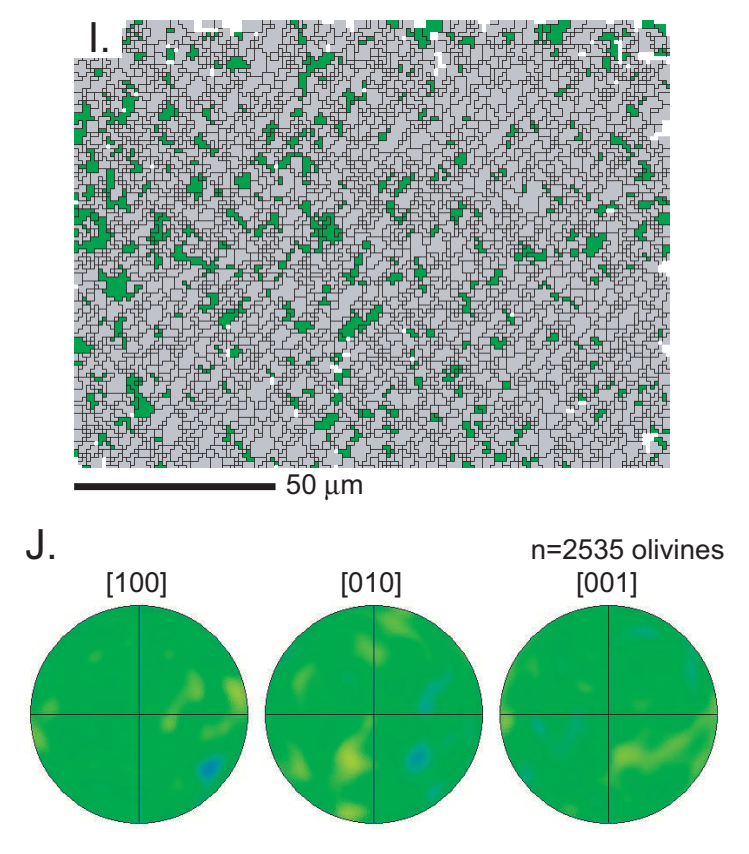

Figure 2.2: (Continued) The coarser grained area was collected at a $2 \mu \mathrm{m}$ step size with a total of $64 \%$ of the area indexed; the finer grained area was collected at a $1 \mu \mathrm{m}$ step size with $52 \%$ indexed. Each grey point represents an olivine orientation collected by EBSD and green points represent secondary phases (orthopyroxene, clinopyroxene, and spinel) for which orientations were measured. White points have a MAD number $\geq 1^{\circ}$. Black lines indicate grain boundaries, defined by a $10^{\circ}$ misorientation between adjacent points. Maps of the processed data, for which wild spikes have been removed and data extrapolated, are shown in (B) and (F). The map in (I) of the fine grained area shows an alternative method of processing the data, in which the data is extrapolated prior to removing wild spikes. Pole figures of one orientation point per olivine grain are shown in $(C),(D),(G),(H)$, and $(J)$. All pole figures are equal area lower hemisphere projections, contoured using a $15^{\circ}$ half width and as multiples of a uniform distribution (MUD) to a maximum of 3 MUD. Contouring of 1 MUD indicates no significant difference from a uniform distribution and corresponds to the absence of an LPO. The shear direction is parallel to the horizontal axis in the pole figures. 

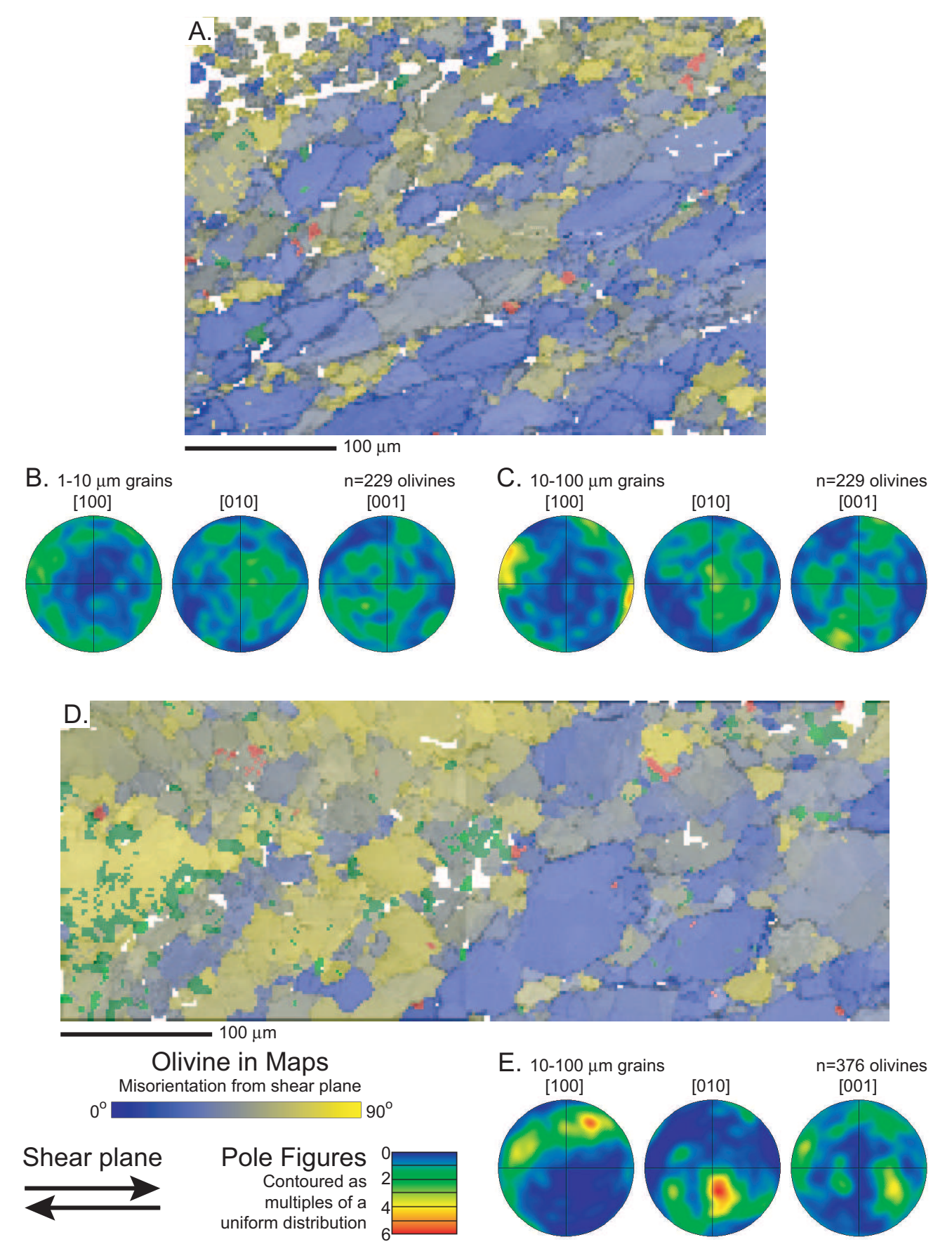

Figure 2.3: Orientation maps collected by EBSD for two coarser grained areas of the mylonite (A, D). The area in (A) is also shown in Fig. 2.2, the area in (D) was collected at a $4 \mu \mathrm{m}$ step size, with $72 \%$ of the area indexed. Olivine is shaded from blue to yellow, with the color range representing the degree of misorientation of each pixel from the shear plane. Dark green corresponds to orthopyroxene, light green to clinopyroxene, red to spinel, and white areas have no data. Pole figures of one orientation per olivine for the area in (A) are shown for 1-10 $\mu \mathrm{m}$ grains in (B) and for 10-100 $\mu \mathrm{m}$ grains in (C). For the area in (D), data are only plotted for $10-100 \mu \mathrm{m}$ grains in (E), due to the large step size of the map. Contouring in all pole figures is to a maximum of 6 MUD. The shear direction is parallel to the horizontal axis in the pole figures. 

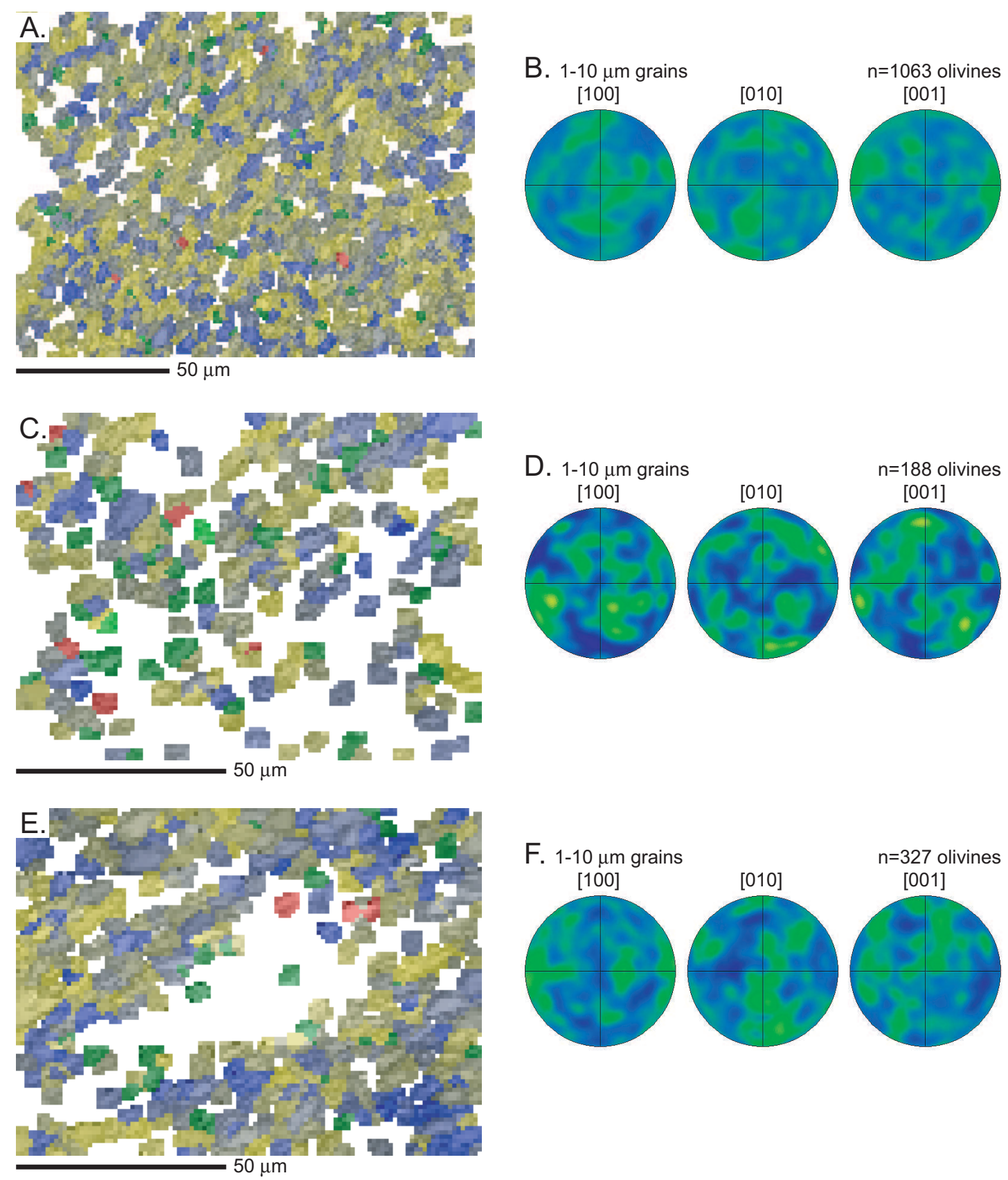

Figure 2.4: Orientation maps for three finer grained areas of the mylonite (A, C, E), using the same color scheme as in Fig. 2.3. The area in (A) is also shown in Fig. 2.2, the area in (C) was collected at a $1 \mu \mathrm{m}$ step size, with $57 \%$ indexed; the area in (E) was also collected at a $1 \mu \mathrm{m}$ step size, with $58 \%$ of the area indexed. Pole figures of one orientation per olivine are shown (B, D, F) for the 3 areas, all of which have grain sizes of 1-10 $\mu \mathrm{m}$. The contour scale is the same as in Fig. 2.3, to a maximum level of 6 MUD. In the first area, the actual maximum is 2 MUD; in the second and third areas it is 3 MUD. 


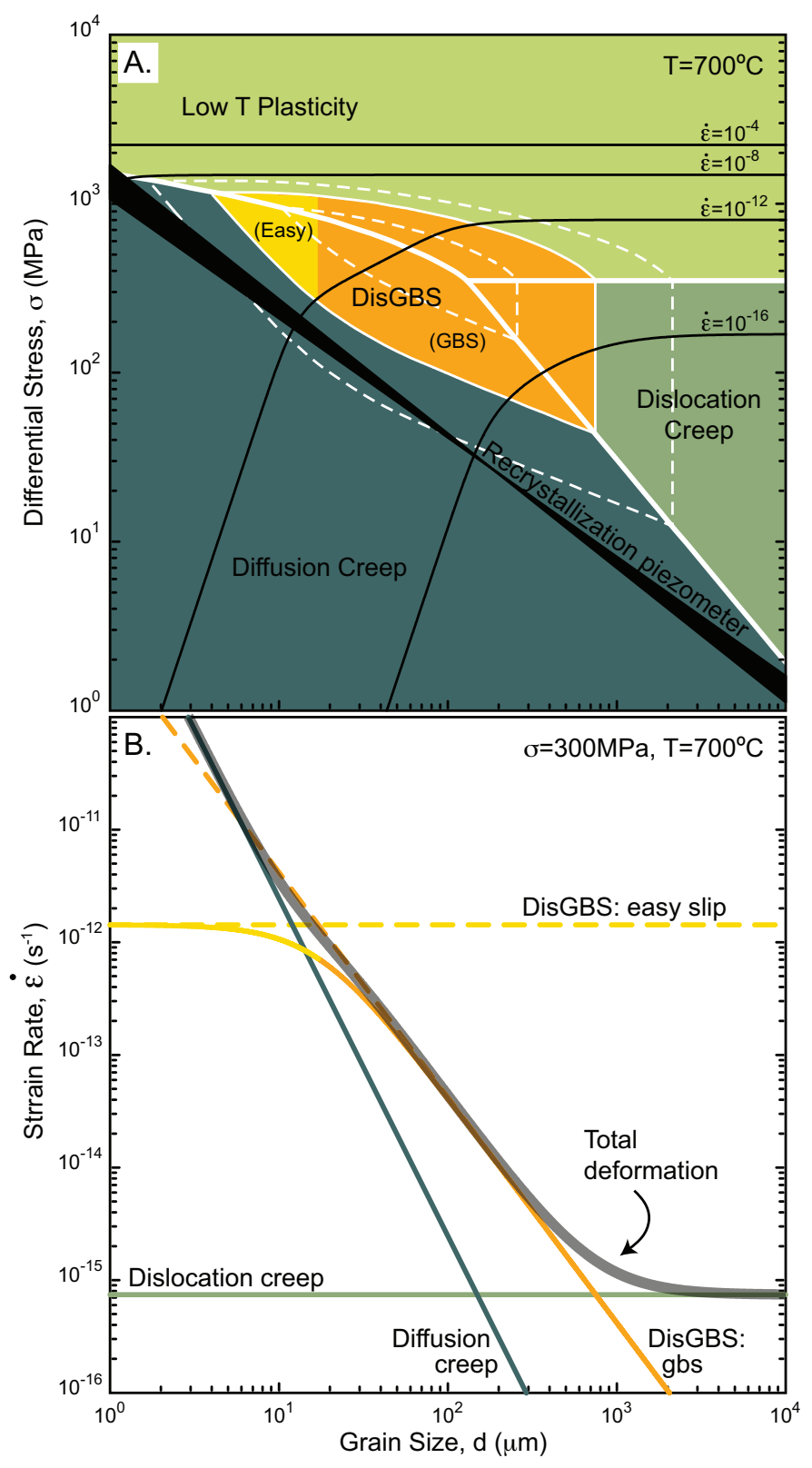

Figure 2.5: (A) An olivine deformation mechanism map, on axes of differential stress versus grain size, contoured for strain rate, plotted using the flow laws for dry, melt free olivine at $700^{\circ} \mathrm{C}$ and $12 \mathrm{~km}$ depth (Goetze, 1978; Evans and Goetze, 1979, Hirth and Kohlstedt, 2003). The black recrystallization piezometer field delimits the grain size predicted by the empirical piezometric relationship for olivine deformed under dry conditions (Karato et al., 1980, Van der Wal et al., 1993). The thick white boundaries between deformation fields indicate field boundaries in the absence of DisGBS. The thin white boundaries delineate the DisGBS field and the dashed boundaries on either side represent uncertainty in the location of the DisGBS boundaries due to uncertainty in its activation energy. The change in shading within the DisGBS field indicates the transition from the regime where creep on the easy slip system limits the strain rate to the regime where GBS limits the strain rate. (B) The variation of total and individual strain rates with grain size, at a differential stress of $300 \mathrm{MPa}$, and at $700^{\circ} \mathrm{C}$ and $12 \mathrm{~km}$ depth. The dashed lines represent the individual components of DisGBS. 


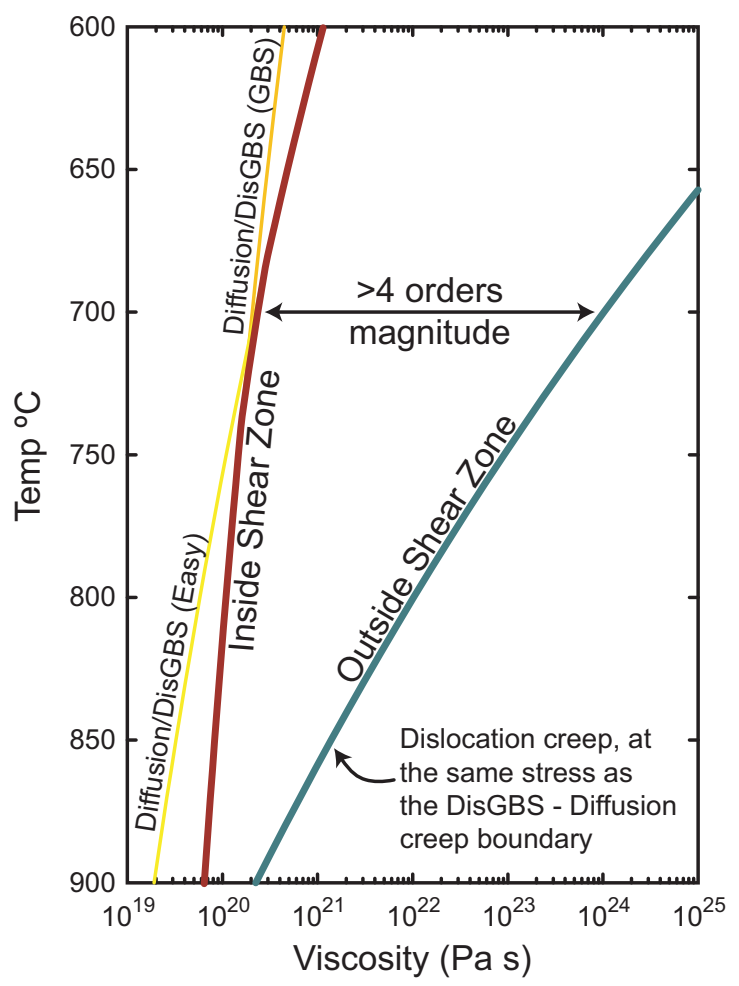

Figure 2.6: The variation of effective viscosity with temperature, for deformation within a shear zone compared to that outside a shear zone. Within the shear zone, viscosity is defined by deformation at the DisGBS-diffusion creep boundary at a total strain rate of $10^{-12} \mathrm{~s}^{-1}$. Deformation outside the shear zone is by dislocation creep, calculated at the same stress as within the shear zone. 


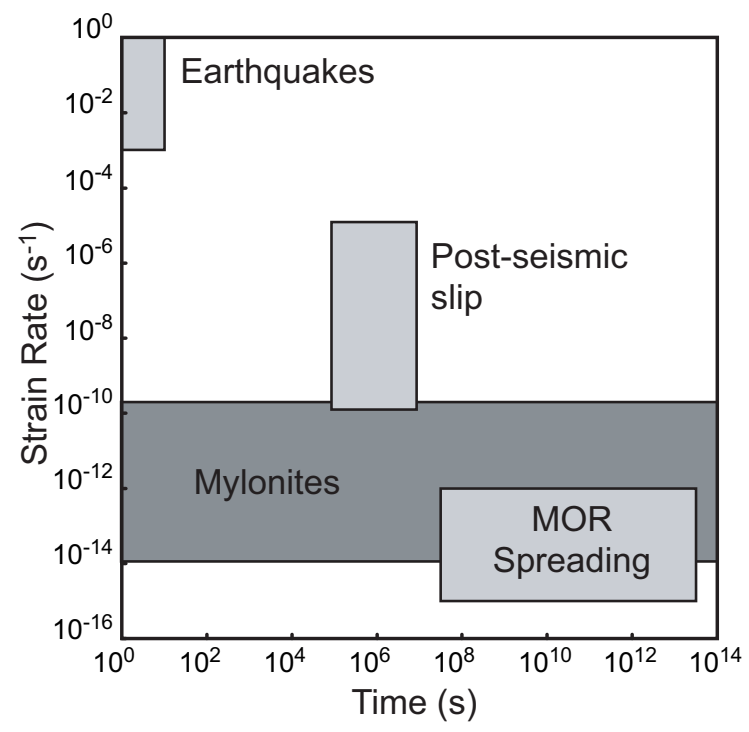

Figure 2.7: Duration versus estimated strain rate for the mylonite and for earthquakes, post-seismic slip and plate spreading. Earthquakes last 1-10 seconds, post-seismic slip lasts 1-100 days, and spreading events from $1 \mathrm{yr}-1 \mathrm{My}$. 


\title{
Chapter 3
}

\section{A Natural Example of Olivine LPO Variation With Shear Strain}

\begin{abstract}
The variation of olivine lattice preferred orientation (LPO) as a function of shear strain is important for models that relate seismic anisotropy to kinematics of deformation in the mantle. We present results on the evolution of olivine orientation in natural samples as a function of increasing shear strain, for a shear zone in the Josephine Peridotite in southwest Oregon. We find that the LPO in harzburgites re-orients from a pre-existing LPO outside the shear zone to a new LPO with the olivine [100] maxima aligned sub-parallel to the shear direction between $168 \%$ and $258 \%$ shear strain. Fabric strengths, quantified using both the J- and M- indexes, do not increase with increasing shear strain. Both (010)[100] and (001)[100] are active in olivine at high strain, suggesting that re-alignment of olivine grains is accommodated by plastic flow during dislocation creep. Unlike experimental observations, our natural samples do not have a secondary LPO peak. We conclude that recrystallization by subgrain rotation dominates over grain boundary migration during fabric realignment in natural samples. The occurrence of girdle patterns among the [010] and [100] axes of harzburgites, but not dunites, suggests that secondary phases affect olivine deformation. We suggest that secondary phases limit olivine grain growth, promoting slip by grain boundary sliding. The activation of grain boundary sliding allows for enhanced activation of the two easiest olivine slip systems, resulting in [010] and [001] girdle patterns. Overall, our results provide an improved framework for calibration of LPO evolution models.
\end{abstract}




\subsection{Introduction}

Understanding olivine orientation as a function of shear strain is critical for quantifying relationships between the kinematics of deformation and the direction and magnitude of seismic anisotropy. For example, constraining the variation of olivine lattice preferred orientation (LPO) produced during simple shear is key to interpreting seismic anisotropy in terms of upper mantle convection (Hess, 1964; Nicolas and Christensen, 1987; Ribe, 1992; Mainprice and Silver, 1993; Blackman and Kendall, 2002). The relationships among olivine deformation, LPO development and seismic anisotropy have been examined experimentally (Nicolas et al., 1973; Zhang and Karato, 1995; Bystricky et al., 2000). Observations from these experiments have been used to place constraints on models (e.g., Wenk and Tomé, 1999; Tommasi et al., 2000; Kaminski and Ribe, 2001) that predict LPO development and thus upper mantle seismic anisotropy. Application of these models to deformation in the earth is improved by comparison of experimental results to rocks deformed under natural conditions, i.e., at lower stress and strain rate than can be achieved in laboratory experiments. To constrain deformation in the upper mantle, we analyzed the evolution of olivine LPO as a function of shear strain in naturally deformed peridotites from a shear zone in the Josephine Peridotite in southwest Oregon.

Mantle anisotropy results from ductile flow in the asthenosphere by dislocation creep, which produces alignment of elastically anisotropic minerals. Olivine and orthopyroxene, the dominant mineral phases in the upper mantle, have orthorhombic symmetry and are anisotropic (Vp anisotropies of $22 \%$ and $16 \%$, respectively; Nicolas and Christensen, 1987). At upper mantle pressure and temperature conditions, they deform by dislocation creep, resulting in an LPO. Deformation is principally accommodated by slip on (010)[100] and (001)[100] in olivine and on (100)[001] in orthopyroxene.

Zhang and Karato (1995) carried out simple shear experiments on olivine aggregates at $1200^{\circ} \mathrm{C}$ and $1300^{\circ} \mathrm{C}$ over a range of shear strains to investigate olivine fabric evolution 
during deformation. They found that the originally random fabric of their aggregates developed an LPO with the [100] maxima parallel to the flow direction by a shear strain of $\sim 150 \%$, as had previously been suggested experimentally by Nicolas et al. (1973). While the Nicolas et al. (1973) experiments were performed in an axial geometry, bubbles in olivine grains aligned with the flow direction at high strain and were interpreted as having deformed by simple shear. Bystricky et al. (2000) demonstrated that the [100] alignment persists to high shear strains (500\%).

The initial theoretical treatments of olivine LPO assumed that olivine grain orientations are controlled by finite strain (e.g., McKenzie, 1979). As slip on (010)[100] has the lowest activation energy (Bai et al., 1991), the olivine [100] axis was predicted to align with the finite strain ellipsoid (McKenzie, 1979; Ribe, 1992). However, experimental results (Nicolas et al., 1973, Zhang and Karato, 1995, Bystricky et al., 2000) indicate that only at low strains $(<100 \%)$ does alignment of the olivine [100] axis coincide with the orientation of the finite strain ellipsoid. This alignment may be more a coincidence than an indication of control on the fabric by the strain geometry. The viscoplastic self-consistent model (VPSC; Lebensohn and Tomé, 1993; Tommasi et al., 2000) approaches alignment of the olivine [100] maxima with the flow direction, but does not achieve alignment due to the lack of dynamic crystallization in the model. Models that include dynamic recrystallization (e.g., Wenk and Tomé, 1999; Kaminski and Ribe, 2001) are able to produce alignment with the shear direction. For example, the DRex model (Kaminski and Ribe, 2001, 2002) achieves a good fit to the experimental data and is parameterized to predict the time-scale for LPO evolution.

We present data from peridotite samples that provide a guide for the extrapolation of experimental results (Nicolas et al., 1973; Zhang and Karato, 1995; Bystricky et al., 2000) to natural conditions. Studies of deformation in naturally deformed peridotites are often hindered by the lack of a well-defined finite strain marker. The Josephine Peridotite is 
ideal for the analysis of fabric evolution with shear strain as it has a pre-existing foliation, defined by variations in pyroxene content, which provide a passive strain marker, as shown in Fig. 3.1. In addition, variations in pyroxene content permit assessment of the effects of secondary phases on olivine LPO development.

The Josephine Peridotite in southwestern Oregon is the mantle section of a $\sim 150 \mathrm{Ma}$ ophiolite from a fore-arc or back-arc setting (Dick, 1976; Harper, 1984; Kelemen and Dick, 1995). The peridotite is predominantly composed of harzburgite, with pyroxene-rich layers in some localities (Dick and Sinton, 1979). A series of shear zones, described by Loney and Himmelberg (1976) and Kelemen and Dick (1995), outcrop over a distance of $300 \mathrm{~m}$ in the Fresno Bench area of the Josephine Peridotite. The shear zones are defined by the sub-vertical to vertical transposition of the originally sub-horizontal lithological layering and by highly lineated pyroxene textures at the centers of the transposed layers (Fig. 3.1). The shear zones vary in width from $\sim 1 \mathrm{~m}$ to $60 \mathrm{~m}$ and exhibit right lateral displacement with a component of NW-down vertical movement (Kelemen and Dick, 1995). Foliations at the shear zone centers strike $035-045^{\circ}$, with a maximum dip of $90^{\circ}$ in the highest strain shear zones.

Maximum temperatures during deformation are constrained by syn-deformational magmatic features. Some of the shear zones cut or are cut by dunites, pyroxenites or gabbroic segregations, implying that temperatures during deformation may have been upwards of $\sim 1200^{\circ} \mathrm{C}$. The lower temperature limit during deformation is constrained by geothermometry of coexisting pyroxene neoblast pairs in deformed harzburgites. Harding (1988) estimated a temperature range of $900-1100^{\circ}$, while Himmelberg and Loney (1973) estimated a temperature of $\sim 1000^{\circ}$, both from two pyroxene thermometry. 


\subsection{Methods}

We analyzed olivine fabrics in harzburgites from the widest of the Josephine shear zones, shown in Fig. 3.1. The shear plane is approximately vertical, based on observations of how it cuts across topography along strike and the similar orientation of nearby shear zones with higher strains (Kelemen and Dick, 1995). Based on our field observations and those of Kelemen and Dick (1995), the shear plane is oriented at $035^{\circ} / 90^{\circ}$ with a lineation plunge of $50^{\circ} \mathrm{NE}$. Harzburgite and inter-layered dunite samples were collected on a NW-SE transect across the shear zone; the pyroxene layer orientation was measured wherever possible. In the geographic reference frame, the pyroxene layers dip $10^{\circ} \mathrm{SW}$ outside of the shear zone and reach a maximum dip of $75^{\circ} \mathrm{SW}$ at the shear zone center (Table 3.1).

A kinematic cross section of the shear zone is shown in Fig. 3.2A, oriented, with the $\mathrm{X}$-axis defined as being parallel to the shear direction and the Z-axis defined normal to the shear plane. This $\mathrm{X}-\mathrm{Z}$ frame of reference is used for the remainder of the figures. For the cross section, the field data are rotated and projected onto the plane $305^{\circ} / 50^{\circ} \mathrm{NE}$, which lies perpendicular to the shear plane. In this kinematic reference frame, the pyroxene layers are at an angle of $78^{\circ}$ to the shear plane outside of the shear zone and are rotated to an angle of $10^{\circ}$ at the center of the shear zone (Table 3.1).

Strain across the shear zone is calculated from the change in pyroxene layer orientation in the kinematic reference frame, shown on the stereonet in Fig. 3.2B. Following the method of Ramsay and Graham (1970), shear strain, $\gamma$, is given by:

$$
\gamma=\cot \left(\alpha^{\prime}\right)-\cot (\alpha)
$$

where $\alpha$ is the initial angle of the pyroxene layering with respect to the shear plane and $\alpha^{\prime}$ is the deflected angle, as shown in Fig. 3.2 C. If the pyroxene layering was initially perpendicular to the shear plane $(\alpha=90)$, shear strain would be calculated from the cotangent of 
the deflection angle. However, as shown in Fig. 3.2 and Table 3.1, the layering is initially at an angle of $78^{\circ}$ to the shear plane.

A maximum shear strain of $525 \%$ is reached at the center of the shear zone. The shear zone is $50-60 \mathrm{~m}$ wide, with a total displacement across the shear zone of $60 \mathrm{~m}$, based on the area under a distance versus strain curve (Ramsay and Graham, 1970). The deflection of the pyroxene layers as a passive strain marker is not the same as the evolution of the finite strain ellipsoid with increasing strain, as shown in Fig. 3.2 C. In addition, when the passive strain marker is not initially perpendicular to the shear plane, it is only coincident with the finite strain ellipsoid at high strain, as indicated in Table 3.1 .

For fabric analyses, the Josephine samples were cut on the plane $305^{\circ} / 50^{\circ} \mathrm{NE}$. Thin sections were prepared with one edge parallel to $305^{\circ}$, so that all fabric data can be oriented with the $\mathrm{X}$-axis parallel to the shear direction and the Z-axis normal to the shear plane. Grain size in two samples, shown in Fig. 3.3. was measured by the line intercept method (Underwood, 1970). We applied a geometric correction factor of 1.75 (Pickering, 1976), which is consistent with the Van der Wal (1993) olivine piezometric data. Average grain size was calculated using the geometric mean, as the grain size distribution is approximately log-normal and thus the geometric mean represents the size with the greatest frequency (Underwood, 1970).

Olivine LPOs were measured on polished thin sections using a JEOL 840 SEM with an electron backscatter diffraction (EBSD) detector and HKL Technology's Channel 5 software package. Thin sections were prepared for analysis by polishing with $0.03 \mu \mathrm{m}$ colloidal silica for $>2$ hours. To limit charging during EBSD analysis, thin sections were coated with gold, then polished for one minute to remove gold from grain surfaces, while leaving gold along cracks and grain boundaries. Samples were mapped for orientations and mineral phases at 40x magnification and 40-100 $\mu \mathrm{m}$ step sizes. Between 24 and 48 overlapping maps were made per thin section and these were combined into a single image using the 
Channel 5 program MapStitcher.

EBSD maps (Fig. 3.4) have 50\% indexed data, following rejection of all points with a mean angular deviation (MAD) number $\geq 1^{\circ}$. The MAD number quantifies the mismatch between lattice planes in a calculated orientation and lattice planes quantified from the digitized diffraction pattern bands. The MAD number provides an indication of data quality, with high numbers resulting from surface roughness and computer mis-indexing.

Data were further processed by removing wild spikes and replacing these, and points with zero solutions, with the most common neighbor orientation. Wild spikes are single pixels (i) which are misoriented by $>10^{\circ}$ from the average orientation of the surrounding eight pixels and (ii) for which the maximum misorientation between any two of the surrounding eight pixels is $<10^{\circ}$. See Warren and Hirth (2006) for a more detailed discussion of our EBSD data processing techniques.

Pole figures and inverse pole figures, shown in Figs. 3.4.3.6, are calculated using one point per grain. Pole figures are equal area lower hemisphere projections and inverse pole figures are equal area upper hemisphere projections. All datasets contain $>200$ grains, as Ben Ismail and Mainprice (1998) have demonstrated that $>100$ grain are necessary to provide robust estimates of fabric pattern and strength. Grain boundaries are defined by misorientations $\geq 10^{\circ}$ between adjacent points and subgrains by $2^{\circ}-10^{\circ}$ misorientations.

\subsection{Results}

From analyses of nine samples across the Josephine shear zone, we find that the olivine [100] maxima, initially oriented at $62^{\circ}$ to the shear plane, is aligned parallel to the shear direction at the center of the shear zone. To visually demonstrate the change in olivine orientation with strain, EBSD orientation maps and inverse pole figures of a low strain and a high strain sample are shown in Fig. 3.4. Olivine is colored as a function of the angle between the [100] axis and the shear plane. In the $65 \%$ strain sample, the majority of 
grains are mid-blue in color, corresponding to a relatively high angle to the shear plane. In contrast, many grains in the $525 \%$ strain sample are dark blue, indicating alignment with the shear plane.

The inverse pole figures in Fig. 3.4 B show the orientation of individual grains parallel $(\mathrm{X})$ and perpendicular $(\mathrm{Z})$ to the shear plane. At $65 \%$ strain, while considerable scatter exists in the distribution, the maximum density of points in the $\mathrm{X}$-section is oriented $37^{\circ}$ to [100]. In the Z-section, the maximum density is close to [001] with a low density around [010], suggesting that (001) is better aligned as the slip plane during the initial realignment of the fabric. At 525\% strain, the highest density of points in the X-section is around [100]. In the Z-section, points cluster around [010] with scatter towards [001], indicating that both (010) and (001) are well oriented as slip planes. The Z-section also indicates that the same grain cannot be well oriented for slip on both (010) and (001).

Pole figures of olivine orientation are shown in Fig. 3.5 for the harzburgites and Fig. 3.6 for the dunite. Outside of the shear zone, the peridotite has a pre-existing LPO, with the olivine [100] maxima sub-parallel to the pre-existing foliation (also shown on the map cross section in Fig. 3.2A). In samples with shear strains up to $168 \%$, the olivine [100] maxima remains inclined to the shear plane, with only a moderate rotation away from the original LPO (Fig. 3.5). Between a shear strain of $168 \%$ and $258 \%$, the olivine LPO rotates so that the [100] maxima is sub-parallel to the shear plane. At higher shear strains, the [100] maxima remains sub-parallel to the shear plane.

The behavior of olivine [010] and [001] axes with increasing strain is more variable than the [100] axis (Fig. 3.5). Outside of the shear zone, (010) planes are sub-parallel to the pyroxene layering, suggesting that (010) was the dominant slip plane during the previous deformation event. At low strain, (001) is sub-parallel to the local layering, suggesting that (001) is initially the dominant slip plane during the fabric realignment. However, at high strain, (010) is sub-parallel to the transposed pyroxene layering. In addition, at high strain, 
(010) and (001) in the harzburgites exhibit girdles, whereas in the dunite they approximate a single maxima (Fig. 3.6).

Grain size and shape remain relatively constant during deformation, despite the change in olivine LPO. Photomicrographs and grain size distributions of two samples, one at low strain and the other at high strain, are shown in Fig. 3.3. At low strain, pyroxenes are slightly elongated, with their long axes approximately aligned with the pyroxene layering and the olivine [100] maxima. Olivine grains are generally equant, with an aspect ratio $(\mathrm{X}: \mathrm{Z})$ of 1.1. At high strain, both orthopyroxenes and olivines are equant, with an olivine aspect ratio of 1.2. The lack of stretched grains indicates significant recrystallization occurred during deformation. The mean grain size is $0.57 \mathrm{~mm}$ in the low strain sample and $0.54 \mathrm{~mm}$ in the high strain sample. The grain size distributions in Fig. $3.3 \mathrm{~B}$ are approximately log-normal, with recrystallization resulting in deviations from the log-normal distribution at small grain sizes $(<0.5 \mathrm{~mm})$.

The variation of the angle of the olivine [100] maxima to the shear plane with strain is compared to experimental results and models in Fig. 3.7. The angle of the olivine [100] maxima relative to the shear plane was determined using eigenvector analysis provided by the program PFch5.app (courtesy of D. Mainprice). The first eigenvector of the orientation tensor represents the mean direction of a crystal axis and is called the principal axis (Woodcock, 1977). We assume that this principal axis is more representative of the average [100] orientation than the location of the maximum density of data on the pole figure. In Fig. 3.7. we use the principal axis orientation to plot the variation of olivine [100] maxima with shear strain. In comparison to experiments, the Josephine samples are observed to require higher strain to align with the shear direction.

The strength of an LPO can be quantified using either the J-index (Bunge, 1982; Mainprice and Silver, 1993) or the M-index (Skemer et al., 2005), both of which are plotted for our samples in Fig. 3.8 as a function of shear strain. In addition, we plot the published 
J-index values for the experimental datasets and models. Both indexes quantify overall fabric strength of all three olivine axes combined. The M-index quantifies the deviation of the uncorrelated misorientation angle distribution from a random crystal misorientation distribution (Skemer et al., 2005). Uncorrelated misorientation angles represent the angular difference in orientation (i.e. misorientation) between random grain pairs (i.e., not necessarily adjacent). The M-index varies between 0 for a random fabric and 1 for a single crystal. The J-index is a dimensionless characterization of the orientation distribution function $(\mathrm{ODF})$ of crystal orientations as specified by Euler angles. It describes the distribution of Euler angle rotations away from a single crystal orientation, varying between 1 for a random LPO and infinity for a single crystal. In practice, the J-index has a maximum value of 250, as the ODF is truncated at degree 22. For our J-index calculations, we used the program SuperJctf.app (courtesy of D. Mainprice) with a $10^{\circ}$ Gaussian half-width, data clustered in $1^{\circ}$ bins and combined even and odd spherical harmonics.

In the Josephine samples, neither the M-index nor the J-index demonstrate a significant increase in fabric strength with strain. The J-index is relatively constant as a function of shear strain and typically in the range 5-8. The M-index initially increases in strength but then is relatively constant with an average value of 0.14 . The only exception is the $386 \%$ strain harzburgite, which has a visibly weaker fabric in the pole figure (Fig. 3.5) and the lowest $\mathrm{J}$ - and $\mathrm{M}$-index values.

\subsection{Discussion}

Our results on olivine LPO evolution during simple shear extend observations of LPO variations to lower stresses and strain rates than available from experimental datasets (Zhang and Karato, 1995, Bystricky et al., 2000). While our observations broadly agree with the experimental observations, our results suggest that a pre-existing LPO influences the strain necessary for LPO alignment with the shear direction. In addition, the pre-existing LPO 
and the presence of secondary phases affect the behavior of olivine slip systems during deformation.

The orientation of the olivine [100] maxima as a function of shear strain in the Josephine shear zone is compared to the experimental datasets and models in Fig. 3.7. The experiments and models initially have a random fabric, whereas the [100] maxima in the Josephine harzburgites initially lies at an angle of $62^{\circ}$ to the shear direction and has a J-index of 6.2. Also in the natural samples, the [100] maxima does not align with the shear direction until $250 \%$ strain, whereas alignment occurs before $200 \%$ strain in the Bystricky experiments and $\sim 150 \%$ strain in the Zhang and Karato experiments. Below, we compare our results in more detail to LPO evolution models and then discuss the effects of a pre-existing LPO, grain size and secondary phases on the behavior of olivine during deformation in the upper mantle.

\subsubsection{Comparison to LPO evolution models}

As a tool for predicting and interpreting seismic anisotropy, various theoretical models predict olivine LPO evolution during deformation (for a review, see Tommasi et al., 2000). The evolution of the olivine [100] axis with strain is shown for four models in Fig. 3.7. Two are end-member models that assume the olivine LPO follows either the shear direction or the finite strain ellipsoid (McKenzie, 1979; Ribe, 1992). The experimental datasets (Nicolas et al., 1973; Zhang and Karato, 1995; Bystricky et al., 2000) demonstrated that these end-member models do not accurately predict the evolution of olivine LPOs with shear strain, and the Josephine data agree with this conclusion. The best fit of the VPSC (Tommasi et al., 2000) and DRex (Kaminski and Ribe, 2001) models to the Zhang and Karato experiments are also shown in Fig. 3.7

The VPSC model is a parameterization of the deformation of an olivine aggregate that treats each grain as an inhomogeneity embedded in a homogeneous effective medium 
(Lebensohn and Tomé, 1993). The average stress and strain rate for all grains is constrained to be consistent with the equivalent macroscopic magnitudes. A reasonable match of VPSC pole figures to experimental pole figures is achieved by relaxing the strain compatibility requirement, but the evolution of the olivine LPO does not occur at low enough shear strain to be consistent with either the experiments or the natural samples. The VPSC line shown in Fig. 3.7 is for a model run to $350 \%$ shear strain with a dimensionless strain compatibility value of $\alpha=100$. Linear extrapolation to higher strain suggests that the [100] maxima will only align with the shear direction at $\sim 1000 \%$ shear strain. However, the VPSC model is not well constrained at $>100 \%$ strain, as it does not account for complexities associated with highly deformed grains (Blackman et al., 2002) or recrystallization.

To obtain a better match to experimental data, Wenk and Tomé (1999) and Kaminski and Ribe (2001) developed models that include dynamic recrystallization, which has been demonstrated to occur at high strain and temperature (Carter, 1976, Karato, 1988). In both models, recrystallization is treated as a balance of grain boundary migration (relatively undeformed grains replace highly deformed grains) and grain nucleation (highly deformed grains nucleate strain-free subgrains with the same orientation). DRex (Kaminski and Ribe, 2001 ) predicts the deformation of an olivine aggregate by defining a local velocity gradient tensor for each grain and a macroscopic velocity gradient tensor. A good fit to the experimental data is provided by optimizing the dimensionless grain boundary migration $\left(M^{*}\right)$ and grain nucleation $\left(\lambda^{*}\right)$ parameters. For $M^{*}=200$ and $\lambda^{*}=5$, the [100] maxima aligns with the flow direction by $100 \%$ strain and pole figures are in good agreement with the Zhang and Karato experiments. DRex is a computationally simpler model than VPSC, but relies on two adjustable parameters, whereas VPSC has only one. In addition, the relative stress necessary for activation of different slip systems is specified in all models based on experimental data (e.g., Bai et al., 1991).

In detail, the Josephine shear zone data do not agree with predictions from either VPSC 
or DRex, which were both optimized to fit the Zhang and Karato experiments (Fig. 3.7). The transition to a shear aligned fabric in the Josephine harzburgites occurs at significantly lower strain than predicted by VPSC, due to the absence of dynamic recrystallization in VPSC. DRex has a similar rate of change of LPO with strain, when compared to the Josephine samples. However, the change occurs at lower shear strain in DRex, probably due to the initially random LPO in DRex. The predicted DRex pole figures have more pronounced maxima than the Josephine samples, which is likely a result of the absence of secondary phases in DRex (discussed below). A more recent version of DRex allows for incorporation of orthopyroxene (Kaminski et al., 2004), but the effect of orthopyroxene on pole figure patterns has not yet been explored.

\subsubsection{Active slip systems and the pre-existing LPO}

We suggest that the high strain necessary for [100] alignment in the Josephine samples is related to the high initial angle of the [100] maxima to the shear plane. The olivine slip system (001)[100] dominates at low strain, which probably relates to the initial orientation of (001) with respect to the principle compressive stress, $\sigma_{1}$. If $\sigma_{1}$ is assumed to be at $45^{\circ}$ to the shear plane and in the plane of deformation, then the [100] maxima is calculated to have an angle of $78^{\circ}$ to $\sigma_{1}$ and to lie outside of the plane of deformation. The olivine [010] and [001] maxima are calculated to have initial angles of $41^{\circ}$ and $53^{\circ}$ to $\sigma_{1}$, respectively. Hence both (010) and (001) are well aligned as slip planes, but [100] is poorly aligned as the slip direction. Movement along any other glide direction apart from [100] in olivine requires higher stress or high water contents (e.g., Jung and Karato, 2001). Re-alignment of the [100] maxima into the plane of deformation and parallel to the shear direction requires dislocation creep and recrystallization. We conclude that the initial angle of the [100] maxima affects the amount of strain necessary for re-alignment. For example, if the olivine [100] maxima was initially at $<45^{\circ}$ to $\sigma_{1}$ and the shear direction, we anticipate that only a 
small amount of strain would be necessary for alignment with the shear direction.

The behavior of the olivine [010] and [001] axes with increasing strain suggests that the dominant slip system in olivine varied during deformation. The orientation of the [100] maxima does not vary significantly until it changes between $161 \%$ and $258 \%$ strain (Fig. 3.5. In contrast, (010) is well aligned for slip outside the shear zone (in the previous kinematic reference frame), whereas at low strain (001) is better aligned. Our observations suggest that from $65 \%$ to $131 \%$ strain, the dominant slip system is (001)[100], instead of the "typical" (010)[100] system. At strains $>168 \%$, both slip systems are equally active, indicated by variable amounts of girdling in the [010] and [001] pole figures (Fig. 3.5).

Variation of the dominant olivine slip plane between (010) and (001) suggests that realignment of the LPO is accommodated by rotation during slip on these two planes, combined with recrystallization. In contrast, in the Zhang and Karato experiments, [010] and [100] are observed to rotate around the perimeter of the pole figure with increasing strain, while [001] is generally inactive in all experiments (Zhang et al., 2000). Their results suggest that alignment of [100] with the shear direction is accomplished predominantly by grain rotation and slip on (010)[100]. In contrast, in the Josephine samples, the fact that [100] and [010] do not rotate around the perimeter of the pole figure indicates that LPO realignment is not accomplished simply by rigid grain rotation. Instead, we suggest that the LPO re-alignment occurs by internal rotation within the olivine crystal during dislocation creep on (010)[100] and (001)[100].

The presence of a pre-existing LPO is particularly relevant to modeling anisotropy during corner flow beneath ridge axes and subduction zones. The rate at which LPO re-aligns has been included in more recent versions of DRex (Kaminski and Ribe, 2002, Kaminski et al., 2004) and in recent mantle flow models that predict anisotropy (e.g., Conrad et al., 2007). Our results can be used in these models to better constrain the amount of strain necessary for LPO alignment. While the upwelling mantle may initially have no fabric, during 
active upwelling it will develop an LPO with the olivine [100] axis vertically aligned (e.g., Blackman et al., 1996). After corner flow, the LPO will be poorly oriented with respect to $\sigma_{1}$, requiring more strain for the [100] axis to align horizontally than if it formed from a random fabric. Alternatively, as the mantle undergoes corner flow, the change in olivine orientation may be able to track the change in $\sigma_{1}$ orientation, depending on the rate at which LPO re-aligns versus the rate of plate spreading.

\subsubsection{LPO Strength}

Fabric strength, or the amount to which minerals align, is another important parameter for constraining seismic anisotropy. In Fig. 3.8, the strengths of Josephine LPOs are compared to the experimental datasets and model predictions. The Zhang and Karato experiments have similar fabric strengths to the Josephine samples at $1200^{\circ} \mathrm{C}$, but at $1300^{\circ} \mathrm{C}$ the experiments reach stronger fabrics at higher strain. Comparison of the pole figures for the high temperature experiments (Zhang et al., 2000) to the Josephine samples reveals that the strengths of the [100] peaks are similar, but that the experimental samples have much stronger [010] and [001] fabrics. Hence, the rapid increase in J-index with shear strain observed in the experiments is a result of alignment of the [010] and [001] axes. In the Josephine samples, [010] and [001] tend to have girdled patterns, leading to weaker J-indexes.

The high strain torsion experiments of Bystricky et al. (2000) have increasing J-indexes with strain, but at a lower rate than observed in the Zhang and Karato experiments. The maximum J-index value among the Bystricky experimental samples is similar to the maximum value among the Josephine natural samples. However, the Bystricky experiments suggest that fabric strength will continue to increase with increasing strain, whereas the Josephine samples do not. These differences may be due to a combination of an initially random fabric and a lack of secondary phases in the experiments. 
Both DRex and VPSC predict rapidly increasing fabric strength with shear strain. While the models initially have a random fabric and hence the fabric strength must increase at low strain when an LPO forms, the continued increase in the models does not match our observations. In the limit of infinite strain, the models would reach a single crystal fabric that has not been observed in natural samples. We suggest that this discrepancy is due to the fact that the models do not account for all processes occurring during deformation. For example, the presence of secondary phases in peridotites is one limitation on fabric strength, as it promotes slip on multiple systems.

The M-index is a more recently developed quantification of fabric strength than the Jindex (Skemer et al., 2005) and has not be calculated for the majority of published data. Both indexes follow the same general trend with shear strain in Fig. 3.8. In Fig. 3.9, we compare the M-index to the J-index for the Josephine samples. The two indexes cannot be directly related as they are based on different parameterizations of crystal orientation. A linear least squares regression through the dataset produces a reasonable correlation between the J-index and M-index, with a correlation coefficient of 0.7. Improved understanding of these indexes of fabric strength requires more published datasets to included values for both the J-and M-indexes.

Overall, we observe lower LPO intensities than predicted by the VPSC and DRex models. The match is better for the experimental datasets, with the exception of the high temperature, high strain experiments of Zhang and Karato (1995). These differences indicate that the models do not replicate all aspects of the natural environment. However, seismic properties are only weakly dependent on LPO intensity (e.g., Tommasi et al., 2000). For the prediction of seismic anisotropy, the rate at which olivine aligns with the shear direction is more important than the fabric strength which is produced. 


\subsubsection{Grain size variation and recrystallization}

Grain size reduction does not occur during the transition from low strain to high strain in the Josephine samples. Both low and high strain samples have a grain size of 0.5-0.6 mm and nearly equant grains (Fig. 3.3). The absence of stretched grains indicates that dynamic recrystallization occurred during deformation. This further supports the observation from the olivine pole figures (Fig. 3.5) that the LPO realignment was not the result of the rigid rotation of olivine grains. Our observations are in contrast to the experiments (Zhang and Karato, 1995; Zhang et al., 2000; Bystricky et al., 2000), which at high strain have stretched and elongated grains. We suggest that these differences are related to the higher differential stress used for the experiments, and the difference between initial and steady-state grain size in the experiments.

The similar grain size at low and high strain in the Josephine samples indicates relatively constant stress during deformation. In addition, stress must be continuous across the shear zone. The olivine piezometer (Karato et al., 1980; Van der Wal et al., 1993) relates dynamically recrystallized grain size to stress. As shown in Fig. 3.10, the piezometer indicates that for a grain size of 0.5-0.6 mm, differential stress during deformation was $\sim 10$ MPa. The experimental datasets are also plotted in Fig. 3.10, for which the stress was measured during the experimental run (Zhang et al., 2000; Bystricky et al., 2000). The grain size estimates from Zhang et al. (2000) have been adjusted to the same geometrical correction factor as the Van der Wal piezometric dataset (Van der Wal, 1993) and show reasonable agreement with the piezometer. Differential stress estimated from the piezometer can be used to estimate the strain rate during deformation of the Josephine peridotite. Using the olivine flow law for dislocation creep (Bai et al., 1991; Hirth and Kohlstedt, 2003) at a temperature of $1100^{\circ} \mathrm{C}$, we estimate a strain rate of $10^{-12} \mathrm{~s}^{-1}$ and a viscosity of $10^{19}$ Pa s.

In the experimental datasets (Zhang and Karato, 1995; Bystricky et al., 2000), a second 
LPO maxima - [100] aligned perpendicular to $\sigma_{1}-$ is observed. Lee et al. (2002) relate this peak to grains that are poorly oriented for slip and thus have low dislocation densities. These grains grow by grain boundary migration at the expense of well-oriented grains that have developed high dislocation densities. The subset of grains with [100] aligned with $\sigma_{1}$ is not observed in the Josephine samples (Figs. 3.5 and 3.6. The important role of grain boundary migration in the experiments is likely due to the higher differential stress, which results a larger driving force for grain boundary migration. In contrast, at low stress, we suggest that subgrain rotation is a more important process for fabric development than grain boundary migration.

In the DRex model, the parameter $M^{*}$ controls grain boundary mobility during LPO formation. At $M^{*}=0$, the LPO predicted by DRex never aligns with the shear plane, but instead aligns with the finite strain ellipsoid. For $M^{*}>0$, the olivine [100] maxima aligns with the shear plane, with decreasing amounts of shear strain necessary for alignment as $M^{*}$ increases. The best fit of DRex to the $1300^{\circ} \mathrm{C}$ Zhang and Karato experimental data is achieved when $M^{*}=200$, as shown in Fig. 3.7. The strain at which [100] aligns in the Josephine samples is consistent with a $M^{*}$ value of $\sim 50$. However, Kaminski and Ribe (2001) also found a second [100] maxima when $M^{*}=50$, observed in the experimental samples but not the Josephine.

None of the current set of models for LPO formation accurately replicate the microstructural observations from the Zhang and Karato experiments. In the experiments, the secondary [100] maxima results from the growth of grains that have low dislocation densities and are poorly aligned for slip. In the DRex model (Kaminski and Ribe, 2001), the secondary peak is produced by the formation of recrystallized grains perpendicular to $\sigma_{1}$ that are well oriented for slip. In the Wenk and Tomé (1999) model, the secondary maxima occurs when grain boundary migration dominates over grain nucleation, similar to the Zhang and Karato experiments. However, the primary [100] maxima is formed by 
nucleation of grains with low dislocation densities, in contrast to the Zhang and Karato experiments (e.g., Lee et al., 2002). In the VPSC model, which does not include dynamic recrystallization, the secondary [100] maxima is not observed, but alignment of the [100] maxima with the shear direction also does not occur. Intriguingly, the model of Etchecopar and Vasseur (1987) produces a single [100] maxima aligned with the shear plane. However, this model does not accurately treat strain compatibility, as it includes only one olivine slip system and assumes recrystallization of all grains to minimize grain misfits.

\subsubsection{Effect of secondary phases}

In the Josephine samples, girdle patterns are observed among the high strain harzburgites, whereas the high strain dunite has point maxima (Figs. 3.5.3.6. In the VPSC model, girdled patterns are produced by relaxing the strain compatibility requirement (e.g., $\alpha=100$ ) and equating the critical resolved shear stress for slip on (010)[100] and (001)[100]. Similarly, DRex produces a girdle pattern by allowing these two slip systems to have equal softness, whereas a point maxima is only produced when slip on (001)[100] is twice as hard as slip on (010)[100]. These observations suggest that the secondary phases (pyroxenes and spinel) in the Josephine harzburgites provide a mechanism for promoting dominant slip on both (010)[100] and (001)[100], by relaxing the strain compatibility requirement.

We suggest that strain compatibility in the harzburgites is effectively relaxed by a reduced grain size that leads to a component of dislocation-accommodated grain boundary sliding (DisGBS). Secondary phases limit olivine grain growth in the harzburgites, as has been observed in mylonites (Warren and Hirth, 2006) and in Oman Ophiolite harzburgites and dunites (Braun, 2004). At a smaller grain size, some deformation is by DisGBS, which accommodates deformation by the movement of dislocations within crystals and by grain boundary sliding (Hirth and Kohlstedt, 2003; Drury, 2005; Warren and Hirth, 2006). Following (Braun, 2004), we conclude that grain boundary sliding during DisGBS relaxes the 
requirement for slip on the hardest olivine slip system, (010)[001], as otherwise required by the von Mises criterion (von Mises, 1928). Consequently, a significant component of slip is accommodated by (001)[100], which has only a slightly larger critical resolved shear stress with respect to the (010)[100] slip system (Bai et al., 1991). In contrast, deformation in the dunite is by dislocation creep due to a slightly larger grain size and thus activity of the hard slip system (010)[001] limits activity on (001)[100].

Evidence for relaxation of the strain compatibility requirements is also observed in the Bystricky et al. (2000) torsion experiments, which have girdled pole figure patterns. The high stress and strain rate of the experiments results in dynamic recrystallization to a grain size of 3-4 $\mu \mathrm{m}$, within the field for dominant deformation by DisGBS (Hirth and Kohlstedt, 2003; Drury, 2005; Warren and Hirth, 2006). In this situation, secondary phases are not necessary to limit grain size during the experiment.

\subsection{Conclusions}

At low strain in a shear zone in the Josephine Peridotite, the olivine LPO is at an angle of $\sim 50^{\circ}$ to the shear direction, whereas at $>258 \%$ strain, the olivine [100] maxima is aligned with the shear direction. Our results on olivine LPO evolution during shear are consistent with the conclusion from experimental data (Zhang and Karato, 1995; Bystricky et al. 2000) that olivine LPO aligns with shear direction during deformation. However, the naturally deformed samples require higher shear strains for alignment to occur and fabric strength does not increase with shear strain. Consequently, the Josephine shear zone data do not agree in detail with predictions from polycrystal plasticity models (Wenk and Tomé, 1999; Tommasi et al., 2000; Kaminski and Ribe, 2001), which have been fit to the experimental datasets.

In comparison to the experimental datasets and the model predictions, the natural sam-

ples have (i) a pre-existing LPO, (ii) no significant variation in LPO strength, (iii) secondary 
phases in addition to olivine, and (iv) recrystallization without grain size reduction at high strain. The higher strain necessary for LPO alignment in the Josephine samples appears to be related to the orientation of the pre-existing LPO. The realignment of the olivine grains is not simply a passive rotation, due to the observation of slip on both (010)[100] and (001)[100] during the fabric realignment. We suggest that the initial activity of (001)[100] is due to the orientation of the pre-existing LPO, whereas at high strain, activation of (001)[100] is facilitated by the presence of additional phases in the peridotite. We also suggest that secondary phases pin olivine grain size, leading to deformation by DisGBS and similar amounts of activity on two olivine slip systems. The lack of significant grain size reduction in the Josephine samples indicates that stress was relatively constant during deformation. In addition, from comparison to the models and from thin section observation, we conclude that recrystallization by subgrain rotation dominates over grain boundary migration in the natural setting. Our results extend the observations of olivine LPO evolution to much lower stresses and strain rates than are accessible experimentally and indicate the importance of a pre-existing fabric and secondary phases for the evolution of anisotropy with shear strain. 


\subsection{Bibliography}

Bai, Q., Mackwell, S. J., Kohlstedt, D. L., 1991. High-temperature creep of olivine single crystals 1. Mechanical results for buffered samples. Journal of Geophysical Research 96 (B2), 2411-2463.

Ben Ismaïl, W., Mainprice, D., 1998. An olivine fabric database: an overview of upper mantle fabrics and seismic anisotropy. Tectonophysics 296, 145-157.

Blackman, D. K., Kendall, J. M., 2002. Seismic anisotropy in the upper mantle: 2. Predictions for current plate boundary flow models. Geochemistry, Geophysics, and Geosystems 3 (9), 10.1029/2001GC000247.

Blackman, D. K., Kendall, J. M., Dawson, P. R., Wenk, H. R., Boyce, D., Morgan, J. P., 1996. Teleseismic imaging of subaxial flow at mid-ocean ridges: traveltime effects of anisotropic mineral texture in the mantle. Geophysical Journal International 127 (415426).

Blackman, D. K., Wenk, H. R., Kendall, J. M., 2002. Seismic anisotropy of the upper mantle: 1. Factors that affect mineral texture and effective elastic properties. Geochemistry, Geophysics, and Geosystems 3 (9), 10.1029/2001GC000248.

Braun, M. G., 2004. Petrologic and microstructural constraints on focused melt transport in dunites and the rheology of the shallow mantle. Ph.D. thesis, MIT/WHOI Joint Program.

Bunge, H. J., 1982. Texture Analysis in Materials Sciences. Butterworths, London.

Bystricky, M., Kunze, K., Burlini, L., Burg, J.-P., 2000. High shear strain of olivine aggregates: Rheological and seismic consequences. Science 290, 1564-1567.

Carter, N. L., 1976. Steady state flow of rocks. Reviews of Geophysics and Space Physics 14 (3), 301-360.

Conrad, C. P., Behn, M. D., Silver, P. G., 2007. Global mantle flow and the development of seismic anisotropy: Differences between the oceanic and continental upper mantle. Journal of Geophysical Research 112, 10.1029/2006JB004608.

Dick, H. J. B., 1976. Origin and emplacement of the Josephine Peridotite of southwestern Oregon. Ph.D. thesis, Yale University.

Dick, H. J. B., Sinton, J. M., 1979. Compositional layering in alpine peridotites: Evidence for pressure solution creep in the mantle. Journal of Geology 87, 403-416.

Drury, M. R., 2005. Dynamic recrystallization and strain softening of olivine aggregates in the laboratory and the lithosphere. In: Gapais, D., Brun, J. P., Cobbold, P. R. (Eds.), Deformation Mechanisms, Rheology and Tectonics: from Minerals to the Lithosphere. No. 243 in Special Publication. Geological Society of London, pp. 143-158. 
Etchecopar, A., Vasseur, G., 1987. A 3-D kinematic model of fabric development in polycrystalline aggregates: comparisons with experimental and natural examples. Journal of Structural Geology 9 (5/6), 705-717.

Grimmer, H., 1979. The distribution of disorientation angles if all relative orientations of neighbouring grains are equally probable. Scripta Metallurgica 13, 161-164.

Harding, D. J., 1988. Josephine peridotite tectonites: A record of upper-mantle plastic flow (Klamath Mountains, Oregon). Ph.D. thesis, Cornell University.

Harper, G. D., September 1984. The Josephine ophiolite, northwestern California. Geological Society of America Bulletin 95, 1009-1026.

Hess, H. H., 1964. Seismic anisotropy of the uppermost mantle under oceans. Nature 203 (4945), 629-631.

Himmelberg, G. R., Loney, R. A., 1973. Petrology of the Vulcan Peak alpine-type peridotite, southwestern Oregon. Geological Society of America Bulletin 84, 1585-1600.

Hirth, G., Kohlstedt, D., 2003. Rheology of the upper mantle and the mantle wedge: A view from the experimentalists. In: Eiler, J. (Ed.), The Subduction Factory. Vol. 138 of Geophysical Monograph. American Geophysical Union, pp. 83-105.

Jung, H., Karato, S.-I., 2001. Water-induced fabric transitions in olivine. Science 293, 1460-1463.

Kaminski, É., Ribe, N. M., 2001. A kinematic model for recrystallization and texture development in olivine polycrystals. Earth and Planetary Science Letters 189, 253-267.

Kaminski, É., Ribe, N. M., 2002. Timescales for the evolution of seismic anisotropy in mantle flow. Geochemistry, Geophysics, and Geosystems 3 (8), 10.1029/2001GC000222.

Kaminski, É., Ribe, N. M., Browaeys, J. T., 2004. D-Rex, a program for calculation of seismic anisotropy due to crystal lattice preferred orientation in the convective upper mantle. Geophysical Journal International 158, 744-752.

Karato, S.-I., 1988. The role of recrystallization in the preferred orientation of olivine. Physics of the Earth and Planetary Interiors 51, 107-122.

Karato, S.-I., Toriumi, M., Fujii, T., 1980. Dynamic recrystallization of olivine single crystals during high-temperature creep. Geophysical Research Letters 7 (9), 649-652.

Kelemen, P. B., Dick, H. J. B., 1995. Focused melt flow and localized deformation in the upper mantle: Juxtaposition of replacive dunite and ductile shear zones in the Josephine peridotite, SW Oregon. Journal of Geophysical Research 100 (B1), 423-438. 
Lebensohn, R. A., Tomé, C. N., 1993. A self-consistent anisotropic approach for the simulation of plastic deformation and texture development of polycrystals: Application to zirconium alloys. Acta Metallurgica et Materialia 41 (9), 2611-2624.

Lee, K.-H., Jian, Z., Karato, S.-I., 2002. A scanning electron microscope study of the effects of dynamic recrystallization on lattice preferred orientation in olivine. Tectonophysics 351, 331-341.

Loney, R. A., Himmelberg, G. R., 1976. Structure of the Vulcan Peak alpine-type peridotite, southwestern Oregon. Geological Society of America Bulletin 87, 259-274.

Mainprice, D., Silver, P. G., 1993. Interpretation of SKS-waves using samples from the subcontinental lithosphere. Physics of the Earth and Planetary Interiors 78, 257-280.

McKenzie, D., 1979. Finite deformation during fluid flow. Geophysical Journal of the Royal Astronomical Society 58, 689-715.

Nicolas, A., Boudier, F., Boullier, A. M., 1973. Mechanisms of flow in naturally and experimentally deformed peridotites. American Journal of Science 273, 853-876.

Nicolas, A., Christensen, N. I., 1987. Formation of anisotropy in upper mantle peridotites - A review. In: Fuchs, K., Froidevaux, C. (Eds.), Composition, Structure and Dynamics of the Lithosphere-Asthenosphere System. Vol. 16 of Geodynamics Series. American Geophysical Union, pp. 111-123.

Pickering, F. B., 1976. The basis of quantitative metallography. Institute of Metallurgical Technicians, London.

Ramsay, J. G., Graham, R. H., 1970. Strain variation in shear belts. Canadian Journal of Earth Sciences 7, 786-813.

Ribe, N. M., 1992. On the relation between seismic anisotropy and finite strain. Journal of Geophysical Research 97 (B6), 8737-8747.

Skemer, P., Katayama, I., Jiang, Z., Karato, S.-I., 2005. The misorientation index: Development of a new method for calculating the strength of lattice-preferred orientation. Tectonophysics 411, 157-167.

Tommasi, A., Mainprice, D., Canova, G., Chastel, Y., 2000. Viscoplastic self-consistent and equilibrium-based modeling of olivine lattice preferred orientations: Implications for the upper mantle seismic anisotropy. Journal of Geophysical Research 105 (B4), 7893-7908.

Underwood, E. E., 1970. Quantitative Stereology. Addison-Wesley, Reading, Massachusetts.

Van der Wal, D., 1993. Deformation processes in mantle peridotites. Ph.D. thesis, Utrecht, Geologica Ultraiectina 102. 
Van der Wal, D., Chopra, P., Drury, M., Fitz Gerald, J., 1993. Relationships between dynamically recrystallized grain size and deformation conditions in experimentally deformed olivine rocks. Geophysical Research Letters 20 (14), 1479-1482.

von Mises, R., 1928. Mechanik der plastischen formanderung von kristallen. Zeitschrift für Angewandte Mathematik und Mechanik 8 (3), 161-185.

Warren, J. M., Hirth, G., 2006. Grain size sensitive deformation mechanisms in naturally deformed peridotites. Earth and Planetary Science Letters 248, 423-435.

Wenk, H. R., Tomé, C. N., 1999. Modeling dynamic recrystallization of olivine aggregates deformed in simple shear. Journal of Geophysical Research 104 (B11), 25513-25527.

Woodcock, N. H., 1977. Specification of fabric shapes using an eigenvalue method. Geological Society of America Bulletin 88, 1231-1236.

Zhang, S., Karato, S.-I., 1995. Lattice preferred orientation of olivine aggregates deformed in simple shear. Nature 375, 774-777.

Zhang, S., Karato, S.-I., Fitz Gerald, J., Faul, U. H., Zhou, Y., 2000. Simple shear deformation of olivine aggregates. Tectonophysics 316, 133-152. 


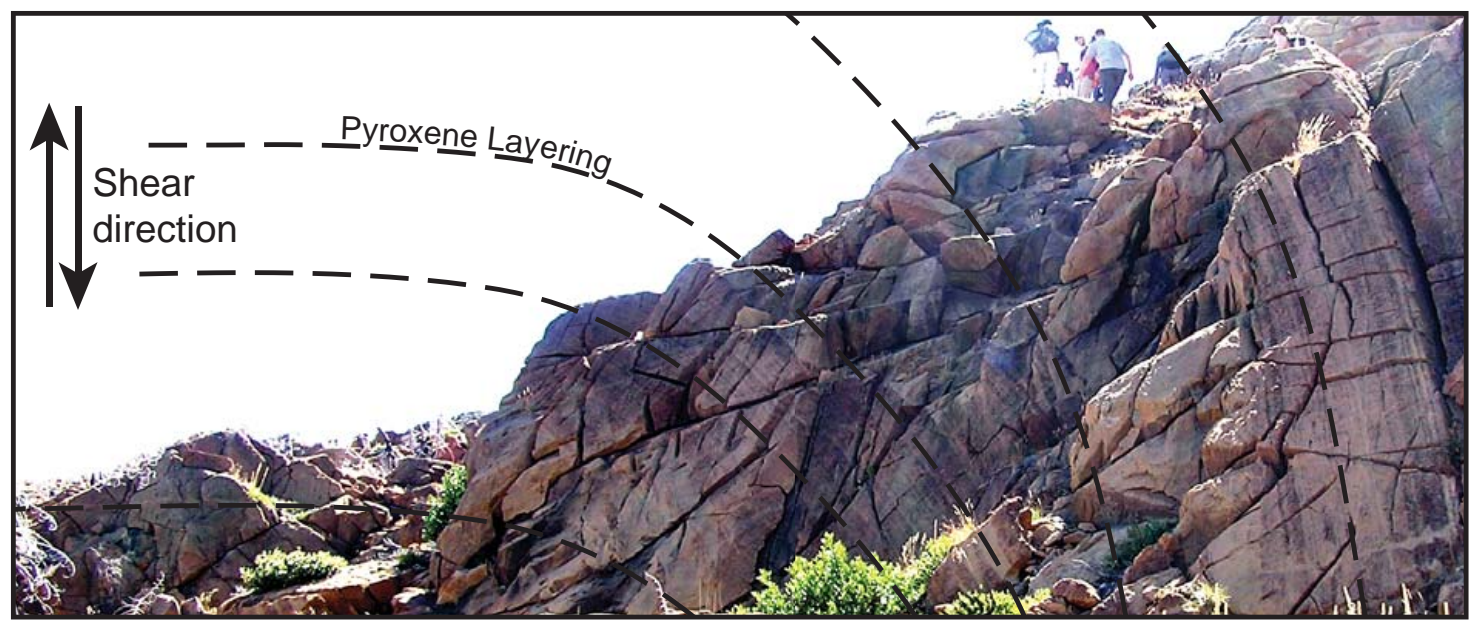

Figure 3.1: Photo of deformed layers in a Josephine shear zone, with the trace of the pyroxene layers outlined. Deflection of the regional pyroxene layering by right lateral shear provides a passive marker of strain. 

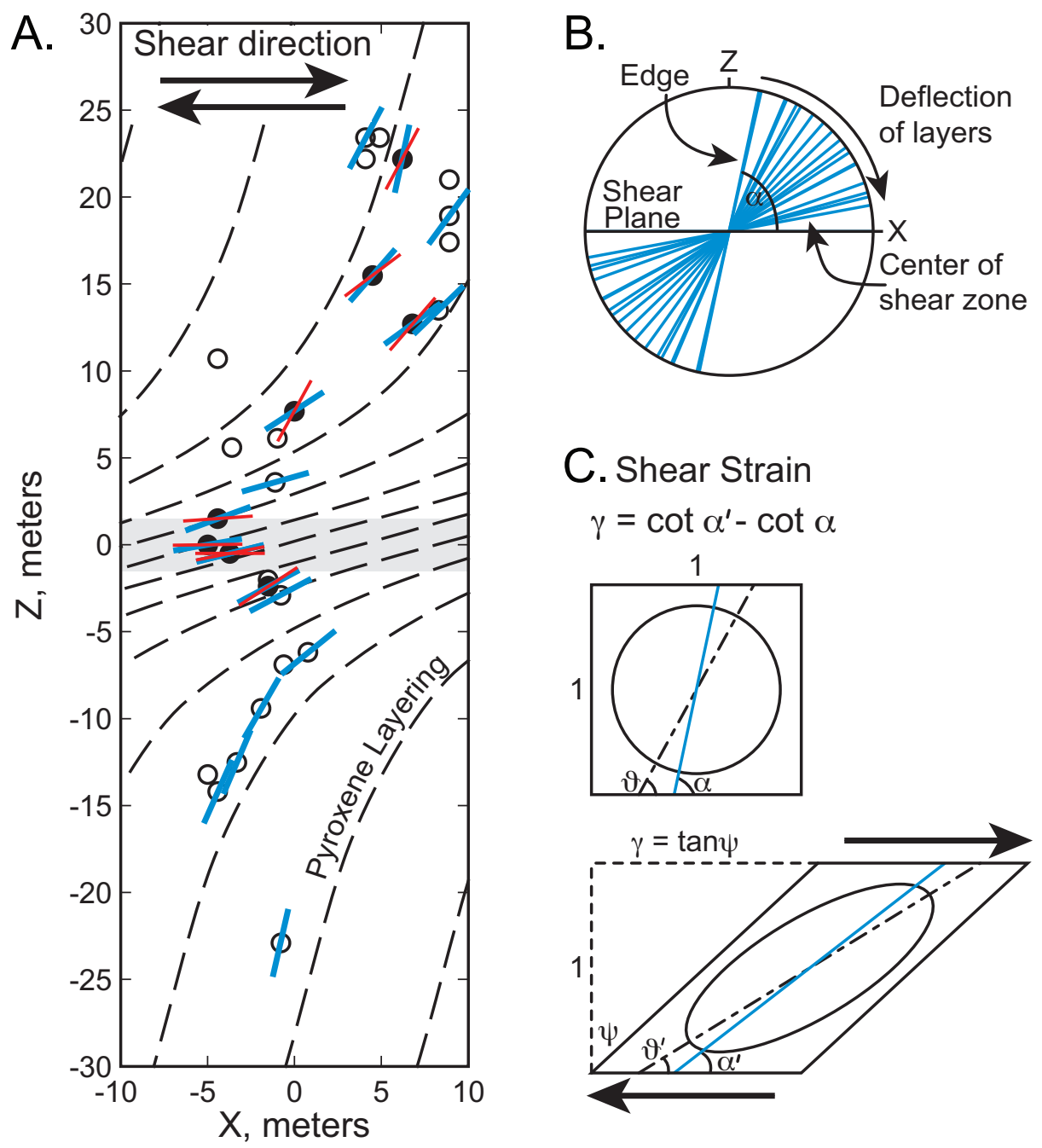

Figure 3.2: (A) $\mathrm{X}-\mathrm{Z}$ cross-section of the shear zone constructed from field data of sample locations and the strike and dip of pyroxene layers. This map is in the kinematic reference frame, perpendicular to the shear plane and parallel to the shear lineation, represented by the plane $305^{\circ} / 50^{\circ}$. Circles indicate sample locations, with analyzed samples indicated by filled circles. The pyroxene layer orientations are shown by blue lines and the orientations of olivine [100] maxima (from EBSD data) by red lines. (B) Stereonet of the variation of pyroxene layer orientations with respect to the shear plane. To represent the true deflection of a passive strain marker by shear deformation, the data have been rotated and projected onto the plane perpendicular to the shear plane, as in the map cross-section. The angle $\alpha$ is the initial angle of the pyroxene layering outside the shear zone. (C) The geometrical relationship of shear strain, $\gamma$, to the orientation of a marker layer, which initially lies at an angle, $\alpha$, to the shear plane and is deflected to a smaller angle, $\alpha^{\prime}$. The orientation of the finite strain ellipsoid long axis, represented by deflection through the angle $\theta$, is not coincident with the marker layer. Diagram adapted from Ramsay and Graham (1970). 
A.
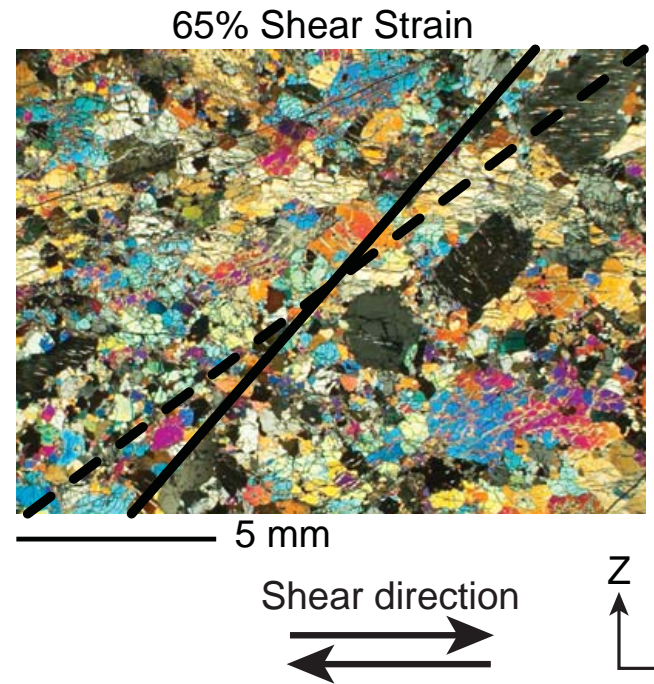

B.

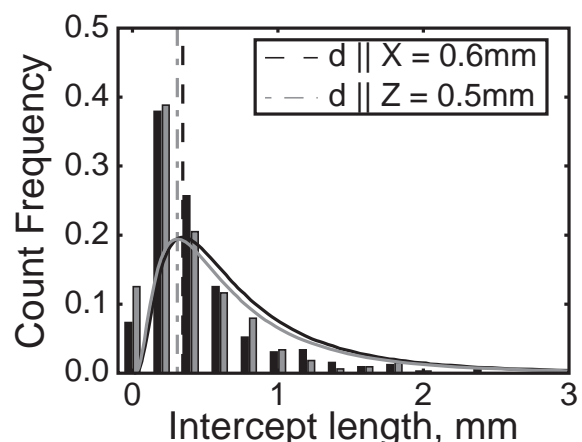

C.

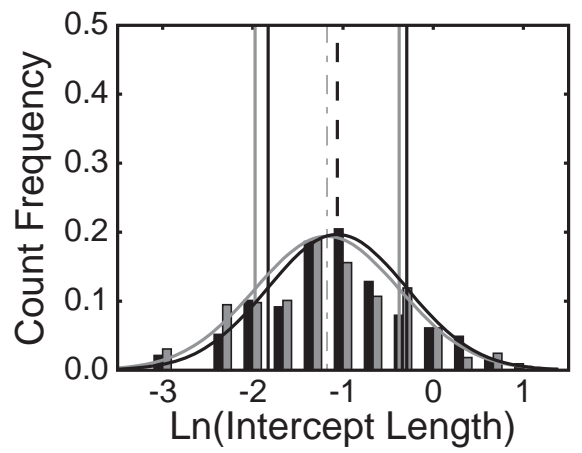

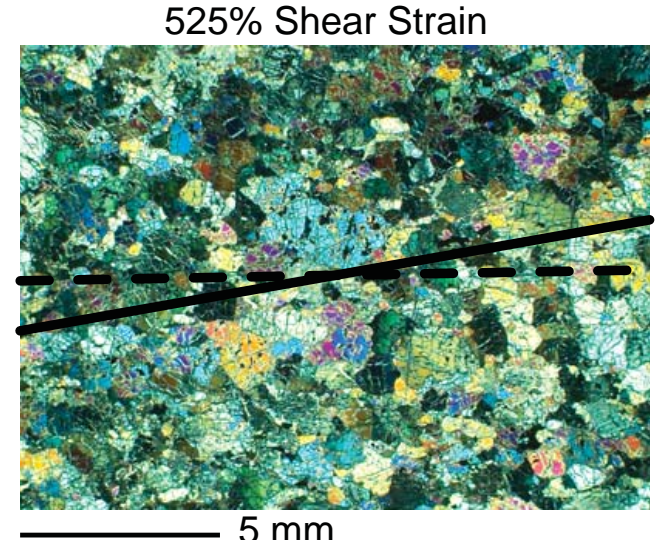

Pyroxene layering

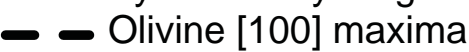

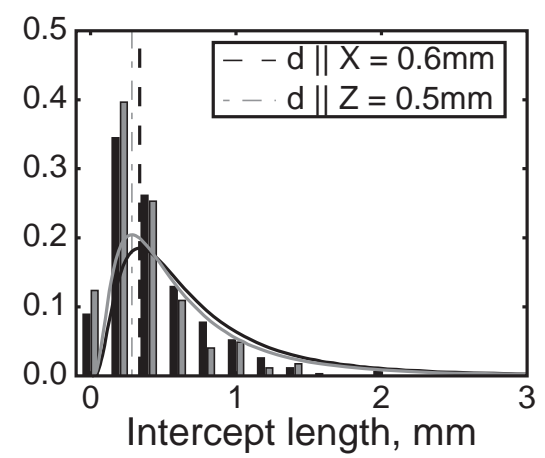

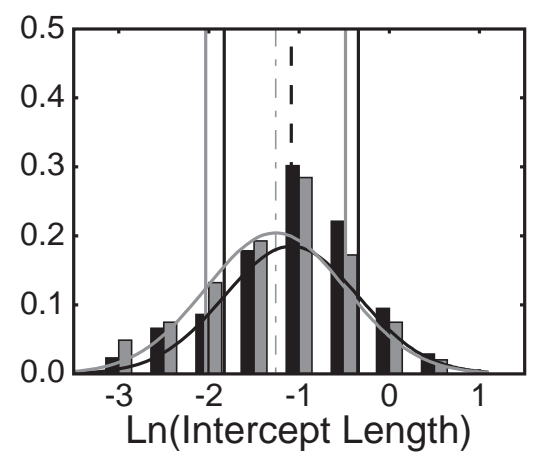

Figure 3.3: (A) Cross-polarized photomicrographs of low strain (65\%) and high strain $(525 \%)$ harzburgites. Solid lines indicate field-measured orientations of pyroxene layers and dashed lines indicate EBSD-determined orientations of olivine [100] maxima. Note that the high strain sample has a higher degree of alteration, especially among pyroxenes. (B) Histograms of grain intercept lengths parallel (black) and perpendicular (grey) to the shear direction. Dashed lines indicate the geometric mean intercept length and solid curves indicate the theoretical log-normal distribution. The average grain size (d) is calculated from intercept length using a geometric conversion factor of 1.75 (Pickering, 1976). (C) Log-normal histograms of intercept length, with geometric mean intercept length (dashed lines), $1 \sigma$ deviations (solid lines) and theoretical distributions (solid curves) also shown. 
A.

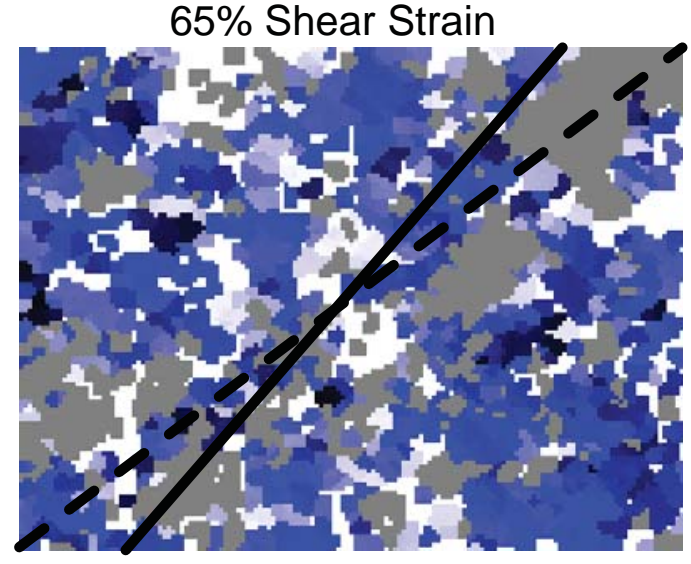

$65 \%$ Shear Strain

$5 \mathrm{~mm}$

B.

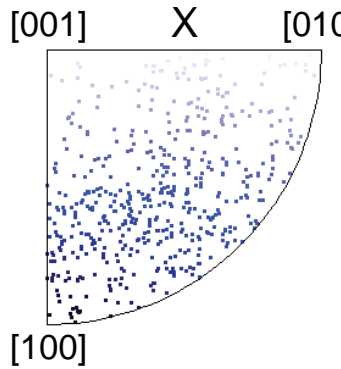

[100]
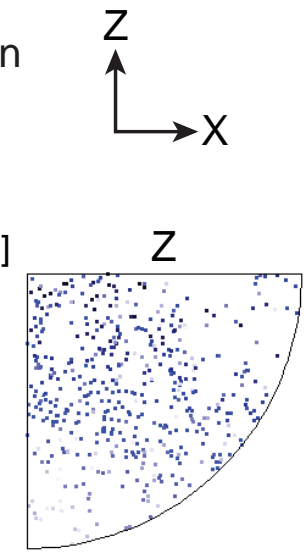

Shear direction

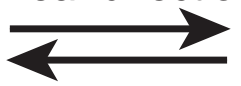

[010]

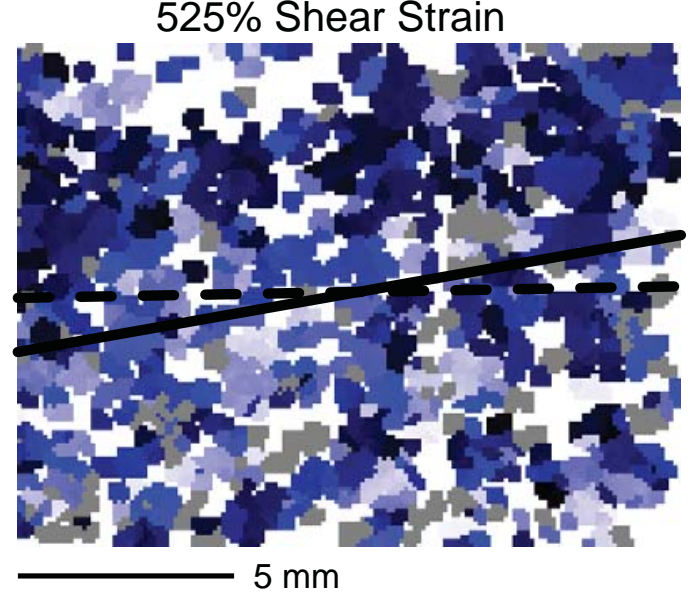

Olivine [100] angle from shear plane

$0^{0}$

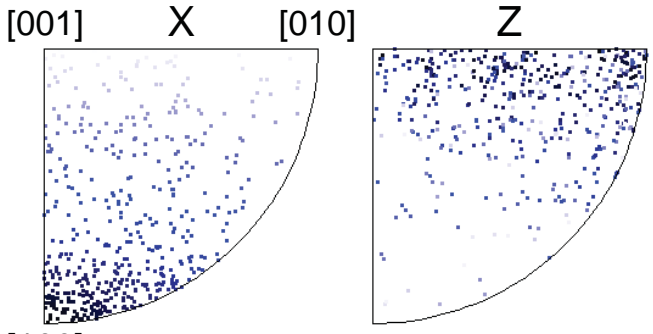

[100]

Figure 3.4: (A) EBSD maps of the same sample areas as shown in Figure 3.3. Grey indicates secondary phases (orthopyroxene, clinopyroxene, and spinel) and white areas have no data. Olivine is shaded as a function of the orientation of the [100] axis from the shear plane. Dark grains are aligned closely with the shear plane whereas light grains are at a high angle to the shear plane. The solid line is the field-measured orientation of the pyroxene layers and the dashed line is the EBSD-determined orientations of the olivine [100] maxima. (B) Inverse pole figures for olivine, demonstrating orientations parallel (X) and perpendicular $(\mathrm{Z})$ to the shear plane. At low strain, grains are oriented with their axes at an angle to both the $\mathrm{X}$ and $\mathrm{Z}$ directions. At high strain, the majority of grains are oriented with [100] parallel to $\mathrm{X}$ and either [010] or [001] parallel to Z. 


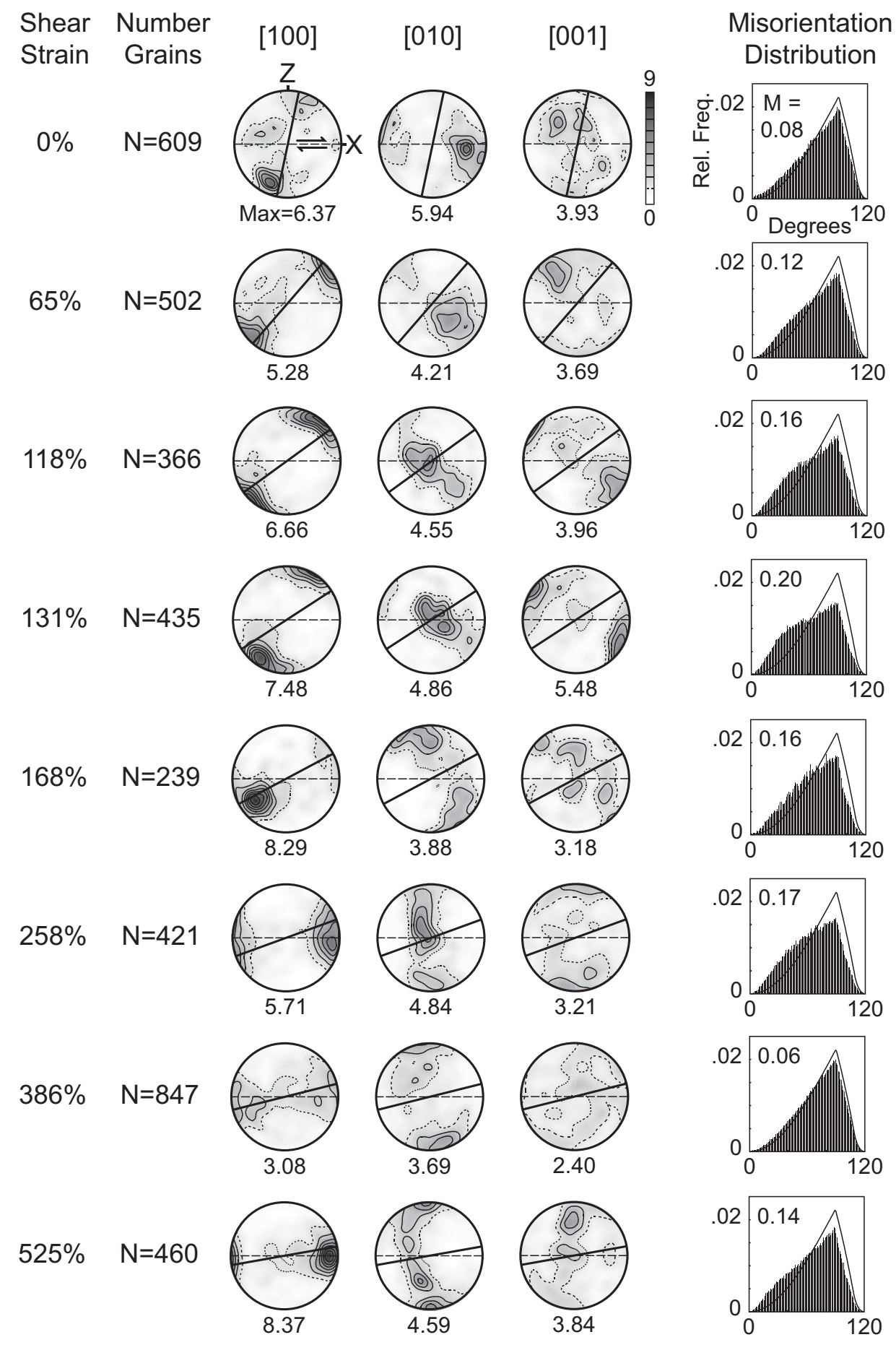

Figure 3.5: Olivine pole figures for harzburgites, with the shear plane (dashed line) parallel to $\mathrm{X}$ and pyroxene layering indicated by a solid line. Contouring is multiples of a uniform distribution (MUD), with a dashed line at 1 MUD. Maximum MUD values are identified below each individual pole figure. Misorientation distributions are for uncorrelated angles, with M-index values indicated. The solid line is the theoretical orthorhombic random distribution (Grimmer, 1979). 


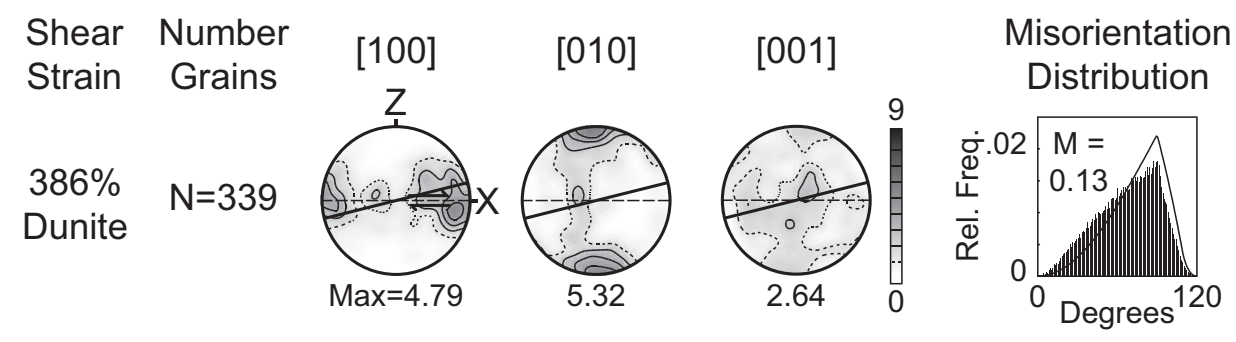

Figure 3.6: Olivine pole figure and misorientation distribution for a high strain dunite sample. As in Figure 3.5, the pole figure is oriented with the shear plane (dashed line) parallel to $X$, the pyroxene layering indicated by a solid line, and contour from 0 to 9 MUD. In contrast to the high strain harzburgites, the dunite has more pronounced [010] and [100] maxima. 


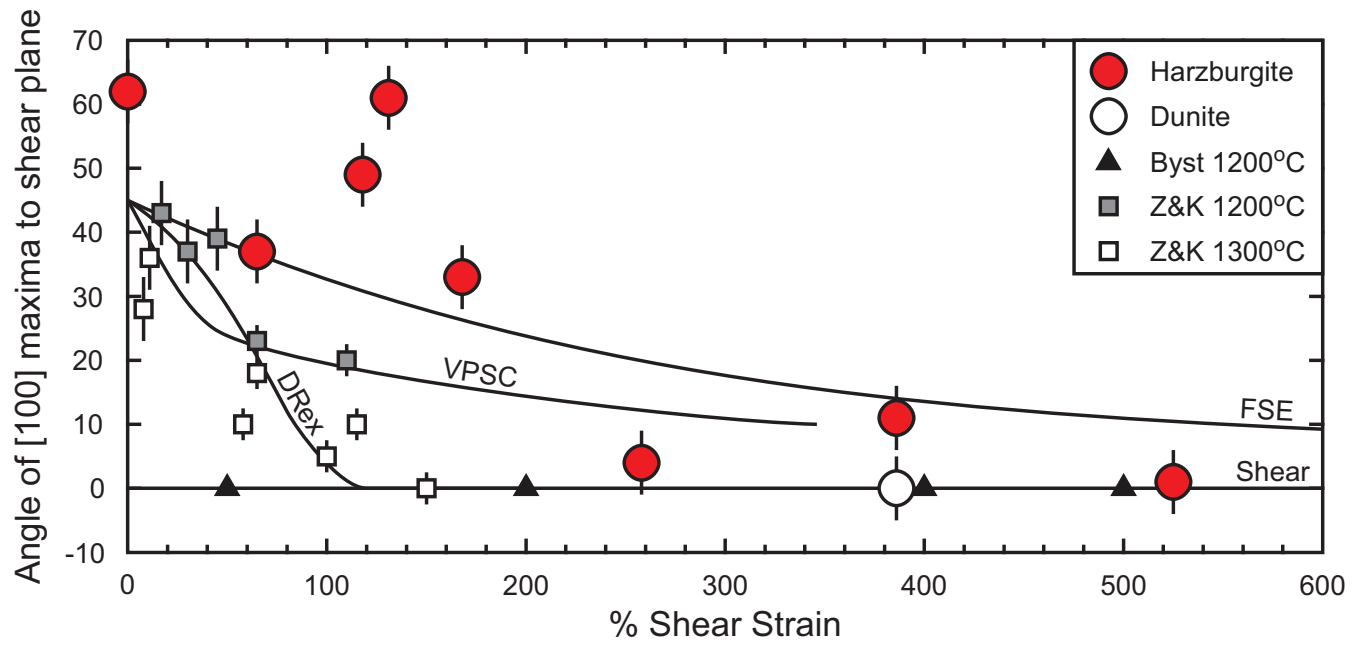

Figure 3.7: Angle of the olivine [100] maxima to the shear plane as a function of shear strain in the Josephine peridotites, experiments and models. The Josephine harzburgites are shown as filled circles and the dunite as an open circle. The models and experiments initially have a random fabric, represented by an average angle of $45^{\circ}$ to the shear direction. The experimental data are from Bystricky et al. (2000) and Zhang and Karato (1995). The simplest models are FSE, which follows the finite strain ellipsoid and Shear, which follows the shear direction. VPSC is the best fit $(\alpha=100)$ of the viscoplastic self-consistent model (Tommasi et al. 2000) to the experiments. DRex is the best fit $\left(M^{*}=200\right)$ of the dynamic recrystallization model to the experiments (Kaminski and Ribe, 2001). Similar results to DRex were reported by Wenk and Tomé (1999) using a VPSC model which included recrystallization. 

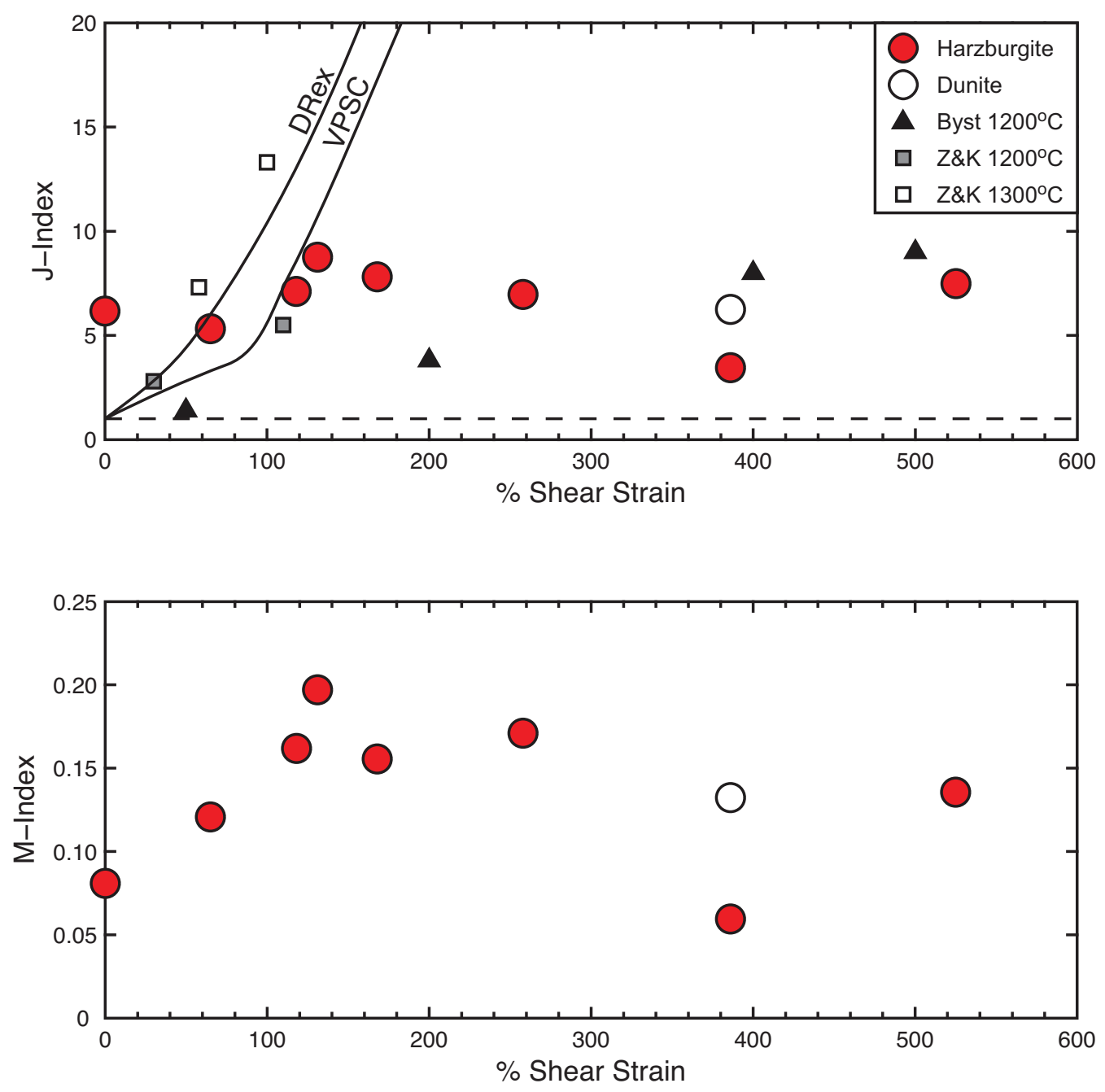

Figure 3.8: (A) Variation in the J-index as a function of shear strain. Dashed line indicates the theoretical lower limit (i.e. a random fabric) for the J-index. The results for the Josephine harzburgites are shown as filled circles and the dunite as an open circle. Also shown are the Bystricky et al. (2000) high strain experiments, the Zhang and Karato (1995) experiments (from the J-index calculation by Tommasi et al., 2000), the VPSC model ( $\alpha=100$; Tommasi et al. 2000) and the DRex model (M*=200; Kaminski and Ribe, 2001). (B) Variation in the M-index as a function of shear strain in the Josephine samples. The M-index varies between 0 for a random fabric and 1 for a single crystal fabric (Skemer et al., 2005). 


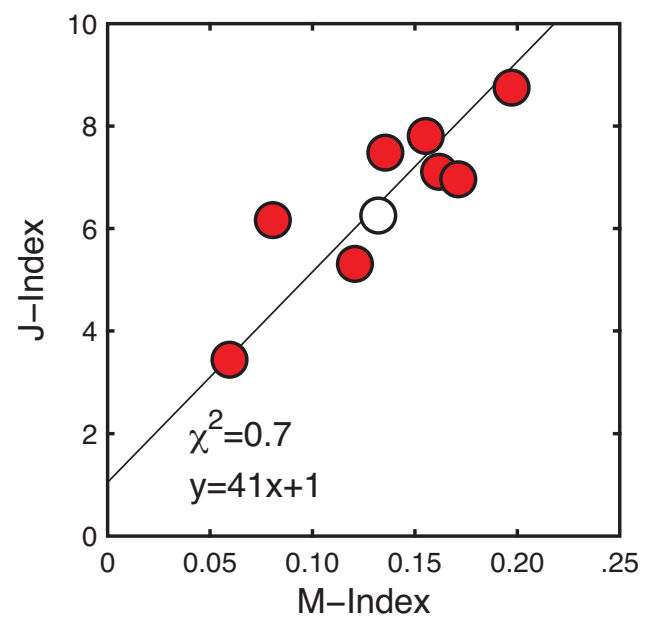

Figure 3.9: Variation of the J-index versus the M-index for the Josephine samples. Filled circles are harzburgites and the open circle is the dunite. The line is a minimum least squares regression through the dataset.

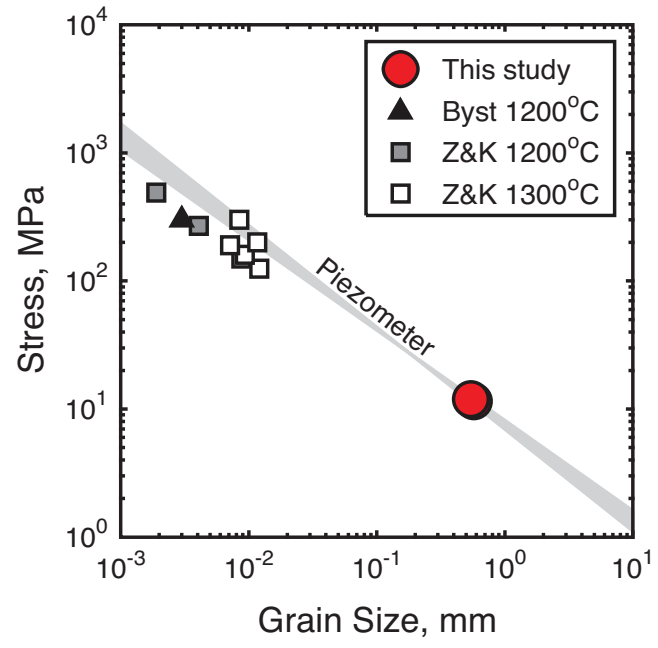

Figure 3.10: The olivine piezometer - the variation of stress with grain size - as determined by experimental data (Karato et al., 1980; Van der Wal et al., 1993). The piezometer is use to estimate differential stress in the shear zone from the grain size of the Josephine samples at $65 \%$ and $525 \%$ shear strain. Also shown are the Zhang and Karato experiments, from the analysis by Zhang et al. (2000), and the Bystricky et al. (2000) experiments. The Zhang and Karato dataset has been re-adjusted to a geometric correction factor of 1.75 (Van der Wal, 1993), for consistency with our results and the piezometer. 
Table 3.1: Sample locations, strikes and dips, and the results of strain and fabric analyses.

\begin{tabular}{|c|c|c|c|c|c|c|c|c|c|c|}
\hline \multirow[b]{2}{*}{ Sample ${ }^{a}$} & \multicolumn{2}{|c|}{ Dist. (m) } & \multirow{2}{*}{$\begin{array}{c}\text { Field } \\
\text { Strike/Dip }\end{array}$} & \multirow{2}{*}{$\begin{array}{l}\text { Rot\&Proj }{ }^{b} \\
\text { Strike/Dip }\end{array}$} & \multirow{2}{*}{$\begin{array}{l}\text { Shear } \\
\text { Strain }\end{array}$} & \multicolumn{3}{|c|}{ Angle $^{c}$} & \multicolumn{2}{|c|}{ Fabric Strength } \\
\hline & $\mathrm{X}$ & $\mathrm{Z}$ & & & & $\alpha$ & $\theta$ & [100] & J-index & M-index \\
\hline 3923J01 H & 6.2 & 22.2 & $245 / 10$ & $192 / 90$ & 0 & $78^{\circ}$ & $\mathrm{n} / \mathrm{a}$ & $62^{\circ}$ & 6.2 & 0.08 \\
\hline 3923J02 D & 4.9 & 23.4 & & & & & & & & \\
\hline 3923J03 H & 8.9 & 18.9 & $210 / 30$ & $216 / 90$ & $51 \%$ & $54^{\circ}$ & $38^{\circ}$ & & & \\
\hline 3923J04 D & 8.9 & 17.4 & & & & & & & & \\
\hline 3923J05 D & 8.9 & 21.0 & & & & & & & & \\
\hline 3923J06 H & 4.1 & 22.2 & & & & & & & & \\
\hline 3923J07 D & 4.1 & 23.4 & $200 / 25$ & $208 / 90$ & $32 \%$ & $62^{\circ}$ & $40^{\circ}$ & & & \\
\hline 3923J08 D & 8.3 & 13.5 & & & & & & & & \\
\hline 3923J09 H & 8.3 & 13.5 & $210 / 40$ & $226 / 90$ & $81 \%$ & $44^{\circ}$ & $34^{\circ}$ & & & \\
\hline 3923J10 H & 4.5 & 15.5 & & & & & & & & \\
\hline 3923J11 H & 4.5 & 15.5 & $210 / 35$ & $221 / 90$ & $65 \%$ & $49^{\circ}$ & $36^{\circ}$ & $37^{\circ}$ & 5.3 & 0.12 \\
\hline 3923J12 D & 6.8 & 12.7 & & & & & & & & \\
\hline 3923J13 H & 6.8 & 12.7 & $215 / 47$ & $234 / 90$ & $118 \%$ & $36^{\circ}$ & $30^{\circ}$ & $49^{\circ}$ & 7.1 & 0.16 \\
\hline 3923J14 H & 0.0 & 7.7 & $210 / 52$ & $237 / 90$ & $131 \%$ & $33^{\circ}$ & $28^{\circ}$ & $61^{\circ}$ & 8.8 & 0.20 \\
\hline 3924J01 H & -3.6 & 5.6 & & & & & & & & \\
\hline 3924J02 D & -4.4 & 10.7 & & & & & & & & \\
\hline 3924J03a H & -1.1 & 3.6 & $215 / 70$ & $254 / 90$ & $337 \%$ & $16^{\circ}$ & $15^{\circ}$ & & & \\
\hline 3924J03b D & -1.1 & 3.6 & $215 / 70$ & $254 / 90$ & $337 \%$ & $16^{\circ}$ & $15^{\circ}$ & & & \\
\hline 3924J04 D & -1.0 & 6.1 & & & & & & & & \\
\hline 3924J05 D & -4.4 & 1.5 & & & & & & & & \\
\hline 3924J06 H & -4.4 & 1.5 & $215 / 65$ & $250 / 90$ & $258 \%$ & $20^{\circ}$ & $19^{\circ}$ & $4^{\circ}$ & 7.0 & 0.17 \\
\hline 3924J07 D & -5.0 & 0.0 & & & & & & & & \\
\hline 3924J08 H & -5.0 & 0.0 & $217 / 65$ & $260 / 90$ & $525 \%$ & $10^{\circ}$ & $10^{\circ}$ & $1^{\circ}$ & 7.5 & 0.14 \\
\hline 3924J09a H & -3.7 & -0.5 & $218 / 65$ & $256 / 90$ & $386 \%$ & $14^{\circ}$ & $14^{\circ}$ & $11^{\circ}$ & 3.4 & 0.06 \\
\hline 3924J09b D & -3.7 & -0.5 & $218 / 65$ & $256 / 90$ & $386 \%$ & $14^{\circ}$ & $14^{\circ}$ & $0^{\circ}$ & 6.3 & 0.13 \\
\hline 3924J10 H & -1.5 & -2.4 & $214 / 56$ & $242 / 90$ & $168 \%$ & $28^{\circ}$ & $25^{\circ}$ & $33^{\circ}$ & 7.8 & 0.16 \\
\hline 3924J11 D & -1.5 & -2.0 & & & & & & & & \\
\hline 3924J12 D & -0.8 & -2.9 & $215 / 55$ & $242 / 90$ & $165 \%$ & $28^{\circ}$ & $25^{\circ}$ & & & \\
\hline 3924J13 H & 0.8 & -6.2 & $215 / 43$ & $231 / 90$ & $100 \%$ & $39^{\circ}$ & $32^{\circ}$ & & & \\
\hline 3924J14 D & -0.6 & -6.9 & & & & & & & & \\
\hline 3924J15 H & -1.9 & -9.4 & $213 / 24$ & $210 / 90$ & $36 \%$ & $60^{\circ}$ & $40^{\circ}$ & & & \\
\hline 3924J16 H & -3.3 & -12.5 & $214 / 18$ & $203 / 90$ & $21 \%$ & $67^{\circ}$ & $42^{\circ}$ & & & \\
\hline 3924J17 D & -5.0 & -13.2 & & & & & & & & \\
\hline 3924J18 H & -4.4 & -14.2 & $228 / 18$ & $204 / 90$ & $23 \%$ & $66^{\circ}$ & $42^{\circ}$ & & & \\
\hline 3924J19 H & -0.8 & -22.9 & $230 / 10$ & $193 / 90$ & $2 \%$ & $77^{\circ}$ & $45^{\circ}$ & & & \\
\hline
\end{tabular}

${ }^{a}$ Sample lithology - harzburgite (H) or dunite (D).

${ }^{b}$ Data have been rotated and projected onto the plane 305/50.

${ }^{c}$ Angle from shear plane to pyroxene foliation $(\alpha)$, finite strain ellipsoid $(\theta)$, and olivine [100] maxima. 


\title{
Chapter 4
}

\section{An Assessment of Mantle Heterogeneity and Depletion Based on Abyssal Peridotite Isotope and Trace Element Compositions}

\begin{abstract}
Abstract

The size and scale of heterogeneity and the full extent of depletion of the asthenospheric mantle cannot be fully constrained by basalt chemistry. We present detailed isotope and trace element analyses of pyroxene mineral separates, from veined and unveined abyssal peridotites, that demonstrate greater variability of the mantle on smaller length-scales than has previously been observed. The isotopic range within one dredge from the Southwest Indian Ridge (SWIR) covers $46 \%$ of the entire Indian Ocean basalt range for ${ }^{143} \mathrm{Nd} /{ }^{144} \mathrm{Nd}$. Radiogenic ingrowth during upwelling and exposure on the seafloor are shown to be negligible, producing $<0.01 \%$ change in $\mathrm{Nd}$ isotopic composition. Cpx and Opx pairs from the same sample are generally in $\mathrm{Sr}$ but not $\mathrm{Nd}$ isotopic equilibrium. This may reflect $\mathrm{Opx}$ rare earth element disequilibrium due to slow diffusion following recent melt-rock reaction. Pyroxenite veins in abyssal peridotites are found to have overlapping compositions with their host peridotites. Combined with other compositional characteristics, we suggest that they formed recently by melt crystallization, rather than as direct remnants of recycled oceanic crust.

The average isotopic composition of peridotites is found to be similar to that of basalts, though peridotites extend to more depleted compositions. These depleted compositions should be accompanied by depletions in trace element concentrations. As basalts are mixtures of melts, they will be dominated by the least depleted peridotite source and the signature of the most depleted peridotite will not be preserved in the melt.
\end{abstract}


Abyssal peridotite $\mathrm{Cpx} \mathrm{Nd}$ isotopic compositions and $\mathrm{Sm} / \mathrm{Nd}$ ratios extend to higher values than can be reconciled with two stage or continuous depletion models of mantle isotopic evolution. We suggest that high $\mathrm{Sm} / \mathrm{Nd}$ ratios were produced during previous episodes of melt extraction that are not included in current models of DMM formation. We conclude that the scale of mantle heterogeneity and extent of melt depletion observed among abyssal peridotites requires a reassessment of current models for mantle evolution and MORB production, which assume that peridotites in the asthenospheric mantle are uniform in composition.

\subsection{Introduction}

The ratios of radiogenic isotopes in basalts from mid-ocean ridges (MORB) and ocean islands (OIB) are highly variable, demonstrating that chemical heterogeneity in the mantle has persisted for long periods of time and indicating that convective mixing of the mantle is relatively inefficient at removing heterogeneities (Zindler and Hart, 1986, van Keken et al., 2002). Ranges in isotopic compositions for individual systems (e.g., a given OIB suite or a specific ridge segment) have led to much debate over the form and size of the distinct man-

tle reservoirs involved. A still significant gap exists between observational geochemistry and numerical models of mantle dynamics (e.g., van Keken et al., 2002), partly because geochemical observations of the length-scales and amplitudes of chemical and isotopic heterogeneities in the mantle are inadequate. Basalts, as mixtures of melt fractions derived from large areas of the mantle that have undergone variable degrees of melting, effectively "smooth-out" heterogeneities. Nevertheless, basalts from individual dredges at some midocean ridge localities reveal significant variations in isotopic compositions and suggest that high-amplitude heterogeneities exist over length-scales $<2 \mathrm{~km}$ (Dosso et al., 1999). Large variations in $\mathrm{Pb}$ isotopic compositions among olivine-hosted melt inclusions from individual MORB and OIB samples (Saal et al., 1998; Shimizu and Layne, 2003; Kobayashi et al. 2004; Shimizu et al., 2005; Maclennan, 2006) provide additional clear evidence for the existence of higher amplitude heterogeneities on smaller length-scales than hitherto 
considered.

The depleted MORB source mantle (DMM) is one of the most important geochemical reservoirs and its compositional heterogeneities are of fundamental importance to geochemistry and mantle dynamics. In this chapter, we use abyssal peridotites - depleted solid residues of ocean ridge melting - to assess the amplitudes and length-scales of chemical and isotopic heterogeneities in DMM. Due to severe hydrothermal alteration and the geochemically depleted character of abyssal peridotites, radiogenic isotope data has previously been collected in only four studies (Snow et al., 1994; Kempton and Stephens, 1997, Salters and Dick, 2002; Cipriani et al., 2004). These studies attempted to reconcile the isotopic compositions of peridotites to those of basalts from the same region, over $>100$ km length-scales.

The present study is different from previous abyssal peridotite studies in two important ways. First, we specifically focus on lithologically-mixed samples from the ultra-slow spreading Southwest Indian Ridge (SWIR), including some of the very few peridotites recovered from a ridge axis. As shown previously (Sleep, 1975; , Reid and Jackson, 1981; Bown and White, 1994; Dick et al., 2003), at slow upwelling rates, conductive cooling limits mantle melting. Thus, peridotites exposed on the seafloor are expected to have experienced limited degrees of melting and represent the closest approach to asthenospheric mantle (DMM) composition. Second, we describe geochemical variations in peridotite samples from individual dredges. Sampling length-scales of individual dredges can be estimated from dredge wire tension records and the dredges in this study represent lengthscales of $<1 \mathrm{~km}$. At this length-scale, in an upwelling and partially melting system, mantle peridotites experience the same pressure and temperature conditions. Any chemical and isotopic variations observed among peridotites from a single dredge must be due to either initial (pre-melting) heterogeneities or recent melt-rock reaction.

This chapter uses detailed trace element and isotope analyses of peridotites from indi- 
vidual dredges to constrain the spatial scale of heterogeneities in the mantle, the extent of depletion of the mantle and the role of melt-rock reaction during ridge processes. We report results from two areas of the Southwest Indian Ridge: the Oblique $9^{\circ}-16^{\circ}$ E Segment and the Atlantis II Fracture Zone (Fig. 4.1). Basalts from the Oblique Segment have already been studied in detail by Standish (2006), providing a MORB framework for comparison to the peridotite systematics. The local geodynamic setting of both localities has important implications as to the degree of mantle melting. Along the Oblique Segment, the obliquity of the angle of spreading to the direction of plate motion (Fig. 4.1) results in reduced degrees of melting. The effective full spreading rate varies along the segment from 7.5 to 14 $\mathrm{mm} / \mathrm{yr}$, at the lowest end of the spectrum of global ridge spreading rates. Peridotites from the Atlantis II Fracture Zone are also expected to have undergone low degrees of melting, due to an ultra-slow spreading rate combined with a transform fault.

Both the Oblique Segment and the Atlantis II Fracture Zone have been extensively sampled. Fig. 4.1 shows the locations and lithologies of dredges from each area and Table 4.1 lists the locations of the four specific dredges used in this study. We focus on two onaxis Oblique Segment dredges from the 2003 RV Melville cruise Vancouver Expedition Leg 7 to $9^{\circ}-25^{\circ} \mathrm{E}$ on the SWIR. This area was also sampled during the 1976 ARA Islas Orcadas cruise IO11/76, the 1981 SA Agulhas cruise AG22, the 1986 RV Polar Stern cruise PS86, and the $2001 R V$ Knorr cruise Kn162. Basalts from these cruises have been analyzed by le Roex et al. (1983, 1992), Mahoney et al. (1992), Janney et al. (2005), Standish (2006), and Standish et al. (submitted). The Atlantis II Fracture Zone has been sampled during the 1976 RV Atlantis II cruise AII93-5, the 1986 RV Conrad cruise RC27-9, and the 1998 RRS James Clark Ross cruise JR31. In addition, Atlantis Bank, an uplifted gabbro massif located along the transform fault and formed by detachment faulting between 9.5 and 13 Ma (Dick et al., 1991), has been the focus of Ocean Drilling Program (ODP) Leg 118 in 1987 and Leg 176 in 2000 and dives using the manned submersible Shinkai 6500 in 
1998 and 2001 and the remotely operated vehicle Kaiko in 2000. Atlantis II Fracture Zone basalts have been analyzed by Mahoney et al. (1989), Dick et al. (1991), Kempton et al. (1991), Snow (1993) and Coogan et al. (2004). In addition, $1.5 \mathrm{~km}$ of gabbro from Hole 735B - drilled on Atlantis Bank during ODP Legs 118 and 176 - have been analyzed for isotopic compositions by Kempton et al. (1991), Hart et al. (1999) and Holm (2002). Finally, the regional scale isotopic variations for peridotites from the Oblique Segment and the Atlantis II Fracture Zone, presented by Salters and Dick (2002), provide a framework for our local-scale datasets.

\subsection{Methods}

Analysis of modal compositions, trace element concentrations, and $\mathrm{Nd}$ and $\mathrm{Sr}$ isotopes were carried out on sixteen samples: eleven peridotites, three pyroxenite veined peridotites, and two pyroxenites. Cpx mineral separates were analyzed for isotopes in all samples and Opx for isotopes in six samples. In the veined samples, Cpx from the vein and matrix were measured separately. Cpx from three peridotites were successfully analyzed for $\mathrm{Pb}$ isotopes. The only basalt recovered in any of the same dredges as the peridotites - a glass fragment in a breccia from dredge Van7-96 - was also analyzed. Trace element and isotope analyses were carried out at the Pheasant Memorial Laboratory at the Institute for Study of the Earth's Interior in Japan.

\subsubsection{Sample selection and characteristics}

Peridotites were analyzed from five dredges, as listed in Table 4.1, with a focus on two dredges: Van7-85 (herein after referred to as Dredge 85), containing typically depleted peridotites, and Van7-96 (referred to as Dredge 96), containing pyroxenite-veined peridotites. Also analyzed were one peridotite from Dredge PS86-6, for interlab-comparison 
to Salters and Dick (2002), and one peridotite from Dredge Van7-86, a more altered peridotite dredge adjacent to Dredge 85, for determination of the effects of alteration on $\mathrm{Sr}$ isotopic composition. From the Atlantis II Fracture Zone, we analyzed sample RC27-9-6-2 (abbreviated to 6-2 in some figures), which contains a clinopyroxenite vein.

Dredge 85 is from an amagmatic region of the Oblique Supersegment (Fig. 4.1) and contains $65 \mathrm{~kg}$ peridotite, $11 \mathrm{~kg}$ dunite, and $2 \mathrm{~kg}$ diabase. The peridotites are "typical" in appearance (Fig. 4.2A), lacking veins and with modal Cpx contents ranging from $2 \%$ to 6\%. As shown in Fig. 4.5, they have trace element concentrations characteristic of depleted abyssal peridotites (e.g., Johnson et al., 1990). Two harzburgites (Van7-85-27 and Van785-30) and three lherzolites (Van7-85-42, Van7-85-47, and Van7-85-49), representative of the modal Cpx range of the dredge, were chosen for isotopic analyses.

Dredge 96 consists predominantly of lherzolites and harzburgites with pyroxenite veins (Fig. 4.2B-F). The dredge is from the inside-corner high of the ridge with the Shaka Fracture Zone (Fig. 4.1) and consists of $36 \mathrm{~kg}$ peridotite, $44 \mathrm{~kg}$ pyroxenite-veined peridotites, $3 \mathrm{~kg}$ pyroxenites, $39 \mathrm{~kg}$ polymict breccias and $8 \mathrm{~kg}$ diabase. Pyroxenite veins range in width from 1 to $10 \mathrm{~cm}$ and either cross-cut larger peridotites samples (Fig. 4.2 C) or occur as individual samples with thin peridotite skins (Fig. 4.2E). The veins themselves are cross-cut by narrower veins (Fig. 4.2E) predominantly composed of altered plagioclase and olivine. The absence of plagioclase in the coarser-grained regions of the pyroxenites and the presence of Opx, which does not appear with plagioclase on the low pressure liquidus of basalt (Stolper, 1980), indicate that plagioclase is related to a second, shallow level melt intrusion event. In addition, rims of $\mathrm{Cpx}$ grains have Eu anomalies whereas $\mathrm{Cpx}$ cores do not (Warren, unpublished ion probe data), further evidence for the later crystallization of plagioclase. Samples selected for analysis from this dredge include pyroxenites with little associated peridotite (Van7-96-09 and Van7-96-16), peridotites with pyroxenite veins (Van7-96-19 and Van 7-96-21), vein-free peridotites (Van7-96-25, Van7-96-28, Van7-96- 
35 and Van7-96-38) and basalt from a breccia (Van7-96-68).

\subsubsection{Modal analyses}

All samples were point counted for mineral modes under an optical microscope using large, $51 \times 75 \mathrm{~mm}$ thin sections and a grid spacing of $1 \mathrm{~mm}$ (Table 4.2). For the peridotites, a minimum of 1700 points were counted. The pyroxenite modes, due to limited material availability, have fewer points and hence larger associated errors. Images of the thin sections, produced by point counting, are shown in Fig. 4.3

\subsubsection{Chemical analyses}

Mineral separates of Opx and Cpx were obtained by lightly crushing thin slices of the peridotite samples, handpicking under a binocular microscope and then re-picking to ensure purity of the concentrate. All grains were visually free of inclusions and uniform in color, except for a less-pure separate of Van7-96-16, included for comparison to a more pure separate of the same sample. Unleached concentrate weights were in the range 25-900 mg. Concentrates were leached ultrasonically in $\mathrm{HCl}$ overnight and rinsed in water. Further light crushing in a SiN mortar and pestle exposed cleavage alteration surfaces. Concentrates were then leached ultrasonically for 5 minutes in HF, rinsed with water, leached ultrasonically twice more with HCL for 8 hours each, rinsed with water and finally leached ultrasonically with $\mathrm{HNO}_{3}$ for 5 minutes. Following a final rinsing with water, samples were dried on a hot plate in a draft chamber with clean air. After leaching, 15-700 mg material remained per mineral separate. Prior to dissolution for high field strength elements (HFSE) and isotope analyses, concentrates were crushed to powder in a SiN mortar and pestle. 


\section{ICP-MS analyses of trace elements}

Samples were analyzed by ICP-MS for 28 trace element concentrations, of which the HFSE were prepared and measured independently of the other trace elements. In addition, blanks and the external rock standard JB-2 (tholeiitic basalt, Geological Survey of Japan) were prepared with the samples. For analyses of $\mathrm{Li}, \mathrm{Be}, \mathrm{Rb}, \mathrm{Sr}, \mathrm{Y}, \mathrm{Cs}, \mathrm{Ba}$, rare earth elements (REEs), $\mathrm{Pb}, \mathrm{Th}$, and $\mathrm{U}$, from 2 to $10 \mathrm{mg}$ of weighed sample was spiked with ${ }^{149} \mathrm{Sm}$ and dissolved in two stages following the method of Makishima and Nakamura (1997). In the first stage, samples were decomposed in $\mathrm{HClO}_{4}$ and $\mathrm{HF}$ using a combination of ultrasonic bath and hotplate heating for several days, followed by stepwise drying. In the second stage, the samples were heated overnight after addition of $\mathrm{HCl}$, followed by stepwise drying. Finally, the samples were dissolved in $\mathrm{HNO}_{3}$ to a dilution factor of 1000 prior to analysis.

Analyses of HFSE - Zr, Nb, Hf, and Ta - used weighed sample amounts of 3-12 mg and a mixed ${ }^{91} \mathrm{Zr}-{ }^{179} \mathrm{Hf}$ spike. Full recovery of HFSE following dissolution requires dissolution in HF, however - in Ca-rich materials - HF leads to the precipitation of fluoride compounds containing HFSE. To suppress the coprecipitation of HFSE, a solution of Al metal dissolved in $\mathrm{HF}$ and $\mathrm{HCl}$ was added prior to dissolution. The amount of Al solution added per sample was calculated to bring the $\mathrm{Al} /(\mathrm{Al}+\mathrm{Ca})$ ratio of the pyroxene to 0.9 , which has been shown to effectively limit HFSE coprecipitation in fluoride compounds (Tanaka et al., 2003). Following the teflon bomb method of Tanaka et al. (2003), samples were dissolved in $\mathrm{HF}$ at $245^{\circ} \mathrm{C}$ for 48 hours. After dissolution, mannitol was added to sample solutions, which were then placed overnight in ultrasonic baths before being dried at $80^{\circ} \mathrm{C}$ in a clean air system. Prior to analysis, samples were dissolved in HF to a dilution factor of 800 , centrifuged and transferred to new containers to remove any remaining fluorides from the solutions.

Trace elements were analyzed using an Agilent 7500cs Q-pole type ICP-MS, following 
the procedures of Makishima and Nakamura (1997, 2006) and Makishima et al. (1999). Samples were introduced via fluid injection using a micro-concentric nebulizer. Every two samples were bracketed by analysis of the JB-2 unspiked standard. Data reduction followed the isotope dilution internal standardization method of Makishima and Nakamura (2006), using ${ }^{149} \mathrm{Sm}$ as the internal standard. For HFSE, the internal standard ${ }^{91} \mathrm{Zr}$ was used for $\mathrm{Zr}$ and $\mathrm{Nb}$ and the internal standard ${ }^{179} \mathrm{Hf}$ was used for $\mathrm{Hf}$ and Ta. The $2 \sigma$ reproducibility of the rock standard JB-2 is $1.4-6.6 \%$, blanks were $<0.01 \mathrm{ppb}$ and detection limits in the range 0.1-10 ppb. The elements $\mathrm{Rb}, \mathrm{Cs}$, and Ta were below detection limits for the samples in this study and are not reported here.

\section{TIMS analyses for $\mathrm{Sm}-\mathrm{Nd}$ and $\mathrm{Rb}-\mathrm{Sr}$}

Analyses of Sm-Nd and $\mathrm{Rb}-\mathrm{Sr}$ isotope ratios and concentrations by TIMS followed the techniques of Nakamura et al. (2003). Sample amounts ranged between 9 and $240 \mathrm{mg}$ (Table 4.4), with the amount used determined by the $\mathrm{Nd}$ and $\mathrm{Sr}$ concentrations of the sample. Sample powders were spiked with ${ }^{84} \mathrm{Sr},{ }^{87} \mathrm{Rb},{ }^{150} \mathrm{Nd}$ and ${ }^{149} \mathrm{Sm}$ prior to dissolution in $\mathrm{HClO}_{4}, \mathrm{HF}, \mathrm{HNO}_{3}$, and $\mathrm{HCl}$ using a combination of ultrasonic bath and heating. The dissolved minerals were stepwise dried using closed-system evaporators to limit contamination; this evaporation system was used in all subsequent drying steps. A combination of $\mathrm{HClO}_{4}$ addition and additional stepwise drying were used to completely decompose insoluble flourides. The first separation step for $\mathrm{Rb}, \mathrm{Sr}$ and REE used $1 \mathrm{ml}$ columns with Bio-Rad AG-50WX10 cation exchange resin and $\mathrm{HCl}$ (Yoshikawa and Nakamura, 1993; , Nakamura et al. 2003). $\mathrm{Rb}$ and $\mathrm{Sr}$ were separated using a second cation exchange column with $0.5 \mathrm{ml}$ of Muromac AG-50WX8 cation exchange resin and $\mathrm{HCl}$. Nd and Sm were separated in a second column with $0.3 \mathrm{ml}$ of Muromac AG-50WX8 resin, but using $\alpha$-hydroxyisobutyric acid for elution.

$\mathrm{Sr}$ and $\mathrm{Nd}$ isotopic compositions and $\mathrm{Rb}, \mathrm{Sr}, \mathrm{Nd}$ and $\mathrm{Sm}$ concentrations were deter- 
mined on a Finnigan-MAT262 solid-source thermal ionization mass spectrometer equipped with 5 Faraday cups. In addition, some Sr analyses were run on a Finnigan-Triton mass spectrometer with 9 Faraday cups. Analytical procedures followed Nakamura et al. (2003). $\mathrm{Sr}$ was dissolved in $\mathrm{HNO}_{3}$ and loaded with a $\mathrm{Ta}_{2} \mathrm{O}_{5}$ activator on trapezoid shaped single W ionization filaments. Repeat analyses of the NBS 987 standard on the MAT262 gave a value of $0.710183 \pm 0.000023\left(2 \sigma_{m}, \mathrm{n}=10\right)$ and on the Triton a value of 0.710271 $\pm 0.000012\left(2 \sigma_{m}, \mathrm{n}=8\right)$. Data are fractionation corrected to ${ }^{86} \mathrm{Sr} /{ }^{88} \mathrm{Sr}=0.1194$ and reported relative to ${ }^{87} \mathrm{Sr} /{ }^{86} \mathrm{Sr}=0.710250$ for the NBS 987 standard (Faure and Mensing, 2005). Rb concentrations were measured using a Ta-Re double filament with Rb dissolved in $\mathrm{HNO}_{3}$ prior to loading on the Ta filament. The $2 \sigma$ analytical reproducibility for $1 \mathrm{pg}$ of $\mathrm{Rb}$ by this method is better than $1 \%$, based on 10 replicate analyses (Nakamura et al., 2003).

$\mathrm{Nd}$ isotope analyses use Re double filaments, with $\mathrm{Nd}$ dissolved in $\mathrm{HNO}_{3}$ prior to loading onto the Re ionization filament. Data were collected relative to the internal PML Nd standard, which has a value of ${ }^{143} \mathrm{Nd} /{ }^{144} \mathrm{Nd}=0.511769 \pm 0.000011\left(2 \sigma_{m}, \mathrm{n}=5\right)$ with respect to $0.511892 \pm 0.000007\left(2 \sigma_{m}, \mathrm{n}=8\right)$ for the La Jolla Nd standard. Data are fractionation corrected to ${ }^{146} \mathrm{Nd} /{ }^{144} \mathrm{Nd}=0.7219$ and reported relative to ${ }^{143} \mathrm{Nd} /{ }^{144} \mathrm{Nd}=0.511858$ for the $\mathrm{La}$ Jolla standard (Lugmair and Carlson, 1978). Determination of Sm concentrations followed the same Ta-Re double filament method used for $\mathrm{Rb}$, with a $2 \sigma$ analytical reproducibility of $1 \%$ for 1 pg Sm, based on 10 replicate analyses (Nakamura et al., 2003).

\section{TIMS analyses for $\mathbf{P b}$}

For $\mathrm{Pb}$ analyses, 50-600 mg of weighed mineral separates were dissolved in equal amounts of $\mathrm{HBr}$ and $\mathrm{HF}$, with $\mathrm{HBr}$ used to suppress fluoride coprecipitation of $\mathrm{Pb}$. Samples were heated and placed in ultrasonic baths for 3-7 days, and then centrifuged before transferring to new containers. The material remaining in the old containers was further treated with $\mathrm{HBr}$ and heating or ultrasonic bath for an additional day to promote fluoride disso- 
lution and $\mathrm{Pb}$ removal from fluorides. In none of the samples were fluorides completely dissolved. Samples were dried in closed-system evaporators and diluted with $\mathrm{HBr}$ prior to column loading. Following the method of Kuritani and Nakamura (2002), a column with $0.1 \mathrm{ml}$ of Bio-Rad AG-1X8 anion exchange resin was used to remove most elements apart from $\mathrm{Pb}$, which was eluted in $\mathrm{H}_{2} \mathrm{O}$. A second column, with $0.01 \mathrm{ml}$ Bio-Rad AG-1X8 resin, was used to remove trace contaminants from the $\mathrm{Pb}$ fraction, which was again eluted using $\mathrm{H}_{2} \mathrm{O}$.

Following column separation, $\mathrm{Pb}$ concentrations where estimated from $\mathrm{Pb}$ count rates on the Agilent 7500cs ICP-MS. Of the $22 \mathrm{Cpx}$ and Opx samples for which $\mathrm{Pb}$ was separated, only $3 \mathrm{Cpx}$ samples yielded $>1 \mathrm{ng} \mathrm{Pb}$, sufficient for measurement of isotope ratios. The low $\mathrm{Pb}$ yields are probably due to the large amount of fluoride coprecipitation during dissolution, which was not adequately suppressed by $\mathrm{HBr}$ addition. Three basalt samples - one from dredge Van7-96 and two repeat analyses (Van7-92-03 and Kn162-61-71) from Standish (2006) - were also prepared and these all yielded $>5 \mathrm{ng} \mathrm{Pb}$.

Analytical procedures for the two Cpx samples followed the two double spikes method of Kuritani and Nakamura (2003). A double spike enriched in ${ }^{207} \mathrm{~Pb}$ and ${ }^{204} \mathrm{~Pb}$ was added to a quarter of the sample and a double spike enriched in ${ }^{205} \mathrm{~Pb}$ and ${ }^{204} \mathrm{~Pb}$ was added to the remainder of the sample. For the basalts, analytical procedures followed the normal double spike method (e.g., Hamelin et al., 1985, Galer, 1999), by adding a spike enriched in ${ }^{207} \mathrm{~Pb}$ and ${ }^{204} \mathrm{~Pb}$ to a quarter of the sample. The dried samples were dissolved in silicic acid and loaded on single Re filaments. All samples were analyzed on a Finnigan-MAT261 mass spectrometer equipped with 6 Faraday cups. Replicate analyses of the NBS 981 standard gave values of ${ }^{206} \mathrm{~Pb} /{ }^{204} \mathrm{~Pb}=16.942 \pm 0.002\left(2 \sigma_{m}\right),{ }^{207} \mathrm{~Pb} /{ }^{204} \mathrm{~Pb}=15.500 \pm 0.002\left(2 \sigma_{m}\right)$ and ${ }^{208} \mathrm{~Pb} /{ }^{204} \mathrm{~Pb}=36.727 \pm 0.004\left(2 \sigma_{m}\right)$. Data are reported relative to the values of NBS 981 from Todt et al. (1996), for consistency with the Standish (2006) Oblique Segment basalt dataset. 


\subsection{Results}

\subsubsection{Data quality}

Analyses of abyssal peridotites are difficult due to the low concentrations of relevant trace elements and the effects of seawater alteration. In Fig. 4.4, we compare concentrations of Sr, Nd and Sm measured by ICP-MS and by TIMS. In general, the data plot either on the 1:1 line or towards slightly higher values for the TIMS results, but with no systematic offset as a function of concentration. The average difference between ICP-MS and TIMS concentrations is 14\%. An average of $3 \mathrm{mg}$ Cpx and $7 \mathrm{mg}$ Opx were used for the ICP-MS analyses and blank amounts were $<10 \mathrm{pg}$. For TIMS analyses, average sample weights were $70 \mathrm{mg}$ for $\mathrm{Cpx}$ and $150 \mathrm{mg}$ Opx, which should produce more precise results. However, the use of larger sample volumes required larger acid volumes for dissolution, leading to increased blanks. Blank amounts for TIMS analyses were $<1 \mathrm{ng}$ and typically in the range 1-50 pg. The competing effects of increased precision and increased blank amounts with sample volume are the likely cause of the non-systematic variation between ICP-MS and TIMS concentrations.

To assess the importance of mineral separate purity, we analyzed two Cpx mineral separates from pyroxenite sample Van7-96-16. While one separate consisted of optically pure grains, the other consisted of Cpx which were not optically pure and contained inclusions of both black and white grains. The REE compositions of both mineral separates are plotted in Fig. 4.5B, with the impure separate shown as a dashed line. The pure Cpx separate is indistinguishable from the other pyroxenites. The impure separate has low REE concentrations with a positive Eu anomaly, both indicative of analysis of $\mathrm{Cpx}$ and plagioclase

combined. The Nd isotope ratios for these two separates are within error, while the pure separate has a higher $\mathrm{Sr}$ isotope ratio than the impure separate. Hence, the purity of the separate appears to affect trace element concentrations more than Nd isotopic ratio. 
To test the precision of our analyses and for interlab comparison, we repeated the analysis of PS86-6-36 from Salters and Dick (2002). As indicated in Table 4.4, our values for ${ }^{143} \mathrm{Nd} /{ }^{144} \mathrm{Nd}$ and ${ }^{87} \mathrm{Sr} /{ }^{86} \mathrm{Sr}$ agree within error with the Salters and Dick values. For Pb isotopes, we ran replicate analyses of two basalt samples from Standish (2006). ${ }^{206} \mathrm{~Pb} /{ }^{204} \mathrm{~Pb}$ agree within error, but our samples have ${ }^{207} \mathrm{~Pb} /{ }^{204} \mathrm{~Pb}$ and ${ }^{208} \mathrm{~Pb} /{ }^{204} \mathrm{~Pb}$ offset to higher values (Fig. 4.7), despite normalization of all data to the same standard values for NBS 981. To check internal reproducibility, we ran a duplicate analysis of Van7-85-47, following the entire procedure starting from a split of the same powdered mineral separate. Table 4.4 shows that the duplicate analyses agree within error for ${ }^{143} \mathrm{Nd} /{ }^{144} \mathrm{Nd}$, but not for ${ }^{87} \mathrm{Sr} /{ }^{86} \mathrm{Sr}$ (0.702286 vs 0.702176$)$. The discrepancy between $\mathrm{Sr}$ isotope ratios may be due to heterogeneous $\mathrm{Sr}$ distribution due to alteration phases not completely removed by leaching. We interpret the lower ${ }^{87} \mathrm{Sr} /{ }^{86} \mathrm{Sr}$ as the more representative value as seawater alteration increases $\mathrm{Sr}$ isotopic ratios.

Abyssal peridotites are generally severely altered by hydrothermal processes at the ridge and our samples are no exception. The majority of olivine is either serpentinized or altered to brownish orange clay minerals. Opx and Cpx are typically much fresher than olivine, but alteration occurs occasionally along rims and cleavage planes or as amphibole pseudomorphs. The alteration process results in isotopic exchange between minerals and fluid, and the precipitation of fluid-derived carbonates. Nd isotopic exchange is negligible due to low $\mathrm{Nd}$ concentrations in seawater, but $\mathrm{Sr}$ isotopic exchange and carbonate precipitation shift the ${ }^{87} \mathrm{Sr} /{ }^{86} \mathrm{Sr}$ of peridotite towards 0.709 , the isotopic composition of seawater. In order to eliminate the seawater $\mathrm{Sr}$ signature, we followed a multi-day, multi-stage leaching procedure using $\mathrm{HCl}, \mathrm{HF}$, and $\mathrm{HNO}_{3}$, with an intermediate step of additional crushing in a $\mathrm{SiN}$ mortar, to remove alteration phases from the rims and cleavage planes of pyroxene grains. This procedure was effective in significantly reducing the seawater alteration signature based on the following three observations. (1) With a few exceptions, data plot on the 
same Nd-Sr isotope trend defined by basalts from the Oblique Segment (Standish, 2006), as illustrated in Fig. 4.6. (2) Coexisting Cpx and Opx have similar ${ }^{87} \mathrm{Sr} /{ }^{86} \mathrm{Sr}$ ratios. As Opx is more susceptible to hydrothermal alteration due to its lower $\mathrm{Sr}$ concentrations, this result strongly supports our contention that alteration affects were minimized by our analytical technique. (3) Our results include a ${ }^{87} \mathrm{Sr} /{ }^{86} \mathrm{Sr}$ ratio of 0.702096 in Cpx from Van7-9638 , the most depleted value measured to date in abyssal peridotites and among the lowest measured in any basalt, thus attesting to the effectiveness of our leaching procedure.

Despite extensive leaching, the two most visibly altered samples have ${ }^{87} \mathrm{Sr} /{ }^{86} \mathrm{Sr}>0.704$ (Van7-85-30 and Van7-86-27) and do not plot on the basalt Nd-Sr isotope trend (Fig. 4.6). We conclude that pristine ${ }^{87} \mathrm{Sr} /{ }^{86} \mathrm{Sr}$ values were not recovered for these samples. The only sample in which a high ratio does not appear to be due to visible alteration is RC27-96-2, which is fresh for an abyssal peridotite. This sample is unusual in various ways, including the greater isotopic and trace element enrichment in the peridotite matrix than in the clinopyroxenite vein. However, until ${ }^{87} \mathrm{Sr} /{ }^{86} \mathrm{Sr}$ can be measured in situ, the origin of ${ }^{87} \mathrm{Sr} /{ }^{86} \mathrm{Sr}$ enrichment in this sample cannot be conclusively identified. We have not, however, found any evidence for the "orphan" ${ }^{87} \mathrm{Sr} /{ }^{86} \mathrm{Sr}$ component identified in this sample by Snow et al. (1993).

\subsubsection{Modes and petrography}

The peridotites in this study are typical of abyssal peridotites (Dick, 1989), ranging in modal Cpx content from 2\% to 13\%. Mineral major element compositions (Appendix 4.A are also typical of abyssal peridotites. The variations of spinel $\mathrm{Cr} \#(\mathrm{Cr} /(\mathrm{Cr}+\mathrm{Al}))$, $\mathrm{Mg} \#(\mathrm{Mg} /(\mathrm{Mg}+\mathrm{Fe}))$ and $\mathrm{TiO}_{2}$ suggest variable degrees of melting and, among veined peridotites, melt refertilization (Fig. 4.All). The most unusual feature among Cpx major element compositions is the relatively low $\mathrm{Cr}_{2} \mathrm{O}_{3}$ among Dredge 96 pyroxenites whereas the clinopyroxenite vein in RC27-9-6-2 has relatively high $\mathrm{Cr}_{2} \mathrm{O}_{3}$ (Fig. 4.A2). 
Dredge 96 pyroxenites consist of 25-39\% Opx and 24-57\% Cpx, with minor amounts of olivine, hence they are properly classified as websterites and Ol-websterites. The boundaries of narrower veins are difficult to distinguish in thin section, as veins are sometimes the width of a single pyroxene porphyroclast (Fig. 4.2 D). Veins of finer grained Ol-Plag-Cpx cross-cut the coarser grained pyroxenites or forms rims around spinel trails. As discussed earlier, we interpret the Ol-Plag-Cpx assemblage to be a late-stage gabbroic melt which crystallized at shallow depths.

The clinopyroxenite vein in RC27-9-6-2 is composed of $82 \%$ large, bright green, Crrich Cpx. Plagioclase is present in trace amounts $(0.01-0.2 \%)$ in the vein and matrix. It may either be the result of spinel breakdown or related to a late stage $0.5 \mathrm{~mm}$ wide magmatic vein that occurs in the peridotite matrix, unconnected to the clinopyroxenite vein. The clinopyroxenite vein boundaries are sharply defined by a transition from large Cpx grains, with associated small olivine, $\mathrm{Cpx}$ and Opx grains, to the coarse grained olivine matrix (Fig. 4.2 G-H).

\subsubsection{Trace elements}

Peridotite Cpx in this study cover the range of trace element compositions previously observed in abyssal peridotite Cpx (e.g., Johnson et al., 1990). Trace element data for Cpx and Opx are presented in Table 4.3 and REE patterns, normalized to primitive upper mantle (PUM; McDonough and Sun, 1995), are plotted in Fig. 4.5. For comparison, the abyssal peridotite Cpx datasets from Johnson et al. (1990) and Johnson and Dick (1992) are also shown, using only samples away from hotspots. Samples from Dredge 85 and the Dredge 86 sample have typical depleted REE patterns for abyssal peridotites, with Cpx falling in the middle of the range of Cpx compositions from Johnson et al. (1990). In contrast, the Dredge 96 samples and the Atlantis II Fracture Zone sample have higher overall REE concentrations and less depleted patterns. 
Both the peridotites and pyroxenites from Dredge 96 have enriched compositions, with almost flat patterns, except for variable depletion in the light REE (LREE), which range over an order of magnitude. The most notable feature of the Dredge 96 samples is that the pyroxenites do not have distinct trace element compositions from the peridotites. The basalt from Dredge 96 has a LREE enriched composition, with only slightly higher heavy REE (HREE) concentrations than the peridotites. The sample from dredge PS86-6 is also relatively undepleted, with a similar composition to the most LREE depleted of the Dredge 96 samples.

The Atlantis II Fracture Zone sample RC27-9-6-2 has a distinctive REE pattern that is nearly flat and relatively depleted in HREE and enriched in LREE, with respect to the field for residual abyssal peridotite Cpx. In addition, the REE pattern of the matrix peridotite Cpx crosses that of the vein Cpx. The matrix Cpx is almost identical to PUM in composition, while vein Cpx is less enriched in LREE but more enriched in HREE. In comparison to other peridotite Cpx from the fracture zone (Johnson and Dick, 1992), LREE in RC279-6-2 are more enriched but HREE are less enriched.

\subsubsection{Isotopes}

Results of $\mathrm{Nd}, \mathrm{Sr}$ and $\mathrm{Pb}$ isotope analyses are presented in Tables 4.4 and 4.5 , revealing variations both within and between dredges and down to the sub-sample scale. In Fig. 4.6, we plot the variation in ${ }^{143} \mathrm{Nd} /{ }^{144} \mathrm{Nd}$ against the variation in ${ }^{87} \mathrm{Sr} /{ }^{86} \mathrm{Sr}$ for both localities. $\mathrm{Pb}$ isotope data are shown for the three Cpx separates successfully analyzed in Fig. 4.7 . In addition, we plot published peridotite $\mathrm{Cpx}$ compositions for the same localities (Snow et al., 1994; Salters and Dick, 2002) and related basalts and gabbros from a compilation of published data (see Fig. 4.6 caption for references). 


\section{The Oblique Segment}

On the Oblique Segment, Dredge 85 samples are isotopically depleted, except for alterationrelated enrichment of $\mathrm{Sr}$ in some samples. One Dredge 85 sample is more depleted in both $\mathrm{Nd}$ and $\mathrm{Sr}$ than the estimated isotopic composition of DMM, which is defined by the average composition of MORBs (Su and Langmuir, 2003). This sample is also more depleted than depleted-DMM (D-DMM), defined as the isotopic composition that is $2 \sigma$ depleted from average MORB (Su and Langmuir, 2003; Workman and Hart, 2005). Similarly, in Dredge 96, Van7-96-38 is more depleted than DMM for both $\mathrm{Nd}$ and $\mathrm{Sr}$, and has among the lowest ${ }^{87} \mathrm{Sr} /{ }^{86} \mathrm{Sr}$ value ever measured in MORBs or abyssal peridotites.

The isotopic composition of Dredge 96 ranges from the extremely depleted composition of Van7-96-38 (unveined peridotite) to the enriched compositions of Van7-96-16 (pyroxenite) and Van7-96-35 (unveined peridotite). The pyroxenites and peridotites do not form two distinct isotopic groups, though the unveined peridotites extend to more depleted compositions than the pyroxenites. The basalt from Dredge 96 plots towards the depleted end of the peridotite trend, close to DMM.

In Fig. 4.6A, we also plot the composition of Bouvet Island basalts, located to the west of the Oblique Segment near the Bouvet Triple Junction (Fig. 4.1). Bouvet Island is the present-day location of Bouvet hotspot, which passed along the African plate section of the Shaka Fracture Zone at 15-25 Ma (Hartnady and le Roex, 1985). Basalts and peridotites from the fracture zone (le Roex et al., 1983; Snow, 1993) have similar Nd isotopic compositions to Bouvet basalts (Fig. 4.6A). The most enriched Dredge 96 samples fall within the range of Bouvet basalt compositions. As a whole, Dredge 96 peridotites, Oblique basalts, and other Oblique peridotites form a trend between Bouvet Hotspot and DMM, with some peridotite ${ }^{87} \mathrm{Sr} /{ }^{86} \mathrm{Sr}$ exceptions due to seawater alteration. In contrast, peridotites from the ridge near Bouvet Island (Snow et al., 1994) have depleted compositions similar to DMM.

The $\mathrm{Pb}$ isotopic variation of the two Dredge 96 peridotites, one veined and the other 
unveined, show significant variation in ${ }^{206} \mathrm{~Pb} /{ }^{204} \mathrm{~Pb}$ and ${ }^{208} \mathrm{~Pb} /{ }^{204} \mathrm{~Pb}$, but less variation in ${ }^{207} \mathrm{~Pb} /{ }^{204} \mathrm{~Pb}$ (Fig. 4.7). Van7-96-28 (unveined peridotite) is similar in composition to Bouvet basalts. Van7-96-21 (veined peridotite) and the Dredge 96 basalt have less radiogenic compositions, with the basalt close in composition to DMM. All three samples are offset in ${ }^{207} \mathrm{~Pb} /{ }^{204} \mathrm{~Pb}$ from the trend of the Oblique basalts from Standish (2006), whereas our replicate analyses of two basalts from the Standish (2006) dataset plot on the trends (Table 4.5, Fig. 4.7).

\section{Atlantis II Fracture Zone}

The peridotite matrix of RC27-9-6-2 is enriched in ${ }^{143} \mathrm{Nd} /{ }^{144} \mathrm{Nd}$, while the clinopyroxenite vein is, surprisingly, less isotopically enriched. Sr isotopes are enriched, also with greater enrichment in the peridotite than in the vein. While seawater alteration cannot be ruled out as the cause of ${ }^{87} \mathrm{Sr} /{ }^{86} \mathrm{Sr}$ enrichment, an isotopic range from 0.704 to 0.705 on a scale of $\sim 10 \mathrm{~cm}$ is unlikely for seawater alteration. The isotopic composition of RC27-96-2 contrasts with previously analyzed Atlantis II Fracture Zone peridotites (Snow et al., 1994, Salters and Dick, 2002), which extend from ${ }^{143} \mathrm{Nd} /{ }^{144} \mathrm{Nd}$ compositions similar to DMM towards values more depleted than D-DMM.

In Fig. 4.6B we plot three types of MORB data from the Atlantis II Fracture Zone region for comparison to the peridotites: samples from (i) the Atlantis II Fracture Zone, (ii) a transform volcano at the northern ridge-transform intersection, and (iii) the ridge segments on either side of the fracture zone. While generally depleted in composition, all three types of basalt have at least one sample with ${ }^{143} \mathrm{Nd} /{ }^{144} \mathrm{Nd}$ similar to RC27-9-6-2. The gabbros from Hole 735B on Atlantis Bank are all depleted in composition, encompassing the range of depleted MORBs from the area. In terms of $\mathrm{Pb}$ isotopes, basalts and gabbros from the fracture zone are depleted, ranging between DMM and D-DMM in composition. Cpx from the peridotite matrix of RC27-9-6-2 is more depleted in ${ }^{206} \mathrm{~Pb} /{ }^{204} \mathrm{~Pb}$ than the 
basalts and gabbros but similar in terms of ${ }^{207} \mathrm{~Pb} /{ }^{204} \mathrm{~Pb}$ and ${ }^{208} \mathrm{~Pb} /{ }^{204} \mathrm{~Pb}$.

\subsection{Discussion}

\subsubsection{Partition coefficients}

In abyssal peridotites, determination of Cpx-Opx partition coefficients is important for constraining the occurrence of mineral-mineral equilibrium during melt-rock reaction and subsolidus re-equilibration in the upwelling mantle. In Table 4.6, we present the first set of Cpx-Opx partition coefficients for abyssal peridotites from bulk mineral analyses. In addition, listed in Table 4.6 are the dominant valence state of each element in pyroxene and their ionic radii (Shannon, 1976) in Cpx and Opx. The ionic radii provide a measure of the relative compatibility of each element in Cpx and Opx and we use these radii to order the elements in the spider diagrams in Fig. 4.8. In $\mathrm{Cpx}$, trace elements vary between VI-fold and VIII-fold coordination, depending on whether they occupy the M1 or M2 site, respectively, whereas elements in Opx are in VI-fold coordination in both the M1 and M2 sites. Thus elements have the same ionic radii in Cpx and Opx if they occupy the M1 site in $\mathrm{Cpx}$, which is the case for cations such as $\mathrm{Zr}$ and $\mathrm{Ti}$ that have relatively small cationic radii. Ordering elements in this way is more relevant to inter-mineral behavior than the commonly used element ordering from Hofmann (1988), which is based on the partitioning of elements into melt.

The range of partition coefficients from Witt-Eickschen and O'Neill (2005) and from Hellebrand et al. (2005) are shown on the spider diagrams in Fig. 4.8. The Witt-Eickschen and O'Neill (2005) dataset consists of ICP-MS analyses of mineral separates from peridotite xenoliths thought to have equilibrated over a temperature range of $900-1250^{\circ} \mathrm{C}$. Their results constrain the change in partition coefficients with temperature and composition combined. These are the main variables controlling partitioning and they cannot be 
separated for pyroxenes with an immiscibility gap. Our results overlap the high temperature end of the Witt-Eickschen and O'Neill dataset and require only a small amount of extrapolation to reach a temperature relevant to mantle melting processes $\left(\sim 1350^{\circ} \mathrm{C}\right)$. Despite this extrapolation, our partition coefficients have the advantage over the Witt-Eickschen and O'Neill coefficients of being determined for pyroxene compositions relevant to the upper oceanic mantle.

The second background dataset in Fig. 4.8 is from Hellebrand et al. (2005) and consists of in situ ion probe analyses of abyssal peridotite pyroxenes. The Hellebrand et al. partition coefficients extend over a range of up to two orders of magnitude, with a larger range among the more incompatible elements. Most pyroxenes in abyssal peridotites exsolve a second pyroxene phase during their ascent to the seafloor, which redistributes the high temperature trace element budget within the mineral. To account for exsolution lamellae, Hellebrand et al. (2005) applied correction factors to their partition coefficients, with larger corrections applied to the more incompatible elements. Application of their correction factors shifts their partition coefficients to higher temperature values, but does not reduce the partition coefficient range for a given element. We suggest that the large range is due to the difficulty in analyzing Opx, which typically exsolves closely spaced, narrow Cpx lamellae. Combined with the lower trace element concentrations of Opx with respect to Cpx, the spread of the Hellebrand et al. dataset towards lower partition coefficients with increasing incompatibility is probably due to overlap of the ion beam onto Cpx lamellae during Opx analysis.

In general, the partition coefficients that we measured vary smoothly as a function of ionic radius. The breaks in slope on the spidergram correspond to large changes in radius, changes in cation valence state, or changes in site occupancy (e.g., between Li and $\mathrm{Zr}$, cations switch from M2 to M1 site occupancy). Only Pb, the most incompatible element, exhibits a large range of partition coefficients, which may be due to measurement 
uncertainty or sulfide control of the $\mathrm{Pb}$ system.

The smooth variation of Cpx/Opx partition coefficients in Fig. 4.8 requires the distribution of trace elements in Cpx to be homogeneous. Diffusion in Cpx is faster for elements with smaller cationic radii (Van Orman et al., 2001), hence disequilibrium in Cpx would fractionate partition coefficients, which we do not observe. Models of REE diffusion in $\mathrm{Cpx}$ at conditions relevant to mid-ocean ridges have shown that $\mathrm{Cpx}$ equilibrates on a timescale of $<1$ My for grains $<5 \mathrm{~mm}$ in diameter (Van Orman et al., 2001; Cherniak and Liang, 2007). In addition, no core to rim variations are observed among $\mathrm{Cpx}$ based on ion probe analyses (Warren, unpublished data). The only exception is RC27-9-6-2, which has core to rim REE variations (Warren, unpublished data), coarser grain sizes and a shallower slope among LREE partition coefficients (Fig. 4.8).

In contrast to $\mathrm{Cpx}$, Opx is typically coarse grained and has lower diffusion rates that are independent of cationic radius (Cherniak and Liang, 2007). Modeling by Cherniak and Liang has demonstrated that significant core to rim variations can form in Opx because of the slow diffusion rates. Opx disequilibrium changes the absolute value of the partition coefficients without changing the shape of the partition coefficient pattern. Hence, Opx in Dredge 96 and RC27-9-6-2 could represent disequilibrium, leading to overestimates of the partition coefficients with respect to their closure temperatures.

\subsubsection{Isotopic disequilibrium between $\mathrm{Cpx}$ and Opx}

Cpx and Opx from the same peridotite samples do not have the same ${ }^{143} \mathrm{Nd} /{ }^{144} \mathrm{Nd}$ ratios, but they generally have the same ${ }^{87} \mathrm{Sr} /{ }^{86} \mathrm{Sr}$. In addition, Cpx from the matrix and vein of the same sample do not have the same ${ }^{143} \mathrm{Nd} /{ }^{144} \mathrm{Nd}$ ratios. Isotopic disequilibrium can result from radiogenic ingrowth in minerals with the same initial isotopic composition or it can be produced by kinetic processes. We test for radiogenic ingrowth by fitting $\mathrm{Sm}-\mathrm{Nd}$ isochrons for the six Cpx-Opx pairs of measurements, plus three subsets of matrix-vein 
Cpx measurements, as shown in Fig. 4.9. We do not determine isochrons for the $\mathrm{Rb}-\mathrm{Sr}$ system, as $\mathrm{Rb}$ concentrations are extremely low in pyroxenes (Table 4.4) and significant isotopic disequilibrium is not observed, with the exception of RC27-9-6-2.

In Fig. 4.9, the mineral "isochrons" are plotted using a linear least squares regression through Cpx-Opx pairs and through Cpx-Opx-Cpx pairs among veined samples. Both the pyroxenites and peridotites that we analyzed have inconsistent ages, ranging from $-98 \mathrm{Ma}$ to $156 \mathrm{Ma}$. Addition of vein Cpx to the calculation emphasizes the inconsistency of the ages, as Van7-96-21 changes from 46 Ma to $274 \mathrm{Ma}$ and RC27-9-6-2 from 68 Ma to 223 Ma. Isochrons regressed through samples from the same dredge also do not demonstrate a coherent set of ages. Hence, the isotopic disequilibrium of the SWIR peridotites is not the result of radiogenic ingrowth and must be related to kinetic processes in the peridotites.

We suggest that the grain-scale $\mathrm{Nd}$ isotopic disequilibrium between $\mathrm{Cpx}$ and $\mathrm{Opx}$ is due to incomplete diffusive equilibration of Opx during melt-rock reaction at the ridge. The general disequilibrium between veins and matrices and among samples from the same dredge suggest variable amounts of melt-rock reaction during melt extraction. As discussed in the previous section, the absence of REE fractionation among our measured partition coefficients requires $\mathrm{Cpx}$ to be equilibrated. In contrast, diffusion in Opx does not fractionate REE, so Opx equilibrium is not required by the partition coefficient data. In addition, experimental and model results from Cherniak and Liang (2007) indicate that REE diffusion in Opx is slow and equilibration requires time scales of $>20 \mathrm{My}$. Sr diffusion is faster than REE diffusion and Cpx-Opx pairs have ${ }^{87} \mathrm{Sr} /{ }^{86} \mathrm{Sr}$ close to or at isotopic equilibrium. Hence, we conclude that the observed isotopic disequilibrium between Cpx and Opx represents incomplete Opx equilibration following melt-rock reaction at the ridge axis. 


\subsubsection{Radiogenic ingrowth}

Peridotites from slow spreading ridges spend a considerable amount of time between passing through their closure temperatures and exposure on the seafloor. The isotopic range among samples may be smaller than measured because of radiogenic ingrowth during this time. To determine the extent to which ingrowth has affected our measured ${ }^{143} \mathrm{Nd} /{ }^{144} \mathrm{Nd}$ compositions, we assess (i) the amount of ingrowth since a sample was at the $1200^{\circ} \mathrm{C}$ isotherm and (ii) the time necessary to produce the observed isotopic range among samples from the same location. Ingrowth of ${ }^{87} \mathrm{Sr} /{ }^{86} \mathrm{Sr}$ is not addressed because $\mathrm{Rb}$ concentrations in peridotite pyroxenes are extremely low.

In order to age-correct peridotites, we calculate the time since the peridotites left the $1200^{\circ} \mathrm{C}$ isotherm below the ridge axis to their exposure at variable distances from the ridge axis. We select the $1200^{\circ} \mathrm{C}$ isotherm as a maximum closure temperature for REE diffusion in pyroxenes (Van Orman et al., 2002), to estimate a maximum upwelling time and thus a maximum value for the amount of ingrowth. The ingrowth time, $t_{I}$, is calculated as a combination of the upwelling time, $t_{U}$, and the seafloor spreading time, $t_{S}$. The value of $t_{S}$ is determined by dividing the measured distance, $d$, between the dredge location and the ridge axis by the effective half-spreading rate, $v_{H}$.

To determine $t_{U}$, we first use the results of a numerical model for the thermal structure of the ridge axis (Montési et al., 2006) to determine the depth, $L_{1200}^{*}$, to the $1200^{\circ} \mathrm{C}$ isotherm:

$$
L_{1200}^{*}=5 \frac{\kappa}{v_{H}}
$$

where $\kappa$ is the thermal conductivity $\left(10^{-6} \mathrm{~m}^{2} \mathrm{~s}^{-1}\right)$. The solution for corner flow beneath the ridge axis (Batchelor, 1967; McKenzie, 1969) provides the relationship between upwelling velocity, $v_{U}$, and spreading rate:

$$
v_{U}=\frac{2}{\pi} v_{H}
$$


leading to an expression for $t_{U}$ :

$$
t_{U}=\frac{5 \pi}{2} \frac{\kappa}{v_{H}^{2}}
$$

Thus, the time available for ingrowth is:

$$
t_{I}=t_{U}+t_{S}=\frac{5 \pi}{2} \frac{\kappa}{v_{H}^{2}}+\frac{d}{v_{H}}
$$

For Dredge 85 and 96 samples, $t_{U}$ is $\sim 7$ My and $t_{S}$ is 0.5 My for Dredge 85 and $4 \mathrm{My}$ for Dredge 96. On the Oblique Segment, at locations where the ridge has a high angle of obliquity to the spreading direction, $t_{U}$ approaches $18 \mathrm{My}$. For ridges with half spreading rates $>10 \mathrm{~mm} / \mathrm{yr}$ and no obliquity, $t_{U} \leq 1 \mathrm{My}$.

In Fig. 4.10A, we plot ${ }^{143} \mathrm{Nd} /{ }^{144} \mathrm{Nd}$ corrected for $t_{I}$ (the "age" corrected value) versus the measured ${ }^{143} \mathrm{Nd} /{ }^{144} \mathrm{Nd}$ value. Samples plot on or to the right of the 1:1 line, with a maximum change of $0.01 \%$ among our samples. The field between DMM and D-DMM is shaded to demonstrate that the age correction does not shift depleted peridotites back to DMM values. In addition, in Fig. 4.10A, we plot age corrected values calculated for the global abyssal peridotite Cpx dataset (Snow, 1993; Snow et al., 1994; Salters and Dick, 2002; Cipriani et al., 2004). The maximum change globally in ${ }^{143} \mathrm{Nd} /{ }^{144} \mathrm{Nd}$ composition is $0.04 \%$, even among samples that are $\sim 20 \mathrm{Ma}$. The small amount of ingrowth in the global dataset indicates that ingrowth can be ignored when interpreting peridotite isotopic data.

The amount of ${ }^{143} \mathrm{Nd}$ ingrowth is a function of time and the $\mathrm{Sm} / \mathrm{Nd}$ ratio, the effects of which are best understood using $\epsilon_{N d}$ notation, as the absolute change in ${ }^{143} \mathrm{Nd} /{ }^{144} \mathrm{Nd}$ is small owing to the long half-life of ${ }^{147} \mathrm{Sm}$. The difference between the measured, $M$, and corrected, $C$, values of $\epsilon_{N d}$ is:

$$
\Delta \epsilon_{N d}=\epsilon_{N d}^{M}-\epsilon_{N d}^{C}=\frac{\left(\frac{143 N d}{144 N d}\right)_{M}-\left(\frac{143 N d}{144 N d}\right)_{C}}{\left(\frac{143 N d}{144 N d}\right)_{C H U R}} \times 10^{4}
$$


where $C H U R$ is the chondritic uniform reservoir, which has a ${ }^{143} \mathrm{Nd} /{ }^{144} \mathrm{Nd}$ value of 0.512638 . The amount of the age correction for variable $\mathrm{Sm} / \mathrm{Nd}$ ratios can be calculated independently of ${ }^{143} \mathrm{Nd} /{ }^{144} \mathrm{Nd}$ :

$$
\Delta \epsilon_{N d}=\frac{\lambda t_{I} c \frac{S m}{N d}}{\left(\frac{143 N d}{144 N d}\right)_{C H U R}} \times 10^{4}
$$

where $c$ is the conversion factor of 0.6049 between $\mathrm{Sm} / \mathrm{Nd}$ and ${ }^{147} \mathrm{Sm} /{ }^{144} \mathrm{Nd}$.

The results of calculations using Equations 4.5 and 4.6 are shown in Fig. 4.10B. For samples in our study, the ingrowth time is generally $\leq 10 \mathrm{Ma}$ and $\mathrm{Sm} / \mathrm{Nd}$ ratios are $<2$. Samples from the global dataset that have longer ingrowth times are either far from the ridge axis or have very low effective spreading rates. Samples with the highest amounts of ingrowth ( $\left.\Delta \epsilon_{N d} \approx 3-4\right)$ have both high $\mathrm{Sm} / \mathrm{Nd}$ ratios and long ingrowth times. Overall, the amount of ingrowth is generally $<2 \epsilon$ units. From Fig. 4.10, the isotopic range among abyssal peridotites is clearly related to long term mantle heterogeneity and not created in the time since melting beneath the ridge axis.

To assess whether the range of isotopic compositions observed within a single dredge can be produced following the recent melting event, by different amounts of ingrowth due to variable $\mathrm{Sm} / \mathrm{Nd}$ ratios, we calculate the time necessary for ingrowth of the measured range of ${ }^{143} \mathrm{Nd} /{ }^{144} \mathrm{Nd}$. Using the parent and daughter ratios for a pair of samples $(A$ and $B)$ and assuming the same initial ${ }^{143} \mathrm{Nd} /{ }^{144} \mathrm{Nd}$ ratio, then the time, $T$, for radiogenic ingrowth is:

$$
T=\frac{1}{\lambda} \ln \left[\frac{\left(\frac{143 N d}{144 N d}\right)_{A}-\left(\frac{143 N d}{144 N d}\right)_{B}}{\left(\frac{147 S m}{144 N d}\right)_{A}-\left(\frac{147 S m}{144 N d}\right)_{B}}+1\right]
$$

where $\lambda$ is the ${ }^{147} \mathrm{Sm}$ to ${ }^{144} \mathrm{Nd}$ decay constant $\left(6.54 \times 10^{-12} y^{-1}\right)$.

From Equation 4.7, we calculate that the range of isotopic compositions observed among the SWIR peridotites is too large to result from recent radiogenic ingrowth in the peridotites following melt extraction under the ridge axis. Comparing each pair of samples analyzed from Dredge 85, we calculate an average ingrowth time of 230 My. For Dredge 
96, the average ingrowth time among all samples is $520 \mathrm{My}$, among peridotites it is $510 \mathrm{My}$, and among pyroxenites it is $240 \mathrm{My}$. All of these times are much longer than the time-scale of mid-ocean ridge processes and should not be considered meaningful model ages. The above sets of calculations indicate that the isotopic heterogeneity in the mantle pre-dates the current melting and melt-rock reaction processes under the ridge axis.

\subsubsection{Origin of the pyroxenite veins}

Coexisting pyroxenites and peridotites in Dredge 96 were selected for analysis to address the possibility of pyroxenites as direct evidence for the "veined mantle hypothesis". Although a consensus exists as to the presence of recycled crustal components in the mantle, based on isotopic heterogeneities among OIBs (e.g., White and Hofmann, 1982; Allègre and Turcotte, 1986; Zindler and Hart, 1986; Hofmann, 1997), no consensus exists as to the form that recycled crust takes in the mantle following millions of years of convection. The occurrence of pyroxenites in peridotite massifs led Allègre and Turcotte (1986) to suggest the marble-cake mantle hypothesis, in which recycled crust has been stretched and boudinaged to length-scales below meaningful thermodynamic integrity and absorbed into the peridotitic lithology. While numerous studies have documented mineralogical, chemical and isotopic variations among pyroxenites (e.g., Frey and Prinz, 1978; Polvé and Allègre, 1980; Zindler et al., 1983; Hamelin and Allègre, 1988; Piccardo et al., 1988, McDonough and Frey, 1989; Mukasa et al., 1991; Shervais and Mukasa, 1991; Pearson et al., 1993; Python and Ceuleneer, 2003), these pyroxenites have all been identified as representing recent magmatic addition to the host peridotite, rather than ancient recycled crust older than the host. Only studies which include $\delta^{18} \mathrm{O}$ analyses have made a compelling case for recycled ancient crust in the mantle as the original source of present-day pyroxenites or eclogites in massifs and xenoliths (e.g., Pearson et al., 1993; Jacob et al., 1994; Barth et al., 2001). The presence of recycled crust in the asthenospheric mantle has also been invoked 
to explain isotopic variations in MORB (e.g., Allègre et al., 1984; Kellogg et al., 2002, Salters and Dick, 2002) and to reconcile geochemical garnet signatures in MORB and the thickness of oceanic crust (Hirschmann and Stolper, 1996).

Pieces of recycled crust in the form of pyroxenites or eclogites should possess certain characteristics. (1) Mineralogically, they are most likely garnet bearing or they should have the signature of garnet breakdown, such as high HREE concentrations in Cpx (Hart and Dunn, 1993, Vannucci et al., 1993). (2) Major element mineral compositions are expected to have lower Mg\# than peridotite counterparts, even if the precursor eclogites underwent melting in a subduction zone. For example, experimental data at 2-3 GPa show that Cpx in residual eclogites have $\mathrm{Mg} \#$ ranging from 0.60 to 0.76 , depending on the degree of melting (Rapp et al., 1999; Pertermann and Hirschmann, 2003a|b). Coexisting garnets have even lower Mg\# (0.48 - 0.63) and the garnet breakdown reaction will decrease the Mg\# of the recrystallized "low-pressure" Cpx. Eclogitic Cpx are also characterized by a high abundance of the jadeite component. For example, Pertermann and Hirschmann (2003b) report 14-28 mol\% jadeite with 2-4 wt $\% \mathrm{Na}_{2} \mathrm{O}$, and $14-17 \mathrm{wt} \% \mathrm{Al}_{2} \mathrm{O}_{3}$. (3) The expected $\mathrm{Nd}$ isotopic composition of recycled oceanic crust depends on the time since its formation. As $(\mathrm{Sm} / \mathrm{Nd})_{M O R B}<(\mathrm{Sm} / \mathrm{Nd})_{\text {Source }}$, radiogenic growth of ${ }^{143} \mathrm{Nd} /{ }^{144} \mathrm{Nd}$ is decelerated in oceanic crust relative to its source mantle. Oceanic crust of $1 \mathrm{Ga}$ with an average MORB $\mathrm{Sm} / \mathrm{Nd}$ ratio of 0.3356 (Hofmann, 1988) would have ${ }^{143} \mathrm{Nd} /{ }^{144} \mathrm{Nd}=0.512829$, assuming that it formed from a depleted mantle source that differentiated from bulk silicate earth (BSE) at $3 \mathrm{Ga}$. Recycled crust of a greater age would have a less radiogenic $\mathrm{Nd}$ isotopic composition because the depleted mantle would have evolved for less time before crustal formation. Thus, coexisting pyroxenites and peridotites should have distinct ${ }^{143} \mathrm{Nd} /{ }^{144} \mathrm{Nd}$ compositions, with the latter having a more radiogenic (i.e. depleted) composition.

Our observations of Dredge 96 pyroxenites and the RC27-9-6-2 clinopyroxenite do not fit any of the expected characteristics for direct samples of recycled crust. No garnet or ev- 
idence for garnet precursors, such as garnet-like REE patterns in pyroxenes, are observed in the pyroxenites and the pyroxenite REE patterns are identical to peridotite REE patterns. Spinel-pyroxene symplectites, a common product of garnet breakdown in peridotite massifs, are not observed. The major element compositions of Cpx, Opx, olivine and spinel in Dredge 96 pyroxenites (Tables 5.4-5.7) are identical to their peridotite counterparts. For example, the Mg\# of Cpx and Opx range from $89.1 \%$ to $90.7 \%$, much greater than typical eclogitic values. The abundance of the jadeite component in Cpx is extremely low, with barely measurable $\mathrm{Na}_{2} \mathrm{O}<1 \mathrm{wt} \%$ and 5.1-7.7 wt $\% \mathrm{Al}_{2} \mathrm{O}_{3}$, significantly lower than the range cited above. Overall, pyroxene compositions are peridotitic rather than eclogitic.

The third characteristic of our pyroxenites that demonstrates that they are not direct remnants of recycled oceanic crust are the pairs of Cpx isotope analyses from pyroxenite veins and host peridotites (Van7-96-19, Van7-96-21, RC27-9-6-2; Table 4.4). For each pair, the pyroxenite and peridotite either have identical $\mathrm{Nd}$ isotope ratios or the pyroxenite is more depleted than the peridotite, neither of which corresponds to the expected composition of mantle containing recycled ancient oceanic crust. The two largest pyroxenite samples (Van7-96-09 and Van7-96-16) are both coarse-grained (5-10 $\mathrm{mm}$ ) and have distinct isotopic compositions (Table 4.4, Fig. 4.6). Pyroxenite Van7-96-16 defines the enriched end of the isotopic spectrum, with both ${ }^{143} \mathrm{Nd} /{ }^{144} \mathrm{Nd}$ and ${ }^{87} \mathrm{Sr} /{ }^{86} \mathrm{Sr}$ compositions indistinguishable from Bouvet OIBs (e.g., O’Nions et al., 1977; Kurz et al., 1998) and the most enriched Oblique Segment MORBs (Standish, 2006). Based on these observations, we conclude that the pyroxenites in this study are not direct samples of recycled oceanic crust, though ultimately the enriched endmember of their isotopic range may have been derived from a recycled crustal component within Bouvet plume.

The range of isotopic compositions and trace element abundance patterns of Dredge 96 peridotites are best explained by reaction with and addition of melt fractions derived from enriched Bouvet material. This material could either be veined or unveined mantle, 
either from Bouvet plume or mantle metasomatized by the Bouvet plume during its passage along the Shaka Fracture Zone at 15-25 Ma. The fact that the pyroxenites share chemical and isotopic compositions with associated peridotites suggests that near-equilibrium conditions prevailed at temperatures close to but slightly above the peridotite solidus. It is conceivable that melts from the Bouvet-generated source migrated through partially melting asthenospheric peridotite and locally reacted with pyroxenes. This resulted in a wide array of reaction products on the sub-kilometer scale, ranging from the almost non-reacted (peridotite Van7-96-38, which has a very depleted isotopic signature) to the extensively reacted (pyroxenite Van7-96-16).

The existing literature on abyssal pyroxenites is limited to descriptions of less than ten samples combined from the EPR (Constantin et al., 1995), MAR (Serri et al., 1988; Juteau et al., 1990; Kempton and Stephens, 1997) and SWIR (Dantas et al., 2007). All these occurrences describe pyroxenites of depleted compositions similar to adjacent peridotites, suggesting that, along with the results of this study, the bulk of the abyssal pyroxenites do not provide direct evidence for the veined mantle hypothesis. Instead, they indicate variable amounts of melt crystallization in the mantle, starting at variable depths.

\subsubsection{Relationship between peridotites and basalts}

Previous studies of radiogenic isotopes in abyssal peridotites have attempted to reconcile the isotopic composition of peridotites with that of basalts, to determine whether they complement basalt compositions or whether they indicate the existence of an additional mantle component. Snow et al. (1994) and Kempton and Stephens (1997) found that abyssal peridotites have similar isotopic compositions to MORBs and are from the same, depleted mantle source. Salters and Dick (2002) looked in detail at the Oblique Segment and the Atlantis II Fracture Zone and concluded that peridotites are isotopically more depleted in comparison to associated basalts. They advocated for the existence of an enriched pyrox- 
enite component in the mantle that is removed by melting and sampled by basalts, but not preserved in the peridotites. Cipriani et al. (2004) analyzed basalts and peridotites from the Vema Lithospheric Section on the MAR and found that the age-corrected averages for the two lithologies are not statistically different.

In this study, we have found large isotopic variations among peridotites and pyroxenites from one dredge (Dredge 96, Fig. 4.6). They cover $46 \%$ of the $\mathrm{Nd}$ isotopic range of Indian Ocean MORB and encompass the $\mathrm{Nd}$ and $\mathrm{Sr}$ isotopic range of basalts from the Oblique Segment (Standish, 2006). Also noticeable is the fact that basalts from Bouvet hotspot plot at the "enriched" end of the Oblique peridotite and basalt spectrums and that the hotspot was proximal to the Oblique Segment at 15-25 Ma (Fig. 4.1). These observations suggest a genetic link between Dredge 96 enriched peridotites and pyroxenites and the Bouvet hotspot, through melt-rock reaction and veining of mantle peridotites by Bouvetderived melts at $\sim 20 \mathrm{Ma}$. Bouvet-modified mantle then upwelled beneath the Oblique ridge axis, producing melts from the metasomatized mantle with chemically and isotopically enriched signatures. These melts subsequently migrated through and reacted with the depleted mantle, resulting in the chemical and isotopic variations observed among both basalts and peridotites at the present-day ridge axis.

A genetic link between Bouvet source mantle and the Oblique Segment is supported by the $\mathrm{Pb}$ isotopic composition of $\mathrm{Cpx}$, which have similar radiogenic compositions to Bouvet basalts (Table 4.5 and Fig. 4.7). Peridotite Cpx also have similar $\mathrm{Pb}$ isotopic compositions to primary sulfide (monosulfide solid solution) grains in peridotite Van7-9628, as determined by in situ analyses with the Misasa multi-collector SIMS 1270 (two grain average: ${ }^{207} \mathrm{~Pb} /{ }^{206} \mathrm{~Pb}=0.7907$ and ${ }^{208} \mathrm{~Pb} /{ }^{206} \mathrm{~Pb}=1.9984$, compared to 0.7947 and 1.9955 for $\mathrm{Cpx}$, Table 4.5). As uranium is absent in sulfide, $\mu\left({ }^{238} \mathrm{U} /{ }^{204} \mathrm{~Pb}\right)=0$, whereas $\mu=17.8$ in Cpx (Table 4.3). Hence, the apparent isotopic equilibrium between $\mathrm{Cpx}$ and sulfide in the peridotite must be recent, suggesting that the radiogenic $\mathrm{Pb}$ signature of both $\mathrm{Cpx}$ and 
sulfide are from migration of a Bouvet-derived melt through the mantle. As Van7-96-28 is among the relatively enriched samples from Dredge 96, both in terms of $\mathrm{Nd}$ and $\mathrm{Sr}$ isotopic ratios and REE abundance patterns (Fig. 4.5), this supports the $\mathrm{Pb}$ isotope argument for recent Bouvet-derived melt metasomatism of the mantle.

The variations in $\mathrm{Nd}$ and $\mathrm{Sr}$ isotopic compositions of peridotites and basalts along the Oblique Segment and the comparison to Bouvet Island basalts are shown in Fig. 4.11. Similar Bouvet-derived metasomatism of the mantle may have occurred in other parts of the Oblique Segment, as the five samples from dredge PS86-6, reported by Salters and Dick (2002), range from ${ }^{143} \mathrm{Nd} /{ }^{144} \mathrm{Nd}$ of 0.513202 (more depleted than DMM) to 0.512985 (similar to Bouvet basalts). Among the basalts, samples from the Narrowgate region, far to the east of the hotspot track, have the greatest overlap with the Bouvet isotopic range (Standish, 2006). From the overlapping ranges of the basalts and peridotites, we conclude that all mantle isotopic components observed in regional basalts are found in the peridotites and that the existence of an enriched component specifically in the form of pyroxenite veins is not required to explain our dataset. Basalts do not extend to the extremely depleted compositions of the peridotites, because of mass balance constraints. Peridotites with depleted ${ }^{143} \mathrm{Nd} /{ }^{144} \mathrm{Nd}$ compositions (such as Dredge 85 ) must be derived from high $\mathrm{Sm} / \mathrm{Nd}$ ratios and thus relatively low $\mathrm{Nd}$ concentrations, with respect to enriched peridotites. Hence, the contribution of depleted peridotites to the melt mixtures that form basalts is small compared to the contribution from enriched compositions.

Atlantis II Fracture Zone is not associated with any hotspot track, but exhibits isotopic enrichment in some basalts. This enrichment is matched by the $\mathrm{Nd}$ isotopic enrichment in the matrix of peridotite RC27-9-6-2. As shown in Fig. 4.12, the isotopic enrichment in basalts does not occur specifically on one side of the fracture zone or at a specific location along the fracture zone. The transform volcano, located adjacent to the sampling location of peridotite RC27-9-6-2 (Fig. 4.1), ranges in composition from DMM $\left({ }^{143} \mathrm{Nd} /{ }^{144} \mathrm{Nd}=\right.$ 
$0.51313)$ to an enriched composition $\left({ }^{143} \mathrm{Nd} /{ }^{144} \mathrm{Nd}=0.51298\right)$. RC27-9-6-2 ranges from this enriched composition in the peridotite matrix $\left({ }^{143} \mathrm{Nd} /{ }^{144} \mathrm{Nd}=0.512915\right)$ to a nearDMM composition in the clinopyroxenite vein $\left({ }^{143} \mathrm{Nd} /{ }^{144} \mathrm{Nd}=0.513099\right)$. Hence, in one peridotite sample we observe the entire isotopic range of basalts from the transform volcano. The randomly distributed isotopic enrichment of the Atlantis II Fracture Zone suggests that isotopic heterogeneities are ubiquitous and exist on a sub-kilometer scale. This enriched component may only be recognizable at low degrees of melting, such as at fracture zones.

As observed in this study, chemical and isotopic heterogeneities could be both ancient and modern, and could occur on the sub-kilometer scale. Isotopic enrichment or depletion requires long term enrichment or depletion in trace element concentrations, so the enrichment signature will dominate over the depletion signature in melts produced from a heterogeneous mantle. If this picture is generally true for the mantle beneath mid-ocean ridges, basalts should carry slightly more enriched (or less depleted) isotopic signatures than their associated peridotites. In Fig. 4.13, we demonstrate this by plotting histograms of basalt and peridotite $\mathrm{Nd}$ isotopic compositions for the Oblique Segment, the Atlantis II Fracture Zone, and the global ridge system. It is particularly noticeable that the global peridotite average $\left({ }^{143} \mathrm{Nd} /{ }^{144} \mathrm{Nd}=0.513167\right)$ is more depleted than the MORB-derived estimate of DMM (0.51313; Workman and Hart, 2005), and that there is a significant population of peridotites with much more depleted $\mathrm{Nd}$ isotopic compositions (extending to 0.51366) than D-DMM (0.51326). This suggests that the asthenospheric mantle is indeed much more depleted than generally thought and the implications of this suggestion are discussed below.

\subsubsection{Variation of isotopic composition with peridotite melt depletion}

Prior to considering the implications of ultra-depleted compositions and mantle heterogeneity, we assess the extent to which peridotites exhibit long term trace element depletion 
associated with isotopic depletion. Peridotites in a heterogeneous mantle should demonstrate correlations between isotope depletion and indicators of degree of melting. In contrast, recent melting at the ridge axis will deplete peridotite concentrations without changing the isotopic composition.

In Fig. 4.14, the variations of $\mathrm{Cpx} \mathrm{Nd}$ isotopic composition with indicators of degree of melting - modal $\mathrm{Cpx}$, spinel $\mathrm{Cr}$, and $\mathrm{Cpx}(\mathrm{Ce} / \mathrm{Yb})_{N}$ - suggest a possible link between mineralogical, chemical and isotopic signatures of depletion. However, as all peridotites have been affected by recent melting processes, considerable scatter exists for the global data set. When samples from Dredge 85 and Dredge 96 are considered by themselves, reasonable correlations between indicators of major and trace element depletion and isotopic depletion or observed. This suggest that at least some of the variability in isotopic composition of the peridotites reflects ancient melting events.

Dredge 85 peridotites, which have more radiogenic ${ }^{143} \mathrm{Nd} /{ }^{144} \mathrm{Nd}$, are more depleted in modal Cpx, with Cpx having lower $(\mathrm{Ce} / \mathrm{Yb})_{N}$ and $(\mathrm{Nd} / \mathrm{Sm})_{N}$ than Dredge 96 peridotites. Among Dredge 96 peridotites, samples with more depleted isotopic signatures have more depleted trace element ratios. Incorporation of available data for abyssal peridotites from the SWIR (Snow et al., 1994; Salters and Dick, 2002) follows the same general trend. These correlations are broad, with correlation coefficients $<0.3$, but no correlation should be present if the SWIR peridotites formed as simple melt extraction residues from a uniform source mantle. Moreover, variable degrees of melting and melt-rock reaction during the recent melting process will have obscured pre-existing trends between major and trace elements and isotopes. The negative correlation between $\mathrm{Nd}$ isotopes and the $\mathrm{Cr} \#$ of coexisting spinel rules out a simple relationship between isotopic and chemical depletion, as spinel Cr\# should increase with increasing melt depletion. These observations suggest a combination of pre-existing heterogeneity, recent melting and in some regions, production of enriched Cpx by melt-rock reaction with an exotic component (e.g., Bouvet plume). 
To examine in more detail the relationship between enriched and depleted sources among peridotites, we plot the variation of ${ }^{143} \mathrm{Nd} /{ }^{144} \mathrm{Nd}$ as a function of inverse $\mathrm{Nd}$ concentration in Fig. 4.15. Mixing between enriched and depleted sources with different daughter isotope concentrations results in a linear relationship on an inverse concentration diagram (Faure and Mensing, 2005). As shown in Fig. 4.15, a linear regression of Oblique Segment data produces only a minimal correlation and regression of the Atlantis II Fracture Zone dataset produce an anti-correlation. The lack of a mixing relationship on the large scale emphasizes both the complicated nature of melt-rock reaction, the effects of melt removal (e.g. the extremely low Nd concentration samples from the fracture zone in Fig. 4.15, and the heterogeneous nature of the mantle.

On the local scale, the three analyzed samples from dredge RC27-9-6 appear to demonstrate mixing between enriched and depleted sources, with a correlation coefficient of 0.8 (Fig. 4.15). Cpx from the vein in RC27-9-6-2 plots on the line between matrix Cpx and a second, depleted sample from the dredge. Hence, the vein is a mixture of the isotopically and chemically enriched peridotite in which it sits and melt from a more isotopically and chemically depleted peridotite. This depleted peridotite is more depleted than DMM, but the products of mixing - recorded in the vein and a third peridotite from the dredge - are chemically and isotopically similar to DMM (Fig. 4.15).

The major element characteristics of Dredge 85 peridotites suggest low degrees of melting, whereas the trace and isotopic composition suggests extreme depletion. Spinel Cr\#'s are low and the dredge is located on an obliquely spreading ridge section (Fig. 4.1) with little evidence for significant mantle melting and thin to absent volcanic crust (Dick et al., 2003; Standish et al., submitted). However, peridotite trace element concentrations and $\mathrm{Nd}$ isotope ratios are considerably more depleted than DMM. Also worth noting is the fact that these samples are unlikely to have been affected by trapped melt, unless this melt was ultra-depleted, as metasomatism would have a considerable effect on samples with 
low trace element concentrations. Dredge 85 peridotites contain no evidence for late melt impregnation and gabbroic rocks are absent in the region. The isotopic, and to some extent the trace element, composition of these peridotites must have been established prior to melt extraction at the SWIR. Hence, the mantle beneath the SWIR has contained depleted peridotites for a long period of time.

Heterogeneously depleted mantle is implied by comparison of the MORB-based estimate of DMM (Su and Langmuir, 2003; Workman and Hart, 2005) to Cpx compositions in Fig. 4.14. DMM and D-DMM are both less depleted than abyssal peridotites, not just in terms of isotopic composition, but also with respect to Cpx mode, LREE/HREE ratios (e.g., $\mathrm{Ce} / \mathrm{Yb}$ ), and $\mathrm{Sp} \mathrm{Cr \# .} \mathrm{As} \mathrm{will} \mathrm{be} \mathrm{discussed} \mathrm{below,} \mathrm{the} \mathrm{present-day} \mathrm{Sm} / \mathrm{Nd}$ ratio of DMM (on the basis of the continuous depletion model) is too low relative to the ratios measured in depleted abyssal peridotites such as those from Dredge 85. This discrepancy cannot be reconciled as an effect of melt extraction, because predicted degrees of melting are too large given the lack of crust (basalts and gabbros) in the region of Dredge 85. Therefore, we suggest that the correlations in Fig. 4.14, although too broad for detailed discussion, carry important information as to the geochemical prehistory of the asthenospheric mantle. We caution against the prevailing assumption that the entire range of chemical variations observed among abyssal peridotites were generated by melt extraction beneath the current set of ocean ridges.

\subsubsection{Implications for mantle composition}

Results from the present study, combined with the data of Salters and Dick (2002) and Cipriani et al. (2004), suggest that the asthenospheric mantle (DMM) is isotopically more depleted than previously considered (e.g., Workman and Hart, 2005). For example, Figs. 4.6 and 4.114 .12 demonstrate that the most depleted SWIR peridotites are more de-

pleted than D-DMM of Workman and Hart (2005), with ${ }^{87} \mathrm{Sr} /{ }^{86} \mathrm{Sr}$ as low as 0.702096 and 
${ }^{143} \mathrm{Nd} /{ }^{144} \mathrm{Nd}$ up to 0.513417 . Since radiogenic ingrowth of ${ }^{143} \mathrm{Nd} /{ }^{144} \mathrm{Nd}$ following melt extraction beneath the SWIR was found to be small, the observed isotopic signature requires a long-term depletion of Nd relative to Sm. Such long-term LREE depletion suggests that there exists, in the asthenospheric mantle, more strongly LREE-depleted regions than suggested by MORBs. These concentration variations are less apparent in surveys of MORB compositions because the $\mathrm{Nd}$ mass balance for aggregated melts formed by melt fractions derived from variously depleted source peridotites is dominated by the least depleted endmember. Hence, MORBs are skewed towards more isotopically enriched compositions than peridotites (Fig. 4.13).

The presence of ultra-depleted mantle requires a reassessment of the history of mantle depletion, to produce higher $\mathrm{Sm} / \mathrm{Nd}$ and lower $\mathrm{Rb} / \mathrm{Sr}$ than current estimates for $\mathrm{DMM}$. The continuous transport, melt depletion model of Workman and Hart (2005) predicts the evolution of a parent/daughter ratio in DMM based on the isotopic ratios of DMM and BSE and the parent/daughter ratio of BSE. In this model, material is continuously removed from the mantle from the time at which depletion begins $(t)$. Workman and Hart estimate $t$ to be $3 \mathrm{Ga}$, as a best estimate for the start of significant continental crustal growth (Taylor and McLennan, 1995). The parent/daughter ratios of BSE and DMM are related by a transport coefficient, $k$ :

$$
k=\frac{1}{t} \ln \left[\frac{\left(\frac{147 \text { Sm }}{{ }^{144} N d}\right)_{B S E}^{0}}{\left(\frac{147 S m}{144 N d}\right)_{D M M}^{0}}\right]
$$

where the subscript 0 indicates present-day values. The evolution of the isotopic composition of DMM is dependent on $k$ and $t$ :

$$
\left(\frac{143 N d}{144 N d}\right)_{D M M}^{0}=\left(\frac{143 N d}{144 N d}\right)_{B S E}^{t}+\frac{\lambda\left(\frac{{ }^{147} S m}{{ }^{144} N d}\right)_{B S E}^{t}\left[1-e^{-(\lambda+k) t}\right]}{\lambda+k}
$$

In Fig. $4.16 \mathrm{~A}$, we calculate the variation of ${ }^{143} \mathrm{Nd} /{ }^{144} \mathrm{Nd}$ as a function of bulk peri- 
dotite $\mathrm{Sm} / \mathrm{Nd}$ ratio, for different initial depletion times. In addition, we show a traditional two-stage evolution model (cf. Workman and Hart, 2005), in which all depletion occurs at initial time $t$. We plot abyssal peridotite data in Fig. 4.16A, using the age corrected $\mathrm{Cpx}{ }^{143} \mathrm{Nd} /{ }^{144} \mathrm{Nd}$ ratios and assuming that these are representative of the whole rock. Bulk $\mathrm{Sm} / \mathrm{Nd}$ ratios are reconstructed from $\mathrm{Cpx}$ concentrations and the bulk partition coefficient calculated from mineral/melt partition coefficients and the peridotite mode (Equations 1-2 in Workman and Hart, 2005). The abyssal peridotite data trend away from the $3 \mathrm{Ga}$ depletion line towards higher $\mathrm{Sm} / \mathrm{Nd}$ ratios. In comparison to the range among abyssal peridotites, the difference between the continuous and two stage depletion models is relatively small.

To explain the peridotite data in the context of DMM evolution, we consider the effects of melting, which produces high $\mathrm{Sm} / \mathrm{Nd}$ ratios without changing the ${ }^{143} \mathrm{Nd} /{ }^{144} \mathrm{Nd}$ ratio. In Fig. 4.16B, we plot $\mathrm{Sm} / \mathrm{Nd}$ ratios produced by different degrees of modal fractional melting from an initial DMM Sm/Nd ratio of 0.411 (Workman and Hart, 2005). We use modal melting instead of non-modal, for consistency with Workman and Hart (2005). While the simple melting model appears to explain the $\mathrm{Sm} / \mathrm{Nd}$ peridotite range, the predicted $\sim 10 \%$ melting for Dredge 85 does not correspond to observations of the dredge location. As discussed previously, Dredge 85 is from an amagmatic section of the ridge (Fig. 4.1) and the combined slow spreading rate and obliquity to the plate direction implies minimal melting during mantle upwelling. Using a more sophisticated melting model might reduce the amount of melting predicted for Dredge 85, but this dredge would still appear to have undergone higher degrees of melting than dredges associated with significant crustal production. A second difficulty with using any melting model to explain observed $\mathrm{Sm} / \mathrm{Nd}$ variations is that peridotites from the same dredge should undergo the same degree of melting, as they have experienced the same temperature regime. Hence, even if variation in degree of melting could explain the $\mathrm{Sm} / \mathrm{Nd}$ ratios between dredges, it cannot explain the few percent 
variation implied by $\mathrm{Sm} / \mathrm{Nd}$ ranges within dredges. The $\mathrm{Sm} / \mathrm{Nd}$ ratios of peridotites, while invariably affected to some degree by recent melting, must largely be inherited signatures that predate recent ridge processes.

In another attempt to explain peridotite isotopic and trace element depletions, we modify the continuous depletion model by removing material at different times and calculating the present day ratio of this material. In Fig. 4.17, we plot the evolution of BSE and DMM $\mathrm{Nd}$ isotopic compositions with time and with $\mathrm{Sm} / \mathrm{Nd}$ ratio. We then calculate the evolution of material removed at various times from DMM, which is found to evolve to compositions between present-day BSE and DMM. As observed in Fig. 4.17, the limitation of this model is that it cannot produce compositions outside the BSE-DMM range, whereas peridotites extend to much higher $\mathrm{Sm} / \mathrm{Nd}$ ratios. Our results indicate that the evolution of the asthenosphere is more complicated than implied by depletion models constrained by BSE and DMM alone, particularly when the $\mathrm{Sm} / \mathrm{Nd}$ ratio of DMM is determined from the present-day ${ }^{143} \mathrm{Nd} /{ }^{144} \mathrm{Nd}$ ratio of DMM. A more accurate model of asthenosphere evolution needs to explicitly include the effect of melting on $\mathrm{Sm} / \mathrm{Nd}$ ratios at various times in the past. In addition, the effects of material return at subduction zones need to be included, to explain the enriched compositions of peridotites such as RC27-9-6-2, which plot on the enriched side of BSE in Fig. 4.17 .

If depleted peridotites such as Dredge 85 form a volumetrically significant component of the asthenospheric mantle and if enriched components such as RC27-9-6-2 are relatively ubiquitous in the mantle, then estimates of melting systematics based on MORB compositions need to be reassessed. Workman and Hart (2005) concluded that MORB is produced by $6 \%$ aggregated fractional melting of DMM, resulting in a $\mathrm{Nd}$ concentration in MORB of $8.37 \mathrm{ppm}$. Alternatively, the upper mantle can be considered a mixture of two (or more) components, for example the E-DMM and D-DMM calculated by Workman and Hart (2005). A 6\% melt of each of these lithologies, mixed in proportions of 55\% D- 
DMM and 45\% E-DMM, produces a MORB-like melt with $8.37 \mathrm{ppm} \mathrm{Nd}$ and ${ }^{143} \mathrm{Nd} /{ }^{144} \mathrm{Nd}$ $=0.51312$. This calculation assumes similar solidi for both end-members, which is fine for variable modes but not for variable mineral compositions (Pickering-Witter and Johnston, 2000; Schwab and Johnston, 2001).

Based on the above discussion of depletion models, the $\mathrm{Nd}$ concentrations of depleted peridotites are likely to be considerably more depleted than D-DMM. Thus, depleted peridotites such as in Dredge 85 would contribute a relatively small amount to the observed trace and isotopic composition of MORBs. In the context of the veined mantle model discussed earlier, this implies that if pyroxenites are present in the mantle, they would dominate the melt isotopic signature and MORBs should have a more enriched isotopic signature than is observed. Hence, we propose that the upper mantle consists of variably depleted and enriched peridotites and that these variations in isotopic, trace, major and modal compositions, when properly incorporated into melt production and extraction models, can explain many of the observed variations in MORB composition.

\subsection{Conclusions}

Analyses of peridotites from the SWIR demonstrate greater isotopic and trace element variability on a smaller lengthscale than has previously been observed. We find that peridotites extend to more depleted compositions than estimates of DMM, with ${ }^{87} \mathrm{Sr} /{ }^{86} \mathrm{Sr}$ as low as 0.702096 and ${ }^{143} \mathrm{Nd} /{ }^{144} \mathrm{Nd}$ as high as 0.513335 among our samples. Other peridotites are relatively enriched and in one SWIR dredge we find $46 \%$ of the $\mathrm{Nd}$ isotopic range of Indian Ocean MORB. On the basis of our analyses, we reach several conclusions:

1. Cpx and Opx in abyssal peridotites are in $\mathrm{Nd}$ isotopic disequilibrium and the disequilibrium is not the result of recent radiogenic ingrowth. In all the peridotites for which both Cpx and Opx were measured, evidence for recent melt-rock reaction is 
found. Hence, we suggest that isotopic disequilibrium reflects Opx REE disequilibrium, as Opx is coarse grained and has slower diffusion rates than Cpx. In addition, if the disequilibrium originated in $\mathrm{Cpx}$, fractionated partition coefficient patterns and core-to-rim variations in trace elements should be observed, but are not.

2. Peridotites spend $\sim 1-20$ My from the time that they pass through their closure temperature to the time that they are collected at variable distances from the ridge axis. However, radiogenic ingrowth during this time is negligible, with $<0.01 \%$ change among our samples, despite slow upwelling rates along the Oblique Segment (partly due to low $\mathrm{Nd} / \mathrm{Sm}$ ratios in many samples). Thus, the observed isotopic range of abyssal peridotites and the extremely depleted compositions among some peridotites reflects the composition of the asthenospheric mantle.

3. Pyroxenite veins in both Dredge 96 and RC27-9-6-2 formed by recent crystallization of melt in a conductively cooling mantle. Veins do not have the predicted compositions of recycled oceanic crust. For example, in sample RC27-9-6-2, the clinopyroxenite vein is more depleted than the host peridotite. In Dredge 96, the major, trace and isotopic compositions of the veins overlap those of the coexisting peridotites. The isotopic compositions of Dredge 96 samples indicate melt-rock reaction with Bouvet Hotspot material, which could have originated as recycled oceanic crust, but the samples do not provide direct evidence for the "veined mantle hypothesis".

4. The same range of isotopic compositions is found among peridotites as among basalts. The average composition of peridotites is skewed towards slightly more depleted values, as the mass balance of aggregated melts formed by melt fractions from variably depleted sources is dominated by the least-depleted component. No missing (vein) component is required to reconcile MORB isotopic compositions with peridotite compositions. In particular, peridotite RC27-9-6-2 provides evidence for enriched 
mantle unrelated to any hotspot.

5. Isotopic depletion requires long term chemical depletion. Peridotites show some evidence of a correlation between ${ }^{143} \mathrm{Nd} /{ }^{144} \mathrm{Nd}$ and indicators of melt depletion. However, peridotites have also undergone recent melt extraction, which complicates identification of long term chemical depletion trends.

6. Portions of the mantle are significantly more depleted than predictions of DMM composition derived from MORB isotopic ratios. The degree of melting suggested by the trace element composition of Dredge 85 peridotites is higher than the amount expected in this region of ultra-slow spreading. The isotopic and trace element compositions of peridotites cannot be reconciled with either a two stage model or a continuous depletion model of mantle isotopic evolution. In addition to recent melt extraction, the combination of high ${ }^{143} \mathrm{Nd} /{ }^{144} \mathrm{Nd}$ and high $\mathrm{Sm} / \mathrm{Nd}$ requires ancient melt extraction episodes that are not accounted for by these models.

We conclude that the asthenospheric mantle is heterogeneous in terms of isotopes, major and trace elements, and modal composition. In some regions, the mantle is more depleted than current MORB-based estimates of DMM. The scale of heterogeneity is relatively small, probably down to $<1 \mathrm{~km}$. These observations require a reassessment of current models of MORB production. 


\section{Appendix 4.A Major elements}

Major element compositions of all primary silicate phases in the peridotites and pyroxenites were determined by electron microprobe, using a JEOL JXA-733 at the Massachusetts Institute of Technology. In Tables 5.4 5.8, mineral compositions are presented as averages of 5 or more spot analyses per grain. For pyroxenes, to average out the effects of exsolution, a $10 \mu \mathrm{m}$ defocussed beam was used and data were collected by line traverses on grain cores and rims. In addition, for all Cpx and some Opx, multiple grains were analyzed per sample and the total number of points measured are listed in Table 4.A2.

Fig. 4.A1 shows the variation of spinel $\mathrm{Cr} \#$ with spinel $\mathrm{Mg \#}$ and with $\mathrm{TiO}_{2}$. During melting, spinel $\mathrm{Cr} \#$ increases and $\mathrm{Mg} \#$ decreases. $\mathrm{TiO}_{2}$ concentrations greater than $\mathrm{DMM}$ $(\sim 0.2 \mathrm{wt} \%)$, are indicative of melt refertilization in the peridotites. Spinels in Dredge 96 and RC27-9-6-2 indicate variable degrees of melting and melt fractional crystallization. In contrast, Dredge 85 peridotites have low $\mathrm{TiO}_{2}$, suggesting that their compositions reflect only melting and melt extraction. In addition, Dredge 96 pyroxenite spinels typically have plagioclase rims, due to the second melt infiltration event and are thus not necessarily representative of processes that occurred during pyroxenite formation.

The variations of major elements in Cpx are shown in Fig. 4.A2. Dredge 96 peridotites and pyroxenites have unusually low $\mathrm{Cr}_{2} \mathrm{O}_{3}, \mathrm{Mg \#}$ and high $\mathrm{Na}_{2} \mathrm{O}$, in comparison to other peridotites and pyroxenites. In contrast, RC27-9-6-2 has high $\mathrm{Cr}_{2} \mathrm{O}_{3}$, as evidenced by the bright green color of the Cpx versus the grey color of Dredge $96 \mathrm{Cpx}$. FeO and $\mathrm{MgO}$ in RC27-9-6-2 form a trend towards high concentrations, corresponding to a Mg\# range of 89.8-92. This variation does not correspond to clinopyroxenite versus peridotite lithology or to distance from the clinopyroxenite vein. 


\subsection{Bibliography}

Abelson, M., Agnon, A., 1997. Mechanics of oblique spreading and ridge segmentation. Earth and Planetary Science Letters 148, 405-421.

Allègre, C. J., Hamelin, B., Dupré, B., 1984. Statistical analysis of isotopic ratios in MORB: the mantle blob cluster model and the convective regime of the mantle. Earth and Planetary Science Letters 71, 71-84.

Allègre, C. J., Turcotte, D. L., 1986. Implications of a two-component marble-cake mantle. Nature 323, 123-127.

Barry, T. L., Pearce, J. A., Leat, P. T., Millar, I. L., le Roex, A. P., 2006. Hf isotope evidence for selective mobility of high-field-strength elements in a subduction setting: South Sandwich islands. Earth and Planetary Science Letters 252, 223-244.

Barth, M. G., Rudnick, R. L., Horn, I., McDonough, W. F., Spicuzza, M. J., Valley, J. W., Haggerty, S. E., 2001. Geochemistry of xenolithic eclogites from West Africa, Part I: A link between low $\mathrm{MgO}$ eclogites and Archean crust formation. Geochimica et Cosmochimica Acta 65 (9), 1499-1527.

Batchelor, G. K., 1967. An Introduction to Fluid Dynamics. Cambridge University Press.

Bown, J. W., White, R. S., 1994. Variation with spreading rate of oceanic crustal thickness and geochemistry. Earth and Planetary Science Letters 121, 435-449.

Brunelli, D., Seyler, M., Cipriani, A., Ottolini, L., Bonatti, E., 2006. Discontinuous melt extraction and weak refertilization of mantle peridotites at the Vema Lithospheric Section (Mid-Atlantic Ridge). Journal of Petrology 47 (4), 745-771.

Cherniak, D. J., Liang, Y., 2007. Rare earth element diffusion in natural enstatite. Geochimica et Cosmochimica Acta 71, 1324-1340.

Cipriani, A., Brueckner, H. K., Bonatti, E., Brunelli, D., 2004. Oceanic crust generated by elusive parents: $\mathrm{Sr}$ and $\mathrm{Nd}$ isotopes in basalt-peridotite pairs from the Mid-Atlantic Ridge. Geology 32 (8), 657-660.

Constantin, M., Hékinian, R., Ackermand, D., Stoffers, P., 1995. Mafic and ultramafic intrusions into upper mantle peridotites from fast spreading centers of the Easter Microplate (South East Pacific). In: Vissers, R. L. M., Nicolas, A. (Eds.), Mantle and Lower Crust Exposed in Oceanic Ridges and in Ophiolites. Kluwer Academic Publishers, pp. $71-120$.

Coogan, L. A., Thompson, G. M., MacLeod, C. J., Dick, H. J. B., Edwards, S. J., Hosford Scheirer, A., Barry, T. L., 2004. A combined basalt and peridotite perspective on 14 million years of melt generation at the Atlantis Bank segment of the Southwest Indian Ridge: evidence for temporal changes in mantle dynamics. Chemical Geology 207, $13-30$. 
Dantas, C., Ceuleneer, G., Gregoire, M., Python, M., Freydier, R., Warren, J., Dick, H. J. B., 2007. Pyroxenites from the Southwest Indian Ridge, 9-16 ${ }^{\circ}$ : Cumulates from incremental melt fractions produced at the top of a cold melting regime. Journal of Petrology 48 (4), 647-660.

Dick, H. J. B., 1989. Abyssal peridotites, very slow spreading ridges and ocean ridge magmatism. In: Saunders, A. D., Norry, M. J. (Eds.), Magmatism in the Ocean Basins. No. 42 in Geological Society of London Special Publication. Geological Society of London, pp. $71-105$.

Dick, H. J. B., Lin, J., Schouten, H., 2003. An ultraslow-spreading class of ocean ridge. Nature 426, 405-412.

Dick, H. J. B., Schouten, H., Meyer, P. S., Gallo, D. G., Bergh, H., Tyce, R., Patriat, P., Johnson, K. T. M., Snow, J., Fisher, A., 1991. Tectonic evolution of the Atlantis II Fracture Zone. In: Von Herzen, R. P., Robinson, P. T. (Eds.), Proceedings of the Ocean Drilling Program, Scientific Results. Vol. 118. College Station, TX, pp. 359-398.

Dosso, L., Bougault, H., Langmuir, C., Bollinger, C., Bonnier, O., Etoubleau, J., 1999. The age and distribution of mantle heterogeneity along the Mid-Atlantic Ridge $\left(31-41^{\circ} \mathrm{N}\right.$. Earth and Planetary Science Letters 170, 269-286.

Faure, G., Mensing, T. M., 2005. Isotopes: Principles and Applications, 3rd Edition. John Wiley and Sons.

Frey, F. A., Prinz, M., 1978. Ultramafic inclusions from San Carlos, Arizona: Petrologic and geochemical data bearing on their petrogenesis. Earth and Planetary Science Letters $38,129-176$.

Galer, S. J. G., 1999. Optimal double and triple spiking for high precision lead isotopic measurement. Chemical Geology 157, 255-274.

Hamelin, B., Allègre, C. J., 1985. Large-scale regional units in the depleted upper mantle revealed by an isotope study of the South-West Indian Ridge. Nature 315, 196-199.

Hamelin, B., Allègre, C. J., 1988. Lead isotope study of orogenic lherzolite massifs. Earth and Planetary Science Letters 91, 117-131.

Hamelin, B., Manhes, G., Albarede, F., Allègre, C. J., 1985. Precise lead isotope measurements by the double spike technique: A reconsideration. Geochimica et Cosmochimica Acta 49, 173-182.

Hart, S. R., Blusztajn, J., Dick, H. J. B., Meyer, P. S., Muehlenbachs, K., 1999. The fingerprint of seawater circulation in a 500-meter section of ocean crust gabbros. Geochimica et Cosmochimica Acta 63 (23/24), 4059-4080.

Hart, S. R., Dunn, T., 1993. Experimental cpx/melt partitioning of 24 trace elements. Contributions to Mineralogy and Petrology 113, 1-8. 
Hartnady, C. J. H., le Roex, A. P., 1985. Southern Ocean hotspot tracks and the Cenozoic absolute motion of the African, Antarctic, and South American plates. Earth and Planetary Science Letters 75, 245-257.

Hellebrand, E., Snow, J. E., Mostefaoui, S., Hoppe, P., 2005. Trace element distribution between orthopyroxene and clinopyroxene in peridotites from the Gakkel Ridge: a SIMS and NanoSIMS study. Contributions to Mineralogy and Petrology 150, 486-504.

Hirschmann, M. M., Stolper, E. M., 1996. A possible role for garnet pyroxenite in the origin of the "garnet signature" in MORB. Contributions to Mineralogy and Petrology 124, 185-208.

Hofmann, A. W., 1988. Chemical differentiation of the Earth: the relationship between mantle, continental crust, and oceanic crust. Earth and Planetary Science Letters 90, 297-314.

Hofmann, A. W., 1997. Mantle geochemistry: the message from oceanic volcanism. Nature $385,219-229$.

Holm, P. M., 2002. Sr, Nd and Pb isotopic composition of in situ lower crust at the Southwest Indian Ridge: results from ODP Leg 176. Chemical Geology 184, 195-216.

Hosford, A., Tivey, M., Matsumoto, T., Dick, H., Schouten, H., Kinoshita, H., 2003. Crustal magnetization and accretion at the Southwest Indian Ridge near the Atlantis II fracture zone, 0-25 Ma. Journal of Geophysical Research 108 (B3), 2169.

Jacob, D., Jagoutz, E., Lowry, D., Mattey, D., Kudrjavtseva, G., 1994. Diamondiferous eclogites from Siberia: Remnants of Archean oceanic crust. Geochimica et Cosmochimica Acta 58 (23), 5191-5207.

Janney, P. E., le Roex, A. P., Carlson, R. W., 2005. Hafnium isotope and trace element constraints on the nature of mantle heterogeneity beneath the Central Southwest Indian Ridge $\left(13^{\circ} \mathrm{E}\right.$ to $\left.47^{\circ} \mathrm{E}\right)$. Journal of Petrology 46 (12), 2427-2464.

Johnson, K. T. M., Dick, H. J. B., June 1992. Open system melting and temporal and spatial variation of peridotite and basalt at the Atlantis II Fracture Zone. Journal of Geophysical Research 97 (B6), 9219-9241.

Johnson, K. T. M., Dick, H. J. B., Shimizu, N., 1990. Melting in the oceanic upper mantle: An ion microprobe study of diopsides in abyssal peridotites. Journal of Geophysical Research 95, 2661-2678.

Juteau, T., Berger, E., Cannat, M., 1990. Serpentinized, residual mantle peridotites from the M.A.R. median valley, ODP Hole 670A $\left(21^{\circ} 10^{\prime} \mathrm{N}, 45^{\circ} 02^{\prime} \mathrm{W}\right.$, Leg 109): Primary mineralogy and geothermometry. In: Detrick, R., Honnorez, J., Bryan, W. B., Juteau, T., et al. (Eds.), Proceedings of the Ocean Drilling Program, Scientific Results. Vol. 106/109. College Station, TX, pp. 27-45. 
Kellogg, J. B., Jacobsen, S. B., O’Connell, R. J., 2002. Modeling the distribution of isotopic ratios in geochemical reservoirs. Earth and Planetary Science Letters 204, 183-202.

Kempton, P. D., Hawkesworth, C. J., Fowler, M., 1991. Geochemistry and isotopic composition of gabbros from layer 3 of the Indian Ocean Crust, Hole 735B. In: Von Herzen, R. P., Robinson, P. T. (Eds.), Proceedings of the Ocean Drilling Program, Scientific Results. Vol. 118. College Station, TX, pp. 127-143.

Kempton, P. D., Stephens, C. J., 1997. Petrology and geochemistry of nodular websterite inclusions in harzburgite, Hole 920D. In: Karson, J. A., Cannat, M., Miller, D. J., Elthon, D. (Eds.), Proceedings of the Ocean Drilling Program, Scientific Results. Vol. 153. College Station, TX, pp. 321-331.

Kobayashi, K., Tanaka, R., Moriguti, T., Shimizu, K., Nakamura, E., 2004. Lithium, boron and lead isotope systematics of glass inclusions in olivines from Hawaiian lavas: evidence for recycled components in the Hawaiian plume. Chemical Geology 212, 143161.

Kuritani, T., Nakamura, E., 2002. Precise isotope analysis of nanogram-level Pb use of double spikes. Chemical Geology 186, 31-43.

Kuritani, T., Nakamura, E., 2003. Highly precise and accurate isotopic analysis of small amounts of $\mathrm{Pb}$ using ${ }^{205} \mathrm{~Pb}-{ }^{204} \mathrm{~Pb}$ and ${ }^{207} \mathrm{~Pb}-{ }^{204} \mathrm{~Pb}$, two double spikes. Journal of Analytical Atomic Spectrometry 18, 1464-1470.

Kurz, M. D., le Roex, A. P., Dick, H. J. B., 1998. Isotope geochemistry of the oceanic mantle near the Bouvet triple junction. Geochimica et Cosmochimica Acta 62 (5), 841852.

le Roex, A. P., Dick, H. J. B., Erlank, A. J., Reid, A. M., Frey, F. A., Hart, S. R., 1983. Geochemistry, mineralogy and petrogenesis of lavas erupted along the Southwest Indian Ridge between the Bouvet Triple Junction and 11 degrees East. Journal of Petrology 24 (3), 267-318.

le Roex, A. P., Dick, H. J. B., Watkins, R. T., 1992. Petrogenesis of anomalous K-enriched MORB from the Southwest Indian Ridge: $11^{\circ} 53^{\prime} \mathrm{E}$ to $14^{\circ} 38^{\prime} \mathrm{E}$. Contributions to Mineralogy and Petrology 110, 253-268.

Lehnert, K., Su, Y., Langmuir, C., Sarbas, B., Nohl, U., 2000. A global geochemical database structure for rocks. Geochemistry, Geophysics, and Geosystems 1.

Lugmair, G. W., Carlson, R. W., 1978. The Sm-Nd history of KREEP. In: Proceedings, Lunar and Planetary Science Conference, 9th. Vol. 1. pp. 689-704.

Maclennan, J., 2006. The generation and destruction of compositional variation in Icelandic magma. Geochimica et Cosmochimica Acta 70, A381. 
Mahoney, J., le Roex, A. P., Peng, Z., Fisher, R. L., Natland, J. H., 1992. Southwestern limits of Indian Ocean ridge mantle and the origin of low ${ }^{206} \mathrm{~Pb} /{ }^{204} \mathrm{~Pb}$ mid-ocean ridge basalt: Isotope systematics of the Central Southwest Indian Ridge $\left(17^{\circ}-50^{\circ} \mathrm{E}\right)$. Journal of Geophysical Research 97 (B13), 19771-19790.

Mahoney, J. J., Natland, J. H., White, W. M., Poreda, R., Bloomer, S. H., Fisher, R. L., Baxter, A. N., 1989. Isotopic and geochemical provinces of the Western Indian Ocean spreading centers. Journal of Geophysical Research 94 (B4), 4033-4052.

Makishima, A., Nakamura, E., 12 1997. Suppression of matrix effects in ICP-MS by high power operation of ICP: Application to precise determination of Rb, Sr, Y, Cs, Ba, REE, $\mathrm{Pb}$, Th and $\mathrm{U}$ at $\mathrm{ng} \mathrm{g}^{-1}$ levels in milligram silicate samples. Geostandards Newsletter 21 (2), 307-319.

Makishima, A., Nakamura, E., 2006. Determination of major, minor and trace elements in silicate samples by ICP-QMS and ICP-SFMS applying isotope dilution-internal standardisation (ID-IS) and multi-stage internal standardisation. Geostandards and Geoanalytical Research 30, 245-271.

Makishima, A., Nakamura, E., Nakano, T., 6 1999. Determination of zirconium, niobium, hafnium and tantalum at $\mathrm{ng} \mathrm{g}^{-1}$ levels in geological materials by direct nebulisation of sample HF solution into FI-ICP-MS. Geostandards Newsletter 23 (1), 7-20.

McDonough, W. F., Frey, F. A., 1989. Rare earth elements in upper mantle rocks. In: Lipin, B. R., McKay, G. A. (Eds.), Geochemistry and Mineralogy of Rare Earth Elements. Vol. 21 of Reviews in Mineralogy. Mineralogical Society of America, pp. 99-145.

McDonough, W. F., Sun, S.-s., 1995. The composition of the Earth. Chemical Geology $120,223-253$.

McKenzie, D. P., 1969. Speculations on the consequences and causes of plate motions. Geophysical Journal of the Royal Astronomical Society 18, 1-32.

Meyzen, C. M., Ludden, J. N., Humler, E., Toplis, M. J., Mével, C., Storey, M., 2005. New insights into the origin and distribution of the DUPAL isotope anomaly in the Indian Ocean mantle from MORB of the Southwest Indian Ridge. Geochemistry, Geophysics, and Geosystems 6 (11).

Montési, L. G. J., Behn, M. D., Barry, J. L., 2006. Mantle flow and melting at oblique segments of the Southwest Indian Ridge. Geophysical Research Abstracts 8, 04319.

Morgan, W. J., 1983. Hotspot tracks and the early rifting of the Atlantic. Tectonophysics 94, 123-139.

Mukasa, S. B., Shervais, J. W., Wilshire, H. G., Nielson, J. E., 1991. Intrinsic Nd, Pb and $\mathrm{Sr}$ isotopic heterogeneities exhibited by the Lherz Alpine Peridotite Massif, French Pyrenees. Journal of Petrology Special Lherzolites Issue, 117-134. 
Nakamura, E., Makishima, A., Moriguti, T., Kobayashi, K., Sakaguchi, C., Yokoyama, T., Tanaka, R., Kuritani, T., Takei, H., 2003. Comprehensive geochemical analyses of small amounts $(<100 \mathrm{mg})$ of extraterrestrial samples for the analytical competition related to the sample return mission MUSES-C. Tech. Rep. SP 16, The Insitute of Space and Astronautical Sciences.

O’Nions, R. K., Hamilton, P. J., Evensen, N. M., 1977. Variations in ${ }^{143} \mathrm{Nd} /{ }^{144} \mathrm{Nd}$ and ${ }^{87} \mathrm{Sr} /{ }^{86} \mathrm{Sr}$ ratios in oceanic basalts. Earth and Planetary Science Letters 34, 13-22.

O’Nions, R. K., Pankhurst, R. J., 1974. Petrogenetic significance of isotope and trace element variations in volcanic rocks from the Mid-Atlantic. Journal of Petrology 15 (3), 603-634.

Pearson, D. G., Davies, G. R., Nixon, P. H., 1993. Geochemical constraints on the petrogenesis of diamond facies pyroxenites from the Beni Bousera Peridotite Massif, North Morocco. Journal of Petrology 34 (1), 125-172.

Pertermann, M., Hirschmann, M. M., 2003a. Anhydrous partial melting experiments on MORB-like eclogite: Phase relations, phase composition and mineral-melt partitioning of major elements at 2-3 GPa. Journal of Petrology 44 (12), 2173-2201.

Pertermann, M., Hirschmann, M. M., 2003b. Partial melting experiments on a MORB-like pyroxenite between 2 and $3 \mathrm{GPa}$ : Constraints on the presence of pyroxenite in basalt source regions from solidus location and melting rate. Journal of Geophysical Research 108 (B2), 2125.

Piccardo, G. B., Messiga, B., Vannucci, R., 1988. The Zabargad peridotite - pyroxenite association: petrological constraints on its evolution. Tectonophysics 150, 135-162.

Pickering-Witter, J., Johnston, A. D., 2000. The effects of variable bulk composition on the melting systematics of fertile peridotitic assemblages. Contributions to Mineralogy and Petrology 140, 190-211.

Polvé, M., Allègre, C. J., 1980. Orogenic lherzolite complexes studied by ${ }^{87} \mathrm{Rb}^{8}{ }^{8} \mathrm{Sr}$ : A clue to understand the mantle convection processes? Earth and Planetary Science Letters 51, 71-93.

Prestvik, T., Goldberg, S., Goles, G. G., 1999. Petrogenesis of the volcanic suite of Bouvetøya (Bouvet Island), South Atlantic. Norsk Geologisk Tidsskrift 79, 205-218.

Python, M., Ceuleneer, G., 2003. Nature and distribution of dykes and related melt migration structures in the mantle section of the Oman ophiolite. Geochemistry, Geophysics, and Geosystems 4 (7).

Rapp, R. P., Shimizu, N., Norman, M. D., Applegate, G. S., 1999. Reaction between slabderived melts and peridotite in the mantle wedge: experimental constraints at $3.8 \mathrm{GPa}$. Chemical Geology 160, 335-356. 
Reid, I., Jackson, H. R., 1981. Oceanic spreading rate and crustal thickness. Marine Geophysical Researches 5, 165-172.

Saal, A. E., Hart, S. R., Shimizu, N., Hauri, E. H., Layne, G. D., 1998. Pb isotopic variability in melt inclusions from oceanic island basalts, Polynesia. Science 282, 1481-1484.

Salters, V. J. M., Dick, H. J. B., 2002. Mineralogy of the mid-ocean-ridge basalt source from neodymium isotopic composition of abyssal peridotites. Nature 418, 68-72.

Schwab, B. E., Johnston, A. D., 2001. Melting systematics of modally variable, compositionally intermediate peridotites and the effects of mineral fertility. Journal of Petrology 42 (10), 1789-1811.

Serri, G., Hébert, R., Hekinian, R., 1988. Petrology of a plagioclase-bearing olivine websterite from the Gorringe Bank (northeastern Atlantic Ocean). Canadian Journal of Earth Sciences 25, 557-569.

Shannon, R. D., 1976. Revised effective ionic radii and systematic studies of interatomic distances in halides and chalcogenides. Acta Crystallographica A32, 751-767.

Shervais, J. W., Mukasa, S. B., 1991. The Balmuccia Orogenic Lherzolite Massif, Italy. Journal of Petrology Special Lherzolites Issue, 155-174.

Shimizu, N., Kobayashi, K., Sisson, T., Layne, G., Nakamura, E., Kurz, M., 2005. Evolution of diverse mantle sources for the Kilauea Volcano over $270 \mathrm{Ka}$. Eos Transactions, AGU 86 (52), Fall Meet. Suppl., Abstract V22A-07.

Shimizu, N., Layne, G. D., 2003. Large local heterogeneities of the MORB source mantle: Melt inclusion Pb isotope studies. Geochimica et Cosmochimica Acta 67, A431.

Sleep, N. H., 1975. Formation of oceanic crust: Some thermal constraints. Journal of Geophysical Research 80 (29), 4037-4042.

Snow, J. E., June 1993. The isotope geochemistry of abyssal peridotites and related rocks. Ph.D. thesis, MIT/WHOI Joint Program.

Snow, J. E., Hart, S. R., Dick, H. J. B., 1993. Orphan strontium-87 in abyssal peridotites: Daddy was a granite. Science 262, 1861-1863.

Snow, J. E., Hart, S. R., Dick, H. J. B., 1994. Nd and Sr isotope evidence linking midocean-ridge basalts and abyssal peridotites. Nature 371, 57-60.

Standish, J. J., 2006. The influence of ridge geometry at the ultraslow-spreading Southwest Indian Ridge $\left(9^{\circ}-25^{\circ} \mathrm{E}\right)$ : Basalt composition sensitivity to variations in source and process. Ph.D. thesis, MIT/WHOI Joint Program.

Standish, J. J., Dick, H. J. B., Michael, P. J., Melson, W. G., O’Hearn, T., submitted. Ridge geometry and major element chemistry on the Southwest Indian Ridge $\left(9^{\circ}-25^{\circ} \mathrm{E}\right)$ : Process versus source during MORB generation at ultraslow spreading rates, submitted. 
Stolper, E., 1980. A phase diagram for mid-ocean ridge basalts: Preliminary results and implications for petrogenesis. Contributions to Mineralogy and Petrology 74, 13-27.

Su, Y., Langmuir, C. H., 2003. Global MORB chemistry compilation at the segment scale. Ph.D. thesis, Dept. of Earth and Environmental Sciences, Columbia University.

Sun, S.-s., 1980. Lead isotopic study of young volcanic rocks from mid-ocean ridges, ocean islands and island arcs. Philosophical Transactions of the Royal Society of London A 297, 409-445.

Tanaka, R., Makishima, A., Kitagawa, H., Nakamura, E., 2003. Suppression of Zr, Nb, Hf and Ta coprecipitation in flouride compounds for determination in Ca-rich materials. Journal of Analytical Atomic Spectrometry 18, 1458-1463.

Taylor, S. R., McLennan, S. M., 1995. The geochemical evolution of the continental crust. Reviews of Geophysics 33 (2), 241-265.

Todt, W., Cliff, R. A., Hanser, A., Hofmann, A. W., 1996. Evaluation of a ${ }^{202} \mathrm{~Pb}^{2}{ }^{205} \mathrm{~Pb}$ double spike for high-precision lead isotope analysis. In: Basu, A., Hart, S. (Eds.), Earth Processes: Reading the Isotopic Code. Vol. 95 of Geophysical Monograph. American Geophysical Union, pp. 429-437.

van Keken, P. E., Hauri, E. H., Ballentine, C. J., 2002. Mantle mixing: The generation, preservation, and destruction of chemical heterogeneity. Annual Review of Earth and Planetary Sciences 30, 493-525.

Van Orman, J. A., Grove, T. L., Shimizu, N., 2001. Rare earth element diffusion in diopside: influence of temperature, pressure, ionic radius, and an elastic model for diffusion in silicates. Contributions to Mineralogy and Petrology 141, 687-703.

Van Orman, J. A., Grove, T. L., Shimizu, N., Layne, G. D., 2002. Rare earth element diffusion in a natural pyrope single crystal at $2.8 \mathrm{GPa}$. Contributions to Mineralogy and Petrology 142, 416-424.

Vannucci, R., Shimizu, N., Piccardo, G. B., Ottolini, L., Bottazzi, P., 1993. Distribution of trace elements during breakdown of mantle garnet: an example from Zabargad. Contributions to Mineralogy and Petrology 113, 437-449.

White, W. M., Hofmann, A. W., 1982. Sr and Nd isotope geochemistry of oceanic basalts and mantle evolution. Nature 296, 821-825.

Witt-Eickschen, G., O'Neill, H. S. C., 2005. The effect of temperature on the equilibrium distribution of trace elements between clinopyroxene, orthopyroxene, olivine and spinel in upper mantle peridotite. Chemical Geology 221, 65-101.

Workman, R. K., Hart, S. R., 2005. Major and trace element composition of the depleted MORB mantle (DMM). Earth and Planetary Science Letters 231, 53-72. 
Yoshikawa, M., Nakamura, E., 1993. Precise isotope determination of trace amounts of $\mathrm{Sr}$ in magnesium-rich samples. Journal of Mineralogy, Petrology and Economic Geology $88,548-561$.

Zindler, A., Hart, S., 1986. Chemical geodynamics. Annual Review of Earth and Planetary Sciences 14, 493-571.

Zindler, A., Staudigel, H., Hart, S. R., Goldstein, S., 1983. Nd and Sr isotopic study of a mafic layer from Ronda ultramafic complex. Nature 304, 226-230. 

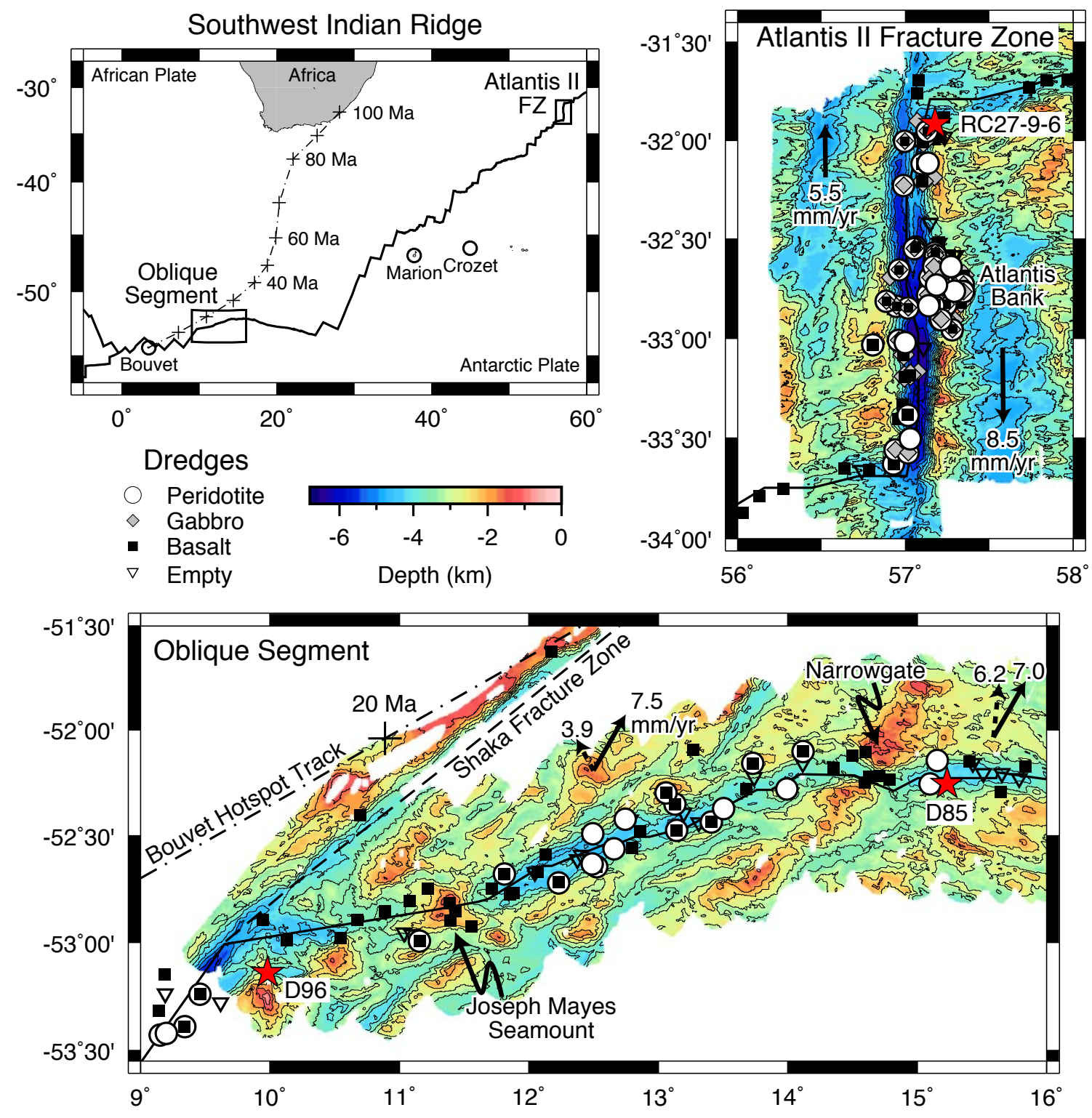

Figure 4.1: Maps of the Southwest Indian Ridge, Oblique Segment and Atlantis II Fracture Zone. Bouvet, Marion and Crozet are hotspots associated with the SWIR. The dot-dashed line indicates the path of Bouvet hotspot, calculated by Hartnady and le Roex (1985) using finite reconstruction poles from Morgan (1983). Bouvet hotspot passed along the trace of the Shaka Fracture Zone (dashed line) at the eastern end of the Oblique Segment from 15-25 Ma. No hotspot tracks are associated with the Atlantis II Fracture Zone. Atlantis Bank is an uplifted gabbroic massif located under the large cluster of dredges along the Atlantis II Fracture Zone. Solid arrows indicate the direction of plate motion. On the Oblique Segment, dashed arrows indicate the obliquity of the spreading direction to the plate direction. 
A.

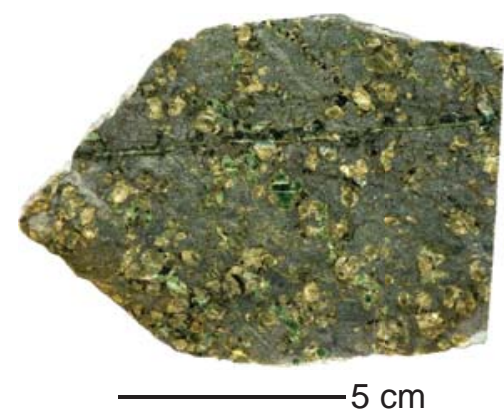

C.

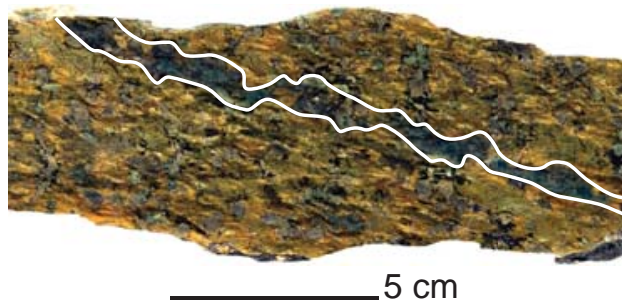

E.

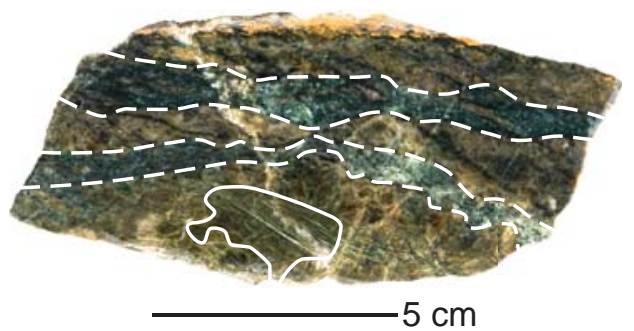

G.

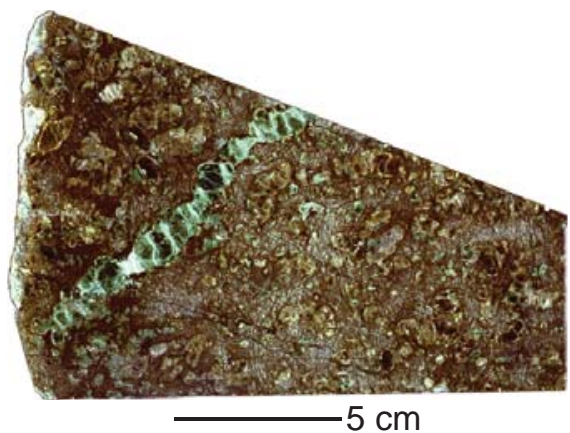

B.
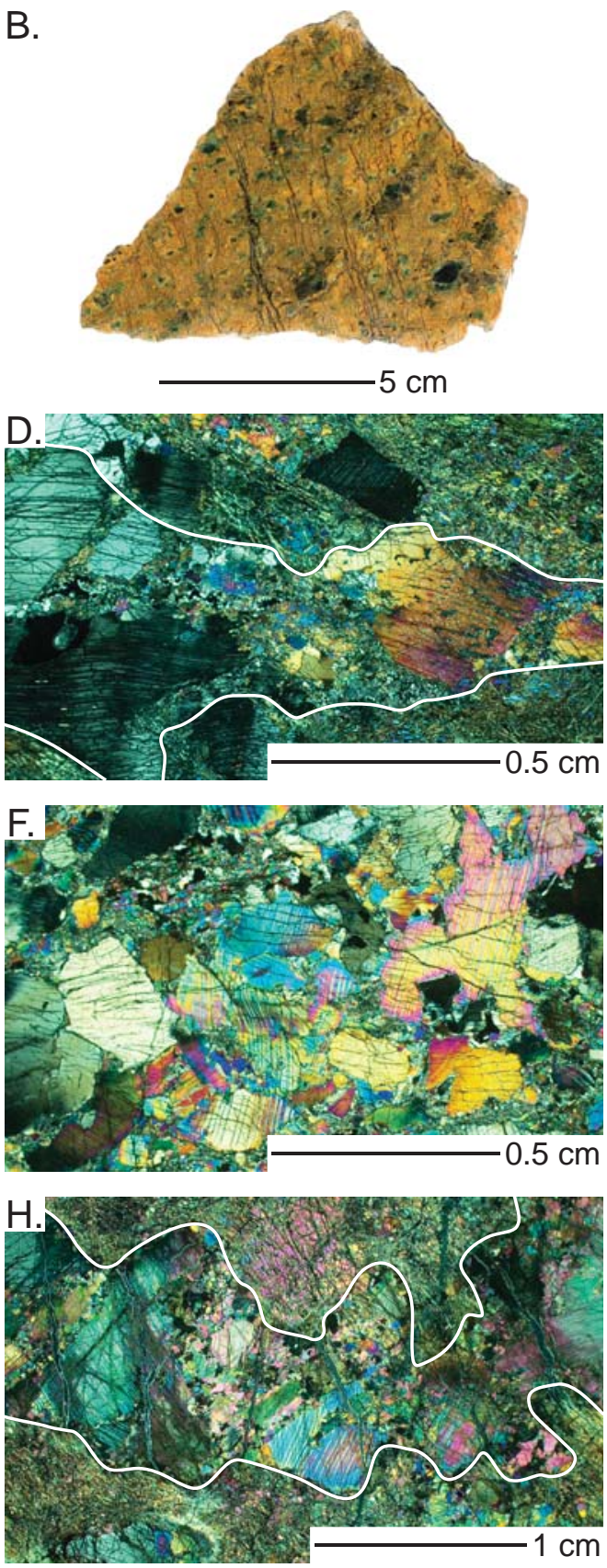

Figure 4.2: A. Depleted lherzolite, Van7-85-49, with 5\% Cpx. B. Enriched peridotite, Van7-96-28, with $5 \%$ Cpx. Apart from the different alteration style, this peridotite has no visual characteristics that distinguish it from the Dredge 85 peridotite. C. Pyroxenite veined peridotite, Van7-96-21, with the vein outlined in white. D. Crossed polarized photomicrograph of the same sample. E. Pyroxenite, Van7-96-16, with a thin, altered, orange peridotite skin at the top. A particularly large Cpx grain is outlined in white. The pyroxenite is crosscut by two later-stage veins of fine-grained Ol-Plag-Cpx, outlined with dashed lines. F. Crossed polarized photomicrograph of a pyroxenite, Van7-96-09, consisting of coarse-grained Cpx and Opx with minor olivine. The fine-grained, cross-cutting assemblage of Ol-Plag-Cpx is from the later-stage melt infiltration event. G. RC27-9-6-2, the clinopyroxenite veined lherzolite. H. Crossed polarized photomicrograph of the same sample, with the vein outlined in white. 

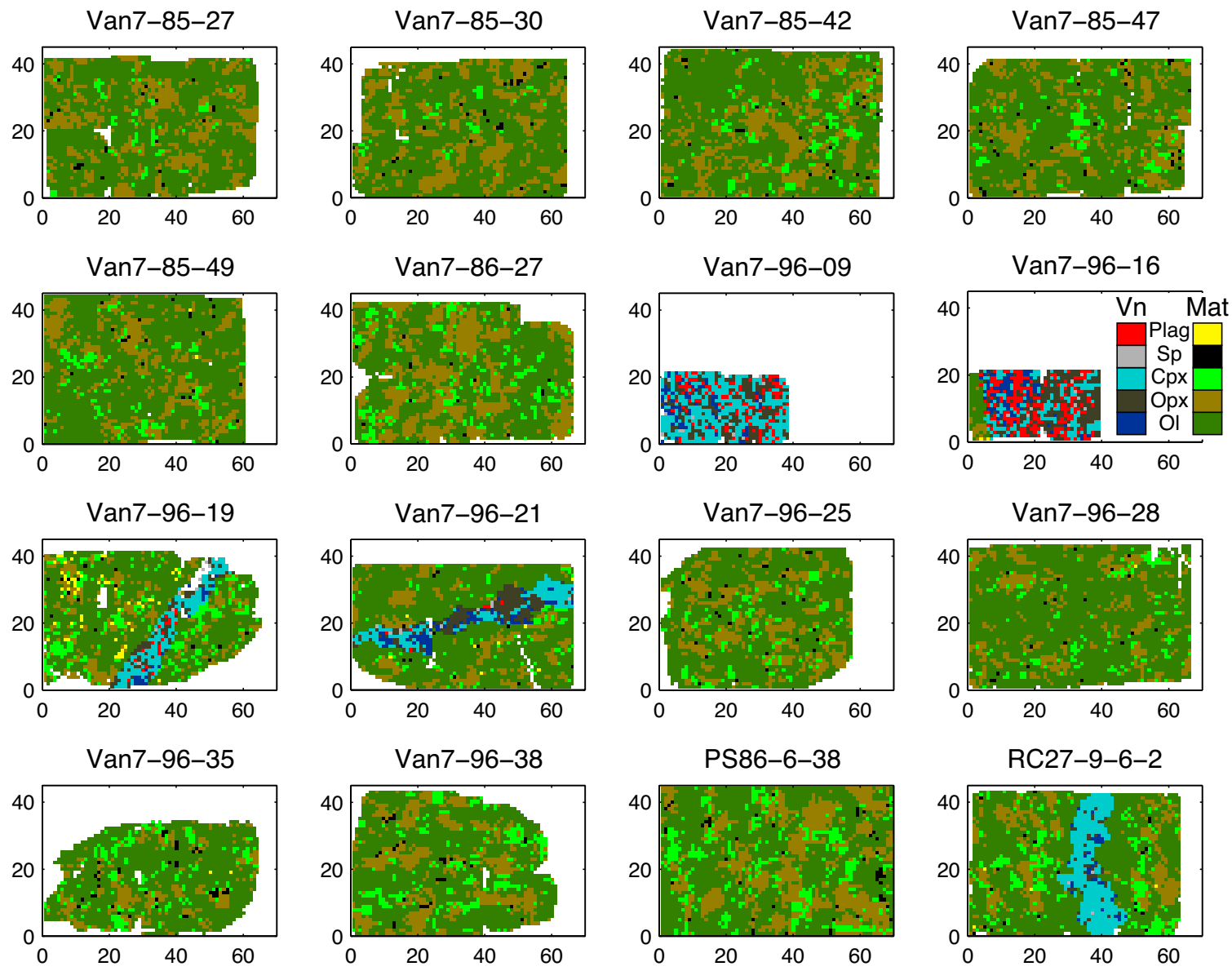

Figure 4.3: Mineral mode maps of peridotite and pyroxenite samples, created by point counting thin sections on a $1 \mathrm{~mm}$ grid. "Mat" refers to peridotite matrix and "Vn" to pyroxenite vein. 


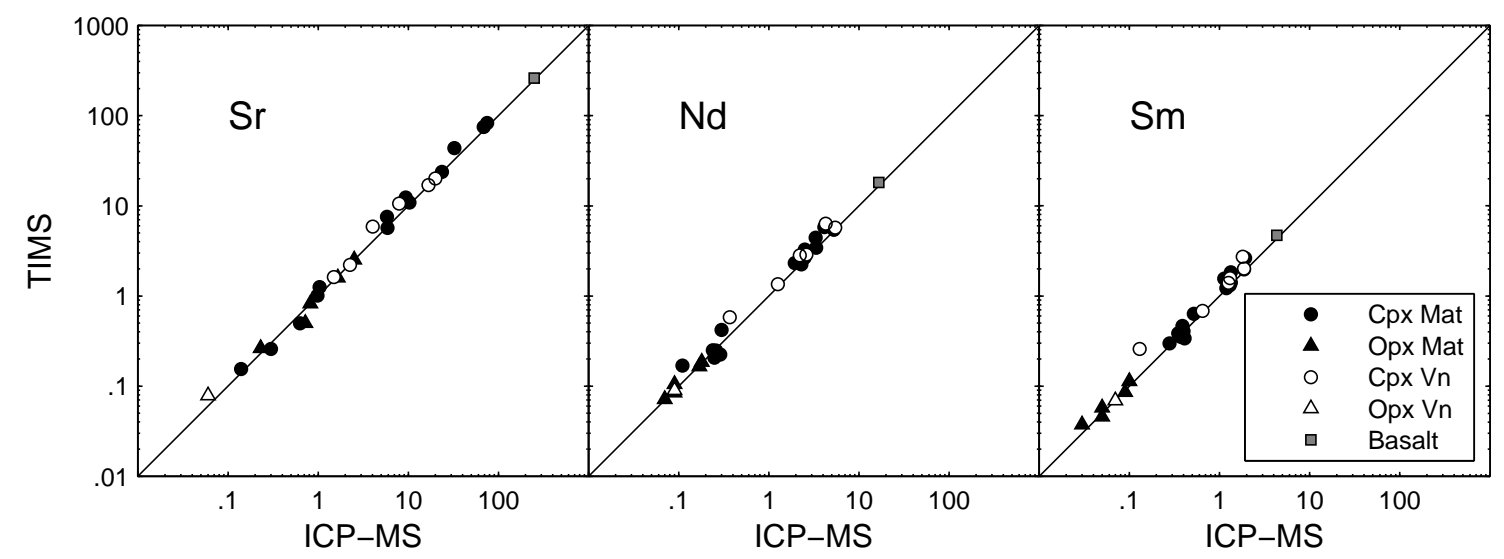

Figure 4.4: Comparison of ICPMS and TIMS data for Sr, Nd and Sm, in ppm. Solid line is a 1:1 correlation. Error bars are smaller than symbols. 

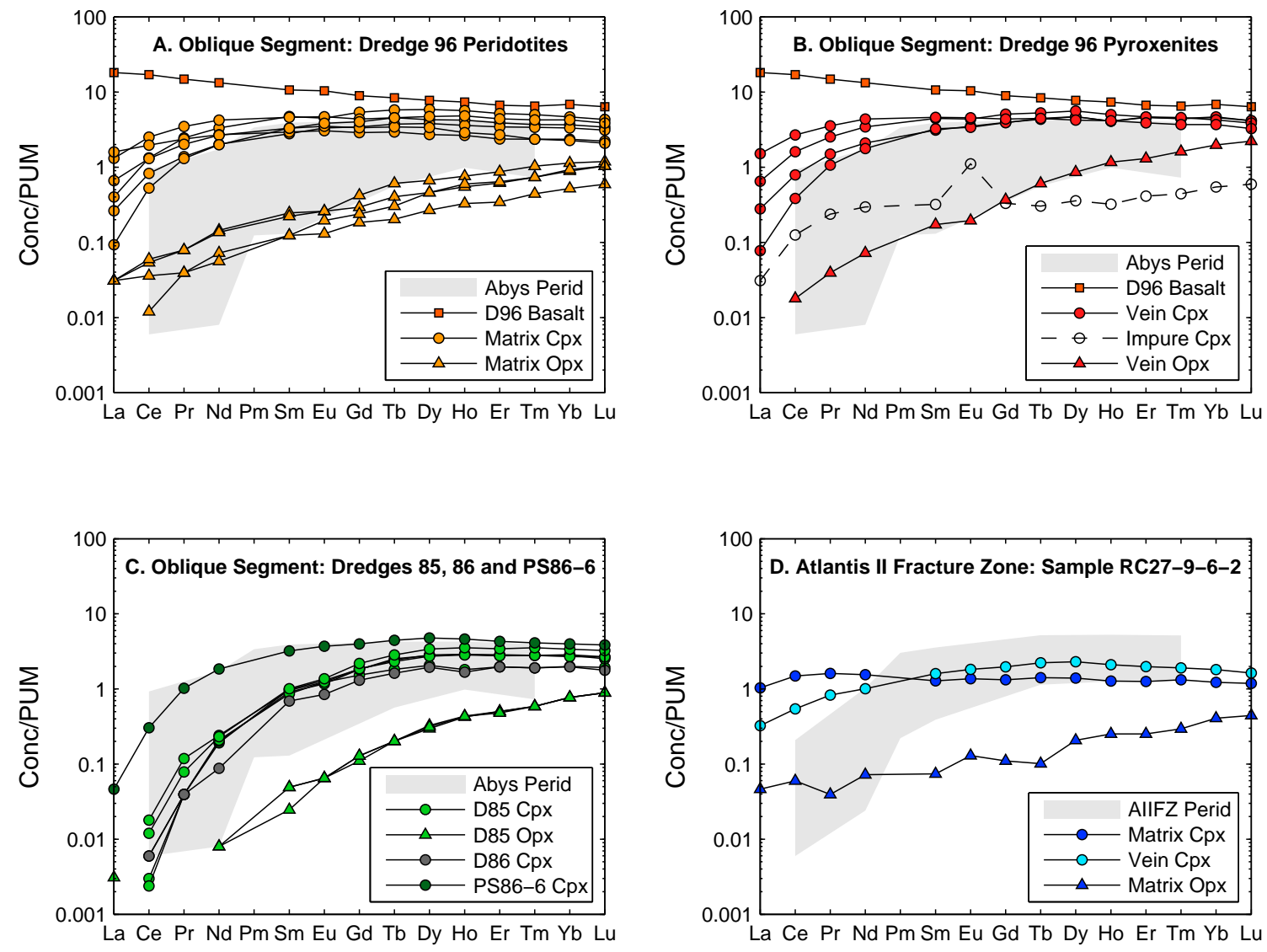

Figure 4.5: ICPMS rare earth element data for Cpx (circles) and Opx (triangles), normalized to PUM (McDonough and Sun, 1995). In A-C, the grey shaded field is the range for abyssal peridotite Cpx from Johnson et al. (1990). In $\mathbf{D}$, the grey shaded field is the range for peridotite Cpx from the Atlantis II Fracture Zone (Johnson and Dick, 1992). 

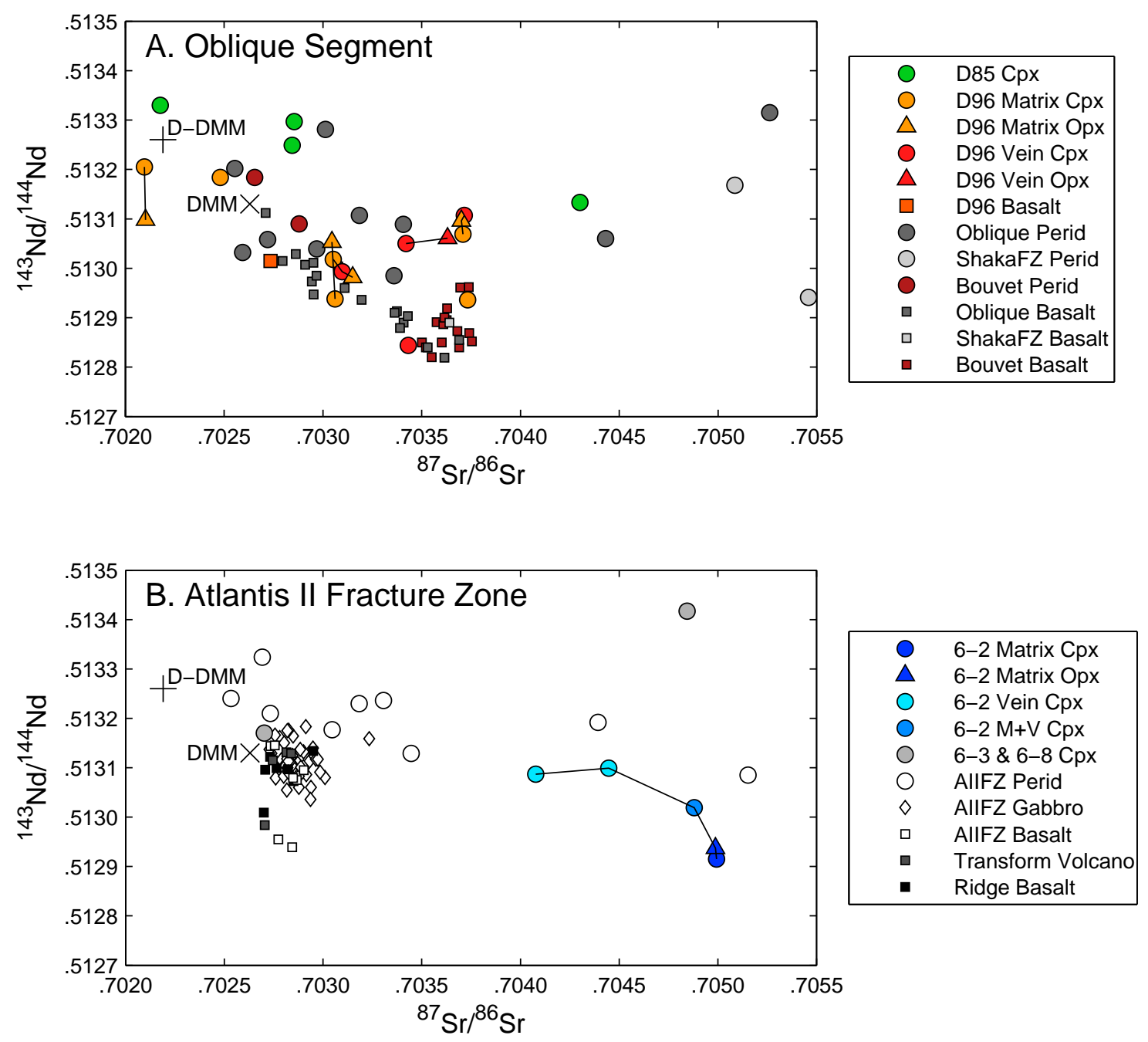

Figure 4.6: $\mathrm{Nd}$ and $\mathrm{Sr}$ isotopic variations in peridotites (from this study and literature), basalts and gabbros. All data are corrected to the standard values used in this study. Peridotite data from other studies are for Cpx mineral separates, except the Shaka Fracture Zone samples, which are whole rock analyses of the fresh cores of mylonitized peridotites. The Cpx referred to as [RC27-9-]6-2 $\mathrm{M}+\mathrm{V}$ is a combined matrix and vein Cpx analysis (Snow et al., 1994) and the Cpx referred to as 6-3 \& 6-8 are two samples from the same dredge as RC27-9-6-2.

Data sources: DMM from Su and Langmuir (2003); D-DMM from Workman and Hart (2005). A. Oblique Segment peridotites from Snow et al. (1994) and Salters and Dick (2002); Shaka Fracture Zone peridotites from Snow (1993); Bouvet regional peridotites from Snow et al. (1994); Oblique Segment basalts from le Roex et al. (1983. 1992), Mahoney et al. (1992), Janney et al. (2005) and Standish (2006); Shaka Fracture Zone basalts from le Roex et al. (1983); Bouvet basalts from O'Nions and Pankhurst (1974), O'Nions et al. (1977), Sun (1980), Kurz et al. (1998), Prestvik et al. (1999), Janney et al. (2005) and Barry et al. (2006). B. Atlantis II Fracture Zone peridotite from Snow et al. (1994) and Salters and Dick (2002); gabbro, all from Hole 735B on Atlantis Bank, from Kempton et al. (1991), Hart et al. (1999) and Holm (2002); fracture zone and transform volcano basalts from Mahoney et al. (1989) and Snow (1993); basalts from adjacent ridge segments from Hamelin and Allègre (1985), Snow (1993) and Meyzen et al. (2005). 

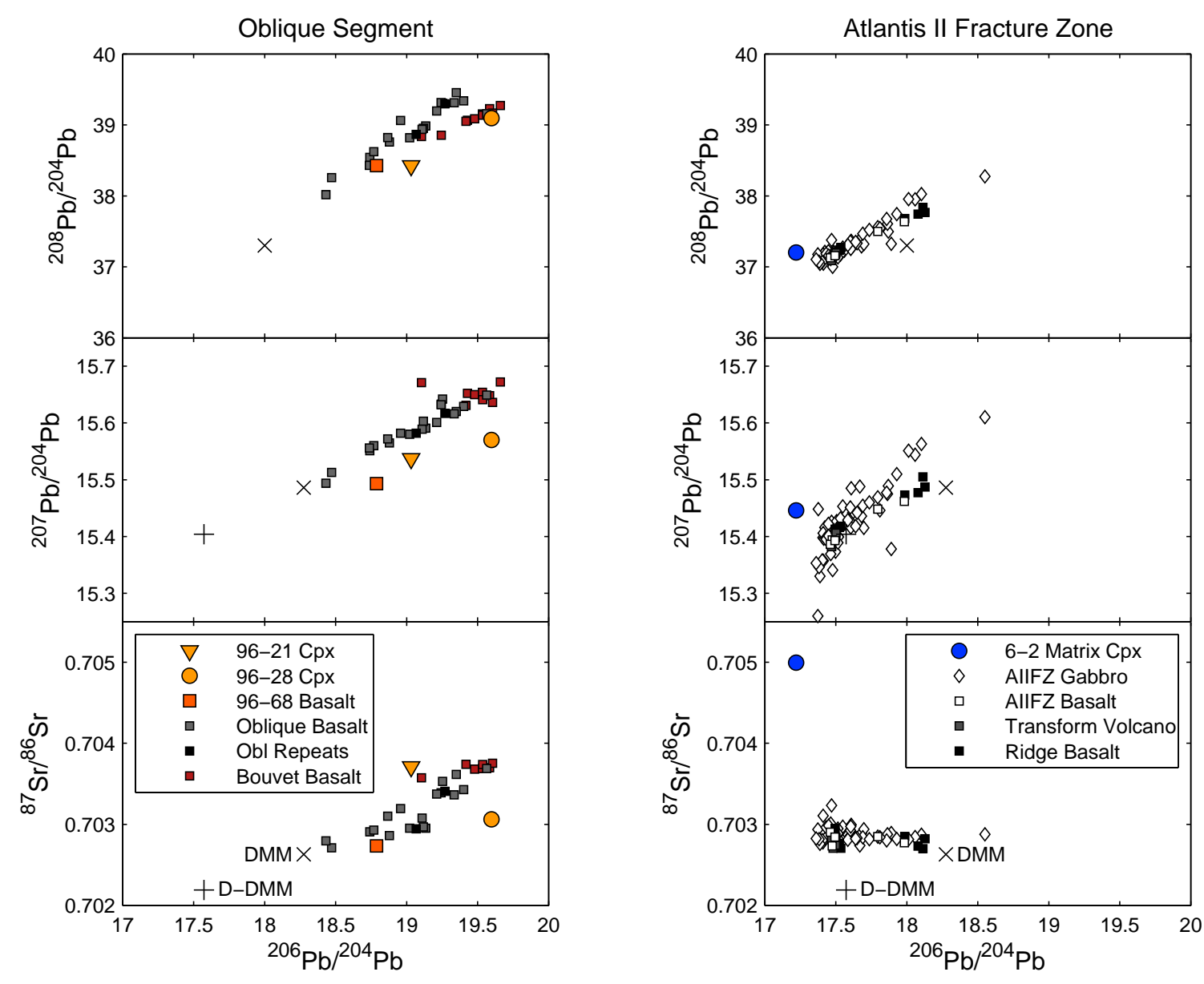

Figure 4.7: Variation of ${ }^{206} \mathrm{~Pb} /{ }^{204} \mathrm{~Pb}$ with ${ }^{208} \mathrm{~Pb} /{ }^{204} \mathrm{~Pb},{ }^{207} \mathrm{~Pb} /{ }^{204} \mathrm{~Pb}$ and ${ }^{87} \mathrm{Sr} /{ }^{86} \mathrm{Sr}$ in peridotite Cpx and basalt glasses from this study. Also shown are related basalts and gabbros and the estimated compositions of DMM and D-DMM; see Figure 4.6 for data references. The two black squares among Oblique Segment basalts are repeat analyses of samples analyzed by Standish (2006), which plot within the general trend between DMM and Bouvet, unlike the Dredge 96 samples. 

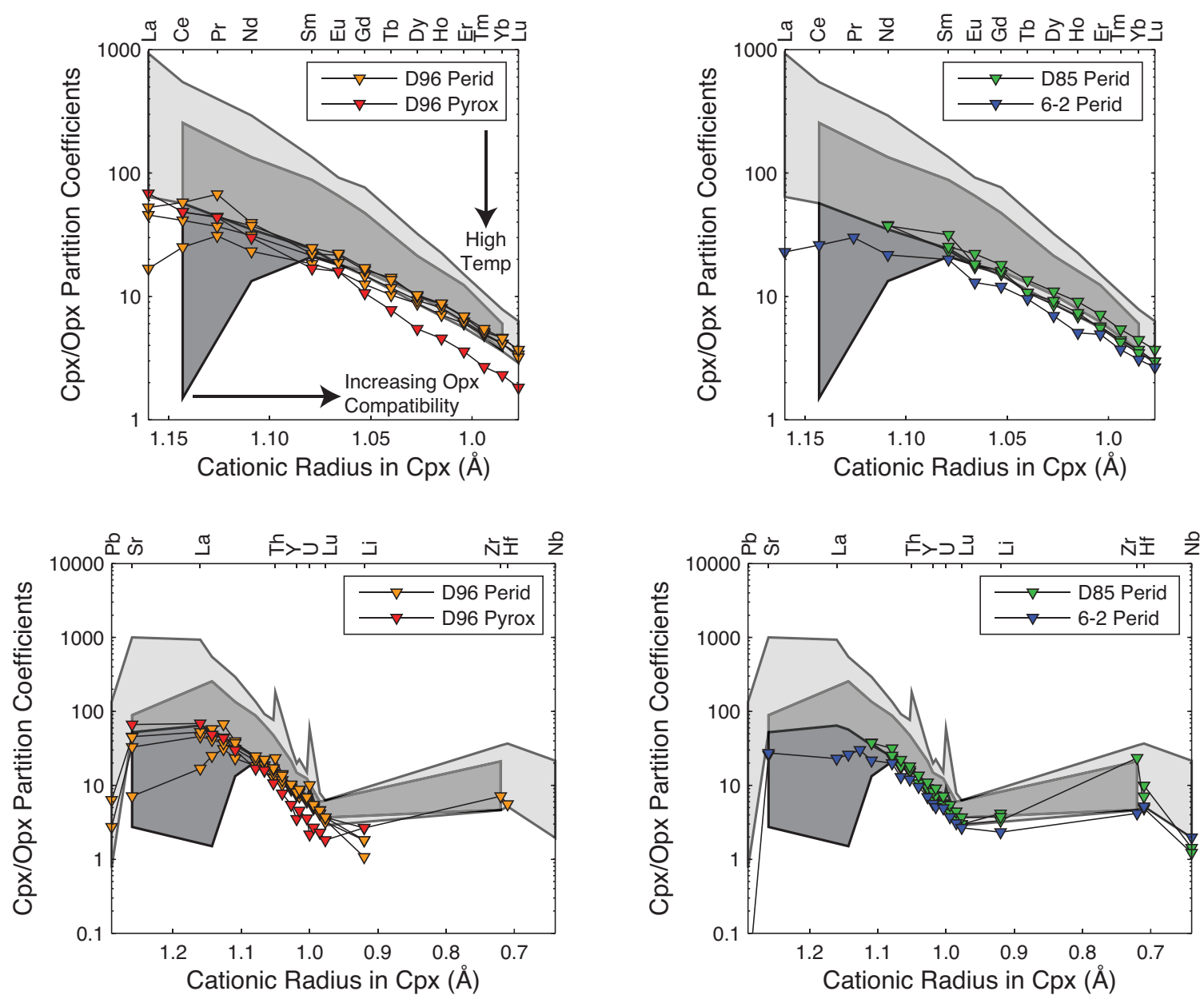

Figure 4.8: Cpx/Opx partition coefficients in abyssal peridotites, plus one pyroxenite, plotted as a function of cationic radius in $\mathrm{Cpx}$. For the elements $\mathrm{Pb}$ to $\mathrm{Li}$, this corresponds to VIII-fold coordination in the M2 sites whereas for the elements $\mathrm{Zr}-\mathrm{Nb}$, this corresponds to VI-fold coordination in the M1 site. REE variations are plotted in the top panels and the full set of trace elements in the bottom panels. The light grey field is the partition coefficient range from Witt-Eickschen and O'Neill (2005) for xenoliths equilibrated over a range of temperatures from $900^{\circ} \mathrm{C}$ (high values) to $1250^{\circ} \mathrm{C}$ (low values). The dark grey field is the partition coefficient range for Hellebrand et al. (2005) from in situ analyses of abyssal peridotite pyroxenes. 

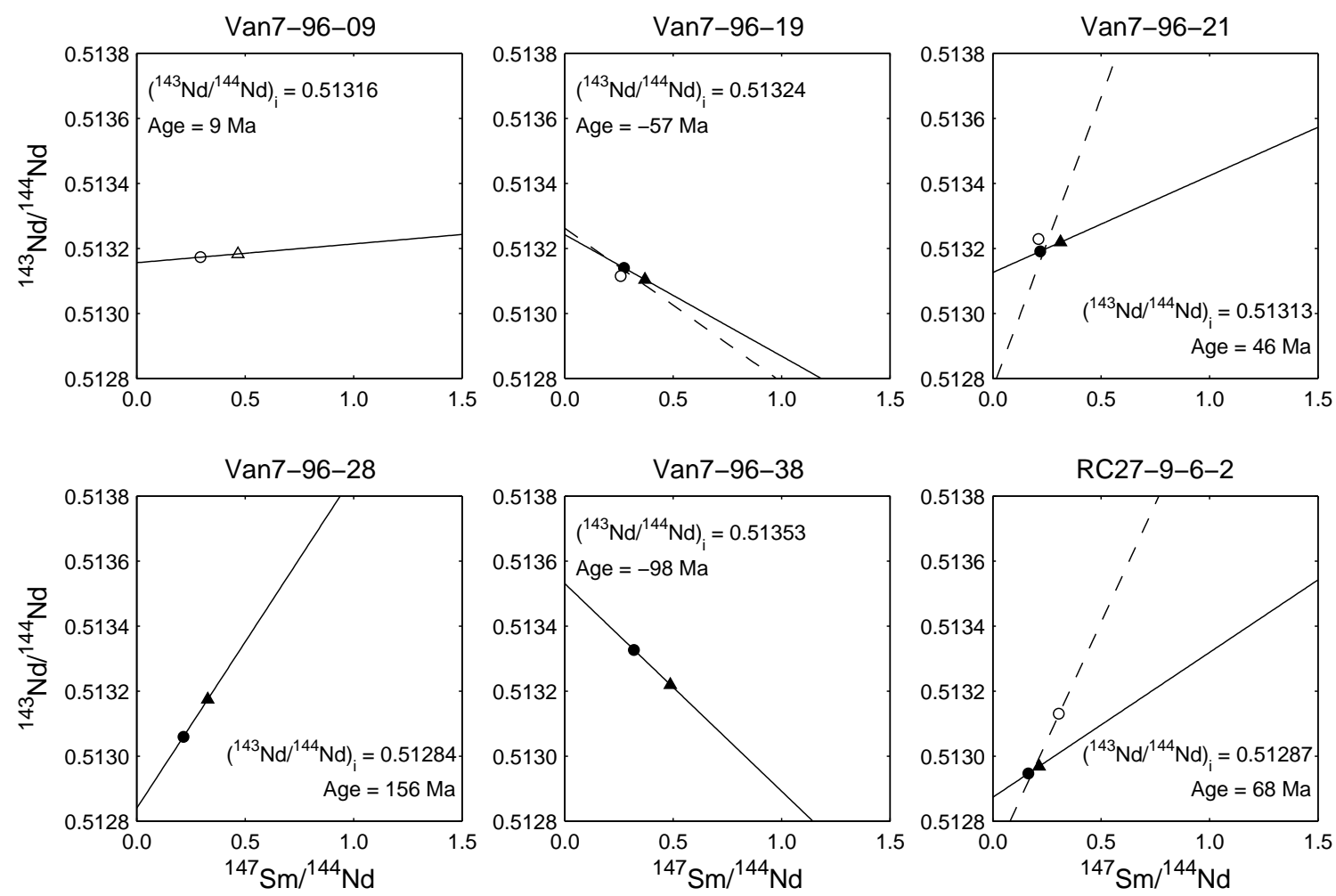

Figure 4.9: Nd isochrons for samples with analyses of more than one mineral phase. Circles are Cpx and triangles are Opx; filled symbols are peridotite minerals and open symbols are vein minerals. Solid line is a linear least squares regression through $\mathrm{Cpx}$ and Opx mineral pairs; dashed line is a regression through matrix Cpx, matrix Opx and vein Cpx. Initial ${ }^{143} \mathrm{Nd} /{ }^{144} \mathrm{Nd}$ and ages are for Cpx-Opx pairs only. 

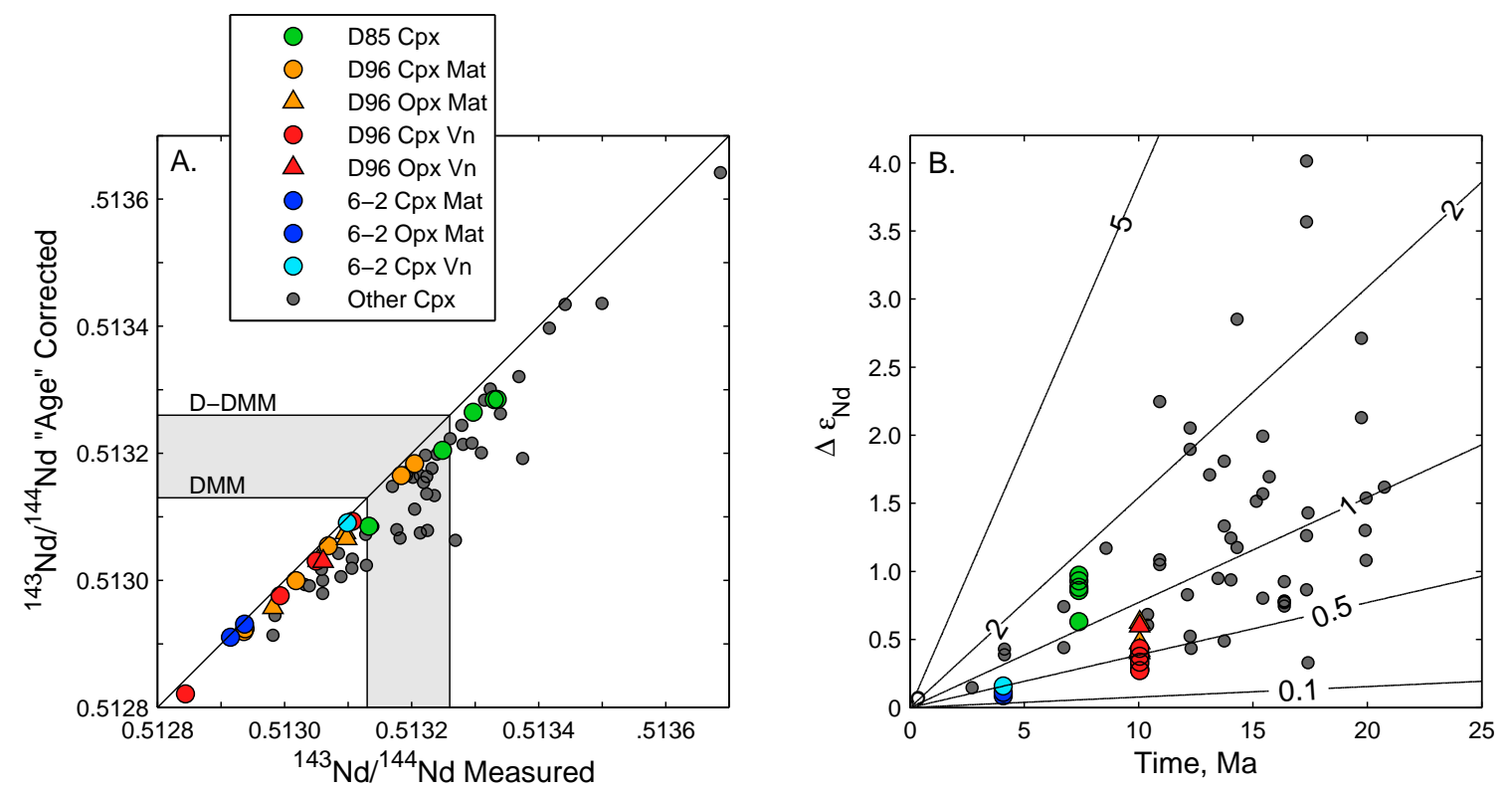

Figure 4.10: A. "Age" corrected ${ }^{143} \mathrm{Nd} /{ }^{144} \mathrm{Nd}$ compared to measured ${ }^{143} \mathrm{Nd} /{ }^{144} \mathrm{Nd}$. The solid line is a 1:1 correlation line. Samples either plot on the line or towards higher measured values, due to ingrowth in the time since the sample left the $1200^{\circ} \mathrm{C}$ isotherm. Data for other Cpx are from Snow (1993), Snow et al.(1994), Salters and Dick (2002), and Cipriani et al. (2004). B. The difference in $\epsilon_{N d}$ between the measured and corrected ${ }^{143} \mathrm{Nd} /{ }^{144} \mathrm{Nd}$ values, as a function of time since the sample left the $1200^{\circ} \mathrm{C}$ isotherm. Contours are for constant $\mathrm{Sm} / \mathrm{Nd}$ ratios. 

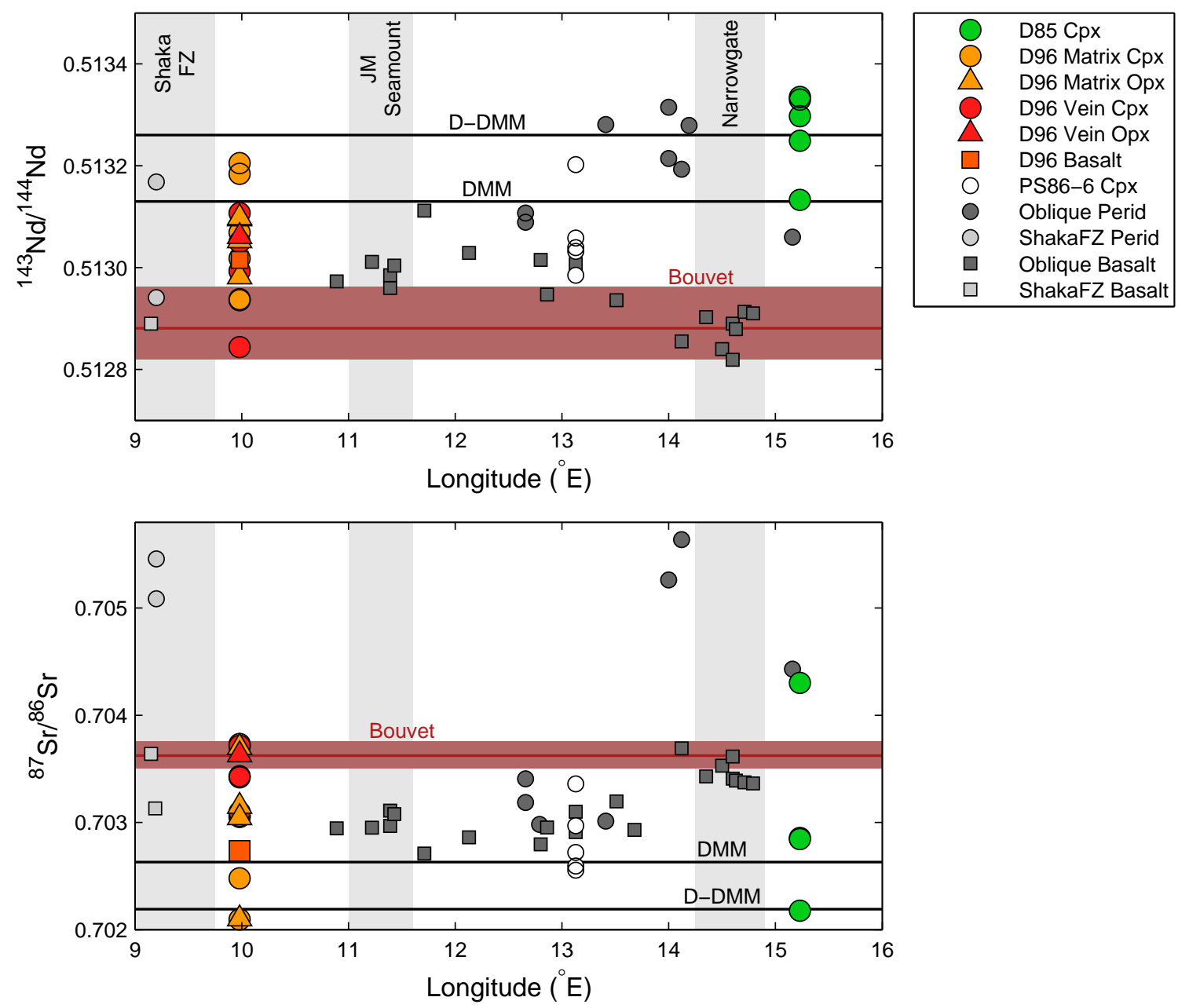

Figure 4.11: Variation of Nd and Sr isotopes along the SWIR Oblique Segment. Joseph Mayes Seamount and Narrowgate are segments where spreading is approximately orthogonal, volcanic activity occurs and significant basaltic crust is present. These features are generally absent along the rest of the Oblique Segment. Data for other peridotite Cpx and basalts are from references in Figure 4.6. 

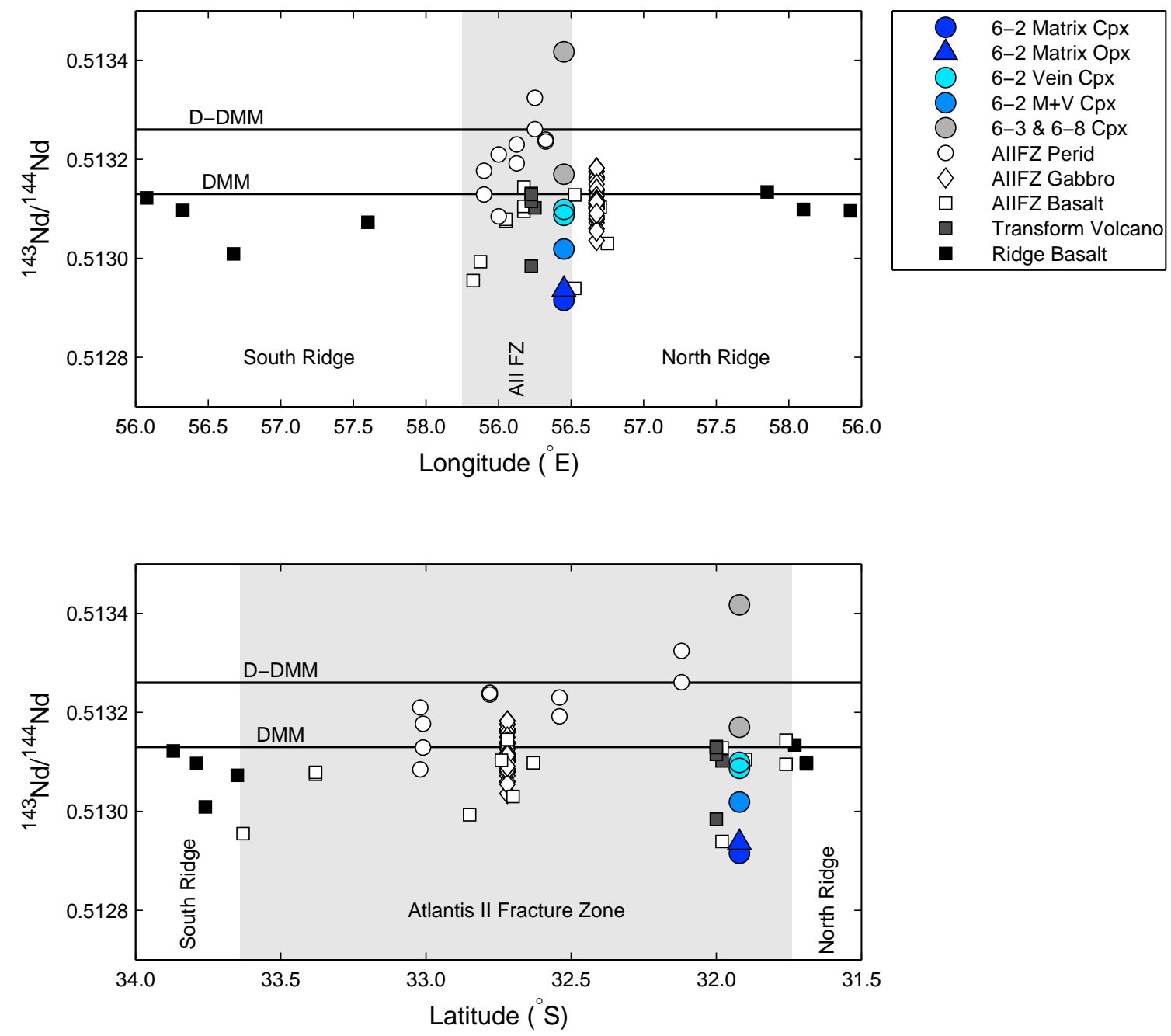

Figure 4.12: Variation of $\mathrm{Nd}$ across (longitude, top panel) and along (latitude, bottom panel) the Atlantis II Fracture Zone. No systematic variation is observed in either direction. Cpx 6-3 \& 6-8 refer to two samples from the same dredge as RC27-9-6-2. Data for other peridotite $\mathrm{Cpx}$, gabbros, and basalts are from references in Figure 4.6, with additional basalt data from Coogan et al. (2004). 

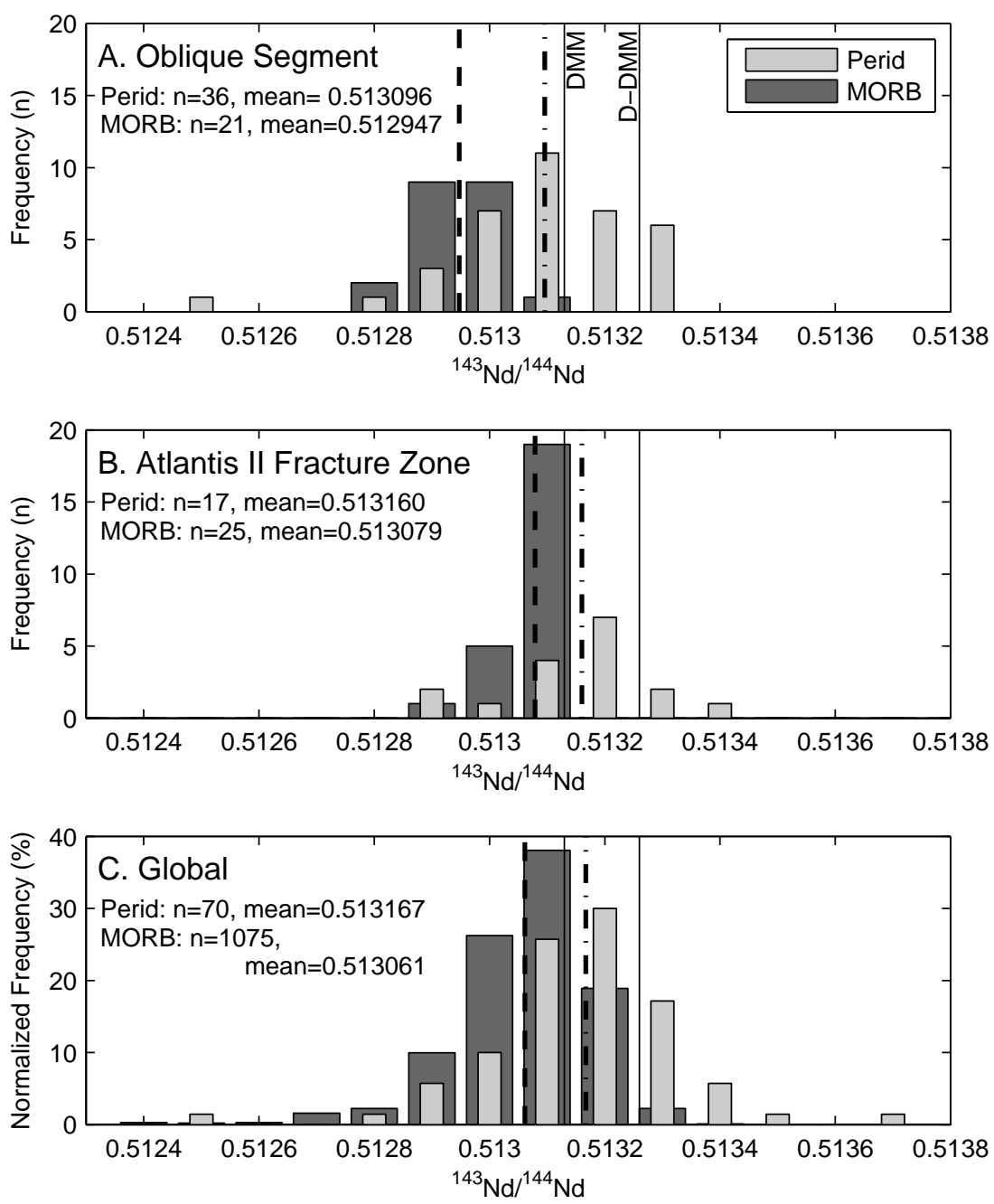

Figure 4.13: Histograms of peridotite and basalt $\mathrm{Nd}$ isotopic ratios for (A) the Oblique Segment, (B) the Atlantis II Fracture Zone, and (C) global abyssal peridotites and MORBs. Mean values for the peridotites are indicated by the dot-dashed lines and the basalts by the dashed lines. Note that Oblique Segment basalts and peridotites are shifted to lower average ${ }^{143} \mathrm{Nd} /{ }^{144} \mathrm{Nd}$ due to the influence of Bouvet Hotspot. Data in A and B are from this study and references in Figure 4.6, global peridotite data in $\mathrm{C}$ also include data from Kempton and Stephens (1997) and Cipriani et al.(2004); global MORB is a compilation from PetDB (http://www.petdb.org, Lehnert et al., 2000). 

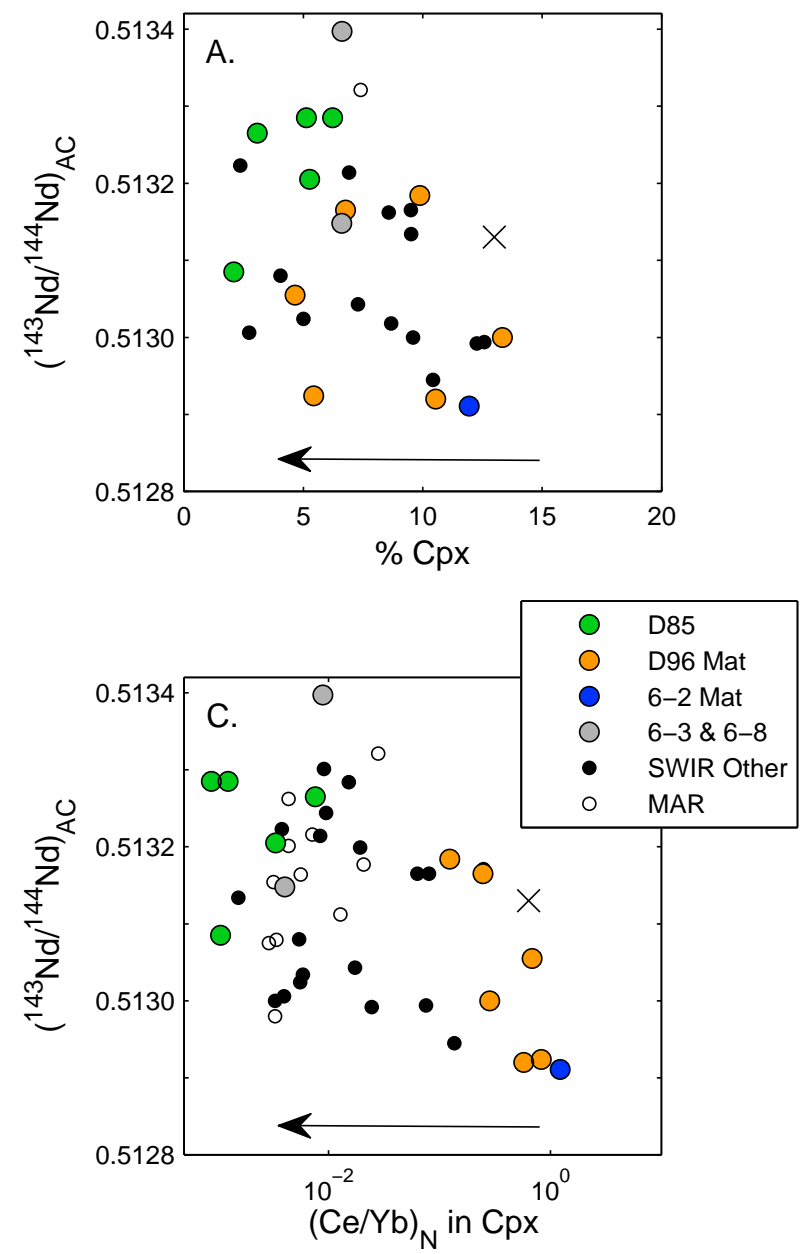
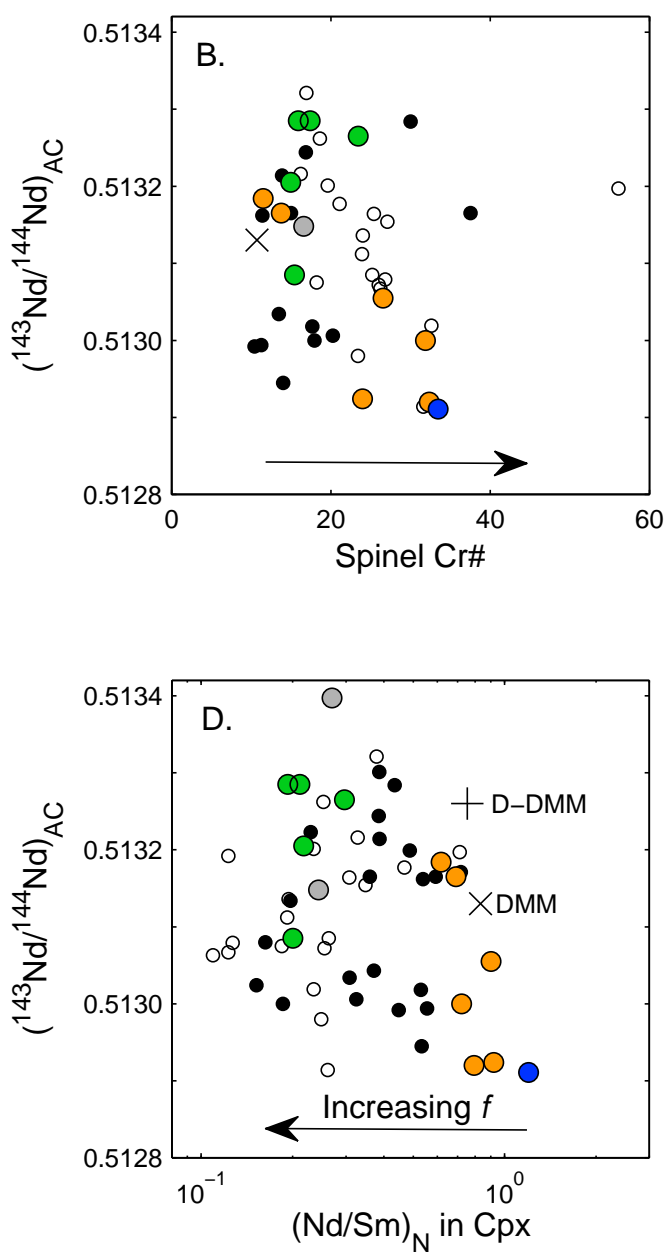

Figure 4.14: The variation of abyssal peridotite $\mathrm{Cpx}{ }^{143} \mathrm{Nd} /{ }^{144} \mathrm{Nd}$ as a function of modal $\mathrm{Cpx}$, spinel $\mathrm{Cr} \#, \mathrm{Ce} / \mathrm{Yb}$, and $\mathrm{Nd} / \mathrm{Sm} .{ }^{143} \mathrm{Nd} /{ }^{144} \mathrm{Nd}$ values are age corrected to the $1200^{\circ} \mathrm{C}$ isotherm, $\mathrm{Cr} \#$ is calculated as $\mathrm{Cr} /(\mathrm{Cr}+\mathrm{Al}) \times 100$, and the $\mathrm{N}$ subscript for REE ratios indicates normalization to PUM. Modal $\mathrm{Cpx}, \mathrm{Ce} / \mathrm{Yb}$ in $\mathrm{Cpx}$ and spinel $\mathrm{Cr} \#$ are traditionally used as indices of degree of peridotite melting, with the first two parameters decreasing with increasing melting and the third parameter increasing during melting. Arrows indicate the direction of change in the compositional parameters with increasing degree of recent melting $(f)$. Data for other SWIR Cpx are from this study and references in Figure 4.6; data for MAR Cpx are from Cipriani et al. (2004) and Brunelli et al. (2006); values for DMM and D-DMM are from Su and Langmuir (2003) and Workman and Hart (2005). 

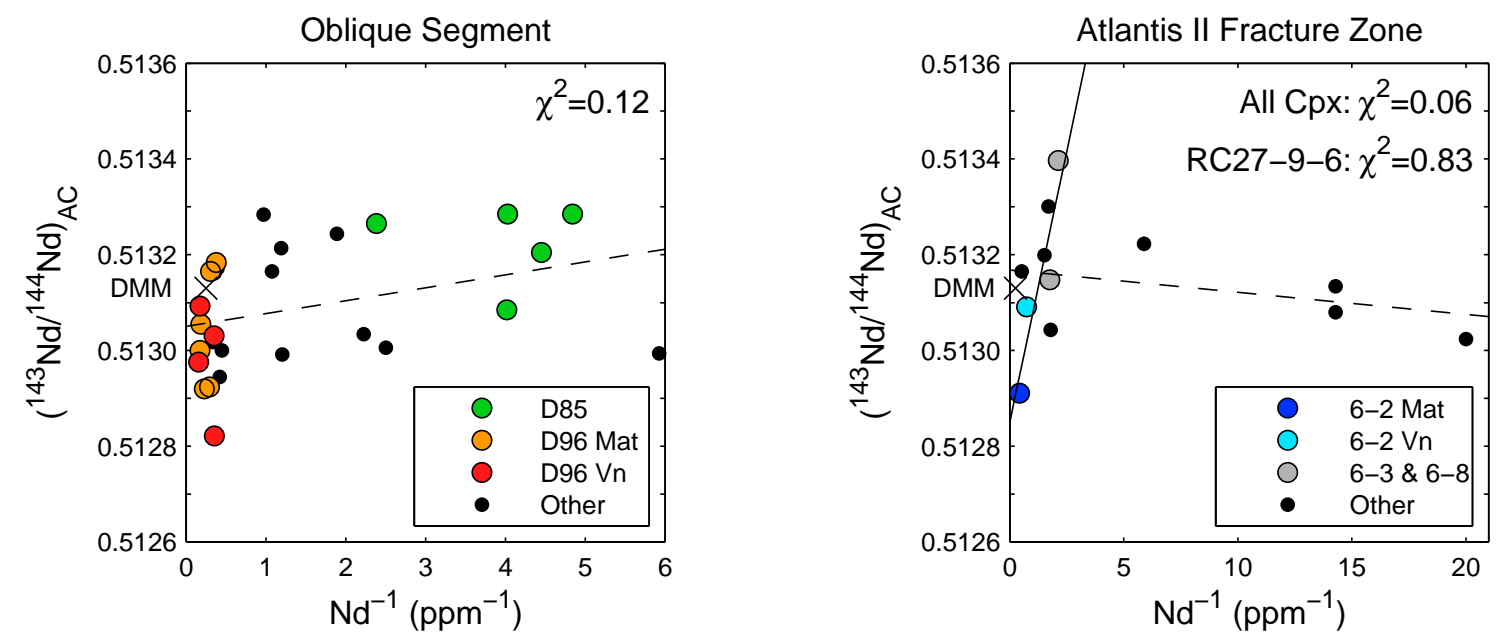

Figure 4.15: Variation of $\mathrm{Nd}$ isotopic ratio as a function of inverse $\mathrm{Nd}$ concentration for the Oblique Segment and the Atlantis II Fracture Zone. ${ }^{143} \mathrm{Nd} /{ }^{144} \mathrm{Nd}$ values are age corrected to the $1200^{\circ} \mathrm{C}$ isotherm and the location of DMM is shown for comparison to observed compositions. Dashed lines are regressions through the datasets for each locality and the $\chi^{2}$ values indicate the lack of a significant correlation. The solid line is a regression through the three samples from dredge RC27-9-6, which yield a good correlation. Data for other SWIR Cpx are from this study and references in Figure 4.6 

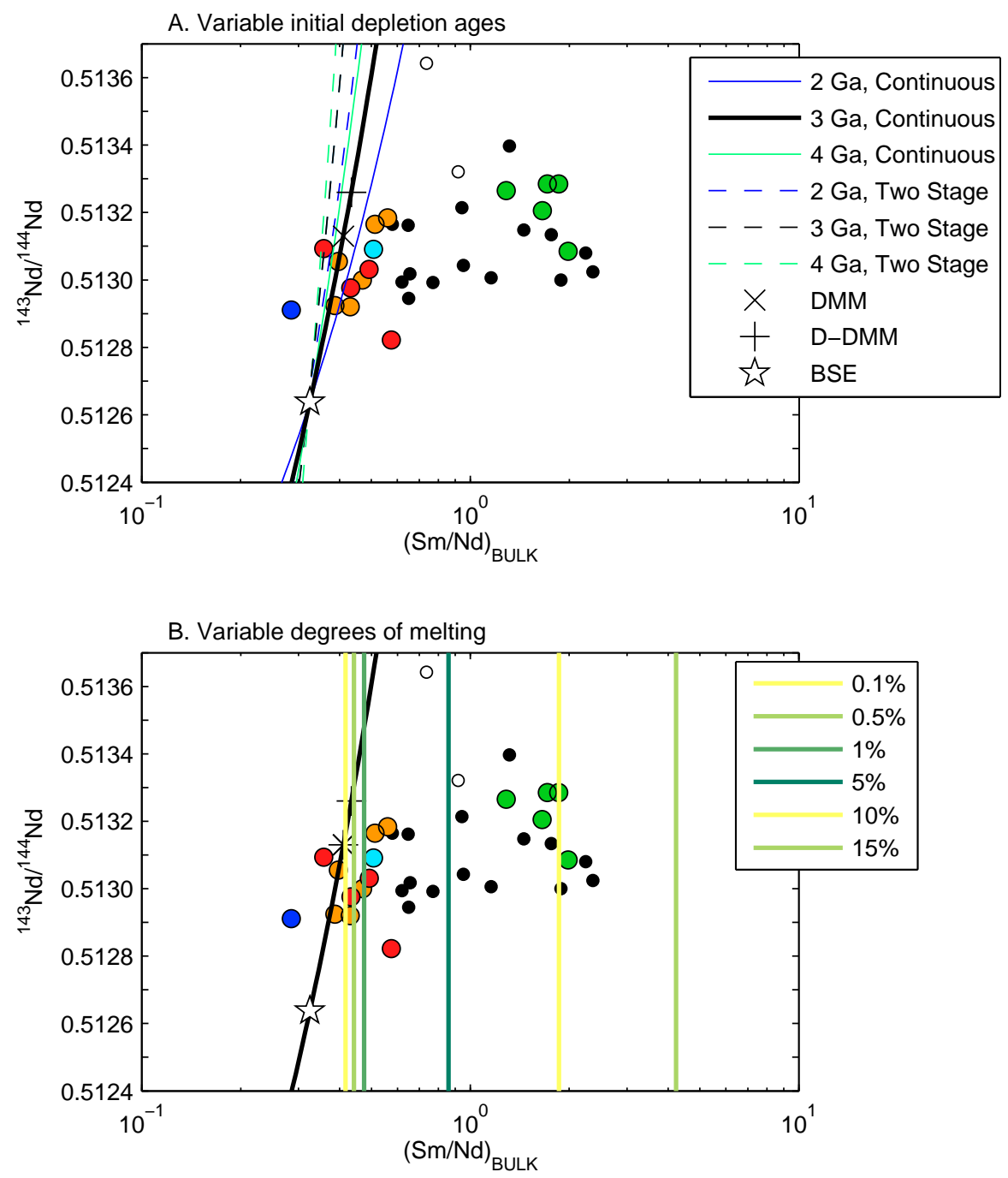

Figure 4.16: A. Predicted present-day mantle composition based on the continuous (solid lines) and two-stage (dashed lines) depletion models and the composition of BSE. The preferred model of Workman and Hart (2005) is the solid black line for continuous depletion at $3 \mathrm{Ga}$ and their estimates of DMM and D-DMM lie on this line. Reconstructed peridotite bulk $\mathrm{Sm} / \mathrm{Nd}$ and ${ }^{143} \mathrm{Nd} /{ }^{144} \mathrm{Nd}$ from this study and the literature (see previous figures for symbols and references) extend over a larger range of $\mathrm{Sm} / \mathrm{Nd}$ compositions than predicted by the models. B. The effect of modal fractional melting on the $\mathrm{Sm} / \mathrm{Nd}$ ratio of DMM. The horizontal spread in the $\mathrm{Sm} / \mathrm{Nd}$ ratios of the peridotites can be explained by variable degrees of melting from an initial DMM composition. However, the highest degree of melting is predicted for Dredge 85 peridotites (green circles), which come from a section of the SWIR that lacks crust and thus cannot have undergone $\sim 10 \%$ melting. Peridotite bulk $\mathrm{Sm} / \mathrm{Nd}$ compositions are reconstructed from $\mathrm{Cpx}$ concentrations and modal analyses. Peridotite $\mathrm{Nd}$ ratios are age corrected values for $\mathrm{Cpx}$, assumed to be representative of the whole rock. 

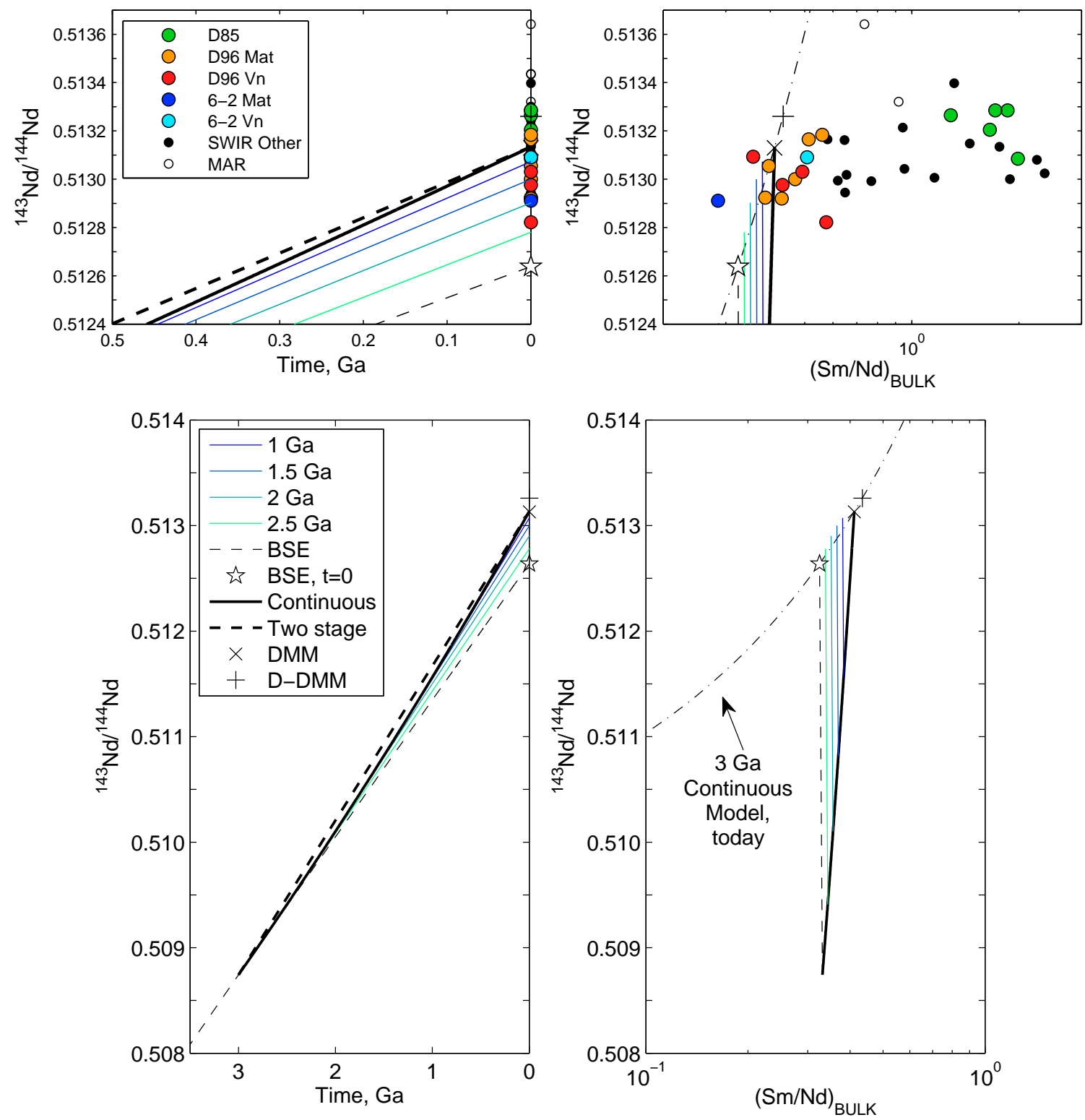

Figure 4.17: Models of DMM isotopic and trace element evolution through time, following the two stage model, the continuous depletion model and the continuous depletion model with periodic removal, all assuming initial depletion of BSE at $3 \mathrm{Ga}$. The continuous depletion and two stage models follow slightly different trajectories, but are constrained to produce the same present-day ${ }^{143} \mathrm{Nd} /{ }^{144} \mathrm{Nd} \mathrm{DMM}$ ratio. Material removed at different times from the continuously depleting mantle produces a range of present-day compositions between DMM and BSE. The dot-dashed line is the present-day variation of ${ }^{143} \mathrm{Nd} /{ }^{144} \mathrm{Nd}$ and $\mathrm{Sm} / \mathrm{Nd}$ ratios for the continuous depletion model (for depletion beginning at $3 \mathrm{Ga}$ ) and is the same as the solid black line in Figure 4.16 . 

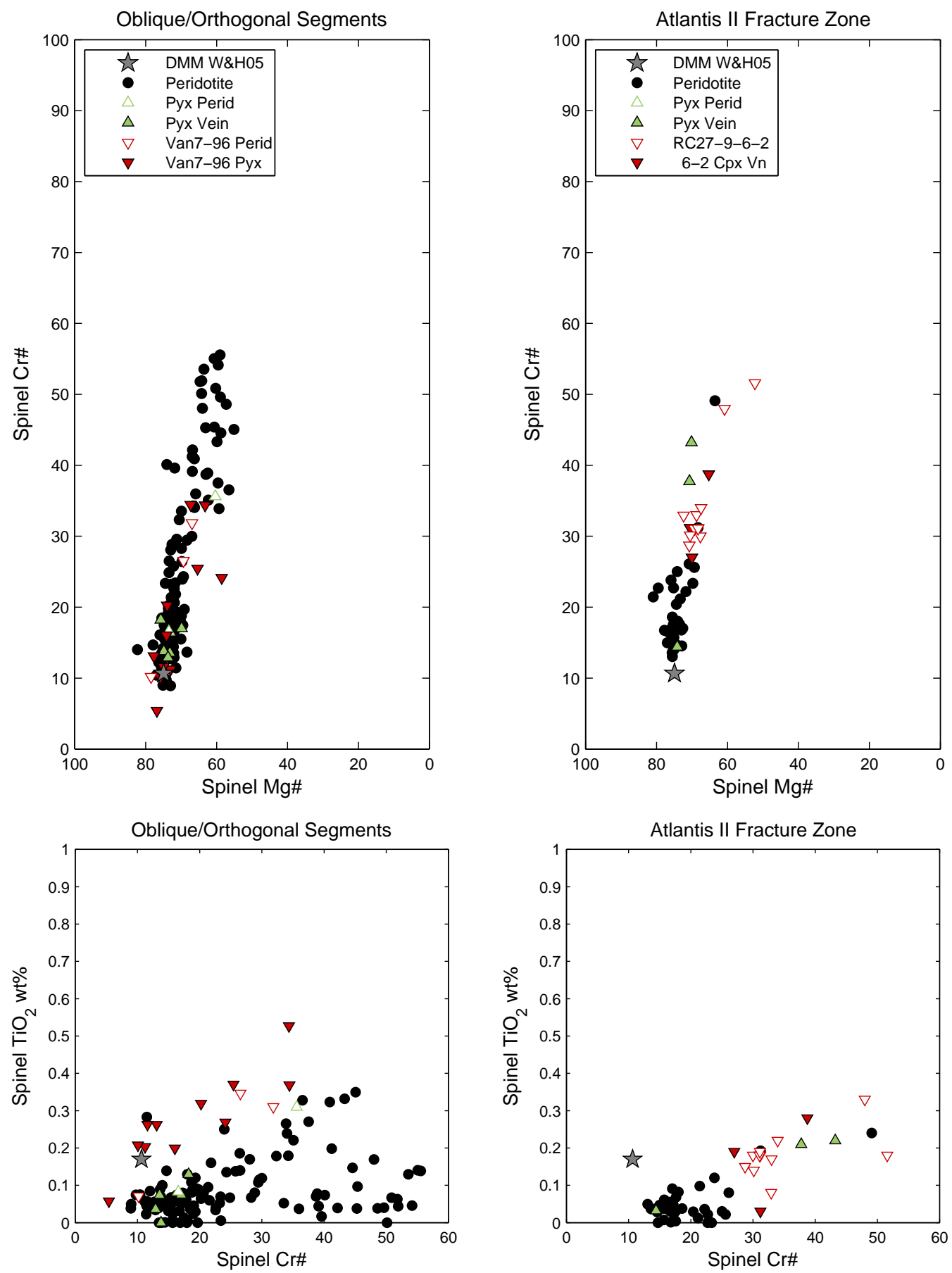

Figure 4.A1: Variations in spinel $\mathrm{Cr} \#, \mathrm{Mg \#}$ and $\mathrm{TiO}_{2}$ in peridotites and pyroxenites from this study. $\mathrm{Cr} \#$ is calculated as $\mathrm{Cr} /(\mathrm{Cr}+\mathrm{Al}) \times 100$ and $\mathrm{Mg} \#$ as $\mathrm{Mg} /(\mathrm{Mg}+\mathrm{Fe}) \times 100$. Also shown are data for spatially associated peridotites and pyroxenites, from the dataset in Chapter 5. The composition of spinel in DMM is from Workman and Hart (2005). 

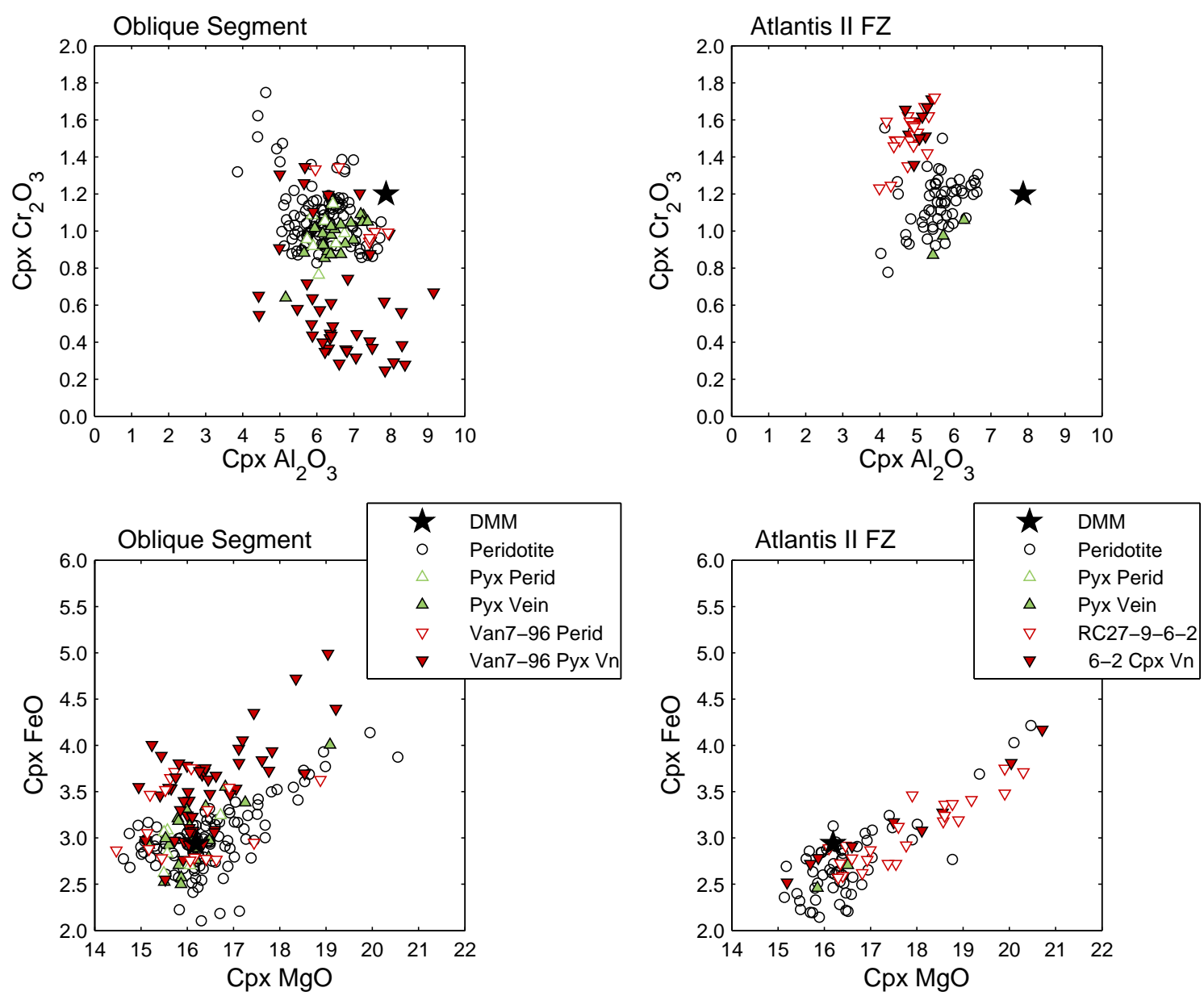

Figure 4.A2: Variations Cpx major element compositions among peridotites and pyroxenites from this study and spatially associated samples (from the dataset in Chapter 5). The composition of Cpx in DMM is from Workman and Hart (2005). 
Table 4.1: Dredge locations

\begin{tabular}{|c|c|c|c|c|c|c|c|c|c|}
\hline \multirow[b]{2}{*}{ Dredge } & \multirow[b]{2}{*}{ Contents } & \multicolumn{6}{|c|}{ On/Off Bottom } & \multirow[b]{2}{*}{$\begin{array}{l}\mathrm{ESR}^{a} \\
\mathrm{~mm} / \mathrm{yr}\end{array}$} & \multirow[b]{2}{*}{ Location } \\
\hline & & $\begin{array}{l}\mathrm{Wt} \\
\mathrm{kg}\end{array}$ & $\begin{array}{l}\text { Lat } \\
{ }^{\circ} \mathrm{S}\end{array}$ & $\begin{array}{l}\text { Long } \\
{ }^{\circ} \mathrm{E}\end{array}$ & $\begin{array}{l}\text { Depth } \\
\mathrm{m}\end{array}$ & $\begin{array}{l}\mathrm{FSR}^{a} \\
\mathrm{~mm} / \mathrm{yr}\end{array}$ & Angle $^{a}$ & & \\
\hline \multicolumn{10}{|c|}{ Oblique Supersegment, SWIR } \\
\hline $\operatorname{Van} 7-85$ & $\begin{array}{l}\text { Peridotite, } \\
\text { dunite, } \\
\text { diabase }\end{array}$ & 90 & $\begin{array}{l}52.25 \\
52.27\end{array}$ & $\begin{array}{l}15.23 \\
15.23\end{array}$ & $\begin{array}{l}4190 \\
3547\end{array}$ & 14.22 & $32.5^{\circ}$ & 11.99 & $\begin{array}{l}\text { S wall of axial } \\
\text { trough, east of } \\
\text { Narrowgate }\end{array}$ \\
\hline Van7-86 & $\begin{array}{l}\text { Dunite, } \\
\text { peridotite }\end{array}$ & 146 & $\begin{array}{l}52.14 \\
52.13\end{array}$ & $\begin{array}{l}15.16 \\
15.15\end{array}$ & $\begin{array}{l}3765 \\
3128\end{array}$ & 14.21 & $32.6^{\circ}$ & 11.97 & $\begin{array}{l}\mathrm{N} \text { wall of axial } \\
\text { trough, east of } \\
\text { Narrowgate }\end{array}$ \\
\hline Van7-96 & $\begin{array}{l}\text { Cataclastites, } \\
\text { perid, pyrox, } \\
\text { diabase }\end{array}$ & 81 & $\begin{array}{l}53.14 \\
53.15\end{array}$ & $\begin{array}{l}9.98 \\
9.97\end{array}$ & $\begin{array}{l}2970 \\
3527\end{array}$ & 14.06 & $28.5^{\circ}$ & 12.36 & $\begin{array}{l}\text { SW wall of } \\
\text { axial trough at } \\
\text { Shaka FZ }\end{array}$ \\
\hline PS86-6 & $\begin{array}{l}\text { Peridotite, } \\
\text { basalt, } \\
\text { gabbro } \\
\text { veined perid }\end{array}$ & 187 & $\begin{array}{l}52.44 \\
52.33\end{array}$ & $\begin{array}{l}13.13 \\
13.15\end{array}$ & $\begin{array}{l}4509 \\
3073\end{array}$ & 14.14 & $51.4^{\circ}$ & 8.82 & $\begin{array}{l}\text { intersection } \\
\mathrm{N} \text { wall of axial } \\
\text { trough, midway } \\
\text { along segment }\end{array}$ \\
\hline \multicolumn{10}{|c|}{ Atlantis II Fracture Zone, SWIR } \\
\hline RC27-9-6 & $\begin{array}{l}\text { Peridotite, } \\
\text { dunite }\end{array}$ & 37 & $\begin{array}{l}31.92 \\
31.93\end{array}$ & $\begin{array}{l}57.18 \\
57.18\end{array}$ & $\begin{array}{l}4010 \\
3500\end{array}$ & $14.00^{b}$ & $0.0^{\circ}$ & 14.00 & $\begin{array}{l}\text { E wall of } \\
\text { transform, at } \\
\text { ridge } \\
\text { intersection }\end{array}$ \\
\hline
\end{tabular}

\footnotetext{
${ }^{a}$ The effective spreading rate (ESR) is calculated from the full spreading rate (FSR) and angle of obliquity, following the method of Abelson and Agnon (1997).

${ }^{b}$ Due to asymmetrical spreading, the half spreading rate is $8.5 \mathrm{~mm} / \mathrm{yr}$ to the south (Hosford et al. 2003).
} 
Table 4.2: Peridotite modal compositions

\begin{tabular}{llrrrrrrr}
\hline Sample & Lithology & Oliv & Opx & Cpx & Spin & Plag & Sum & Points \\
\hline Van7-85-27 & Harzburgite & 68.6 & 27.5 & 3.1 & 0.9 & 0.0 & 100.0 & 2506 \\
Van7-85-30 & Harzburgite & 67.4 & 29.2 & 2.1 & 1.2 & 0.2 & 100.0 & 2483 \\
Van7-85-42 & Lherzolite & 67.1 & 25.6 & 6.2 & 1.0 & 0.0 & 100.0 & 2825 \\
Van7-85-47 & Lherzolite & 68.7 & 24.7 & 5.1 & 1.5 & 0.0 & 100.0 & 2594 \\
Van7-85-49 & Lherzolite & 71.6 & 22.2 & 5.3 & 0.9 & 0.1 & 100.0 & 2607 \\
Van7-86-27 & Lherzolite & 55.8 & 34.0 & 9.6 & 0.6 & 0.0 & 100.0 & 2566 \\
Van7-96-09V & Pyx Vein & 9.3 & 25.8 & 48.5 & 1.9 & 14.6 & 100.0 & 756 \\
Van7-96-16V & Pyx Vein & 11.6 & 34.0 & 24.4 & 1.6 & 28.4 & 100.0 & 697 \\
Van7-96-19M & Lherz w/ Pyx Vein & 64.8 & 17.9 & 13.3 & 0.8 & 3.1 & 100.0 & 1883 \\
Van7-96-19V & Pyx Vein in Lherz & 7.2 & 26.4 & 57.2 & 2.8 & 6.3 & 100.0 & 318 \\
Van7-96-21M & Harz w/ Pyx Vein & 76.2 & 18.1 & 4.6 & 0.6 & 0.4 & 100.0 & 1894 \\
Van7-96-21V & Pyx Vein in Harz & 19.7 & 39.3 & 37.5 & 2.2 & 1.3 & 100.0 & 461 \\
Van7-96-25 & Lherzolite & 66.2 & 25.6 & 6.8 & 1.4 & 0.0 & 100.0 & 2215 \\
Van7-96-28 & Lherzolite & 76.7 & 17.2 & 5.4 & 0.7 & 0.0 & 100.0 & 2738 \\
Van7-96-35 & Lherzolite & 70.4 & 16.7 & 10.5 & 2.3 & 0.1 & 100.0 & 1765 \\
Van7-96-38 & Lherzolite & 64.2 & 24.1 & 9.9 & 1.6 & 0.2 & 100.0 & 2278 \\
PS86-6-38 & Lherzolite & 56.7 & 29.0 & 12.6 & 1.7 & 0.0 & 100.0 & 3124 \\
RC27-9-6-2M & Lherz w/ Cpx Vein & 67.5 & 19.5 & 11.9 & 0.9 & 0.2 & 100.0 & 2194 \\
RC27-9-6-2V & Cpx Vein in Lherz & 7.6 & 9.2 & 82.6 & 0.7 & 0.0 & 100.0 & 436 \\
\hline
\end{tabular}


Table 4.3: Trace element concentrations in ppm for Cpx, Opx and basalt

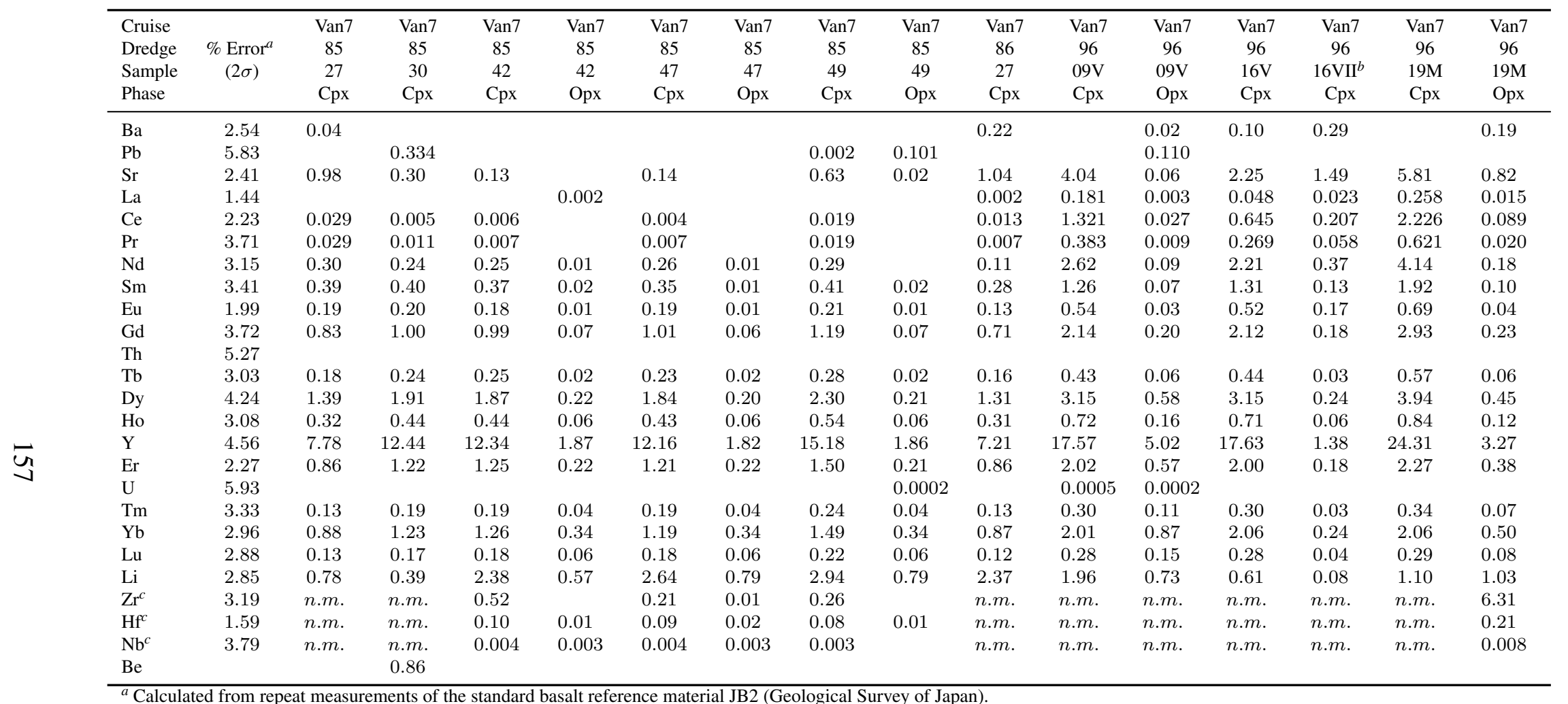

${ }^{b}$ Less pure Cpx separate: non-optically pure grains contain small black inclusions and white alteration material.

${ }^{c}$ Empty values are below detection limit; n.m. indicates not measured. 
Table 4.3: Trace elements Cont.

\begin{tabular}{|c|c|c|c|c|c|c|c|c|c|c|c|c|c|c|c|}
\hline $\begin{array}{l}\text { Cruise } \\
\text { Dredge } \\
\text { Sample } \\
\text { Phase }\end{array}$ & $\begin{array}{c}\text { Van7 } \\
96 \\
19 \mathrm{~V} \\
\mathrm{Cpx}\end{array}$ & $\begin{array}{c}\text { Van7 } \\
96 \\
21 \mathrm{M} \\
\mathrm{Cpx}\end{array}$ & $\begin{array}{c}\text { Van7 } \\
96 \\
21 \mathrm{M} \\
\text { Opx }\end{array}$ & $\begin{array}{c}\text { Van7 } \\
96 \\
21 \mathrm{~V} \\
\text { Cpx }\end{array}$ & $\begin{array}{c}\text { Van7 } \\
96 \\
25 \\
\text { Cpx }\end{array}$ & $\begin{array}{c}\text { Van7 } \\
96 \\
28 \\
\text { Cpx }\end{array}$ & $\begin{array}{c}\text { Van7 } \\
96 \\
28 \\
\text { Opx }\end{array}$ & $\begin{array}{c}\text { Van7 } \\
96 \\
35 \\
\text { Cpx }\end{array}$ & $\begin{array}{c}\text { Van7 } \\
96 \\
38 \\
\text { Cpx }\end{array}$ & $\begin{array}{c}\text { Van7 } \\
96 \\
38 \\
\text { Opx }\end{array}$ & $\begin{array}{c}\text { Van7 } \\
96 \\
68 \\
\text { Basalt }\end{array}$ & $\begin{array}{c}\text { PS86 } \\
6 \\
38 \\
\text { Cpx }\end{array}$ & $\begin{array}{c}\text { RC27-9 } \\
6 \\
2 \mathrm{M} \\
\mathrm{Cpx}\end{array}$ & $\begin{array}{c}\mathrm{RC} 27-9 \\
6 \\
2 \mathrm{M} \\
\mathrm{Opx}\end{array}$ & $\begin{array}{c}\mathrm{RC} 27-\mathrm{C} \\
6 \\
2 \mathrm{~V} \\
\mathrm{Cpx}\end{array}$ \\
\hline $\begin{array}{l}\mathrm{Ba} \\
\mathrm{Pb}\end{array}$ & 1.12 & 0.005 & 0.002 & 0.005 & & 0.016 & 0.003 & & & 0.004 & $\begin{array}{c}105.21 \\
1.073\end{array}$ & & & 0.012 & \\
\hline $\mathrm{Sr}$ & 7.94 & 23.73 & 0.72 & 20.04 & 9.38 & 74.86 & 1.65 & 32.44 & 10.33 & 0.23 & 248.91 & 5.87 & 68.81 & 2.51 & 16.77 \\
\hline $\mathrm{La}$ & 0.417 & 0.851 & 0.019 & 0.984 & 0.170 & 1.026 & 0.020 & 0.433 & 0.064 & & 11.77 & 0.025 & 0.668 & 0.029 & 0.208 \\
\hline $\mathrm{Ce}$ & 2.693 & 4.196 & 0.102 & 4.486 & 1.380 & 3.292 & 0.057 & 2.184 & 0.882 & 0.018 & 28.40 & 0.508 & 2.503 & 0.096 & 0.911 \\
\hline $\operatorname{Pr}$ & 0.643 & 0.878 & 0.024 & 0.901 & 0.351 & 0.596 & 0.009 & 0.508 & 0.327 & 0.007 & 3.77 & 0.255 & 0.411 & 0.014 & 0.212 \\
\hline $\mathrm{Nd}$ & 4.29 & 5.27 & 0.17 & 5.47 & 2.52 & 3.37 & 0.09 & 3.32 & 2.49 & 0.07 & 16.63 & 2.30 & 1.94 & 0.09 & 1.26 \\
\hline $\mathrm{Sm}$ & 1.81 & 1.87 & 0.09 & 1.87 & 1.13 & 1.19 & 0.05 & 1.34 & 1.34 & 0.05 & 4.32 & 1.30 & 0.52 & 0.03 & 0.65 \\
\hline $\mathrm{Eu}$ & 0.67 & 0.72 & 0.04 & 0.70 & 0.51 & 0.47 & 0.02 & 0.54 & 0.59 & 0.03 & 1.60 & 0.57 & 0.21 & 0.02 & 0.28 \\
\hline $\mathrm{Gd}$ & 2.75 & 2.37 & 0.16 & 2.37 & 1.86 & 1.57 & 0.10 & 1.82 & 2.18 & 0.13 & 4.86 & 2.17 & 0.72 & 0.06 & 1.07 \\
\hline Th & 0.0013 & & 0.0003 & 0.0057 & & 0.0177 & 0.0008 & 0.0183 & & & 1.42 & & 0.0051 & & 0.0023 \\
\hline $\mathrm{Tb}$ & 0.52 & 0.45 & 0.04 & 0.44 & 0.37 & 0.29 & 0.02 & 0.34 & 0.45 & 0.03 & 0.83 & 0.44 & 0.14 & 0.01 & 0.22 \\
\hline Dy & 3.76 & 2.88 & 0.31 & 2.85 & 2.57 & 1.83 & 0.18 & 2.26 & 3.17 & 0.31 & 5.20 & 3.21 & 0.94 & 0.14 & 1.55 \\
\hline Ho & 0.79 & 0.64 & 0.08 & 0.63 & 0.57 & 0.39 & 0.05 & 0.46 & 0.72 & 0.08 & 1.10 & 0.70 & 0.20 & 0.04 & 0.33 \\
\hline ப) & 21.55 & 18.15 & 2.35 & 17.85 & 15.40 & 11.36 & 1.41 & 12.36 & 20.68 & 2.57 & 31.54 & 19.84 & 5.49 & 1.08 & 9.04 \\
\hline $\mathrm{Er}$ & 2.04 & 1.70 & 0.27 & 1.70 & 1.50 & 1.04 & 0.15 & 1.18 & 1.92 & 0.28 & 2.92 & 1.88 & 0.55 & 0.11 & 0.87 \\
\hline U & 0.0005 & & 0.0001 & & & 0.0046 & 0.0005 & 0.0064 & & & 0.42 & & 0.0026 & & 0.0010 \\
\hline $\mathrm{Tm}$ & 0.31 & 0.25 & 0.05 & 0.25 & 0.23 & 0.16 & 0.03 & 0.16 & 0.29 & 0.05 & 0.44 & 0.28 & 0.09 & 0.02 & 0.13 \\
\hline $\mathrm{Yb}$ & 1.87 & 1.61 & 0.39 & 1.63 & 1.46 & 1.04 & 0.23 & 1.00 & 1.87 & 0.41 & 3.01 & 1.75 & 0.54 & 0.18 & 0.80 \\
\hline $\mathrm{Lu}$ & 0.26 & 0.23 & 0.07 & 0.22 & 0.21 & 0.15 & 0.04 & 0.14 & 0.26 & 0.07 & 0.43 & 0.26 & 0.08 & 0.03 & 0.11 \\
\hline $\mathrm{Li}$ & 2.11 & 1.70 & 0.94 & 1.52 & 2.64 & 1.47 & 0.81 & 1.88 & 4.36 & 1.64 & 6.14 & 2.75 & 14.32 & 6.19 & 12.80 \\
\hline $\mathrm{Zr}$ & 35.31 & n.m. & 4.28 & n.m. & n.m. & n.m. & 1.65 & n.m. & 14.28 & 2.01 & n.m. & 7.93 & 3.64 & 0.87 & 4.53 \\
\hline $\mathrm{Hf}$ & 1.14 & n.m. & 0.16 & n.m. & n.m. & n.m. & 0.06 & n.m. & 0.64 & 0.12 & n.m. & 0.46 & 0.14 & 0.03 & 0.22 \\
\hline $\mathrm{Nb}$ & 0.014 & $n . m$. & 0.001 & n.m. & n.m. & n.m. & 0.013 & n.m. & 0.003 & & n.m. & 0.002 & 0.028 & 0.014 & 0.037 \\
\hline $\mathrm{Be}$ & & & & & & & & 0.020 & 0.024 & & 0.86 & & 0.043 & & \\
\hline
\end{tabular}




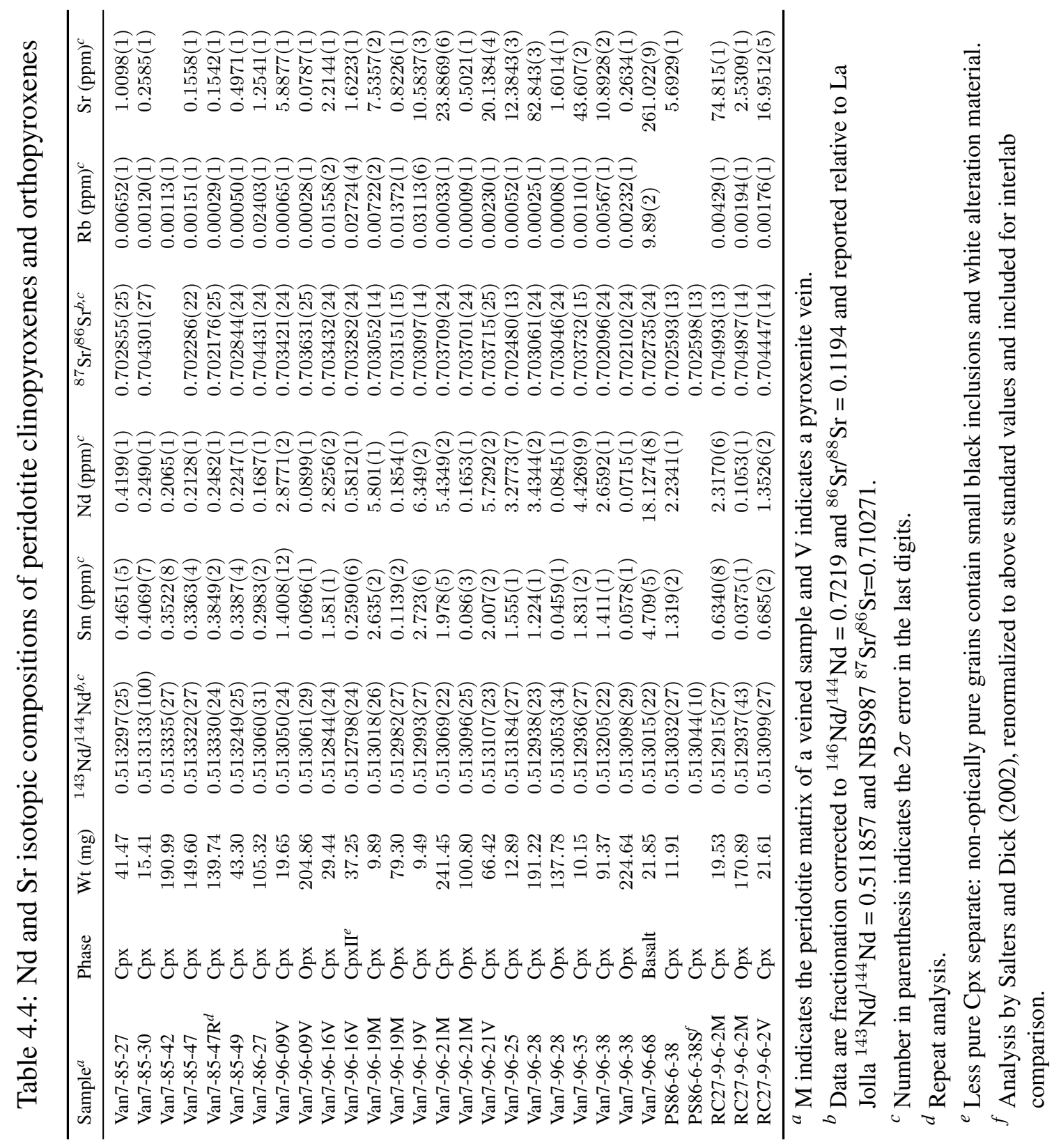


Table 4.5: $\mathrm{Pb}$ isotopic compositions of peridotite $\mathrm{Cpx}$ and basalt glasses

\begin{tabular}{llcccccc}
\hline Sample & Phase & ${ }^{206} \mathrm{~Pb} /{ }^{204} \mathrm{~Pb}^{a}$ & $2 \sigma$ & ${ }^{207} \mathrm{~Pb} /{ }^{204} \mathrm{~Pb}^{a}$ & $2 \sigma$ & ${ }^{208} \mathrm{~Pb}^{204} \mathrm{~Pb}^{a}$ & $2 \sigma$ \\
\hline Van7-96-21M & Cpx & 19.032 & 0.015 & 15.537 & 0.012 & 38.423 & 0.025 \\
Van7-96-28 & Cpx & 19.598 & 0.016 & 15.570 & 0.012 & 39.096 & 0.026 \\
RC27-9-6-2M & Cpx & 17.221 & 0.002 & 15.446 & 0.002 & 37.201 & 0.005 \\
Van7-96-68 & Basalt & 18.789 & 0.015 & 15.493 & 0.012 & 38.426 & 0.025 \\
Van7-92-03 & Basalt & 19.068 & 0.002 & 15.582 & 0.002 & 38.866 & 0.006 \\
Van7-92-03S & Basalt & 19.065 & 0.002 & 15.601 & 0.001 & 38.893 & 0.004 \\
Kn162-61-71 & Basalt & 19.270 & 0.002 & 15.617 & 0.002 & 39.297 & 0.006 \\
Kn162-61-71S $^{b}$ & Basalt & 19.288 & 0.001 & 15.642 & 0.001 & 39.368 & 0.002 \\
\hline
\end{tabular}

${ }^{a}$ All data are normalized to the NBS981 values from Todt et al. $(1996):{ }^{206} \mathrm{~Pb} /{ }^{204} \mathrm{~Pb}=16.936$, ${ }^{207} \mathrm{~Pb} /{ }^{204} \mathrm{~Pb}=15.489$ and ${ }^{208} \mathrm{~Pb} /{ }^{204} \mathrm{~Pb}=36.701$.

${ }^{b}$ Values from Standish (2006), for interlaboratory comparison. 
Table 4.6: Cpx/Opx partition coefficients.

\begin{tabular}{|c|c|c|c|c|c|c|c|c|c|c|c|c|}
\hline & $\begin{array}{c}\operatorname{Van} 7 \\
85 \\
42\end{array}$ & $\begin{array}{c}\operatorname{Van} 7 \\
85 \\
47\end{array}$ & $\begin{array}{c}\operatorname{Van} 7 \\
85 \\
49\end{array}$ & $\begin{array}{c}\operatorname{Van} 7 \\
96 \\
09 \mathrm{~V}\end{array}$ & $\begin{array}{c}\operatorname{Van} 7 \\
96 \\
19 \mathrm{M}\end{array}$ & $\begin{array}{c}\operatorname{Van} 7 \\
96 \\
21 \mathrm{M}\end{array}$ & $\begin{array}{c}\operatorname{Van} 7 \\
96 \\
28\end{array}$ & $\begin{array}{c}\operatorname{Van} 7 \\
96 \\
38\end{array}$ & $\begin{array}{c}\mathrm{RC} 27-9 \\
6 \\
2 \mathrm{~V}\end{array}$ & Valence & $\begin{array}{c}\mathrm{Cpx} \operatorname{IR}^{a} \\
(\AA)\end{array}$ & $\begin{array}{c}\text { Opx } \operatorname{IR}^{a} \\
(\AA)\end{array}$ \\
\hline $\mathrm{Pb}$ & & & 0.02 & & & 2.73 & 6.34 & & & 2 & 1.29 & 1.19 \\
\hline $\mathrm{Sr}$ & & & 25.80 & 66.38 & 7.13 & 32.81 & 45.39 & 44.88 & 27.43 & 2 & 1.26 & 1.18 \\
\hline $\mathrm{La}$ & & & & 68.39 & 16.79 & 45.78 & 52.60 & & 22.94 & 3 & 1.16 & 1.03 \\
\hline $\mathrm{Ce}$ & & & & 48.43 & 25.03 & 41.34 & 57.72 & 48.02 & 26.05 & 3 & 1.14 & 1.01 \\
\hline $\operatorname{Pr}$ & & & & 43.61 & 31.01 & 36.94 & 67.34 & 44.26 & 30.05 & 3 & 1.13 & 0.99 \\
\hline $\mathrm{Nd}$ & 37.94 & 37.37 & & 29.90 & 23.21 & 31.22 & 39.44 & 37.31 & 21.68 & 3 & 1.11 & 0.98 \\
\hline $\mathrm{Sm}$ & 23.42 & 31.55 & 25.24 & 16.87 & 18.33 & 21.35 & 22.15 & 24.71 & 19.88 & 3 & 1.08 & 0.96 \\
\hline $\mathrm{Eu}$ & 17.33 & 18.18 & 22.13 & 15.96 & 15.87 & 18.70 & 21.64 & 22.20 & 12.94 & 3 & 1.07 & 0.95 \\
\hline Gd & 15.16 & 16.04 & 18.02 & 10.64 & 12.53 & 14.68 & 16.34 & 17.00 & 11.99 & 3 & 1.05 & 0.94 \\
\hline $\mathrm{Th}$ & & & & & & & 23.24 & & & 4 & 1.05 & 0.94 \\
\hline $\mathrm{Tb}$ & 10.66 & 10.70 & 13.53 & 7.73 & 10.27 & 11.73 & 14.19 & 13.59 & 9.54 & 3 & 1.04 & 0.92 \\
\hline Dy & 8.53 & 9.19 & 10.98 & 5.44 & 8.75 & 9.32 & 10.00 & 10.27 & 6.95 & 3 & 1.03 & 0.91 \\
\hline Ho & 6.88 & 7.33 & 9.05 & 4.55 & 7.09 & 8.04 & 8.63 & 8.78 & 5.63 & 3 & 1.02 & 0.90 \\
\hline $\mathrm{Y}$ & 6.61 & 6.67 & 8.16 & 3.50 & 7.42 & 7.72 & 8.08 & 8.06 & 5.07 & 3 & 1.02 & 0.90 \\
\hline $\mathrm{Er}$ & 5.71 & 5.52 & 7.12 & 3.57 & 6.04 & 6.28 & 6.82 & 6.88 & 4.92 & 3 & 1.00 & 0.89 \\
\hline $\mathrm{U}$ & & & & 2.17 & & & 10.03 & & & 4 & 1.00 & 0.89 \\
\hline $\mathrm{Tm}$ & 4.41 & 4.24 & 5.41 & 2.68 & 4.87 & 5.01 & 5.14 & 5.46 & 3.71 & 3 & 0.99 & 0.88 \\
\hline $\mathrm{Yb}$ & 3.69 & 3.47 & 4.43 & 2.30 & 4.12 & 4.14 & 4.63 & 4.57 & 3.07 & 3 & 0.99 & 0.87 \\
\hline $\mathrm{Lu}$ & 2.97 & 2.97 & 3.69 & 1.82 & 3.39 & 3.20 & 3.68 & 3.69 & 2.66 & 3 & 0.98 & 0.86 \\
\hline $\mathrm{Li}$ & 4.15 & 3.32 & 3.74 & 2.66 & 1.07 & 1.81 & 1.82 & 2.65 & 2.32 & 1 & 0.92 & 0.76 \\
\hline $\mathrm{Zr}$ & & 23.47 & & & & & & 7.12 & 4.17 & 4 & 0.72 & 0.72 \\
\hline Hf & 9.91 & 4.87 & 7.07 & & & & & 5.58 & 5.18 & 4 & 0.71 & 0.71 \\
\hline $\mathrm{Nb}$ & 1.43 & 1.22 & & & & & & & 1.98 & 5 & 0.64 & 0.64 \\
\hline
\end{tabular}

\footnotetext{
${ }^{a}$ Ionic radii from Shannon (1976).
} 
Table 4.A1: Olivine major element concentrations (wt \%)

\begin{tabular}{lcccccccccccc}
\hline Sample & $\mathrm{Pts}$ & $\mathrm{SiO}_{2}$ & $\mathrm{TiO}_{2}$ & $\mathrm{Al}_{2} \mathrm{O}_{3}$ & $\mathrm{Cr}_{2} \mathrm{O}_{3}$ & $\mathrm{FeO}$ & $\mathrm{MnO}$ & $\mathrm{MgO}$ & $\mathrm{CaO}$ & $\mathrm{NiO}$ & $\mathrm{Total}$ & $\mathrm{Mg \#}$ \\
\hline Van7-85-27 & 5 & 40.06 & 0.01 & 0.01 & 0.00 & 8.87 & 0.16 & 49.23 & 0.05 & 0.33 & 98.72 & 90.8 \\
Van7-85-30 & 4 & 40.17 & 0.01 & 0.00 & 0.01 & 9.28 & 0.15 & 48.78 & 0.04 & 0.34 & 98.80 & 90.4 \\
Van7-85-42 & 6 & 40.03 & 0.01 & 0.00 & 0.01 & 9.57 & 0.13 & 49.36 & 0.04 & 0.35 & 99.50 & 90.2 \\
Van7-85-47 & 6 & 40.34 & 0.00 & 0.00 & 0.01 & 9.76 & 0.16 & 49.48 & 0.04 & 0.33 & 100.12 & 90.0 \\
Van7-85-49 & 6 & 40.49 & 0.01 & 0.00 & 0.00 & 9.57 & 0.15 & 48.91 & 0.04 & 0.40 & 99.57 & 90.1 \\
Van7-86-27 & 6 & 40.26 & 0.00 & 0.00 & 0.00 & 9.91 & 0.14 & 49.00 & 0.01 & 0.35 & 99.68 & 89.8 \\
Van7-96-09V & 6 & 40.30 & 0.00 & 0.01 & 0.01 & 9.21 & 0.11 & 50.44 & 0.02 & 0.45 & 100.55 & 90.7 \\
Van7-96-16V & 5 & 40.18 & 0.02 & 0.01 & 0.01 & 10.89 & 0.22 & 47.75 & 0.03 & 0.37 & 99.50 & 88.7 \\
Van7-96-19M & 11 & 40.13 & 0.01 & 0.00 & 0.00 & 10.27 & 0.15 & 48.96 & 0.04 & 0.40 & 99.95 & 89.5 \\
Van7-96-19V & 6 & 40.15 & 0.00 & 0.00 & 0.00 & 10.51 & 0.14 & 48.47 & 0.02 & 0.38 & 99.67 & 89.2 \\
Van7-96-21M & 6 & 40.16 & 0.01 & 0.01 & 0.00 & 9.69 & 0.16 & 49.85 & 0.03 & 0.35 & 100.27 & 90.2 \\
Van7-96-21V & 6 & 40.17 & 0.02 & 0.01 & 0.00 & 9.76 & 0.16 & 50.03 & 0.02 & 0.34 & 100.51 & 90.1 \\
Van7-96-25 & 6 & 40.09 & 0.00 & 0.01 & 0.00 & 10.10 & 0.12 & 48.87 & 0.06 & 0.39 & 99.64 & 89.6 \\
Van7-96-28 & 6 & 40.42 & 0.00 & 0.01 & 0.00 & 9.18 & 0.13 & 49.33 & 0.03 & 0.36 & 99.47 & 90.5 \\
Van7-96-35 & 6 & 40.62 & 0.00 & 0.01 & 0.00 & 8.66 & 0.11 & 50.34 & 0.03 & 0.43 & 100.19 & 91.2 \\
Van7-96-38 & 6 & 40.41 & 0.01 & 0.02 & 0.01 & 9.80 & 0.15 & 49.81 & 0.01 & 0.35 & 100.55 & 90.1 \\
PS86-6-38 & 6 & 40.50 & 0.01 & 0.01 & 0.00 & 9.95 & 0.11 & 48.88 & 0.02 & 0.41 & 99.89 & 89.8 \\
RC27-9-6-2M & 76 & 40.42 & 0.00 & 0.00 & 0.02 & 9.64 & 0.13 & 49.85 & 0.02 & 0.34 & 100.41 & 90.2 \\
RC27-9-6-2V & 20 & 40.30 & 0.00 & 0.00 & 0.01 & 9.67 & 0.14 & 49.40 & 0.03 & 0.33 & 99.88 & 90.1 \\
\hline
\end{tabular}


Table 4.A2: Pyroxene major element concentrations (wt \%)

\begin{tabular}{|c|c|c|c|c|c|c|c|c|c|c|c|c|c|}
\hline Sample & Pts & $\mathrm{SiO}_{2}$ & $\mathrm{TiO}_{2}$ & $\mathrm{Al}_{2} \mathrm{O}_{3}$ & $\mathrm{Cr}_{2} \mathrm{O}_{3}$ & $\mathrm{FeO}$ & $\mathrm{MnO}$ & $\mathrm{MgO}$ & $\mathrm{CaO}$ & $\mathrm{Na}_{2} \mathrm{O}$ & Total & Mg\# & $\overline{\mathrm{Cr} \#}$ \\
\hline \multicolumn{14}{|c|}{ Orthopyroxene } \\
\hline Van7-85-27 & 28 & 55.02 & 0.09 & 3.99 & 0.66 & 5.74 & 0.11 & 31.81 & 1.80 & 0.04 & 100.74 & 90.8 & 10.0 \\
\hline Van7-85-30 & 17 & 55.42 & 0.06 & 3.91 & 0.51 & 6.11 & 0.12 & 32.11 & 1.56 & 0.02 & 101.33 & 90.4 & 8.0 \\
\hline Van7-85-42 & 30 & 55.08 & 0.08 & 5.20 & 0.72 & 6.23 & 0.12 & 31.50 & 2.03 & 0.03 & 102.45 & 90.0 & 8.5 \\
\hline Van7-85-47 & 21 & 54.76 & 0.10 & 5.24 & 0.76 & 6.18 & 0.14 & 31.01 & 2.55 & 0.05 & 107.02 & 89.9 & 8.9 \\
\hline $\operatorname{Van} 7-85-49$ & 16 & 54.59 & 0.04 & 4.48 & 0.64 & 6.17 & 0.10 & 31.99 & 1.72 & 0.01 & 101.91 & 90.2 & 8.8 \\
\hline Van7-86-27 & 17 & 54.85 & 0.08 & 4.61 & 0.69 & 6.16 & 0.13 & 31.64 & 1.88 & 0.05 & 106.68 & 90.1 & 9.1 \\
\hline Van7-96-09V & 18 & 54.17 & 0.15 & 4.69 & 0.28 & 6.49 & 0.18 & 31.11 & 1.69 & 0.02 & 102.32 & 89.5 & 3.8 \\
\hline Van7-96-16V & 21 & 54.45 & 0.23 & 5.03 & 0.57 & 6.94 & 0.15 & 31.79 & 1.28 & 0.04 & 101.45 & 89.1 & 7.0 \\
\hline Van7-96-19M & 19 & 54.31 & 0.21 & 4.18 & & 6.49 & 0.11 & 32.88 & 1.40 & 0.00 & 101.37 & 90.0 & \\
\hline Van7-96-19V & 9 & 55.42 & 0.21 & 2.74 & & 6.95 & 0.11 & 32.92 & 1.32 & 0.00 & 101.06 & 89.4 & \\
\hline Van7-96-21M & 27 & 53.92 & 0.15 & 6.02 & 0.62 & 6.42 & 0.14 & 31.30 & 1.14 & 0.04 & 101.16 & 89.7 & 6.4 \\
\hline Van7-96-21V & 35 & 55.09 & 0.19 & 3.97 & 0.54 & 6.25 & 0.14 & 31.99 & 1.25 & 0.03 & 101.89 & 90.1 & 8.3 \\
\hline Van7-96-25 & 17 & 53.46 & 0.11 & 5.58 & & 6.68 & 0.11 & 31.50 & 1.48 & 0.04 & 100.11 & 89.4 & \\
\hline Van7-96-28 & 14 & 53.75 & 0.14 & 5.38 & & 5.99 & 0.10 & 31.38 & 2.44 & 0.04 & 106.34 & 90.3 & \\
\hline Van7-96-35 & 20 & 55.21 & 0.10 & 3.91 & 0.92 & 5.55 & 0.12 & 32.02 & 1.59 & 0.08 & 100.45 & 91.1 & 13.7 \\
\hline Van7-96-38 & 44 & 53.64 & 0.14 & 6.36 & 0.57 & 6.45 & 0.13 & 30.49 & 1.36 & 0.06 & 100.61 & 89.4 & 5.6 \\
\hline PS86-6-38 & 16 & 53.78 & 0.14 & 6.12 & 0.61 & 6.33 & 0.15 & 30.71 & 1.76 & 0.08 & 102.01 & 89.6 & 6.3 \\
\hline RC27-9-6-2M & 79 & 55.67 & 0.08 & 3.16 & 0.76 & 6.30 & 0.11 & 32.75 & 1.48 & 0.02 & 100.33 & 90.3 & 13.9 \\
\hline $\mathrm{RC} 27-9-6-2 \mathrm{~V}$ & 10 & 56.10 & 0.09 & 2.29 & 0.62 & 6.54 & 0.18 & 33.38 & 0.81 & 0.02 & 100.03 & 90.1 & 15.4 \\
\hline \multicolumn{14}{|l|}{ Clinopyroxene } \\
\hline $\operatorname{Van} 7-85-27$ & 33 & 51.64 & 0.23 & 5.38 & 1.22 & 2.83 & 0.09 & 16.63 & 20.84 & 0.54 & 99.40 & 91.3 & 13.2 \\
\hline Van7-85-30 & 54 & 51.01 & 0.22 & 6.22 & 1.09 & 3.01 & 0.09 & 16.30 & 21.58 & 0.37 & 99.89 & 90.6 & 10.5 \\
\hline Van7-85-42 & 31 & 51.65 & 0.22 & 6.28 & 1.08 & 3.27 & 0.10 & 17.06 & 21.09 & 0.36 & 101.11 & 90.3 & 10.4 \\
\hline Van7-85-47 & 46 & 51.54 & 0.22 & 6.31 & 1.07 & 3.21 & 0.10 & 17.08 & 20.88 & 0.37 & 100.78 & 90.5 & 10.2 \\
\hline Van7-85-49 & 29 & 51.34 & 0.17 & 6.08 & 1.08 & 3.23 & 0.07 & 17.48 & 20.27 & 0.29 & 100.02 & 90.6 & 10.7 \\
\hline Van7-86-27 & 62 & 51.64 & 0.24 & 5.80 & 1.03 & 2.98 & 0.09 & 16.84 & 21.59 & 0.29 & 100.51 & 91.0 & 10.6 \\
\hline Van7-96-09V & 72 & 50.51 & 0.44 & 6.75 & 0.60 & 3.41 & 0.12 & 16.46 & 20.51 & 0.51 & 99.33 & 89.6 & 5.6 \\
\hline Van7-96-16V & 90 & 51.03 & 0.74 & 6.50 & 0.51 & 3.43 & 0.13 & 16.44 & 21.22 & 0.46 & 100.45 & 89.5 & 5.0 \\
\hline Van7-96-19M & 66 & 50.84 & 0.63 & 6.26 & 1.34 & 2.92 & 0.08 & 16.52 & 21.40 & 0.62 & 100.61 & 91.0 & 12.5 \\
\hline Van7-96-19V & 63 & 51.16 & 0.58 & 6.02 & 1.26 & 3.02 & 0.08 & 16.11 & 21.35 & 0.56 & 100.14 & 90.5 & 12.3 \\
\hline Van7-96-21M & 39 & 50.37 & 0.55 & 7.58 & 0.97 & 3.19 & 0.09 & 15.74 & 20.96 & 0.73 & 100.19 & 89.8 & 7.9 \\
\hline Van7-96-21V & 27 & 50.70 & 0.49 & 7.70 & 0.96 & 3.57 & 0.10 & 16.77 & 19.01 & 0.84 & 100.16 & 89.3 & 7.8 \\
\hline Van7-96-25 & 53 & 51.08 & 0.36 & 7.06 & 1.05 & 3.35 & 0.07 & 14.79 & 20.18 & 1.31 & 99.24 & 88.7 & 9.1 \\
\hline Van7-96-28 & 55 & 51.22 & 0.35 & 6.75 & 1.32 & 3.21 & 0.07 & 15.97 & 19.96 & 1.05 & 99.89 & 89.9 & 11.6 \\
\hline Van7-96-35 & 55 & 52.17 & 0.32 & 5.33 & 1.69 & 2.58 & 0.08 & 16.02 & 20.27 & 1.38 & 99.85 & 91.7 & 17.6 \\
\hline Van7-96-38 & 44 & 51.05 & 0.45 & 7.83 & 0.87 & 3.56 & 0.09 & 15.98 & 18.68 & 1.20 & 99.72 & 88.9 & 7.0 \\
\hline PS86-6-38 & 33 & 51.20 & 0.41 & 7.23 & 0.93 & 3.12 & 0.12 & 15.37 & 20.96 & 1.09 & 100.43 & 89.8 & 7.9 \\
\hline $\mathrm{RC} 27-9-6-2 \mathrm{M}$ & 197 & 52.27 & 0.17 & 4.76 & 1.50 & 3.13 & 0.09 & 18.21 & 19.70 & 0.63 & 100.46 & 91.2 & 17.5 \\
\hline $\mathrm{RC} 27-9-6-2 \mathrm{~V}$ & 113 & 51.98 & 0.23 & 5.08 & 1.59 & 3.28 & 0.11 & 17.96 & 19.66 & 0.61 & 100.50 & 90.7 & 17.3 \\
\hline
\end{tabular}


Table 4.A3: Spinel major element concentrations (wt \%)

\begin{tabular}{|c|c|c|c|c|c|c|c|c|c|c|c|c|c|}
\hline Sample & Pts & $\mathrm{TiO}_{2}$ & $\mathrm{Al}_{2} \mathrm{O}_{3}$ & $\mathrm{Cr}_{2} \mathrm{O}_{3}$ & $\mathrm{Fe}_{2} \mathrm{O}_{3}$ & $\mathrm{FeO}$ & $\mathrm{MnO}$ & $\mathrm{MgO}$ & $\mathrm{CaO}$ & $\mathrm{NiO}$ & $\mathrm{ZnO}$ & Total & $\mathrm{Mg \#}$ \\
\hline $\operatorname{Van} 7-85-27$ & 6 & 0.01 & 47.18 & 21.50 & 0.51 & 12.28 & 0.10 & 17.44 & 0.00 & 0.18 & 0.04 & 99.23 & 71.7 \\
\hline Van7-85-30 & 6 & 0.06 & 53.52 & 14.56 & 0.43 & 12.18 & 0.08 & 18.16 & 0.01 & 0.27 & 0.17 & 99.44 & 72.6 \\
\hline $\operatorname{Van} 7-85-42$ & 6 & 0.06 & 53.70 & 15.15 & 0.72 & 11.69 & 0.11 & 18.70 & 0.00 & 0.30 & 0.21 & 100.65 & 74.0 \\
\hline $\operatorname{Van} 7-85-47$ & 6 & 0.07 & 52.47 & 16.48 & 0.94 & 11.69 & 0.09 & 18.65 & 0.01 & 0.29 & 0.18 & 100.86 & 74.0 \\
\hline Van7-85-49 & 6 & 0.03 & 54.14 & 14.19 & 0.63 & 11.49 & 0.12 & 18.61 & 0.00 & 0.37 & 0.16 & 99.76 & 74.3 \\
\hline Van7-86-27 & 6 & 0.00 & 51.80 & 16.87 & 0.00 & 12.69 & 0.08 & 17.75 & 0.00 & 0.12 & 0.00 & 99.30 & 71.4 \\
\hline Van7-96-09V & 6 & 0.37 & 36.73 & 28.76 & 4.02 & 13.62 & 0.14 & 15.76 & 0.02 & 0.21 & 0.21 & 99.87 & 67.3 \\
\hline Van7-96-16V & 6 & 0.21 & 58.19 & 9.73 & 0.78 & 11.04 & 0.16 & 19.50 & 0.00 & 0.43 & 0.12 & 100.17 & 75.9 \\
\hline Van7-96-19M & 5 & 0.31 & 39.70 & 27.66 & 2.01 & 13.95 & 0.20 & 15.84 & 0.00 & 0.24 & 0.01 & 99.99 & 66.9 \\
\hline Van7-96-19V & 6 & 0.53 & 37.78 & 29.47 & 1.84 & 15.43 & 0.22 & 14.90 & 0.00 & 0.22 & 0.02 & 100.46 & 63.2 \\
\hline Van7-96-21M & 5 & 0.35 & 43.08 & 23.20 & 2.40 & 13.08 & 0.16 & 16.62 & 0.02 & 0.25 & 0.33 & 99.52 & 69.4 \\
\hline Van7-96-21V & 12 & 0.29 & 51.40 & 15.26 & 2.45 & 10.79 & 0.13 & 19.01 & 0.01 & 0.31 & 0.21 & 99.88 & 75.8 \\
\hline Van7-96-25 & 5 & 0.07 & 53.35 & 12.68 & 2.81 & 12.28 & 0.14 & 18.13 & 0.00 & 0.38 & 0.00 & 99.89 & 72.5 \\
\hline Van7-96-28 & 5 & 0.25 & 45.92 & 21.56 & 1.37 & 13.15 & 0.16 & 16.97 & 0.01 & 0.25 & 0.02 & 99.76 & 69.7 \\
\hline $\operatorname{Van} 7-96-35$ & 5 & 0.18 & 40.15 & 28.60 & 1.56 & 12.51 & 0.18 & 16.82 & 0.00 & 0.16 & 0.00 & 100.16 & 70.5 \\
\hline Van7-96-38 & 6 & 0.28 & 56.04 & 10.85 & 1.58 & 11.20 & 0.08 & 19.20 & 0.01 & 0.33 & 0.18 & 99.74 & 75.3 \\
\hline PS86-6-38 & 3 & 0.05 & 57.31 & 10.84 & 0.58 & 11.15 & 0.10 & 19.23 & 0.00 & 0.33 & 0.00 & 99.58 & 75.4 \\
\hline RC27-9-6-2M & 50 & 0.20 & 38.46 & 28.82 & 3.63 & 13.55 & 0.27 & 15.99 & 0.07 & 0.31 & & 101.31 & 67.8 \\
\hline $\mathrm{RC} 27-9-6-2 \mathrm{~V}$ & 16 & 0.12 & 37.04 & 30.09 & 3.30 & 14.02 & 0.21 & 15.63 & 0.03 & 0.20 & & 100.73 & 66.5 \\
\hline
\end{tabular}

Table 4.A4: Plagioclase major element concentrations (wt \%)

\begin{tabular}{lcccccccccc}
\hline Sample & $\mathrm{Pts}$ & $\mathrm{SiO}_{2}$ & $\mathrm{Al}_{2} \mathrm{O}_{3}$ & $\mathrm{FeO}$ & $\mathrm{MgO}$ & $\mathrm{CaO}$ & $\mathrm{Na}_{2} \mathrm{O}$ & $\mathrm{K}_{2} \mathrm{O}$ & Total & An \\
\hline Van7-96-09V & 11 & 47.95 & 33.34 & 0.12 & 0.01 & 15.78 & 2.28 & 0.00 & 99.48 & 79.2 \\
Van7-96-16V & 12 & 46.40 & 34.88 & 0.14 & 0.01 & 17.71 & 1.33 & 0.01 & 100.47 & 88.0 \\
Van7-96-19M & 5 & 51.23 & 30.37 & 0.12 & 0.37 & 12.87 & 4.24 & 0.00 & 99.20 & 62.6 \\
Van7-96-19V & 5 & 51.86 & 30.27 & 0.11 & 0.00 & 12.53 & 4.57 & 0.01 & 99.34 & 60.2 \\
Van7-96-21V & 15 & 51.53 & 31.40 & 0.10 & 0.01 & 13.24 & 3.77 & 0.00 & 100.06 & 66.0 \\
RC27-9-6-2M & 2 & 54.15 & 29.79 & 0.14 & 0.03 & 11.87 & 5.03 & 0.09 & 101.10 & 56.3 \\
RC27-9-6-2V & 6 & 49.8 & 32.60 & 0.12 & 0.05 & 15.24 & 3.00 & 0.00 & 100.81 & 73.7 \\
\hline
\end{tabular}




\title{
Chapter 5
}

\section{Variations in Abyssal Peridotite Composition: Implications for Oceanic Upper Mantle Composition and Processes}

\begin{abstract}
Abyssal peridotites are typically assumed to be the residues of near-fractional melting of a uniform initial source composition. We present new data on 67 veined and unveined peridotites to assess the extent to which abyssal peridotite compositions conform to this model. We find that peridotite Cpx trace element concentrations vary by 2-4 orders of magnitude at length-scales ranging from the grain-scale to the ridge segment-scale. We assess estimates of mantle degree of melting based on Cpx trace elements and spinel Cr\#. We demonstrate that variations in predicted degree of melting occur on too small a scale to be the result of variation in mantle thermal structure. Instead, we find that peridotite compositions reflect melt-rock reaction and a heterogeneous initial source composition. Melt-rock reaction during peridotite melting is demonstrated to be an important process during the creation of oceanic lithosphere. Via subduction, this provides a mechanism for the creation of a heterogeneous source mantle. The magnitude of chemical variations in abyssal peridotites is found to be scale independent.
\end{abstract}




\subsection{Introduction}

The composition of the upper mantle is commonly assumed to be homogeneous when using MORB (Mid-Ocean Ridge Basalt) compositions to determine the degree of melting and variation in mantle potential temperature of a ridge segment. This composition is represented by DMM (Depleted MORB Mantle), a model average composition, most recently derived from the average global isotopic composition of MORB and the depletion trend among abyssal peridotites (Workman and Hart, 2005). This composition produces a good fit to parental normal MORB composition - as predicted from global MORB compositions (Su and Langmuir, 2003) - by 6\% aggregated fractional melting. In this chapter, we use abyssal peridotites to assess the extent to which mantle composition deviates from the predicted average composition and we assess the role of melt-rock reaction in modifying mantle composition.

Abyssal peridotites are samples of the oceanic upper mantle and are thought to be the depleted residues of MORB formation. The pioneering work by Johnson et al. (1990) concluded that trace element variations observed in abyssal peridotite $\mathrm{Cpx}$ (clinopyroxene) were produced by near-fractional melting of a uniform initial upper mantle composition. This study has become a benchmark for our understanding of melting processes beneath ocean ridges. Two important assumptions were made by Johnson et al. (1990): (1) the mantle has a uniform initial composition and (2) all chemical variations are due to melting. Subsequent studies have attempted to use abyssal peridotites to constrain degrees and/or depths of melting (e.g., Johnson et al., 1990; Bonatti et al., 1993; Hellebrand et al., 2001), based on these assumptions. However, some studies of MORBs and abyssal peridotites have questioned these assumptions. For example, Elthon (1992) argued that major element variations in abyssal peridotites are better fit by a model of mixing between depleted peridotites and basaltic melts, rather than variable degrees of melt extraction. Niu et al. (1997) concluded that the $\mathrm{FeO}-\mathrm{MgO}$ variations in abyssal peridotites show strong effects of olivine 
addition, attributable to precipitation of olivine as a result of melt-rock reaction during melt migration.

Large isotopic heterogeneities have been observed among basalts from individual dredges and individual ridge segments (e.g., Dupré and Allègre, 1983; Hamelin et al., 1985; Dosso et al., 1999), suggesting the existence of long-term chemical (parent/daughter ratio) heterogeneities in the MORB source upper mantle. In Chapter 4, we documented isotopic heterogeneities among peridotites from the Southwest Indian Ridge (SWIR) and argued that the upper mantle beneath the SWIR was heterogeneously depleted prior to upwelling at the ridge. Evidence for large chemical heterogeneities in the form of pre-melting depletions have also been suggested for the easternmost end of the SWIR. In this region, ultra-slow spreading rates and thin crust imply a low degree of melting (Cannat et al., 1999; Sauter et al., 2004), yet basalt compositions indicate a depleted harzburgitic source (Meyzen et al., 2003 ) and spatially associated peridotites are harzburgites (Seyler et al., 2004).

Available data for abyssal peridotites obtained from all major mid-ocean ridges (Fig. 5.1) provide a global context for the evaluation of geochemical variations. Fig. 5.2 illustrates the variations of several peridotite indicators of melt extraction, as a function of spreading rate. Each panel has model reference trends for residues of melt extraction from DMM (Workman and Hart, 2005), based on the predicted maximum degree of melting as a function of spreading rate, including the effect of conductive cooling on ridge thermal structure following the method of Bown and White (1994). The variation in Yb was calculated using the non-modal fractional melting formulation (Johnson et al., 1990) with melting reactions from Kinzler (1997) and mineral/melt partition coefficients compiled by Kelemen et al. (2003). Variation in modal Cpx was calculated using the lever-rule to predict changes in phase proportions during melting. The variation of spinel $\mathrm{Cr} \#$ with degree of melting was predicted from the empirical correlation of spinel Cr\# with heavy rare earth elements (HREE) in Cpx (Hellebrand et al., 2001). 
Two features are evident from Fig. 5.2: first, the amount of variation is greater at slow and ultra-slow spreading rates than at fast spreading rates. Second, the most depleted peridotite compositions - indicated by low modal $\mathrm{Cpx}$, low $\mathrm{Yb}_{N}$ in $\mathrm{Cpx}$ and high spinel $\mathrm{Cr} \#$ - occur at all ridges, independent of spreading rate. These features are contrary to predictions derived from prevalent views of upper mantle composition and melting processes beneath mid-ocean ridges. Instead, these features suggest that (1) parts of the upper mantle have previously been depleted, as discussed in Chapter 4, and (2) large chemical variations observed at slow to ultra-slow spreading ridges involve melt-rock interaction mechanisms which have not yet been considered in detail in the context of abyssal peridotites. A comprehensive abyssal peridotite trace element dataset at various sampling length-scales needs to be established, so that processes operating beneath ridges can be more critically examined and mechanisms responsible for creating chemical heterogeneities in abyssal peridotites can be quantitatively understood.

This chapter presents ion probe Cpx trace element abundance data obtained from 67 veined and unveined peridotite samples from a ridge segment and a fracture zone on the SWIR. This dataset includes a detailed evaluation of sample-scale and dredge-scale variations in peridotite compositions, to establish a database for evaluating the magnitude of local-scale chemical variations. We emphasize the importance of any chemical variations at length-scales less than individual dredges, as peridotites at these length-scales would have experienced the same temperature regime during mantle upwelling and theoretically should have undergone the same degree of melting. Any chemical variations at the localscale must be due to either initial (pre-melting) heterogeneities or melt-rock reaction at the ridge. The data from this study, combined with the global peridotite dataset, are used to assess the influence of melt-rock reaction and initial chemical heterogeneities of the upper mantle on the composition of abyssal peridotites exposed at mid-ocean ridges. 


\subsection{Methods}

The SWIR Oblique and Orthogonal Segments $\left(9^{\circ}-25^{\circ} \mathrm{E}\right)$ and the Atlantis II Fracture Zone are the focus areas for this study. Both areas have been extensively sampled, as shown in Fig. 5.3, and peridotites with a range of characteristics were recovered. For the $9^{\circ}-25^{\circ}$ E region, 5 Oblique Segment dredges, 2 Orthogonal Segment dredges, and 1 dredge from the Shaka Fracture Zone were analyzed. From Atlantis II Fracture Zone, 1 dredge and 1 dive were analyzed from the ridge-transform intersection (RTI) and 1 dredge and 5 dives from Atlantis Bank. Both locations on Atlantis II are uplifted massifs of lower crust and upper mantle, often termed oceanic core complexes (Dick et al., 1991; Baines et al., 2003).

In total, 67 samples were analyzed, of which 47 are unveined peridotites, 11 are veined peridotites, 2 are veined dunites and 7 are various pyroxenites varieties. Dredge and dive locations, sample descriptions and modal mineralogy are presented in Tables 5.2 and 5.3 . Modes were determined by point counting on a $1 \mathrm{~mm}$ grid, with a minimum of 1700 grains, except veins, for which sample material was limited.

Major element compositions of all primary phases were determined in situ on polished thin sections by wavelength dispersive spectroscopy using the JEOL JXA-733 Superprobes at the Massachusetts Institute of Technology (Tables 5.4-5.9]. The electron microprobes were operated at $15 \mathrm{kV}$ accelerating potential with a $10 \mathrm{nA}$ beam current and calibrated using a standard set of silicate minerals. Olivine, spinel, plagioclase and additional minor phases were analyzed using a focussed beam, with 6 points analyzed per grain. For pyroxenes, all porphyroclasts in abyssal peridotites exhibit exsolution of a second pyroxene phase, due to the relatively slow exhumation rate of mantle upwelling that results in phase re-equilibration during cooling. To average out the effects of exsolution and thus recover the high temperature mineral composition, pyroxenes were analyzed using a beam defocussed to a spot size of $10 \mu \mathrm{m}$ and line transects of $\geq 10$ points with $10 \mu \mathrm{m}$ steps. Data were reduced using modified matrix correction factors (Bence and Albee, 1968; Albee and 
Ray, 1970). Analyses were discarded if their totals were $<98.5 \mathrm{wt} \%$ or $>101.5 \mathrm{wt} \%$, or if their stoichiometry varied by $>1.5 \%$. Elements occurring at $>10 \mathrm{wt} \%$ levels have reproducibilities within $2 \%$, elements at $<10 \mathrm{wt} \%$ levels have reproducibilities within $5 \%$ and elements at $<1 \mathrm{wt} \%$ level have reproducibilities within $30 \%$, based on repeat analyses of a basaltic glass by Gaetani and Grove (1998).

Abundances of $\mathrm{Na}, \mathrm{Ti}, \mathrm{Cr}, \mathrm{Sr}, \mathrm{Y}, \mathrm{Zr}$ (referred to collectively as TE) and REE (La, Ce, $\mathrm{Nd}, \mathrm{Sm}, \mathrm{Eu}, \mathrm{Dy}, \mathrm{Er}, \mathrm{Yb}$ ) were determined using the Cameca IMS-3f at the Woods Hole Oceanographic Institution Northeast National Ion Microprobe Facility (Tables 5.10,5.13). Samples were ionized using a primary beam of $\mathrm{O}^{-}$with an accelerating voltage of -8.30 $\mathrm{kV}$ and a current of 6-7 $\mathrm{nA}$. The beam was focussed to a $\sim 10 \mu \mathrm{m}$ spot diameter for REEs and $\mathrm{a} \sim 4 \mu \mathrm{m}$ spot for TE. The energy filtering technique of Shimizu et al. (1978) was used to suppress molecular ion interferences, with a high voltage offset of $60 \mathrm{~V}$ for REE and 90 $\mathrm{V}$ for TE.

Working curves, which relate secondary ion intensity to concentration, were determined using Cpx from KH1 (Kilbourne Hole peridotite, Irving and Frey, 1984) as the REE standard and basalt glass KL2G (Kilauea tholeiite, Jochum et al., 2000) as the TE standard. Standards were typically measured 2 or more times at the start of a session and occasionally at the middle or end of a session. The average value of all standard analyses for a session were used to calculate session-specific working curves, with the deviation among repeat measurements providing a estimate of analytical reproducibility (Tables 5.14 and 5.15).

Data were collected in 5 count cycles with count times of $30 \mathrm{~s}$ for REE and 5-20 s for TE. For REE, ${ }^{30} \mathrm{Si}$ was measured at the start and end of each analysis, with the time interpolated average used to calculate REE/Si ratios, for determination of concentrations from the working curves. For trace elements, ${ }^{28} \mathrm{Si}$ was measured during each cycle, with the average value after all cycles used to determine TE concentrations. Traditionally, within-cycle 
ratios of REE/Dy and TE/Si are used to account for temporal variability in peak intensities (e.g., Johnson et al., 1990; Johnson and Dick, 1992). Due to random background noise that produced occasional extreme high counts, the ratio scheme was abandoned. However, the error introduced by temporal variability in peak intensity is insignificant compared to primary beam instability, which cannot be monitored on the IMS-3f.

To remove the effects of random background noise, the 5-cycle raw count data were averaged by element. Low count rates among REEs are best treated statistically by a Poisson distribution, with the standard deviation given by $\sqrt{\bar{x}}$, where $\bar{x}$ is the count average. Any individual REE count greater than $3 \sqrt{\bar{x}}$ away from the median count value was discarded. After recalculating $\bar{x}$, any count more than $2 \sqrt{\bar{x}}$ from the average count value was discarded. For TE, which have higher count rates, any count greater than 2 standard deviations from the median count value was discarded. After a final re-averaging of counts, $\mathrm{REE}$ and TE ratios to Si were calculated and concentrations derived from working curves.

\subsection{Ion probe data quality}

Trace element analyses in abyssal peridotites are difficult due to their low concentrations, particularly for REE. We assess data quality from (1) repeated standard measurements, (2) measurements of an additional standard, (3) sample count statistics, (4) sample duplicate analyses, (5) REE pattern shape, and (6) comparison to ICP-MS and TIMS bulk mineral separate analyses. In addition, we compare ion probe data to electron probe data for $\mathrm{Na}_{2} \mathrm{O}$, $\mathrm{TiO}_{2}$ and $\mathrm{Cr}_{2} \mathrm{O}_{3}$. Overall, the smoothness of REE pattern shape and the orders of magnitude variation in trace element concentrations means that ion probe data are significant, despite their relatively large errors.

Variations in standard concentrations from repeat measurements provide an estimate of analytical reproducibility. In Tables 5.14 and 5.15, we calculate the average $\%$ deviation of standard measurements for each analytical session. The variation for REEs is $6-10 \%$ and 
for TEs is 3-5\%. We also measured REEs in an independent standard, KLB1 (lherzolite, Takahashi, 1986), with a reproducibility of 9\%-17\% among 21 analyses over 15 months (Table 5.10.

Analytical error can also be estimated from the count statistics of each analysis and by comparison of duplicate analyses (Table 5.10). The statistical counting error for each analysis is the square root of the total counts for an element. The average \% error in concentration based on the counting error ranges from 0.2-21\% (Table 5.10), with LREE having the largest errors. The error based on the average difference between duplicate analyses is also given in Table 5.10 and shown on a comparison plot in Fig. 5.4. In general, samples plot on a 1:1 correspondence line over 3-4 orders of magnitude, with an average deviation for Cpx ranging from $7 \%$ to $37 \%$. While errors are relatively large for REE, a final check on data quality is provided by the shape of the REE pattern, which should vary smoothly, with the exception of Eu due to its behavior as both a $2+$ and $3+$ cation. Analyses with irregular patterns that were not reproduced by repeat analysis were discarded and are not reported here.

In Fig. 5.5, ion probe data for 16 samples are compared to TIMS and ICP-MS data (from Chapter 4) for mineral separates. The ion probe data have been averaged by sample, or by vein and matrix occurrence, and are shown with a horizontal bar representing the range of measured values. In general, Cpx data plot on a 1:1 line, except at low concentrations for $\mathrm{Sr}, \mathrm{Zr}$ and $\mathrm{Ce} / \mathrm{Yb}$. Opx data have more scatter, but only one ion probe analysis is available for each sample where Opx was measured as a mineral separate. An accurate comparison to bulk mineral separate data cannot be made, especially if - as suggested in Chapter 4 - some Opx are zoned. At low concentrations, the scatter in the comparison of ion probe in situ data to bulk mineral separate data probably indicates the minimum ion probe detection limit for these elements. The scatter is not the result of the repartitioning of elements following $\mathrm{Cpx} / \mathrm{Opx}$ exsolution, as such a process would result in a systematic 
offset of ion probe data from TIMS and ICP-MS data at all concentration levels. As we demonstrated in Chapter 4, Cpx have $\geqslant 90 \%$ of the Cpx-Opx trace element budget and the effect of exsolution on trace element concentrations is relatively minor.

Elements measured by both ion probe and electron probe are compared in Fig. 5.6. $\mathrm{Na}_{2} \mathrm{O}$ in abyssal peridotite phases has not previously been reported by ion probe. In this study, we used tholeiitic basalt KL2G as a standard (Jochum et al., 2000) and 5 s count times. In general, $\mathrm{Na}_{2} \mathrm{O}, \mathrm{TiO}_{2}$ and $\mathrm{Cr}_{2} \mathrm{O}_{3}$ all show reasonable agreement between the two analytical methods. Only for plagioclase, where $\mathrm{Na}_{2} \mathrm{O}$ is present at higher concentrations, do the data fall consistently off the 1:1 line towards higher electron probe concentrations. We suggest that because the KL2G standard has 2.27 wt $\% \mathrm{Na}_{2} \mathrm{O}$, whereas $\mathrm{Na}_{2} \mathrm{O}$ in plagioclase extends to $6 \mathrm{wt} \%$, the ion probe data are unreliable at concentrations $\gtrsim 2 \mathrm{wt} \%$.

The electron probe analyses in Fig. 5.6 are the average of multiple points located near an individual ion probe analysis. The standard deviation of electron probe analyses, shown in Fig. 5.6, is considerably larger than the estimated error for ion probe analyses. In particular, Cpx have large standard deviations when measured by electron probe, due to the inclusion of exsolution lamellae in the analysis. In addition, long count times were not used during electron probe analyses, resulting in limited precision at the $<1 \mathrm{wt} \%$ level. Hence, we conclude that ion probe data provide a better estimate of $\mathrm{Na}, \mathrm{Ti}$ and $\mathrm{Cr}$ concentrations, with the exception of $\mathrm{Na}$ in plagioclase.

\subsection{Results}

Mineral major element data for the peridotites are presented in Tables 5.4 5.9 and trace element data in Tables $5.10,5.13$. Included in the tables are additional data for samples RC27-9-6-2 and RC27-9-6-5 from Lee (1997), with ion probe trace element data reprocessed following the above method. The major element variations among spinel and Cpx are presented in Figs. 5.7 5.8 and 5.9. In Figs. 5.10 and 5.11, we plot the trace element 
variations in individual Cpx by location. In Appendix 5.A, each individual REE analysis is plotted by sample.

The peridotites in this study can be classified into four general groups - "typical" residual peridotites, gabbro veined and plagioclase peridotites (abbreviated to gabbro/plag peridotites), pyroxenite veined peridotites and cryptically metasomatized peridotites (Table 5.3. Of the samples analyzed, 41 are classified as residual peridotites, due to the absence of veins and trace element compositions in the abyssal peridotite range of Johnson et al. (1990). Plagioclase, if present, does not account for $>.05 \%$ of the modal mineralogy and is assumed to be the result of spinel plus two pyroxene breakdown to plagioclase plus olivine. The gabbro/plag peridotite group consists of 4 peridotites with gabbro veins, 1 dunite with a central gabbro vein and surrounding harzburgite, and 3 peridotites with significant amounts of matrix plagioclase. The group of 15 pyroxenite peridotites consists of 7 peridotites with pyroxenite veins, 1 peridotite with a clinopyroxenite vein, 6 pyroxenite veins and 1 orthopyroxenite vein.

The three cryptically metasomatized peridotites have no veins and look like other residual peridotites. However, they are classified as a separate group on the basis of 1-3 orders of magnitude variation in trace element concentrations at the thin section and grain scales (Fig. 5.12). These variations are in contrast to the generally uniform composition of $\mathrm{Cpx}$ cores, rims and interstitial ( $<1 \mathrm{~mm}$ diameter) grains in the residual peridotites, as shown in Fig. 5.14 The variations in trace element concentrations in the cryptic peridotites is not limited to interstitial grains, as shown in the photomicrograph of a zoned Cpx porphyroclast in Fig. 5.15 .

Spinel compositions for the four peridotite lithologies are shown in Figs. 5.7 and 5.8 . Spinels in Fig. 5.7 plot on the general melting trend of $\mathrm{Cr} \#=\mathrm{Cr} /(\mathrm{Cr}+\mathrm{Al})$ increasing from $\sim 10 \%$ to $\sim 60 \%$ during melting, while $\mathrm{Mg} \#=\mathrm{Mg} /(\mathrm{Mg}+\mathrm{Fe})$ decreases over a more limited range of $\sim 80 \%-60 \%$. The decrease in spinel $\mathrm{Mg} \#$ reflects re-equilibration of $\mathrm{Mg}^{2+}$ and 
$\mathrm{Fe}^{2+}$ between olivine and spinel with decreasing temperature during upwelling (Dick and Bullen, 1984). Samples which plot off the trend towards lower Mg\#'s, such as the gabbro/plag peridotites, have been refertilized by differentiated melts. $\mathrm{TiO}_{2}$ is incompatible in spinel, so values $>0.2 \mathrm{wt} \%$ (the approximate composition of spinel in DMM; Workman and Hart, 2005) indicate melt refertilization of the peridotite (Dick and Bullen, 1984). In Fig. 5.8, gabbro/plag peridotites, dunites and some pyroxenites have high $\mathrm{TiO}_{2}$ concentrations.

Cpx major element compositions have small variations among the different lithological groups (Fig. 5.9). Depleted peridotites and pyroxenite peridotites, with some exceptions, have $\sim 6-8 \mathrm{wt} \% \mathrm{Al}_{2} \mathrm{O}_{3}$ and $1 \mathrm{wt} \% \mathrm{Cr}_{2} \mathrm{O}_{3}$. The exceptions are dredge Van7-96 pyroxenites, which have similar $\mathrm{Al}_{2} \mathrm{O}_{3}$ but $0.4 \mathrm{wt} \% \mathrm{Cr}_{2} \mathrm{O}_{3}$, and the clinopyroxenite-veined sample RC27-9-6-2, which has $1.5 \mathrm{wt} \% \mathrm{Cr}_{2} \mathrm{O}_{3}$. These two pyroxenite lithologies, described in detail in Chapter 4, appear to be different from the majority of other abyssal pyroxenites. Gabbro/plag peridotites generally have similar $\mathrm{Cr}_{2} \mathrm{O}_{3}$ to residual peridotites, but $\mathrm{Al}_{2} \mathrm{O}_{3}$ extends to $2 \mathrm{wt} \%$. Cpx in some gabbro veins are low in $\mathrm{Cr}_{2} \mathrm{O}_{3}(<0.3 \mathrm{wt} \%)$. Finally, the cryptically metasomatized samples have similar $\mathrm{Cr}_{2} \mathrm{O}_{3}$ compositions to the residual peridotites but a relatively large range of 2.5-7 wt $\% \mathrm{Al}_{2} \mathrm{O}_{3}$.

Peridotites from the four different lithological groups have overlapping trace element compositions (Figs. 5.10 and 5.11). In Fig. 5.13, we plot histograms of $\mathrm{Ce} / \mathrm{Yb}$ using the global dataset, to demonstrate the similar compositional range of all four peridotite lithologies. Trace element concentrations range from depleted to relatively enriched, with compositions similar to DMM. Variations in the most incompatible trace elements extend over 3 orders of magnitude in the depleted, pyroxenite and cryptic peridotites, while the gabbro/plag peridotites extend to 4 orders of magnitude. In comparison, the Johnson and Dick (1992) dataset from the Atlantis II Fracture Zone covers 1.5 orders of magnitude for LREE (Fig. 5.10). 


\subsection{Discussion}

\subsubsection{Justification for the use of $\mathrm{Cpx}$ to interpret whole-rock processes}

In attempting to extract geochemical information about melt-rock reaction and source composition from abyssal peridotites, we assume that Cpx trace element concentrations accurately reflect the whole rock budget. This assumption is necessary given the highly altered nature of abyssal peridotites, but can be tested using the mineral modes and Cpx/Opx partitioning data presented in Chapter 4, Tables 4.2 and 4.3. We do not consider the role of olivine and spinel on the trace element budget, as these are generally negligible on the basis of mineral structure and mineral/melt partition coefficients (with some exceptions, e.g., spinel can contain significant amounts of $\mathrm{TiO}_{2}$ ). We calculate that Cpx contains $>90 \%$ of the whole rock budget for LREE and $\mathrm{Sr}$ in lherzolites (i.e., for $\mathrm{Cpx}>5 \%$ ), whereas in harzburgites, Cpx carries $\sim 70 \%$. For HREEs, Cpx in lherzolites represents $\sim 50 \%$ of the budget, whereas in harzburgites it represents $\sim 20 \%$. Overall, these calculations suggest that Cpx adequately record LREE/HREE fractionation during melting. However, wholerocks provide a more sensitive record of the process, as decreasing modal Cpx with increasing degree of melting results in a decrease in the contribution of $\mathrm{Cpx}$ to whole-rock HREE. Thus, in more depleted peridotites, the LREE/HREE whole-rock ratio is lower than the ratio measured in Cpx.

Trace element abundances measured in Cpx have been modified by cooling and subsolidus re-equilibration between $\mathrm{Cpx}$ and Opx. The magnitude of this effect can be assessed from pyroxene phase relations, represented by the temperature-dependent pyroxene miscibility gap at appropriate pressures and Cpx/Opx trace element partition coefficients as a function of temperature. Witt-Eickschen and O'Neill (2005) demonstrated that Cpx/Opx trace element partitioning co-varies with pyroxene closure temperature in natural peridotites, in the direction of increasing partition coefficients with increasing temperature. 
If the Witt-Eickschen and O'Neill (2005) conclusion on the temperature effect on Cpx/Opx

trace element partitioning is correct, $\mathrm{D}_{C p x / O p x}^{L a}$ varies from $\sim 60$ at $1250^{\circ} \mathrm{C}$ to $\sim 1000$ at $900^{\circ} \mathrm{C}$. In contrast, $\mathrm{D}_{C p x / O p x}^{Y b}$ varies from 3 to 7 over the same temperature interval. Extrapolating the Witt-Eickschen and O'Neill (2005) trends to $1350^{\circ} \mathrm{C}$, according to a $\ln (\mathrm{D})$ versus 1/T relationship, we calculate $\mathrm{D}_{C p x / O p x}^{L a} \sim 30$ and $\mathrm{D}_{C p x / O p x}^{Y b} \sim 2.5$. Lindsley $(1980)$ showed that the Opx side of the miscibility gap is considerably steeper than the Cpx side and that at $1.5 \mathrm{GPa}$, cooling from $1350^{\circ} \mathrm{C}$ to $1250^{\circ} \mathrm{C}$ will change the $\mathrm{Cpx} / \mathrm{Opx}$ ratio by $\sim 15 \%$, for a fixed Opx-rich bulk composition. Given these conditions, mass balance calculations demonstrate that the concentration of La measured in $1250^{\circ} \mathrm{C} \mathrm{Cpx} \mathrm{underestimates}$ $\mathrm{La}$ in $1350^{\circ} \mathrm{C} \mathrm{Cpx}$ by about $8 \%$, whereas $\mathrm{Yb}$ is overestimated by $\sim 7 \%$. These values are both within analytical error, indicating that, to a first approximation, the effect of the subsolidus re-distribution of trace elements between Cpx and Opx can be ignored. Hence, Cpx trace element concentrations provide a reasonably accurate picture of whole rock systematics.

\subsubsection{Mechanisms of melt-rock reaction}

Melting and melt extraction in upwelling peridotites beneath ocean ridges proceeds via the interaction of minerals with the melt percolating around them. This process is one of several mechanisms often referred to as melt-rock reaction. At the site of melt generation, melt first forms at grain junctions when the solidus of the system is overstepped. Melt mass increases via reaction with minerals as it wets grain boundaries and begins to migrate upward. Experimental and theoretical studies of dissolution-precipitation mechanisms (e.g., Iwamori, 1992; Liang, 2003; Lo Cascio et al., 2004; Morgan and Liang, 2005) provide constraints on the grain-scale kinetics of this process.

Melt extraction by fractional or near-fractional melting results in residual peridotites that are depleted in modal Cpx and incompatible trace elements. As degree of melting 
increases, so does the degree of depletion. Melt migration is faster than the upward flow of residual peridotites, creating conditions for reactive porous flow. Through this process, depleted peridotites can be chemically and mineralogically modified by reaction with enriched small-degree melts, producing significant changes in Cpx trace element compositions. The general aspects of focused reactive porous flow and its importance for the extraction of melt from mid-ocean ridges have been developed by Dick et al. (1994), Kelemen et al.(1997) and colleagues. This approach is particularly successful in explaining the formation of dunite channels in the uppermost part of the mantle beneath the EPR (Dick and Natland, 1996) and the Oman Ophiolite (Kelemen et al., 1995). Open system melting models, such as those of Johnson and Dick (1992) and Ozawa and Shimizu (1995) were also developed in this context. Further development of the reactive porous flow approach has been made in the form of dissolution channel models (e.g., Spiegelman and Kenyon, 1992; Kelemen et al., 1995; Spiegelman and Kelemen, 2003), which predict the range of trace element depletion patterns expected for abyssal peridotites at large sampling lengthscales.

Descriptions and models of the interactions of peridotites with migrating melts and fluids are not restricted to the ridge environment and have a long history in studies of mantle metasomatism of the continental lithosphere. Navon and Stolper (1987) and Bodinier et al. (1990) were among the first to attempt to explain melt-rock reaction in a quantitative fashion. Particularly interesting and relevant to this study is the chromatographic fractionation of trace elements predicted by their models. As melt percolates around mantle minerals, fractionation of trace elements occurs because of the differences among mineral-melt partition coefficients for different elements. When an enriched small-degree melt enters a column of depleted peridotite, REE patterns of $\mathrm{Cpx}$ in the peridotite will be modified successively, beginning with an increase in the more incompatible LREE and progressing towards less incompatible HREE. This process can result in Cpx with "spoon-shaped" and 
"sharply inflected" REE patterns, as observed by Takazawa et al.(1992) in depleted lherzolites from the Horoman peridotite massif and by Sen et al. (1993) in xenoliths from Oahu. These early models concentrated on explaining variations among peridotite $\mathrm{Cpx}$ trace element patterns and did not include the modal changes that occur during melt-rock reaction. More generalized models that include mineralogical reactions have since been developed (Godard et al., 1995; Vernières et al., 1997).

In general, the nature of melt-rock reaction depends on whether melt mass is increasing (i.e., melting), constant, or decreasing (i.e., crystallization). The effect of decreasing melt mass on lithospheric mantle composition is important in the context of both ridge and subduction processes. The lithospheric mantle that is transported back into the asthenosphere may have a substantially different and more variable composition than surveys of depleted abyssal peridotites alone imply. Fig. 5.1 demonstrates that veined peridotites are found from the entire spectrum of spreading rates and at most localities where depleted abyssal peridotites are collected. Cannat (1996) argued that incomplete melt extraction (or melt entrapment) is important during lithosphere formation at lower spreading rates. Sleep and Barth (1997) used thermal modeling to demonstrate that melts can freeze directly in the mantle due to cooling from the surface and that this effect occurs at higher spreading rates than those at which conductive cooling limits the extent of melting. Lizarralde et al. (2004) presented seismic evidence for the retainment of a gabbroic phase in the mantle at low spreading rates.

The thermal regime for peridotites in this study is constrained by ultra-slow spreading rates and/or fracture zone proximity - i.e., the degree of melting is generally limited due to conductive cooling from above. Under these conditions, migrating melt is also cooled and melt extraction is expected to be incomplete. In systems where melt mass is decreasing, reaction of melt with the peridotite can refertilize a depleted peridotite. The nature of refertilization and its effect on peridotites will depend on several variables: melt/rock ratio, melt 
composition, degree of peridotite depletion, pressure and temperature. Clear evidence for incomplete melt extraction at high melt/rock ratios over a range of pressures is recognized in the form of pyroxenite and gabbro veins in peridotites (Dick, 1989; Cannat et al., 1992, Constantin et al., 1995; Seyler and Bonatti, 1997, Dantas et al., 2007). Refertilization by low volume melts percolating along grain boundaries results in more cryptic forms of refertilization, the signature of which is difficult to detect. However, recent detailed studies by Seyler and co-workers (Seyler et al., 2001, 2004; Brunelli et al., 2006; Seyler et al., 2007) have documented that many residual peridotites have been weakly refertilized, with small enrichments in the most incompatible trace elements, interstitial $\mathrm{Cpx}$ veinlets and trace metasomatic phases.

In Fig. 5.2, we emphasized the range of compositions among unveined abyssal peridotites. In Fig. 5.13, we use the same global dataset to compare residual peridotite compositions to the compositions of veined and cryptically metasomatized peridotites. Depleted peridotites have a mean normalized $\mathrm{Ce} / \mathrm{Yb}$ ratio of $\sim 0.01$, but range from $\sim 0.001$ 10. Gabbro/plag peridotites and pyroxenite-veined peridotites span close to the same range as residual peridotites. The cryptically metasomatized peridotites - represented by individual analyses from only 3 samples - also span a similar range. The $\mathrm{Ce} / \mathrm{Yb}$ range among residual peridotites probably reflects melt-rock reaction, in addition to melt depletion.

\subsubsection{Length-scales of peridotite variations and their origins}

We observe orders of magnitude variation in abyssal peridotite trace element concentrations at length-scales ranging from single grains to ridge segments. At the smallest length-scales, kinetics and cooling rate are important, as volume diffusion at high temperature rapidly equilibrates compositional variations, even in the absence of melt (Hofmann and Hart, 1978). Thus, variations at the dredge and outcrop scale often reflect melt-rock reaction processes over a range of temperatures. For example, among Oblique/Orthogonal 
Segment dredges and the two uplifted massifs on Atlantis II Fracture Zone, a variety of vein compositions are observed. At the ridge segment scale, the Oblique Segment has large variations among residual peridotites, which we will discuss in the context of meltrock reaction and pre-existing heterogeneities.

\section{Porphyroclast and interstitial grain variations}

Cpx in the majority of peridotites are present as both porphyroclasts and interstitial grains. Interstitial grains are $<1 \mathrm{~mm}$ diameter and lack exsolution lamellae, whereas porphyroclast grains are typically 2-5 $\mathrm{mm}$ diameter, with exsolution lamellae. The morphology of some interstitial grains suggests that they formed by crystallization of melt on grain boundaries, but the majority are more equant in shape. To investigate the possibilities of mineral zoning and of crystallization from melt, we analyzed porphyroclast cores and rims and interstitial grains wherever possible. Core, rim and interstitial compositions among vein-free peridotites are compared in Fig. 5.14. With the exception of the cryptically metasomatized samples, no systematic difference exists between porphyroclast core and rim or between porphyroclast and interstitial grain. While some analyses do not show an exact correspondence, the majority of these occur at low concentrations where error is probably larger than estimated (due to low count rates).

During mantle melting, various studies have attempted to constrain whether minerals remain in equilibrium with melt or whether diffusion limits equilibrium Qin, 1992; Iwamori, 1992, 1993; Van Orman et al., 2002; Cherniak and Liang, 2007). The lack of clear evidence for systematic incompatible element depletion of Cpx grain rims with respect to cores indicates that disequilibrium mantle melting does not occur with respect to Cpx. The approximation $x=\sqrt{D_{i} t}$, where $x$ is distance, $D_{i}$ is the diffusion coefficient for an element $i$, and $t$ is time, can be used to assess diffusive homogenization time-scales. For $\mathrm{Ce}$ and $\mathrm{Yb}$ in $\mathrm{Cpx}$ at $1.5 \mathrm{GPa}$ and $1350^{\circ} \mathrm{C}$, using diffusion coefficients from Van Orman 
et al. (2001) and a grain diameter of $2 \mathrm{~mm}, \sim 1 \mathrm{My}$ is required for Ce equilibration and $\sim 0.1 \mathrm{My}$ for $\mathrm{Yb}$ equilibration. For these time-scales and at relevant ridge spreading rates, cooling rates for mantle upwelling along an adiabat are not fast enough to limit diffusive re-equilibration during melting. In contrast, significant core-to-rim enrichment of $\mathrm{Ce}$ in Cpx is observed in the cryptically metasomatized peridotites, suggesting that metasomatism occurred at shorter time-scales, as discussed below.

\section{Sample- and grain- scale variations}

The three cryptically metasomatized peridotites represent the smallest length-scale at which compositional variation has been observed in abyssal peridotites. These samples are unveined protogranular lherzolites. Samples 6K-465-2 and RC27-9-6-5 are from the northern ridge-transform intersection of the Atlantis II Fracture Zone and 6K-458-3 is from Atlantis Bank. In these samples, Cpx grains with typical, depleted trace element concentrations and those with enriched concentrations, similar to or greater than DMM, occur within 1-2 cm of each other. Fig. 5.12 shows REE patterns for these samples, including the zoned "transitional" Cpx in 6K-465-2 and RC27-9-6-2. Transitional Cpx are grains with gradients in trace element concentrations, from depleted cores to enriched rims, which are found spatially between depleted Cpx and enriched Cpx. The samples have 2-3 orders of magnitude range in LREE, with transitional grains covering 2 orders of magnitude alone. In sample 6K-465-2, the transitional grain, shown in Fig. 5.15, is $2 \mathrm{~mm}$ in the longest dimension and has variations in Ce from $0.1 \mathrm{ppm}$ up to $2 \mathrm{ppm}$ (Cpx 6 in Table 5.10). The lowest trace element concentrations occur at Point 4 (Fig. 5.15), suggesting that this point is close to the true center of the grain in three dimensions. The REE variations in the cryptic peridotites are similar to the theoretical predictions of chromatographic melt-rock reaction models, for example by Vernières et al. (1997). However, given the limited number of analyses for our samples and the lack of spatial information on the exact shape of the zoning 
front, detailed modeling is precluded at this point.

Sample 6K-465-2 can be used to constrain the time-scales of metasomatic processes, as it has the greatest number of analyses. Of 28 points analyzed in $10 \mathrm{Cpx}$ grains distributed over a $3 \times 4 \mathrm{~cm}$ area of the thin section (Table 5.10), 21 points have uniform, low $\mathrm{Sr}$ concentrations $(\mathrm{Sr}=1.18 \pm 0.24 \mathrm{ppm})$. In contrast, Ce varies by a factor of almost $400(0.02$ $7.99 \mathrm{ppm})$. As Cpx-melt partition coefficients for these elements are similar $\left(\mathrm{K}_{d}^{C e}=0.09\right.$, $\mathrm{K}_{d}^{S r}=0.13$; Hart and Dunn, 1993), the observed decoupling is unusual and probably reflects diffusion kinetics. Sr appears to have remained constant, while Ce increased 400-fold during the metasomatism, resulting in large negative $\mathrm{Sr}$ anomalies on a spidergram. We interpret this seemingly anomalous behavior as a result of cryptic metasomatism followed by diffusive homogenization of $\mathrm{Sr}$.

At $1350^{\circ} \mathrm{C}$, the diffusion coefficient for $\mathrm{Sr}$ is $4.6 \times 10^{-16} \mathrm{~m}^{2} / \mathrm{s}$ (Sneeringer et al. 1984), and that for Ce is $9.9 \times 10^{-20} \mathrm{~m}^{2} / \mathrm{s}$ (Van Orman et al. 2001). This implies that $\mathrm{Sr}$ in a $2 \mathrm{~mm}$ grain will homogenize in $\sim 300 \mathrm{yr}$, while a crystal the size of the analyzed region of the thin section will homogenize in $\sim 0.1 \mathrm{My}$. For a crystal aggregate, the equilibration time-scale across the same area is shorter, as diffusion along grain boundaries is faster than volume diffusion across a grain. In contrast, homogenization of Ce in a $2 \mathrm{~mm} \mathrm{Cpx} \mathrm{grain} \mathrm{takes} \sim 1$ My at $1350^{\circ} \mathrm{C}$. Thus, cryptic metasomatism produces large variations in $\mathrm{Ce}$ and $\mathrm{Sr}$, on a time-scale that is considerably shorter than the time-scale associated with near-fractional melting (e.g., $>0.1$ My but $<1 \mathrm{My}$ ).

The upwelling rate of the SWIR at the Atlantis II Fracture Zone is $5.4 \mathrm{~mm} / \mathrm{yr}$, based on corner flow at a half-spreading rate of $8.5 \mathrm{~mm} / \mathrm{yr}$ (Hosford et al., 2003). At this upwelling rate, if melt-rock reaction occurred at $1350^{\circ} \mathrm{C}$, which corresponds to a depth of $\sim 26 \mathrm{~km}$, Cpx grains would have time for Ce homogenization. Thus, melt-rock reaction must have occurred at a lower temperature. At Atlantis Bank, gabbro intrusion occurred on-axis to relatively shallow depths (Dick et al., 2000; John et al., 2004). This agrees with the re- 
quirement for cryptic metasomatism to occur at relatively low temperature $\left(<1200^{\circ} \mathrm{C}\right)$ and suggests that metasomatism occurred in peridotite wallrock adjacent to a gabbro intrusion.

Trace amounts of plagioclase, intergrown with spinel, olivine and pyroxenes, is present in sample 6K-465-2. We suggest that plagioclase is the result of the breakdown reaction of spinel, Opx and Cpx to form plagioclase and olivine. Plagioclase crystallization appears to post-date the cryptic metasomatism event, as both enriched and depleted Cpx have negative $\mathrm{Eu}$ anomalies on their rims but not their cores (Fig. 5.12). The spinel/plagioclase transition occurs around $\sim 15-20 \mathrm{~km}$ depth, but this is highly dependent on bulk composition and temperature. In particular, the presence of $\mathrm{Cr}$ promotes the persistence of spinel (O’Neill, 1981), while low Na suppresses plagioclase formation. Spinel is locally enriched in $\mathrm{Cr}(\mathrm{Cr} \#=47$ near plagioclase, versus $\mathrm{Cr} \#=22$ away from plagioclase, Table 5.8), while plagioclase has very low $\mathrm{Na}$ concentrations $\left(\mathrm{An}_{90-93}\right.$, Table 5.8), suggesting a relatively shallow depth for plagioclase formation. Plagioclase also has variable Sr concentrations, ranging from $1 \mathrm{ppm}$ to $60 \mathrm{ppm}$ (Table 5.11), with the lower concentrations suggestive of partitioning with Cpx, not with a melt.

Sr concentrations in 6K-465-2 are sporadically high in some Cpx rims (up to $6 \mathrm{ppm}$ ) and some interstitial plagioclase (up to $60 \mathrm{ppm}$ ). This implies a final stage of melt-rock reaction, which led to crystallization of a small amount of melt along grain boundaries. If true, a first metasomatic event occurred deeper than the depth of stability for anorthitic plagioclase, whereas the second melt infiltrated at a shallower depth. Our observations are compatible with the first event occurring, for example, in the range $\sim 1000-1200^{\circ} \mathrm{C}$, equivalent to a depth of $\sim 11-19 \mathrm{~km}$ or an upwelling time to the seafloor of 2-3 My. This first metasomatic event was followed by plagioclase breakdown around 10-15 km depth, before a second episode of metasomatism. Our interpretation coincides with observations of a complex magmatic history at Atlantis Bank, involving several cycles of melt intrusion, including late-stage, off-axis events (John et al., 2004). While 6K-465-2 is located at the present- 
day inside corner high, the processes that are recorded at Atlantis Bank are assumed to be equivalent to the processes that are currently occurring at the ridge-transform intersection. The multiple episodes of melt-rock reaction recorded in the peridotites demonstrate the complexity of the path of melt through the upwelling mantle.

\section{Massif-scale variations on the Atlantis II Fracture Zone}

In Fig. 5.16, we plot sample averaged Cpx REEs for dredges and dives from the Atlantis II Fracture Zone ridge-transform intersection and Atlantis Bank. Individual analyses for the cryptically metasomatized peridotites are shown as sample averages to emphasize the variation among other peridotites. The large variations in the cryptically metasomatized peridotites (Fig. 5.12) are mirrored in the range of compositions observed among all samples at the Atlantis II Fracture Zone localities. In contrast, the range of depleted Atlantis II Fracture Zone peridotite compositions from the full length of the active transform fault (Johnson and Dick, 1992) is much more limited (Fig. 5.16) and residual peridotites at Atlantis Bank extend over most of this range.

Johnson and Dick (1992) related the variation in peridotite composition along the fracture zone to variations in degree of melting. Our observations suggest that their sample suite is not representative of the range of peridotite characteristics along the fracture zone. In particular, we note the role of melt-rock reaction in modifying peridotite composition at both localities that we have sampled in detail. In addition, in Chapter 4 we presented evidence for source heterogeneity beneath the fracture zone. Clinopyroxenite-veined peridotite RC27-9-6-2 has an enriched isotopic composition, implying that it originated from a long-term mantle heterogeneity. As noted in Chapter 4, the sample is depleted in all REE with respect to DMM and the vein is more depleted than the host peridotite, suggesting that the vein post-dates the initial isotopic heterogeneity of the sample.

Both the ridge-transform intersection and Atlantis Bank are uplifted oceanic massifs 
of lower crust and upper mantle. At Atlantis Bank, gabbro is the dominant lithology and peridotites have been collected in close proximity to the gabbros (Dick et al., 2000). In addition, the gabbros at Atlantis Bank are cut by many late small ferrogabbro intrusions (Dick et al., 2000). The most enriched gabbro vein compositions at Atlantis Bank are considerably more enriched than Atlantis II basalts and are probably compatible with derivation from an evolved melt similar to the one that produced the ferrogabbros. In peridotite $6 \mathrm{~K}$ 465-3, one of the cross-cutting veins contains plagioclase, kaersutite, rutile, ilmenite, and apatite. In addition, clinopyroxene in the peridotite matrix have unusual exsolution consisting of olivine, plagioclase and spinel, as discussed in Appendix 5.D. Gabbro veins and pyroxenite veins in Atlantis II Fracture Zone peridotites also extend to relatively depleted compositions, suggesting that crystallizing vein melts had a variety of compositions.

\section{Dredge-scale variations on the Oblique/Orthogonal Segments}

We analyzed 6 dredges in detail from the Oblique and Orthogonal Segments, to assess the degree of within- and between-dredge variability. Samples analyzed were chosen to represent the range of macroscopic dredge characteristics, so we assume that we have accurately sampled the compositional range of each dredge. REE patterns in Fig. 5.17 demonstrate that within-dredge variations are relatively small but that considerable differences exist between dredges. Dredge tracks are typically $1 \mathrm{~km}$ in length, though wire tension records indicate that sampling is discontinuous and often dominated by one section. Dredge Kn162-47 is unusual in containing both pyroxenites and plagioclase peridotites. In addition, the dredge contains peridotite mylonites, suggesting that samples come from different, fault-juxtaposed, mantle domains. In contrast, most dredges are characterized by samples with a single set of characteristics, such as vein-free residual peridotites (PS86-6, Van7-85 and Van7-86), pyroxenite veins (Van7-96) or peridotites with gabbro veins and matrix plagioclase (Van7-78). 
Among the three vein-free peridotite dredges, Van7-85 and Van7-86 have "typical" depleted compositions, with samples plotting in the middle of the residual peridotite field from Johnson et al. (1990). One sample, Van7-86-37, deviates from the general trend, with elevated LREE and a negative Eu anomaly. These observations suggest melt refertilization and plagioclase crystallization, but alteration of the sample is too great for fresh plagioclase to be identified. The third unveined peridotite dredge, PS86-6, is less depleted in LREE than dredges Van7-85 and Van7-85, and has high modal Cpx (8-12\%, Table 5.3). These peridotites could either have undergone a relatively low degree of melting or they could have been refertilized following a more typical amount of melt extraction. As discussed in Chapter 4, these peridotites are isotopically heterogeneous and may have been influenced by proximity of Bouvet hotspot along the Shaka Fracture Zone at $20 \mathrm{Ma}$ (Fig. 5.3).

Dredge Van7-96 contains peridotites with pyroxenite veins that are relatively undepleted with respect to DMM. Variations in trace element concentrations among these samples are greater than the observed variations among depleted dredges. As discussed in detail in Chapter 4, the pyroxenite veins and host peridotites have a range of isotopic compositions between DMM and Bouvet hotspot, suggesting that they represent hotspot-modified mantle. A negative correlation between ${ }^{143} \mathrm{Nd} /{ }^{144} \mathrm{Nd}$ and $\mathrm{Ce} / \mathrm{Yb}$ (Chapter 4, Fig. 4.14) further suggests that the isotopic and LREE enriched signatures are due to interaction with the Bouvet hotspot. The isotopically most depleted peridotite (Van7-96-38: ${ }^{143} \mathrm{Nd} /{ }^{144} \mathrm{Nd}=$ $\left.0.513205,{ }^{87} \mathrm{Sr} /{ }^{86} \mathrm{Sr}=0.702096\right)$ is the most depleted in LREE (Fig. 5.17). In addition the pyroxenites have a secondary, cross-cutting gabbroic vein assemblage, suggesting multiple stages of melt-rock reaction over a range of pressures. Dredge 96 has an effective spreading rate of $12 \mathrm{~mm} / \mathrm{yr}$ and is located adjacent to Shaka Fracture Zone, implying minimal melting during upwelling, yet even at this locality melt-rock reaction occurred.

The gabbro veined peridotites in dredge Van7-78 do not exhibit a large compositional range and have concentrations similar to DMM, with a slight fanning out of LREE among 
different samples. The veins are not enriched with respect to their host peridotites (see the REE plots in Appendix 5.A for detailed within-sample comparisons). With respect to the gabbro-veined peridotites from Atlantis II Fracture Zone (Fig. 5.16), these veins and their host peridotites have compositions in the middle of the gabbro range. Variations among these samples are probably due to variable amounts of melt refertilization.

Dredge Kn162-47 contains residual peridotites, pyroxenite-veined peridotites, and a plagioclase peridotite. All three lithologies have typical depleted compositions, with the exception of Kn162-47-09. The depleted composition of the pyroxenite and plagioclase peridotites implies that they formed from unaggregated melts in equilibrium with the surrounding peridotite.

Sample Kn162-47-09 has an unusual, sinusoidal shaped REE pattern, accompanied by large negative $\mathrm{Ti}$ and $\mathrm{Zr}$ anomalies on a spidergram. Together with its $\mathrm{Nd}$ isotopic composition $\left(\epsilon_{N d}=-2.8\right)$ reported by Salters and Dick (2002), the geochemical characteristics of this sample, highly unusual for abyssal peridotites, resemble continental lithosphere. Cpx from a spinel harzburgite xenolith from the Premier Mine, South Africa (PHN 5266, Boyd et al., 1999) has an almost identical spidergram (N. Shimizu, unpublished data). In addition, Opx and Cpx have high Mg\# - 91.7 for Opx and 93.1 for Cpx, compared to global average values for residual peridotites of 91 for both Opx and $\mathrm{Cpx} . \mathrm{Cr}_{2} \mathrm{O}_{3}$ is also high $(0.82 \mathrm{wt} \%$ for Opx and $1.55 \mathrm{wt} \%$ for Cpx; cf. $0.57-1.08 \mathrm{wt} \%)$, whereas $\mathrm{Al}_{2} \mathrm{O}_{3}$ is low (3.29 wt $\%$ for Opx and $4.32 \mathrm{wt} \%$ for Cpx; cf. $5.20-7.83 \mathrm{wt} \%$ ). These mineral compositions are consistent with the Kaapvaal spinel peridotite data (Boyd et al., 1999).

The alteration features and general appearance of sample Kn162-47-09 are identical to other peridotite samples from the same dredge, indicating that this peridotite was part of the oceanic lithosphere when it was emplaced on the seafloor (and not ice-rafted debris). On the basis of this sample, we suggest that rocks from the continental lithosphere can maintain mineralogical and geochemical integrity throughout the process of entrainment 
into the convecting mantle, surviving the melt-rock reaction process during upwelling beneath ocean ridges. We note that in the global abyssal peridotite dataset, 6 other samples, including 3 from the Gakkel Ridge, have similar REE patterns, but no isotopic data are available. Recent studies by Goldstein et al. (2006) and Michael et al. (2006) postulated that continental lithosphere is involved in magma genesis at the Gakkel Ridge, on the basis of MORB geochemistry.

Overall, dredges along the Oblique/Orthogonal Segments indicate variations in the occurrence, amount and depth of melt-rock reaction. However, the compositional range among Oblique/Orthogonal samples is small with respect to Atlantis II Fracture Zone samples. The larger variations at smaller length-scales at Atlantis II imply that the nature of melt-mantle interaction is different between these localities. At Atlantis Bank, magmatism occurred for a long time, ultimately intruding into relatively cool lithosphere (John et al. 2004). In contrast, spreading along the Oblique Segment is ultra-slow and large gabbro bodies, such as Atlantis Bank, are not observed. In fact, small gabbro intrusions are also absent from peridotite dredges along the Oblique Segment. Therefore, melt-mantle interaction at the Oblique Segment was likely more limited in spatial and temporal extent, than at faster upwelling rates.

\subsubsection{Estimates of degree of melting}

In previous sections, we have suggested that many abyssal peridotites have undergone melt-rock reaction during melt extraction. We have also suggested that the mantle may not be homogenous in composition, as commonly assumed (e.g., Johnson et al., 1990). To assess the role of source heterogeneity on peridotite composition, we use peridotite compositions to calculate degrees of melting along the Oblique Segment. We then compare these calculations to predictions from a thermal model of the Oblique Segment by Montési et al. (2006). 
The data that we use to assess Oblique Segment source composition are Cpx trace elements from 11 dredges and spinel major elements from 23 dredges, for residual peridotites only. Trace elements have been determined in Cpx from 38 residual peridotites (this study; H. J. B. Dick unpublished data; Johnson et al., 1990; Salters and Dick, 2002). For spinel, using additional unpublished data from H. J. B. Dick, data are available from 132 samples, with multiple samples analyzed per dredge, except for two dredges. In Fig. 5.18, spinel $\mathrm{Cr} \#, \mathrm{Mg} \#$ and $\mathrm{TiO}_{2}$ are shown for this expanded dataset of Oblique Segment residual peridotites. Oblique Segment spinels are offset to slightly lower Mg\# at a given Cr\#, in comparison to the global dataset. As Mg\# reflects thermal re-equilibration between olivine and spinel (Dick and Bullen, 1984), the offset may reflect the ultra-slow upwelling rate along the Oblique Segment.

In Fig. 5.19, the variation of $\mathrm{Cpx} \mathrm{Ce} / \mathrm{Yb}$ and spinel $\mathrm{Cr} \#$ are shown as a function of longitude along the $\sim 500 \mathrm{~km}$ long Oblique Segment. Both indices of peridotite depletion show large variations within individual dredges and among closely spaced dredges. For example, at $13^{\circ}-13.5^{\circ} \mathrm{E}$ (a distance of $\sim 55 \mathrm{~km}$ ), spinel Cr\# covers the entire global range, from $\sim 10 \%-60 \%$. This includes dredge PS86-6, for which the Cpx Nd isotopic range is $30 \%$ of the Indian Ocean MORB range (Chapter 4). Pre-melting chemical variation in the mantle is expected to accompany this isotopic variability.

To demonstrate the implications of the large range in peridotite composition in Fig. 5.19, we estimate degree of melting for the peridotites, assuming an initial DMM composition. In calculating degree of melting from spinel compositions, we first filtered the dataset for high $\mathrm{TiO}_{2}$ (Fig. 5.18), using the composition of DMM spinel (0.17 wt\%, Workman and Hart, 2005), to remove spinels that have been affected by melt infiltration. Degree of melting is calculated from the empirical correlation of Cr\# with Cpx HREE, based on a non-modal fractional melting model for HREE (Hellebrand et al., 2001, see Appendix 5.B for a discussion of the calibration). For Cpx trace elements, we also use fractional melt- 
ing, to provide a direct comparison to the predictions from spinel Cr\#. Degree of melting for $\mathrm{Ce}$ and $\mathrm{Yb}$ are calculated using the melting reaction from Kinzler (1997) and partition coefficients compiled by Kelemen et al. (2003). These parameters are similar to those used by Hellebrand et al. (2001) to calibrate the Cr\# relationship to melting.

The results of the fractional melting calculations are shown in Fig. 5.19. If the maximum $\mathrm{Cr} \#$ in a dredge represents the maximum degree of melting, then the average maximum degree of melting based on spinel composition is $9 \%$. The within-dredge range in spinel $\mathrm{Cr} \#$ translates to an average within-dredge melting range of 5\%. However, at the dredge length-scale $(<1 \mathrm{~km})$, this range cannot result from degree of melting and must reflect either initial heterogeneity or melt-rock reaction. $\mathrm{Ce}$ in $\mathrm{Cpx}$ and $\mathrm{Yb}$ in $\mathrm{Cpx}$ predict $5 \%$ and $7 \%$ melting, respectively, with an average per dredge difference between these two estimates of 3\%. Brunelli et al. (2006) suggest, on the basis of trace element modeling, that the majority of residual peridotites have undergone a small amount of refertilization by melts that are close to being in equilibrium with the peridotite. These melts result in a larger increase in LREE than in HREE. If true, $\mathrm{Ce}$ is expected to underestimate degree of melting while $\mathrm{Yb}$ is expected to provide a more representative estimate. However, $\mathrm{Ce}$ does not consistently provide the lower estimate of melting, which may be a signal of initial source heterogeneity in relative REE abundances. The differences in average degree of melting among the three estimates $(\mathrm{Cr} \#, \mathrm{Ce}$, and $\mathrm{Yb})$ could be related to the simplified melting model, but the range within and between dredges is significant and model independent.

In Fig. 5.19, we also plot the predicted variation in degree of melting from a thermal model by Montési et al. (2006). This 3-D model of thermal structure combines the effect of conductive cooling on ridge thermal structure with the specific geometry of the Oblique Segment. As discussed by Dick et al. (2003) and Standish et al. (submitted), the Oblique Segment consists of three long, obliquely spreading, amagmatic segments separated by two short, orthogonally spreading, volcanic centers (Joseph Mayes Seamount and Narrowgate, 
Fig. 5.3). The model predicts an overall maximum degree of melting $<12 \%$, with reduced degrees of melting along the amagmatic segments and enhanced melting at the two volcanic centers. To a first order, the model agrees with bathymetry, gravity, and basalt chemistry, except for the $15^{\circ}-16^{\circ} \mathrm{E}$ segment between Narrowgate and the Orthogonal Segment. In this region, the model predicts a higher degree of melting than expected from geological observations (L. Montési, personal communication, 2007).

We focus on the $\sim 12^{\circ}-14^{\circ} \mathrm{E}$ section in Fig. 5.19, where the model is robust and abundant observations are available from the peridotites. The thermal model predicts $\sim 4-6 \%$ melting, with a continuous decrease towards the segment center. Predicted degree of melting varies between 2-6\% for $\mathrm{Ce}$ in $\mathrm{Cpx}$ and 2-9\% for $\mathrm{Yb}$ in $\mathrm{Cpx}$. Given the simplicity of the trace element model and the precision of the thermal model, these estimates agree within error. However, the trace element data exhibit variability at shorter length-scales than predicted by the thermal model. Spinel Cr\# exhibits even greater variability and predicts considerably higher degrees of melting. Using the maximum $\mathrm{Cr} \#$, the predicted range for degree of melting is $3-18 \%$, whereas using the minimum $\mathrm{Cr} \#$, the range is $0-15 \%$.

The thermal model of Montési et al. (2006) demonstrates the length-scale over which temperature is expected to produce variations in degree of melting. The shorter lengthscale variations in peridotite composition along the Oblique Segment must reflect either compositional heterogeneity or melt-rock reaction. From the Cpx trace element data, we suggest that within-dredge variability is dominated by melt-rock reaction, but that the offset among dredges dominantly reflects source heterogeneity. However, the within-dredge variation among spinel $\mathrm{Cr} \#$ cannot result from melt-rock reaction, as spinel $\mathrm{TiO}_{2}$ and, to some

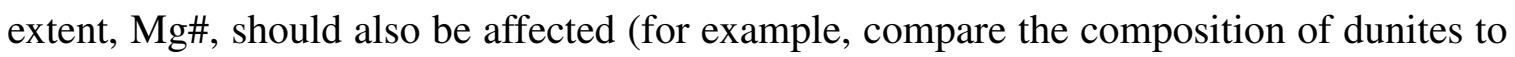
peridotites in Figs. 5.7 and 5.8. Therefore, we suggest that Cpx trace elements may be decoupled from spinel major elements, reflecting recent melt-rock interaction. In contrast, spinel $\mathrm{Cr} \#$ variations, unaccompanied by $\mathrm{TiO}_{2}$ variations, may reflect pre-existing major 
element heterogeneity of the mantle.

\subsubsection{Towards an understanding of mantle initial composition and re- gional variability}

We interpret the large range in $\mathrm{Cr} \#$ at the single dredge scale and the variation in $\mathrm{Cpx}$ trace elements among dredges as indicators of initial source heterogeneity. Our working model is that heterogeneous lithosphere is created at mid-ocean ridges by large-scale variations in degree of melting and the small-scale effects of melt-rock reaction. This litho-

sphere is eventually returned to the convecting mantle at subduction zones. Consequently, the mantle exposed at the ridge axis today is one whose composition over time has become increasingly heterogeneous. The important question then becomes, how variable is mantle bulk composition?

The issue of initial heterogeneity has important implications for the interpretation of peridotite and MORB compositions. Assuming a homogeneous source, basalts and peridotites can be used to calculate asthenospheric mantle composition (e.g., Workman and Hart, 2005). This source, DMM, is then combined with the local composition of basalts or peridotites to estimate degree of mantle melting. Variations in degree of melting are used to reflect variations in mantle thermal structure. However, if the mantle is heterogeneous, variations in predicted degree of melting could be a result of chemical variations, not thermal variations. With a heterogeneous source, degree of melting and extent of melt-rock reaction are difficult to determine for a given abyssal peridotite composition.

The issue of local-scale variability in abyssal peridotite and MORB compositions has been noted before (Dick et al., 1984; Klein and Langmuir, 1989). Dick et al. (1984) suggested that averaging peridotite modal compositions on a regional scale defines separate melting trends among peridotites, interpreting this as indicative of regional differences in mantle composition. They also observed modal variations within-dredges and among 
dredge from the same locality, which they attributed to variations in degree of melt extraction for the same degree of melting. Klein and Langmuir (1989) suggested that local variations in MORB composition result from variable sampling of instantaneous melts throughout the melt column, but they could not rule out major element source heterogeneity as an origin.

In this study, we have documented variations in peridotite composition at the scale of a grain, a sample, a dredge, a massif, a fracture zone and a ridge segment. We use these observations in Fig. 5.20 to assess the length-scales of compositional variability at ridges. In Fig. 5.20, variations in peridotite composition are observed to extend over similar ranges in $\mathrm{Cpx} \mathrm{Ce} / \mathrm{Yb}$ at all length-scales. The modal data from Dick et al.(1984) suggests a similar picture, with peridotite modes varying from the ridge-scale down to the dredge-scale. Data from this study and Hellebrand et al. (2002) suggest that spinel Cr\# is also heterogeneous at all lengthscales. Thus, we suggest that the composition of the mantle is heterogeneous over a range of length-scales.

\subsection{Conclusions}

Abyssal peridotites are typically interpreted as the residues of variable degrees of melting. However, the range of abyssal peridotite compositions, shown in Fig. 5.13, cannot result from melt depletion alone. In this chapter, we considered two additional origins for peridotite compositional variations: melt-rock reaction and initial heterogeneity. The occurrence of melt-rock reaction is readily observed in veined samples. In vein-free samples, distinguishing between melt-rock reaction, degree of melting and initial heterogeneity requires careful analysis. Peridotite compositions are frequently used to predict the degree of melting at a ridge (e.g., Johnson and Dick, 1992; Hellebrand et al., 2001; Le Mée et al., 2004). If source heterogeneity and melt-rock reaction are significant, as we suggest they are, then peridotites can only be used with great care to determine melting histories. 
Melting and melt extraction in the oceanic upper mantle are often assumed to be two distinct processes, such that melt and mantle do not significantly interact following melt formation. This view is based on the composition of basalts, which require melt transport out of equilibrium with the mantle, and by the occurrence of dunites, which provide pathways for disequilibrium melt extraction (e.g., Dick et al., 1994; Kelemen et al., 1995). Consideration of these processes has often resulted in the exclusion of other mechanisms from the interpretation of abyssal peridotite compositions. However, the compositional and lithological variation among abyssal peridotites (Fig. 5.13) and the global distribution of these lithologies (Fig. 5.1) indicates that interaction of melt with the mantle is important at ridges.

We conclude that at least one of the major processes for creating large chemical variations in abyssal peridotites is melt-rock reaction and refertilization, in addition to melt extraction by focussed flow. Abyssal peridotites have compositions that vary over 3 orders of magnitude in $\mathrm{Ce} / \mathrm{Yb}$, as demonstrated in Fig. 5.13. The dataset for 67 peridotites presented in this study indicates that refertilization of peridotites occurs at many length-scales and to varying extents. Consequently, when the oceanic lithosphere is eventually recycled back into the mantle, it introduces a greater range of heterogeneity than expected from a simple melt extraction model for mid-ocean ridge melting.

On the basis of significant small-scale variations in peridotite compositions from the Oblique Segment, we suggest that the mantle is compositionally heterogeneous. If Oblique Segment peridotites are interpreted entirely in terms of degree of melting, spinel Cr\# and Cpx trace element concentrations predict different degrees of melting and variations on a shorter length-scale than predicted by the thermal modeling by Montési et al. (2006). We suggest that some of the dredge-scale variation in peridotite trace elements is related to melt-rock reaction processes. However, the large range in spinel $\mathrm{Cr} \#$ is not accompanied by increasing $\mathrm{TiO}_{2}$, indicating that the range does not reflect melt infiltration. Consequently, 
we conclude that the peridotites were compositionally heterogeneous before the onset of melting, as degree of melting does not vary at the length-scale of a dredge.

Our interpretations in this chapter are based on data obtained at small sampling lengthscales. This study expands the observational length-scales for variations in abyssal peridotite compositions down to the single grain $(\sim 1-5 \mathrm{~mm})$ and single rock $(\sim 10-50 \mathrm{~cm})$ scales and up to the single dredge $(<1 \mathrm{~km})$ and single ridge segment $(\sim 500 \mathrm{~km})$ scales. We demonstrate that the ranges and nature of chemical variations are similar at all the length-scales: the magnitude of chemical variation in the mantle is scale independent. 


\section{Appendix 5.A}

\section{Plots of REE variations in individual samples}

In Fig. 5.A1, REE plots of each individual analysis for Cpx, Opx and Plag are shown by sample. For Oblique Segment peridotites, the background field from Johnson et al. (1990) for residual peridotites away from hotspots is included for comparison. For Atlantis II Fracture Zone peridotites, the peridotite field from Johnson and Dick (1992) is used instead, to provide a direct comparison to the previous assessment of Atlantis II variability.

\section{Appendix 5.B}

\section{Spinel Cr\# and predictions of degree of melting}

Hellebrand et al. (2001) proposed that the co-variation of spinel Cr\# with Cpx HREE (Dy, Er and $\mathrm{Yb}$ ) reflects variation in degree of melting and used this to calibrate a degree of melting relationship for spinel Cr\#. In Fig. 5.19, we used this relationship to derive an estimate of the variation in degree of melting along the Oblique Segment. However, the Cr\# estimates for degree of melting do not agree with the estimate from Cpx trace elements. In addition, a considerable range in spinel $\mathrm{Cr} \#$ is observed within dredges, which does not reflect the degree of recent melting.

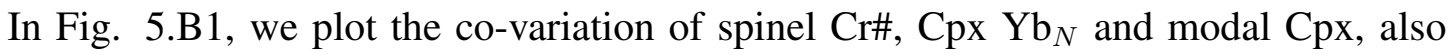
an indicator of degree of melting. Using the full global dataset, the correlation coefficient between Cr\# and Cpx Yb is 0.57, versus 0.75 reported by Hellebrand et al. (2001). Similar decreases in correlation coefficients are observed for Dy and Er. Oblique Segment peridotites are offset to slightly lower Cr\#'s with respect to the global dataset. However, the correlation is worse if these samples are excluded.

We suggest that the correlation of spinel Cr\# with Cpx HREE is only loosely applicable. 
Considerable within-dredge variation in spinel Cr\# is observed at the Oblique Segment. If the average spinel Cr\# per dredge is used to estimate degree of melting, instead of the highest $\mathrm{Cr} \#$, the estimate is still higher than trace element and thermal model estimates (Fig. 5.19). The extent of sample-scale variation in spinel $\mathrm{Cr} \#$ has not been thoroughly assessed, though Hellebrand et al. (2002) found a Cr\# range of 26-49 in spinels from a single Central Indian Ridge peridotite. These observations imply that spinel Cr\# should only be used with caution in estimating degree of melting from peridotite composition.

\section{Appendix 5.C}

\section{Armalcolite in Dredge 96}

The mineral armalcolite $\left(\mathrm{MgFeTi}_{2} \mathrm{O}_{5}\right)$ was identified in pyroxenites from dredge Van796 (Fig. 5.Cl1). Armalcolite is present as small grains at the tips of spinel grains, which are themselves surrounded by plagioclase within secondary gabbro veins (Fig. 5.C1). The approximate composition of the armalcolite is $71 \mathrm{wt} \% \mathrm{TiO}_{2}, 12 \% \mathrm{FeO}, 5 \% \mathrm{Cr}_{2} \mathrm{O}_{3}, 5 \%$ $\mathrm{CaO}, 3 \% \mathrm{MgO}$, and $1 \% \mathrm{Al}_{2} \mathrm{O}_{3}$. An unidentified trace element oxide must also be present, on the basis of the $97 \mathrm{wt} \%$ total and comparison to xenolith armalcolites (Haggerty, 1991). Further work is necessary to constrain the extent of the armalcolite occurrence in dredge Van7-96. We have not yet determined whether the armalcolite originated with the peridotite, the pyroxenites veins or the secondary gabbro veins that crosscut the pyroxenites.

To our knowledge, the armalcolite in dredge Van7-96 is the first observation of this mineral in abyssal peridotites, though it has been identified in continental peridotite xenoliths (e.g., Haggerty, 1987; Ionov et al., 1999) and in harzburgite xenoliths from the Kerguelen islands (Grégoire et al., 2000). Its presence in xenoliths is associated with melt metasomatic assemblages (Haggerty, 1991). We suggest that armalcolite formation in mantle assemblages is related to the breakdown of high-Ti spinel at high temperature to low-Ti spinel 
and a pseudobrookite phase at low temperature (Muan et al., 1971). Armalcolite is a solid solution between ferropseudobrookite and karrooite and can undergo further breakdown to ilmenite solid solution and rutile with decreasing temperature or decreasing $\mathrm{MgO}$ (Lindsley et al., 1974; Xirouchakis et al., 2001). Both rutile and ilmenite have been observed in another SWIR abyssal peridotite in this study, 6K-465-3, suggesting that low volume, highly $\mathrm{TiO}_{2}$ enriched melts are not entirely uncommon during late-stage melt-rock reaction at the ridge axis.

\section{Appendix 5.D}

\section{Notes on gabbro-veined peridotite $6 \mathrm{~K}-465-3$}

Sample 6K-465-3 from the Atlantis II Fracture Zone contains two melt veins of distinct compositions and matrix Cpx with unusual exsolution. One of the melt veins is gabbroic, consisting of plagioclase and Cpx with accessory ilmenite. Cpx porphyroclast cores have been altered to actinolite by high-temperature hydrothermal alteration. The second vein contains kaersutite, plagioclase, ilmenite, rutile, and apatite (Fig. 5.D1), indicating crystallization from a highly differentiated melt. In the peridotite matrix, Cpx porphyroclasts have blebby exsolution of plagioclase, olivine, and spinel, as shown in Fig. 5.D2. Opx does not appear to be present as an exsolution phase in Cpx. Major and trace element compositions

of these accessory mineral phases and the unusual exsolution are presented in Table 5.D11. 


\subsection{Bibliography}

Abelson, M., Agnon, A., 1997. Mechanics of oblique spreading and ridge segmentation. Earth and Planetary Science Letters 148, 405-421.

Albee, A. L., Ray, L., 1970. Correction factors for electron probe microanalysis of silicates, oxides, carbonates, phosphates, and sulfates. Analytical Chemistry 42 (12), 1408-1414.

Anders, E., Grevesse, N., 1989. Abundances of the elements: Meteoritic and solar. Geochimica et Cosmochimica Acta 53, 197-214.

Baines, A. G., Cheadle, M. J., Dick, H. J. B., Hosford Scheirer, A., John, B. E., Kusznir, N. J., Matsumoto, T., 2003. Mechanism for generating the anomalous uplift of oceanic core complexes: Atlantis Bank, southwest Indian Ridge. Geology 31 (12), 1105-1108.

Bence, A. E., Albee, A. L., 1968. Empirical correction factors for the electron microanalysis of silicates and oxides. Journal of Geology 76, 382-403.

Bodinier, J. L., Vasseur, G., Vernieres, J., Dupuy, C., Fabries, J., 1990. Mechanisms of mantle metasomatism: Geochemical evidence from the Lherz Orogenic Peridotite. Journal of Petrology 31 (3), 597-628.

Bonatti, E., Peyve, A., Kepezhinskas, P., Kurentsova, N., Seyler, M., Skolotnev, S., Udintsev, G., 1992. Upper mantle heterogeneity below the Mid-Atlantic Ridge, $0^{\circ}-15^{\circ} \mathrm{N}$. Journal of Geophysical Research 97 (B4), 4461-4476.

Bonatti, E., Seyler, M., Sushevskaya, N., 1993. A cold suboceanic mantle belt at the Earth's equator. Science 261, 315-320.

Bown, J. W., White, R. S., 1994. Variation with spreading rate of oceanic crustal thickness and geochemistry. Earth and Planetary Science Letters 121, 435-449.

Boyd, F. R., Pearson, D. G., Mertzman, S. A., 1999. Spinel-facies peridotites from the kaapvaal root. In: Gurney, J. J., Gurney, J. L., Pascoe, M. D., Richardson, S. H. (Eds.), The J. B. Dawson Volume, Proceedings of the $7^{\text {th }}$ International Kimberlite Conference. Red Roof Design, Cape Town, pp. 40-48.

Brunelli, D., Seyler, M., Cipriani, A., Ottolini, L., Bonatti, E., 2006. Discontinuous melt extraction and weak refertilization of mantle peridotites at the Vema Lithospheric Section (Mid-Atlantic Ridge). Journal of Petrology 47 (4), 745-771.

Cannat, M., 1996. How thick is the magmatic crust at slow spreading ridges. Journal of Geophysical Research 101 (B2), 2847-2857.

Cannat, M., Bideau, D., Bougault, H., 1992. Serpentinized peridotites and gabbros in the Mid-Atlantic Ridge axial valley at $15^{\circ} 37^{\prime} \mathrm{N}$ and $16^{\circ} 52^{\prime} \mathrm{N}$. Earth and Planetary Science Letters 109, 87-106. 
Cannat, M., Rommevaux-Jestin, C., Sauter, D., Deplus, C., Mendel, V., 1999. Formation of the axial relief at the very slow spreading Southwest Indian Ridge $\left(49^{\circ}\right.$ to $\left.69^{\circ} \mathrm{e}\right)$. Journal of Geophysical Research 104 (B10), 22825-22843.

Cannat, M., Seyler, M., 1995. Transform tectonics, metamorphic plagioclase and amphibolitization in ultramafic rocks of the Vema transform fault (Atlantic Ocean). Earth and Planetary Science Letters 133, 283-298.

Cherniak, D. J., Liang, Y., 2007. Rare earth element diffusion in natural enstatite. Geochimica et Cosmochimica Acta 71, 1324-1340.

Constantin, M., 1999. Gabbroic intrusions and magmatic metasomatism in harzburgites from the Garrett transform fault: implications for the nature of the mantle-crust transition at fast-spreading ridges. Contributions to Mineralogy and Petrology 136, 111-130.

Constantin, M., Hékinian, R., Ackermand, D., Stoffers, P., 1995. Mafic and ultramafic intrusions into upper mantle peridotites from fast spreading centers of the Easter Microplate (South East Pacific). In: Vissers, R. L. M., Nicolas, A. (Eds.), Mantle and Lower Crust Exposed in Oceanic Ridges and in Ophiolites. Kluwer Academic Publishers, pp. $71-120$.

Coogan, L. A., Thompson, G. M., MacLeod, C. J., Dick, H. J. B., Edwards, S. J., Hosford Scheirer, A., Barry, T. L., 2004. A combined basalt and peridotite perspective on 14 million years of melt generation at the Atlantis Bank segment of the Southwest Indian Ridge: evidence for temporal changes in mantle dynamics. Chemical Geology 207, 13-30.

Dantas, C., Ceuleneer, G., Gregoire, M., Python, M., Freydier, R., Warren, J., Dick, H. J. B., 2007. Pyroxenites from the Southwest Indian Ridge, $9-16^{\circ} \mathrm{E}$ : Cumulates from incremental melt fractions produced at the top of a cold melting regime. Journal of Petrology 48 (4), 647-660.

Dick, H. J. B., 1989. Abyssal peridotites, very slow spreading ridges and ocean ridge magmatism. In: Saunders, A. D., Norry, M. J. (Eds.), Magmatism in the Ocean Basins. No. 42 in Special Publication. Geological Society of London, pp. 71-105.

Dick, H. J. B., Bullen, T., 1984. Chromian spinel as a petrogenetic indicator in abyssal and alpine-type peridotites and spatially associated lavas. Contributions to Mineralogy and Petrology 86, 54-76.

Dick, H. J. B., Fisher, R. L., Bryan, W. B., 1984. Mineralogic variability of the uppermost mantle along mid-ocean ridges. Earth and Planetary Science Letters 69, 88-106.

Dick, H. J. B., Lin, J., Schouten, H., 2003. An ultraslow-spreading class of ocean ridge. Nature 426, 405-412. 
Dick, H. J. B., Natland, J., Party, L. . S., 1994. Melt transport and evolution in the shallow mantle beneath the East Pacific Rise: preliminary results from ODP site 895. Mineralogical Magazine 58A, 229-230.

Dick, H. J. B., Natland, J. H., 1996. Late-stage melt evolution and transport in the shallow mantle beneath the East Pacific Rise. In: Mével, C., Gillis, K. M., Allan, J. F., Meyer, P. S. (Eds.), Proceedings of the Ocean Drilling Program, Scientific Results. Vol. 147. College Station, TX, pp. 103-134.

Dick, H. J. B., Natland, J. H., Alt, J. C., Bach, W., Bideau, D., Gee, J. S., Haggas, S., Hertogen, J. G. H., Hirth, G., Holm, P. M., Ildefonse, B., Iturrino, G. J., John, B. E., Kelley, D. S., Kikawa, E., Kingdon, A., LeRoux, P. J., Maeda, J., Meyer, P. S., Miller, D. J., NAslund, H. R., Niu, Y.-L., Robinson, P. T., Snow, J., Stephen, R. A., Trimby, P. W., Worm, H.-U., Yoshinobu, A., 2000. A long in situ section of the lower ocean crust: results of ODP Leg 176 drilling at the Southwest Indian Ridge. Earth and Planetary Science Letters 179, 31-51.

Dick, H. J. B., Schouten, H., Meyer, P. S., Gallo, D. G., Bergh, H., Tyce, R., Patriat, P., Johnson, K. T. M., Snow, J., Fisher, A., 1991. Tectonic evolution of the Atlantis II Fracture Zone. In: Von Herzen, R. P., Robinson, P. T. (Eds.), Proceedings of the Ocean Drilling Program, Scientific Results. Vol. 118. College Station, TX, pp. 359-398.

Dosso, L., Bougault, H., Langmuir, C., Bollinger, C., Bonnier, O., Etoubleau, J., 1999. The age and distribution of mantle heterogeneity along the Mid-Atlantic Ridge $\left(31-41^{\circ} \mathrm{N}\right.$. Earth and Planetary Science Letters 170, 269-286.

Dupré, B., Allègre, C. J., 1983. Pb-Sr isotope variation in Indian Ocean basalts and mixing phenomena. Nature 303, 142-146.

Elthon, D., 1992. Chemical trends in abyssal peridotites: refertilization of depleted suboceanic mantle. Journal of Geophysical Research 97 (B6), 9015-9025.

Fujii, T., 1990. Petrology of peridotites from Hole 670A, Leg 109. In: Detrick, R., Honnorez, J., Bryan, W. B., Juteau, T., et al. (Eds.), Proceedings of the Ocean Drilling Program, Scientific Results. Vol. 106/109. College Station, TX, pp. 19-25.

Gaetani, G. A., Grove, T. L., 1998. The influence of water on melting of mantle peridotite. Contributions to Mineralogy and Petrology 131, 323-346.

Godard, M., Bodinier, J.-L., Vasseur, G., 1995. Effects of mineralogical reactions on trace element redistributions in mantle rocks during percolation processes: A chromatographic approach. Earth and Planetary Science Letters 133, 449-461.

Goldstein, S. L., Langmuir, C. H., Soffer, G., Lehnert, K., Cai, Y., Graham, D. W., Michael, P. J., 2006. A "DUPAL" geochemical signature in Gakkel Ridge MORB and relationship to Cenozoic Arctic tectonics. In: AGU 2006 Fall Meeting Supplement. Vol. 87. pp. V12C-02. 
Grégoire, M., Lorand, J. P., O’Reilly, S. Y., Cottin, J. Y., 2000. Armalcolite-bearing, Tirich metasomatic assemblages in harburgitic xenoliths from the Kerguelen Islands: Implications for the oceanic mantle budget of high-field strength elements. Geochimica et Cosmochimica Acta 64, 673-694.

Haggerty, S. E., 1987. Metasomatic mineral titanates in upper mantle xenoliths. In: Nixon, P. H. (Ed.), Mantle Xenoliths. Wiley, pp. 671-690.

Haggerty, S. E., 1991. Oxide mineralogy of the upper mantle. In: Lindsley, D. H. (Ed.), Oxide Minerals: Petrologic and Magnetic Significance. Vol. 25 of Reviews in Mineralogy. Mineralogical Society of America, pp. 355-416.

Hamelin, B., Dupré, B., Allègre, C. J., 1985. Pb-Sr-Nd isotopic data of Indian Ocean ridges: new evidence of large-scale mapping of mantle heterogeneities. Earth and Planetary Science Letters 76, 288-298.

Hamlyn, P. R., Bonatti, E., 1980. Petrology of mantle-derived ultramafics from the Owen Fracture Zone, northwest Indian Ocean: Implications for the nature of the oceanic upper mantle. Earth and Planetary Science Letters 48, 65-79.

Hart, S. R., Dunn, T., 1993. Experimental cpx/melt partitioning of 24 trace elements. Contributions to Mineralogy and Petrology 113, 1-8.

Hartnady, C. J. H., le Roex, A. P., 1985. Southern Ocean hotspot tracks and the Cenozoic absolute motion of the African, Antarctic, and South American plates. Earth and Planetary Science Letters 75, 245-257.

Hellebrand, E., Snow, J. E., 2003. Deep melting and sodic metasomatism underneath the highly oblique-spreading Lena Trough (Arctic Ocean). Earth and Planetary Science Letters 216, 283-299.

Hellebrand, E., Snow, J. E., Dick, H. J. B., Hofmann, A. W., 2001. Coupled major and trace elements as indicators of the extent of meting in mid-ocean-ridge peridotites. Nature 410, $677-681$.

Hellebrand, E., Snow, J. E., Hoppe, P., Hofmann, A. W., 2002. Garnet-field melting and late-stage refertilization in 'residual' abyssal peridotites from the Central Indian Ridge. Journal of Petrology 43 (12), 2305-2338.

Hellebrand, E., Snow, J. E., Mostefaoui, S., Hoppe, P., 2005. Trace element distribution between orthopyroxene and clinopyroxene in peridotites from the Gakkel Ridge: a SIMS and NanoSIMS study. Contributions to Mineralogy and Petrology 150, 486-504.

Hofmann, A. W., Hart, S. R., 1978. An assessment of local and regional isotopic equilibrium in the mantle. Earth and Planetary Science Letters 38, 44-62. 
Hosford, A., Tivey, M., Matsumoto, T., Dick, H., Schouten, H., Kinoshita, H., 2003. Crustal magnetization and accretion at the Southwest Indian Ridge near the Atlantis II fracture zone, 0-25 Ma. Journal of Geophysical Research 108 (B3), 10.1029/2001JB000604.

Ionov, D. A., Grégoire, M., Prikhod'ko, V. S., 1999. Feldspar-Ti-oxide metasomatism in off-cratonic continental and oceanic upper mantle. Earth and Planetary Science Letters $165,37-44$.

Irving, A. J., Frey, F. A., 1984. Trace element abundances in megacrysts and their host basalts: Constraints on partition coefficients and megacryst genesis. Geochimica et Cosmochimica Acta 48, 1201-1221.

Iwamori, H., 1992. Melt-solid flow with diffusion-controlled chemical reaction. Geophysical Research Letters 19, 309-312.

Iwamori, H., 1993. A model for disequilibrium mantle melting incorporating melt transport by porous and channel flows. Nature 366, 734-737.

Jaroslow, G. E., Hirth, G., Dick, H. J. B., 1996. Abyssal peridotite mylonites: implications for grain-size sensitive flow and strain localization in the oceanic lithosphere. Tectonophysics $256,17-37$.

Jochum, K. P., Dingwell, D. B., Rocholl, A., Stoll, B., Hofmann, A. W., et al., 2000. The preparation and preliminary characterisation of eight geological MPI-DING reference glasses for in-situ microanalysis. Geostandards Newsletter 24 (1), 87-133.

John, B. E., Foster, D. A., Murphy, J. M., Cheadle, M. J., Baines, A. G., Fanning, C. M., Copeland, P., 2004. Determining the cooling history of in situ lower oceanic crust Atlantis Bank, SW Indian Ridge. Earth and Planetary Science Letters 222, 145-160.

Johnson, K. T. M., 1990. Trace element geochemistry of oceanic peridotites and silicate melt inclusions: implications for mantle melting and ocean ridge magmagenesis. Ph.D. thesis, MIT/WHOI Joint Program.

Johnson, K. T. M., Dick, H. J. B., June 1992. Open system melting and temporal and spatial variation of peridotite and basalt at the Atlantis II Fracture Zone. Journal of Geophysical Research 97 (B6), 9219-9241.

Johnson, K. T. M., Dick, H. J. B., Shimizu, N., 1990. Melting in the oceanic upper mantle: An ion microprobe study of diopsides in abyssal peridotites. Journal of Geophysical Research 95, 2661-2678.

Juteau, T., Berger, E., Cannat, M., 1990. Serpentinized, residual mantle peridotites from the M.A.R. median valley, ODP Hole 670A $\left(21^{\circ} 10^{\prime} \mathrm{N}, 45^{\circ} 02^{\prime} \mathrm{W}\right.$, Leg 109): Primary mineralogy and geothermometry. In: Detrick, R., Honnorez, J., Bryan, W. B., Juteau, T., et al. (Eds.), Proceedings of the Ocean Drilling Program, Scientific Results. Vol. 106/109. College Station, TX, pp. 27-45. 
Kelemen, P. B., Hirth, G., Shimizu, N., Spiegelman, M., Dick, H. J. B., 1997. A review of melt migration processes in the adiabatically upwelling mantle beneath oceanic spreading ridges. Philosophical Transactions of the Royal Society of London A 355, 283-318.

Kelemen, P. B., Shimizu, N., Salters, V. J. M., 1995. Extraction of mid-ocean-ridge basalt from the upwelling mantle by focused flow of melt in dunite channels. Nature 375, 747753.

Kelemen, P. B., Yogodzinski, G. M., Scholl, D. W., 2003. Along-strike variation in lavas of the Aleutian island arc: Implications for the genesis of high $\mathrm{Mg \#}$ andesite and the continental crust. In: Eiler, J. (Ed.), The Subduction Factory. Vol. 138 of Geophysical Monograph. American Geophysical Union, pp. 223-276.

Kempton, P. D., Stephens, C. J., 1997. Petrology and geochemistry of nodular websterite inclusions in harzburgite, Hole 920D. In: Karson, J. A., Cannat, M., Miller, D. J., Elthon, D. (Eds.), Proceedings of the Ocean Drilling Program, Scientific Results. Vol. 153. College Station, TX, pp. 321-331.

Kinzler, R. J., 1997. Melting of mantle peridotite at pressures approaching the spinel to garnet transition: Application to mid-ocean ridge basalt petrogenesis. Journal of Geophysical Research 102 (B1), 853-874.

Klein, E. M., Langmuir, C. H., 1989. Loval versus global variations in ocean ridge basalt composition. Journal of Geophysical Research 94 (B4), 4241-4252.

Komor, S. C., Grove, T. L., Hébert, R., 1990. Abyssal peridotites from ODP Hole 670A $\left(21^{\circ} 10^{\prime} \mathrm{N}, 45^{\circ} 02^{\prime} \mathrm{W}\right)$ : residues of mantle melting exposed by non-constructive axial divergence. In: Detrick, R., Honnorez, J., Bryan, W. B., Juteau, T., et al. (Eds.), Proceedings of the Ocean Drilling Program, Scientific Results. Vol. 106/109. College Station, TX, pp. 85-101.

Kumagai, H., Dick, H. J. B., Kaneoka, I., 2003. Noble gas signatures of abyssal gabbros and peridotites at an Indian Ocean core complex. Geochemistry, Geophysics, and Geosystems 4 (12), 10.1029/2003GC000540.

Le Mée, L., Girardeau, J., Monnier, C., 2004. Mantle segmentation along the Oman ophiolite fossil mid-ocean ridge. Nature 432, 167-172.

Lee, K.-L., 1997. Petrological and geochemical studies of an abyssal peridotite from the Atlantis II Fracture Zone. Master's thesis, MIT/WHOI Joint Program.

Liang, Y., 2003. Kinetics of crystal-melt reaction in partially molten silicates: 1. grain scale processes. Geochemistry, Geophysics, and Geosystems 4 (5), 10.1029/2002GC000375.

Lindsley, D. H., 1980. Phase equilibria of pyroxenes at pressures $>1$ atmosphere. In: Prewitt, C. T. (Ed.), Pyroxenes. Vol. 7 of Reviews in Mineralogy. Mineralogical Society of America, pp. 289-307. 
Lindsley, D. H., Kesson, S. E., Hartzman, M. J., Cushman, M. K., 1974. The stability of armalcolite: Experimental studies in the system $\mathrm{MgO}-\mathrm{Fe}-\mathrm{Ti}-\mathrm{O}$. In: Proceedings of the Fifth Lunar Conference. pp. 521-534.

Lizarralde, D., Gaherty, J. B., Collins, J. A., Hirth, G., Kim, S. D., 2004. Spreading-rate dependence of melt extraction at mid-ocean ridges from mantle seismic refraction data. Nature 432, 744-747.

Lo Cascio, M., Liang, Y., Hess, P. C., 2004. Grain-scale processes during isothermal-isobaric melting of lherzolite. Geophysical Research Letters 31 (L16605), 10.1029/2004GL020602.

Luguet, A., Lorand, J.-P., Seyler, M., 2003. Sulfide petrology and highly siderophile element geochemistry of abyssal peridotites: A coupled study of samples from the kane fracture zone $\left(45^{\circ} \mathrm{w} 23^{\circ} 20 \mathrm{n}\right.$, mark area, atlantic ocean). Geochimica et Cosmochimica Acta 67 (8), 1553-1570.

Meyzen, C. M., Toplis, M. J., Humler, E., Ludden, J. N., Mével, C., 2003. A discontinuity in mantle composition beneath the southwest Indian ridge. Nature 421, 731-733.

Michael, P. J., Bonatti, E., 1985. Peridotite composition from the North Atlantic: regional and tectonic variations and implications for partial melting. Earth and Planetary Science Letters 73, 91-104.

Michael, P. J., Langmuir, C. H., Goldstein, S. L., Graham, D. W., Ionov, D. A., Matzen, A. K., 2006. Evidence from volatiles and trace elements for continental mantle in the source of Gakkel Ridge MORB. In: AGU 2006 Fall Meeting Supplement. Vol. 87. pp. V12C-03.

Montési, L. G. J., Behn, M. D., Barry, J. L., 2006. Mantle flow and melting at oblique segments of the Southwest Indian Ridge. Geophysical Research Abstracts 8, 04319.

Morgan, Z., Liang, Y., 2005. An experimental study of the kinetics of lherzolite reactive dissolution with applications to melt channel formation. Contributions to Mineralogy and Petrology 150, 369-385.

Muan, A., Hauck, J., Osborn, E. F., Schairer, J. F., 1971. Equilibrium relations among phases occurring in lunar rocks. In: Proceedings of the Second Lunar Science Conference. Vol. 1. pp. 497-505.

Navon, O., Stolper, E., 1987. Geochemical consequences of melt percolation: the upper mantle as a chromatographic column. Journal of Geology 95, 285-307.

Niu, Y., Hékinian, R., 1997. Basaltic liquids and harzburgitic residues in the Garrett Transform: a case study at fast-spreading ridges. Earth and Planetary Science Letters 146, $243-258$. 
Niu, Y., Langmuir, C. H., Kinzler, R. J., 1997. The origin of abyssal peridotites: a new perspective. Earth and Planetary Science Letters 152, 251-265.

O’Neill, H. S. C., 1981. The transition between spinel lherzolite and garnet lherzolite, and its use as a geobarometer. Contributions to Mineralogy and Petrology 77, 185-197.

Ozawa, K., Shimizu, N., 1995. Open-system melting in the upper mantle: Constraints from the Hayachine-Miyamori ophiolite, northeastern Japan. Journal of Geophysical Research 100 (B11), 22315-22335.

Prinz, M., Keil, K., Green, G. A., Reid, A. M., Bonatti, E., Honnorez, J., 1976. Ultramafic and mafic dredge sampels from the equatorial mid-Atlantic ridge and fracture zones. Journal of Geophysical Research 81, 4087-4103.

Qin, Z., 1992. Disequilibrium partial melting model and its implications for trace element fractionations during mantle melting. Earth and Planetary Science Letters 112, 75-90.

Reid, I., Jackson, H. R., 1981. Oceanic spreading rate and crustal thickness. Marine Geophysical Researches 5, 165-172.

Ross, K., Elthon, D., 1997. Extreme incompatible trace-element depletion of diopside in residual mantle from south of the Kane Fracture Zone. In: Karson, J. A., Cannat, M., Miller, D. J., Elthon, D. (Eds.), Proceedings of the Ocean Drilling Program, Scientific Results. Vol. 153. College Station, TX, pp. 277-284.

Salters, V. J. M., Dick, H. J. B., 2002. Mineralogy of the mid-ocean-ridge basalt source from neodymium isotopic composition of abyssal peridotites. Nature 418, 68-72.

Sauter, D., Mendel, V., Rommevaux-Jestin, C., Parson, L. M., Fujimoto, H., Mével, C., Cannat, M., Tamaki, K., 2004. Focused magmatism versus amagmatic spreading along the ultra-slow spreading Southwest Indian Ridge: Evidence from TOBI side scan sonar imagery. Geochemistry, Geophysics, and Geosystems 5 (10), 10.1029/2004GC000738.

Sen, G., Frey, F. A., Shimizu, N., Leeman, W. P., 1993. Evolution of the lithosphere beneath Oahu, Hawaii: rare earth element abundances in mantle xenoliths. Earth and Planetary Science Letters 119, 53-69.

Seyler, M., Bonatti, E., 1997. Regional-scale melt-rock interaction in lherzolitic mantle in the Romanche Fracture Zone (Atlantic Ocean). Earth and Planetary Science Letters 146, 273-287.

Seyler, M., Cannat, M., Mével, C., 2003. Evidence for major-element heterogeneity in the mantle source of abyssal peridotites from the Southwest Indian Ridge $\left(52^{\circ}\right.$ to $68^{\circ} \mathrm{e}$. Geochemistry, Geophysics, and Geosystems 4 (2), 10.1029/2002GC000305.

Seyler, M., Lorand, J.-P., Dick, H. J. B., Drouin, M., 2007. Pervasive melt percolation reactions in ultra-depleted refractory harzburgites at the Mid-Atlantic Ridge, $15^{\circ} 20^{\prime} \mathrm{N}$ : ODP Hole 1274A. Contributions to Mineralogy and Petrology 153, 303-319. 
Seyler, M., Lorand, J.-P., Toplis, M. J., Godard, G., 2004. Asthenospheric metasomatism beneath the mid-ocean ridge: Evidence from depleted abyssal peridotites. Geology 32 (4), 301-304.

Seyler, M., Toplis, M. J., Lorand, J.-P., Luguet, A., Cannat, M., 2001. Clinopyroxene microtextures reveal incompletely extracted melts in abyssal peridotites. Geology 29 (2), $155-158$.

Shimizu, N., Semet, M. P., Allègre, C. J., 1978. Geochemical applications of quantitative ion-microprobe analysis. Geochimica et Cosmochimica Acta 42, 1321-1334.

Sleep, N. H., Barth, G. A., 1997. The nature of oceanic lower crust and shallow mantle emplaced at low spreading rates. Tectonophysics 279, 181-191.

Sneeringer, M., Hart, S. R., Shimizu, N., 1984. Strontium and samarium diffusion in diopside. Geochimica et Cosmochimica Acta 48, 1589-1608.

Snow, J. E., June 1993. The isotope geochemistry of abyssal peridotites and related rocks. Ph.D. thesis, MIT/WHOI Joint Program.

Spiegelman, M., Kelemen, P. B., 2003. Extreme chemical variability as a consequence of channelized melt transport. Geochemistry, Geophysics, and Geosystems 4 (7), 10.1029/2002GC000336.

Spiegelman, M., Kenyon, P., 1992. The requirements for chemical disequilibrium during magma migration. Earth and Planetary Science Letters 109, 611-620.

Standish, J. J., 2006. The influence of ridge geometry at the ultraslow-spreading Southwest Indian Ridge $\left(9^{\circ}-25^{\circ} \mathrm{E}\right)$ : Basalt composition sensitivity to variations in source and process. Ph.D. thesis, MIT/WHOI Joint Program.

Standish, J. J., Dick, H. J. B., Michael, P. J., Melson, W. G., O’Hearn, T., submitted. Ridge geometry and major element chemistry on the Southwest Indian Ridge $\left(9^{\circ}-25^{\circ} \mathrm{E}\right)$ : Process versus source during MORB generation at ultraslow spreading rates. Geochemistry, Geophysics, and Geosystems.

Stephens, C. J., 1997. Heterogeneity of oceanic peridotite from the western canyon wall at MARK: Results from Site 920. In: Karson, J. A., Cannat, M., Miller, D. J., Elthon, D. (Eds.), Proceedings of the Ocean Drilling Program, Scientific Results. Vol. 153. College Station, TX, pp. 285-303.

Su, Y., Langmuir, C. H., 2003. Global MORB chemistry compilation at the segment scale. Ph.D. thesis, Dept. of Earth and Environmental Sciences, Columbia University.

Takahashi, E., 1986. Melting of a dry peridotite KLB-1 up to 14 GPa: Implications on the origin of peridotitic upper mantle. Journal of Geophysical Research 91 (B9), 9367-9382. 
Takazawa, E., Frey, F. A., Shimizu, N., Obata, M., Bodinier, J. L., 1992. Geochemical evidence for melt migration and reaction in the upper mantle. Nature 359, 55-58.

Tartarotti, P., Susini, S., Nimis, P., Ottolini, L., 2002. Melt migration in the upper mantle along the Romanche Fracture Zone (Equatorial Atlantic). Lithos 63, 125-149.

Van Orman, J. A., Grove, T. L., Shimizu, N., 2001. Rare earth element diffusion in diopside: influence of temperature, pressure, ionic radius, and an elastic model for diffusion in silicates. Contributions to Mineralogy and Petrology 141, 687-703.

Van Orman, J. A., Grove, T. L., Shimizu, N., 2002. Diffusive fractionation of trace elements during production and transport of melt in earth's upper mantle. Earth and Planetary Science Letters 198, 93-112.

Vernières, J., Godard, M., Bodinier, J.-L., 1997. A plate model for the simulation of trace element fractionation during partial melting and magma transport in the Earth's upper mantle. Journal of Geophysical Research 102 (B11), 2471-24784.

Witt-Eickschen, G., O’Neill, H. S. C., 2005. The effect of temperature on the equilibrium distribution of trace elements between clinopyroxene, orthopyroxene, olivine and spinel in upper mantle peridotite. Chemical Geology 221, 65-101.

Workman, R. K., Hart, S. R., 2005. Major and trace element composition of the depleted MORB mantle (DMM). Earth and Planetary Science Letters 231, 53-72.

Xirouchakis, D., Hirschmann, M. M., Simpson, J. A., 2001. The effect of titanium on the silica content and on mineral-liquid partitioning of mantle-equilibrated melts. Geochimica et Cosmochimica Acta 65 (14), 2201-2217. 

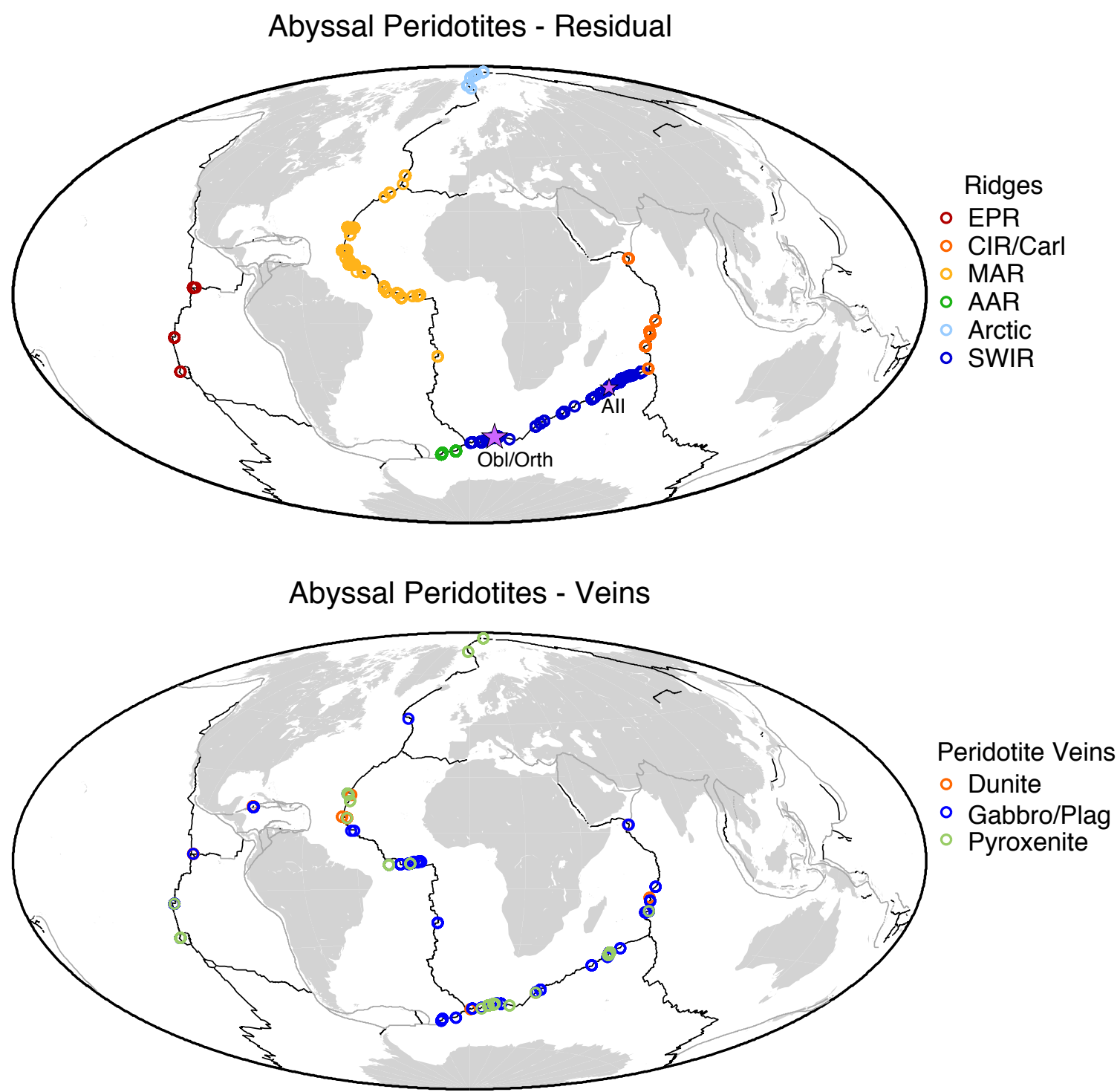

Figure 5.1: Global distribution of depleted (top) and veined (bottom) abyssal peridotites. Peridotite locations are for peridotites with published modal, Cpx trace element, or spinel $\mathrm{Cr} \#$ analyses; sources are listed by location in Table 5.1. Depleted peridotites have been filtered for any peridotites with veins or $>.05 \%$ plagioclase and are colored according to ridge location: East Pacific Rise (EPR), Mid-Cayman Rise (MCR), Central Indian Ridge/Carlsberg Ridge (CIR/Carl), Mid-Atlantic Ridge (MAR), American-Antarctic Ridge (AAR), Gakkel Ridge/Lena Trough/Knipovitch Ridge (Arctic) and the Southwest Indian Ridge (SWIR). Locations of the two focus areas for this study, the Oblique and Orthogonal Segments and the Atlantis II Fracture Zone are indicated by purple stars. Veined peridotites are colored according to their dominant vein lithology. Gabbro/Plag refers to both gabbro veins in peridotites and peridotites with $>.05 \%$ matrix plagioclase. 

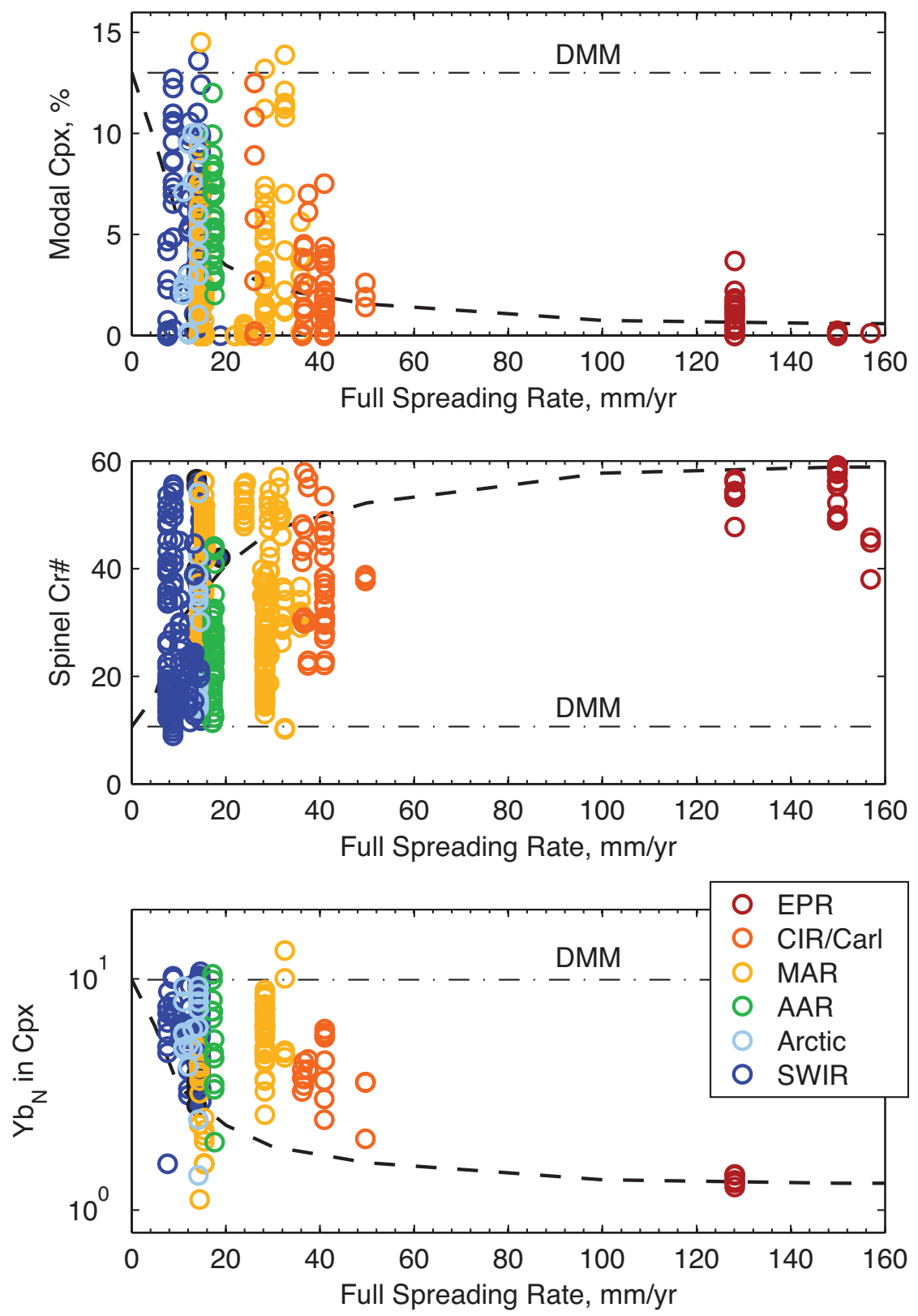

Figure 5.2: Variations in peridotite compositions as a function of spreading rate. Data are from this study and references in Table 5.1. Dashed lines are the predicted variations in composition based on (i) the degree of melting predicted by a simple plate model with conductive cooling (Reid and Jackson, 1981, Bown and White, 1994) and (ii) non-modal fractional melting using parameters and equations from Johnson et al. (1990), Kinzler (1997), Hellebrand et al. (2001), Kelemen et al. (2003) and Workman and Hart (2005). Yb is normalized to chondrite (Anders and Grevesse, 1989), $\mathrm{Cr} \#$ is calculated as $\mathrm{Cr} /(\mathrm{Cr}+\mathrm{Al})$ and the composition of DMM is from Workman and Hart (2005). 

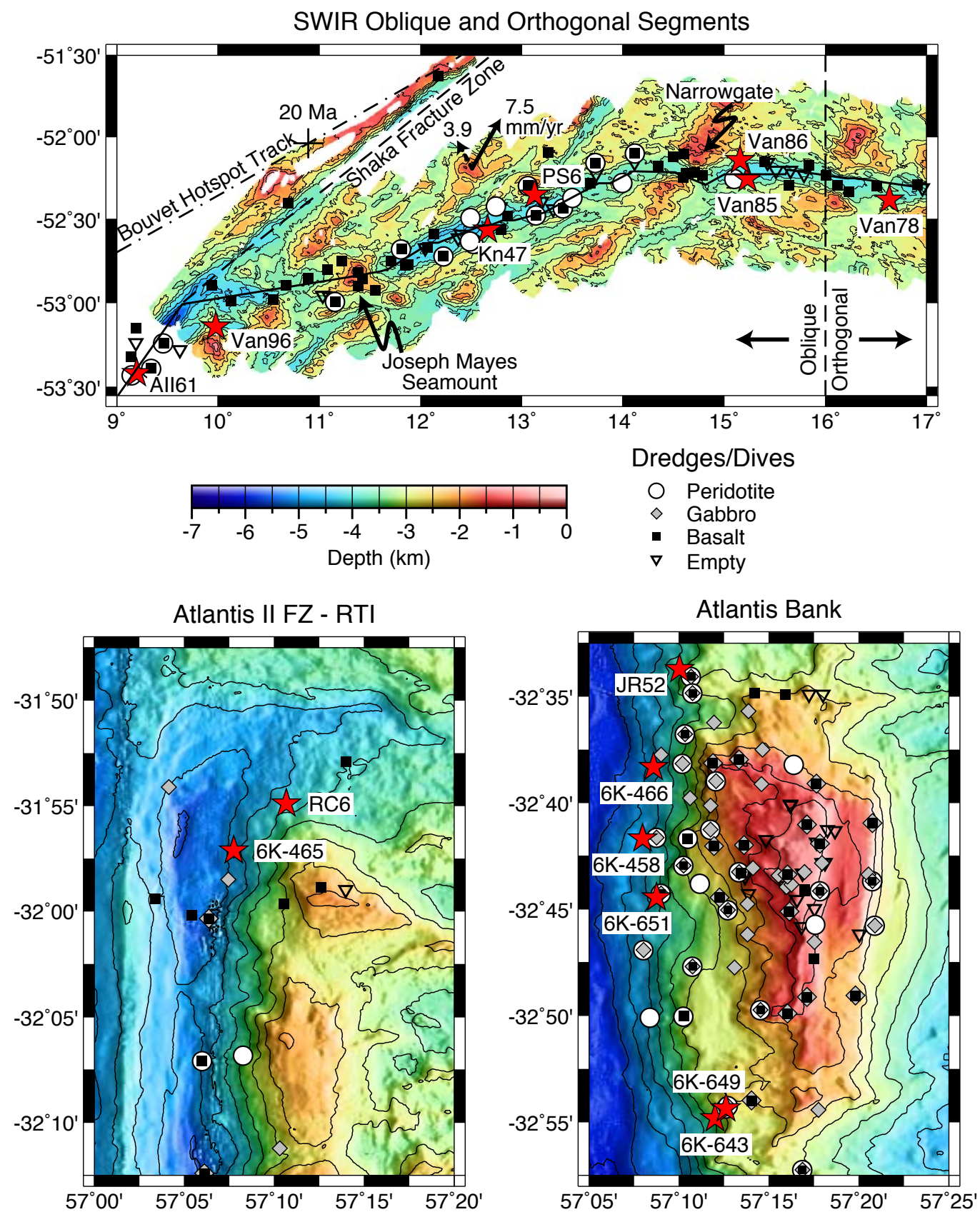

Figure 5.3: Maps of the SWIR study areas. Shown at top are the Oblique Segment and western end of the Orthogonal Segment, along with the Bouvet hotspot path Hartnady and le Roex (1985). At bottom, two localities on Atlantis II Fracture Zone are shown - the northern ridge-transform intersection (RTI) and Atlantis Bank. The fracture zone is parallel to the western edge of both maps, with Atlantis Bank located on the active portion of the transform fault at 11-12 Ma (John et al., 2004). Red stars indicate sample locations for this study. Dredges are labeled with a letter abbreviation to indicate the cruise (see Table 5.2). Dives are indicated by the prefix 6K, to indicate sampling by the submersible Shinkai 6500 . 

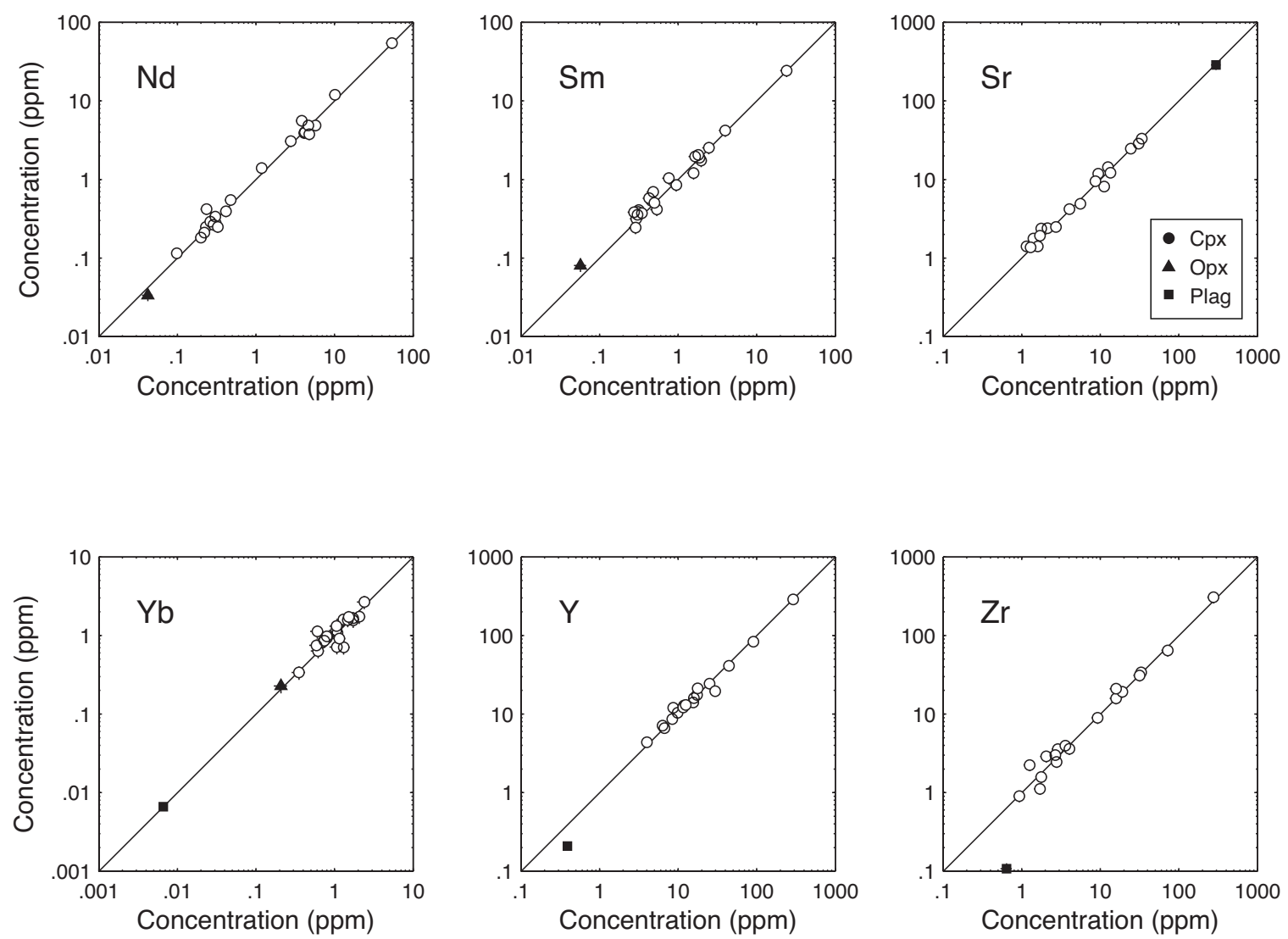

Figure 5.4: Comparison of duplicate ion probe concentration analyses for Cpx, plus one Opx and one Plag analysis. Error bars are generally smaller than the symbol size. 

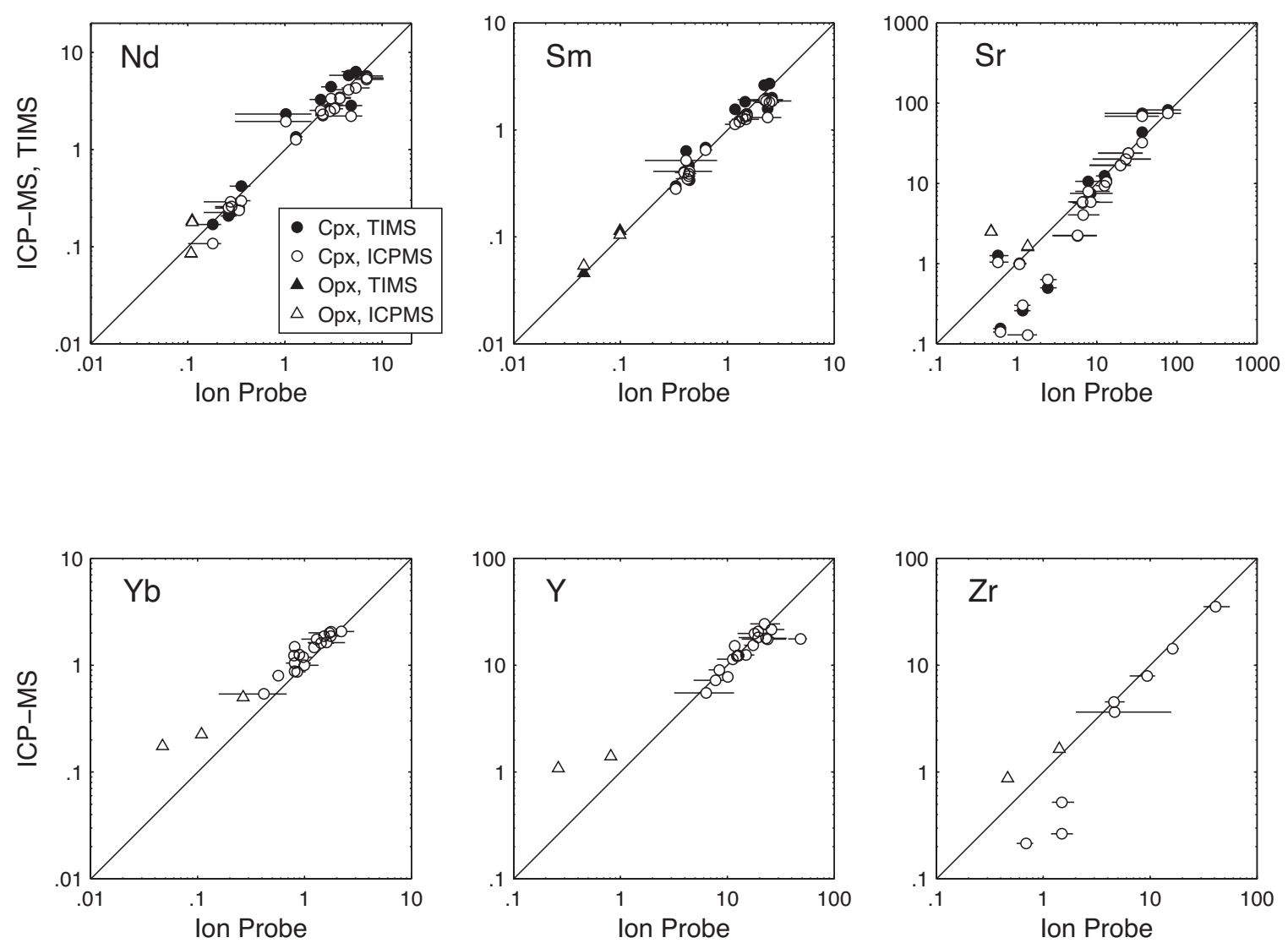

Figure 5.5: Comparison of ion probe concentration data (in ppm) with ICP-MS and TIMS data for Cpx and Opx. The ICP-MS and TIMS data were determined for mineral separates and the error is generally smaller than the symbol size. The ion probe Cpx data are averages of several in situ analyses per sample and the horizontal bar indicates the compositional range of the sample. For the three Opx analyses, the ion probe data is not representative of the bulk Opx composition as only one point was measured per sample. 

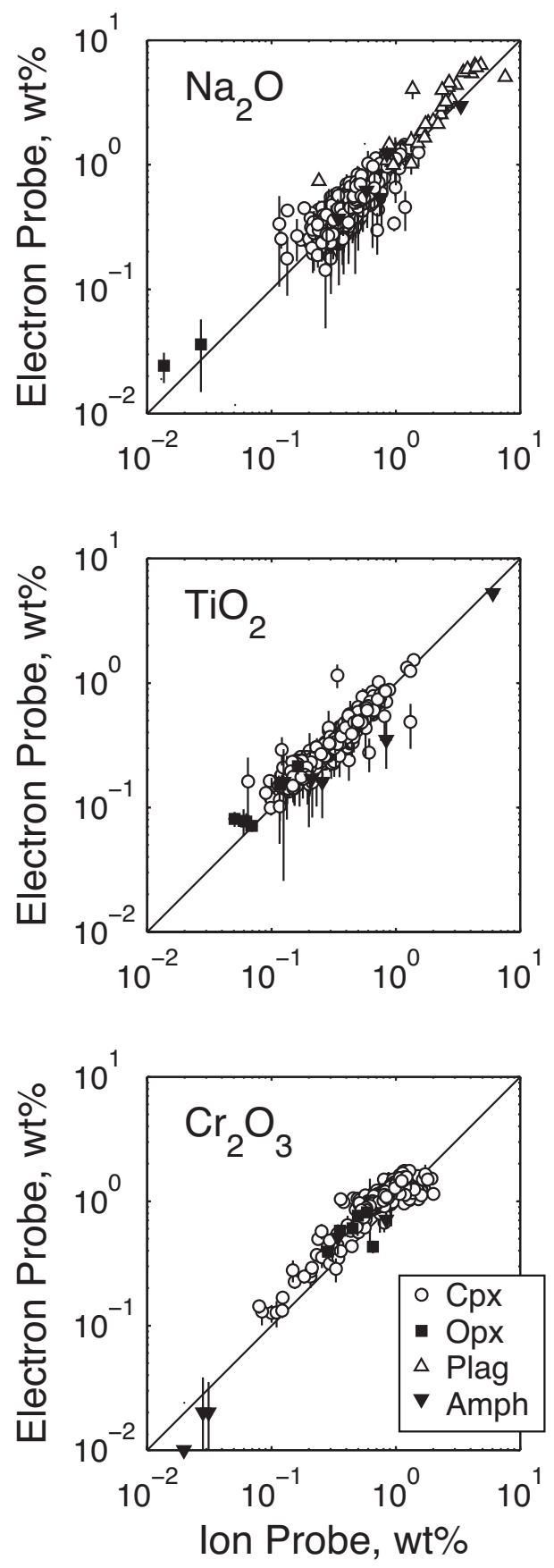

Figure 5.6: Comparison of $\mathrm{Na}_{2} \mathrm{O} \mathrm{TiO}$ and $\mathrm{Cr}_{2} \mathrm{O}_{3}$ concentrations, in wt $\%$, measured by ion probe and electron probe, for Cpx, Opx, Plag, and amphibole. Error bars for ion probe analyses are calculated based on from the average percent deviation of duplicate Cpx analyses (Table 5.10) and are generally smaller than the symbol size. Electron probe analyses are the averages of multiple analyses and vertical bars are the standard deviations. Variations are largest for pyroxenes, due to exsolution effects. 

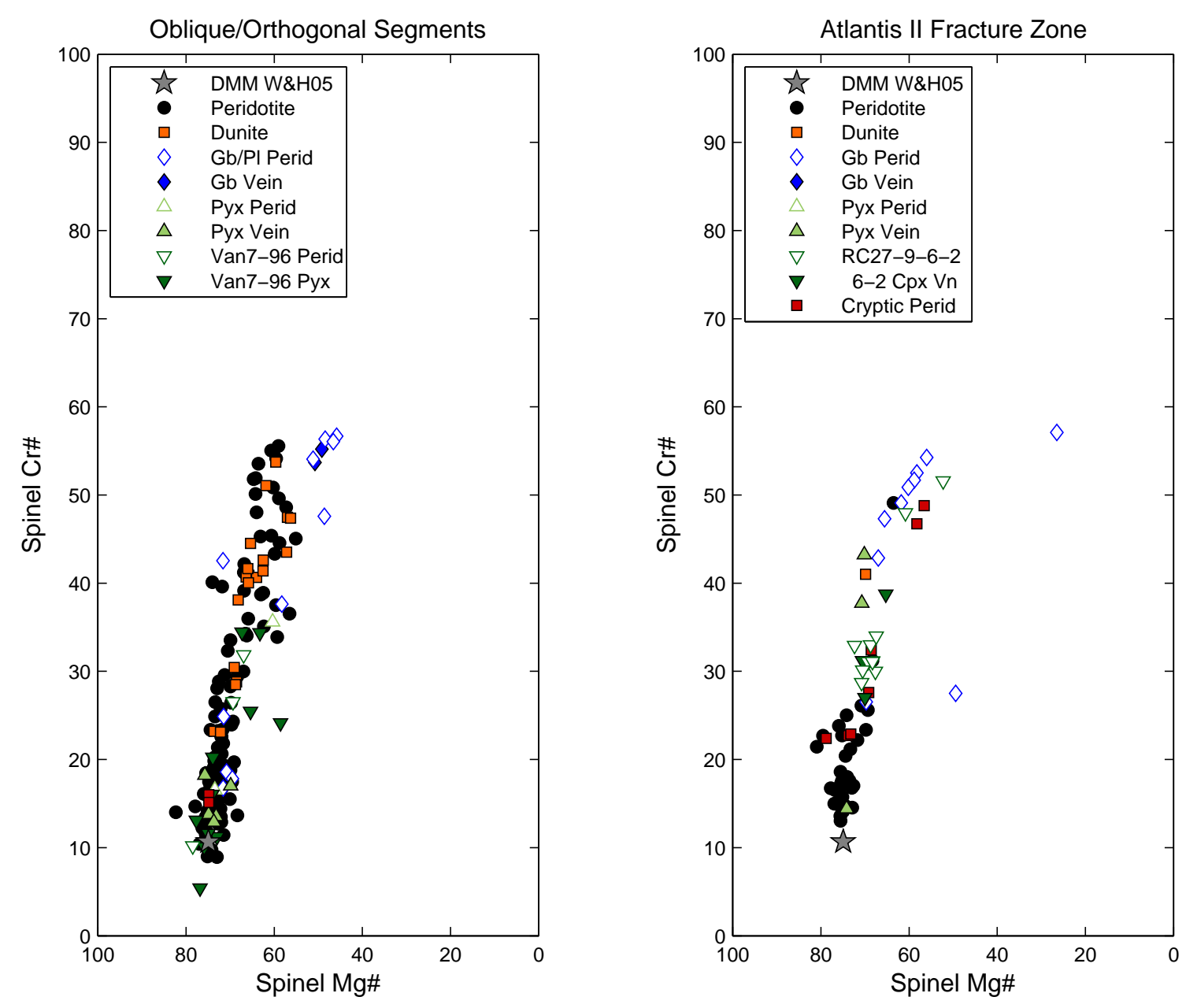

Figure 5.7: Variation of Spinel Cr\# with $\mathrm{Mg \#}$ in peridotites, veined peridotites, and dunites. The range of the residual peridotites is typical for abyssal peridotites (see Figure 5.18 for a comparison). Additional spinel data for these localities are from the peridotite compilation in Table 5.1 and unpublished data from H. J. B. Dick. 

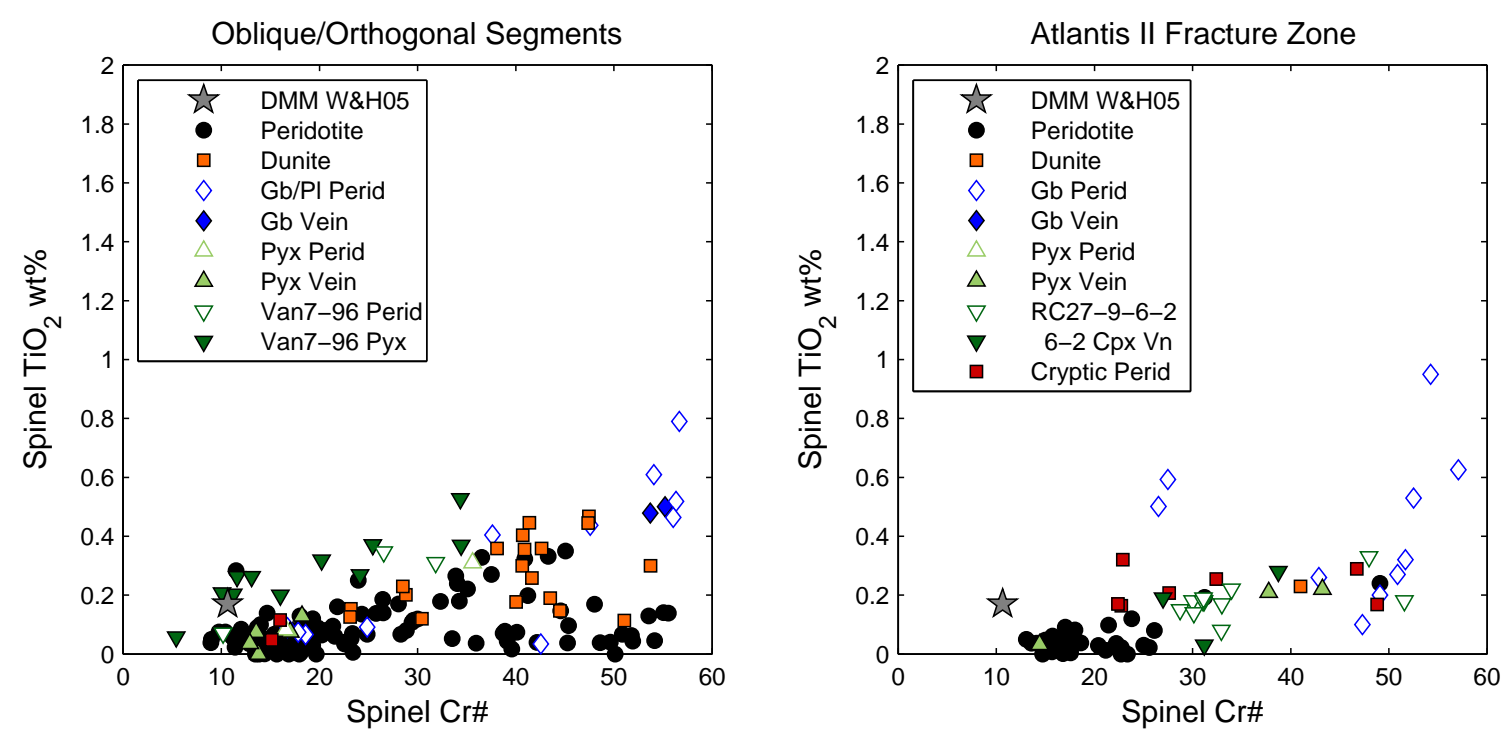

Figure 5.8: Variation of Spinel $\mathrm{TiO}_{2}$ with $\mathrm{Cr} \#$ among veined and unveined peridotites and dunites. $\mathrm{TiO}_{2}$ concentrations greater than $0.2 \mathrm{wt} \%$ (e.g., greater than DMM) are indicative of melt crystallization (Dick and Bullen, 1984).
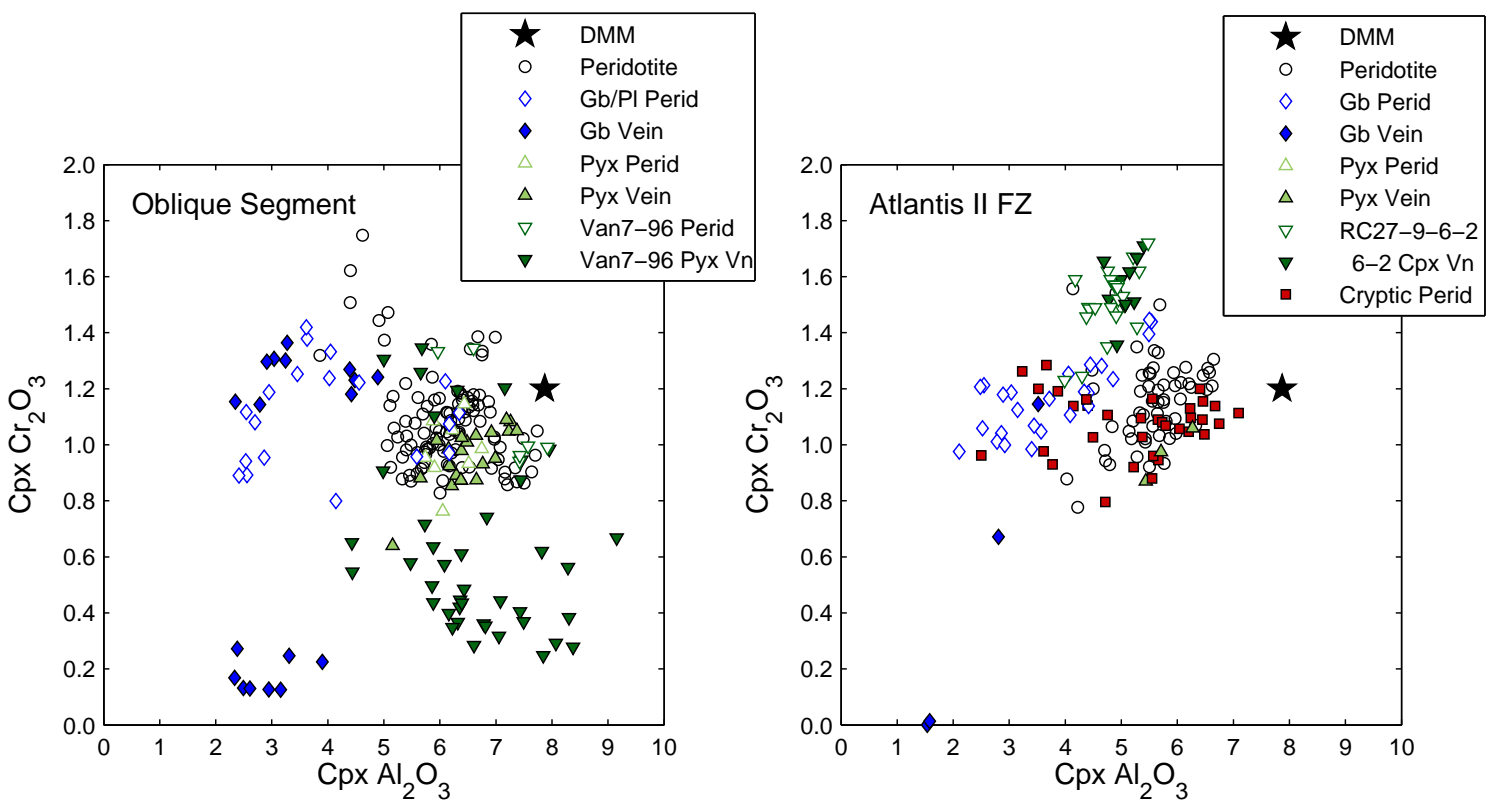

Figure 5.9: Variations of $\mathrm{Cr}_{2} \mathrm{O}_{3}$ with $\mathrm{Al}_{2} \mathrm{O}_{3}$ in $\mathrm{Cpx}$ from veined and unveined peridotites. The pyroxenite-veined peridotites from dredge Van7-96 and clinopyroxenite-veined peridotite sample RC27-9-6-2 were the focus of Chapter 4. Additional data for these localities are from Johnson et al. (1990), Johnson and Dick (1992) and H. J. B. Dick unpublished data. 

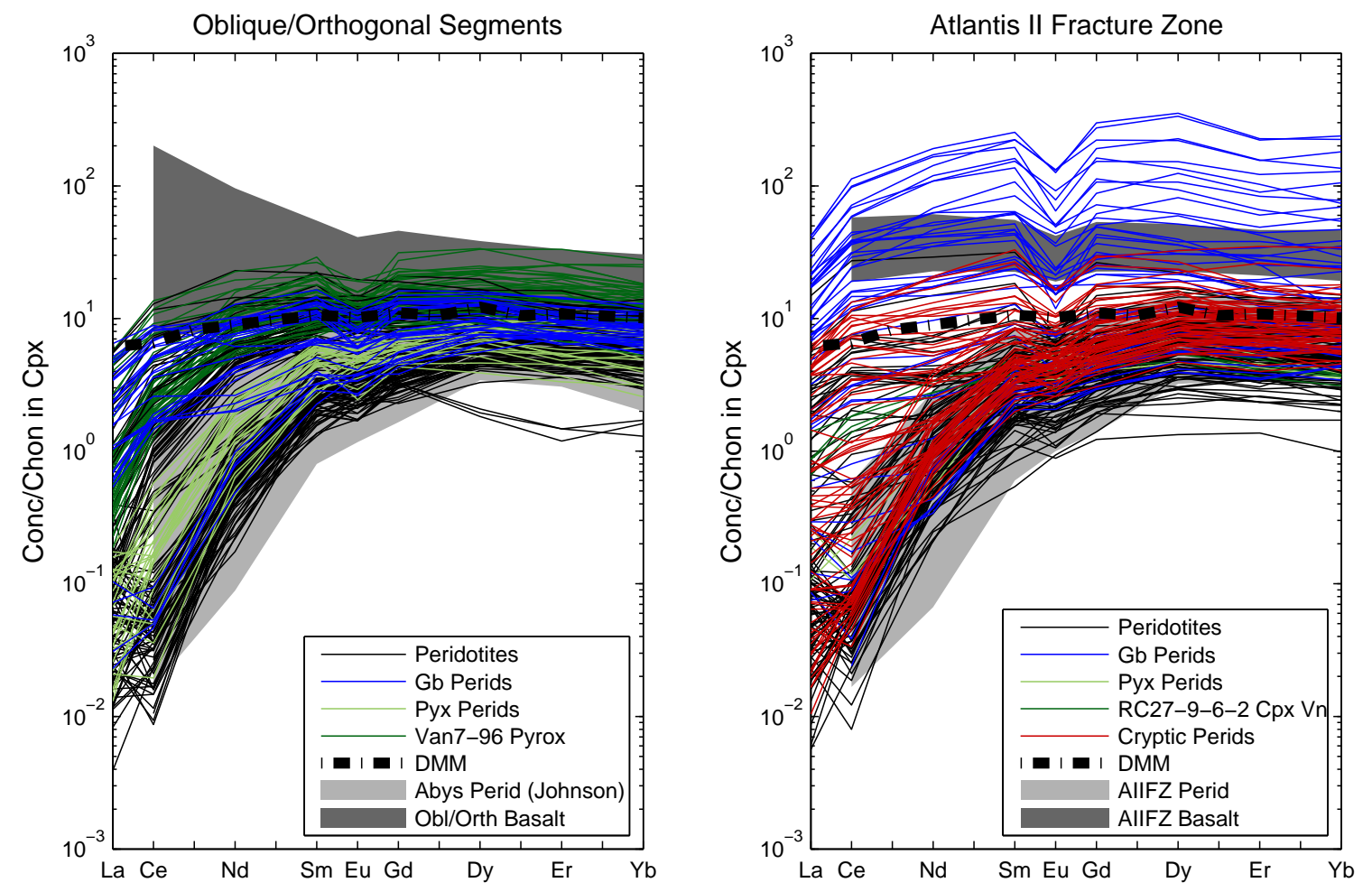

Figure 5.10: Variations in REEs among individual Cpx from veined and unveined peridotites. For the Oblique/Orthogonal Segments, the light grey field is abyssal peridotites away from hotspots (Johnson et al., 1990) and the dark grey field is Oblique/Orthogonal Segment basalts (Standish, 2006). For the Atlantis II Fracture Zone, the background fields are peridotites (light grey) and basalts (dark grey) along the fracture zone (Johnson and Dick, 1992). 

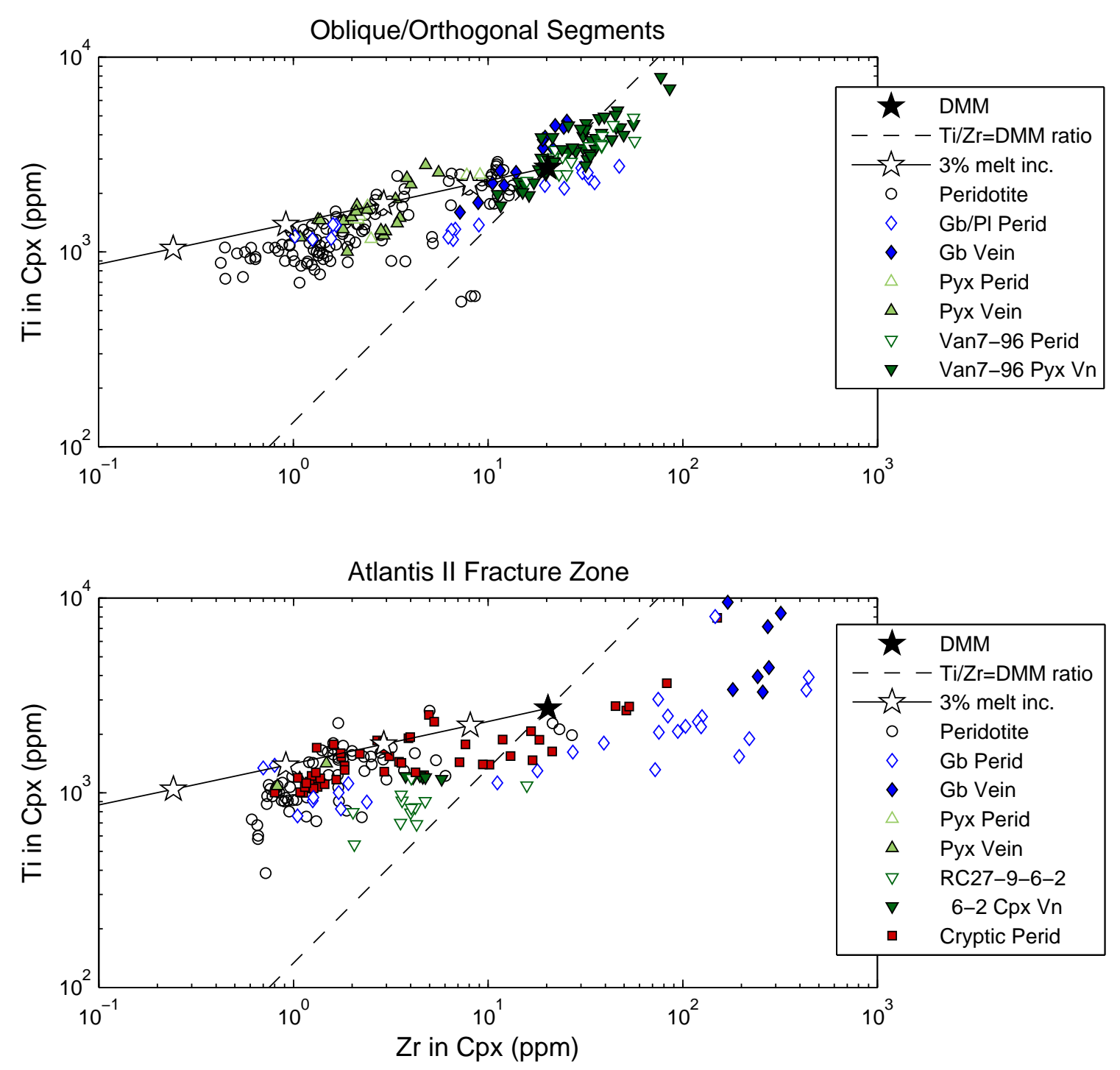

Figure 5.11: Co-variations of $\mathrm{Ti}$ and $\mathrm{Zr}$ in peridotite $\mathrm{Cpx}$ from the Oblique and Orthogonal Segments and the Atlantis II Fracture Zone. The melting trend, labeled for 3\% fractional melting increments, was calculated using melt modes from Kinzler (1997) and partition coefficients from the compilation in Kelemen et al. (2003). DMM is from Workman and Hart (2005) and the dashed line indicates the variation of $\mathrm{Ti}$ with $\mathrm{Zr}$ at a constant DMM Ti:Zr ratio. 

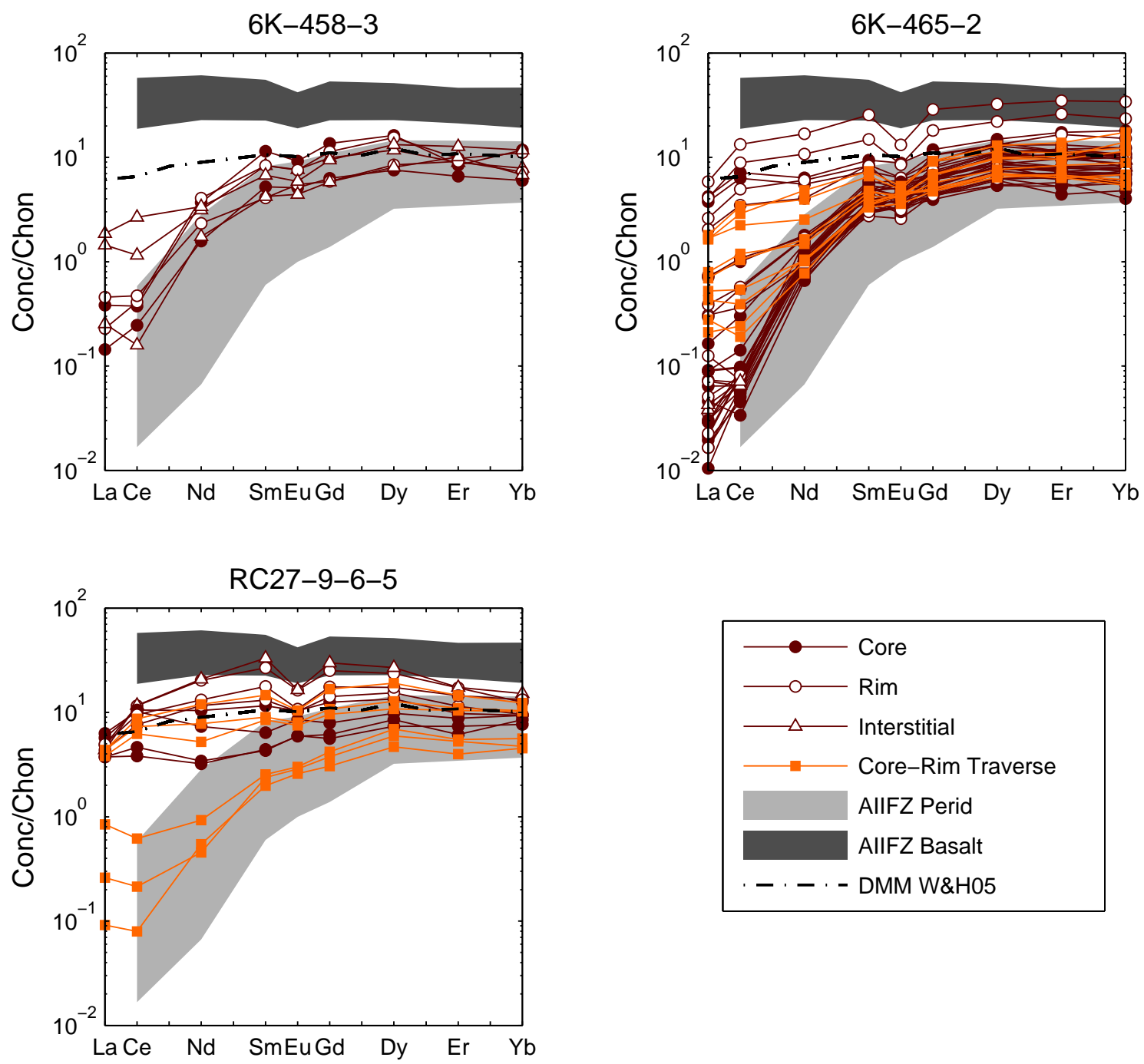

Figure 5.12: Variation of REEs in cryptically metasomatized peridotites from Atlantis II Fracture Zone. 6K-458-3 is from Atlantis Bank and the other two samples are from the ridge-transform intersection (Figure 5.3). The core-rim traverses in two of the plots are for individual grains. In $6 \mathrm{~K}-465-2$, this grain is located between depleted and enriched grains and is shown in Figure 5.15. In the other two samples, the location of the boundary between depleted and enriched compositions has not been fully mapped out. Background fields are from Johnson and Dick (1992). 

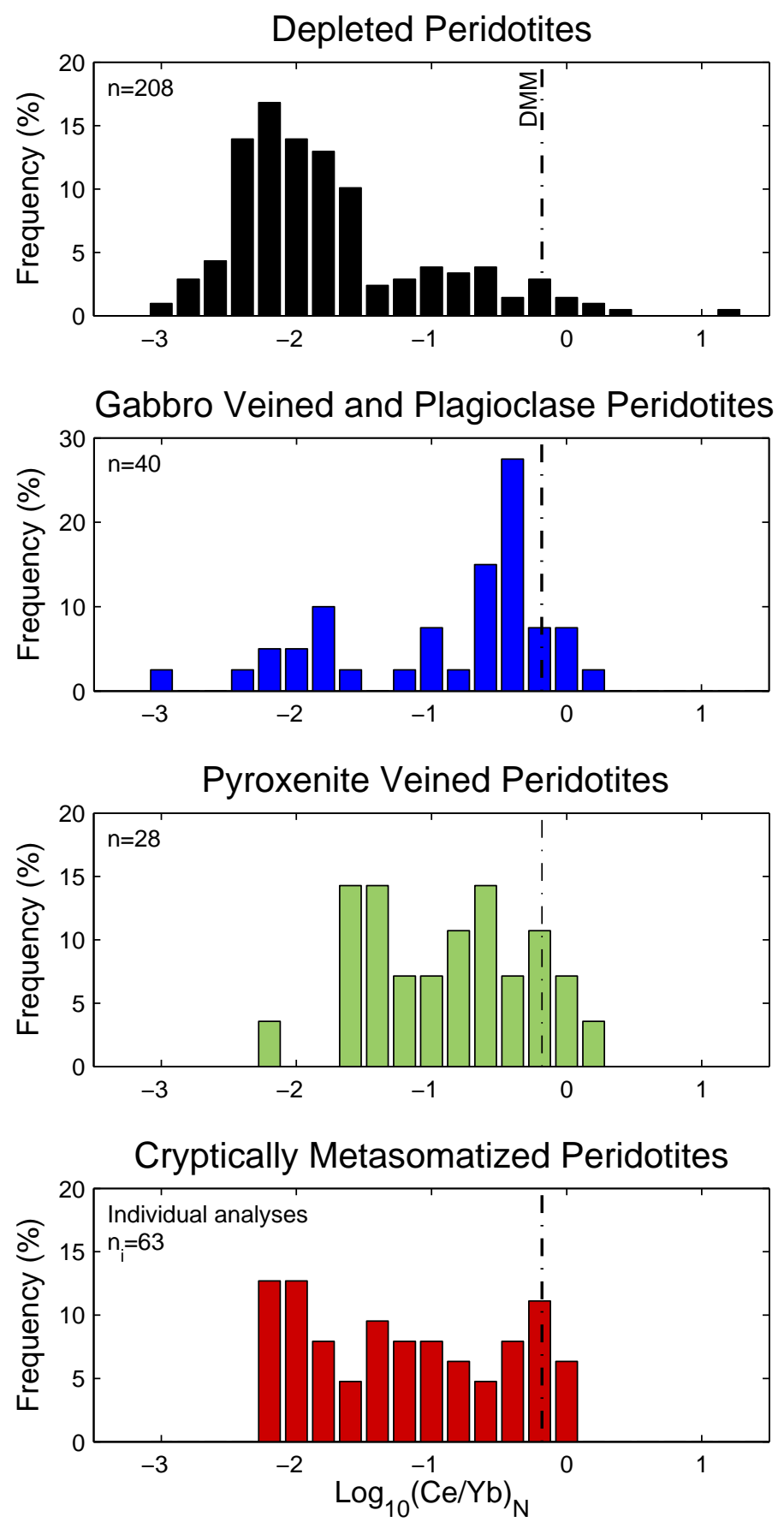

Figure 5.13: Histograms of $\mathrm{Ce} / \mathrm{Yb}$ in $\mathrm{Cpx}$, for the global abyssal peridotite dataset. Histograms are based on sample average compositions, with the exception of the cryptically metasomatized peridotites. For these three samples, individual analyses were used due to their large within-sample variations. The composition of DMM is from Workman and Hart (2005) and peridotite compositions are from this study, H. J. B. Dick unpublished data, and the compilation in Table 5.1 . 

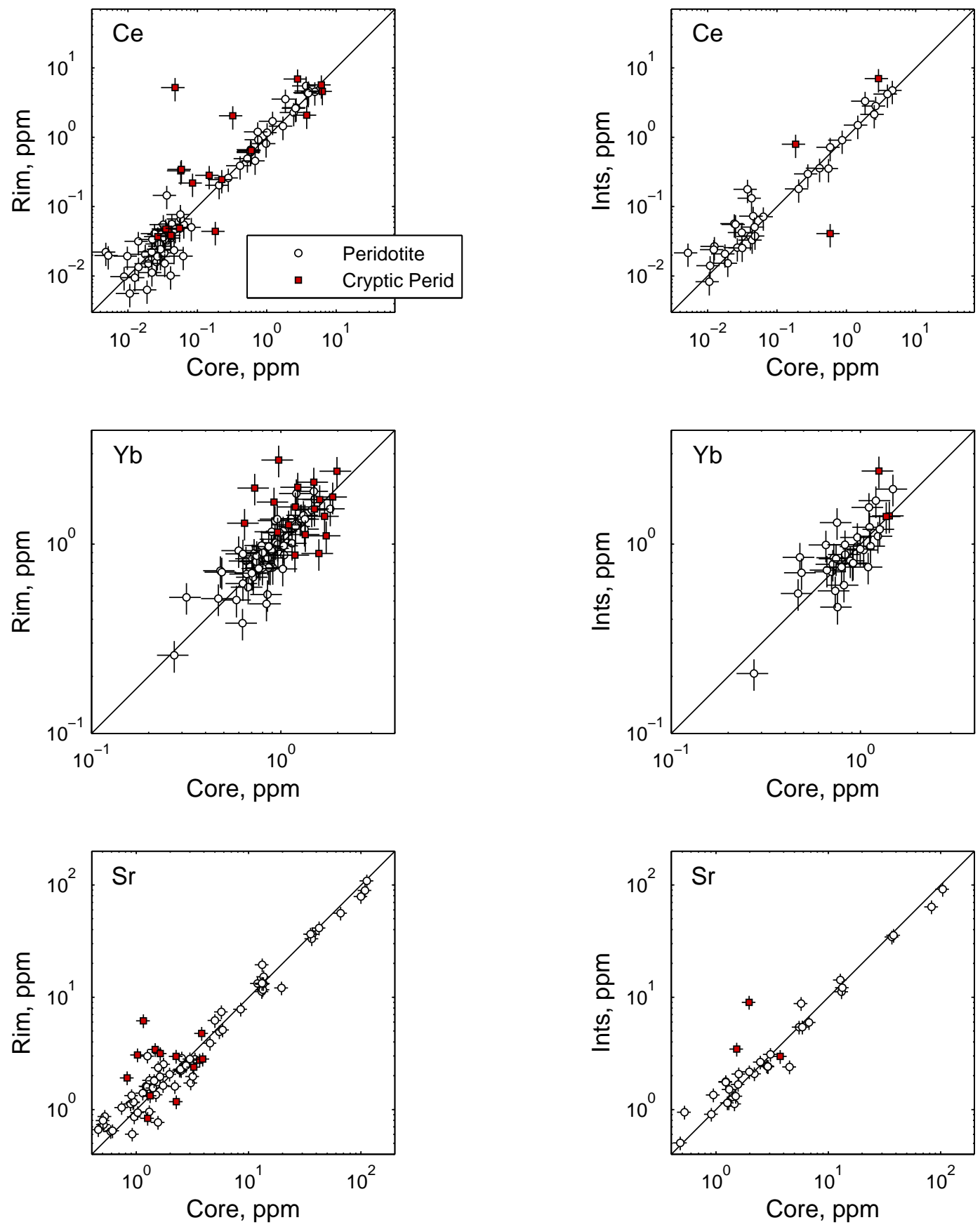

Figure 5.14: Comparisons of Cpx porphyroclast core and rim analyses and porphyroclast core and interstitial grain analyses, for vein-free peridotites. Cryptic refers to the 3 cryptically metasomatized peridotites. Interstitial grains are $<1 \mathrm{~mm}$ diameter and typically have no exsolution lamellae. Error bars are based on the percent error among duplicate analyses (Table 5.10). 


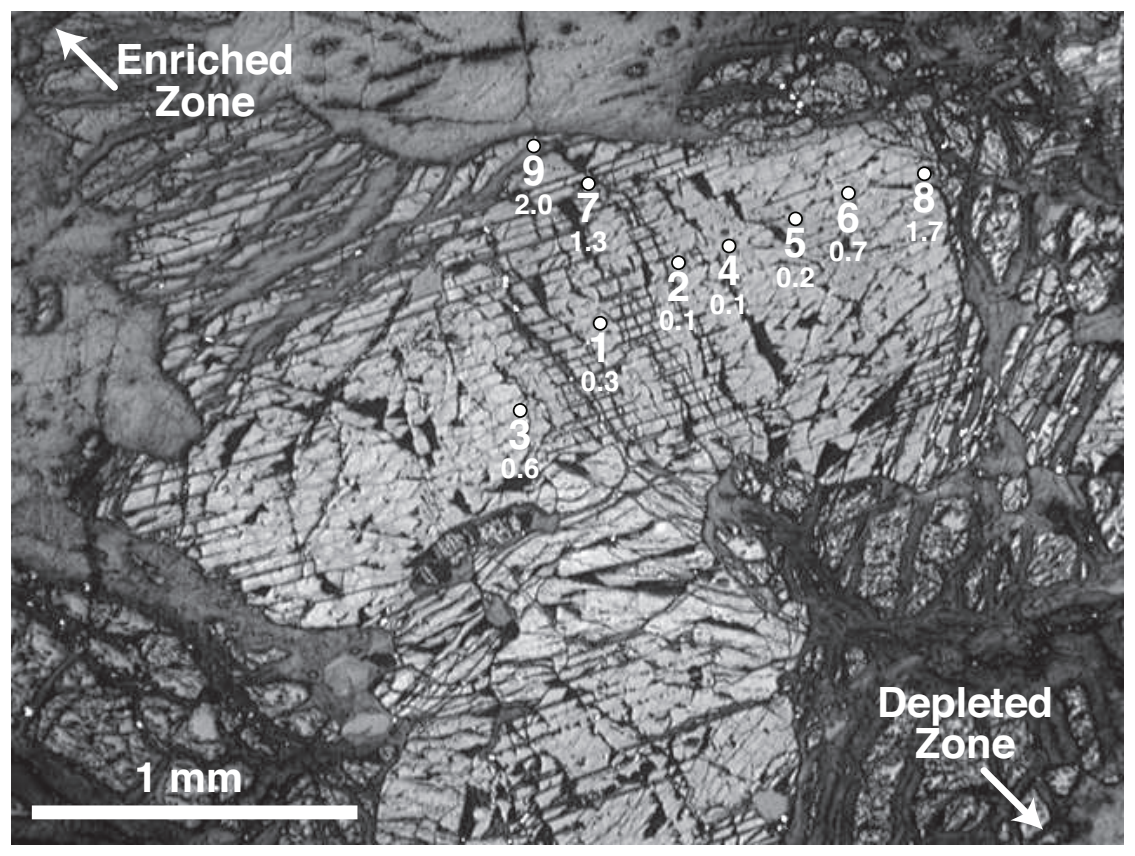

Figure 5.15: Photomicrograph of compositionally zoned Cpx6 from sample 6K-465-2. Numbering of analytical points corresponds to the numbering in Tables 5.6 and 5.10. Smaller numbers are Ce concentrations in ppm. The lowest trace element concentrations are centered around Point 4. Point 3, while appearing to be near the gain center, has high concentrations, suggesting that in the third dimension it is near the grain rim. 

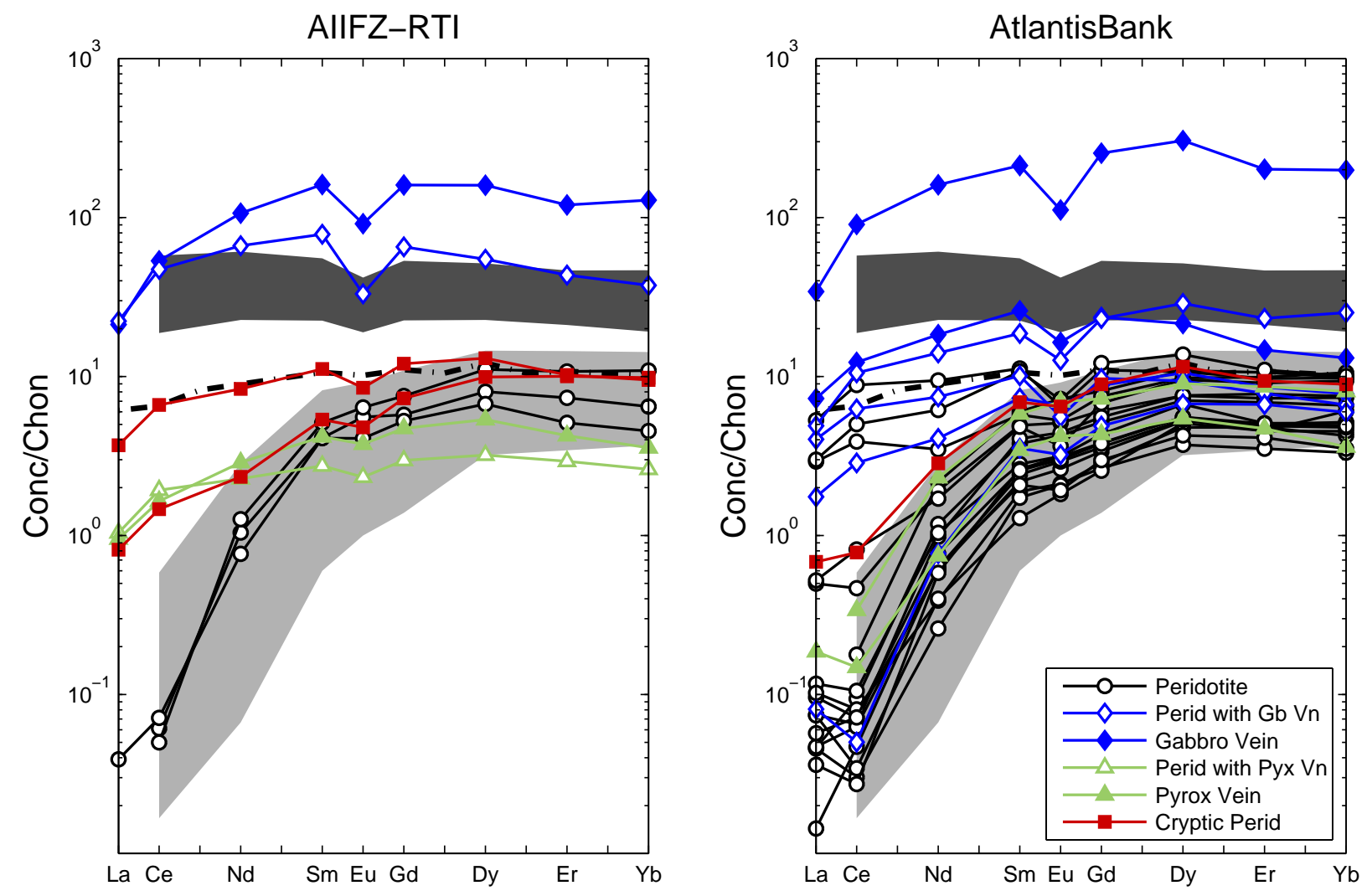

Figure 5.16: Atlantis II Fracture Zone REE variations at the ridge-transform intersection (RTI) and on Atlantis Bank. Peridotites, shown as sample averages, have large compositional variations at both locations. The sample averages for the chromatographic peridotites (red), when plotted as individual analyses (Figure 5.12) extend over almost the entire range of other peridotites from these locations. Background fields are for fracture zone peridotites (light grey) and basalts (dark grey) from Johnson and Dick (1992). Additional individual samples for the two locations are from Johnson (1990) and unpublished data from H. J. B. Dick. 

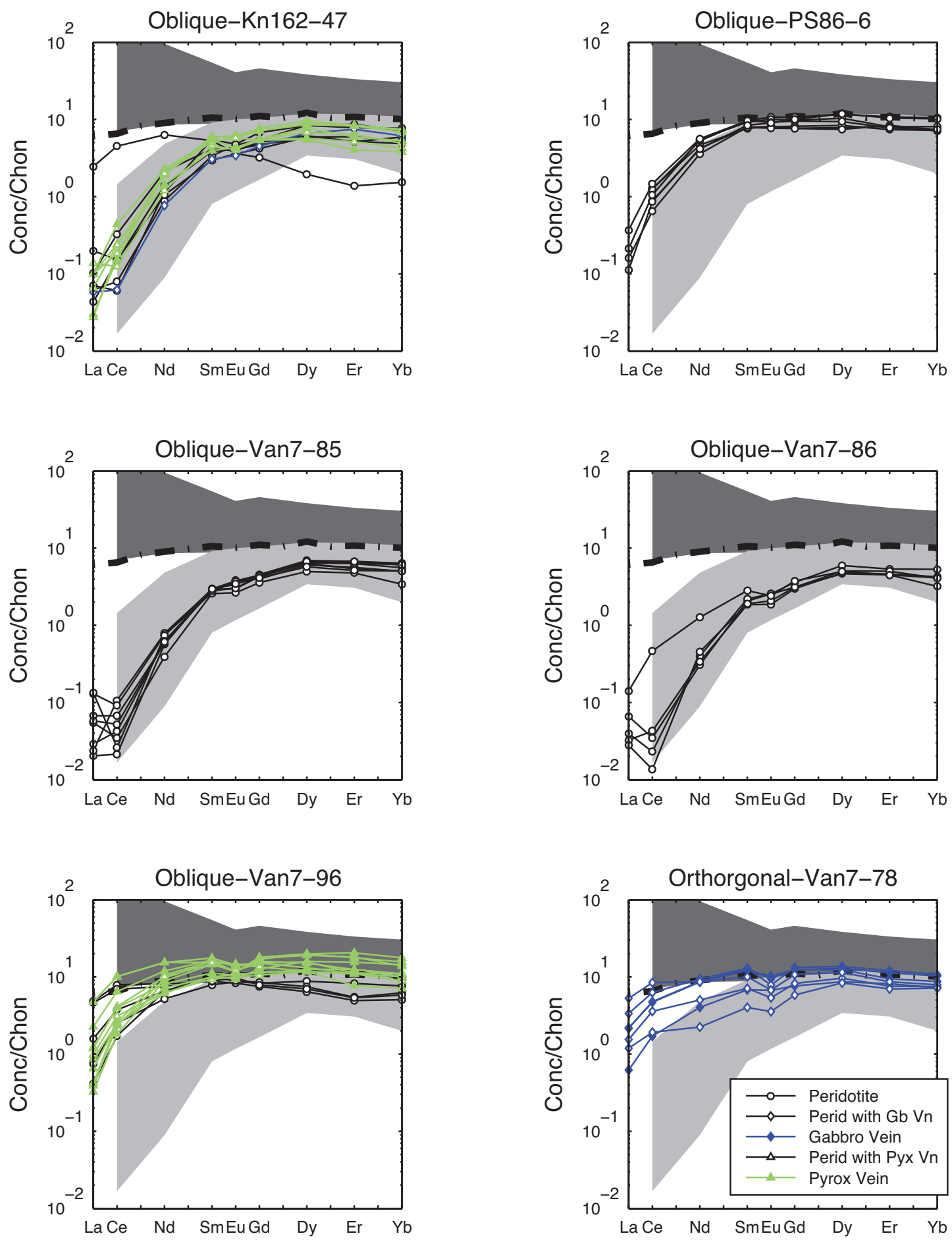

Figure 5.17: Variation in REEs for dredges from the Oblique and Orthogonal Segments. Additional data for PS86-6 from Johnson et al. (1990) and unpublished data from H. J. B. Dick. Background fields are for abyssal peridotites (light grey, Johnson et al., 1990) and Oblique/Orthogonal Segment basalts (dark grey, Standish, 2006). 

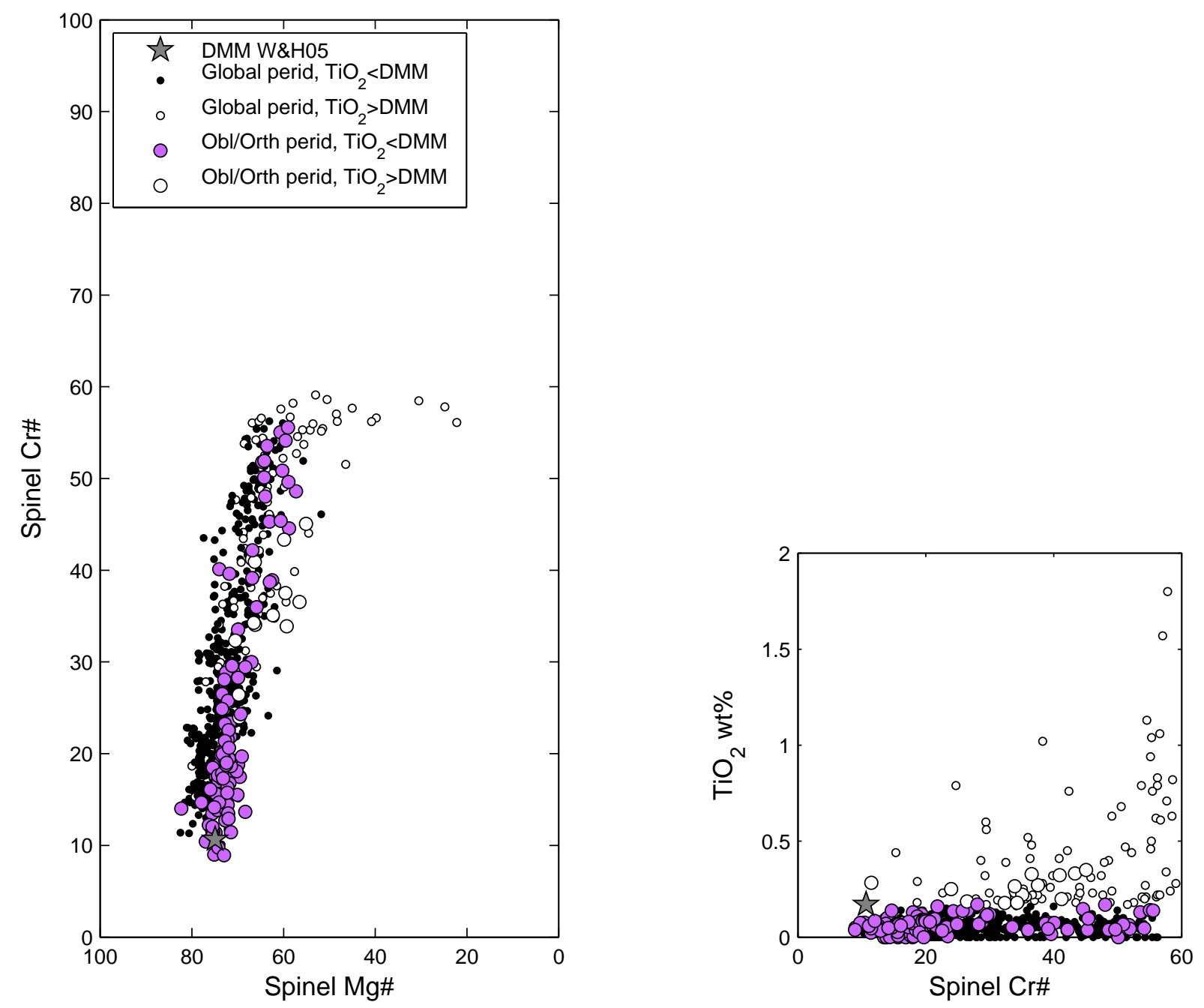

Figure 5.18: Variation of spinel compositions in the global peridotite dataset (small symbols) and the Oblique/Orthogonal Segments (large symbols). Spinels with $\mathrm{TiO}_{2}$ concentrations greater than DMM spinel $(0.17 \mathrm{wt} \%$ Workman and Hart, 2005) are identified by unfilled symbols. These spinels reflect melt addition to the peridotite (Dick and Bullen, 1984). 

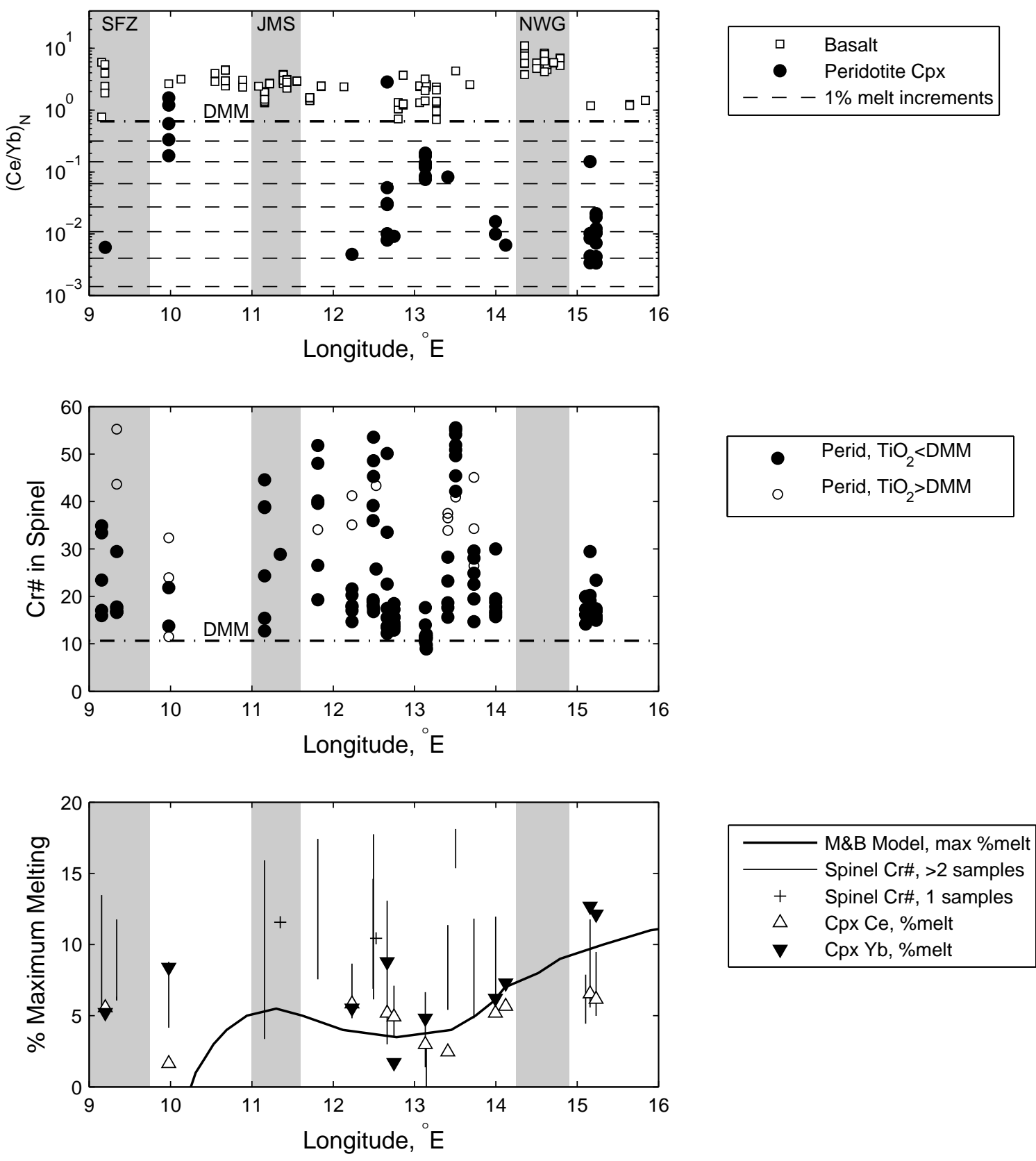

Figure 5.19: Variations along the Oblique Segment in trace element compositions, Spinel $\mathrm{Cr} \#$, and predicted degree of melting. Degree of melting from $\mathrm{Ce}, \mathrm{Yb}$ and $\mathrm{Ce} / \mathrm{Yb}$ in $\mathrm{Cpx}$ are calculated for fractional melting using parameters discussed in the text. Degree of melting from spinel $\mathrm{Cr} \#$ is calculated using the empirical relationship from Hellebrand et al. (2001). The predicted maximum degree of melting line is from the model by Montési et al. (2006), which accounts for variations in ridge thermal structure due to changes in ridge geometry along the Oblique Segment. The grey shaded areas indicate the location of the Shaka Fracture Zone (SFZ), Joseph-Mayes Seamount (JMS), and Narrowgate (NWG). Basalt data are from Standish (2006). 


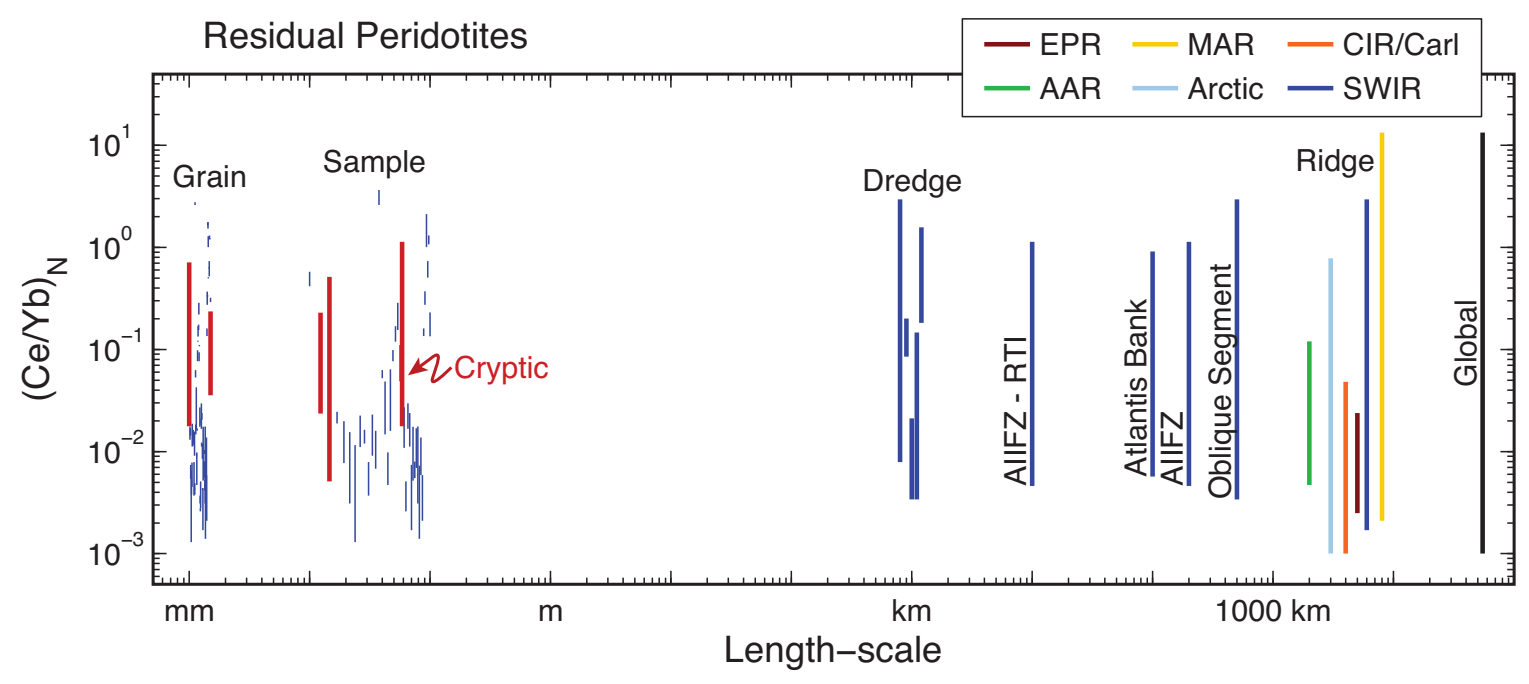

Figure 5.20: Length-scales of residual peridotite variability, based on the $\mathrm{Ce} / \mathrm{Yb}$ range among Cpx. Data for the smallest length-scales are from this study; at the ridge-scale, data are from the compilation summarized in Table 5.1 . 

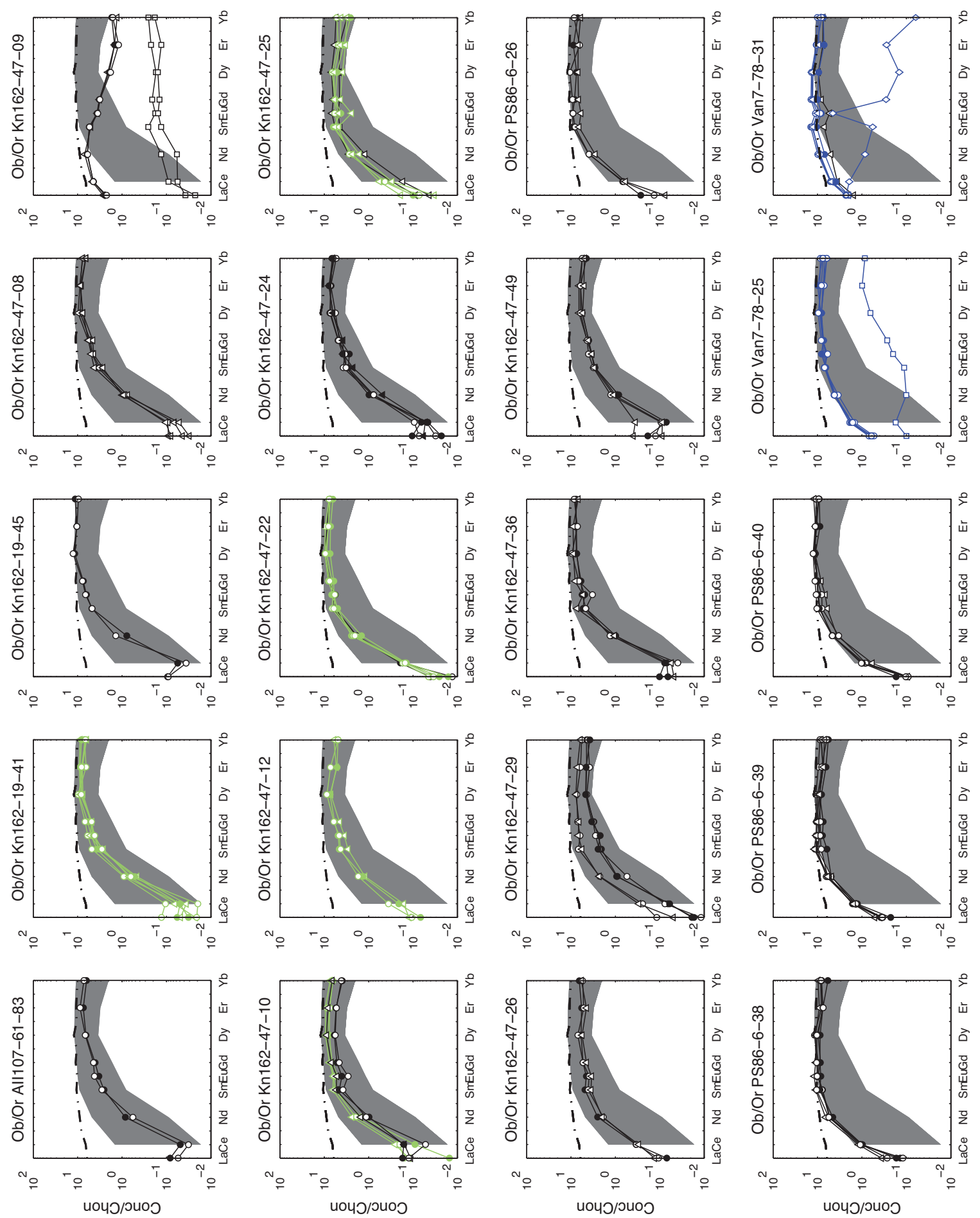

Figure 5.A 1: REE plots of each analysis, by sample. See last page of figure for legend. 

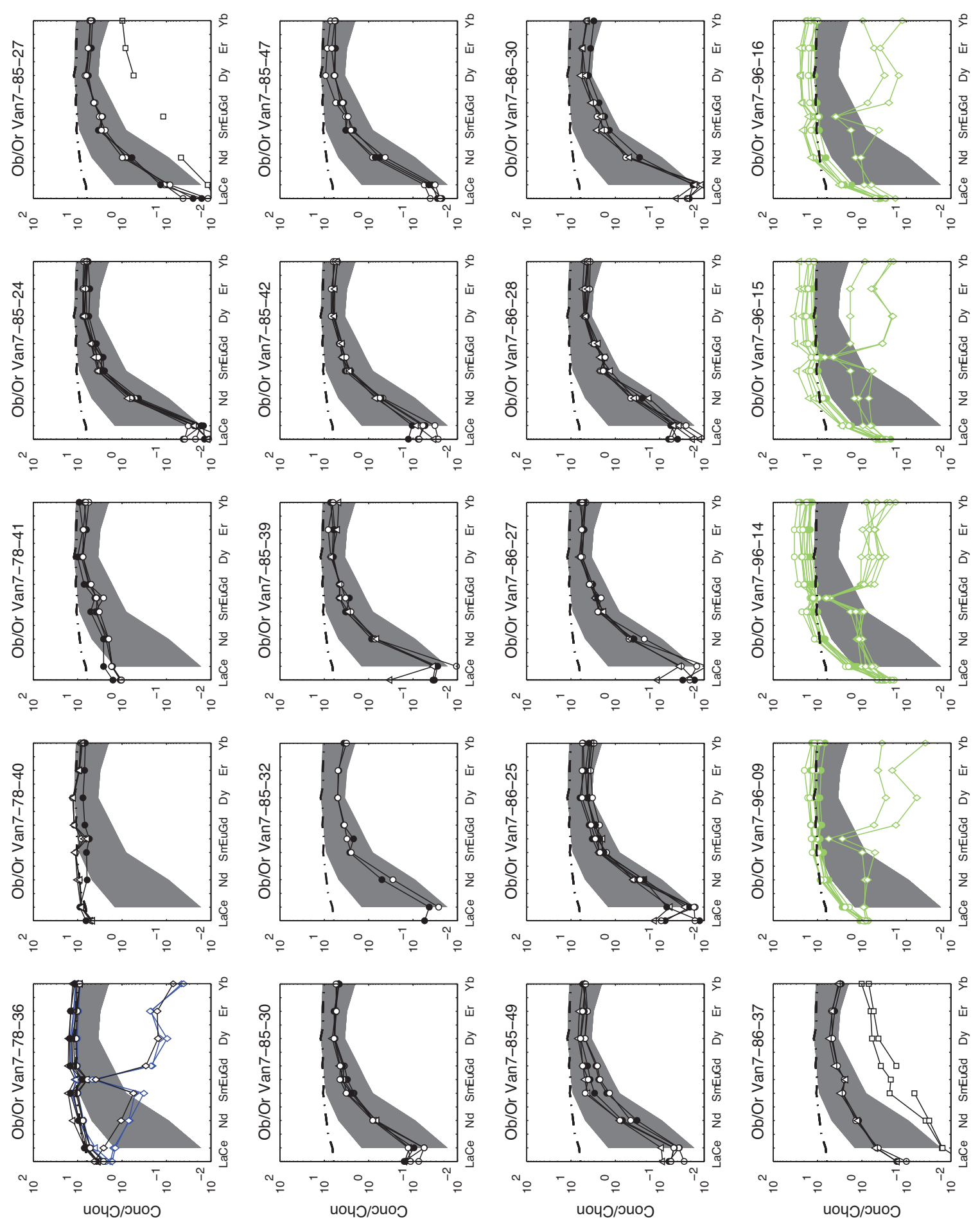

Figure 5.A 1: (Continued) 

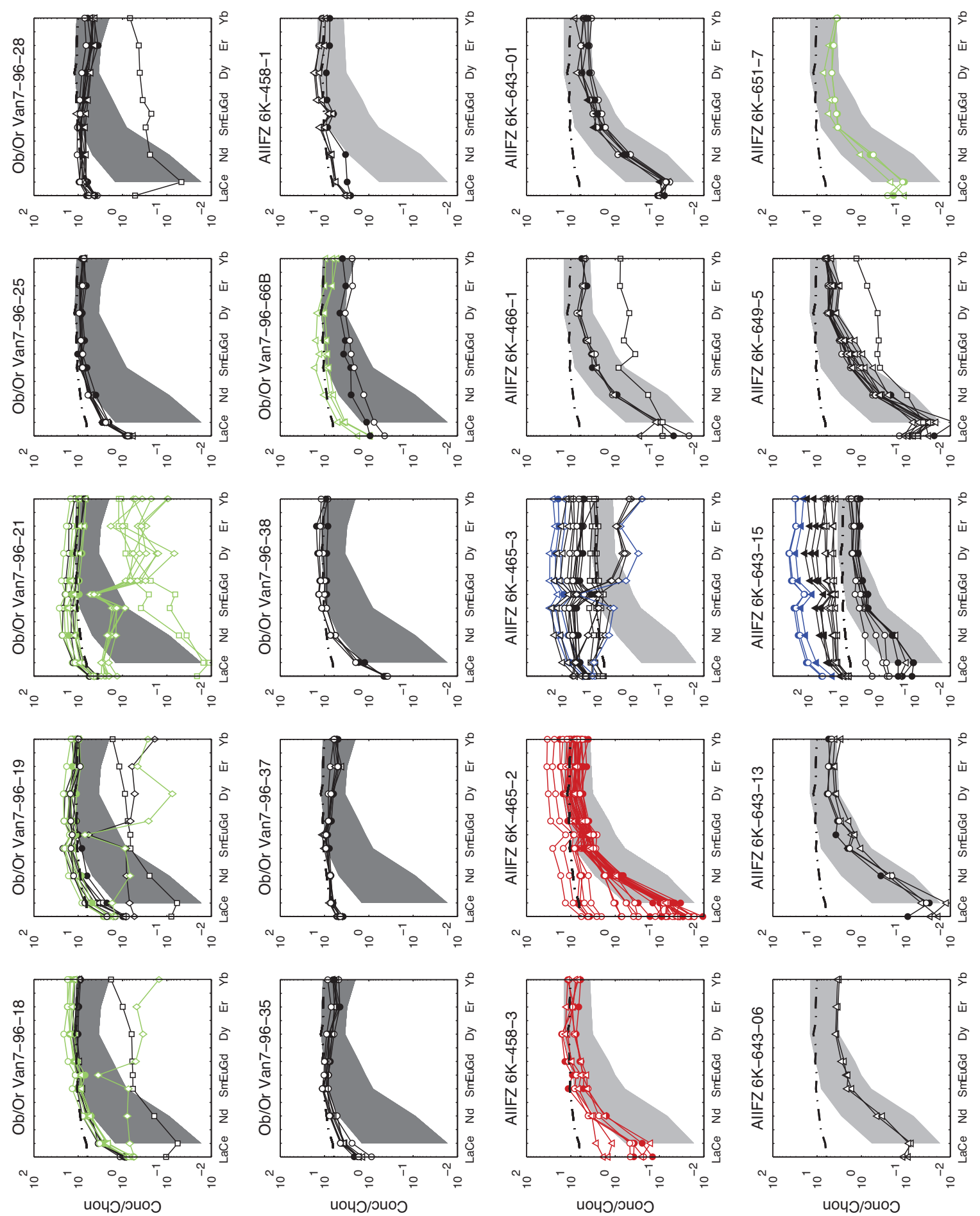

Figure 5.A 1: (Continued) 

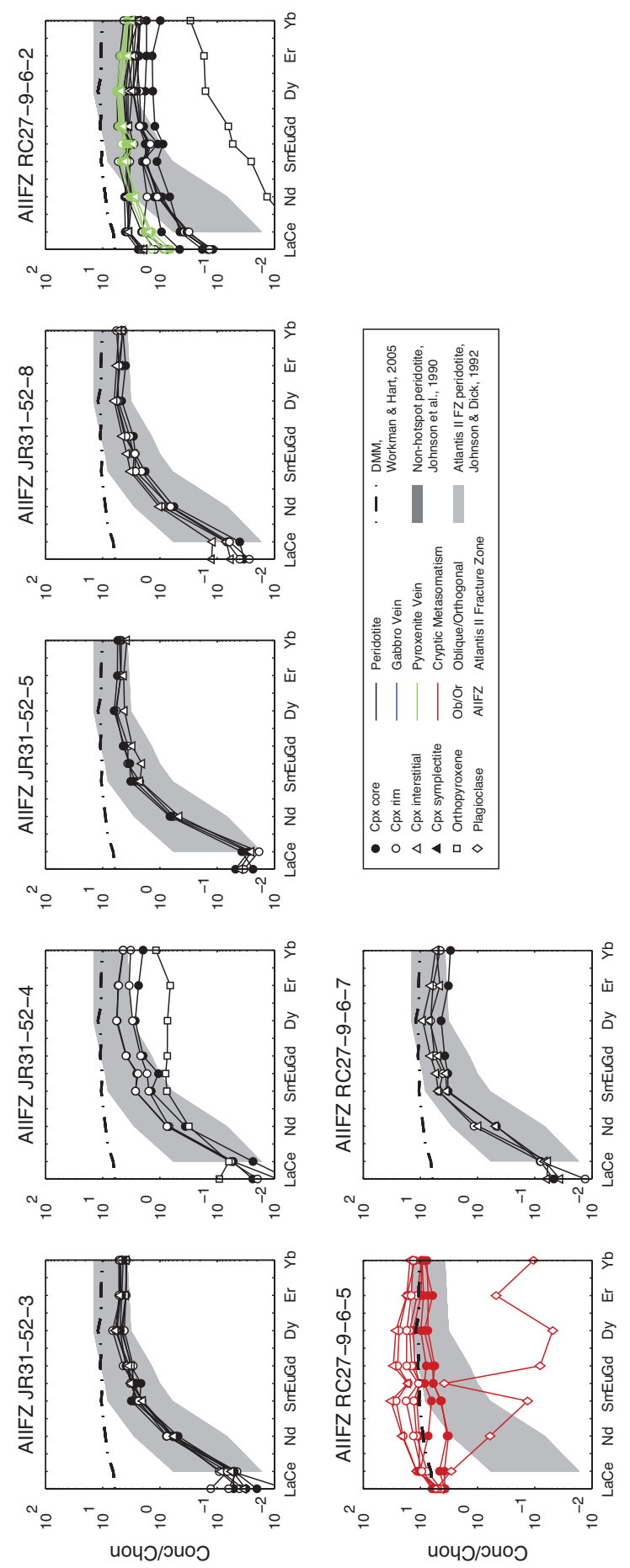

Figure 5.A 1: (Continued) 


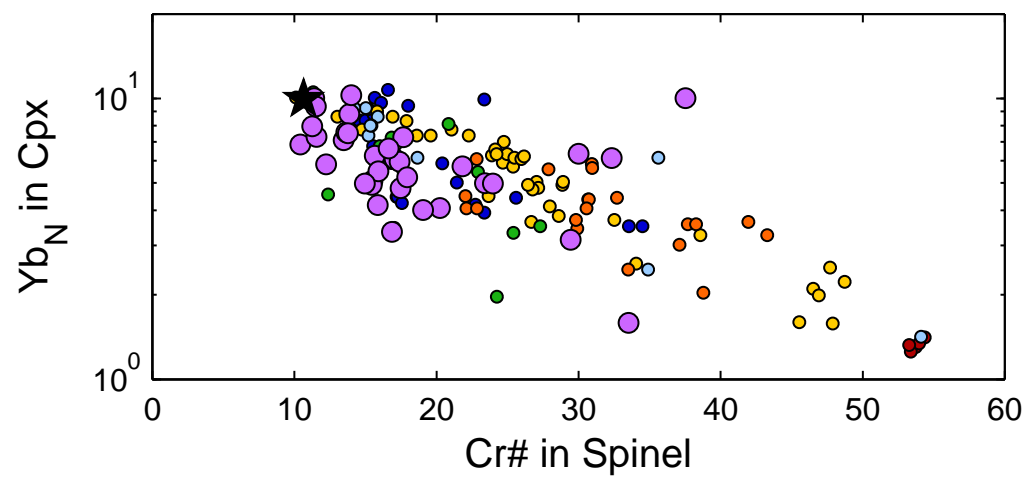

\begin{tabular}{|ll|}
\hline \multirow{1}{*}{} & DMM \\
$\bullet$ & EPR \\
$\circ$ & CIR/Carl \\
$\circ$ & MAR \\
$\circ$ & AAR \\
$\circ$ & Arctic \\
$\bullet$ & SWIR \\
0 & Oblique \\
\hline
\end{tabular}
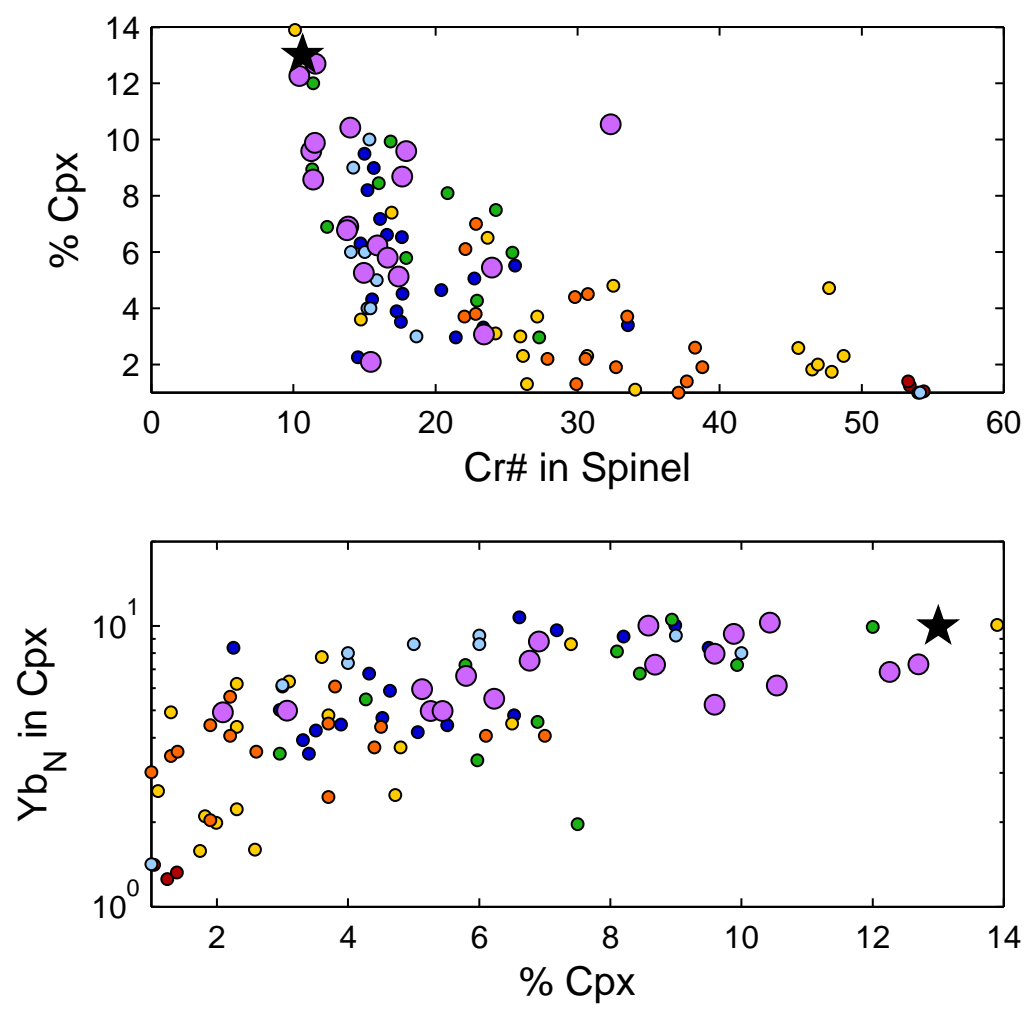

Figure 5.B 1: Co-variation of Spinel $\mathrm{Cr} \#, \mathrm{Yb}_{N}$ in $\mathrm{Cpx}$ and modal Cpx. The variation of spinel Cr\# with Cpx HREE (Dy, Er and $\mathrm{Yb}$ ) has been used to calibrate a degree of melting relationship for spinel Cr\#. As modal $\mathrm{Cpx}$ is also an indicator of degree of melting in peridotite, we compare the co-variation among all three parameters. 


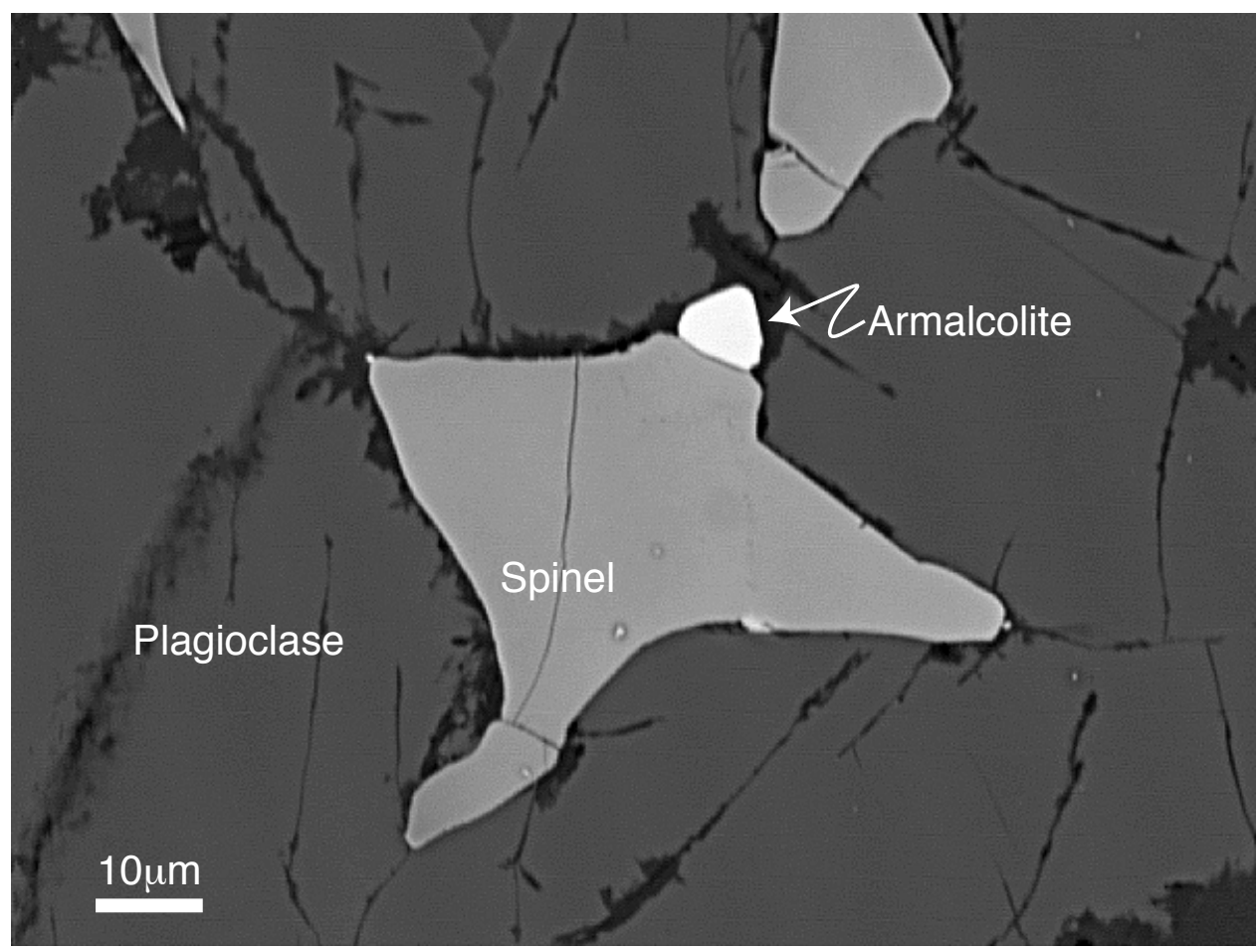

Figure 5.C1: Armalcolite, associated with spinel and plagioclase in pyroxenite vein (Van796-14). 


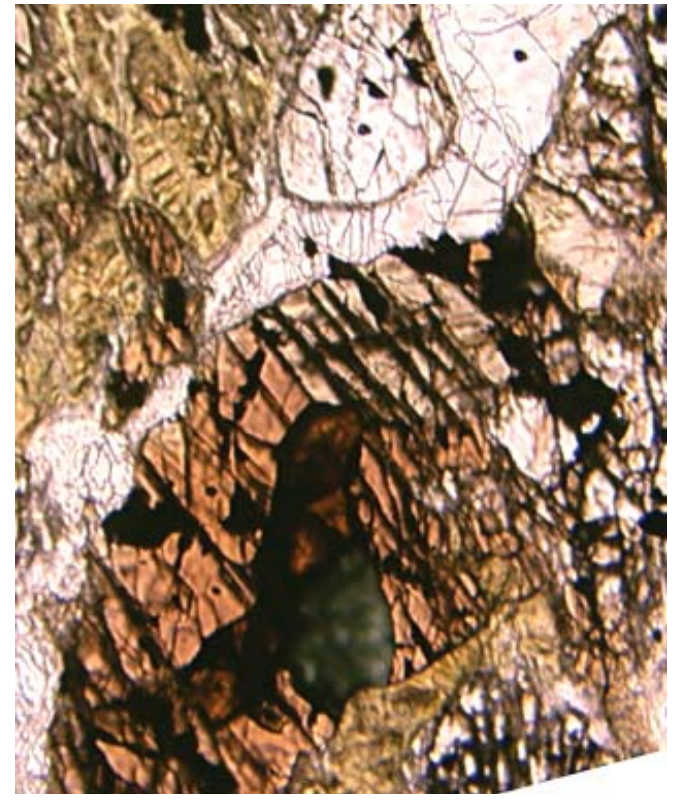

$1 \mathrm{~mm}$

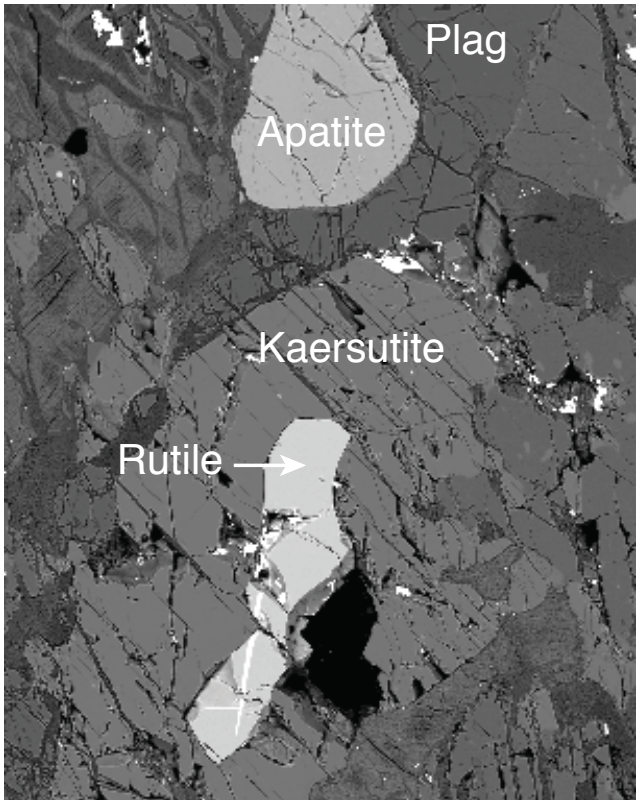

$1 \mathrm{~mm}$

Figure 5.D1: Photomicrograph and backscattered electron image of a vein in sample 6K465-3 from Atlantis II Fracture Zone. Compositions of kaersutite, apatite, rutile and plagioclase in the vein are given in Table 5.D11. Bright spots in the backscattered image are remnants of the gold coat from ion probe analyses. 


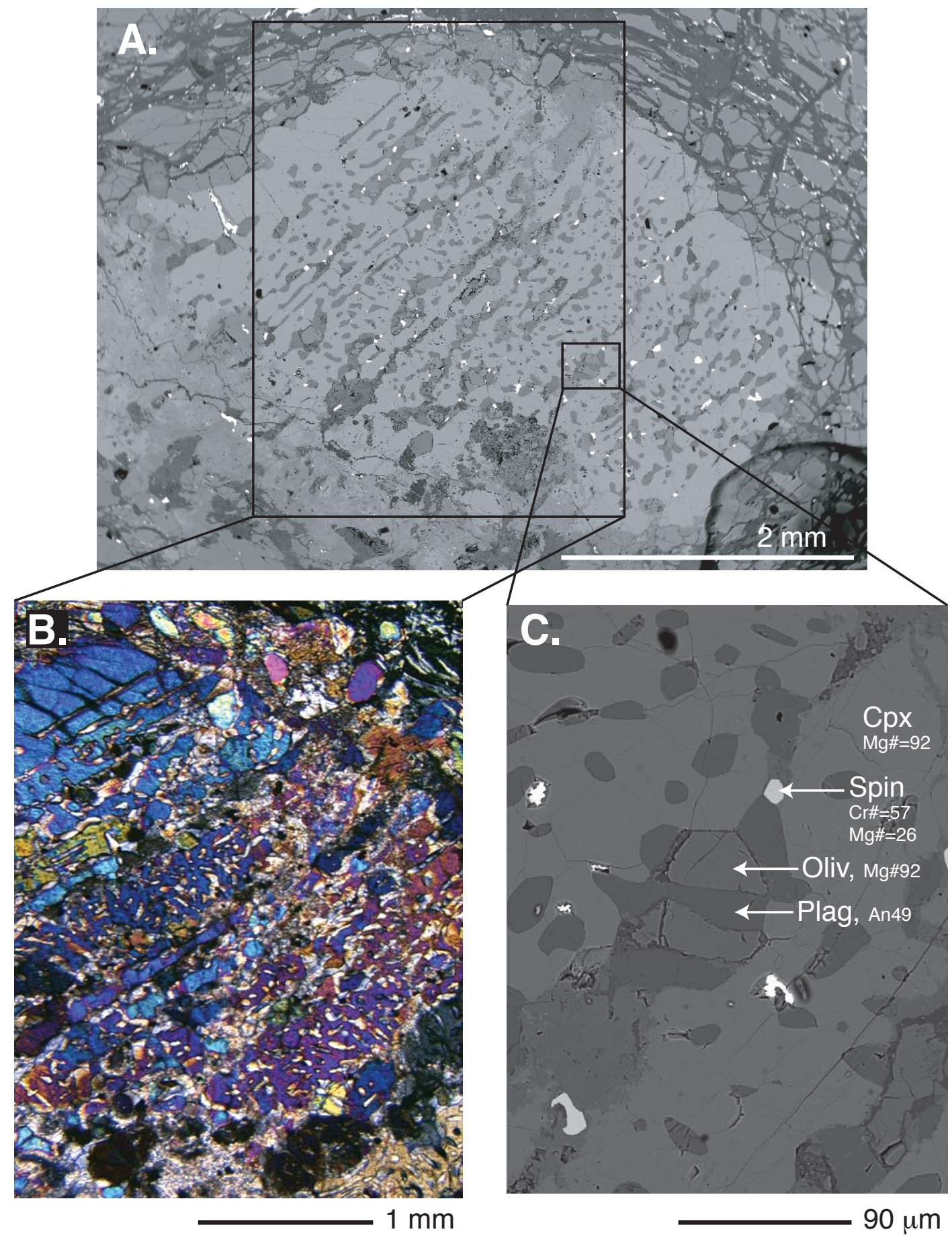

Figure 5.D2: Photomicrograph and backscattered electron images of unusual exsolution in gabbro-veined sample 6K-465-3 from Atlantis II Fracture Zone. Major and trace element analyses of Cpx12 and exsolved plagioclase, spinel and olivine are presented in Table 5.D1. along with analyses for similar occurrences in three other Cpx porphyroclasts. Bright spots in the backscattered images are remnants of the gold coat from ion probe analyses. 
Table 5.1: Summary of global peridotite compilation.

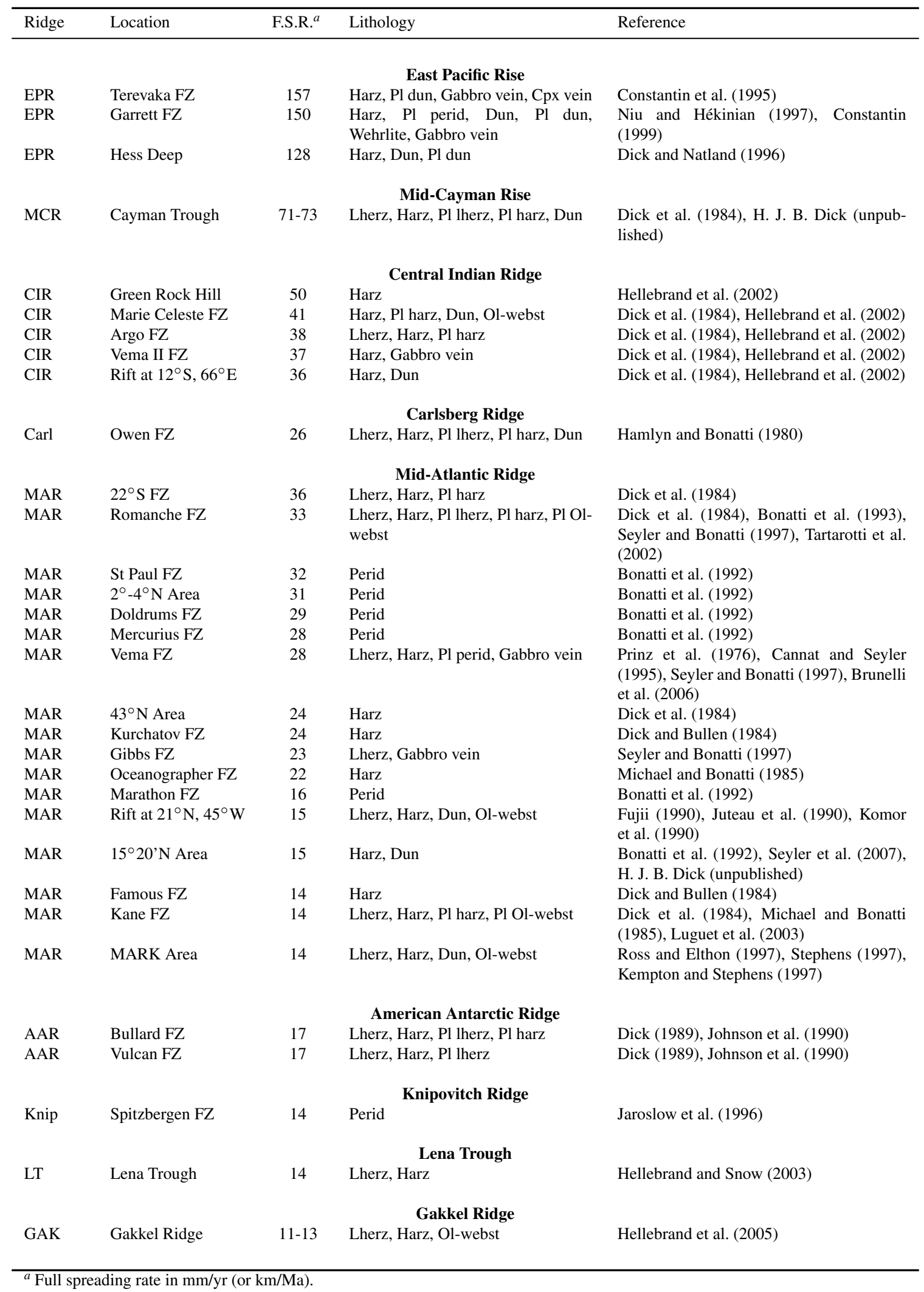


Table 5.1: Global compilation Cont.

\begin{tabular}{|c|c|c|c|c|}
\hline Ridge & Location & F.S.R. ${ }^{a}$ & Lithology & Reference \\
\hline \multicolumn{5}{|c|}{ Southwest Indian Ridge } \\
\hline SWIR & Speiss Ridge & 19 & Harz, Dun & H. J. B. Dick (unpublished) \\
\hline SWIR & Andrew Bain FZ & 15 & Lherz, Harz, Pl harz, Dun, Webst & Johnson et al. (1990) \\
\hline SWIR & Discovery II FZ & 15 & Lherz, Harz & Dick et al. (1984), Johnson et al. (1990) \\
\hline SWIR & Gallieni FZ & 15 & Lherz, Harz, Pl harz & Dick et al. $(\overline{1984})$, Jaroslow et al. $(\overline{1996})$ \\
\hline SWIR & Indomed FZ & 15 & Lherz & Johnson et al. $(1990)$ \\
\hline SWIR & Melville FZ & 15 & Lherz, Harz, Pl lherz & Dick et al. $(1984)$ \\
\hline SWIR & Prince Edward FZ & 15 & Lherz, Harz, Pl harz & Johnson et al. (1990, Jaroslow et al. (1996) \\
\hline SWIR & SWIR $52^{\circ}-68^{\circ} \mathrm{E}$ & $14-15$ & Lherz, Harz & Seyler et al. $(2003)$, Seyler et al. $(2004)$ \\
\hline SWIR & Atlantis II FZ & 14 & $\begin{array}{l}\text { Lherz, Harz, Pl perid, Dun, Webst, } \\
\text { Ol-webst, Cpx vein, Gabbro vein }\end{array}$ & $\begin{array}{l}\text { Johnson and Dick (1992), Jaroslow et al. } \\
\text { (1996), Lee (1997), Salters and Dick } \\
(2002), \text { Kumagai et al. (2003), Coogan } \\
\text { et al. (2004), H. J. B. Dick (unpublished), } \\
\text { This study }\end{array}$ \\
\hline SWIR & Bouvet FZ & 14 & Harz, Pl harz, Dun & Dick et al. (1984), Johnson et al. (1990) \\
\hline SWIR & Islas Orcadas FZ & 14 & $\begin{array}{l}\text { Lherz, Harz, Pl lherz, Pl harz, Ol- } \\
\text { webst }\end{array}$ & $\begin{array}{l}\text { Dick (1989), Johnson et al. (1990), Snow } \\
\text { (1993) }\end{array}$ \\
\hline SWIR & Orthogonal Seg. & 14 & $\begin{array}{l}\text { Harz, Pl perid, Dun, Ol-webst, Gab- } \\
\text { bro vein }\end{array}$ & This Study \\
\hline SWIR & Rift at $26^{\circ} \mathrm{S}, 67^{\circ} \mathrm{E}$ & 14 & Lherz & Dick and Bullen (1984,, Dick et al. (1984) \\
\hline SWIR & Rift at $54^{\circ} \mathrm{S}, 7^{\circ} \mathrm{E}$ & 14 & Harz & Dick et al. (1984) \\
\hline SWIR & Shaka FZ & 14 & Perid & \begin{tabular}{|l} 
Johnson et al. $(1990)$, \\
Jaroslow et al.(1996), This Study
\end{tabular} \\
\hline SWIR & Oblique Segment & $8-14$ & $\begin{array}{l}\text { Lherz, Harz, Pl perid, Dun, Webst, } \\
\text { Ol-webst, Gabbro vein }\end{array}$ & $\begin{array}{l}\text { Johnson et al. (1990), Salters and Dick } \\
\text { (2002), Dantas et al. (2007), H. J. B. Dick } \\
\text { (unpublished), This study }\end{array}$ \\
\hline
\end{tabular}


Table 5.2: Dredge locations

\begin{tabular}{|c|c|c|c|c|c|c|c|}
\hline Dredge/Dive & Dredge description & $\begin{array}{l}\mathrm{Wt} \\
\mathrm{kg}\end{array}$ & $\begin{array}{l}\text { Lat } \\
{ }^{\circ} \mathrm{S}\end{array}$ & $\begin{array}{l}\text { Long } \\
{ }^{\circ} \mathrm{E}\end{array}$ & $\begin{array}{l}\text { Depth } \\
\text { (m) }\end{array}$ & $\begin{array}{c}\mathrm{FSR}^{a} \\
(\mathrm{~mm} / \mathrm{yr})\end{array}$ & Location \\
\hline \multicolumn{8}{|c|}{ SWIR $9^{\circ}-25^{\circ} \mathrm{E}$} \\
\hline \multicolumn{8}{|c|}{ R/V Atlantis II, 1980} \\
\hline AII107-61 & Peridotites, perid mylonites & 48 & -53.42 & 9.20 & 4063 & 14 & Shaka FZ \\
\hline \multicolumn{8}{|c|}{ R/V Polarstern, 1986} \\
\hline PS86-6 & $\begin{array}{l}\text { Peridotite, basalt, gabbro } \\
\text { veined perid }\end{array}$ & 187 & -52.35 & 13.13 & 3332 & 9 & Oblique \\
\hline \multicolumn{8}{|c|}{ R/V Knorr, 2000} \\
\hline Kn162-19 & $\begin{array}{l}\text { Basalt, peridotite, } \\
\text { pyroxenite, diabase }\end{array}$ & 81 & -53.05 & 21.38 & 3992 & 14 & Orthogonal \\
\hline Kn162-47 & $\begin{array}{l}\text { Peridotite, pyroxenites, plag } \\
\text { perid }\end{array}$ & 144 & -52.56 & 12.66 & 4361 & 8 & Oblique \\
\hline \multicolumn{8}{|c|}{ R/V Melville, 2003} \\
\hline Van7-78 & $\begin{array}{l}\text { Peridotite, dunite, } \\
\text { gabbros/veined perid, plag } \\
\text { perid, basalt }\end{array}$ & 192 & -52.38 & 16.64 & 3901 & 14 & Orthogonal \\
\hline Van7-85 & Peridotite, dunite, diabase & 90 & -52.25 & 15.23 & 4190 & 12 & Oblique \\
\hline Van7-86 & Dunite, peridotite & 146 & -52.14 & 15.16 & 3738 & 12 & Oblique \\
\hline Van7-96 & $\begin{array}{l}\text { Perid/pyrox/bas } \\
\text { cataclastites, perid, pyrox, } \\
\text { diabase }\end{array}$ & 81 & -53.14 & 9.98 & 3134 & 12 & Oblique \\
\hline \multicolumn{8}{|c|}{ ATLANTIS II FRACTURE ZONE } \\
\hline \multicolumn{8}{|c|}{ R/V Conrad, 1986} \\
\hline $\mathrm{RC} 27-9-6$ & Peridotite, dunite & 37 & -31.92 & 57.18 & 3930 & 14 & $\mathrm{AIIFZ} \mathrm{RTI}^{b}$ \\
\hline \multicolumn{8}{|c|}{ R.R.S. James Clark Ross, 1998} \\
\hline JR31-52 & Peridotite, diabase, gabbro & 125 & -32.56 & 57.17 & 3200 & 14 & Atlantis Bank \\
\hline \multicolumn{8}{|c|}{ R/V Yokosuka, Shinkai 6500 submersible, 1998} \\
\hline $6 \mathrm{~K}-458-1$ & & 3 & -32.70 & 57.13 & 4609 & 14 & Atlantis Bank \\
\hline $6 \mathrm{~K}-458-3$ & & 8 & -32.70 & 57.13 & 4609 & 14 & Atlantis Bank \\
\hline $6 \mathrm{~K}-465-2$ & & 10 & -31.95 & 57.13 & 4988 & 14 & AIIFZ RTI \\
\hline $6 \mathrm{~K}-465-3$ & & 6 & -31.95 & 57.13 & 4899 & 14 & AIIFZ RTI \\
\hline $6 \mathrm{~K}-466-1$ & & 3 & -32.64 & 57.14 & 4714 & 14 & Atlantis Bank \\
\hline \multicolumn{8}{|c|}{ R/V Yokosuka, Shinkai 6500 submersible, 2001} \\
\hline $6 \mathrm{~K}-643-1$ & & 9 & -32.91 & 57.20 & 3396 & 14 & Atlantis Bank \\
\hline $6 \mathrm{~K}-643-6$ & & 2 & -32.91 & 57.21 & 2974 & 14 & Atlantis Bank \\
\hline $6 \mathrm{~K}-643-13$ & & 13 & -32.91 & 57.21 & 2712 & 14 & Atlantis Bank \\
\hline $6 \mathrm{~K}-643-15$ & & 13 & -32.91 & 57.21 & 2605 & 14 & Atlantis Bank \\
\hline $6 \mathrm{~K}-649-5$ & & 3 & -32.91 & 57.21 & 2564 & 14 & Atlantis Bank \\
\hline $6 \mathrm{~K}-651-7$ & & 2 & -32.74 & 57.15 & 4088 & 14 & Atlantis Bank \\
\hline
\end{tabular}

\footnotetext{
${ }^{a}$ Full spreading rate. For Oblique Segment dredges, the effective full spreading rate is given, calculated following the method of Abelson and Agnon (1997) and using the measured angle of obliquity of the ridge axis to the plate spreading direction. For the Atlantis II Fracture Zone, the half spreading rate to the south is $8.5 \mathrm{~mm} / \mathrm{yr}$, due to asymmetrical spreading (Hosford et al. 2003).

${ }^{b}$ Ridge-transform intersection.
} 
Table 5.3: Sample descriptions and modal analyses

\begin{tabular}{|c|c|c|c|c|c|c|c|c|c|}
\hline Sample & Location & Description & $\mathrm{Ol}$ & Opx & Cpx & $\mathrm{Sp}$ & $\mathrm{Pl}$ & Sum & $\mathrm{Pts}^{a}$ \\
\hline \multicolumn{10}{|c|}{ SWIR $9^{\circ}-25^{\circ} \mathrm{E}$} \\
\hline AII107-61-83 & Shaka FZ & Lherzolite mylonite & 72.4 & 19.8 & 5.8 & 1.4 & 0.0 & $99.4^{b}$ & \\
\hline PS86-6-26 & Oblique & Lherzolite & 60.7 & 26.2 & 12.3 & 0.9 & 0.0 & $100.0^{c}$ & \\
\hline PS86-6-38 & Oblique & Lherzolite & 59.5 & 29.9 & 9.6 & 1.0 & 0.0 & 100.0 & 3124 \\
\hline PS86-6-39 & Oblique & Lherzolite & 69.7 & 20.9 & 8.7 & 0.8 & 0.0 & $100.0^{c}$ & \\
\hline PS86-6-40 & Oblique & Lherzolite & 66.7 & 23.4 & 8.6 & 1.4 & 0.0 & $100.0^{c}$ & \\
\hline Kn162-19-41 & Orthogonal & Olivine websterite & & & & & & & \\
\hline Kn162-19-45 & Orthogonal & Harzburgite & 82.4 & 16.6 & 0.4 & 0.7 & 0.0 & $100.0^{d}$ & 2132 \\
\hline Kn162-47-08 & Oblique & Harzburgite & & & & & & & \\
\hline Kn162-47-09 & Oblique & Lherzolite & & & & & & & \\
\hline Kn162-47-10 & Oblique & $\begin{array}{l}\text { Websterite vein in peridotite, } \\
\text { mylonite }\end{array}$ & 4.0 & 50.0 & 40.0 & 6.0 & 0.0 & $100.0^{e}$ & \\
\hline Kn162-47-12 & Oblique & $\begin{array}{l}\text { Websterite vein in peridotite, } \\
\text { mylonite }\end{array}$ & 0.0 & 50.0 & 45.0 & 5.0 & 0.0 & $100.0^{e}$ & \\
\hline Kn162-47-22 & Oblique & $\begin{array}{l}\text { Ol-websterite vein in } \\
\text { hazburgite }\end{array}$ & 12.0 & 35.0 & 45.0 & 8.0 & 0.0 & $100.0^{e}$ & \\
\hline Kn162-47-24 & Oblique & Plag peridotite & & & & & & & \\
\hline $\mathrm{Kn} 162-47-25$ & Oblique & Websterite vein in peridotite & 0.0 & 32.0 & 65.0 & 3.0 & 0.0 & $100.0^{e}$ & \\
\hline $\mathrm{Kn} 162-47-26$ & Oblique & Harzburgite & & & & & & & \\
\hline Kn162-47-29 & Oblique & Peridotite mylonite & & & & & & & \\
\hline $\mathrm{Kn} 162-47-36$ & Oblique & Harzburgite mylonite & & & & & & & \\
\hline Kn162-47-49 & Oblique & Peridotite protomylonite & & & & & & & \\
\hline Van7-78-25 & Orthogonal & Dunite with gabbro vein & & & & & & & \\
\hline Van7-78-31 & Orthogonal & $\begin{array}{l}\text { Plag peridotite with gabbro } \\
\text { vein }\end{array}$ & & & & & & & \\
\hline Van7-78-36 & Orthogonal & $\begin{array}{l}\text { Plag peridotite with gabbro } \\
\text { vein }\end{array}$ & & & & & & & \\
\hline $\operatorname{Van} 7-78-40$ & Orthogonal & Plag harzburgite & & & & & & & \\
\hline Van7-78-41 & Orthogonal & $\begin{array}{l}\text { Plag harzburgite, } \\
\text { protomylonite }\end{array}$ & & & & & & & \\
\hline Van7-85-24 & Oblique & Lherzolite & & & & & & & \\
\hline $\operatorname{Van} 7-85-27$ & Oblique & Harzburgite & 68.6 & 27.5 & 3.1 & 0.9 & 0.0 & 100.0 & 2506 \\
\hline Van7-85-30 & Oblique & Harzburgite, trace Plag & 67.4 & 29.2 & 2.1 & 1.2 & 0.2 & 100.0 & 2483 \\
\hline $\operatorname{Van} 7-85-32$ & Oblique & Harzburgite & & & & & & & \\
\hline Van7-85-39 & Oblique & Lherzolite & & & & & & & \\
\hline $\operatorname{Van} 7-85-42$ & Oblique & Lherzolite & 67.1 & 25.6 & 6.2 & 1.0 & 0.0 & 100.0 & 2825 \\
\hline Van7-85-47 & Oblique & Lherzolite & 68.7 & 24.7 & 5.1 & 1.5 & 0.0 & 100.0 & 2594 \\
\hline Van7-85-49 & Oblique & Lherzolite, trace Plag & 71.6 & 22.2 & 5.3 & 0.9 & 0.1 & 100.0 & 2607 \\
\hline Van7-86-25 & Oblique & Lherzolite & & & & & & & \\
\hline Van7-86-27 & Oblique & Lherzolite & 55.8 & 34.0 & 9.6 & 0.6 & 0.0 & 100.0 & 2566 \\
\hline Van7-86-28 & Oblique & Lherzolite & & & & & & & \\
\hline Van7-86-30 & Oblique & Harzburgite & & & & & & & \\
\hline Van7-86-37 & Oblique & Harzburgite & & & & & & & \\
\hline Van7-96-09 & Oblique & Pyroxenite vein & 9.3 & 25.8 & 48.5 & 1.9 & 14.6 & 100.0 & 756 \\
\hline Van7-96-14 & Oblique & $\begin{array}{l}\text { Pyroxenite vein, with thin } \\
\text { peridotite rim }\end{array}$ & & & & & & & \\
\hline Van7-96-15 & Oblique & $\begin{array}{l}\text { Pyroxenite vein, with thin } \\
\text { peridotite rim }\end{array}$ & & & & & & & \\
\hline Van7-96-16 & Oblique & $\begin{array}{l}\text { Pyroxenite vein, with thin } \\
\text { peridotite rim }\end{array}$ & 11.6 & 34.0 & 24.4 & 1.6 & 28.4 & 100.0 & 697 \\
\hline Van7-96-18 & Oblique & $\begin{array}{l}\text { Lherzolite with pyroxenite } \\
\text { vein }\end{array}$ & & & & & & & \\
\hline Van7-96-19 (Matrix) & Oblique & $\begin{array}{l}\text { Lherzolite with pyroxenite } \\
\text { vein }\end{array}$ & 64.8 & 17.9 & 13.3 & 0.8 & 3.1 & 100.0 & 1883 \\
\hline Van7-96-19 (Vein) & Oblique & Pyroxenite vein in lherzolite & 7.2 & 26.4 & 57.2 & 2.8 & 6.3 & 100.0 & 318 \\
\hline Van7-96-21 (Matrix) & Oblique & $\begin{array}{l}\text { Harzburgite with pyroxenite } \\
\text { vein }\end{array}$ & 76.2 & 18.1 & 4.6 & 0.6 & 0.4 & 100.0 & 1894 \\
\hline Van7-96-21 (Vein) & Oblique & Pyroxenite vein in harzburgite & 19.7 & 39.3 & 37.5 & 2.2 & 1.3 & 100.0 & 461 \\
\hline Van7-96-25 & Oblique & Lherzolite & 66.2 & 25.6 & 6.8 & 1.4 & 0.0 & 100.0 & 2215 \\
\hline Van7-96-28 & Oblique & Lherzolite, trace Plag & 76.7 & 17.2 & 5.4 & 0.7 & 0.0 & 100.0 & 2738 \\
\hline Van7-96-35 & Oblique & Lherzolite, trace Plag & 70.4 & 16.7 & 10.5 & 2.3 & 0.1 & 100.0 & 1765 \\
\hline
\end{tabular}


Table 5.3: Sample descriptions Cont.

\begin{tabular}{|c|c|c|c|c|c|c|c|c|c|}
\hline Sample & Location & Description & $\mathrm{Ol}$ & Opx & Cpx & $\mathrm{Sp}$ & $\mathrm{Pl}$ & Sum & $\mathrm{Pts}^{a}$ \\
\hline Van7-96-37 & Oblique & Peridotite & & & & & & & \\
\hline Van7-96-38 & Oblique & Lherzolite, trace Plag & 64.2 & 24.1 & 9.9 & 1.6 & 0.2 & 100.0 & 2278 \\
\hline Van7-96-66B & Oblique & $\begin{array}{l}\text { Subangular clast of } \\
\text { orthopyroxenite in breccia }\end{array}$ & & & & & & & \\
\hline & & Atlantis II Fracture Zone & & & & & & & \\
\hline RC27-9-6-2 (Matrix) & AIIFZ RTI & $\begin{array}{l}\text { Lherzolite with } \\
\text { clinopyroxenite vein, trace } \\
\text { Plag }\end{array}$ & 67.5 & 19.5 & 11.9 & 0.9 & 0.2 & 100.0 & 2194 \\
\hline RC27-9-6-2 (Vein) & AIIFZ RTI & $\begin{array}{l}\text { Clinopyroxenite vein in } \\
\text { lherzolite, trace Plag }\end{array}$ & 7.6 & 9.2 & 82.6 & 0.7 & 0.0 & 100.0 & 436 \\
\hline $\mathrm{RC} 27-9-6-5$ & AIIFZ RTI & $\begin{array}{l}\text { Lherzolite, cryptic } \\
\text { metasomatism, trace Plag }\end{array}$ & & & & & & & \\
\hline $\mathrm{RC} 27-9-6-7$ & AIIFZ RTI & Lherzolite & & & & & & & \\
\hline JR31-52-3 & Atlantis Bank & Harzburgite & 57.6 & 37.5 & 3.9 & 1.0 & 0.0 & 100.0 & 2056 \\
\hline JR31-52-4 & Atlantis Bank & Lherzolite & & & & & & & \\
\hline JR31-52-5 & Atlantis Bank & Harzburgite & 66.8 & 27.3 & 4.5 & 1.4 & 0.0 & 100.0 & 2258 \\
\hline JR31-52-8 & Atlantis Bank & Lherzolite & 62.8 & 29.9 & 6.5 & 0.8 & 0.0 & 100.0 & 1975 \\
\hline $6 \mathrm{~K}-458-1$ & Atlantis Bank & Peridotite & & & & & & & \\
\hline $6 \mathrm{~K}-458-3$ & Atlantis Bank & $\begin{array}{l}\text { Peridotite, cryptic } \\
\text { metasomatism }\end{array}$ & & & & & & & \\
\hline $6 \mathrm{~K}-465-2$ & AIIFZ RTI & $\begin{array}{l}\text { Lherzolite, cryptic } \\
\text { metasomatism, trace Plag }\end{array}$ & 71.0 & 22.0 & 5.9 & 1.1 & 0.0 & 100.0 & 1926 \\
\hline $6 \mathrm{~K}-465-3$ & AIIFZ RTI & $\begin{array}{l}\text { Lherz, with gabbro vein and } \\
\text { kaersutite/oxide vein }\end{array}$ & 76.2 & 13.4 & 8.6 & 1.0 & 0.8 & 100.0 & 2028 \\
\hline $6 \mathrm{~K}-466-1$ & Atlantis Bank & Harzburgite & 74.8 & 21.2 & 3.0 & 1.1 & 0.0 & 100.0 & 1489 \\
\hline $6 \mathrm{~K}-643-01$ & Atlantis Bank & Lherzolite & & & & & & & \\
\hline $6 \mathrm{~K}-643-06$ & Atlantis Bank & Harzburgite & & & & & & & \\
\hline $6 \mathrm{~K}-643-13$ & Atlantis Bank & Lherzolite & 68.7 & 24.9 & 5.1 & 0.7 & 0.0 & 99.4 & 1566 \\
\hline $6 \mathrm{~K}-643-15$ & Atlantis Bank & Lherzolite/dunite/gabbro vein & & & & & & & \\
\hline $6 \mathrm{~K}-649-5$ & Atlantis Bank & Lherzolite & & & & & & & \\
\hline $6 \mathrm{~K}-651-7$ & Atlantis Bank & Olivine websterite & & & & & & & \\
\hline
\end{tabular}


Table 5.4: Major element composition of olivines, in wt\%.

\begin{tabular}{|c|c|c|c|c|c|c|c|c|c|c|c|c|c|c|c|}
\hline Sample & $\mathrm{Grn}^{a}$ & Pts & $\mathrm{SiO}_{2}$ & \pm & $\mathrm{FeO}$ & \pm & $\mathrm{MnO}$ & \pm & $\mathrm{MgO}$ & \pm & $\mathrm{NiO}$ & \pm & Total & $\mathrm{Mg \#}$ & Notes $^{b}$ \\
\hline $6 \mathrm{~K}-458-1$ & 1 & 6 & 40.55 & 0.26 & 9.22 & 0.18 & 0.08 & 0.03 & 49.64 & 0.29 & 0.34 & 0.04 & 99.87 & 90.6 & \\
\hline $6 \mathrm{~K}-465-2$ & 1 & 6 & 40.53 & 0.28 & 9.63 & 0.11 & 0.14 & 0.02 & 50.00 & 0.36 & 0.32 & 0.03 & 100.68 & 90.3 & Dep \\
\hline $6 \mathrm{~K}-465-2$ & 2 & 6 & 41.91 & 0.28 & 9.39 & 0.09 & & & 49.32 & 0.19 & & & 100.67 & 90.3 & Dep \\
\hline $6 \mathrm{~K}-465-3$ & 1 & 9 & 39.45 & 0.14 & 10.52 & 0.13 & 0.15 & 0.02 & 48.50 & 0.16 & 0.35 & 0.02 & 99.03 & 89.2 & NrMat \\
\hline $6 \mathrm{~K}-465-3$ & 2 & 6 & 38.02 & 0.15 & 22.94 & 0.30 & 0.43 & 0.04 & 39.16 & 0.09 & 0.28 & 0.04 & 100.86 & 75.3 & NrMat \\
\hline JR31-52-3 & 1 & 7 & 40.10 & 0.08 & 9.45 & 0.12 & 0.14 & 0.02 & 49.48 & 0.26 & 0.40 & 0.03 & 99.61 & 90.3 & \\
\hline JR31-52-5 & 1 & 6 & 40.47 & 0.12 & 9.43 & 0.15 & 0.16 & 0.02 & 49.06 & 0.09 & 0.35 & 0.03 & 99.51 & 90.3 & \\
\hline JR31-52-8 & 1 & 6 & 40.22 & 0.09 & 9.59 & 0.24 & 0.14 & 0.02 & 49.04 & 0.14 & 0.37 & 0.02 & 99.38 & 90.1 & \\
\hline Kn162-19-41 & 1 & 6 & 40.58 & 0.21 & 9.32 & 0.14 & 0.13 & 0.02 & 48.91 & 0.25 & 0.31 & 0.03 & 99.29 & 90.3 & PyxVn \\
\hline $\mathrm{Kn} 162-47-22$ & 1 & 6 & 40.79 & 0.16 & 10.66 & 0.14 & 0.11 & 0.02 & 48.75 & 0.16 & 0.38 & 0.03 & 100.75 & 89.1 & PyxVn \\
\hline Kn162-47-25 & 1 & 4 & 40.51 & 0.18 & 9.25 & 0.10 & 0.12 & 0.01 & 48.98 & 0.29 & 0.32 & 0.04 & 99.22 & 90.4 & NrMat \\
\hline $\mathrm{Kn} 162-47-26$ & 1 & 6 & 41.04 & 0.21 & 9.69 & 0.51 & 0.14 & 0.02 & 48.60 & 0.06 & 0.19 & 0.01 & 99.69 & 89.9 & \\
\hline Kn162-47-29 & 1 & 6 & 41.20 & 0.22 & 8.83 & 0.35 & 0.11 & 0.02 & 49.87 & 0.17 & 0.21 & 0.03 & 100.23 & 91.0 & \\
\hline Kn162-47-36 & 1 & 6 & 40.62 & 0.14 & 10.10 & 0.45 & 0.14 & 0.02 & 49.02 & 0.37 & 0.40 & 0.03 & 100.31 & 89.6 & \\
\hline Kn162-47-49 & 1 & 6 & 41.03 & 0.09 & 10.08 & 0.18 & 0.12 & 0.03 & 48.24 & 0.26 & 0.25 & 0.02 & 99.76 & 89.5 & \\
\hline PS86-6-26 & 1 & 6 & 41.33 & 0.34 & 9.29 & 0.22 & 0.10 & 0.02 & 49.11 & 0.40 & 0.19 & 0.03 & 100.05 & 90.4 & \\
\hline PS86-6-38 & 1 & 6 & 40.50 & 0.16 & 9.95 & 0.20 & 0.11 & 0.02 & 48.88 & 0.26 & 0.41 & 0.02 & 99.89 & 89.8 & \\
\hline PS86-6-39 & 1 & 6 & 40.61 & 0.18 & 9.15 & 0.31 & 0.11 & 0.03 & 49.60 & 0.26 & 0.39 & 0.04 & 99.92 & 90.6 & \\
\hline PS86-6-40 & 1 & 6 & 40.42 & 0.27 & 9.71 & 0.14 & 0.10 & 0.04 & 48.85 & 0.35 & 0.37 & 0.05 & 99.47 & 90.0 & \\
\hline RC27-9-6-2 & $\mathrm{L} 1$ & 5 & 40.40 & 0.30 & 9.91 & 0.10 & 0.13 & 0.02 & 49.46 & 0.41 & 0.33 & 0.01 & 100.26 & 89.9 & FarMat \\
\hline RC27-9-6-2 & L6 & 5 & 40.40 & 0.10 & 9.74 & 0.14 & 0.12 & 0.02 & 50.21 & 0.12 & 0.34 & 0.03 & 100.86 & 90.2 & FarMat \\
\hline RC27-9-6-2 & L7 & 5 & 40.40 & 0.20 & 9.71 & 0.10 & 0.13 & 0.01 & 50.17 & 0.22 & 0.33 & 0.02 & 100.79 & 90.2 & FarMat \\
\hline $\mathrm{RC} 27-9-6-2$ & L8 & 5 & 40.50 & 0.10 & 9.58 & 0.09 & 0.11 & 0.02 & 49.77 & 0.28 & 0.32 & 0.01 & 100.30 & 90.3 & FarMat \\
\hline RC27-9-6-2 & L9 & 5 & 40.40 & 0.20 & 9.60 & 0.23 & 0.14 & 0.01 & 49.75 & 0.17 & 0.34 & 0.01 & 100.27 & 90.2 & FarMat \\
\hline RC27-9-6-2 & L12 & 5 & 40.50 & 0.10 & 9.51 & 0.10 & 0.12 & 0.02 & 49.44 & 0.17 & 0.33 & 0.02 & 99.94 & 90.3 & NrMat \\
\hline RC27-9-6-2 & L13 & 5 & 40.50 & 0.10 & 9.60 & 0.16 & 0.14 & 0.02 & 49.28 & 0.14 & 0.33 & 0.02 & 99.90 & 90.1 & NrMat \\
\hline RC27-9-6-2 & L14 & 5 & 40.60 & 0.20 & 9.74 & 0.17 & 0.13 & 0.00 & 49.60 & 0.29 & 0.34 & 0.02 & 100.45 & 90.1 & NrMat \\
\hline RC27-9-6-2 & L15 & 6 & 40.30 & 0.20 & 9.71 & 0.17 & 0.14 & 0.02 & 49.97 & 0.09 & 0.32 & 0.02 & 100.50 & 90.2 & NrMat \\
\hline RC27-9-6-2 & L16 & 5 & 40.20 & 0.20 & 9.60 & 0.12 & 0.13 & 0.01 & 50.02 & 0.22 & 0.35 & 0.03 & 100.33 & 90.3 & NrMat \\
\hline RC27-9-6-2 & L17 & 5 & 40.40 & 0.30 & 9.76 & 0.18 & 0.15 & 0.01 & 49.47 & 0.27 & 0.32 & 0.02 & 100.14 & 90.0 & CpxVn \\
\hline $\mathrm{RC} 27-9-6-2$ & L18 & 5 & 40.30 & 0.20 & 9.64 & 0.18 & 0.13 & 0.01 & 49.47 & 0.29 & 0.34 & 0.01 & 99.92 & 90.1 & $\mathrm{CpxVn}$ \\
\hline $\mathrm{RC} 27-9-6-2$ & L19 & 5 & 40.40 & 0.20 & 9.55 & 0.12 & 0.13 & 0.02 & 49.04 & 0.15 & 0.35 & 0.02 & 99.51 & 90.1 & CpxVn \\
\hline RC27-9-6-2 & L20 & 5 & 40.10 & 0.10 & 9.74 & 0.11 & 0.13 & 0.01 & 49.62 & 0.33 & 0.32 & 0.01 & 99.96 & 90.1 & AdjVn \\
\hline RC27-9-6-2 & L22 & 5 & 40.20 & 0.30 & 9.56 & 0.17 & 0.13 & 0.01 & 49.85 & 0.27 & 0.33 & 0.02 & 100.11 & 90.3 & NrMat \\
\hline RC27-9-6-2 & L23 & 5 & 40.50 & 0.30 & 9.64 & 0.11 & 0.12 & 0.02 & 50.33 & 0.56 & 0.35 & 0.02 & 100.98 & 90.3 & NrMat \\
\hline RC27-9-6-2 & L24 & 5 & 40.40 & 0.10 & 9.51 & 0.14 & 0.13 & 0.01 & 49.98 & 0.45 & 0.36 & 0.02 & 100.40 & 90.4 & NrMat \\
\hline RC27-9-6-2 & L25 & 5 & 40.50 & 0.20 & 9.60 & 0.10 & 0.14 & 0.02 & 50.05 & 0.16 & 0.34 & 0.02 & 100.66 & 90.3 & NrMat \\
\hline RC27-9-6-2 & L26 & 5 & 40.50 & 0.50 & 9.56 & 0.20 & 0.13 & 0.01 & 49.89 & 0.52 & 0.33 & 0.03 & 100.44 & 90.3 & FarMat \\
\hline RC27-9-6-5 & L1 & 6 & 40.50 & 0.02 & 10.32 & 0.07 & 0.11 & 0.01 & 49.43 & 0.07 & 0.35 & 0.02 & 100.76 & 89.5 & \\
\hline RC27-9-6-5 & L2 & 6 & 40.70 & 0.30 & 9.85 & 0.11 & 0.11 & 0.02 & 49.98 & 0.31 & 0.39 & 0.02 & 101.12 & 90.0 & \\
\hline $\mathrm{RC} 27-9-6-5$ & 1 & 5 & 40.76 & 0.17 & 9.93 & 0.26 & 0.13 & 0.04 & 49.16 & 0.31 & 0.34 & 0.03 & 100.36 & 89.8 & Enr \\
\hline RC27-9-6-7 & 1 & 6 & 41.08 & 0.18 & 9.60 & 0.06 & 0.14 & 0.01 & 49.33 & 0.61 & 0.31 & 0.02 & 100.50 & 90.2 & \\
\hline $\operatorname{Van} 7-78-25$ & 1 & 6 & 40.12 & 0.06 & 10.19 & 0.31 & 0.20 & 0.01 & 48.57 & 0.16 & 0.28 & 0.02 & 99.41 & 89.5 & GbVn \\
\hline Van7-78-31 & 1 & 6 & 40.26 & 0.08 & 9.82 & 0.17 & 0.16 & 0.02 & 48.57 & 0.20 & 0.31 & 0.03 & 99.16 & 89.8 & NrMat \\
\hline Van7-78-31 & 2 & 5 & 39.90 & 0.11 & 10.61 & 0.15 & 0.17 & 0.02 & 48.29 & 0.08 & 0.29 & 0.03 & 99.33 & 89.0 & AdjVn \\
\hline Van7-78-36 & 2 & 6 & 39.71 & 0.32 & 11.57 & 0.08 & 0.20 & 0.02 & 47.27 & 0.25 & 0.31 & 0.03 & 99.13 & 87.9 & AdjVn \\
\hline $\operatorname{Van} 7-78-36$ & 11 & 6 & 40.41 & 0.11 & 9.75 & 0.20 & 0.16 & 0.02 & 48.80 & 0.16 & 0.32 & 0.03 & 99.48 & 89.9 & FarMat \\
\hline Van7-78-40 & 1 & 6 & 40.15 & 0.29 & 9.09 & 0.13 & 0.15 & 0.02 & 49.70 & 0.22 & 0.32 & 0.02 & 99.48 & 90.7 & \\
\hline Van7-78-41 & 1 & 6 & 40.35 & 0.15 & 10.22 & 0.16 & 0.17 & 0.02 & 48.43 & 0.14 & 0.31 & 0.04 & 99.53 & 89.4 & \\
\hline Van7-85-24 & 1 & 6 & 40.12 & 0.11 & 9.31 & 0.05 & 0.15 & 0.02 & 48.87 & 0.16 & 0.34 & 0.02 & 98.85 & 90.3 & \\
\hline $\operatorname{Van} 7-85-27$ & 1 & 2 & 40.01 & 0.04 & 8.92 & 0.11 & 0.17 & 0.02 & 49.30 & 0.25 & 0.31 & 0.02 & 98.77 & 90.8 & \\
\hline $\operatorname{Van} 7-85-27$ & 2 & 3 & 40.11 & 0.11 & 8.82 & 0.22 & 0.15 & 0.02 & 49.16 & 0.08 & 0.35 & 0.03 & 98.67 & 90.9 & \\
\hline $\operatorname{Van} 7-85-30$ & 1 & 4 & 40.17 & 0.10 & 9.28 & 0.08 & 0.15 & 0.03 & 48.78 & 0.24 & 0.34 & 0.04 & 98.80 & 90.4 & \\
\hline Van7-85-32 & 1 & 6 & 40.24 & 0.10 & 9.52 & 0.13 & 0.14 & 0.02 & 49.26 & 0.32 & 0.30 & 0.03 & 99.51 & 90.2 & \\
\hline Van7-85-39 & 1 & 5 & 40.19 & 0.13 & 9.47 & 0.15 & 0.16 & 0.03 & 49.07 & 0.39 & 0.37 & 0.02 & 99.29 & 90.2 & \\
\hline Van7-85-42 & 1 & 6 & 40.03 & 0.26 & 9.57 & 0.14 & 0.13 & 0.02 & 49.36 & 0.27 & 0.35 & 0.02 & 99.50 & 90.2 & \\
\hline $\operatorname{Van} 7-85-47$ & 1 & 6 & 40.34 & 0.26 & 9.76 & 0.18 & 0.16 & 0.03 & 49.48 & 0.12 & 0.33 & 0.03 & 100.12 & 90.0 & \\
\hline Van7-85-49 & 1 & 6 & 40.49 & 0.11 & 9.57 & 0.16 & 0.15 & 0.01 & 48.91 & 0.18 & 0.40 & 0.03 & 99.57 & 90.1 & \\
\hline Van7-86-25 & 1 & 6 & 41.14 & 0.47 & 9.02 & 0.23 & 0.10 & 0.02 & 49.17 & 0.52 & 0.22 & 0.02 & 99.70 & 90.7 & \\
\hline Van7-86-27 & 1 & 6 & 40.26 & 0.26 & 9.91 & 0.10 & 0.14 & 0.02 & 49.00 & 0.27 & 0.35 & 0.05 & 99.68 & 89.8 & \\
\hline $\operatorname{Van} 7-86-28$ & 1 & 6 & 40.29 & 0.20 & 9.69 & 0.21 & 0.15 & 0.02 & 48.77 & 0.40 & 0.39 & 0.03 & 99.30 & 90.0 & \\
\hline
\end{tabular}


Table 5.4: Olivine major elements Cont.

\begin{tabular}{|c|c|c|c|c|c|c|c|c|c|c|c|c|c|c|c|}
\hline Sample & $\mathrm{Grn}^{a}$ & Pts & $\mathrm{SiO}_{2}$ & \pm & $\mathrm{FeO}$ & \pm & $\mathrm{MnO}$ & \pm & $\mathrm{MgO}$ & \pm & $\mathrm{NiO}$ & \pm & Total & $\mathrm{Mg \#}$ & Notes $^{b}$ \\
\hline $\operatorname{Van} 7-86-30$ & 1 & 4 & 40.49 & 0.18 & 9.11 & 0.26 & 0.14 & 0.01 & 49.24 & 0.26 & 0.41 & 0.04 & 99.43 & 90.6 & \\
\hline $\operatorname{Van} 7-86-37$ & 1 & 3 & 40.19 & 0.11 & 9.32 & 0.07 & 0.15 & 0.03 & 48.53 & 0.09 & 0.35 & 0.02 & 98.65 & 90.3 & \\
\hline Van7-96-09 & 1 & 6 & 40.30 & 0.09 & 9.21 & 0.17 & 0.11 & 0.01 & 50.44 & 0.16 & 0.45 & 0.02 & 100.55 & 90.7 & PyxVn \\
\hline Van7-96-14 & 1 & 7 & 40.00 & 0.16 & 11.64 & 0.15 & 0.20 & 0.01 & 48.38 & 0.07 & 0.40 & 0.03 & 100.71 & 88.1 & AdjVn \\
\hline Van7-96-14 & 2 & 6 & 39.75 & 0.17 & 12.19 & 0.32 & 0.24 & 0.03 & 47.78 & 0.13 & 0.43 & 0.01 & 100.45 & 87.5 & PyxVn \\
\hline $\operatorname{Van} 7-96-15$ & 1 & 6 & 39.88 & 0.18 & 10.98 & 0.15 & 0.22 & 0.02 & 48.08 & 0.13 & 0.37 & 0.03 & 99.61 & 88.6 & PyxVn \\
\hline Van7-96-16 & 2 & 5 & 40.18 & 0.19 & 10.89 & 0.18 & 0.22 & 0.02 & 47.75 & 0.13 & 0.37 & 0.02 & 99.50 & 88.7 & PyxVn \\
\hline $\operatorname{Van} 7-96-18$ & 1 & 5 & 40.27 & 0.21 & 10.49 & 0.19 & 0.14 & 0.03 & 48.84 & 0.17 & 0.38 & 0.03 & 100.19 & 89.2 & NrMat \\
\hline Van7-96-18 & 2 & 6 & 40.02 & 0.11 & 10.56 & 0.33 & 0.16 & 0.02 & 48.51 & 0.21 & 0.39 & 0.02 & 99.68 & 89.1 & PyxVn \\
\hline Van7-96-19 & 1 & 6 & 40.20 & 0.12 & 10.11 & 0.29 & 0.13 & 0.02 & 49.51 & 0.28 & 0.40 & 0.02 & 100.40 & 89.7 & NrMat \\
\hline $\operatorname{Van} 7-96-19$ & 2 & 5 & 40.07 & 0.15 & 10.43 & 0.40 & 0.16 & 0.03 & 48.40 & 0.22 & 0.40 & 0.02 & 99.51 & 89.2 & PyxVn \\
\hline Van7-96-19 & 3 & 6 & 40.15 & 0.14 & 10.51 & 0.16 & 0.14 & 0.01 & 48.47 & 0.33 & 0.38 & 0.05 & 99.67 & 89.2 & PyxVn \\
\hline $\operatorname{Van} 7-96-21$ & 2 & 6 & 40.17 & 0.13 & 9.76 & 0.21 & 0.16 & 0.03 & 50.03 & 0.24 & 0.34 & 0.03 & 100.51 & 90.1 & PyxVn \\
\hline Van7-96-21 & 3 & 6 & 40.16 & 0.23 & 9.69 & 0.11 & 0.16 & 0.03 & 49.85 & 0.12 & 0.35 & 0.04 & 100.27 & 90.2 & AdjVn \\
\hline $\operatorname{Van} 7-96-25$ & 1 & 6 & 40.09 & 0.16 & 10.10 & 0.32 & 0.12 & 0.02 & 48.87 & 0.24 & 0.39 & 0.04 & 99.64 & 89.6 & \\
\hline Van7-96-28 & 1 & 6 & 40.42 & 0.09 & 9.18 & 0.15 & 0.13 & 0.03 & 49.33 & 0.39 & 0.36 & 0.03 & 99.47 & 90.5 & \\
\hline $\operatorname{Van} 7-96-35$ & 1 & 6 & 40.62 & 0.14 & 8.66 & 0.21 & 0.11 & 0.02 & 50.34 & 0.23 & 0.43 & 0.04 & 100.19 & 91.2 & \\
\hline Van7-96-37 & 1 & 6 & 40.40 & 0.43 & 9.22 & 0.25 & 0.10 & 0.01 & 49.39 & 0.12 & 0.37 & 0.03 & 99.53 & 90.5 & \\
\hline Van7-96-38 & 1 & 6 & 40.41 & 0.12 & 9.80 & 0.20 & 0.15 & 0.02 & 49.81 & 0.14 & 0.35 & 0.04 & 100.55 & 90.1 & \\
\hline
\end{tabular}

${ }^{a}$ Grain number; L preceding a grain number indicates Lee $\overline{1997}$ data for dredge RC27-9-6 samples.

${ }^{b}$ Abbreviations for lithologies (blank indicates residual peridotite): Dep, Trans and Enr are depleted, transitional and enriched zones in cryptically metasomatized sample; GbVn refers to a gabbroic vein, PyxVn to a pyroxenite vein, CpxVn to a clinopyroxenite vein, and OpxVn to an orthopyroxenite vein; AdjVn is adjacent to a vein, NrMat is $<5 \mathrm{~cm}$ from a vein and FarMat is $>5 \mathrm{~cm}$ from a vein. 
Table 5.5: Major element composition of Opx, in wt\%.

\begin{tabular}{|c|c|c|c|c|c|c|c|c|c|c|c|c|c|c|c|c|c|c|c|c|c|c|}
\hline Analysis & $\mathrm{Grn}^{a}$ & Pts & $\mathrm{SiO}_{2}$ & \pm & $\mathrm{TiO}_{2}$ & \pm & $\mathrm{Al}_{2} \mathrm{O}_{3}$ & $3 \pm$ & $\mathrm{Cr}_{2} \mathrm{O}_{3}$ & $3 \pm$ & $\mathrm{FeO}$ & \pm & $\mathrm{MnO}$ & \pm & $\mathrm{MgO}$ & \pm & $\mathrm{CaO}$ & \pm & $\mathrm{Na}_{2} \mathrm{O}$ & \pm & Total & Notes $^{b}$ \\
\hline $6 \mathrm{~K}-458-1$ & $1 \mathrm{C}$ & 8 & 53.01 & 1.81 & 0.10 & 0.04 & 4.17 & 0.89 & 1.38 & 0.81 & 6.43 & 1.08 & 0.21 & 0.07 & 32.27 & 1.15 & 1.24 & 1.26 & 0.07 & 0.07 & 98.88 & \\
\hline $6 \mathrm{~K}-458-1$ & $1 \mathrm{R}$ & 8 & 54.82 & 0.44 & 0.09 & 0.02 & 5.05 & 0.14 & 0.85 & 0.03 & 6.05 & 0.15 & 0.14 & 0.01 & 32.43 & 0.51 & 1.29 & 0.71 & 0.02 & 0.02 & 100.74 & \\
\hline $6 \mathrm{~K}-458-3$ & $1 \mathrm{C}$ & 13 & 54.17 & 0.29 & 0.09 & 0.03 & 5.64 & 0.24 & 0.75 & 0.03 & 6.12 & 0.23 & 0.12 & 0.02 & 30.56 & 0.88 & 1.97 & 1.04 & 0.01 & 0.01 & 99.42 & \\
\hline $6 \mathrm{~K}-458-3$ & $1 \mathrm{C}$ & 9 & 54.77 & 0.24 & 0.08 & 0.02 & 4.91 & 0.11 & 0.62 & 0.02 & 6.23 & 0.16 & 0.12 & 0.03 & 31.18 & 0.46 & 1.32 & 0.65 & 0.00 & 0.00 & 99.24 & \\
\hline $6 \mathrm{~K}-465-2$ & $1 \mathrm{C}$ & 10 & 55.44 & 0.29 & 0.09 & 0.01 & 4.17 & 0.16 & 0.64 & 0.01 & 6.32 & 0.12 & 0.12 & 0.01 & 32.18 & 0.37 & 1.58 & 0.41 & 0.03 & 0.01 & 100.57 & Dep \\
\hline $6 \mathrm{~K}-465-2$ & $1 \mathrm{R}$ & 10 & 55.78 & 0.34 & 0.09 & 0.01 & 3.34 & 0.46 & 0.61 & 0.02 & 6.35 & 0.10 & 0.12 & 0.02 & 33.04 & 0.45 & 1.19 & 0.20 & 0.03 & 0.01 & 100.54 & Dep \\
\hline $6 \mathrm{~K}-465-2$ & $2 \mathrm{C}$ & 3 & 53.42 & 0.30 & 0.07 & 0.02 & 5.51 & 0.21 & 0.81 & 0.05 & 6.12 & 0.29 & 0.13 & 0.03 & 31.24 & 0.53 & 1.77 & 0.84 & 0.00 & 0.00 & 99.07 & Dep \\
\hline $6 \mathrm{~K}-643-3$ & $2 \mathrm{C}$ & 14 & 54.25 & 0.05 & 0.12 & 0.01 & 4.37 & 0.22 & 0.65 & 0.01 & 6.58 & 0.09 & 0.12 & 0.00 & 31.51 & 0.07 & 1.78 & 0.24 & 0.02 & 0.02 & 99.41 & NrMat \\
\hline $6 \mathrm{~K}-643-3$ & $2 \mathrm{R}$ & 15 & 54.81 & 0.37 & 0.18 & 0.07 & 3.24 & 0.69 & 0.68 & 0.06 & 6.80 & 0.00 & 0.13 & 0.01 & 31.44 & 0.56 & 1.64 & 0.09 & 0.13 & 0.12 & 99.05 & NrMat \\
\hline $6 \mathrm{~K}-466-1$ & $1 \mathrm{C}$ & 10 & 54.70 & 0.50 & 0.08 & 0.03 & 4.57 & 0.15 & 0.77 & 0.03 & 5.80 & 0.29 & 0.14 & 0.05 & 31.80 & 0.91 & 2.37 & 1.22 & 0.04 & 0.04 & 100.27 & \\
\hline $6 \mathrm{~K}-466-1$ & $1 \mathrm{R}$ & 10 & 55.77 & 0.30 & 0.07 & 0.01 & 3.98 & 0.07 & 0.60 & 0.03 & 5.92 & 0.15 & 0.14 & 0.02 & 32.74 & 0.36 & 1.36 & 0.45 & 0.02 & 0.02 & 100.59 & \\
\hline 6K-466-1 & 2I & 6 & 54.89 & 0.33 & 0.07 & 0.01 & 3.49 & 0.14 & 0.44 & 0.02 & 5.96 & 0.13 & 0.17 & 0.02 & 34.22 & 0.30 & 0.78 & 0.06 & & & 100.01 & \\
\hline $6 \mathrm{~K}-643-13$ & $1 \mathrm{C}$ & 10 & 54.19 & 0.21 & 0.05 & 0.01 & 5.07 & 0.10 & 0.90 & 0.04 & 5.97 & 0.16 & 0.13 & 0.02 & 31.15 & 0.56 & 2.18 & 0.55 & 0.02 & 0.01 & 99.65 & \\
\hline $6 \mathrm{~K}-643-13$ & $1 \mathrm{R}$ & 9 & 54.90 & 0.46 & 0.05 & 0.02 & 3.98 & 0.27 & 0.67 & 0.05 & 6.01 & 0.30 & 0.13 & 0.02 & 32.05 & 1.29 & 1.92 & 1.75 & 0.01 & 0.01 & 99.71 & \\
\hline $6 \mathrm{~K}-651-7$ & $1 \mathrm{C}$ & 10 & 54.48 & 0.18 & 0.05 & 0.01 & 4.97 & 0.08 & 0.68 & 0.02 & 6.57 & 0.16 & 0.12 & 0.03 & 31.38 & 0.50 & 0.90 & 0.57 & 0.00 & 0.00 & 99.14 & PyxVn \\
\hline $6 \mathrm{~K}-651-7$ & $1 \mathrm{R}$ & 13 & 54.28 & 0.32 & 0.07 & 0.02 & 5.31 & 0.09 & 0.73 & 0.02 & 6.37 & 0.17 & 0.12 & 0.02 & 31.03 & 0.56 & 1.40 & 0.76 & 0.00 & 0.01 & 99.32 & PyxVn \\
\hline JR31-52-03 & $1 \mathrm{C}$ & 13 & 54.36 & 0.29 & 0.06 & 0.02 & 5.45 & 0.13 & 0.90 & 0.03 & 5.97 & 0.17 & 0.13 & 0.02 & 30.94 & 0.47 & 1.96 & 0.56 & 0.06 & 0.03 & 99.84 & \\
\hline JR31-52-03 & $1 \mathrm{R}$ & 10 & 55.17 & 0.36 & 0.05 & 0.01 & 4.29 & 0.29 & 0.58 & 0.07 & 6.01 & 0.19 & 0.13 & 0.02 & 32.00 & 0.39 & 1.21 & 0.40 & 0.02 & 0.01 & 99.45 & \\
\hline JR31-52-04 & $1 \mathrm{C}$ & 16 & 54.25 & 0.25 & 0.08 & 0.02 & 5.25 & 0.09 & 0.71 & 0.08 & 5.97 & 0.20 & 0.12 & 0.03 & 31.24 & 0.62 & 1.80 & 0.79 & 0.06 & 0.03 & 99.47 & \\
\hline JR31-52-04 & $1 \mathrm{R}$ & 11 & 54.46 & 0.12 & 0.08 & 0.01 & 5.18 & 0.07 & 0.79 & 0.02 & 5.91 & 0.23 & 0.12 & 0.02 & 31.07 & 0.96 & 2.12 & 1.28 & 0.06 & 0.04 & 99.80 & \\
\hline JR31-52-04 & $2 \mathrm{I}$ & 12 & 55.77 & 0.28 & 0.08 & 0.01 & 3.63 & 0.20 & 0.43 & 0.05 & 6.12 & 0.11 & 0.13 & 0.02 & 32.81 & 0.19 & 0.89 & 0.08 & 0.02 & 0.01 & 99.89 & \\
\hline JR31-52-05 & $1 \mathrm{C}$ & 13 & 54.17 & 0.49 & 0.08 & 0.01 & 5.38 & 0.15 & 0.81 & 0.04 & 5.84 & 0.16 & 0.14 & 0.03 & 30.86 & 0.68 & 2.30 & 0.89 & 0.05 & 0.03 & 99.63 & \\
\hline JR31-52-05 & $1 \mathrm{R}$ & 11 & 54.59 & 0.40 & 0.05 & 0.02 & 5.15 & 0.28 & 0.76 & 0.04 & 5.93 & 0.18 & 0.08 & 0.02 & 31.78 & 0.42 & 1.20 & 0.37 & 0.04 & 0.01 & 99.58 & \\
\hline JR31-52-08 & $1 \mathrm{C}$ & 15 & 54.45 & 0.42 & 0.09 & 0.02 & 5.16 & 0.24 & 0.80 & 0.05 & 5.93 & 0.18 & 0.11 & 0.03 & 30.88 & 0.72 & 2.30 & 1.00 & 0.06 & 0.03 & 99.79 & \\
\hline JR31-52-08 & $1 \mathrm{R}$ & 15 & 55.82 & 0.51 & 0.08 & 0.01 & 3.68 & 0.31 & 0.42 & 0.09 & 6.16 & 0.16 & 0.12 & 0.02 & 32.64 & 0.34 & 0.83 & 0.26 & 0.02 & 0.02 & 99.76 & \\
\hline JR31-52-08 & $3 \mathrm{I}$ & 10 & 56.00 & 0.20 & 0.05 & 0.01 & 3.94 & 0.11 & 0.57 & 0.02 & 6.10 & 0.10 & 0.12 & 0.02 & 32.37 & 0.19 & 1.32 & 0.17 & 0.05 & 0.01 & 100.53 & \\
\hline Kn162-19-41 & $1 \mathrm{C}$ & 10 & 55.24 & 0.19 & 0.07 & 0.02 & 4.47 & 0.14 & 0.53 & 0.03 & 5.83 & 0.22 & 0.12 & 0.02 & 32.13 & 0.23 & 1.55 & 0.31 & 0.00 & 0.01 & 99.96 & PyxVn \\
\hline Kn162-19-41 & $1 \mathrm{R}$ & 10 & 54.88 & 0.34 & 0.06 & 0.02 & 4.68 & 0.28 & 0.54 & 0.04 & 6.26 & 0.11 & 0.13 & 0.03 & 32.26 & 0.39 & 0.94 & 0.39 & 0.00 & 0.00 & 99.76 & PyxVn \\
\hline Kn162-47-02 & 1I & 10 & 56.70 & 0.16 & 0.00 & 0.01 & 2.51 & 0.07 & 0.97 & 0.04 & 4.89 & 0.11 & 0.13 & 0.02 & 34.06 & 0.19 & 1.32 & 0.30 & 0.00 & 0.02 & 100.59 & \\
\hline Kn162-47-08 & $1 \mathrm{C}$ & 10 & 53.77 & 0.28 & 0.14 & 0.03 & 5.94 & 0.18 & 0.74 & 0.04 & 6.22 & 0.20 & 0.13 & 0.02 & 30.54 & 0.81 & 2.95 & 1.17 & 0.00 & 0.01 & 100.43 & \\
\hline Kn162-47-08 & $1 \mathrm{R}$ & 14 & 54.53 & 0.48 & 0.09 & 0.01 & 4.79 & 0.64 & 0.57 & 0.09 & 6.42 & 0.16 & 0.15 & 0.02 & 31.16 & 0.48 & 1.24 & 0.27 & 0.03 & 0.02 & 98.99 & \\
\hline Kn162-47-09 & $1 \mathrm{C}$ & 14 & 56.02 & 0.34 & 0.06 & 0.02 & 3.57 & 0.22 & 0.96 & 0.04 & 5.31 & 0.22 & 0.11 & 0.02 & 32.66 & 0.79 & 1.84 & 0.91 & 0.09 & 0.05 & 100.63 & \\
\hline Kn162-47-09 & $1 \mathrm{R}$ & 14 & 56.56 & 0.43 & 0.06 & 0.01 & 3.33 & 0.14 & 0.76 & 0.04 & 5.30 & 0.13 & 0.12 & 0.02 & 33.30 & 0.30 & 1.26 & 0.29 & 0.07 & 0.03 & 100.75 & \\
\hline Kn162-47-09 & $2 \mathrm{C}$ & 11 & 55.41 & 0.27 & 0.07 & 0.01 & 3.33 & 0.20 & 0.88 & 0.06 & 5.23 & 0.17 & 0.13 & 0.02 & 32.02 & 0.63 & 1.81 & 0.84 & 0.04 & 0.04 & 98.93 & \\
\hline Kn162-47-09 & $2 \mathrm{R}$ & 11 & 55.55 & 0.15 & 0.06 & 0.01 & 3.08 & 0.07 & 0.76 & 0.03 & 5.34 & 0.09 & 0.13 & 0.02 & 32.64 & 0.32 & 1.27 & 0.17 & 0.04 & 0.02 & 98.88 & \\
\hline Kn162-47-09 & $4 \mathrm{C}$ & 7 & 56.51 & 0.59 & 0.05 & 0.01 & 3.12 & 0.08 & 0.74 & 0.03 & 5.32 & 0.17 & 0.10 & 0.02 & 33.48 & 0.49 & 1.35 & 0.44 & 0.09 & 0.02 & 100.75 & \\
\hline Kn162-47-10 & $1 \mathrm{C}$ & 8 & 53.98 & 0.18 & 0.08 & 0.01 & 5.59 & 0.18 & 0.70 & 0.02 & 6.31 & 0.20 & 0.13 & 0.02 & 30.94 & 0.47 & 1.78 & 0.43 & 0.01 & 0.01 & 99.52 & PyxVn \\
\hline Kn162-47-10 & $1 \mathrm{R}$ & 10 & 54.40 & 0.53 & 0.09 & 0.04 & 4.50 & 0.23 & 0.52 & 0.05 & 6.17 & 0.75 & 0.13 & 0.02 & 30.64 & 2.67 & 2.97 & 3.70 & 0.03 & 0.07 & 99.46 & PyxVn \\
\hline Kn162-47-10 & $2 \mathrm{C}$ & 8 & 54.38 & 0.70 & 0.07 & 0.02 & 4.89 & 0.47 & 0.63 & 0.05 & 6.31 & 0.16 & 0.14 & 0.01 & 31.34 & 0.64 & 1.41 & 0.61 & 0.01 & 0.03 & 99.18 & FarMat \\
\hline Kn162-47-10 & $2 \mathrm{R}$ & 4 & 55.59 & 0.24 & 0.08 & 0.02 & 3.10 & 0.15 & 0.29 & 0.02 & 6.59 & 0.12 & 0.15 & 0.02 & 32.58 & 0.14 & 0.97 & 0.04 & 0.00 & 0.00 & 99.35 & FarMat \\
\hline
\end{tabular}


Table 5.5: Opx major elements Cont.

\begin{tabular}{|c|c|c|c|c|c|c|c|c|c|c|c|c|c|c|c|c|c|c|c|c|c|c|}
\hline Analysis & $\mathrm{srn}^{a}$ & Pts & $\mathrm{SiO}_{2}$ & \pm & $\mathrm{TiO}_{2}$ & \pm & $\mathrm{Al}_{2} \mathrm{O}_{3}$ & $3 \pm$ & $\mathrm{Cl}_{1}$ & $3 \pm$ & $\mathrm{FeO}$ & \pm & $\mathrm{MnO}$ & \pm & $\mathrm{MgO}$ & \pm & $\mathrm{CaO}$ & \pm & $\mathrm{a}_{2} \mathrm{O}$ & \pm & Total & $b$ \\
\hline Kn162-47-12 & $1 \mathrm{C}$ & 9 & 53.82 & 32 & 0.09 & 0.03 & 5.71 & 0.26 & 0.75 & 0.04 & 6.26 & 0.20 & 0.14 & 0.03 & .97 & 0.94 & 1.78 & 1.19 & 0.01 & 0.02 & 99.54 & $y x V n$ \\
\hline Kn162-47-12 & 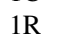 & 9 & 54.36 & 32 & 0.09 & 0.03 & 4.86 & 0.38 & 0.64 & 0.06 & 6.22 & 0.27 & 0.15 & 0.02 & 31.10 & 0.95 & 2.13 & 1.55 & 0.01 & 0.02 & 99.56 & Vn \\
\hline & $\mathrm{r}$ & 10 & & o & 09 & 01 & & 0.06 & & 0.02 & 6.89 & 0.10 & & 0.02 & & & 1.73 & 0.30 & .00 & 0.00 & & \\
\hline & R & 10 & 87 & 29 & 07 & 0.01 & 72 & 0.09 & 70 & 0.02 & .89 & 0.10 & 14 & 0.01 & .97 & 0.36 & 1.31 & 0.24 & .00 & 0.00 & & $x V n$ \\
\hline Kn162-47-24 & $\mathrm{C}$ & 10 & 1.36 & 0.47 & 0.06 & 0.02 & 5.41 & 0.64 & .83 & 0.04 & 6.32 & 0.19 & 0.11 & 0.02 & 30.82 & 0.75 & 2.29 & 0.80 & 0.02 & 0.02 & 100.22 & \\
\hline Kn162-47-24 & $\mathrm{R}$ & 10 & 54.98 & 0.70 & 0.05 & 0.03 & 5.08 & 0.61 & 75 & 0.07 & 6.47 & 0.28 & 0.10 & 0.03 & 31.34 & 1.26 & 1.72 & 1.17 & 0.02 & 0.02 & 100.50 & \\
\hline Kn162-47-25 & $1 \mathrm{C}$ & 10 & 53.69 & 0.46 & 0.16 & 0.03 & 5.35 & 0.12 & 0.66 & 0.03 & 6.50 & 0.37 & 0.14 & 0.02 & 30.38 & 1.31 & 2.43 & 1.79 & 0.03 & 0.06 & 99.35 & $y x V n$ \\
\hline & 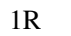 & 8 & 54.22 & 0.27 & 0.11 & 0.02 & 5.00 & 0.08 & 61 & 0.02 & 6.70 & 0.11 & 0.14 & 0.02 & 31.55 & 0.27 & 1.16 & 0.08 & 0.00 & 0.00 & 99.49 & $\mathrm{Vn}$ \\
\hline & & 9 & .50 & 0.1 & 07 & 0.02 & 46 & 0.21 & $\$ 4$ & 0.03 & .41 & 0.11 & 0.12 & 0.02 & 31.11 & 0.27 & 1.67 & 0.39 & .04 & 0.03 & 100.03 & \\
\hline & & 10 & 54.21 & 0.30 & 09 & 0.02 & 6 & 0.24 & 79 & 0.04 & 5.56 & 0.32 & & 0.03 & & 1.12 & 2.48 & 1.52 & & 0.04 & & \\
\hline Kn162-47-29 & $\mathrm{R}$ & 10 & 54.91 & 0.24 & 0.08 & 0.01 & 5.50 & 0.15 & 65 & 0.04 & 5.74 & 0.10 & 0.08 & 0.02 & 31.98 & 0.29 & 1.49 & 0.30 & 0.03 & 0.02 & 100.44 & \\
\hline & $1 \mathrm{C}$ & 10 & 54.53 & 0.43 & 0.06 & 0.01 & 5.24 & 0.18 & 074 & 0.03 & 6.66 & 0.21 & 0.10 & 0.03 & & 0.37 & 2.01 & 0.35 & 0.04 & 0.05 & 100.49 & \\
\hline & & 9 & 5 & 0 & 06 & 0.0 & & 0.4 & 58 & 0.1 & 1 & 0.1 & 0 & 0.0 & & 0. & 1.48 & 0. & 2 & 0.03 & 77 & \\
\hline & & 10 & 65 & 0 & .08 & 0.0 & & 0.5 & & 0.0 & 34 & 0.3 & 0.10 & 0.0 & & & 2.35 & 1. & & 0.03 & & \\
\hline & & 0 & & 0 & .04 & 0.0 & & 0.8 & & 0.0 & 6.77 & 0.34 & 0.11 & 0.02 & & & 0.89 & & & 0.04 & & \\
\hline & & 10 & 54.56 & 0.7 & 0.11 & 0.0 & & 0.28 & 0 & 0 & 5.99 & 0.47 & & 0.04 & & 2. & 2.03 & 2. & & 0.15 & & \\
\hline & & 14 & 5 & 0.42 & 0.09 & 0.02 & 5. & 0.22 & 0.43 & 0.0 & 6.27 & 0.18 & & 0.02 & & & 1.16 & 0.23 & 2 & 0.02 & 100.21 & \\
\hline & & 8 & & 0 & 14 & 0.0 & & 0.1 & & 0.0 & & 0. & & 0.0 & & & 4 & 0 . & & 0.04 & 7 & \\
\hline & & 8 & .80 & 0.2 & .14 & 0.0 & c & 0.1 & 1 & 0.0 & 28 & 0.2 & 0.16 & 0.0 & 30.60 & 0. & 1.97 & 1.2 & & 0.08 & & \\
\hline & & 8 & 67 & 0.65 & 10 & 0.02 & & 0.0 & & 0 & 25 & 0.20 & 0.15 & 0.03 & & 0. & 1.10 & 0 . & & 0.03 & & \\
\hline $6-40$ & & 11 & 54.40 & 0.57 & 0.14 & 0.03 & 4.94 & 0.72 & 0.48 & 0.0 & 6.44 & 0.22 & 0.11 & 0.02 & 31.14 & 0.57 & 1.31 & 0.45 & & 0.03 & 99.02 & \\
\hline & & 10 & & 0 & & 0 & & & & & & & & 0.0 & & 0. & & 0 . & & & & \\
\hline & 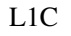 & 10 & 5 & 0.2 & 7 & 0.0 & 2 & 0.0 & 67 & 0.0 & 6.23 & 0. & 0 & 0.0 & & 0. & 1.46 & 0.46 & 0. & $0 .($ & 4 & \\
\hline & & 9 & & & 7 & 0.0 & & 0 & & 0.0 & 6.13 & 0.25 & & 0.02 & & 0 . & 1.92 & 1. & 0 & 0. & 1 & \\
\hline & & 10 & & 0.3 & & 0.02 & & 0.27 & & & 6.54 & 0.1 & & 0.02 & & 0 . & 0.81 & 0. & 4 & 0.02 & & $\mathrm{kn}$ \\
\hline RC27-9-6-2 & L7C & 10 & 54.9 & 0.2 & 0.09 & 0.02 & 3.87 & 0.12 & 0.92 & 0.05 & 6.80 & 0.12 & 0.08 & 0.02 & 32.41 & 0. & 1.63 & 0.4 & 0.05 & 0.03 & 99.37 & JrMat \\
\hline RC27-9-6-2 & L8R & 10 & 56.4 & 0.6 & 0.20 & 0.03 & & 0.09 & 0.62 & 0.03 & 6.22 & 0.19 & 0.17 & 0.01 & & 0 . & 1.15 & 0.76 & 0.02 & 0.03 & & arMat \\
\hline & & 10 & & & & 0.0 & & 0.0 & & $0 .(1$ & & & & 0.0 & & 0 . & & 0. & & 0. & & \\
\hline & $9 \mathrm{R}$ & 10 & & & 0.05 & 0.0 & & 03 & & 0.0 & 6. & $0 .($ & & 0.0 & & 0 . & 06 & 0. & & $0 .($ & & Tat \\
\hline & & 10 & 5 & & & & & & & & & & & 0.02 & & & 2.36 & 0.22 & & 0.03 & & \\
\hline RC27-9-6-2 & $13 \mathrm{R}$ & 10 & 56.00 & 0.34 & 0.04 & 0.01 & 3.12 & 0.18 & 0.59 & 0.07 & 6.48 & 0.07 & 0.14 & 0.01 & 33.02 & 0.41 & 0.77 & 0.18 & 0.02 & 0.02 & 100.19 & FarMat \\
\hline & $1 \mathrm{C}$ & 9 & 55.02 & 0.52 & 0.09 & 0.02 & 3.82 & 0.55 & 0.68 & 0.04 & 6.30 & 0.14 & 0.09 & 0.02 & 31.30 & 0.60 & 1.56 & 0.71 & 0.04 & 0.03 & 98.91 & Trans \\
\hline & $1 \mathrm{R}$ & 10 & 56.31 & 0.45 & 13 & 0.02 & 2.40 & 0.19 & 1 & 0.03 & 6.54 & 0.1 & 0 . & 0.0 & & 0. & 0.88 & 0.36 & 0.06 & 0.08 & 66 & Trans \\
\hline 65 & 51 & 7 & & & 0 & 0.0 & 3.3 & 0.3 & .70 & & & & & 0. & & 0. & & 0. & & 0. & & \\
\hline & & 10 & & & & & & & & & & & & & & 1. & & 2. & & & & \\
\hline & & 10 & & & & & & & & & & & & 0.02 & & 0.65 & 1.86 & 0.58 & & 0.02 & & \\
\hline RC27-9-6-7 & $1 \mathrm{~F}$ & 10 & 55.13 & 0.27 & 0.06 & 0.01 & 4.22 & 0.15 & .38 & 0.02 & 6.46 & 0.12 & 0.14 & 0.02 & 32.88 & 0.27 & 0.59 & 0.11 & 0.00 & 0.01 & 99.84 & \\
\hline Van7-78-25 & $3 \mathrm{I}$ & 7 & 56.85 & 0.36 & 0.15 & 0.02 & 1.81 & 0.19 & .58 & 0.07 & 6.84 & 0.10 & 0.18 & 0.02 & 33.02 & 0.0 & 0.88 & 0.08 & 0.00 & 0.00 & 100.31 & \\
\hline Van7-78-31 & $1 \mathrm{C}$ & 12 & 57.12 & 0.31 & 0.13 & 0.02 & 1.54 & 0.11 & 0.43 & 0.05 & 6.40 & 0.18 & 0.15 & 0.03 & 33.20 & 0.48 & 1.13 & 0.74 & 0.01 & 0.01 & 100.11 & NrMat \\
\hline
\end{tabular}


Table 5.5: Opx major elements Cont.

\begin{tabular}{|c|c|c|c|c|c|c|c|c|c|c|c|c|c|c|c|c|c|c|c|c|c|c|}
\hline Analysis & $\mathrm{Grn}^{a}$ & Pts & $\mathrm{SiO}_{2}$ & \pm & $\mathrm{TiO}_{2}$ & \pm & $\mathrm{Al}_{2} \mathrm{O}$ & $3 \pm$ & $\mathrm{Cr}_{2} \mathrm{O}$ & $3 \pm$ & $\mathrm{FeO}$ & \pm & $\mathrm{MnO}$ & \pm & $\mathrm{MgO}$ & \pm & $\mathrm{CaO}$ & \pm & $\mathrm{Na}_{2} \mathrm{O}$ & \pm & Total & Notes $^{b}$ \\
\hline $\operatorname{Van} 7-78-31$ & $1 \mathrm{R}$ & 13 & 57.32 & 0.26 & 0.12 & 0.01 & 1.52 & 0.13 & 0.39 & 0.04 & 6.55 & 0.10 & 0.16 & 0.02 & 33.38 & 0.17 & 0.69 & 0.10 & 0.01 & 0.02 & 100.13 & NrMat \\
\hline Van7-78-31 & $2 \mathrm{C}$ & 7 & 56.06 & 0.18 & 0.14 & 0.02 & 1.90 & 0.03 & 0.61 & 0.01 & 7.10 & 0.12 & 0.13 & 0.03 & 31.95 & 0.25 & 1.01 & 0.35 & 0.03 & 0.02 & 98.95 & $\operatorname{Adj} V n$ \\
\hline Van7-78-31 & $2 \mathrm{R}$ & 10 & 56.61 & 0.10 & 0.17 & 0.02 & 1.20 & 0.06 & 0.31 & 0.03 & 7.16 & 0.10 & 0.15 & 0.01 & 32.62 & 0.20 & 0.60 & 0.10 & 0.02 & 0.02 & 98.84 & AdjVn \\
\hline Van7-78-36 & $1 \mathrm{C}$ & 13 & 55.35 & 1.10 & 0.17 & 0.03 & 2.73 & 0.39 & 0.99 & 0.66 & 7.83 & 0.41 & 0.17 & 0.03 & 31.78 & 0.65 & 1.37 & 0.70 & 0.04 & 0.03 & 100.43 & AdjVn \\
\hline Van7-78-36 & $1 \mathrm{R}$ & 12 & 56.49 & 0.33 & 0.22 & 0.01 & 1.47 & 0.16 & 0.37 & 0.06 & 7.89 & 0.14 & 0.19 & 0.02 & 32.99 & 0.13 & 0.69 & 0.13 & 0.01 & 0.02 & 100.31 & AdjVn \\
\hline $\operatorname{Van} 7-78-36$ & $11 \mathrm{C}$ & 13 & 56.86 & 0.88 & 0.16 & 0.02 & 1.79 & 0.28 & 0.54 & 0.03 & 6.72 & 0.28 & 0.14 & 0.06 & 33.38 & 1.16 & 1.28 & 1.17 & 0.03 & 0.02 & 100.90 & FarMat \\
\hline Van7-78-36 & $11 \mathrm{R}$ & 12 & 56.65 & 0.50 & 0.17 & 0.02 & 1.92 & 0.11 & 0.51 & 0.05 & 6.61 & 0.22 & 0.14 & 0.03 & 33.24 & 0.52 & 1.23 & 0.61 & 0.02 & 0.01 & 100.49 & FarMat \\
\hline Van7-78-40 & $1 \mathrm{C}$ & 11 & 56.13 & 0.25 & 0.10 & 0.01 & 2.90 & 0.18 & 0.72 & 0.06 & 6.03 & 0.24 & 0.14 & 0.02 & 32.98 & 0.44 & 1.19 & 0.55 & 0.01 & 0.01 & 100.20 & \\
\hline $\operatorname{Van} 7-78-40$ & $1 \mathrm{R}$ & 12 & 57.35 & 0.26 & 0.12 & 0.02 & 1.35 & 0.18 & 0.34 & 0.06 & 6.11 & 0.12 & 0.16 & 0.02 & 34.25 & 0.14 & 0.49 & 0.07 & 0.01 & 0.01 & 100.18 & \\
\hline $\operatorname{Van} 7-78-41$ & $1 \mathrm{C}$ & 12 & 56.67 & 0.31 & 0.09 & 0.02 & 1.82 & 0.19 & 0.54 & 0.04 & 7.02 & 0.18 & 0.15 & 0.02 & 33.26 & 0.38 & 0.98 & 0.47 & 0.01 & 0.01 & 100.53 & \\
\hline $\operatorname{Van} 7-78-41$ & $1 \mathrm{R}$ & 13 & 56.40 & 0.23 & 0.09 & 0.02 & 2.38 & 0.14 & 0.64 & 0.04 & 6.92 & 0.22 & 0.15 & 0.02 & 32.90 & 0.50 & 1.08 & 0.68 & 0.02 & 0.02 & 100.57 & \\
\hline Van7-85-24 & $1 \mathrm{C}$ & 8 & 54.69 & 0.47 & 0.06 & 0.01 & 4.78 & 0.23 & 0.69 & 0.03 & 6.23 & 0.14 & 0.14 & 0.02 & 30.99 & 0.49 & 1.76 & 0.41 & 0.04 & 0.03 & 99.36 & \\
\hline Van7-85-24 & $1 \mathrm{R}$ & 7 & 54.26 & 0.14 & 0.05 & 0.01 & 5.14 & 0.07 & 0.71 & 0.02 & 6.38 & 0.12 & 0.12 & 0.03 & 31.03 & 0.13 & 1.18 & 0.03 & 0.04 & 0.02 & 98.90 & \\
\hline $\operatorname{Van} 7-85-27$ & $2 \mathrm{C}$ & 11 & 54.86 & 0.35 & 0.09 & 0.02 & 3.98 & 0.22 & 0.70 & 0.03 & 5.84 & 0.11 & 0.12 & 0.01 & 31.91 & 0.35 & 1.75 & 0.36 & 0.03 & 0.02 & 99.27 & \\
\hline Van7-85-27 & $2 \mathrm{R}$ & 10 & 55.02 & 0.22 & 0.10 & 0.01 & 4.10 & 0.24 & 0.68 & 0.02 & 5.61 & 0.21 & 0.12 & 0.01 & 31.36 & 0.61 & 2.21 & 0.80 & 0.05 & 0.03 & 99.24 & \\
\hline Van7-85-27 & $3 I$ & 7 & 55.19 & 0.14 & 0.08 & 0.02 & 3.88 & 0.05 & 0.60 & 0.04 & 5.77 & 0.09 & 0.11 & 0.02 & 32.16 & 0.25 & 1.45 & 0.22 & 0.04 & 0.02 & 99.27 & \\
\hline $\operatorname{Van} 7-85-30$ & $1 \mathrm{C}$ & 9 & 54.88 & 0.29 & 0.07 & 0.01 & 4.51 & 0.19 & 0.61 & 0.01 & 6.04 & 0.18 & 0.11 & 0.01 & 31.49 & 0.40 & 1.90 & 0.46 & 0.02 & 0.02 & 99.64 & \\
\hline Van7-85-30 & $1 \mathrm{R}$ & 8 & 55.97 & 0.22 & 0.06 & 0.01 & 3.30 & 0.31 & 0.40 & 0.05 & 6.18 & 0.12 & 0.12 & 0.03 & 32.72 & 0.33 & 1.23 & 0.42 & 0.01 & 0.01 & 99.98 & \\
\hline Van7-85-32 & $3 \mathrm{C}$ & 11 & 54.42 & 0.25 & 0.07 & 0.02 & 5.06 & 0.12 & 0.68 & 0.03 & 6.13 & 0.21 & 0.13 & 0.01 & 31.74 & 0.40 & 1.64 & 0.59 & 0.01 & 0.01 & 99.87 & \\
\hline Van7-85-32 & $3 \mathrm{R}$ & 8 & 55.33 & 0.42 & 0.08 & 0.01 & 4.02 & 0.13 & 0.52 & 0.02 & 6.19 & 0.16 & 0.13 & 0.01 & 31.49 & 0.32 & 1.40 & 0.15 & 0.04 & 0.02 & 99.18 & \\
\hline Van7-85-39 & $1 \mathrm{C}$ & 9 & 53.97 & 0.23 & 0.07 & 0.01 & 4.84 & 0.11 & 0.66 & 0.02 & 6.23 & 0.18 & 0.10 & 0.01 & 31.68 & 0.44 & 1.81 & 0.52 & 0.00 & 0.01 & 99.35 & \\
\hline $\operatorname{Van} 7-85-39$ & $1 \mathrm{R}$ & 10 & 54.47 & 0.30 & 0.05 & 0.01 & 4.84 & 0.22 & 0.67 & 0.04 & 6.29 & 0.18 & 0.14 & 0.02 & 31.75 & 0.36 & 1.51 & 0.27 & 0.02 & 0.02 & 99.74 & \\
\hline Van7-85-42 & $1 \mathrm{C}$ & 8 & 55.15 & 0.22 & 0.08 & 0.01 & 5.09 & 0.18 & 0.72 & 0.02 & 6.33 & 0.12 & 0.10 & 0.01 & 31.83 & 0.18 & 1.72 & 0.24 & 0.02 & 0.02 & 101.04 & \\
\hline Van7-85-42 & $3 \mathrm{C}$ & 11 & 54.87 & 0.27 & 0.08 & 0.01 & 5.26 & 0.12 & 0.73 & 0.02 & 6.21 & 0.17 & 0.12 & 0.02 & 31.49 & 0.40 & 2.17 & 0.56 & 0.03 & 0.02 & 100.95 & \\
\hline Van7-85-42 & $3 \mathrm{R}$ & 11 & 55.20 & 0.51 & 0.08 & 0.01 & 5.25 & 0.29 & 0.71 & 0.03 & 6.15 & 0.17 & 0.13 & 0.03 & 31.17 & 0.37 & 2.21 & 0.44 & 0.04 & 0.03 & 100.94 & \\
\hline Van7-85-47 & $1 \mathrm{C}$ & 11 & 54.43 & 0.90 & 0.11 & 0.06 & 5.45 & 0.27 & 0.83 & 0.08 & 5.94 & 0.94 & 0.13 & 0.01 & 30.12 & 3.87 & 3.65 & 5.26 & 0.08 & 0.09 & 100.74 & \\
\hline $\operatorname{Van} 7-85-47$ & $1 \mathrm{R}$ & 10 & 55.10 & 0.30 & 0.08 & 0.02 & 5.03 & 0.09 & 0.69 & 0.02 & 6.42 & 0.15 & 0.14 & 0.02 & 31.90 & 0.17 & 1.46 & 0.29 & 0.03 & 0.01 & 100.85 & \\
\hline Van7-85-49 & $1 \mathrm{C}$ & 10 & 54.06 & 0.51 & 0.06 & 0.02 & 5.30 & 0.25 & 0.78 & 0.03 & 6.21 & 0.17 & 0.09 & 0.02 & 31.43 & 0.58 & 2.15 & 0.65 & 0.00 & 0.00 & 100.09 & \\
\hline Van7-85-49 & $1 \mathrm{R}$ & 6 & 55.12 & 0.30 & 0.03 & 0.02 & 3.66 & 0.54 & 0.50 & 0.11 & 6.14 & 0.18 & 0.12 & 0.02 & 32.56 & 0.52 & 1.28 & 0.38 & 0.02 & 0.02 & 99.42 & \\
\hline $\operatorname{Van} 7-86-25$ & $1 \mathrm{C}$ & 10 & 54.96 & 0.15 & 0.04 & 0.01 & 4.71 & 0.12 & 0.79 & 0.02 & 5.94 & 0.09 & 0.11 & 0.02 & 31.57 & 0.41 & 1.68 & 0.35 & 0.03 & 0.02 & 99.82 & \\
\hline $\operatorname{Van} 7-86-25$ & $1 \mathrm{R}$ & 10 & 54.67 & 0.28 & 0.04 & 0.01 & 4.97 & 0.18 & 0.83 & 0.04 & 6.01 & 0.10 & 0.10 & 0.02 & 31.32 & 0.38 & 1.65 & 0.27 & 0.02 & 0.01 & 99.59 & \\
\hline Van7-86-27 & $1 \mathrm{C}$ & 11 & 54.31 & 0.78 & 0.10 & 0.06 & 5.38 & 0.14 & 0.82 & 0.07 & 6.14 & 0.93 & 0.14 & 0.03 & 30.88 & 3.61 & 2.53 & 5.02 & 0.05 & 0.07 & 100.34 & \\
\hline Van7-86-27 & $1 \mathrm{R}$ & 6 & 55.40 & 0.52 & 0.07 & 0.02 & 3.84 & 0.44 & 0.56 & 0.08 & 6.19 & 0.25 & 0.12 & 0.02 & 32.40 & 0.97 & 1.24 & 0.23 & 0.05 & 0.06 & 99.86 & \\
\hline Van7-86-28 & $1 \mathrm{C}$ & 6 & 54.14 & 0.24 & 0.06 & 0.01 & 4.98 & 0.20 & 0.77 & 0.03 & 6.25 & 0.16 & 0.07 & 0.02 & 31.52 & 0.47 & 1.26 & 0.44 & 0.00 & 0.00 & 99.05 & \\
\hline $\operatorname{Van} 7-86-28$ & $1 \mathrm{R}$ & 8 & 54.38 & 0.23 & 0.06 & 0.01 & 4.50 & 0.26 & 0.71 & 0.06 & 6.10 & 0.31 & 0.08 & 0.02 & 31.33 & 0.41 & 1.81 & 0.50 & 0.00 & 0.00 & 98.99 & \\
\hline $\operatorname{Van} 7-86-30$ & $1 \mathrm{C}$ & 9 & 55.18 & 0.15 & 0.07 & 0.02 & 4.40 & 0.05 & 0.68 & 0.02 & 6.03 & 0.08 & 0.08 & 0.03 & 32.50 & 0.27 & 1.61 & 0.33 & 0.00 & 0.00 & 100.54 & \\
\hline Van7-86-30 & $1 \mathrm{R}$ & 8 & 55.41 & 0.45 & 0.05 & 0.01 & 3.54 & 0.16 & 0.52 & 0.01 & 5.99 & 0.15 & 0.09 & 0.01 & 32.47 & 0.51 & 1.47 & 0.22 & 0.00 & 0.00 & 99.56 & \\
\hline $\operatorname{Van} 7-86-37$ & $1 \mathrm{C}$ & 7 & 54.73 & 0.24 & 0.07 & 0.01 & 3.88 & 0.14 & 0.96 & 0.04 & 5.79 & 0.15 & 0.08 & 0.03 & 31.35 & 0.53 & 2.14 & 0.36 & 0.00 & 0.00 & 99.00 & \\
\hline Van7-86-37 & $1 \mathrm{R}$ & 8 & 55.19 & 0.39 & 0.06 & 0.01 & 3.27 & 0.21 & 0.77 & 0.07 & 5.81 & 0.08 & 0.09 & 0.03 & 32.38 & 0.34 & 1.60 & 0.21 & 0.00 & 0.00 & 99.14 & \\
\hline Van7-86-37 & $3 \mathrm{C}$ & 9 & 55.01 & 0.22 & 0.07 & 0.01 & 3.56 & 0.06 & 0.82 & 0.02 & 5.80 & 0.10 & 0.07 & 0.01 & 31.74 & 0.39 & 2.04 & 0.37 & 0.00 & 0.01 & 99.11 & \\
\hline $\operatorname{Van} 7-86-37$ & $3 \mathrm{R}$ & 6 & 55.27 & 0.29 & 0.08 & 0.01 & 3.38 & 0.24 & 0.76 & 0.04 & 5.81 & 0.20 & 0.09 & 0.03 & 32.17 & 0.38 & 1.72 & 0.43 & 0.00 & 0.01 & 99.29 & \\
\hline
\end{tabular}


Table 5.5: Opx major elements Cont.

\begin{tabular}{|c|c|c|c|c|c|c|c|c|c|c|c|c|c|c|c|c|c|c|c|c|c|c|}
\hline Analysis & $\mathrm{Grn}^{a}$ & Pts & $\mathrm{SiO}_{2}$ & \pm & $\mathrm{TiO}_{2}$ & \pm & $\mathrm{Al}_{2} \mathrm{O}$ & $3 \pm$ & $\mathrm{Cr}_{2} \mathrm{O}$ & $3 \pm$ & $\mathrm{FeO}$ & \pm & $\mathrm{MnO}$ & \pm & $\mathrm{MgO}$ & \pm & $\mathrm{CaO}$ & \pm & $\mathrm{Na}_{2} \mathrm{O}$ & \pm & Total & Notes $^{b}$ \\
\hline Van7-96-09 & $2 \mathrm{C}$ & 10 & 53.01 & 0.46 & 0.16 & 0.03 & 6.33 & 0.58 & 0.30 & 0.02 & 6.51 & 0.16 & 0.16 & 0.02 & 30.54 & 0.58 & 1.62 & 0.90 & 0.02 & 0.02 & 98.66 & PyxVn \\
\hline Van7-96-09 & $2 \mathrm{R}$ & 8 & 55.33 & 0.45 & 0.14 & 0.04 & 3.04 & 0.40 & 0.25 & 0.04 & 6.48 & 0.29 & 0.20 & 0.01 & 31.69 & 1.36 & 1.76 & 1.76 & 0.02 & 0.03 & 98.89 & PyxVn \\
\hline Van7-96-14 & $1 \mathrm{C}$ & 12 & 54.53 & 0.25 & 0.22 & 0.04 & 4.86 & 0.12 & 0.38 & 0.02 & 7.26 & 0.35 & 0.16 & 0.02 & 30.48 & 0.95 & 1.95 & 1.41 & 0.06 & 0.04 & 99.90 & PyxVn \\
\hline Van7-96-14 & $1 \mathrm{R}$ & 12 & 55.81 & 0.27 & 0.26 & 0.02 & 2.66 & 0.30 & 0.41 & 0.02 & 7.63 & 0.17 & 0.18 & 0.03 & 32.02 & 0.23 & 0.90 & 0.17 & 0.03 & 0.02 & 99.91 & PyxVn \\
\hline Van7-96-14 & $2 \mathrm{C}$ & 17 & 55.39 & 0.58 & 0.30 & 0.03 & 3.49 & 0.68 & 0.31 & 0.01 & 7.03 & 0.18 & 0.18 & 0.03 & 31.62 & 0.59 & 1.30 & 0.56 & 0.05 & 0.02 & 99.67 & PyxVn \\
\hline Van7-96-14 & $2 \mathrm{R}$ & 16 & 55.78 & 0.39 & 0.34 & 0.02 & 2.84 & 0.30 & 0.45 & 0.04 & 6.98 & 0.09 & 0.20 & 0.02 & 32.11 & 0.22 & 0.88 & 0.23 & 0.05 & 0.02 & 99.62 & PyxVn \\
\hline Van7-96-15 & $1 \mathrm{C}$ & 14 & 54.14 & 0.16 & 0.22 & 0.03 & 5.26 & 0.08 & 0.26 & 0.01 & 7.50 & 0.37 & 0.17 & 0.02 & 30.83 & 0.61 & 1.96 & 0.82 & 0.04 & 0.03 & 100.39 & PyxVn \\
\hline Van7-96-15 & $1 \mathrm{R}$ & 12 & 55.63 & 0.20 & 0.24 & 0.02 & 3.26 & 0.22 & 0.27 & 0.02 & 7.70 & 0.18 & 0.19 & 0.02 & 32.04 & 0.19 & 1.19 & 0.28 & 0.02 & 0.02 & 100.52 & PyxVn \\
\hline Van7-96-16 & $2 \mathrm{C}$ & 11 & 54.19 & 0.12 & 0.23 & 0.02 & 5.52 & 0.04 & 0.55 & 0.02 & 6.84 & 0.16 & 0.15 & 0.02 & 31.21 & 0.27 & 1.71 & 0.47 & 0.05 & 0.02 & 100.46 & PyxVn \\
\hline Van7-96-16 & $2 \mathrm{R}$ & 10 & 54.71 & 0.19 & 0.24 & 0.02 & 4.54 & 0.13 & 0.58 & 0.02 & 7.03 & 0.24 & 0.16 & 0.02 & 32.37 & 0.13 & 0.86 & 0.05 & 0.03 & 0.02 & 100.51 & PyxVn \\
\hline Van7-96-18 & $1 \mathrm{C}$ & 7 & 54.57 & 0.24 & 0.13 & 0.01 & 5.35 & 0.10 & & & 6.99 & 0.08 & 0.15 & 0.03 & 32.29 & 0.52 & 1.53 & 0.16 & 0.01 & 0.01 & 101.01 & NrMat \\
\hline Van7-96-18 & $1 \mathrm{R}$ & 7 & 54.40 & 0.25 & 0.14 & 0.02 & 5.20 & 0.09 & & & 7.00 & 0.25 & 0.13 & 0.03 & 32.50 & 0.42 & 1.39 & 0.26 & 0.00 & 0.01 & 100.77 & NrMat \\
\hline Van7-96-18 & $2 \mathrm{C}$ & 10 & 53.99 & 0.35 & 0.17 & 0.02 & 4.65 & 0.11 & & & 7.25 & 0.11 & 0.16 & 0.02 & 31.96 & 0.26 & 1.58 & 0.33 & 0.00 & 0.00 & 99.75 & PyxVn \\
\hline Van7-96-18 & $2 \mathrm{R}$ & 10 & 55.81 & 0.32 & 0.16 & 0.02 & 2.19 & 0.21 & & & 7.11 & 0.10 & 0.16 & 0.03 & 33.21 & 0.43 & 1.26 & 0.14 & 0.00 & 0.00 & 99.91 & PyxVn \\
\hline Van7-96-19 & $1 \mathrm{C}$ & 9 & 53.51 & 0.40 & 0.20 & 0.04 & 5.45 & 0.11 & & & 6.41 & 0.22 & 0.11 & 0.02 & 32.19 & 0.36 & 1.62 & 0.55 & 0.01 & 0.02 & 99.50 & NrMat \\
\hline Van7-96-19 & $1 \mathrm{R}$ & 10 & 55.11 & 0.59 & 0.21 & 0.03 & 2.92 & 0.38 & & & 6.57 & 0.13 & 0.12 & 0.03 & 33.58 & 0.39 & 1.18 & 0.29 & 0.00 & 0.00 & 99.70 & NrMat \\
\hline Van7-96-19 & 2I & 9 & 55.42 & 0.36 & 0.21 & 0.03 & 2.74 & 0.22 & & & 6.95 & 0.07 & 0.11 & 0.02 & 32.92 & 0.54 & 1.32 & 0.15 & 0.00 & 0.00 & 99.67 & PyxVn \\
\hline Van7-96-21 & $1 \mathrm{C}$ & 10 & 53.79 & 0.37 & 0.18 & 0.05 & 5.80 & 0.36 & 0.63 & 0.02 & 6.09 & 0.32 & 0.13 & 0.02 & 30.80 & 0.70 & 1.83 & 0.87 & 0.06 & 0.02 & 99.31 & PyxVn \\
\hline Van7-96-21 & $1 \mathrm{R}$ & 14 & 55.17 & 0.89 & 0.18 & 0.03 & 3.83 & 1.03 & 0.59 & 0.04 & 6.39 & 0.33 & 0.13 & 0.02 & 32.02 & 0.65 & 1.17 & 0.43 & 0.04 & 0.04 & 99.52 & PyxVn \\
\hline Van7-96-21 & $2 \mathrm{C}$ & 12 & 53.76 & 0.25 & 0.15 & 0.03 & 6.34 & 0.19 & 0.61 & 0.03 & 6.37 & 0.16 & 0.14 & 0.02 & 31.09 & 0.46 & 1.22 & 0.51 & 0.06 & 0.03 & 99.74 & $\operatorname{Adj} V n$ \\
\hline Van7-96-21 & $2 \mathrm{R}$ & 15 & 54.08 & 0.31 & 0.14 & 0.02 & 5.71 & 0.10 & 0.62 & 0.02 & 6.47 & 0.14 & 0.15 & 0.02 & 31.51 & 0.28 & 1.07 & 0.26 & 0.03 & 0.01 & 99.78 & AdjVn \\
\hline Van7-96-21 & $3 \mathrm{I}$ & 11 & 56.31 & 0.35 & 0.22 & 0.03 & 2.28 & 0.19 & 0.39 & 0.04 & 6.28 & 0.09 & 0.15 & 0.03 & 33.16 & 0.26 & 0.75 & 0.18 & 0.01 & 0.01 & 99.54 & PyxVn \\
\hline Van7-96-25 & $1 \mathrm{C}$ & 9 & 53.24 & 0.29 & 0.11 & 0.02 & 5.81 & 0.11 & & & 6.71 & 0.18 & 0.09 & 0.02 & 31.18 & 0.41 & 1.65 & 0.49 & 0.06 & 0.05 & 98.86 & \\
\hline Van7-96-25 & $1 \mathrm{R}$ & 8 & 53.69 & 0.16 & 0.11 & 0.02 & 5.35 & 0.08 & & & 6.65 & 0.07 & 0.12 & 0.03 & 31.82 & 0.26 & 1.31 & 0.15 & 0.03 & 0.02 & 99.08 & \\
\hline Van7-96-28 & $1 \mathrm{C}$ & 8 & 53.63 & 1.32 & 0.17 & 0.18 & 5.35 & 1.07 & & & 5.78 & 0.75 & 0.09 & 0.02 & 30.66 & 3.81 & 3.38 & 4.66 & 0.07 & 0.17 & 99.13 & \\
\hline $\operatorname{Van} 7-96-28$ & $1 \mathrm{R}$ & 6 & 53.87 & 0.44 & 0.11 & 0.03 & 5.41 & 0.31 & & & 6.20 & 0.18 & 0.11 & 0.03 & 32.10 & 0.73 & 1.50 & 0.72 & 0.01 & 0.01 & 99.31 & \\
\hline Van7-96-35 & $1 \mathrm{C}$ & 10 & 54.88 & 0.27 & 0.11 & 0.01 & 4.16 & 0.07 & 1.05 & 0.01 & 5.47 & 0.18 & 0.12 & 0.04 & 31.60 & 0.41 & 1.92 & 0.21 & 0.13 & 0.04 & 99.44 & \\
\hline Van7-96-35 & $1 \mathrm{R}$ & 10 & 55.53 & 0.15 & 0.10 & 0.01 & 3.66 & 0.14 & 0.80 & 0.01 & 5.63 & 0.14 & 0.11 & 0.02 & 32.44 & 0.17 & 1.27 & 0.05 & 0.03 & 0.02 & 99.57 & \\
\hline Van7-96-37 & $1 \mathrm{C}$ & 10 & 54.49 & 0.27 & 0.11 & 0.02 & 4.82 & 0.09 & 0.86 & 0.04 & 6.06 & 0.11 & 0.14 & 0.02 & 31.22 & 0.47 & 1.68 & 0.27 & 0.03 & 0.04 & 99.42 & \\
\hline Van7-96-37 & $1 \mathrm{R}$ & 9 & 54.95 & 0.30 & 0.10 & 0.02 & 4.43 & 0.09 & 0.77 & 0.03 & 6.09 & 0.16 & 0.17 & 0.04 & 31.79 & 0.26 & 1.41 & 0.34 & 0.01 & 0.02 & 99.72 & \\
\hline Van7-96-38 & $1 \mathrm{C}$ & 12 & 53.31 & 0.21 & 0.15 & 0.03 & 6.88 & 0.09 & 0.61 & 0.02 & 6.38 & 0.17 & 0.14 & 0.02 & 30.04 & 0.57 & 1.56 & 0.61 & 0.10 & 0.06 & 99.19 & \\
\hline Van7-96-38 & $1 \mathrm{R}$ & 10 & 53.45 & 0.19 & 0.12 & 0.03 & 6.47 & 0.10 & 0.59 & 0.02 & 6.61 & 0.19 & 0.12 & 0.02 & 30.68 & 0.24 & 1.09 & 0.26 & 0.03 & 0.02 & 99.15 & \\
\hline Van7-96-38 & $2 \mathrm{C}$ & 10 & 53.86 & 0.23 & 0.16 & 0.03 & 6.21 & 0.24 & 0.57 & 0.02 & 6.19 & 0.15 & 0.12 & 0.01 & 30.28 & 0.45 & 1.74 & 0.67 & 0.11 & 0.05 & 99.26 & \\
\hline Van7-96-38 & $2 \mathrm{R}$ & 12 & 53.96 & 0.25 & 0.11 & 0.01 & 5.89 & 0.21 & 0.50 & 0.02 & 6.63 & 0.12 & 0.14 & 0.03 & 30.96 & 0.22 & 1.03 & 0.21 & 0.02 & 0.02 & 99.24 & \\
\hline $\operatorname{Van} 7-96-66 \mathrm{~B}$ & $1 \mathrm{C}$ & 10 & 53.18 & 0.20 & 0.21 & 0.03 & 6.84 & 0.10 & 0.41 & 0.02 & 6.80 & 0.13 & 0.16 & 0.03 & 30.26 & 0.27 & 1.76 & 0.49 & 0.05 & 0.04 & 99.65 & OpxVn \\
\hline $\operatorname{Van} 7-96-66 B$ & $1 \mathrm{R}$ & 8 & 53.83 & 0.57 & 0.20 & 0.05 & 5.58 & 0.59 & 0.38 & 0.05 & 6.89 & 0.13 & 0.18 & 0.03 & 31.39 & 0.49 & 1.09 & 0.48 & 0.01 & 0.02 & 99.56 & OpxVn \\
\hline
\end{tabular}


Table 5.6: Major element composition of Cpx, in wt\%.

\begin{tabular}{|c|c|c|c|c|c|c|c|c|c|c|c|c|c|c|c|c|c|c|c|c|c|c|}
\hline Analysis & $\mathrm{Grn}^{a}$ & Pts & $\mathrm{SiO}_{2}$ & \pm & $\mathrm{TiO}_{2}$ & \pm & $\mathrm{Al}_{2} \mathrm{O}_{3}$ & $3 \pm$ & $\mathrm{Cr}_{2} \mathrm{O}_{3}$ & $3 \pm$ & $\mathrm{FeO}$ & \pm & $\mathrm{MnO}$ & \pm & $\mathrm{MgO}$ & \pm & $\mathrm{CaO}$ & \pm & $\mathrm{Na}_{2} \mathrm{O}$ & \pm & Total & Notes $^{b}$ \\
\hline $6 \mathrm{~K}-458-1$ & $1 \mathrm{C}$ & 9 & 51.38 & 0.76 & 0.23 & 0.02 & 5.69 & 1.19 & 1.50 & 0.13 & 2.20 & 0.11 & 0.10 & 0.02 & 15.70 & 0.38 & 23.12 & 0.29 & 0.53 & 0.04 & 100.44 & \\
\hline $6 \mathrm{~K}-458-1$ & $1 \mathrm{R}$ & 8 & 52.36 & 1.81 & 0.26 & 0.08 & 5.28 & 1.34 & 1.35 & 0.26 & 2.77 & 1.42 & 0.10 & 0.03 & 18.77 & 6.48 & 19.69 & 8.07 & 0.48 & 0.20 & 101.05 & \\
\hline $6 \mathrm{~K}-458-1$ & $2 \mathrm{I}$ & 9 & 51.92 & 0.59 & 0.33 & 0.03 & 5.37 & 0.72 & 1.25 & 0.05 & 2.22 & 0.13 & 0.10 & 0.03 & 16.47 & 0.30 & 22.77 & 0.88 & 0.50 & 0.07 & 100.93 & \\
\hline $6 \mathrm{~K}-458-1$ & $3 I$ & 9 & 52.43 & 0.48 & 0.31 & 0.05 & 4.14 & 0.60 & 1.56 & 0.13 & 2.21 & 0.13 & 0.10 & 0.03 & 16.51 & 0.26 & 23.24 & 0.19 & 0.48 & 0.03 & 100.98 & \\
\hline $6 \mathrm{~K}-458-3$ & 1I & 10 & 52.09 & 0.34 & 0.32 & 0.02 & 4.71 & 0.22 & 0.80 & 0.02 & 2.51 & 0.15 & 0.09 & 0.01 & 15.97 & 0.15 & 22.54 & 0.55 & 0.41 & 0.04 & 99.43 & \\
\hline $6 \mathrm{~K}-458-3$ & $2 \mathrm{I}$ & 12 & 52.21 & 0.28 & 0.27 & 0.01 & 5.66 & 0.19 & 0.95 & 0.05 & 2.53 & 0.18 & 0.09 & 0.02 & 15.66 & 0.39 & 22.73 & 0.69 & 0.47 & 0.05 & 100.57 & \\
\hline $6 \mathrm{~K}-458-3$ & $3 \mathrm{C}$ & 13 & 51.43 & 1.36 & 0.24 & 0.08 & 7.09 & 1.05 & 1.11 & 0.21 & 3.21 & 1.54 & 0.10 & 0.03 & 17.30 & 5.37 & 19.68 & 7.70 & 0.44 & 0.16 & 100.60 & \\
\hline $6 \mathrm{~K}-458-3$ & $3 \mathrm{R}$ & 8 & 52.78 & 0.38 & 0.45 & 0.05 & 3.77 & 0.42 & 0.93 & 0.08 & 2.22 & 0.07 & 0.07 & 0.01 & 16.34 & 0.42 & 23.76 & 0.38 & 0.36 & 0.03 & 100.67 & \\
\hline $6 \mathrm{~K}-458-3$ & $4 \mathrm{C}$ & 9 & 51.41 & 0.68 & 0.20 & 0.05 & 6.48 & 0.17 & 1.04 & 0.06 & 3.57 & 0.87 & 0.11 & 0.02 & 18.22 & 3.15 & 18.06 & 4.09 & 0.42 & 0.14 & 99.50 & \\
\hline $6 \mathrm{~K}-458-3$ & $4 \mathrm{R}$ & 8 & 50.96 & 0.62 & 0.27 & 0.04 & 6.20 & 0.55 & 1.05 & 0.03 & 2.36 & 0.18 & 0.07 & 0.01 & 15.58 & 0.86 & 22.51 & 0.93 & 0.54 & 0.18 & 99.55 & \\
\hline $6 \mathrm{~K}-458-3$ & $5 \mathrm{I}$ & 11 & 51.69 & 0.43 & 0.32 & 0.04 & 5.22 & 0.42 & 0.92 & 0.06 & 2.24 & 0.12 & 0.06 & 0.02 & 15.47 & 0.42 & 23.07 & 0.31 & 0.44 & 0.05 & 99.42 & \\
\hline $6 \mathrm{~K}-458-3$ & $6 \mathrm{I}$ & 10 & 51.96 & 0.31 & 0.43 & 0.02 & 4.50 & 0.66 & 1.03 & 0.03 & 2.21 & 0.09 & 0.10 & 0.01 & 15.49 & 0.42 & 23.29 & 0.26 & 0.47 & 0.06 & 99.46 & \\
\hline $6 \mathrm{~K}-465-2$ & $1 \mathrm{C}$ & 8 & 50.64 & 0.59 & 0.23 & 0.04 & 6.24 & 0.06 & 1.10 & 0.05 & 3.13 & 0.68 & 0.11 & 0.02 & 17.38 & 2.89 & 20.57 & 3.81 & 0.30 & 0.09 & 99.69 & Dep \\
\hline $6 \mathrm{~K}-465-2$ & $1 \mathrm{R}$ & 13 & 51.99 & 0.56 & 0.30 & 0.02 & 3.66 & 0.38 & 1.28 & 0.05 & 2.49 & 0.17 & 0.05 & 0.02 & 16.64 & 0.51 & 23.02 & 0.81 & 0.26 & 0.05 & 99.71 & Dep \\
\hline $6 \mathrm{~K}-465-2$ & $2 \mathrm{C}$ & 10 & 51.18 & 0.39 & 0.21 & 0.03 & 6.45 & 0.06 & 1.09 & 0.04 & 3.25 & 0.55 & 0.03 & 0.03 & 17.10 & 2.25 & 20.63 & 3.06 & 0.30 & 0.06 & 100.23 & Dep \\
\hline $6 \mathrm{~K}-465-2$ & $2 \mathrm{R}$ & 10 & 51.72 & 0.52 & 0.24 & 0.03 & 5.57 & 0.42 & 0.96 & 0.06 & 3.07 & 0.47 & 0.04 & 0.02 & 17.05 & 1.83 & 21.50 & 2.58 & 0.31 & 0.06 & 100.46 & Dep \\
\hline $6 \mathrm{~K}-465-2$ & $3 \mathrm{C}$ & 8 & 51.25 & 0.15 & 0.25 & 0.03 & 5.38 & 0.52 & 1.03 & 0.02 & 2.90 & 0.13 & 0.06 & 0.02 & 16.40 & 0.23 & 22.98 & 0.63 & 0.19 & 0.06 & 100.45 & Dep \\
\hline $6 \mathrm{~K}-465-2$ & $3 R$ & 8 & 51.33 & 0.48 & 0.33 & 0.02 & 4.75 & 0.21 & 1.11 & 0.03 & 2.81 & 0.18 & 0.07 & 0.02 & 16.59 & 0.63 & 22.95 & 0.89 & 0.22 & 0.05 & 100.16 & Dep \\
\hline $6 \mathrm{~K}-465-2$ & $4 \mathrm{C}$ & 10 & 51.91 & 0.34 & 0.26 & 0.04 & 4.15 & 0.40 & 1.14 & 0.04 & 2.67 & 0.16 & 0.07 & 0.01 & 16.92 & 0.27 & 23.01 & 0.47 & 0.19 & 0.04 & 100.30 & Dep \\
\hline $6 \mathrm{~K}-465-2$ & $4 \mathrm{R}$ & 10 & 51.60 & 0.65 & 0.30 & 0.03 & 4.40 & 0.51 & 1.14 & 0.03 & 2.80 & 0.12 & 0.06 & 0.02 & 16.62 & 0.54 & 22.90 & 0.70 & 0.18 & 0.05 & 99.99 & Dep \\
\hline $6 \mathrm{~K}-465-2$ & $5 \mathrm{C}$ & 10 & 50.45 & 0.43 & 0.24 & 0.03 & 6.41 & 0.56 & 1.20 & 0.03 & 3.01 & 0.09 & 0.10 & 0.02 & 15.98 & 0.30 & 22.37 & 0.33 & 0.41 & 0.06 & 100.17 & Enr \\
\hline $6 \mathrm{~K}-465-2$ & $6 \mathrm{C}$ & 9 & 51.38 & 0.54 & 0.18 & 0.04 & 6.04 & 0.34 & 1.06 & 0.04 & 3.78 & 0.45 & 0.11 & 0.01 & 19.24 & 2.14 & 18.03 & 2.79 & 0.39 & 0.05 & 100.20 & Trans \\
\hline $6 \mathrm{~K}-465-2$ & $6 \mathrm{R}$ & 9 & 51.15 & 1.11 & 0.26 & 0.06 & 5.35 & 0.26 & 1.10 & 0.13 & 2.98 & 1.18 & 0.10 & 0.03 & 16.84 & 4.98 & 21.66 & 6.63 & 0.41 & 0.15 & 99.85 & Trans \\
\hline $6 \mathrm{~K}-465-2$ & $8 \mathrm{C}$ & 15 & 51.34 & 0.49 & 0.20 & 0.02 & 6.46 & 0.16 & 1.15 & 0.03 & 3.51 & 0.15 & 0.10 & 0.01 & 18.15 & 0.43 & 19.43 & 0.45 & 0.38 & 0.05 & 100.72 & Dep \\
\hline $6 \mathrm{~K}-465-2$ & $8 \mathrm{R}$ & 18 & 51.08 & 1.23 & 0.26 & 0.08 & 5.55 & 0.31 & 1.16 & 0.13 & 2.84 & 1.37 & 0.10 & 0.02 & 15.97 & 5.63 & 22.89 & 7.71 & 0.39 & 0.20 & 100.25 & Dep \\
\hline $6 \mathrm{~K}-465-2$ & $9 \mathrm{C}$ & 8 & 52.59 & 0.57 & 0.25 & 0.03 & 3.23 & 0.52 & 1.26 & 0.03 & 2.56 & 0.08 & 0.10 & 0.02 & 17.01 & 0.49 & 23.08 & 0.24 & 0.42 & 0.05 & 100.51 & Enr \\
\hline $6 \mathrm{~K}-465-2$ & $9 \mathrm{R}$ & 10 & 52.37 & 0.75 & 0.31 & 0.05 & 3.52 & 0.85 & 1.20 & 0.11 & 2.55 & 0.07 & 0.11 & 0.02 & 16.82 & 0.39 & 23.04 & 0.43 & 0.40 & 0.05 & 100.29 & Enr \\
\hline $6 \mathrm{~K}-465-3$ & $5 \mathrm{R}$ & 10 & 53.33 & 0.19 & 0.63 & 0.04 & 1.54 & 0.06 & 0.00 & 0.00 & 6.97 & 0.29 & 0.32 & 0.03 & 16.41 & 0.49 & 20.25 & 0.77 & 0.44 & 0.03 & 99.87 & GbVn \\
\hline $6 \mathrm{~K}-465-3$ & $6 \mathrm{C}$ & 8 & 52.37 & 0.26 & 0.57 & 0.05 & 1.58 & 0.05 & 0.01 & 0.01 & 7.90 & 0.47 & 0.31 & 0.02 & 15.50 & 0.44 & 21.25 & 0.91 & 0.39 & 0.06 & 99.89 & $\mathrm{GbVn}$ \\
\hline $6 \mathrm{~K}-465-3$ & $8 \mathrm{I}$ & 14 & 52.40 & 0.38 & 0.69 & 0.10 & 3.57 & 0.58 & 1.05 & 0.05 & 2.87 & 0.09 & 0.11 & 0.02 & 16.14 & 0.11 & 22.25 & 0.45 & 0.60 & 0.06 & 99.67 & NrMat \\
\hline $6 \mathrm{~K}-465-3$ & 9I & 9 & 52.46 & 0.77 & 0.69 & 0.14 & 3.44 & 0.65 & 1.07 & 0.04 & 2.83 & 0.08 & 0.11 & 0.03 & 16.25 & 0.40 & 22.20 & 0.74 & 0.66 & 0.14 & 99.69 & NrMat \\
\hline $6 \mathrm{~K}-465-3$ & $10 \mathrm{C}$ & 8 & 53.24 & 0.37 & 0.42 & 0.03 & 2.55 & 0.13 & 1.21 & 0.03 & 2.72 & 0.07 & 0.12 & 0.03 & 16.25 & 0.15 & 22.53 & 0.16 & 0.57 & 0.03 & 99.61 & NrMat \\
\hline $6 \mathrm{~K}-465-3$ & $10 \mathrm{R}$ & 12 & 53.35 & 0.24 & 0.38 & 0.03 & 2.48 & 0.15 & 1.21 & 0.04 & 2.89 & 0.11 & 0.11 & 0.02 & 16.50 & 0.10 & 22.36 & 0.18 & 0.57 & 0.03 & 99.84 & NrMat \\
\hline $6 \mathrm{~K}-465-3$ & $11 \mathrm{I}$ & 13 & 53.32 & 0.59 & 0.48 & 0.06 & 2.52 & 0.26 & 1.06 & 0.08 & 2.91 & 0.22 & 0.13 & 0.04 & 16.86 & 0.46 & 21.94 & 0.69 & 0.58 & 0.04 & 99.80 & NrMat \\
\hline $6 \mathrm{~K}-465-3$ & $12 \mathrm{R}$ & 14 & 53.21 & 0.36 & 0.46 & 0.07 & 3.40 & 2.04 & 0.98 & 0.10 & 2.73 & 0.22 & 0.07 & 0.02 & 16.51 & 1.48 & 22.22 & 1.23 & 0.76 & 0.45 & 100.36 & NrMat \\
\hline $6 \mathrm{~K}-465-3$ & $13 \mathrm{C}$ & 12 & 52.77 & 0.64 & 0.50 & 0.17 & 3.04 & 0.57 & 1.19 & 0.07 & 2.85 & 0.13 & 0.08 & 0.02 & 16.44 & 0.27 & 22.08 & 0.60 & 0.62 & 0.18 & 99.56 & NrMat \\
\hline $6 \mathrm{~K}-465-3$ & $13 \mathrm{R}$ & 8 & 52.76 & 0.47 & 0.55 & 0.09 & 2.89 & 0.40 & 1.18 & 0.04 & 2.87 & 0.12 & 0.08 & 0.03 & 16.46 & 0.16 & 22.15 & 0.51 & 0.62 & 0.06 & 99.56 & NrMat \\
\hline $6 \mathrm{~K}-465-3$ & $15 \mathrm{R}$ & 9 & 53.07 & 0.36 & 0.37 & 0.06 & 3.15 & 0.76 & 1.12 & 0.07 & 2.48 & 0.18 & 0.06 & 0.02 & 16.27 & 0.52 & 22.50 & 0.48 & 0.58 & 0.16 & 99.61 & NrMat \\
\hline $6 \mathrm{~K}-466-1$ & $1 \mathrm{C}$ & 10 & 51.97 & 0.29 & 0.26 & 0.02 & 5.55 & 0.10 & 1.16 & 0.03 & 2.51 & 0.34 & 0.04 & 0.02 & 16.42 & 1.16 & 21.88 & 1.49 & 0.64 & 0.05 & 100.44 & \\
\hline $6 \mathrm{~K}-466-1$ & $1 \mathrm{R}$ & 10 & 51.94 & 0.29 & 0.29 & 0.02 & 5.34 & 0.33 & 1.19 & 0.06 & 2.14 & 0.06 & 0.04 & 0.02 & 15.89 & 0.22 & 23.21 & 0.22 & 0.58 & 0.05 & 100.64 & \\
\hline
\end{tabular}


Table 5.6: Cpx major elements Cont.

\begin{tabular}{|c|c|c|c|c|c|c|c|c|c|c|c|c|c|c|c|c|c|c|c|c|c|c|}
\hline Analysis & $\mathrm{rn}^{a}$ & Pts & $\mathrm{SiO}_{2}$ & \pm & $\mathrm{TiO}_{2}$ & \pm & $\mathrm{Al}_{2} \mathrm{O}_{3}$ & $3 \pm$ & $\mathrm{Cr}_{2} \mathrm{O}_{3}$ & $3 \pm$ & $\mathrm{FeO}$ & \pm & $\mathrm{MnO}$ & \pm & $\mathrm{MgO}$ & \pm & $\mathrm{CaO}$ & \pm & $\mathrm{Na}_{2} \mathrm{O}$ & \pm & Total & Notes $^{b}$ \\
\hline $6 \mathrm{~K}-466-1$ & $3 \mathrm{I}$ & 13 & 52.16 & 0.93 & 0.25 & 0.06 & 5.18 & 0.36 & 1.02 & 0.18 & 2.98 & 1.05 & 0.13 & 0.03 & 17.90 & 4.56 & 19.72 & 5.84 & 0.70 & 0.14 & 100.05 & \\
\hline $6 \mathrm{~K}-643-13$ & 1I & 8 & 51.78 & 0.30 & 0.15 & 0.02 & 5.14 & 0.15 & 1.05 & 0.04 & 2.79 & 0.20 & 0.10 & 0.02 & 17.03 & 0.47 & 21.90 & 0.63 & 0.27 & 0.04 & 100.20 & \\
\hline$-643-13$ & $2 \Gamma$ & 10 & 51.39 & 94 & 0.13 & 0.04 & 6.15 & 0.22 & 1.28 & 0.12 & 4.03 & 1.12 & 0.12 & 0.02 & 20.10 & 4.98 & 16.47 & 6.97 & 0.18 & 0.09 & 99.84 & \\
\hline $6 \mathrm{~K}-651-7$ & I & 11 & .39 & 57 & 0.22 & 0.03 & 5.71 & 0.28 & 0.97 & 0.05 & 2.71 & 0.83 & 0.08 & 0.02 & 16.51 & 2.52 & 21.66 & 3.45 & 0.26 & 0.04 & 99.50 & PyxVn \\
\hline $6 \mathrm{~K}-651-7$ & $\mathrm{C}$ & 11 & 50.84 & 0.27 & 0.21 & 0.02 & 6.27 & 0.09 & 1.06 & 0.05 & 2.90 & 0.62 & 0.09 & 0.01 & 16.10 & 1.83 & 21.35 & 2.64 & 0.28 & 0.07 & 99.10 & PyxVn \\
\hline $6 \mathrm{~K}-651-7$ & $\mathrm{R}$ & 12 & 51.38 & 0.29 & 0.25 & 0.02 & 5.44 & 0.21 & 0.87 & 0.03 & 2.46 & 0.24 & 0.07 & 0.01 & 15.85 & 0.99 & 22.63 & 1.29 & 0.27 & 0.05 & 99.22 & PyxVn \\
\hline JR31-52-03 & $\mathrm{C}$ & 12 & 51.13 & 0.31 & 0.18 & 0.02 & 6.46 & 0.10 & 1.25 & 0.04 & 2.66 & 0.22 & 0.08 & 0.01 & 16.12 & 0.80 & 21.46 & 0.88 & 0.61 & 0.05 & 99.95 & \\
\hline 33 & & 10 & .25 & 0.32 & 0.18 & 0.01 & 6.25 & 0.08 & 1.20 & 0.05 & 2.60 & 0.13 & 0.08 & 0.02 & 16.40 & 0.63 & 21.27 & 0.74 & .60 & 0.03 & 99.82 & \\
\hline $1-52-03$ & & 12 & 50.81 & 0.39 & 0.19 & 0.02 & 6.65 & 0.10 & 1.30 & 0.04 & 2.60 & 0.20 & 0.07 & 0.03 & 15.97 & 0.77 & 21.54 & 1.02 & 0.59 & 0.05 & & \\
\hline JR31-52-03 & $6 \mathrm{I}$ & 12 & 51.21 & 0.21 & 0.20 & 0.02 & 6.54 & 0.06 & 1.27 & 0.04 & 2.63 & 0.13 & 0.08 & 0.03 & 15.75 & 0.39 & 21.66 & 0.51 & 0.58 & 0.05 & 99.93 & \\
\hline JR31-52-03 & $C$ & 11 & 51.30 & 0.49 & 0.18 & 0.01 & 6.06 & 0.08 & 1.22 & 0.02 & 2.62 & 0.19 & 0.12 & 0.02 & 16.27 & 0.76 & 21.20 & 0.98 & .60 & 0.04 & 99.59 & \\
\hline & & 10 & 5 & 0 & 0.19 & 0.02 & 5. & 0.26 & 1.02 & 0.06 & 2.41 & 0.17 & 0.09 & 0.0 & 16.47 & 0.34 & 21.88 & 0. & 6 & 0.05 & 62 & \\
\hline-03 & 8 & 9 & 51.81 & 0.3 & 0.18 & 0.03 & 5.56 & 0.10 & 1.07 & 0.04 & 2.65 & 0.36 & 0.09 & 0.0 & 16.94 & 1.23 & 21.14 & 1.6 & 0.58 & 0.05 & 100.04 & \\
\hline & 9 & 11 & 51.10 & 0.2 & 0.20 & 0.02 & 5.80 & 0.11 & 1.08 & 0.03 & 2.57 & 0.14 & 0.07 & 0.0 & 16.62 & 0.47 & 21.25 & 0.69 & 81 & 0.02 & & \\
\hline $1-52-04$ & 4 & 11 & 51.82 & 0.20 & 0.21 & 0.02 & 5.96 & 0.25 & 1.21 & 0.05 & 2.23 & 0.11 & 0.07 & 0.02 & & 0.13 & & 0.17 & & 0.04 & 99 & \\
\hline IR 31-52-04 & $4 \mathrm{R}$ & 11 & 51.84 & 0.32 & 0.23 & 0.03 & 5.75 & 0.52 & 1.15 & 0.10 & 2.32 & 0.08 & 0.07 & 0.01 & 15.47 & 0.22 & 22.55 & 0.19 & 0.55 & 0.04 & 99.92 & \\
\hline & & 10 & 2 & 1.14 & 0.17 & 0.06 & & 0.28 & 1.21 & 0.1 & 3 & 1.6 & 0.11 & 0.0 & 18.01 & 6.21 & & 8. & 49 & 0.22 & 100 & \\
\hline-05 & $1 \mathrm{R}$ & 10 & .19 & 0.2 & 0.21 & 0.02 & 5.28 & 0.54 & 0.96 & 0.08 & 2.19 & 0.0 & 0.09 & 0.0 & 15.75 & 0.46 & 23.15 & 0.27 & 0.42 & 0.07 & 100.23 & \\
\hline 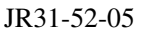 & $5 \mathrm{I}$ & 11 & 51.78 & 0.34 & 0.18 & 0.02 & 5.98 & 0.18 & 1.04 & 0.04 & 2.64 & 0.26 & 0.04 & 0.02 & 16.31 & 1.07 & 21.46 & 1.25 & 0.56 & 0.04 & 99.99 & \\
\hline JR31-52-05 & 6 & 8 & 51.57 & 0.37 & 0.22 & 0.03 & 5.96 & 0.09 & 1.09 & 0.03 & 2.51 & 0.06 & 0.04 & 0.03 & 15.86 & 0.22 & 22.06 & 0.35 & 0.56 & 0.04 & 99.86 & \\
\hline & & 10 & & 0 & 0.18 & 0.02 & & 0.11 & 122 & 0.0 & 2.77 & 0.3 & & 0.0 & & 1. & & 1.92 & & 0.0 & & \\
\hline-08 & $1 \mathrm{~F}$ & 20 & .55 & 0.4 & 0.21 & 0.0 & 6.06 & 0.38 & 1.16 & 0.10 & 2.60 & 0.45 & 0.10 & 0.0 & 16.39 & 1.09 & 21.21 & 1. & 0.57 & 0.07 & 99. & \\
\hline & 3 & 9 & 51.71 & 0.1 & 0.18 & 0.01 & 5.64 & 0.10 & 1.11 & 0.0 & 2.62 & 0.27 & 0.08 & 0.0 & 16.17 & 0.98 & 21.21 & 1.35 & 0.66 & 0.07 & 99.38 & \\
\hline$J R 31-52-0$ & $4 \mathrm{R}$ & 9 & 51.91 & 0.25 & 0.22 & 0.02 & 5.43 & 0.28 & 1.01 & 0.10 & 2.46 & 0.08 & 0.09 & 0.02 & 16.19 & 0.35 & 21.80 & 0.40 & 0.62 & 0.06 & 99.74 & \\
\hline Kn162-19-41 & $1 \mathrm{C}$ & 5 & 50.85 & 0.45 & 0.26 & 0.01 & 6.38 & 0.20 & 0.87 & 0.01 & 2.53 & 0.14 & 0.11 & 0.02 & 15.50 & 0.42 & 23.12 & 0.50 & 0.24 & 0.02 & 99.86 & PyxVn \\
\hline Kn162-19-41 & $1 \mathrm{R}$ & 8 & 51.35 & 0.48 & 0.24 & 0.03 & 6.21 & 0.15 & 0.85 & 0.05 & 2.71 & 0.54 & 0.09 & 0.02 & 15.82 & 2.10 & 22.56 & 2.68 & 0.23 & 0.04 & 100.06 & PyxVn \\
\hline $0-41$ & 2I & 10 & & 027 & 0.27 & 0.02 & 6.29 & 0.37 & 0.89 & 0.0 & 2.57 & 0.14 & 0.10 & 0.0 & & 0.4 & & 0.65 & 0. & 0.03 & & \\
\hline 11 & $\pi$ & 9 & .73 & 0 & 0.28 & 0.0 & 6. & 0.4 & 0.87 & 0.0 & 27 & 0.1 & 0. & 0.0 & 16.18 & 0.6 & 22.38 & 0.79 & 0 & 0.03 & 99.90 & $P_{y y}$ \\
\hline 1) & $4 \mathrm{C}$ & 7 & 50.49 & 2 & 0.22 & 0.02 & 6.99 & 2.77 & 0.95 & 0.2 & 2.98 & 0.57 & 0.11 & 0.02 & 16.48 & 0.99 & 21.66 & 1.67 & 0.21 & 0.01 & 100.09 & PyxVn \\
\hline Kn162-19-41 & $4 \mathrm{R}$ & 10 & 51.46 & 0.35 & 0.23 & 0.03 & 5.65 & 0.28 & 0.88 & 0.04 & 2.50 & 0.19 & 0.09 & 0.02 & 15.86 & 0.70 & 23.00 & 0.83 & 0.21 & 0.03 & 99.90 & PyxVn \\
\hline Kn162-47-08 & 1I & 10 & 50.60 & 0.46 & 0.37 & 0.01 & 6.97 & 0.11 & 1.03 & 0.03 & 2.99 & 0.15 & 0.12 & 0.02 & 15.81 & 0.33 & 21.80 & 0.44 & 0.51 & 0.06 & 100.21 & \\
\hline & $2 \mathrm{I}$ & 10 & 51.38 & 0.38 & 0.30 & 0.02 & 6.17 & 0.10 & 0.92 & 0.0 & 3.01 & 0.1 & 0.11 & 0.02 & 16.18 & 0.66 & 21.51 & 0.78 & 0.53 & 0.06 & 100.12 & \\
\hline & $3 I$ & 15 & & 0.3 & 0.33 & 0.0 & $6 .($ & 0.27 & 0.87 & 0.0 & $3 .(1$ & 0.1 & $0 .($ & 0.02 & 16.13 & 0.30 & 21.57 & 0.38 & 0.66 & 0.05 & 100.66 & \\
\hline 6017 & 31 & 11 & 51.95 & & 0.31 & 0.0 & & 0.1 & 0.93 & 0.0 & 3.2 & 0.5 & 0.0 & 0.02 & 16.92 & 1.95 & 20.32 & 2.60 & 0.62 & 0.10 & 100.53 & \\
\hline Kn162-47-09 & 2I & 12 & & 0.37 & 0.13 & 0.02 & 4.40 & 0.17 & 1.51 & 0.05 & 2.18 & 0.16 & 0.08 & 0.02 & 16.71 & 0.69 & 21.70 & 0.77 & 0.90 & 0.04 & 100.80 & \\
\hline Kn162-47-09 & $3 \mathrm{C}$ & 8 & 52.89 & 0.67 & 0.12 & 0.02 & 4.62 & 0.11 & 1.75 & 0.04 & 2.11 & 0.08 & 0.07 & 0.02 & 16.31 & 0.30 & 21.90 & 0.30 & 0.98 & 0.07 & 100.73 & \\
\hline Kn162-47-09 & $3 R$ & 6 & 53.03 & 0.58 & 0.10 & 0.01 & 4.41 & 0.43 & 1.62 & 0.13 & 2.23 & 0.26 & 0.08 & 0.02 & 15.83 & 0.88 & 21.75 & 1.00 & 0.81 & 0.07 & 99.85 & \\
\hline Kn162-47-09 & $6 \mathrm{I}$ & 7 & 53.36 & 0.24 & 0.09 & 0.02 & 3.86 & 0.06 & 1.32 & 0.03 & 2.21 & 0.15 & 0.08 & 0.02 & 17.13 & 0.71 & 21.68 & 0.69 & 0.82 & 0.06 & 100.54 & \\
\hline
\end{tabular}


Table 5.6: Cpx major elements Cont.

\begin{tabular}{|c|c|c|c|c|c|c|c|c|c|c|c|c|c|c|c|c|c|c|c|c|c|c|}
\hline Analysis & $\mathrm{rn}^{a}$ & Pts & $\mathrm{SiO}_{2}$ & \pm & $\mathrm{TiO}_{2}$ & \pm & $\mathrm{Al}_{2} \mathrm{O}_{3}$ & \pm & ${ }_{2} \mathrm{O}_{3}$ & \pm & $\mathrm{FeO}$ & \pm & $\mathrm{MnO}$ & \pm & $\mathrm{MgO}$ & \pm & $\mathrm{CaO}$ & \pm & $\mathrm{Na}_{2} \mathrm{O}$ & \pm & Total & Notes $^{b}$ \\
\hline Kn162-47-10 & $1 \mathrm{C}$ & 10 & 51.45 & 1.22 & 0.20 & 0.08 & 6.65 & 0.61 & 0.87 & 0.14 & 4.01 & 1.60 & 0.13 & 0.04 & 19.09 & 6.13 & 16.85 & 8.28 & 0.29 & 0.16 & 99.54 & $y x V n$ \\
\hline Kn162-47-10 & $1 \mathrm{R}$ & 10 & 50.86 & 0.32 & 0.22 & 0.03 & 6.77 & 0.30 & 0.93 & 0.05 & 2.92 & 0.07 & 0.10 & 0.01 & 15.60 & 0.67 & 21.77 & 0.76 & 0.43 & 0.03 & 99.60 & $\mathrm{x} V \mathrm{n}$ \\
\hline$-47-10$ & $\Omega_{0}$ & 7 & .38 & 46 & 0.24 & 0.04 & 5.16 & 0.67 & 0.64 & 0.12 & 2.89 & 0.17 & 0.10 & 0.02 & 16.22 & 0.39 & 22.26 & 0.32 & .32 & 0.04 & 99.21 & $\mathrm{x} \times \mathrm{Vn}$ \\
\hline $7-10$ & 5 & 10 & .09 & 36 & 23 & 0.02 & 05 & 0.48 & 0.76 & 0.08 & 3.01 & 0.43 & 0.11 & 0.03 & .12 & 0.84 & 21.68 & 1.02 & .37 & 0.05 & & Mat \\
\hline $162-47-10$ & $\mathrm{C}$ & 7 & .98 & 18 & 0.27 & 0.02 & .22 & 0.35 & 1.05 & 0.07 & 3.08 & 0.41 & 0.12 & 0.06 & 15.57 & 0.28 & 21.91 & 0.30 & .49 & 0.06 & 9.70 & arMat \\
\hline Kn162-47-10 & $6 \mathrm{R}$ & 7 & 51.30 & 0.37 & 0.29 & 0.02 & 5.74 & 0.42 & 0.96 & 0.09 & 2.83 & 0.21 & 0.10 & 0.02 & 15.57 & 0.30 & 22.16 & 0.15 & 0.55 & 0.02 & 50 & arMat \\
\hline Kn162-47-10 & $7 \mathrm{I}$ & 4 & 51.32 & 0.27 & 0.26 & 0.05 & 5.90 & 0.39 & 0.92 & 0.06 & 2.72 & 0.23 & 0.08 & 0.04 & 15.96 & 0.18 & 21.99 & 0.33 & & & 99.19 & arMat \\
\hline Kn162-47-12 & 1I & 10 & 51.24 & 0.90 & 0.25 & 0.04 & 5.94 & 0.80 & 1.02 & 0.15 & 2.79 & 0.79 & 0.09 & 0.02 & 16.46 & 2.61 & 21.62 & 3.26 & 0.41 & 0.10 & 99.82 & $y x V n$ \\
\hline & 26 & 10 & .06 & 0.82 & 0.23 & 0.05 & 6.16 & 0.20 & 0.99 & 0.07 & 3.38 & 0.94 & 0.11 & 0.03 & 17.25 & 3.40 & 19.62 & 4.64 & .38 & 0.10 & 18 & \\
\hline 22 & & 9 & 51.26 & 0.4 & 0.22 & 0.02 & 6.75 & 0.24 & 0.99 & 0.03 & 3.06 & 0.11 & 0.09 & 0.02 & & 0.30 & & 0.28 & 51 & 0.06 & & \\
\hline Kn162-47-22 & $1 \mathrm{R}$ & 8 & 51.82 & 0.39 & 0.24 & 0.04 & 6.51 & 0.15 & 0.93 & 0.04 & 3.24 & 0.74 & 0.10 & 0.03 & 16.72 & 2.27 & 20.78 & 3.06 & 0.48 & 0.10 & & $\mathrm{jVn}$ \\
\hline & $2 C$ & 8 & 50.84 & 0.28 & 0.27 & 0.02 & 7.26 & 0.13 & 1.08 & 0.03 & 3.21 & 0.33 & 0.10 & 0.03 & 15.80 & 0.79 & 21.56 & 1.04 & .49 & 0.04 & & $\mathrm{Vn}$ \\
\hline & & 0 & - & 0 & 0.29 & 0.0 & 7.19 & 0.14 & 09 & 0.0 & 3.07 & 0.2 & 0 . & 0.0 & 10 & 0.91 & 21.55 & 1. & 7 & 0.07 & & \\
\hline & 3 & 10 & .92 & 0.3 & 0.24 & 0.0 & 23 & 0.24 & 1.05 & 0.0 & 3.55 & 0.4 & 0.1 & 0.0 & 16.82 & 1.51 & 20.17 & $2 .($ & .36 & 0.08 & & \\
\hline & & 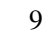 & .04 & 0.6 & 0.26 & 0.0 & 92 & 0.24 & 94 & 0.0 & 3.13 & 0.12 & 0. & 0.0 & & 0.42 & 21.63 & 0. & & 0.03 & & \\
\hline $47-22$ & $\mathrm{~T}$ & 10 & 66 & 0.2 & 0.26 & 0.0 & 7.37 & 0.20 & 05 & 0.0 & 3.31 & 0.18 & 0.10 & 0.0 & & 0.71 & & 0. & & 0.06 & & \\
\hline Kn162-47-24 & $1 \mathrm{C}$ & 6 & 50.83 & 1.40 & 0.19 & 0.08 & 6.17 & 0.58 & 107 & 0.20 & 3.65 & 1.84 & 0.11 & 0.0 & & 6.65 & 18.54 & 8.88 & & 0.21 & 99.21 & \\
\hline & & 7 & & 1.0 & 0.21 & 0.0 & & 1.5 & & 0.2 & 2.50 & 0.3 & 0. & 0.0 & & 0. & & 1. & & 0.23 & 2 & \\
\hline & 26 & 0 & .98 & 0.7 & 0.19 & 0.0 & 6.35 & 0.2 & 1.11 & 0.08 & 3.55 & 1.3 & 0.1 & 0.0 & 18.24 & 4.5 & 18.38 & 6. & 8 & 0.16 & & \\
\hline 24 & 3 & 10 & 12 & 0.48 & 0.25 & 0.0 & 6.17 & 0.32 & 97 & $0.0^{\prime}$ & 3.04 & 0.77 & 0.09 & 0.0 & & 2.60 & & 3.54 & & 0.10 & 99.51 & \\
\hline Kn162-47-25 & 1 & 7 & 51.07 & 0.22 & 0.43 & 0.03 & 6.43 & 0.05 & 1.15 & 0.01 & 2.62 & 0.16 & 0.11 & 0.03 & 15.49 & 0.32 & 21.36 & 0.47 & 0.79 & 0.05 & 99.45 & NrMat \\
\hline & & 10 & & & 0.44 & 0.0 & & 0.0 & & 0.0 & & 0. & & 0.0 & & 0. & & 0. & & & & \\
\hline & 1 & 10 & 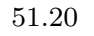 & 0.4 & 0.40 & 0.0 & 6. & 0.1 & 0.98 & 0.0 & $3:$ & 0. & 0 . & 0.0 & 40 & $1 .($ & 20 & 1. & 7 & 0.05 & 10 & \\
\hline & 11 & 8 & 0 & 0 & 0.44 & 0.0 & 8 & 0.1 & 01 & 0.0 & 0 & 0. & 0. & 0.0 & & 0.5 & 18 & 0. & 99 & 0.0 & & \\
\hline $\mathrm{Kn}$ & 13 & 8 & & & 0.43 & 0.0 & 6.39 & 0.25 & 00 & 0.0 & 3.00 & 0.25 & 0.12 & 0.0 & & 0.99 & & 1.35 & & 0.08 & & \\
\hline Kn162-47-25 & $14 \mathrm{I}$ & 10 & 50.66 & 0.66 & 0.43 & 0.02 & 6.65 & 0.19 & 1.03 & 0.02 & 2.93 & 0.10 & 0.12 & 0.03 & 15.17 & 0.48 & 22.02 & 0.41 & 0.57 & 0.05 & 99.58 & PyxVn \\
\hline Kn162-47-26 & $1 \mathrm{C}$ & 9 & & 0.50 & 0.23 & 0.02 & 6.97 & 0.17 & 1.02 & 0.03 & 2.88 & 0.12 & & 0.02 & & 0.31 & 21.82 & 0.42 & 0.47 & 0.04 & 99.68 & \\
\hline & & 4 & & & 0.30 & 0.0 & & 0.3 & & 0.0 & & $0 .($ & & 0.0 & & 0. & & 0. & & 0.07 & & \\
\hline & & 7 & 5 & 0 & 024 & 0.0 & & 0.3 & 87 & 0.0 & 8 & 0. & $0 .($ & 0.0 & 16 & 0. & 21 & 0. & & 0.05 & 99 & \\
\hline & $3 \mathrm{I}$ & 9 & 50 & & 0.22 & 0.0 & & 0.0 & & 0.0 & & 0.17 & & 0.0 & & 0.30 & & 0.44 & & 0.03 & & \\
\hline Kn162-47-29 & $1 \mathrm{C}$ & 8 & 51.44 & 0.66 & 0.23 & 0.06 & 6.90 & 0.48 & 1.12 & 0.08 & 3.00 & 1.14 & 0.07 & 0.02 & 17.68 & 3.90 & 19.25 & 5.21 & 0.37 & 0.12 & 100.05 & \\
\hline Kn162-47-29 & $1 \mathrm{R}$ & 10 & 52.00 & 0.57 & 0.23 & 0.06 & 6.28 & 0.29 & 0.98 & 0.06 & 2.78 & 1.13 & 0.07 & 0.04 & 17.38 & 4.32 & 20.29 & 5.90 & 0.33 & 0.10 & 100.35 & \\
\hline & $2 \mathrm{R}$ & 10 & & 0.2 & 0.26 & 0.02 & 6.21 & 0.1 & 0.97 & 0.0 & 2.5 & 0.4 & 0.07 & 0.0 & & 1.3 & 21.74 & 1.84 & 0.35 & 0.05 & & \\
\hline 17 & 31 & 0 & & 0.4 & 0.26 & 0.0 & 5. & 0.1 & & 0.0 & & 0.1 & $0 .($ & 0.1 & & 0.68 & & 0. & & 0.02 & & \\
\hline 50 & $1 \mathrm{C}$ & 9 & & 0 & 0.22 & 0.0 & & 0.1 & & & 3.5 & 0.7 & & & 17 & 2.64 & & & & 0.13 & & \\
\hline 0 & $1 \mathrm{P}$ & 7 & & 0 & 0.25 & 0.0 & 6.25 & 0.46 & & 0.08 & 3.00 & 0.17 & 0.11 & 0.04 & & 0.24 & 22.70 & 0.21 & & 0.06 & & \\
\hline Kn162-47-36 & $2 \mathrm{C}$ & 9 & 51.71 & 1.02 & 0.21 & 0.08 & 5.87 & 1.00 & 1.00 & 0.16 & 3.77 & 1.67 & 0.11 & 0.03 & 18.98 & 5.55 & 18.42 & 7.61 & 0.32 & 0.18 & 100.40 & \\
\hline Kn162-47-36 & $2 \mathrm{R}$ & 8 & 51.12 & 0.5 & 0.30 & 0.0 & 5.70 & 0.43 & 0.92 & 0.08 & 2.99 & 0.3 & 0.09 & 0.0 & 16.21 & 0.37 & 22.52 & 0.92 & 0.38 & 0.10 & & \\
\hline Kn162-47-36 & $3 I$ & 10 & 51.24 & 0.60 & 0.26 & 0.02 & 6.07 & 0.22 & 0.98 & 0.04 & 3.13 & 0.15 & 0.11 & 0.03 & 16.19 & 0.32 & 22.18 & 0.28 & 0.42 & 0.06 & 100.58 & \\
\hline
\end{tabular}


Table 5.6: Cpx major elements Cont.

\begin{tabular}{|c|c|c|c|c|c|c|c|c|c|c|c|c|c|c|c|c|c|c|c|c|c|c|}
\hline Analysis & $\mathrm{rn}^{a}$ & Pts & $\mathrm{SiO}_{2}$ & \pm & $\mathrm{TiO}_{2}$ & \pm & $\mathrm{Al}_{2} \mathrm{O}_{3}$ & \pm & $\mathrm{Cr}_{2} \mathrm{O}_{3}$ & $3 \pm$ & $\mathrm{FeO}$ & \pm & $\mathrm{MnO}$ & \pm & $\mathrm{MgO}$ & \pm & $\mathrm{CaO}$ & \pm & $\mathrm{Na}_{2} \mathrm{O}$ & \pm & Total & $\operatorname{Jotes}^{b}$ \\
\hline Kn162-47-49 & 1I & 8 & 51.19 & 0.73 & 0.26 & 0.01 & 5.59 & 0.33 & 0.90 & 0.08 & 2.56 & 0.20 & 0.06 & 0.02 & 16.78 & 0.29 & 22.12 & 0.21 & 0.30 & 0.02 & 99.77 & \\
\hline Kn162-47-49 & $2 \mathrm{C}$ & 6 & 51.85 & 1.23 & 0.18 & 0.08 & 5.41 & 0.38 & 1.03 & 0.15 & 3.50 & 2.09 & 0.10 & 0.06 & 17.82 & 6.07 & 19.68 & 8.98 & 0.30 & 0.11 & 99.87 & \\
\hline $62-47-49$ & & 9 & .03 & 0.46 & 0.23 & 0.03 & 5.99 & 0.58 & 1.05 & 0.05 & 2.67 & 0.23 & 0.06 & 0.01 & 15.91 & 0.20 & 22.30 & 0.54 & .45 & 0.09 & 99.69 & \\
\hline$-47-49$ & & 10 & .21 & 39 & 22 & 0.01 & 17 & 0.20 & 1.04 & 0.03 & 2.74 & 0.46 & 0.06 & 0.02 & 16.17 & 0.92 & 21.80 & 1.59 & .39 & 0.05 & 9.80 & \\
\hline PS86-6-26 & $\mathrm{C}$ & 9 & .39 & 0.52 & 0.39 & 0.07 & 37 & 0.39 & 0.87 & 0.07 & 3.14 & 0.52 & 0.08 & 0.03 & 16.12 & 2.46 & 19.40 & 3.06 & .77 & 0.16 & 99.53 & \\
\hline PS86-6-26 & & 9 & 51.03 & 0.60 & 0.43 & 0.02 & 7.16 & 0.25 & 0.88 & 0.04 & 2.68 & 0.17 & 0.07 & 0.02 & 14.76 & 0.25 & 21.93 & 0.35 & 0.86 & 0.07 & 99.80 & \\
\hline PS86-6-26 & $2 \mathrm{I}$ & 10 & 51.25 & 0.51 & 0.44 & 0.02 & 7.21 & 0.16 & 0.86 & 0.03 & 2.88 & 0.33 & 0.08 & 0.02 & 15.34 & 0.98 & 21.01 & 1.33 & 0.78 & 0.07 & 99.85 & \\
\hline PS86-6-26 & $3 \mathrm{C}$ & 10 & 51.29 & 0.34 & 0.36 & 0.05 & 7.64 & 0.16 & 0.90 & 0.06 & 3.28 & 0.73 & 0.08 & 0.02 & 16.39 & 2.65 & 19.03 & 3.42 & 0.75 & 0.15 & 99.72 & \\
\hline$-6-26$ & & 10 & .31 & 0.30 & 0.42 & 0.02 & 50 & 0.13 & 0.86 & 0.01 & 2.84 & 0.20 & 0.07 & 0.02 & 15.06 & 0.26 & 21.12 & 0.32 & .79 & 0.06 & 99.98 & \\
\hline$P s$ & & 7 & 51.54 & 0.54 & 0.42 & 0.0 & 04 & 0.36 & 0.95 & 0.04 & 2.98 & 0.22 & 0.11 & 0.03 & 15.34 & 0.83 & & 0.92 & 1.10 & 0.09 & & \\
\hline PS86-6-38 & 2 & 6 & 51.68 & 0.75 & 0.39 & 0.05 & 7.16 & 0.18 & 0.90 & 0.03 & 3.32 & 0.44 & 0.13 & 0.04 & 16.48 & 2.00 & 19.97 & 2.67 & 0.99 & 0.13 & 101.03 & \\
\hline PS86-6-38 & & 7 & 51.19 & 0.42 & 0.42 & 0.01 & 6.92 & 0.11 & 0.92 & 0.02 & 3.05 & 0.10 & 0.09 & 0.02 & 14.75 & 0.39 & 21.30 & 0.44 & .11 & 0.04 & 74 & \\
\hline & & 7 & 5 & 0 & 0.41 & 0.0 & 34 & 0.1 & 0.92 & 0.0 & 3.12 & 0.1 & 0.13 & 0.0 & 34 & 0.48 & 20.76 & 0. & 1 & 0.08 & 5 & \\
\hline $6-39$ & & 7 & .42 & 0.1 & 0.33 & 0.0 & 6.99 & 0.20 & 38 & 0.0 & 2.90 & 0.1 & 0.10 & 0.0 & 15.00 & 0.29 & 20.79 & 0.3 & 31 & 0.05 & 100.23 & \\
\hline & & 8 & & 0.5 & 0.32 & 0.0 & 6.76 & 0.1 & 33 & 0.0 & 2.94 & 0.24 & 0.10 & 0.0 & & 0.93 & & 0. & 8 & 0.13 & & \\
\hline 6.36 & & 9 & 51.60 & 0.3 & 0.34 & 0.0 & 6.32 & 0.09 & 19 & 0.0 & 2.84 & 0.20 & 0.13 & 0.0 & & 0.62 & & 0. & 1.29 & 0.07 & & \\
\hline 6.30 & & 7 & 51.35 & 0.41 & 0.30 & 0.02 & 6.68 & 0.21 & 1.39 & 0.0 & 2.82 & 0.25 & 0.10 & 0.0 & 15.01 & 0.50 & 20.85 & 0.50 & 1.33 & 0.10 & 99.84 & \\
\hline & & 7 & & 0.26 & 0.37 & 0.0 & 6.75 & 0.1 & & 0.0 & 98 & 0.3 & 0.11 & 0.0 & & 1. & & 1. & 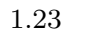 & 0.09 & & \\
\hline $5-3$ & 4 & 0 & .45 & 0.2 & 0.35 & 0.0 & 6.54 & 0.1 & 34 & 0.0 & 2.79 & 0.2 & 0.09 & 0.0 & 15.21 & 0.54 & 20.69 & $1 .(\mathrm{r}$ & 1.27 & 0.08 & 99.73 & \\
\hline $6-6-40$ & & 13 & 51.00 & 0.47 & 0.40 & 0.0 & 7.74 & 0.29 & 1.05 & 0.0 & 3.17 & 0.23 & 0.09 & 0.02 & 15.16 & 0.82 & 20.43 & 1.20 & 1.06 & 0.09 & & \\
\hline PS86-6-40 & & 5 & 50.96 & 0.13 & 0.46 & 0.01 & 7.48 & 0.15 & 1.02 & 0.05 & 2.78 & 0.05 & 0.11 & 0.02 & 14.62 & 0.18 & 22.00 & 0.35 & 1.00 & 0.10 & 100.43 & \\
\hline & & 5 & & & 0.41 & 0.0 & 7.07 & 0.1 & & 0.0 & & 0.1 & & 0.0 & & 0. & & 0. & & 0.07 & & \\
\hline $586-6-40$ & & 7 & 0 & 0.3 & 0.46 & 0.0 & 6.53 & 0.2 & 0.92 & 0.0 & 2.96 & 0.29 & 0. & 0.0 & 88 & 0. & 21.66 & 0. & 4 & 0.09 & 10 & \\
\hline & 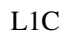 & 20 & & 0.4 & 0.13 & 0.0 & 4.76 & 0.1 & .62 & 0.0 & 3.41 & 0.16 & 0.1 & 0.0 & 19.18 & 0.7 & 18.43 & 0.77 & 0.51 & 0.04 & 100.46 & \\
\hline RC27-6-9-2 & & 10 & 51.8 & 1.0 & 0.23 & 0.04 & 4.18 & 0.16 & 1.59 & 0.17 & 2.62 & 1.12 & 0.11 & 0.03 & 16.82 & 4.63 & 22.02 & 5.85 & 0.60 & 0.16 & & Mat \\
\hline RC27-6-9-2 & L2C & 10 & 52.1 & 0.5 & 0.15 & 0.03 & 4.85 & 0.19 & 1.59 & 0.11 & 2.92 & 0.67 & 0.10 & 0.02 & 17.77 & 3.17 & 19.85 & 3.92 & 0.84 & 0.14 & 100.17 & FarMat \\
\hline RC27-6-9-2 & $2 \mathrm{R}$ & 10 & 51.9 & 1.9 & 0.17 & 0.09 & 4.99 & 2.05 & 1.49 & 0.24 & 2.72 & 0.70 & 0.08 & 0.03 & 17.55 & 2.43 & 20.12 & 3.81 & 1.11 & 0.55 & 100.13 & FarMat \\
\hline$D C 2$ & & 10 & & 0.4 & 023 & 0.0 & 78 & 0.16 & 52 & 0.0 & & 0. & 0 . & 0.0 & & 1.6 & & 1. & 0. & 0.08 & & \\
\hline C2 & & 20 & & 1 & 029 & 0.1 & 4.69 & 0.3 & 66 & 0.3 & 3 & 1.1 & 0. & 0.0 & 18 & 4.7 & 19.10 & 5. & 0 & 0.17 & 10 & $\mathrm{Vn}$ \\
\hline RC27-9-6-2 & LJI & 10 & 51.5 & 0.2 & 0.25 & 0.0 & 4.99 & 0.0 & 1.09 & 0.0 & 2.72 & 0.17 & 0.11 & 0.02 & 15.70 & 0.42 & 22.55 & 0.60 & 0.57 & 0.04 & 99.98 & $\mathrm{ppx} V \mathrm{n}$ \\
\hline RC27-9-6-2 & L6C & 10 & 51.9 & 1.2 & 0.16 & 0.05 & 4.82 & 0.31 & 1.49 & 0.18 & 3.18 & 1.11 & 0.10 & 0.02 & 18.57 & 4.37 & 18.89 & 5.46 & 0.66 & 0.16 & 99.77 & NrMat \\
\hline RC27-9-6-2 & L7C & 20 & 52.2 & 0.4 & 0.20 & 0.03 & 4.30 & 0.16 & 1.25 & 0.05 & 2.72 & 0.44 & 0.11 & 0.03 & 17.38 & 1.65 & 21.34 & 2.13 & 0.62 & 0.07 & 100.04 & NrMat \\
\hline RC27-9-6-2 & L11C & 11 & 52.3 & 1.0 & 0.14 & 0.03 & 4.81 & 0.27 & 1.59 & 0.1 & 3.24 & 0.99 & 0.1 & 0.0 & 18.60 & 4.50 & 19.60 & 5.90 & 0.50 & 0.19 & & rMat \\
\hline 627066 & & 6 & & 0.2 & 0.17 & 0.0 & 4.4 & 0.2 & & 0.0 & & $0 .($ & & 0.0 & & 0.1 & & 0.20 & & 0.04 & & arMat \\
\hline$-7-0=2$ & & 5 & & 1. & 0.14 & 0.0 & 5.21 & 0.1 & 1.0 & & & 1.70 & & 0.0 & & 7.10 & & 9.20 & & 0.32 & & rMat \\
\hline RC27-9-6-2 & L15C & 5 & 52.1 & 1.0 & 22 & 0.0 & 5.40 & 0.13 & 1.71 & 0.15 & 3.17 & 1.20 & 0.10 & 0.02 & 50 & 4.60 & 20.30 & 6.20 & 0.70 & 0.23 & & $p x V n$ \\
\hline RC27-9-6-2 & L16C & 10 & 52.2 & 0.6 & 0.20 & 0.04 & 5.23 & 0.18 & 1.51 & 0.11 & 4.17 & 0.73 & 0.14 & 0.02 & 20.71 & 2.94 & 15.92 & 3.76 & 0.50 & 0.14 & 100.58 & $\mathrm{CpxVn}$ \\
\hline RC27-9-6-2 & L16R & 10 & 52.5 & 0.6 & 0.18 & 0.03 & 5.05 & 0.18 & .50 & 0.14 & 3.81 & 0.67 & 0.13 & 0.02 & 20.04 & 3.07 & 16.94 & 3.74 & 0.55 & 0.13 & & CpxVn \\
\hline RC27-9-6-2 & L18I & 5 & 51.7 & 0.3 & 0.27 & 0.06 & 5.48 & 0.18 & 1.72 & 0.06 & 2.89 & 0.12 & 0.10 & 0.02 & 16.10 & 0.60 & 22.20 & 0.90 & 0.69 & 0.07 & 101.15 & AdjVn \\
\hline
\end{tabular}


Table 5.6: Cpx major elements Cont.

\begin{tabular}{|c|c|c|c|c|c|c|c|c|c|c|c|c|c|c|c|c|c|c|c|c|c|c|}
\hline Analysis & $\mathrm{rn}^{a}$ & Pts & $\mathrm{SiO}_{2}$ & \pm & $\mathrm{TiO}_{2}$ & \pm & $\mathrm{Al}_{2} \mathrm{O}_{3}$ & \pm & $\mathrm{r}_{2} \mathrm{O}_{3}$ & $3 \pm$ & $\mathrm{FeO}$ & \pm & $\mathrm{MnO}$ & \pm & $\mathrm{MgO}$ & \pm & $\mathrm{CaO}$ & \pm & $\mathrm{Na}_{2} \mathrm{O}$ & \pm & Total & Notes $^{b}$ \\
\hline RC27-9-6-2 & L19R & 5 & 52.0 & 0.9 & 0.25 & 0.05 & 5.32 & 0.22 & 1.62 & 0.12 & 3.46 & 1.05 & 0.09 & 0.03 & 17.90 & 3.40 & 19.80 & 4.40 & 0.61 & 0.17 & 101.05 & $\mathrm{dj} V \mathrm{n}$ \\
\hline RC27-9-6-2 & $20 \mathrm{I}$ & 5 & 52.4 & 0.7 & 0.23 & 0.06 & 5.07 & 0.38 & 1.50 & 0.20 & 3.36 & 0.90 & 0.10 & 0.02 & 18.60 & 3.50 & 19.50 & 4.40 & 0.43 & 0.27 & 101.19 & Mat \\
\hline RC27-9-6-2 & $1 \mathrm{C}$ & 5 & 52.6 & 1.2 & 17 & 0.07 & 494 & 0.32 & 1.57 & 0.27 & 3.48 & 1.58 & 0.09 & 0.03 & 9.90 & 6.90 & 18.00 & 8.80 & .56 & 0.28 & & rMat \\
\hline & $1 \mathrm{R}$ & 5 & 2.2 & 0.3 & 24 & & & 0.20 & & 0.04 & & 0.20 & & 0.01 & & 0.70 & 22.90 & 1.20 & & 0.03 & & \\
\hline RC27-9-6-2 & $2 \mathrm{C}$ & 10 & 53.0 & 0.9 & 10 & 0.12 & 4.91 & 0.26 & 1.46 & 0.08 & 4.26 & 1.07 & 0.11 & 0.03 & 22.50 & 0.05 & 14.40 & 0.10 & .48 & 0.01 & 101.22 & rMat \\
\hline $\mathrm{RC} 27$ & $2 \mathrm{R}$ & 5 & 51.6 & 1.5 & 0.23 & 0.07 & 5.28 & 0.43 & 1.42 & 0.30 & 3.12 & 1.90 & 0.09 & 0.03 & 17.60 & 7.50 & 20.50 & 9.60 & 0.70 & 0.33 & & rMat \\
\hline RC27-9-6-2 & $24 \mathrm{C}$ & 5 & 52.3 & 0.4 & 0.14 & 0.07 & 4.88 & 0.43 & 1.57 & 0.33 & 3.71 & 1.75 & 0.11 & 0.04 & 20.30 & 7.10 & 15.50 & 9.30 & 0.49 & 0.36 & 99.00 & rMat \\
\hline RC27-9-6-2 & $24 \mathrm{R}$ & 5 & 52.3 & 0.5 & 0.19 & 0.07 & 489 & 0.51 & 1.57 & 0.15 & 3.19 & 1.17 & 0.09 & 0.04 & 18.90 & 4.70 & 19.00 & 5.80 & .56 & 0.25 & 100.69 & rMat \\
\hline & $7 \mathrm{C}$ & 5 & 53.3 & 1.9 & 14 & 0.0 & $r$ & 0.32 & .35 & 0.33 & 4.22 & 2.23 & 0.09 & 0.04 & 22.90 & 9.60 & 14.20 & 12.30 & .43 & 0.39 & 38 & Mat \\
\hline & & 10 & 52.21 & 1.12 & 0.12 & 0.0 & 4.93 & 0.28 & 1.56 & 0.20 & 3.37 & 1.16 & 0.11 & 0.03 & & 4.59 & & 6.20 & & 0.25 & & \\
\hline$-9-6-2$ & & 10 & 52.62 & 1.08 & 0.14 & 0.03 & 4.43 & 0.53 & 1.49 & 0.23 & 2.76 & 0.87 & 0.10 & 0.02 & 16.93 & 3.75 & 21.62 & 4.65 & 59 & 0.17 & & Mat \\
\hline RC27-9-6-2 & & 7 & 51.91 & 0.28 & 0.14 & 0.01 & & 0.06 & 1.49 & 0.04 & 2.92 & 0.21 & 0.08 & 0.0 & 16.46 & 0.57 & 21.02 & 0.68 & 2 & 0.0 & & Mat \\
\hline & & 11 & 2.03 & & 0.15 & 0.0 & & 0.0 & 46 & 0.0 & 2. & 0.4 & 0. & 0.0 & 00 & 1. & 20.53 & 1. & 2 & 0.0 & & \\
\hline 6- & & 7 & .41 & 0.12 & 16 & 0.0 & 9 & 0.0 & 23 & 0.0 & 2.73 & 0.2 & 0.09 & 0.0 & 16.34 & 0.5 & 21.72 & 0.7 & 7 & 0.0 & 99 & Iat \\
\hline & & 9 & 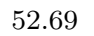 & & 0.15 & 0.0 & & 0.5 & 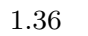 & 0.2 & 4.59 & $1.7^{\circ}$ & 0 . & 0.0 & & 6.47 & & 8. & & 0.2 & & \\
\hline $\mathrm{RC}$ & & 10 & 5 & 0 & 0.21 & 0.0 & 5.28 & 0.09 & 1.67 & 0.0 & 2.52 & 0.08 & 0.10 & 0.0 & & 0.47 & & 0. & & 0 & & \\
\hline RC27-9-6-2 & & 9 & 51.46 & 0.35 & 0.22 & 0.0 & 5.15 & 0.09 & 1.62 & 0.0 & 2.78 & 0.17 & 0.09 & 0.0 & & 0.51 & & 0.5 & & 0.07 & & $\mathrm{Vn}$ \\
\hline & & 10 & & & 0.21 & 0.0 & & 0.4 & 1.50 & 0.0 & 2 & 0.7 & 0 . & 0.1 & & 1. & & 2. & & 0. & & \\
\hline $\mathrm{RC}$ & & 8 & .00 & 1.1 & 0.16 & 0.0 & 6. & 0.1 & .08 & 0.1 & 3.96 & 1.9 & 0. & 0.0 & 19.09 & 6.2 & 16 & 8.8 & 6 & 0.1 & 99 & Enr \\
\hline & & 8 & 51.26 & & 0.17 & 0.0 & 6. & 0.19 & 1.14 & 0.1 & 3.71 & 1.63 & 0.11 & 0.04 & 18.34 & 5.21 & 18.74 & 7.56 & & 0.15 & & \\
\hline RC27-9-6-5 & & 9 & 51.44 & 0.71 & 0.49 & 0.13 & 5.65 & 0.35 & 1.09 & 0.04 & 3.14 & 0.36 & 0.09 & 0.02 & 17.15 & 1.22 & 21.39 & 1.54 & 2 & 0.06 & 100.86 & Trans \\
\hline & & 6 & & & 0.49 & & & 0.8 & & & & 0.1 & & 0.0 & & 0. & & 0. & & & & \\
\hline $\mathrm{RC}$ & & 13 & 5 & 0 & 0.31 & 0.0 & 0 & 0.1 & 08 & 0.0 & 3. & 0.4 & 0 . & 0. & 5 & 1. & 21 & 1. & .50 & 0. & 10 & \\
\hline & & 10 & & & 0.47 & 0. & & 0.8 & 98 & 0. & 0 & 0.2 & 0 . & 0.1 & & 0.8 & 22.22 & 0.8 & & 0. & & \\
\hline & & 8 & 01.10 & & 0.34 & 0.1 & & 0.5 & 1.01 & & 3.91 & 1.75 & & 0.0 & & 5.68 & 17.42 & 7.94 & & 0.27 & & \\
\hline RC27-9-6-5 & $\mathrm{R}$ & 11 & 52.45 & 1.08 & 0.55 & 0.15 & 3.87 & 0.84 & 1.19 & 0.20 & 2.58 & 0.49 & 0.04 & 0.03 & 17.39 & 2.14 & 21.28 & 2.57 & 0.71 & 0.25 & 100.06 & Enr \\
\hline & L11C & 10 & 51.3 & 0.6 & 0.24 & 0.03 & 6.23 & 1.06 & 1.13 & 0.08 & & 0.29 & & 0.02 & & 0.87 & & 1.67 & & 0.23 & 100.85 & \\
\hline & $1 \mathrm{R}$ & 10 & & & 025 & 0.0 & & 0.8 & & 0. & & 0. & & $0 .(1-x)$ & & & & 1. & & 0. & & \\
\hline & & 10 & & & 16 & 0 & & 0.2 & 07 & 0. & 4 & 2.0 & & $0 .($ & & 7. & 15.561 & 10.0 & & 0 & 5 & \\
\hline & & 10 & & & 0.22 & 0.0 & & 0.5 & & & & 0.93 & & 0.1 & & 3.37 & 21.22 & 4.40 & & 0.09 & & \\
\hline RC27-9-6-7 & 3. & 10 & 51.49 & 0.38 & 0.23 & 0.03 & 5.76 & 0.12 & 0.93 & 0.06 & 3.09 & 0.56 & 0.08 & 0.02 & 17.04 & 2.04 & 21.26 & 2.57 & 0.39 & 0.09 & 100.27 & \\
\hline RC27-9-6-7 & $5 \mathrm{I}$ & 7 & 50.83 & 0.99 & 0.25 & 0.04 & 5.50 & 0.93 & 0.92 & 0.17 & 2.78 & 0.22 & 0.09 & 0.02 & 16.39 & 0.55 & 22.59 & 1.03 & 0.41 & 0.09 & 99.78 & \\
\hline & & 14 & & & 0.32 & 0.0 & & 0.34 & 1.23 & 0.1 & 3.26 & 1.2 & 0. & 0.0 & & 5.0 & 19.82 & 6.8 & & 0.15 & & \\
\hline & & 13 & & & 37 & 0.0 & & 0.5 & & & & 0.6 & 0. & $0 .($ & & 2 . & & 3. & & 0. & & \\
\hline & & 13 & & & 20 & 0.0 & & & & & & & & & & & & 1. & & & & \\
\hline & & 10 & & & 0.33 & 0.0 & & & & & 2.53 & 0.10 & & $0 .(1$ & & 0.10 & 23.14 & 0.31 & & 0.03 & & bVn \\
\hline Van7-78-25 & $3 \mathrm{C}$ & 9 & 52.21 & 0.53 & 0.33 & 0.02 & 4.89 & 0.10 & 1.24 & 0.04 & 2.66 & 0.21 & 0.12 & 0.03 & 16.57 & 0.74 & 22.40 & 0.91 & .43 & 0.05 & 00.85 & $\mathrm{GbVn}$ \\
\hline & $3 R$ & 11 & n & 0.2 & 35 & 0.0 & 2.91 & 0.1 & 1.30 & 0.0 & 2.32 & 0.0 & 0.11 & 0.0 & 16.94 & 0.11 & 23.00 & 0.27 & 45 & 0.03 & & \\
\hline Van7-78-25 & $4 \mathrm{C}$ & 9 & 52.89 & 1.13 & 0.35 & 0.10 & 4.39 & 0.33 & 1.27 & 0.19 & 3.27 & 1.43 & 0.12 & 0.02 & 18.69 & 5.02 & 19.38 & 6.91 & 0.38 & 0.13 & 100.74 & GbVn \\
\hline
\end{tabular}


Table 5.6: Cpx major elements Cont.

\begin{tabular}{|c|c|c|c|c|c|c|c|c|c|c|c|c|c|c|c|c|c|c|c|c|c|c|}
\hline Analysis & $\mathrm{rn}^{a}$ & Pts & $\mathrm{SiO}_{2}$ & \pm & $\mathrm{TiO}_{2}$ & \pm & $\mathrm{Al}_{2} \mathrm{O}_{3}$ & \pm & $\mathrm{Cr}_{2} \mathrm{O}_{3}$ & $3 \pm$ & $\mathrm{FeO}$ & \pm & $\mathrm{MnO}$ & \pm & $\mathrm{MgO}$ & \pm & $\mathrm{CaO}$ & \pm & $\mathrm{Na}_{2} \mathrm{O}$ & \pm & Total & Notes $^{b}$ \\
\hline Van7-78-25 & $4 \mathrm{R}$ & 11 & 53.20 & 1.32 & 0.44 & 0.10 & 3.27 & 0.47 & 1.36 & 0.25 & 3.03 & 1.36 & 0.12 & 0.04 & 18.75 & 5.06 & 20.26 & 6.91 & 0.38 & 0.14 & 100.81 & GbVn \\
\hline Van7-78-25 & $\mathrm{C}$ & 10 & 52.42 & 0.33 & 0.34 & 0.03 & 4.42 & 0.37 & 1.18 & 0.06 & 2.88 & 0.53 & 0.12 & 0.02 & 16.89 & 1.54 & 22.00 & 2.28 & 0.39 & 0.07 & 100.64 & GbVn \\
\hline Van7-78-25 & $\mathrm{R}$ & 13 & 53.64 & 0.44 & 0.34 & 0.05 & 2.79 & 0.36 & 1.14 & 0.09 & 2.44 & 0.15 & 0.11 & 0.03 & 17.12 & 0.34 & 22.83 & 0.40 & 0.41 & 0.05 & 100.82 & $\mathrm{GbVn}$ \\
\hline Van7-78-31 & I & 14 & .06 & 0.77 & 0.47 & 0.03 & .95 & 0.24 & 1.19 & 0.17 & 2.59 & 0.09 & 0.10 & 0.03 & 16.51 & 0.44 & 23.12 & 0.30 & .46 & 0.05 & & Mat \\
\hline Van7-78-31 & $\mathrm{C}$ & 10 & 52.47 & 0.41 & 0.74 & 0.08 & 3.16 & 0.39 & 0.13 & 0.02 & 4.12 & 0.81 & 0.14 & 0.04 & 17.76 & 2.27 & 20.76 & 3.16 & 0.40 & 0.05 & 99.67 & $\mathrm{GbVn}$ \\
\hline Van7-78-31 & R & 10 & 52.48 & 0.57 & 0.81 & 0.09 & 2.95 & 0.31 & 0.13 & 0.03 & 3.93 & 0.73 & 0.13 & 0.03 & 17.74 & 2.15 & 21.10 & 2.86 & 0.37 & 0.08 & 99.63 & GbVn \\
\hline Van7-78-31 & $3 R$ & 11 & 52.75 & 0.50 & 0.75 & 0.06 & 2.49 & 1.10 & 0.13 & 0.02 & 3.67 & 0.24 & 0.12 & 0.02 & 16.52 & 0.87 & 22.89 & 0.34 & 0.33 & 0.04 & 99.66 & GbVn \\
\hline Van7-78-31 & $4 \mathrm{I}$ & 12 & 52.79 & 0.20 & 0.80 & 0.03 & 2.34 & 0.13 & 0.17 & 0.01 & 4.22 & 0.15 & 0.13 & 0.02 & 16.74 & 0.13 & 22.39 & 0.19 & 0.39 & 0.05 & 99.95 & $\mathrm{GbVn}$ \\
\hline-31 & 5 & 13 & 52.55 & 1.05 & 0.71 & 0.06 & 2.61 & 1.49 & 0.13 & 0.02 & 3.75 & 0.27 & 0.13 & 0.02 & 16.69 & 0.54 & 22.58 & 0.58 & 0.35 & 0.03 & 99.50 & GbVn \\
\hline Van7-78-36 & I & 12 & 53.28 & 0.23 & 0.45 & 0.04 & 2.70 & 0.10 & 1.08 & 0.03 & 2.58 & 0.12 & 0.08 & 0.02 & 17.04 & 0.27 & 23.44 & 0.32 & 0.41 & 0.03 & & Mat \\
\hline Van7-78-36 & $2 \mathrm{C}$ & 12 & 52.51 & 0.20 & 0.53 & 0.03 & 3.62 & 0.13 & 1.42 & 0.03 & 2.68 & 0.12 & 0.08 & 0.02 & 16.48 & 0.15 & 23.28 & 0.22 & 0.47 & 0.05 & 101.06 & FarMat \\
\hline Van7-78-36 & $12 \mathrm{R}$ & 11 & 53.08 & 0.24 & 0.44 & 0.02 & 2.54 & 0.06 & 1.12 & 0.03 & 2.61 & 0.06 & 0.09 & 0.01 & 17.13 & 0.09 & 23.55 & 0.14 & 0.40 & 0.03 & 100.95 & FarMat \\
\hline Va & $1 \mathrm{C}$ & 11 & 51.99 & 0.73 & 0.66 & 0.10 & 3.90 & 0.34 & 0.23 & 0.03 & 3.79 & 0.18 & 0.11 & 0.02 & 16.42 & 0.57 & 22.70 & 0.77 & 19 & 0.16 & 10 & \\
\hline-36 & $1 \mathrm{~F}$ & 12 & 52.37 & 0.1 & 0.77 & 0.12 & 3.31 & 0.17 & 0.25 & 0.05 & 3.59 & 0.16 & 0.13 & 0.01 & 16.28 & 0.53 & 23.21 & 0.49 & .45 & 0.05 & 10 & GbVn \\
\hline & 3 & 11 & 52.86 & 0.1 & 0.69 & 0.0 & 2.86 & 0.06 & 0.95 & 0.02 & 3.20 & 0.10 & 0.09 & 0.02 & 16.75 & 0.14 & 22.78 & 0.24 & 0.51 & 0.03 & & \\
\hline Van & $4 \mathrm{I}$ & 13 & 52.98 & 0.27 & 0.71 & 0.07 & 2.39 & 0.20 & 0.27 & 0.02 & 3.65 & 0.14 & 0.13 & 0.03 & & 0.42 & 22.70 & 0.50 & 0.39 & 0.04 & & GbVn \\
\hline $3-40$ & $1 \mathrm{C}$ & 13 & 51.12 & 0.41 & 0.30 & 0.03 & 6.10 & 0.38 & 1.23 & 0.04 & 2.92 & 0.06 & 0.08 & 0.02 & 15.69 & 0.28 & 22.86 & 0.55 & 0.43 & 0.12 & 100.74 & \\
\hline $\mathrm{Va}$ & $\mathrm{R}$ & 12 & 02 & 0.21 & 0.52 & 0.02 & 4.56 & 0.24 & 1.22 & 0.0 & 2.77 & 0.06 & 0.10 & 0.0 & 16.19 & 0.27 & 22.98 & 0.33 & 40 & 0.04 & 100 & \\
\hline Van & 2 & 10 & 52.27 & 0.2 & 0.56 & 0.02 & 4.03 & 0.09 & 1.24 & 0.02 & 2.71 & $0.0^{7}$ & 0.10 & 0.0 & 16.52 & 0.13 & 22.94 & 0.22 & 0.40 & 0.03 & 100.76 & \\
\hline Van7 & $1 \mathrm{C}$ & 12 & 52.24 & 0.51 & 0.25 & 0.03 & 4.05 & 0.16 & 1.33 & 0.07 & 2.98 & 0.47 & 0.09 & 0.02 & 16.78 & 1.78 & 22.33 & 2.34 & 0.36 & 0.05 & 100.41 & \\
\hline Van7-78-41 & $\mathrm{R}$ & 13 & 53.40 & 0.27 & 0.25 & 0.01 & 2.53 & 0.15 & 0.94 & 0.07 & 2.57 & 0.07 & 0.08 & 0.02 & 16.99 & 0.11 & 23.48 & 0.15 & 0.31 & 0.04 & 100.56 & \\
\hline & & 12 & 6 & 0. & & 0.02 & 3.46 & 0.07 & 125 & 0.0 & 3.05 & 0.12 & & 0.0 & & 0.3 & 22.41 & 0. & & 0.03 & & \\
\hline Van & $2 \mathrm{R}$ & 13 & 53.36 & 0.3 & 0. & 0.0 & 2.42 & 0.15 & 0.89 & 0.0 & 2.74 & 0.10 & 0.1 & 0.0 & 17.24 & 0.1 & 23.04 & 0.16 & 0.31 & 0.04 & 100.34 & \\
\hline $\mathrm{Var}$ & 1 & 8 & 49.79 & 0.2 & 1.32 & $0.0^{\circ}$ & 5.02 & 0.20 & 0.79 & 0.0 & 5.52 & 0.13 & 0.13 & 0.0 & 15.46 & 0.25 & 21.38 & 0.18 & 34 & 0.06 & 99.75 & \\
\hline Van7- & 2 & 6 & 49.22 & 0.31 & 1.35 & 0.06 & 4.48 & 0.27 & 0.96 & 0.04 & 5.46 & 0.20 & 0.11 & 0.01 & 15.60 & 0.30 & 21.39 & 0.25 & 0.35 & 0.06 & 98.92 & \\
\hline Van7-85-24 & $1 \mathrm{C}$ & 12 & 50.52 & 0.52 & 0.22 & 0.04 & 6.59 & 0.51 & 1.14 & 0.07 & 2.97 & 0.50 & 0.08 & 0.03 & 16.47 & 1.89 & 21.21 & 2.43 & 0.37 & 0.08 & 99.56 & \\
\hline Van7-85-24 & $1 \mathrm{R}$ & 10 & 51.25 & 0.29 & 0.23 & 0.02 & 5.33 & 0.26 & 0.88 & 0.03 & 2.67 & 0.18 & 0.09 & 0.02 & 16.34 & 0.54 & 22.19 & 0.54 & 0.33 & 0.02 & 99.32 & \\
\hline & & 11 & 5115 & 0.60 & & 0.03 & 619 & 0.16 & & 0.06 & 3.26 & 0.74 & 0.09 & 0.0 & & 2.76 & 19.87 & 3.79 & 0. & 0.10 & 2 & \\
\hline $\mathrm{V}_{\mathrm{i}}$ & & 13 & 7 & 0.3 & 0 & 0.0 & 5. & 0.5 & 99 & 0.0 & 3.0 & 0.68 & 0. & 0.0 & 16 & 2.12 & 21.65 & 2.98 & 0.34 & 0.07 & 100.02 & \\
\hline Van7- & 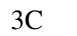 & 14 & 51.22 & 0.97 & 0.20 & 0.05 & 6.34 & 0.31 & 1.09 & 0.10 & 3.69 & 1.16 & 0.10 & 0.03 & 18.64 & 4.81 & 18.27 & 6.49 & 0.30 & 0.13 & 99.83 & \\
\hline Van7-85-24 & $3 \mathrm{R}$ & 8 & 50.74 & 0.43 & 0.23 & 0.02 & 6.57 & 0.25 & 1.16 & 0.03 & 3.21 & 0.47 & 0.09 & 0.03 & 16.51 & 1.68 & 21.14 & 2.27 & 0.34 & 0.05 & 99.99 & \\
\hline Van7-85-24 & $4 \mathrm{I}$ & 11 & 50.66 & 0.45 & 0.25 & 0.02 & 6.36 & 0.17 & 1.18 & 0.03 & 2.93 & 0.29 & 0.08 & 0.02 & 16.00 & 0.83 & 22.05 & 1.15 & 0.39 & 0.04 & 99.90 & \\
\hline & $C^{2}$ & 12 & 50.77 & 0.54 & 0.21 & 0.03 & 6.49 & 0.14 & 1.17 & 0.05 & 3.17 & 0.63 & 0.10 & 0.02 & 16.70 & 2.35 & 20.87 & 3.24 & 0.33 & 0.06 & 99.81 & \\
\hline Van7-85-2 & $n$ & 14 & 50.69 & 0.2 & 0.23 & 0.0 & 6.7 & 0.1 & & 0.0 & $3 .(1$ & 0.28 & 0. & 0.0 & 16.0 & 0.8 & 21.51 & 1.18 & 0.37 & 0.06 & 99.83 & \\
\hline Van7-85-27 & $1 \mathrm{C}$ & 10 & 5 & 0.36 & 0.25 & 0.01 & 5.3 & 0.11 & 1.22 & 0.0 & 2.68 & 0.19 & 0. & 0.02 & & 0.37 & 21.68 & 0.50 & 0.56 & 0.05 & & \\
\hline Van7-85-27 & $1 \mathrm{R}$ & 6 & 51.70 & 0.20 & 0.22 & 0.02 & 5.17 & 0.14 & 1.17 & 0.02 & 2.57 & 0.24 & 0.10 & 0.01 & 15.81 & 0.43 & 22.10 & 0.46 & 0.57 & 0.03 & 99.42 & \\
\hline Van7-85-27 & $2 \mathrm{C}$ & 10 & 51.30 & 0.70 & 0.20 & 0.05 & 5.85 & 0.09 & 1.36 & 0.11 & 3.41 & 1.03 & 0.11 & 0.02 & 18.39 & 4.34 & 18.16 & 5.80 & 0.48 & 0.17 & 99.27 & \\
\hline Van7-85-27 & $2 \mathrm{R}$ & 7 & 52.28 & 0.66 & 0.24 & 0.01 & 5.11 & 0.26 & 1.14 & 0.09 & 2.65 & 0.14 & 0.08 & 0.01 & 16.16 & 0.41 & 21.40 & 0.55 & 0.56 & 0.05 & 99.61 & \\
\hline Van7-85-30 & $1 \mathrm{C}$ & 10 & 51.01 & 0.43 & 0.20 & 0.02 & 6.60 & 0.20 & 1.18 & 0.04 & 3.20 & 0.38 & 0.10 & 0.02 & 16.65 & 1.39 & 20.64 & 1.89 & 0.35 & 0.05 & 99.94 & \\
\hline
\end{tabular}


Table 5.6: Cpx major elements Cont.

\begin{tabular}{|c|c|c|c|c|c|c|c|c|c|c|c|c|c|c|c|c|c|c|c|c|c|c|}
\hline Analysis & $\mathrm{Grn}^{a}$ & Pts & $\mathrm{SiO}_{2}$ & \pm & $\mathrm{TiO}_{2}$ & \pm & $\mathrm{Al}_{2} \mathrm{O}_{3}$ & $3 \pm$ & $\mathrm{Cr}_{2} \mathrm{O}_{3}$ & $3 \pm$ & $\mathrm{FeO}$ & \pm & $\mathrm{MnO}$ & \pm & $\mathrm{MgO}$ & \pm & $\mathrm{CaO}$ & \pm & $\mathrm{Na}_{2} \mathrm{O}$ & \pm & Total & Notes $^{b}$ \\
\hline Van7-85-30 & $1 \mathrm{R}$ & 11 & 50.93 & 0.21 & 0.22 & 0.01 & 6.18 & 0.15 & 1.07 & 0.03 & 2.88 & 0.26 & 0.09 & 0.02 & 16.11 & 0.96 & 21.95 & 1.31 & 0.35 & 0.04 & 99.80 & \\
\hline Van7-85-30 & $3 \mathrm{I}$ & 14 & 50.86 & 0.49 & 0.23 & 0.02 & 6.18 & 0.23 & 1.11 & 0.03 & 2.88 & 0.42 & 0.08 & 0.02 & 16.13 & 1.26 & 21.96 & 1.86 & 0.42 & 0.06 & 99.85 & \\
\hline Van7-85-30 & $4 \mathrm{C}$ & 8 & 51.06 & 0.52 & 0.21 & 0.02 & 6.38 & 0.13 & 1.12 & 0.04 & 3.13 & 0.53 & 0.08 & 0.03 & 16.40 & 1.64 & 21.31 & 2.30 & 0.35 & 0.05 & 100.05 & \\
\hline Van7-85-30 & $4 \mathrm{R}$ & 11 & 51.21 & 0.48 & 0.23 & 0.01 & 5.77 & 0.18 & 0.98 & 0.04 & 2.94 & 0.23 & 0.08 & 0.02 & 16.22 & 0.54 & 22.02 & 0.79 & 0.37 & 0.15 & 99.84 & \\
\hline Van7-85-32 & $3 \mathrm{C}$ & 13 & 51.12 & 0.76 & 0.16 & 0.06 & 6.72 & 0.38 & 1.08 & 0.08 & 3.93 & 1.78 & 0.12 & 0.03 & 18.95 & 5.42 & 17.95 & 8.12 & 0.28 & 0.14 & 100.32 & \\
\hline Van7-85-32 & $3 \mathrm{R}$ & 8 & 50.97 & 0.45 & 0.22 & 0.02 & 6.34 & 0.29 & 1.04 & 0.02 & 2.81 & 0.18 & 0.11 & 0.03 & 15.72 & 0.40 & 22.82 & 0.66 & 0.33 & 0.03 & 100.35 & \\
\hline Van7-85-39 & $3 C$ & 8 & 50.55 & 0.80 & 0.19 & 0.03 & 6.45 & 0.31 & 1.09 & 0.07 & 3.36 & 0.63 & 0.08 & 0.02 & 17.53 & 2.95 & 19.73 & 3.93 & 0.28 & 0.08 & 99.25 & \\
\hline Van7-85-39 & $3 R$ & 7 & 50.89 & 0.37 & 0.23 & 0.02 & 5.46 & 0.29 & 0.89 & 0.07 & 2.75 & 0.12 & 0.06 & 0.02 & 16.06 & 0.21 & 22.44 & 0.40 & 0.34 & 0.07 & 99.11 & \\
\hline Van7-85-39 & $4 \mathrm{I}$ & 9 & 50.54 & 0.20 & 0.21 & 0.08 & 5.82 & 0.08 & 0.99 & 0.03 & 2.85 & 0.21 & 0.07 & 0.03 & 16.12 & 0.58 & 22.13 & 0.74 & 0.30 & 0.06 & 99.02 & \\
\hline Van7-85-42 & $1 \mathrm{R}$ & 6 & 51.38 & 0.71 & 0.26 & 0.04 & 6.69 & 0.55 & 1.14 & 0.07 & 3.15 & 0.46 & 0.09 & 0.02 & 16.60 & 1.81 & 21.60 & 2.20 & 0.35 & 0.03 & 101.26 & \\
\hline $\operatorname{Van} 7-85-42$ & $2 \mathrm{C}$ & 10 & 51.94 & 0.44 & 0.19 & 0.02 & 6.12 & 0.21 & 1.05 & 0.04 & 3.42 & 0.55 & 0.11 & 0.01 & 17.54 & 2.46 & 20.19 & 3.08 & 0.34 & 0.07 & 100.89 & \\
\hline Van7-85-42 & $2 \mathrm{R}$ & 6 & 52.16 & 0.29 & 0.22 & 0.01 & 5.67 & 0.15 & 0.91 & 0.04 & 3.10 & 0.07 & 0.09 & 0.01 & 17.23 & 0.23 & 21.54 & 0.41 & 0.36 & 0.04 & 101.28 & \\
\hline Van7-85-42 & $3 \mathrm{I}$ & 6 & 51.27 & 0.57 & 0.23 & 0.02 & 6.52 & 0.21 & 1.14 & 0.03 & 3.31 & 0.56 & 0.09 & 0.01 & 16.90 & 2.01 & 21.16 & 2.84 & 0.36 & 0.05 & 100.97 & \\
\hline Van7-85-47 & $2 \mathrm{C}$ & 8 & 51.43 & 0.35 & 0.22 & 0.02 & 6.44 & 0.23 & 1.12 & 0.05 & 2.92 & 0.49 & 0.11 & 0.02 & 16.06 & 1.68 & 22.04 & 2.43 & 0.40 & 0.06 & 100.74 & \\
\hline Van7-85-47 & $2 R$ & 13 & 51.73 & 0.43 & 0.24 & 0.02 & 5.99 & 0.23 & 1.00 & 0.03 & 2.95 & 0.29 & 0.09 & 0.02 & 16.45 & 1.17 & 22.05 & 1.45 & 0.39 & 0.07 & 100.88 & \\
\hline $\operatorname{Van} 7-85-47$ & $3 \mathrm{C}$ & 15 & 51.66 & 1.25 & 0.20 & 0.07 & 6.87 & 0.28 & 1.15 & 0.10 & 3.73 & 1.61 & 0.10 & 0.02 & 18.52 & 6.02 & 18.46 & 8.62 & 0.33 & 0.15 & 101.01 & \\
\hline Van7-85-47 & $3 R$ & 10 & 51.34 & 0.54 & 0.23 & 0.03 & 5.94 & 0.32 & 1.02 & 0.05 & 3.24 & 0.84 & 0.09 & 0.03 & 17.31 & 3.24 & 20.97 & 4.12 & 0.36 & 0.07 & 100.50 & \\
\hline $\operatorname{Van} 7-85-49$ & $3 \mathrm{I}$ & 9 & 51.07 & 0.37 & 0.18 & 0.02 & 6.12 & 0.09 & 1.12 & 0.02 & 3.17 & 0.43 & 0.06 & 0.02 & 17.09 & 1.69 & 20.52 & 2.08 & 0.32 & 0.06 & 99.65 & \\
\hline $\operatorname{Van} 7-85-49$ & $4 \mathrm{C}$ & 10 & 51.42 & 0.78 & 0.16 & 0.04 & 6.40 & 0.15 & 1.16 & 0.09 & 3.61 & 1.18 & 0.08 & 0.02 & 18.54 & 4.30 & 18.68 & 6.00 & 0.25 & 0.10 & 100.30 & \\
\hline Van7-86-25 & $1 \mathrm{C}$ & 7 & 51.81 & 0.72 & 0.14 & 0.02 & 5.86 & 0.72 & 1.24 & 0.13 & 2.60 & 0.23 & 0.07 & 0.02 & 15.72 & 0.78 & 22.26 & 0.53 & 0.33 & 0.04 & 100.03 & \\
\hline Van7-86-25 & $1 \mathrm{R}$ & 10 & 51.78 & 0.49 & 0.15 & 0.03 & 5.61 & 0.24 & 1.17 & 0.04 & 2.54 & 0.35 & 0.07 & 0.02 & 16.31 & 1.02 & 21.99 & 1.26 & 0.36 & 0.04 & 99.99 & \\
\hline Van7-86-25 & $2 \mathrm{I}$ & 9 & 52.56 & 0.87 & 0.15 & 0.02 & 5.06 & 0.14 & 1.00 & 0.04 & 2.74 & 0.18 & 0.07 & 0.02 & 16.61 & 0.62 & 21.70 & 0.68 & 0.33 & 0.03 & 100.20 & \\
\hline Van7-86-25 & $3 \mathrm{I}$ & 9 & 51.93 & 0.45 & 0.14 & 0.01 & 5.25 & 0.06 & 1.03 & 0.03 & 2.97 & 0.22 & 0.07 & 0.02 & 16.87 & 0.59 & 21.13 & 0.84 & 0.33 & 0.04 & 99.72 & \\
\hline Van7-86-25 & $4 \mathrm{C}$ & 10 & 52.61 & 1.32 & 0.10 & 0.05 & 5.78 & 0.40 & 1.14 & 0.20 & 3.87 & 1.61 & 0.08 & 0.02 & 20.55 & 6.56 & 15.81 & 8.91 & 0.24 & 0.15 & 100.17 & \\
\hline Van7-86-25 & $4 \mathrm{R}$ & 9 & 52.23 & 0.31 & 0.16 & 0.02 & 5.18 & 0.26 & 1.06 & 0.05 & 2.41 & 0.28 & 0.07 & 0.01 & 16.12 & 0.50 & 22.60 & 0.71 & 0.32 & 0.05 & 100.15 & \\
\hline Van7-86-27 & $1 \mathrm{C}$ & 12 & 51.65 & 0.82 & 0.21 & 0.05 & 6.33 & 0.21 & 1.15 & 0.10 & 3.55 & 1.19 & 0.11 & 0.02 & 18.29 & 4.25 & 19.04 & 5.95 & 0.27 & 0.10 & 100.60 & \\
\hline Van7-86-27 & $1 \mathrm{R}$ & 10 & 51.47 & 0.13 & 0.24 & 0.04 & 5.75 & 0.11 & 0.97 & 0.02 & 2.99 & 0.47 & 0.08 & 0.46 & 16.36 & 0.07 & 22.29 & 0.29 & 0.30 & 0.00 & 100.44 & \\
\hline Van7-86-27 & $2 \mathrm{I}$ & 17 & 51.89 & 1.92 & 0.22 & 0.03 & 5.60 & 2.12 & 0.97 & 0.55 & 2.99 & 0.48 & 0.09 & 0.02 & 17.27 & 0.91 & 21.21 & 2.08 & 0.34 & 0.24 & 100.57 & \\
\hline Van7-86-27 & $3 \mathrm{C}$ & 10 & 51.42 & 0.34 & 0.23 & 0.02 & 5.93 & 0.10 & 1.06 & 0.0 & 2.88 & 0.24 & 0.10 & 0.02 & 16.20 & 0.61 & 22.33 & 0.85 & 0.30 & 0.03 & 100.45 & \\
\hline Van7-86-27 & $3 \mathrm{R}$ & 13 & 51.77 & 0.55 & 0.29 & 0.08 & 5.40 & 0.34 & 0.98 & 0.06 & 2.51 & 0.28 & 0.08 & 0.02 & 16.10 & 0.78 & 23.10 & 1.10 & 0.25 & 0.04 & 100.49 & \\
\hline Van7-86-28 & $1 \mathrm{C}$ & 10 & 51.31 & 0.73 & 0.14 & 0.03 & 6.14 & 0.15 & 1.11 & 0.09 & 4.14 & 1.46 & 0.05 & 0.03 & 19.95 & 4.75 & 16.41 & 6.79 & 0.14 & 0.09 & 99.39 & \\
\hline Van7-86-28 & $1 \mathrm{R}$ & 9 & 50.93 & 0.46 & 0.19 & 0.02 & 5.72 & 0.17 & 1.04 & 0.04 & 2.93 & 0.38 & 0.05 & 0.02 & 16.50 & 1.41 & 21.63 & 1.97 & 0.22 & 0.05 & 99.21 & \\
\hline Van7-86-28 & $2 \mathrm{I}$ & 9 & 51.15 & 0.24 & 0.20 & 0.02 & 5.33 & 0.25 & 0.96 & 0.09 & 2.75 & 0.41 & 0.04 & 0.02 & 16.53 & 0.84 & 21.94 & 1.29 & 0.21 & 0.04 & 99.11 & \\
\hline Van7-86-28 & $3 \mathrm{C}$ & 10 & 50.74 & 0.26 & 0.18 & 0.01 & 5.99 & 0.16 & 1.17 & 0.02 & 3.01 & 0.28 & 0.06 & 0.02 & 16.37 & 0.72 & 21.31 & 0.96 & 0.19 & 0.04 & 99.03 & \\
\hline Van7-86-28 & $3 \mathrm{R}$ & 10 & 51.13 & 0.34 & 0.19 & 0.02 & 5.70 & 0.31 & 1.11 & 0.05 & 2.61 & 0.19 & 0.09 & 0.02 & 15.54 & 0.30 & 22.37 & 0.41 & 0.33 & 0.04 & 99.05 & \\
\hline Van7-86-28 & $4 \mathrm{I}$ & 9 & 51.25 & 0.62 & 0.19 & 0.03 & 5.48 & 0.54 & 1.00 & 0.06 & 3.17 & 0.85 & 0.04 & 0.02 & 17.02 & 2.18 & 21.00 & 3.54 & 0.22 & 0.07 & 99.37 & \\
\hline Van7-86-30 & $1 \mathrm{C}$ & 7 & 50.85 & 0.63 & 0.17 & 0.02 & 5.90 & 0.09 & 1.16 & 0.04 & 3.14 & 0.46 & 0.04 & 0.02 & 17.68 & 2.19 & 19.64 & 3.02 & 0.24 & 0.07 & 98.83 & \\
\hline Van7-86-30 & $1 \mathrm{R}$ & 8 & 51.37 & 0.68 & 0.18 & 0.02 & 5.39 & 0.21 & 1.08 & 0.04 & 2.79 & 0.21 & 0.05 & 0.01 & 17.02 & 1.15 & 21.00 & 1.81 & 0.28 & 0.02 & 99.15 & \\
\hline Van7-86-30 & $2 \mathrm{I}$ & 10 & 51.63 & 0.56 & 0.20 & 0.03 & 5.56 & 0.07 & 1.08 & 0.04 & 2.89 & 0.45 & 0.05 & 0.03 & 16.92 & 1.64 & 21.73 & 2.18 & 0.28 & 0.07 & 100.33 & \\
\hline
\end{tabular}


Table 5.6: Cpx major elements Cont.

\begin{tabular}{|c|c|c|c|c|c|c|c|c|c|c|c|c|c|c|c|c|c|c|c|c|c|c|}
\hline Analysis & $\mathrm{rn}^{a}$ & Pts & $\mathrm{SiO}_{2}$ & \pm & $\mathrm{TiO}_{2}$ & \pm & $\mathrm{Al}_{2} \mathrm{O}_{3}$ & \pm & $\mathrm{Cr}_{2} \mathrm{O}_{3}$ & $3 \pm$ & $\mathrm{FeO}$ & \pm & $\mathrm{nO}$ & \pm & $\mathrm{MgO}$ & \pm & $\mathrm{CaO}$ & \pm & $\mathrm{Na}_{2} \mathrm{O}$ & \pm & otal & Tot \\
\hline Van7-86-30 & $3 I$ & 9 & 52.18 & 42 & 0.21 & 0.01 & 5.12 & 0.21 & 92 & 0.05 & 2.69 & 0.24 & 0.05 & 0.02 & 16.88 & 0.60 & 22.03 & 0.79 & 0.27 & 0.04 & 100.36 & \\
\hline Van7-86-37 & & 10 & 52.44 & 0.47 & 0.15 & 0.02 & 5.07 & 010 & 1.47 & 0.08 & 2.97 & 0.47 & 0.09 & 0.03 & 17.44 & 1.92 & 19.90 & 2.35 & 0.57 & 0.08 & 100.10 & \\
\hline & & 6 & & & & & & 0.13 & & 0.03 & 2.79 & 0.09 & 0.05 & 0.02 & & 0.22 & & 0.37 & 53 & 0.05 & & \\
\hline & & 9 & & 27 & 17 & 0.02 & 01 & 0.13 & 37 & 0.05 & .70 & 0.23 & 0.07 & 0.02 & 3.27 & 0.62 & 21.60 & 0.70 & .55 & 0.03 & 99.77 & \\
\hline $5-09$ & & 10 & .27 & 0.54 & 37 & 0.05 & 43 & 0.27 & 0.40 & 0.03 & 3.81 & 0.69 & 0.12 & 0.03 & 17.12 & 3.06 & 19.29 & 4.00 & .47 & 0.12 & 99.28 & $y x V n$ \\
\hline Van7-96-09 & & 10 & 50.56 & 0.28 & 0.44 & 0.04 & 6.35 & 0.21 & 0.42 & 0.02 & 3.40 & 0.30 & 0.13 & 0.03 & 16.04 & 1.28 & 21.23 & 1.66 & 0.47 & 0.06 & 99.05 & \\
\hline Van7-96-09 & & 11 & 49.71 & 0.29 & 0.37 & 0.03 & 8.30 & 0.15 & 0.38 & 0.02 & 3.53 & 0.26 & 0.14 & 0.01 & 15.65 & 1.30 & 20.69 & 1.73 & .58 & 0.06 & 99.36 & $y x V n$ \\
\hline Van7- & & 10 & 50.50 & 0.32 & 0.50 & 0.08 & 6.36 & 0.47 & 0.45 & 0.04 & 3.24 & 0.22 & 0.14 & 0.02 & 16.00 & 0.70 & 21.57 & 0.87 & 49 & 0.04 & 99.26 & $x \mathrm{Vn}$ \\
\hline-09 & & 10 & .04 & 0 & 35 & 0.1 & 44 & 0.33 & 87 & 0.10 & 3.70 & 1.11 & 0.10 & 0.02 & 18.54 & 5.32 & 17.17 & 6.85 & .52 & 0.22 & 53 & \\
\hline & & 11 & 33 & 0 & 56 & 0.0 & 48 & 0.28 & 0.58 & 0.0 & 3.23 & 0.11 & 0.12 & 0.02 & & 0.44 & & 0.47 & & 0.03 & & \\
\hline Van7-96-14 & & 12 & 51.16 & 0.62 & 0.72 & 0.10 & 6.39 & 0.28 & 0.43 & 0.02 & 3.96 & 0.72 & 0.14 & 0.02 & 17.11 & 2.48 & 20.08 & 3.29 & 0.51 & 0.10 & & $y x V n$ \\
\hline & & 12 & 52.03 & 0.22 & 0.86 & 0.04 & 4.44 & 0.27 & 0.55 & 0.04 & 3.11 & 0.09 & 0.12 & 0.02 & 16.05 & 0.16 & 22.87 & 0.22 & 2 & 0.04 & 54 & $\mathrm{x} \mathrm{x} \mathrm{n}$ \\
\hline & & 13 & 72 & 0 & 52 & 0.1 & 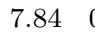 & 0.2 & 0.25 & 0.0 & 35 & 1. & 0 . & 0.0 & 17.44 & 4.25 & 18.78 & 5.8 & & 0.16 & & \\
\hline & & 19 & .38 & . & 74 & 0.0 & 86 & 0.38 & 50 & 0.0 & 3.69 & 0.4 & 0.14 & 0.0 & 16.32 & $1.3^{3}$ & 21.24 & 1.8 & & 0.07 & & \\
\hline & & 12 & .85 & 0 & 77 & 0.1 & 43 & 0.3 & & 0.0 & 71 & 0.62 & 0.1 & 0.1 & 16.37 & 1.98 & 20.36 & 2.71 & & 0.09 & & \\
\hline & & 15 & 50.75 & 13 & 1.16 & 0.2 & 608 & 0.94 & 0.57 & 0.0 & 3.63 & 1.1 & & 0.0 & & 4.18 & 20.22 & 5. & & 0 & & \\
\hline & & 19 & 1 & 0.6 & 0.52 & 0.09 & 8.07 & 0.79 & 0.29 & 0.0 & 3.78 & 0.74 & & 0.0 & 00 & 2.70 & 20.72 & 3. & & 0.09 & & \\
\hline & & 16 & & 0 & 0.70 & 0.0 & & 0.2 & & 0.0 & 34 & 0. & 0. & 0.1 & & 0.5 & 22.00 & 0 . & & 0. & & \\
\hline$V_{a}$ & & 16 & 69 & 1.3 & 54 & 0.1 & 50 & 0.90 & .37 & 0.0 & 3.94 & 1.3 & 0.15 & 0.0 & 17.83 & 5.4 & 18.40 & 7. & & 0.17 & & \\
\hline & & 10 & .26 & ( & 1.24 & 0.0 & 99 & 0.26 & 91 & 0.0 & 09 & 0.14 & 0.13 & 0.02 & 16.60 & 0.55 & 21.75 & 0. & & 0.06 & & $\mathrm{Vn}$ \\
\hline Van7- & & 12 & 52.24 & 0.43 & 0.89 & 0.08 & 4.43 & 0.50 & 0.65 & 0.05 & 3.06 & 0.15 & 0.13 & 0.02 & 16.58 & 0.28 & 22.05 & 0.33 & 9 & 0.03 & & $\mathrm{x} V \mathrm{n}$ \\
\hline & & 10 & & & & & & 0.6 & & 0.0 & & & & 0.0 & & & & 2. & & & & \\
\hline & & 11 & 99 & 0 & 58 & 0.0 & 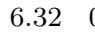 & 0.1 & 0. & 0.0 & 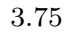 & 0.6 & 0 . & $0 .(1$ & 39 & 1.8 & 21.77 & 2. & .43 & 0.08 & & \\
\hline & & 12 & & 1.5 & 44 & 0.1 & & 0.9 & 0.28 & 0.0 & 4.72 & 1.7 & 0. & 0.0 & 35 & 6.1 & 17.92 & 8. & & 0.20 & & \\
\hline & & 12 & & & 00 & 0.1 & 22 & 1.0 & 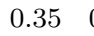 & 0. & 06 & 1.30 & 0.12 & 0.03 & 17.19 & 4.30 & 20.75 & 5.73 & & 0.13 & & Vn \\
\hline Van7-96-16 & 10 & 13 & 50.08 & 0.52 & 0.56 & 0.06 & 8.28 & 0.16 & 0.56 & 0.04 & 3.46 & 0.50 & 0.14 & 0.02 & 15.41 & 1.78 & 21.38 & 2.44 & .54 & 0.09 & & $y x V n$ \\
\hline & 11 & 13 & & 0.51 & 1.01 & 0.12 & 5.73 & 0.50 & 0.72 & 0.06 & 2.76 & 0.15 & 0.10 & 0.02 & & 0.29 & 22.74 & 0.48 & & 0.03 & & $y x V n$ \\
\hline & & 14 & & & 076 & 0.1 & & 0.3 & 061 & 0.0 & & 0. & & 0.0 & & 1. & 20.35 & 2. & & 0. & & \\
\hline & & 10 & & 0.6 & 0.65 & 0.0 & 6.1 & 0.8 & O & 0.0 & 2 & 0.2 & 0. & 0.0 & 15 & 0.5 & 22.18 & 1. & & 0.1 & & \\
\hline & & 11 & 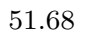 & & 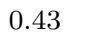 & 0 & & 1.12 & & 0. & U & 1.6 & & & & 5.66 & 17.29 & 7.96 & & 0.16 & & \\
\hline Van7-96-16 & 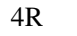 & 12 & 51.12 & 0.41 & 0.71 & 0.03 & 5.88 & 0.37 & 0.44 & 0.03 & 3.50 & 0.15 & 0.12 & 0.02 & 16.02 & 0.27 & 22.28 & 0.64 & .36 & 0.03 & 100.42 & $y x V n$ \\
\hline Van7-96-16 & $5 \mathrm{C}$ & 8 & 50.83 & 0.61 & 0.63 & 0.06 & 7.08 & 0.75 & 0.44 & 0.04 & 3.40 & 0.44 & 0.12 & 0.02 & 15.93 & 1.65 & 21.80 & 2.39 & .44 & 0.07 & 100.68 & $y x V n$ \\
\hline & & 9 & 50.81 & 0.6 & 1.18 & 0.11 & 5.88 & 0.25 & 0.64 & 0.03 & 3.08 & 0.17 & 0.1 & 0.03 & 16.13 & 0.66 & 21.76 & 1.06 & 7 & 0.06 & 10 & $x \vee n$ \\
\hline & & 9 & & 0.4 & 0.47 & 0.0 & 7.78 & 0.34 & & & 3.47 & 0.2 & $0 .($ & 0.0 & 15.20 & 0.9 & 21.36 & 1.07 & & & & at \\
\hline & & 10 & & & & & & 0.28 & & & & & & 0.0 & & & 21.10 & 1.44 & & & & \\
\hline & & 9 & & & & & & 0.32 & & & & & & 0.01 & & 0.53 & & 0.46 & & & & \\
\hline Van7-96-18 & 31 & 9 & 50.05 & 0.32 & 0.47 & 0.03 & 7.64 & 0.15 & & & 3.75 & 0.37 & 0.11 & 0.03 & 16.09 & 1.62 & 20.02 & 1.78 & 1.06 & 0.14 & 99.19 & NrMat \\
\hline Van7-96-18 & $4 \mathrm{I}$ & 9 & 50.58 & 0.22 & 0.50 & 0.02 & 7.62 & 0.12 & & & 3.65 & 0.15 & 0.10 & 0.02 & 15.63 & 0.49 & 20.56 & 0.67 & 1.22 & 0.07 & 99.87 & NrMat \\
\hline Van7-96-18 & $6 \mathrm{C}$ & 10 & 49.99 & 1.08 & 0.32 & 0.11 & 8.30 & 0.25 & & & 4.99 & 1.48 & 0.15 & 0.02 & 19.04 & 5.71 & 16.54 & 7.65 & 0.45 & 0.25 & 99.78 & PyxVn \\
\hline
\end{tabular}


Table 5.6: Cpx major elements Cont.

\begin{tabular}{|c|c|c|c|c|c|c|c|c|c|c|c|c|c|c|c|c|c|c|c|c|c|c|}
\hline Analysis & $\mathrm{rn}^{a}$ & Pts & $\mathrm{SiO}_{2}$ & \pm & $\mathrm{TiO}_{2}$ & \pm & $\mathrm{Al}_{2} \mathrm{O}_{3}$ & $3 \pm$ & $\mathrm{Cr}_{2} \mathrm{O}_{3}$ & $3 \pm$ & $\mathrm{FeO}$ & \pm & $\mathrm{MnO}$ & \pm & $\mathrm{MgO}$ & \pm & $\mathrm{CaO}$ & \pm & $\mathrm{Na}_{2} \mathrm{O}$ & \pm & Total & Notes $^{b}$ \\
\hline Van7-96-18 & $6 \mathrm{R}$ & 10 & 50.20 & 0.32 & 0.64 & 0.08 & 5.91 & 0.29 & & & 3.66 & 0.14 & 0.11 & 0.01 & 15.75 & 0.35 & 22.44 & 0.43 & 0.55 & 0.04 & 99.27 & $y x V n$ \\
\hline Van7-96-18 & C & 10 & 49.37 & 0.22 & 0.41 & 0.02 & 7.98 & 0.11 & & & 3.89 & 0.15 & 0.10 & 0.02 & 15.44 & 0.59 & 21.71 & 0.63 & 0.51 & 0.04 & 99.42 & $y x V n$ \\
\hline Van7-96-18 & $7 \mathrm{R}$ & 10 & 49.93 & 0.25 & 0.63 & 0.04 & 6.83 & 0.24 & & & 3.81 & 0.14 & 0.10 & 0.03 & 15.82 & 0.28 & 21.82 & 0.44 & 0.54 & 0.04 & 99.48 & $y x V n$ \\
\hline Van7-96-18 & I & 8 & 51.23 & 0.60 & 0.50 & 0.03 & 35 & 0.08 & & & .47 & 0.33 & 0.10 & 0.02 & 16.49 & 0.79 & 21.86 & 0.91 & .49 & 0.06 & & $y x V n$ \\
\hline Van7-96-19 & $\mathrm{C}$ & 7 & 50.44 & 1.04 & 0.47 & 0.12 & 7.29 & 0.31 & & & 3.63 & 1.26 & 0.10 & 0.02 & 18.88 & 4.89 & 17.68 & 6.17 & .53 & 0.24 & 99.02 & IrMat \\
\hline Van7-96-19 & n & 5 & 49.94 & 0.18 & 0.78 & 0.02 & 6.70 & 0.09 & & & 2.79 & 0.18 & 0.07 & 0.03 & 16.16 & 0.28 & 21.77 & 0.39 & 0.66 & 0.08 & 88 & rMat \\
\hline Van7-96-19 & $2 \mathrm{C}$ & 9 & 50.39 & 0.41 & 0.60 & 0.04 & 6.83 & 0.27 & & & 2.76 & 0.28 & 0.09 & 0.02 & 16.06 & 1.29 & 21.64 & 1.54 & 0.73 & 0.09 & 99.11 & NrMat \\
\hline Van7-96-19 & $2 \mathrm{R}$ & 8 & 51.18 & 0.73 & 0.76 & 0.06 & 5.37 & 0.85 & & & 2.77 & 0.20 & 0.09 & 0.02 & 16.41 & 0.48 & 22.65 & 0.88 & 0.55 & 0.11 & 99.79 & rMat \\
\hline 5-19 & 31 & 10 & 51.39 & 0.22 & 0.71 & 0.05 & 5.83 & 0.26 & & & 2.76 & 0.34 & 0.08 & 0.01 & 16.63 & 1.41 & 22.24 & 1.80 & .68 & 0.08 & 00.34 & Mat \\
\hline Van7-96-19 & $\mathrm{C}$ & 9 & 51.08 & 0.48 & 0.61 & 0.08 & 6.31 & 0.35 & 1.19 & 0.06 & 3.06 & 0.68 & 0.07 & 0.01 & 16.06 & 1.89 & 21.06 & 2.84 & 0.53 & 0.08 & & $x V n$ \\
\hline Van7-96-19 & $\mathrm{R}$ & 10 & 51.15 & 0.32 & 0.82 & 0.04 & 5.66 & 0.49 & 1.26 & 0.03 & 2.55 & 0.13 & 0.07 & 0.02 & 15.53 & 0.28 & 22.27 & 0.56 & 0.56 & 0.04 & 99.86 & $y x V n$ \\
\hline Van7-96-19 & $6 \mathrm{I}$ & 10 & 51.83 & 0.23 & 0.59 & 0.03 & 5.00 & 0.24 & 1.30 & 0.05 & 2.96 & 0.20 & 0.08 & 0.01 & 15.94 & 0.59 & 21.66 & 0.73 & 0.55 & 0.04 & 99.90 & $y x V n$ \\
\hline Va & $7 \mathrm{C}$ & 9 & 50.88 & 0.2 & 0.48 & 0.05 & 6.70 & 0.08 & & & 3.73 & 0.52 & 0.09 & 0.02 & 17.76 & 1.60 & 19.31 & 2.48 & 0.55 & 0.07 & 1 & $\mathrm{Vn}$ \\
\hline $\mathrm{Va}$ & $7 \mathrm{R}$ & 7 & 51.32 & 0.4 & 0.58 & 0.03 & 5.63 & 0.30 & & & 2.94 & 0.11 & 0.08 & 0.01 & 16.35 & 0.28 & 22.23 & 0.35 & 0.62 & 0.05 & 99 & $\mathrm{Vn}$ \\
\hline & & 10 & 50.54 & 0.2 & 0.50 & 0.03 & 7.16 & 0.13 & 1.20 & 0.04 & 2.98 & 0.22 & 0.08 & 0.02 & 15.10 & 0.64 & 21.81 & 0.83 & 0.56 & 0.06 & & Vn \\
\hline Van7-96-19 & & 8 & 51.33 & 0.50 & 0.51 & 0.05 & 5.68 & 0.23 & 1.35 & 0.05 & 2.93 & 0.37 & 0.09 & 0.02 & & 1.20 & & 1.47 & & 0.04 & & Vn \\
\hline Van7- & $9 \mathrm{C}$ & 9 & 50.81 & 0.64 & 0.46 & 0.05 & 6.60 & 0.44 & 1.34 & 0.05 & 2.88 & 0.16 & 0.08 & 0.02 & 15.17 & 0.55 & 21.87 & 0.60 & 0.62 & 0.04 & & $\mathrm{jVn}$ \\
\hline $\mathrm{Va}$ & $\mathrm{R}$ & 8 & 51.09 & 0.3 & 0.63 & 0.06 & 5.96 & 0.46 & 1.33 & 0.07 & 2.78 & 0.16 & 0.07 & 0.0 & 15.45 & 0.3 & 22.07 & 0.42 & 0.60 & 0.05 & & $\mathrm{nn}$ \\
\hline Van & $1 \mathrm{C}$ & 14 & 50.72 & 0.7 & 0.50 & 0.10 & 7.45 & 0.31 & 0.95 & 0.06 & 3.47 & 0.81 & 0.10 & 0.0 & 16.93 & 3.32 & 19.43 & 4.44 & 0.65 & 0.16 & 100.20 & $\mathrm{Vn}$ \\
\hline Van7 & $4 \mathrm{C}$ & 8 & 50.57 & 0.28 & 0.50 & 0.06 & 7.57 & 0.32 & 1.00 & 0.03 & 3.30 & 0.34 & 0.10 & 0.01 & 16.44 & 1.24 & 20.19 & 1.49 & 0.67 & 0.06 & & $\mathrm{j} \mathrm{Vn}$ \\
\hline Van7-96-21 & $\mathrm{R}$ & 11 & 50.47 & 0.96 & 0.54 & 0.19 & 7.42 & 0.38 & 0.94 & 0.09 & 3.54 & 1.30 & 0.10 & 0.03 & 16.91 & 4.96 & 19.51 & 6.65 & 0.68 & 0.24 & 100.11 & $\operatorname{Adj} V n$ \\
\hline & & 10 & 5008 & 0 & & 0.0 & 7.92 & 0.28 & 0.99 & 0.0 & & 0.37 & & 0.0 & & 1. & & 1. & & 0.08 & & \\
\hline Van & $5 \mathrm{R}$ & 10 & 50.34 & 0.4 & 0.60 & 0.0 & 7.43 & 0.25 & 0.96 & 0.03 & 2. & 0.17 & 0.09 & 0.0 & 14.47 & 0.24 & 22.73 & 0.24 & 0.77 & 0.06 & 100.25 & AdjVn \\
\hline Van & 10 & 6 & 51.39 & 0.34 & 0.36 & 0.0 & 6.96 & 0.26 & & & 3.32 & 0.23 & 0.08 & 0.0 & 15.11 & 0.81 & 20.51 & 0.77 & 1.44 & 0.10 & 99.18 & \\
\hline Van7-96-25 & 2 & 8 & 51.27 & 0.44 & 0.35 & 0.02 & 6.72 & 0.31 & 0.98 & 0.03 & 3.16 & 0.18 & 0.06 & 0.02 & 14.83 & 0.69 & 20.21 & 0.80 & 1.34 & 0.05 & 98.92 & \\
\hline Van7-96-25 & 31 & 10 & 51.15 & 0.26 & 0.37 & 0.02 & 7.08 & 0.14 & 1.01 & 0.03 & 3.39 & 0.11 & 0.07 & 0.02 & 14.90 & 0.44 & 19.89 & 0.54 & 1.31 & 0.09 & 99.17 & \\
\hline Van7-96-25 & 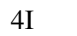 & 9 & 50.89 & 0.26 & 0.36 & 0.02 & 7.26 & 0.16 & 1.12 & 0.04 & 3.35 & 0.28 & 0.06 & 0.02 & 14.55 & 0.84 & 20.27 & 1.05 & 1.29 & 0.11 & 99.14 & \\
\hline$Y=7$ & & 10 & 5105 & 0.36 & 0.33 & 0.03 & 7.32 & 0.20 & 105 & 0.05 & & 0.40 & 0.08 & 0.01 & & 1.37 & 19.42 & 1.69 & 1.29 & 0.15 & & \\
\hline $\mathrm{Va}$ & & 10 & 2 & 0.1 & 0 & 0.0 & 7.05 & 0.2 & 1.08 & 0.0 & $3:$ & 0.2 & 0.0 & 0.0 & 14.43 & 0.8 & 20.77 & 1.05 & 1.16 & 0.10 & 99.05 & \\
\hline Van7 & 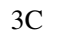 & 10 & 51.23 & 0.54 & 0.30 & 0.0 & 6.67 & 0.21 & 1.36 & 0.10 & 3.26 & 0.85 & 0.08 & 0.02 & 16.21 & 3.48 & 18.99 & 4.32 & 1.03 & 0.26 & 99.13 & \\
\hline Van7-96-28 & $3 \mathrm{R}$ & 8 & 51.18 & 0.94 & 0.37 & 0.09 & 6.79 & 0.52 & & & 3.50 & 1.26 & 0.08 & 0.02 & 16.88 & 4.45 & 19.17 & 5.64 & 0.96 & 0.37 & 98.93 & \\
\hline Van7-96-28 & $4 \mathrm{I}$ & 10 & 51.18 & 0.37 & 0.36 & 0.04 & 6.65 & 0.13 & & & 3.24 & 0.37 & 0.07 & 0.02 & 16.13 & 1.39 & 20.68 & 1.67 & 0.97 & 0.09 & 99.30 & \\
\hline Van7-96-28 & $C^{2}$ & 8 & 51.19 & 0.46 & 0.37 & 0.05 & 7.22 & 0.39 & & & 3.23 & 0.45 & 0.06 & 0.02 & 16.06 & 1.47 & 20.24 & 1.87 & 1.11 & 0.10 & 99.51 & \\
\hline $\operatorname{Van} 7-96-28$ & $5 \mathrm{R}$ & 9 & 0 & 0.1 & 0.3 & 0.0 & 6.75 & 0.12 & 2 & 0.0 & 2.8 & 0.21 & $0 .($ & 0.0 & $14.5^{5}$ & 0.6 & 21.22 & 0.76 & 1. & 0.09 & 99.23 & \\
\hline Van7-96-28 & bl & 10 & 51.59 & 0.52 & 0.3 & 0.0 & 6.42 & 0.31 & 1.27 & 0.06 & 3.13 & 0.56 & & 0.01 & & 2.35 & & 2.69 & 1.13 & 0.17 & & \\
\hline Van7-96-35 & $3 \mathrm{C}$ & 8 & 52.10 & 0.44 & 0.31 & 0.02 & 5.37 & 0.12 & 1.73 & & 2.63 & 0.20 & 0.09 & 0.02 & 16.03 & 1.04 & 20.33 & 1.17 & 1.38 & 0.07 & 99.98 & \\
\hline Van7-96-35 & $3 R$ & 9 & 51.90 & 0.33 & 0.33 & 0.02 & 5.46 & 0.09 & 1.73 & 0.04 & 2.61 & 0.21 & 0.09 & 0.02 & 15.91 & 1.01 & 20.28 & 0.99 & 1.39 & 0.08 & 99.72 & \\
\hline Van7-96-35 & $4 \mathrm{I}$ & 10 & 52.17 & 0.26 & 0.34 & 0.01 & 5.29 & 0.07 & 1.68 & 0.03 & 2.46 & 0.09 & 0.08 & 0.01 & 15.72 & 0.21 & 20.94 & 0.27 & 1.39 & 0.04 & 100.06 & \\
\hline Van7-96-35 & $5 \mathrm{I}$ & 10 & 52.33 & 0.18 & 0.33 & 0.02 & 5.13 & 0.10 & 1.60 & 0.03 & 2.56 & 0.10 & 0.08 & 0.01 & 15.97 & 0.31 & 20.48 & 0.42 & 1.35 & 0.06 & 99.82 & \\
\hline
\end{tabular}


Table 5.6: Cpx major elements Cont.

\begin{tabular}{|c|c|c|c|c|c|c|c|c|c|c|c|c|c|c|c|c|c|c|c|c|c|c|}
\hline Analysis & $\mathrm{Grn}^{a}$ & Pts & $\mathrm{SiO}_{2}$ & \pm & $\mathrm{TiO}_{2}$ & \pm & $\mathrm{Al}_{2} \mathrm{O}_{3}$ & $3 \pm$ & $\mathrm{Cr}_{2} \mathrm{O}_{3}$ & $3 \pm$ & $\mathrm{FeO}$ & \pm & $\mathrm{MnO}$ & \pm & $\mathrm{MgO}$ & \pm & $\mathrm{CaO}$ & \pm & $\mathrm{Na}_{2} \mathrm{O}$ & \pm & Total & Notes $^{b}$ \\
\hline Van7-96-35 & $6 \mathrm{C}$ & 8 & 52.24 & 0.45 & 0.27 & 0.03 & 5.48 & 0.18 & 1.75 & 0.11 & 2.83 & 0.45 & 0.10 & 0.02 & 17.18 & 2.32 & 18.68 & 2.79 & 1.33 & 0.20 & 99.85 & \\
\hline Van7-96-35 & $6 \mathrm{R}$ & 10 & 52.29 & 0.12 & 0.36 & 0.03 & 5.23 & 0.06 & 1.67 & 0.02 & 2.38 & 0.05 & 0.07 & 0.02 & 15.30 & 0.50 & 20.93 & 0.39 & 1.45 & 0.10 & 99.68 & \\
\hline Van7-96-37 & $1 \mathrm{C}$ & 10 & 51.37 & 0.52 & 0.30 & 0.03 & 6.54 & 0.26 & 1.56 & 0.08 & 3.25 & 0.72 & 0.10 & 0.03 & 15.73 & 2.58 & 19.43 & 3.05 & 1.29 & 0.25 & 99.57 & \\
\hline Van7-96-37 & $1 \mathrm{R}$ & 9 & 51.28 & 0.52 & 0.33 & 0.06 & 6.29 & 0.16 & 1.53 & 0.10 & 2.96 & 0.60 & 0.09 & 0.02 & 15.96 & 2.42 & 20.51 & 3.08 & 1.02 & 0.18 & 99.99 & \\
\hline Van7-96-37 & 2I & 6 & 51.38 & 0.45 & 0.32 & 0.02 & 6.51 & 0.14 & 1.48 & 0.06 & 3.34 & 0.47 & 0.11 & 0.04 & 16.01 & 1.80 & 19.93 & 2.13 & 0.94 & 0.13 & 100.01 & \\
\hline Van7-96-37 & $4 \mathrm{I}$ & 6 & 51.53 & 0.80 & 0.37 & 0.04 & 6.50 & 0.24 & 1.44 & 0.06 & 2.85 & 0.41 & 0.10 & 0.03 & 15.00 & 0.91 & 20.90 & 1.30 & 1.35 & 0.07 & 100.05 & \\
\hline Van7-96-37 & $5 \mathrm{C}$ & 9 & 51.93 & 0.77 & 0.32 & 0.06 & 6.70 & 0.22 & 1.56 & 0.13 & 3.56 & 0.89 & 0.14 & 0.04 & 17.53 & 3.47 & 18.00 & 4.19 & 1.25 & 0.29 & 101.00 & \\
\hline Van7-96-37 & $5 \mathrm{R}$ & 10 & 51.56 & 0.56 & 0.33 & 0.06 & 6.30 & 0.20 & 1.45 & 0.10 & 3.24 & 0.62 & 0.13 & 0.04 & 16.47 & 2.45 & 19.29 & 3.07 & 1.17 & 0.19 & 99.94 & \\
\hline Van7-96-38 & $1 \mathrm{C}$ & 11 & 50.81 & 0.42 & 0.44 & 0.05 & 8.16 & 0.26 & 0.92 & 0.06 & 3.44 & 0.81 & 0.08 & 0.04 & 15.64 & 2.94 & 19.01 & 3.56 & 1.32 & 0.26 & 99.82 & \\
\hline Van7-96-38 & $1 \mathrm{R}$ & 13 & 51.00 & 0.43 & 0.48 & 0.07 & 7.88 & 0.44 & 0.89 & 0.07 & 3.40 & 0.88 & 0.09 & 0.02 & 15.62 & 2.54 & 19.09 & 3.33 & 1.22 & 0.24 & 99.67 & \\
\hline Van7-96-38 & $2 \mathrm{C}$ & 10 & 51.25 & 0.89 & 0.39 & 0.14 & 7.62 & 0.53 & 0.85 & 0.11 & 4.04 & 1.70 & 0.11 & 0.03 & 17.68 & 5.52 & 16.49 & 7.18 & 1.12 & 0.44 & 99.55 & \\
\hline Van7-96-38 & $2 \mathrm{R}$ & 10 & 51.13 & 0.17 & 0.49 & 0.02 & 7.66 & 0.10 & 0.84 & 0.02 & 3.35 & 0.16 & 0.10 & 0.02 & 14.98 & 0.54 & 20.14 & 0.58 & 1.15 & 0.09 & 99.84 & \\
\hline Van7-96-66B & 1I & 10 & 48.24 & 1.32 & 0.87 & 0.10 & 9.15 & 1.64 & 0.67 & 0.14 & 4.01 & 0.74 & 0.15 & 0.06 & 15.24 & 1.97 & 21.00 & 2.89 & 0.56 & 0.11 & 99.88 & OpxVn \\
\hline $\operatorname{Van} 7-96-66 B$ & 2I & 10 & 49.53 & 0.50 & 0.74 & 0.04 & 7.82 & 0.26 & 0.62 & 0.04 & 3.55 & 0.34 & 0.12 & 0.03 & 14.95 & 0.81 & 22.12 & 1.10 & 0.58 & 0.08 & 100.03 & OpxVn \\
\hline Van7-96-66B & $3 I$ & 10 & 50.10 & 0.47 & 0.86 & 0.08 & 6.84 & 0.28 & 0.74 & 0.06 & 3.72 & 0.67 & 0.13 & 0.04 & 16.26 & 1.88 & 20.99 & 2.56 & 0.55 & 0.08 & 100.19 & OpxVn \\
\hline Van7-96-66B & $5 \mathrm{C}$ & 10 & 50.92 & 0.99 & 0.17 & 0.05 & 7.92 & 0.62 & 0.13 & 0.03 & 4.52 & 1.39 & 0.15 & 0.03 & 15.81 & 4.27 & 20.28 & 5.70 & 0.65 & 0.19 & 100.55 & Brecci \\
\hline $\operatorname{Van} 7-96-66 B$ & $5 \mathrm{R}$ & 8 & 49.94 & 0.58 & 0.18 & 0.01 & 9.13 & 0.56 & 0.14 & 0.02 & 4.47 & 0.33 & 0.12 & 0.03 & 14.89 & 1.39 & 20.84 & 1.96 & 0.70 & 0.06 & 100.39 & Breccia \\
\hline
\end{tabular}

$\mathrm{N} \quad{ }^{a}$ Grain number; core (C), rim (R), interstitial (I) or symplectite (S). Interstitial grains are $<1 \mathrm{~mm}$ diameter. L preceding a grain number indicates Lee $[1997)$ data for dredge RC27-9-6 samples.

${ }^{b}$ Abbreviations for lithologies (blank indicates residual peridotite): Dep, Trans and Enr are depleted, transitional and enriched zones in cryptically metasomatized samples; GbVn refers to a

gabbroic vein, PyxVn to a pyroxenite vein, $\mathrm{CpxVn}$ to a clinopyroxenite vein, and OpxVn to an orthopyroxenite vein; AdjVn is adjacent to a vein, $\mathrm{NrMat}$ is $<5 \mathrm{~cm}$ from a vein and FarMat is

$>5 \mathrm{~cm}$ from a vein. 
Table 5.7: Major element composition of spinels, in wt\%.

\begin{tabular}{|c|c|c|c|c|c|c|c|c|c|c|c|c|c|c|c|c|c|c|c|c|c|c|}
\hline Sample & $\mathrm{Grn}^{a}$ & Pts & $\mathrm{TiO}_{2}$ & \pm & $\mathrm{Al}_{2} \mathrm{O}_{3}$ & \pm & $\mathrm{Cr}_{2} \mathrm{O}_{3}$ & \pm & $\mathrm{Fe}_{2} \mathrm{O}_{3}$ & \pm & $\mathrm{FeO}$ & \pm & $\mathrm{MnO}$ & \pm & $\mathrm{MgO}$ & \pm & $\mathrm{NiO}$ & \pm & $\mathrm{ZnO}$ & \pm & Total & Notes $^{b}$ \\
\hline $6 \mathrm{~K}-458-1$ & 1 & 5 & 0.07 & 0.06 & 48.28 & 1.62 & 21.93 & 1.91 & 0.30 & 0.27 & 11.30 & 0.31 & 0.12 & 0.04 & 18.49 & 0.33 & 0.27 & 0.04 & 0.00 & 0.00 & 100.80 & \\
\hline $6 \mathrm{~K}-458-3$ & 1 & 6 & 0.05 & 0.01 & 55.41 & 0.41 & 14.72 & 0.52 & 0.00 & 0.00 & 11.33 & 0.15 & 0.15 & 0.03 & 18.90 & 0.19 & 0.32 & 0.02 & 0.12 & 0.04 & 101.06 & \\
\hline $6 \mathrm{~K}-465-2$ & 1 & 6 & 0.17 & 0.01 & 46.54 & 0.27 & 20.02 & 0.22 & 4.06 & 0.58 & 9.34 & 0.56 & 0.08 & 0.02 & 19.50 & 0.32 & 0.27 & 0.02 & & & 99.99 & Dep \\
\hline $6 \mathrm{~K}-465-2$ & 2 & 6 & 0.29 & 0.02 & 28.89 & 1.05 & 37.78 & 0.59 & 2.55 & 0.56 & 16.49 & 0.49 & 0.25 & 0.04 & 12.89 & 0.17 & 0.11 & 0.03 & & & 99.34 & Dep \\
\hline $6 \mathrm{~K}-465-2$ & 3 & 6 & 0.26 & 0.03 & 39.47 & 1.12 & 28.23 & 1.18 & 1.58 & 0.33 & 13.18 & 0.26 & 0.17 & 0.02 & 16.16 & 0.26 & 0.18 & 0.02 & & & 99.25 & Dep \\
\hline $6 \mathrm{~K}-465-3$ & 1 & 4 & 0.59 & 0.03 & 38.38 & 0.31 & 21.70 & 0.46 & 5.79 & 0.37 & 20.50 & 0.18 & 0.28 & 0.04 & 11.24 & 0.07 & 0.20 & 0.03 & & & 98.72 & NrMat \\
\hline $6 \mathrm{~K}-465-3$ & 4 & 7 & 0.50 & 0.13 & 43.85 & 4.56 & 23.59 & 4.27 & 1.37 & 0.42 & 13.09 & 1.32 & 0.14 & 0.04 & 16.92 & 1.22 & 0.27 & 0.04 & & & 99.82 & NrMat \\
\hline $6 \mathrm{~K}-466-1$ & 1 & 6 & 0.10 & 0.02 & 48.21 & 0.16 & 19.61 & 0.16 & 2.97 & 0.31 & 8.47 & 0.15 & 0.09 & 0.02 & 20.17 & 0.14 & 0.29 & 0.02 & & & 99.92 & \\
\hline $6 \mathrm{~K}-643-13$ & 1 & 4 & 0.02 & 0.03 & 47.53 & 0.31 & 20.85 & 0.14 & 1.18 & 0.19 & 10.78 & 0.14 & 0.11 & 0.03 & 18.36 & 0.03 & 0.33 & 0.01 & 0.00 & 0.00 & 99.17 & \\
\hline $6 \mathrm{~K}-651-7$ & 1 & 6 & 0.03 & 0.01 & 55.60 & 0.39 & 13.95 & 0.29 & 0.00 & 0.00 & 11.49 & 0.43 & 0.14 & 0.01 & 18.50 & 0.29 & 0.30 & 0.04 & 0.23 & 0.03 & 100.27 & PyxVn \\
\hline JR31-52-3 & 1 & 6 & 0.02 & 0.02 & 53.01 & 0.44 & 16.48 & 0.27 & 0.36 & 0.31 & 11.03 & 0.29 & 0.15 & 0.03 & 19.01 & 0.13 & 0.31 & 0.03 & & & 100.37 & \\
\hline JR31-52-4 & 2 & 6 & 0.09 & 0.11 & 52.57 & 0.18 & 16.07 & 0.31 & 0.00 & 0.00 & 12.13 & 0.26 & 0.12 & 0.03 & 18.08 & 0.14 & 0.28 & 0.03 & & & 99.37 & \\
\hline JR31-52-5 & 1 & 6 & 0.04 & 0.01 & 51.41 & 1.23 & 17.53 & 1.09 & 0.86 & 0.50 & 10.90 & 0.39 & 0.13 & 0.01 & 18.90 & 0.25 & 0.30 & 0.03 & & & 100.09 & \\
\hline JR31-52-8 & 1 & 6 & 0.07 & 0.02 & 52.46 & 0.17 & 16.73 & 0.18 & 0.19 & 0.20 & 11.07 & 0.36 & 0.11 & 0.03 & 18.86 & 0.15 & 0.31 & 0.03 & & & 99.81 & \\
\hline Kn162-19-41 & 1 & 2 & 0.04 & 0.00 & 56.08 & 0.73 & 12.38 & 0.13 & 0.04 & 0.06 & 11.74 & 0.70 & 0.16 & 0.00 & 18.48 & 0.59 & 0.21 & 0.05 & 0.00 & 0.00 & 99.17 & PyxVn \\
\hline Kn162-47-02 & 2 & 6 & 0.00 & 0.00 & 28.67 & 0.95 & 42.95 & 0.97 & 0.00 & 0.00 & 13.95 & 0.68 & 0.15 & 0.04 & 14.05 & 0.25 & 0.03 & 0.01 & 0.17 & 0.04 & 100.00 & \\
\hline Kn162-47-08 & 1 & 6 & 0.00 & 0.00 & 55.59 & 0.33 & 12.90 & 0.23 & 0.80 & 0.24 & 11.07 & 0.21 & 0.09 & 0.02 & 19.20 & 0.18 & 0.26 & 0.02 & 0.10 & 0.05 & 100.01 & \\
\hline Kn162-47-09 & 1 & 6 & 0.05 & 0.01 & 39.67 & 0.63 & 29.82 & 0.72 & 0.33 & 0.15 & 12.63 & 0.15 & 0.17 & 0.02 & 16.47 & 0.10 & 0.17 & 0.02 & 0.16 & 0.04 & 99.48 & \\
\hline Kn162-47-10 & 1 & 6 & 0.07 & 0.02 & 51.56 & 0.42 & 15.78 & 0.39 & 0.69 & 0.36 & 13.23 & 0.43 & 0.15 & 0.02 & 17.24 & 0.32 & 0.25 & 0.04 & 0.01 & 0.01 & 99.04 & PyxVn \\
\hline Kn162-47-10 & 2 & 6 & 0.08 & 0.01 & 52.58 & 0.26 & 15.55 & 0.12 & 0.80 & 0.42 & 11.82 & 0.31 & 0.19 & 0.03 & 18.35 & 0.30 & 0.24 & 0.03 & 0.37 & 0.11 & 100.00 & FarMat \\
\hline Kn162-47-12 & 1 & 6 & 0.07 & 0.02 & 54.36 & 0.34 & 12.70 & 0.46 & 1.31 & 0.13 & 12.00 & 0.15 & 0.13 & 0.01 & 18.36 & 0.12 & 0.26 & 0.03 & 0.01 & 0.01 & 99.21 & PyxVn \\
\hline Kn162-47-22 & 1 & 5 & 0.00 & 0.00 & 55.82 & 0.30 & 13.30 & 0.09 & 0.25 & 0.32 & 11.36 & 0.31 & 0.10 & 0.03 & 19.03 & 0.28 & 0.31 & 0.02 & 0.02 & 0.02 & 100.19 & PyxVn \\
\hline Kn162-47-24 & 1 & 4 & 0.09 & 0.01 & 51.34 & 0.41 & 15.40 & 0.43 & 1.50 & 0.26 & 12.53 & 0.36 & 0.15 & 0.02 & 17.69 & 0.26 & 0.22 & 0.03 & 0.04 & 0.03 & 99.02 & \\
\hline Kn162-47-24 & 3 & 5 & 0.07 & 0.01 & 50.43 & 0.45 & 16.31 & 0.31 & 1.27 & 0.40 & 13.34 & 0.52 & 0.15 & 0.02 & 17.04 & 0.39 & 0.21 & 0.03 & 0.09 & 0.08 & 99.07 & \\
\hline Kn162-47-25 & 1 & 3 & 0.13 & 0.02 & 51.42 & 0.28 & 17.08 & 0.20 & 0.44 & 0.38 & 10.79 & 0.31 & 0.13 & 0.02 & 18.90 & 0.22 & 0.21 & 0.01 & 0.00 & 0.00 & 99.13 & NrMat \\
\hline Kn162-47-26 & 1 & 6 & 0.04 & 0.01 & 57.12 & 0.27 & 11.85 & 0.18 & 0.23 & 0.23 & 10.84 & 0.40 & 0.12 & 0.02 & 19.59 & 0.25 & 0.20 & 0.02 & 0.25 & 0.11 & 100.27 & \\
\hline Kn162-47-29 & 1 & 6 & 0.08 & 0.01 & 52.66 & 0.21 & 16.61 & 0.26 & 0.38 & 0.24 & 11.34 & 0.26 & 0.11 & 0.02 & 18.87 & 0.20 & 0.18 & 0.04 & 0.19 & 0.11 & 100.45 & \\
\hline Kn162-47-36 & 1 & 6 & 0.09 & 0.01 & 55.68 & 0.89 & 13.13 & 0.67 & 0.01 & 0.01 & 14.03 & 0.47 & 0.12 & 0.02 & 17.00 & 0.45 & 0.37 & 0.03 & 0.24 & 0.03 & 100.73 & \\
\hline Kn162-47-49 & 1 & 6 & 0.03 & 0.01 & 52.38 & 0.97 & 14.32 & 0.62 & 1.17 & 0.40 & 13.20 & 0.48 & 0.13 & 0.02 & 17.33 & 0.35 & 0.19 & 0.02 & 0.51 & 0.06 & 99.34 & \\
\hline PS86-6-26 & 1 & 6 & 0.07 & 0.02 & 57.73 & 0.39 & 10.01 & 0.19 & 0.95 & 0.68 & 10.51 & 0.17 & 0.10 & 0.02 & 19.71 & 0.21 & 0.19 & 0.03 & 0.26 & 0.09 & 99.55 & \\
\hline PS86-6-38 & 1 & 3 & 0.05 & 0.02 & 57.31 & 0.10 & 10.84 & 0.12 & 0.58 & 0.51 & 11.15 & 0.15 & 0.10 & 0.01 & 19.23 & 0.06 & 0.33 & 0.01 & 0.00 & 0.00 & 99.58 & \\
\hline PS86-6-39 & 1 & 6 & 0.06 & 0.03 & 51.89 & 0.33 & 16.58 & 0.32 & 0.85 & 0.21 & 11.43 & 0.19 & 0.13 & 0.03 & 18.55 & 0.12 & 0.28 & 0.02 & 0.00 & 0.00 & 99.77 & \\
\hline PS86-6-40 & 1 & 6 & 0.02 & 0.02 & 56.85 & 0.32 & 10.90 & 0.19 & 0.72 & 0.30 & 11.36 & 0.16 & 0.11 & 0.01 & 18.97 & 0.09 & 0.31 & 0.03 & 0.00 & 0.00 & 99.24 & \\
\hline RC27-9-6-2 & L1 & 5 & 0.18 & 0.01 & 25.83 & 0.75 & 41.01 & 1.35 & 3.14 & & 19.06 & 0.41 & 0.28 & 0.03 & 11.71 & 0.20 & 0.09 & 0.02 & & & 101.30 & FarMat \\
\hline RC27-9-6-2 & L3 & 5 & 0.33 & 0.01 & 28.13 & 0.39 & 38.67 & 0.46 & 4.33 & & 15.63 & 0.23 & 0.34 & 0.01 & 13.64 & 0.17 & 0.27 & 0.02 & & & 101.41 & FarMat \\
\hline RC27-9-6-2 & L4 & 5 & 0.17 & 0.02 & 38.57 & 1.29 & 28.31 & 1.40 & 4.26 & & 13.15 & 0.64 & 0.28 & 0.05 & 16.22 & 0.42 & 0.33 & 0.02 & & & 101.38 & FarMat \\
\hline RC27-9-6-2 & L6 & 5 & 0.18 & 0.01 & 40.18 & 0.68 & 27.11 & 0.72 & 3.55 & & 13.44 & 0.12 & 0.27 & 0.03 & 16.24 & 0.28 & 0.32 & 0.04 & & & 101.36 & NrMat \\
\hline RC27-9-6-2 & L9 & 5 & 0.22 & 0.00 & 38.28 & 1.33 & 29.37 & 1.37 & 3.23 & & 13.67 & 0.65 & 0.29 & 0.03 & 15.89 & 0.65 & 0.33 & 0.03 & & & 101.35 & NrMat \\
\hline RC27-9-6-2 & L10 & 6 & 0.03 & 0.02 & 40.64 & 3.78 & 27.45 & 3.56 & 3.02 & & 12.57 & 1.34 & 0.13 & 0.03 & 16.91 & 1.04 & 0.15 & 0.04 & & & 100.93 & CpxVn \\
\hline RC27-9-6-2 & L11 & 5 & 0.19 & 0.01 & 43.67 & 0.89 & 24.08 & 0.88 & 2.56 & & 12.87 & 0.33 & 0.26 & 0.02 & 16.88 & 0.22 & 0.36 & 0.02 & & & 100.93 & $\mathrm{CpxVn}$ \\
\hline
\end{tabular}


Table 5.7: Spinel major elements Cont.

\begin{tabular}{|c|c|c|c|c|c|c|c|c|c|c|c|c|c|c|c|c|c|c|c|c|c|c|}
\hline Sample & $\mathrm{Grn}^{a}$ & Pts & $\mathrm{TiO}_{2}$ & \pm & $\mathrm{Al}_{2} \mathrm{O}_{3}$ & \pm & $\mathrm{Cr}_{2} \mathrm{O}_{3}$ & \pm & $\mathrm{Fe}_{2} \mathrm{O}_{3}$ & \pm & $\mathrm{FeO}$ & \pm & $\mathrm{MnO}$ & \pm & $\mathrm{MgO}$ & \pm & $\mathrm{NiO}$ & \pm & $\mathrm{ZnO}$ & \pm & Total & Notes $^{b}$ \\
\hline RC27-9-6-2 & L12 & 5 & 0.28 & 0.02 & 34.66 & 0.58 & 32.68 & 0.83 & 3.76 & & 4.49 & 0.37 & 0.18 & 0.01 & 15.29 & 0.18 & 0.14 & 0.03 & & & 101.49 & $\mathrm{CpxVn}$ \\
\hline RC27-9-6-2 & L14 & 5 & 15 & 0.01 & 42.11 & 1.33 & 25.29 & 1.05 & 3.36 & & 12.49 & 0.41 & 0.28 & 0.02 & 16.95 & 0.36 & 0.35 & 0.03 & & & 101.05 & NrMat \\
\hline $9-6-2$ & L15 & 5 & 18 & 0.01 & 19 & 0.61 & 31 & 0.42 & 96 & & 73 & .48 & 28 & 0.02 & 16.10 & 0.12 & 0.33 & 0.03 & & & & Mat \\
\hline RC27-9-6-2 & L17 & 5 & 18 & 0.01 & 0.02 & 0.71 & 6.89 & 1.03 & 4.04 & & 2.99 & 0.16 & .27 & 0.02 & 16.48 & 0.15 & 0.33 & 0.03 & & & 01.27 & rMat \\
\hline RC27-9-6-2 & L18 & 5 & 14 & 0.01 & 41.13 & 0.82 & 6.43 & 0.80 & 3.55 & & 2.54 & 0.18 & 0.26 & 0.02 & 16.86 & 0.11 & 0.38 & 0.03 & & & 101.38 & NrMat \\
\hline RC27-9-6-2 & L20 & 5 & .19 & 0.02 & 40.31 & 1.10 & 27.13 & 1.09 & 3.27 & & 13.41 & 0.20 & 0.28 & 0.03 & 16.21 & 0.24 & 0.34 & 0.03 & & & 101.24 & rMat \\
\hline RC27-9-6-5 & 1 & 6 & .21 & 0.03 & 42.99 & 3.91 & 24.44 & 3.71 & 2.07 & 0.66 & 13.16 & 0.96 & 0.17 & 0.05 & 16.57 & 0.96 & 0.30 & 0.03 & 0.18 & 0.07 & 100.12 & Dep \\
\hline RC27-9-6-5 & 2 & 6 & 17 & 0.03 & 27.59 & 1.14 & & 0.61 & 2.71 & 0.39 & 17.01 & 0.30 & 0.23 & 0.03 & 12.43 & 0.28 & 0.19 & 0.03 & 0.05 & 0.10 & 99.66 & Dep \\
\hline $\mathrm{RC} 27-9-6-5$ & L1 & 6 & 32 & 0.09 & 56 & 2.30 & 61 & 2.26 & 2.43 & & 1.63 & 0.60 & 0.25 & 0.02 & 17.87 & 0.44 & 0.41 & 0.03 & & & 100.14 & \\
\hline $9-6-7$ & 1 & 3 & 00 & 0.01 & & 2.90 & & 0.46 & 3.74 & 234 & 11.29 & 1.03 & .24 & 0.26 & 18.12 & 1.03 & 0.33 & 0.03 & 0.00 & .00 & 99.03 & \\
\hline RC27-9-6-7 & 2 & 6 & 00 & 0.00 & 51.79 & 0.76 & & 0.57 & 1.67 & 0.44 & .95 & 0.31 & .07 & 0.03 & 18.15 & 0.38 & 0.31 & 0.02 & 0.00 & 0.00 & 99.57 & \\
\hline $\operatorname{Van} 7-78-25$ & 1 & 6 & 50 & 0.02 & 24.16 & 0.40 & 44.38 & 0.63 & 0.58 & 0.20 & 9.69 & 0.20 & .35 & 0.03 & 10.69 & 0.11 & 0.07 & 0.02 & 0.13 & 0.03 & 100.56 & GbVn \\
\hline Van7-78-25 & 2 & 6 & 48 & 0.04 & & 0.45 & & 0.48 & 0.92 & 0.41 & 19.11 & 0.21 & .34 & 0.02 & 11.05 & 0.08 & 0.08 & 0.02 & 0.19 & 0.05 & 100.50 & $\mathrm{GbVn}$ \\
\hline Va & 2 & 7 & 52 & 0.02 & 02 & 0.68 & & 0.76 & & 0.58 & .67 & 0.43 & .29 & 0.0 & 10.36 & 0.3 & 0.09 & 0.01 & .19 & 0.04 & 100.19 & AdjVn \\
\hline Van & 1 & 6 & 61 & 0.01 & .46 & 1.07 & 17 & 1.03 & 3.65 & 0.1 & 3.82 & 0.23 & 0.18 & 0.0 & 11.07 & 0.27 & 0.00 & 0.00 & 00 & 0.00 & & Mat \\
\hline $\operatorname{Van} 7$ & 1 & 4 & 79 & 0.02 & 51 & 0.62 & & 0.46 & 0 & 0.1 & .79 & 0.28 & .29 & 0.01 & 9.87 & 0.28 & 0.11 & 0.01 & 0.29 & 0.07 & & \\
\hline $\operatorname{Van} 7-78-41$ & 1 & 6 & 46 & 0.02 & .75 & 0.78 & 41 & 0.96 & 595 & 0.33 & .31 & 0.13 & 0.28 & 0.03 & 9.95 & 0.17 & 0.05 & 0.03 & 0.04 & 0.03 & 100.15 & \\
\hline Van7- & 1 & 6 & 00 & 0.00 & 87 & 0.67 & 14 & 0.52 & 0.00 & 0.00 & 2.18 & 0.43 & 0.06 & 0.01 & 18.09 & 0.23 & 0.20 & 0.03 & 0.04 & 0.05 & 99.34 & \\
\hline & 2 & 6 & 1 & .01 & & 0.95 & & 1.14 & & 0.1 & .28 & 0.32 & 0 & 0.02 & 17.44 & 0.25 & 0.18 & 0.01 & 4 & 0.04 & 99.23 & \\
\hline Van & 1 & 6 & 06 & 0.01 & 3.52 & 0.37 & 36 & 0.34 & 0.43 & 0.1 & 2.18 & 0.17 & 0.08 & 0.0 & 18.16 & 0.13 & 0.27 & 0.01 & 0.17 & 0.04 & 99.44 & \\
\hline & 2 & 6 & 00 & 0.00 & 56 & 0.46 & & 0.34 & & 0.41 & .46 & 0.24 & .01 & 0.0 & 18.66 & 0.09 & 0.21 & 0.02 & 0.00 & 0.00 & 99.64 & \\
\hline Van7-85-39 & 1 & 6 & 05 & 0.01 & 19 & 0.19 & & 0.18 & 1.49 & 0.2 & .72 & 0.20 & 0.11 & 0.03 & 18.53 & 0.17 & 0.32 & 0.03 & 0.13 & 0.05 & 100.57 & \\
\hline $\operatorname{Van} 7-85-42$ & 1 & 6 & .06 & 0.01 & 53.70 & 0.77 & 15.15 & 0.49 & 0.72 & 0.19 & 11.69 & 0.26 & 0.11 & 0.02 & 18.70 & 0.28 & 0.30 & 0.03 & 0.21 & 0.03 & 100.65 & \\
\hline & 1 & 6 & & 0.02 & & 0.17 & & 0.20 & & 0.0 & & 025 & & 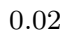 & & 0.11 & 0.29 & 0.01 & & 0.02 & & \\
\hline $\mathrm{V}$ & 1 & 6 & 03 & 0.01 & 14 & 0.47 & & 0.12 & 0.63 & 0.4 & .49 & 0.43 & 2 & $0 .($ & 18.61 & 0. & 0.37 & 0.05 & 6 & 0.03 & 99.76 & \\
\hline$V_{c}$ & 1 & 5 & 06 & .01 & 17 & 0.26 & & 0.21 & 1 & 0.3 & .76 & 0.29 & 5 & 0.0 & 18.30 & 0.25 & 0.19 & 0.02 & 0.27 & 0.03 & 100.23 & \\
\hline Van7- & 1 & 6 & 00 & 0.00 & & 0.90 & & 0.9 & & & & 0.23 & 08 & $0 .($ & 17.75 & 0.30 & 0.12 & 0.04 & 0.00 & 0.00 & 99.30 & \\
\hline $\operatorname{Van} 7-86-28$ & 1 & 6 & .03 & 0.01 & 54.00 & 0.39 & 15.17 & 0.38 & 0.41 & 0.37 & 11.67 & 0.13 & 0.13 & 0.03 & 18.71 & 0.09 & 0.33 & 0.03 & 0.18 & 0.05 & 100.65 & \\
\hline Van7-86-30 & 1 & 6 & .05 & 0.01 & 0.81 & 0.44 & 17.83 & 0.47 & 0.89 & 0.34 & 11.64 & 0.24 & 0.14 & 0.02 & 18.35 & 0.13 & 0.26 & 0.04 & 0.18 & 0.04 & 100.18 & \\
\hline $\operatorname{Von} 7-7$ & 1 & 6 & 11 & 0.01 & 2.46 & 0.76 & & 0.44 & & 0.52 & & 1.03 & 0.20 & 0.03 & & 0.64 & 0.23 & 0.02 & 0.22 & 0.05 & 100.37 & \\
\hline Van7-96-09 & 1 & 6 & .37 & 0.06 & 673 & 2.21 & & 2.1 & 40 & 03 & 3.62 & 0.7 & 0.14 & 0.0 & 15.76 & 0.6 & 0.21 & 0.02 & 0.21 & 0.04 & 99.87 & PyxVn \\
\hline$V_{z}$ & 3 & 6 & 20 & 008 & & 5.29 & & 4.77 & 4 & & .18 & 1.07 & 4 & & 18.46 & 1.26 & 0.30 & 0. & 0.20 & 0.06 & 99.85 & PyxVn \\
\hline $\operatorname{Van} 7-96-14$ & 4 & 5 & 0.37 & 0.06 & 43.21 & 1.55 & 21.99 & 1.36 & 2.94 & 0.46 & 14.65 & 0.56 & 0.18 & 0.04 & 15.53 & 0.49 & 0.24 & 0.02 & 0.19 & 0.04 & 99.39 & PyxVn \\
\hline Van7-96-14 & 5 & 6 & 0.27 & 0.09 & 44.32 & 0.96 & 21.02 & 0.87 & 2.41 & 0.19 & 17.47 & 2.12 & 0.37 & 0.11 & 13.86 & 1.54 & 0.24 & 0.03 & 0.36 & 0.08 & 100.37 & PyxVn \\
\hline $\operatorname{Van} 7-96-15$ & 1 & 6 & 0.26 & 0.03 & 56.15 & 0.42 & 10.99 & 0.30 & 1.53 & 0.16 & 11.35 & 0.13 & 0.17 & 0.02 & 19.11 & 0.14 & 0.40 & 0.03 & 0.18 & 0.03 & 100.17 & PyxVn \\
\hline Van7-96-16 & 1 & 6 & .21 & 0.03 & 8.19 & 0.22 & & 0.20 & 0.78 & 0.2 & 11.04 & 0.19 & 0.16 & 0.03 & 19.50 & 0.11 & 0.43 & 0.02 & 0.12 & 0.03 & 100.17 & PyxVn \\
\hline & 1 & 5 & & & & 0.37 & & & & & & 0.1 & & 0.0 & 20.14 & 0.29 & 0.41 & 0.03 & 0.00 & 0.00 & & JrMat \\
\hline $\operatorname{Van} 7-9$ & 2 & 6 & & 0.08 & & 1.42 & & 1.12 & & & & 0. & & & 18.54 & 0.41 & 0.43 & 0.03 & 0.00 & 0.00 & 100.34 & $y x \vee n$ \\
\hline $\operatorname{Van} 7-96-19$ & 1 & 5 & 0.31 & 0.21 & 39.70 & 0.84 & 27.66 & 0.98 & 2.01 & 0.55 & 13.95 & 0.60 & 0.20 & 0.03 & 15.84 & 0.29 & 0.24 & 0.03 & 0.01 & 0.01 & 99.99 & NrMat \\
\hline Van7-96-19 & 3 & 6 & 0.53 & 0.19 & 37.78 & 1.67 & 29.47 & 1.27 & 1.84 & 0.42 & 15.43 & 0.97 & 0.22 & 0.04 & 14.90 & 0.70 & 0.22 & 0.02 & 0.02 & 0.02 & 100.46 & PyxVn \\
\hline Van7-96-21 & 1 & 6 & 0.26 & 0.26 & 54.38 & 1.01 & 12.21 & 1.10 & 2.39 & 0.25 & 10.08 & 0.43 & 0.11 & 0.02 & 19.70 & 0.24 & 0.37 & 0.02 & 0.17 & 0.03 & 99.69 & PyxVn \\
\hline
\end{tabular}


Table 5.7: Spinel major elements Cont.

\begin{tabular}{|c|c|c|c|c|c|c|c|c|c|c|c|c|c|c|c|c|c|c|c|c|c|c|}
\hline Sample & $\mathrm{Grn}^{a}$ & Pts & $\mathrm{TiO}_{2}$ & \pm & $\mathrm{Al}_{2} \mathrm{O}_{3}$ & \pm & $\mathrm{Cr}_{2} \mathrm{O}_{3}$ & \pm & $\mathrm{Fe}_{2} \mathrm{O}_{3}$ & \pm & $\mathrm{FeO}$ & \pm & $\mathrm{MnO}$ & \pm & $\mathrm{MgO}$ & \pm & $\mathrm{NiO}$ & \pm & $\mathrm{ZnO}$ & \pm & Total & Notes $^{b}$ \\
\hline Van7-96-21 & 2 & 6 & 0.32 & 0.08 & 48.43 & 0.85 & 18.31 & 0.66 & 2.51 & 0.40 & 11.49 & 0.15 & 0.15 & 0.03 & 18.31 & 0.21 & 0.26 & 0.03 & 0.25 & 0.05 & 100.07 & PyxVn \\
\hline Van7-96-21 & 4 & 5 & 0.35 & 0.05 & 43.08 & 1.61 & 23.20 & 1.58 & 2.40 & 0.23 & 13.08 & 0.45 & 0.16 & 0.03 & 16.62 & 0.41 & 0.25 & 0.05 & 0.33 & 0.04 & 99.52 & AdjVn \\
\hline Van7-96-25 & 1 & 5 & 0.07 & 0.03 & 53.35 & 0.21 & 12.68 & 0.08 & 2.81 & 0.27 & 12.28 & 0.20 & 0.14 & 0.02 & 18.13 & 0.17 & 0.38 & 0.04 & 0.00 & 0.00 & 99.89 & \\
\hline Van7-96-28 & 1 & 5 & 0.25 & 0.04 & 45.92 & 0.99 & 21.56 & 0.61 & 1.37 & 0.25 & 13.15 & 0.30 & 0.16 & 0.02 & 16.97 & 0.38 & 0.25 & 0.04 & 0.02 & 0.03 & 99.76 & \\
\hline Van7-96-35 & 1 & 5 & 0.18 & 0.02 & 40.15 & 1.62 & 28.60 & 1.49 & 1.56 & 0.19 & 12.51 & 0.26 & 0.18 & 0.02 & 16.82 & 0.29 & 0.16 & 0.03 & 0.00 & 0.00 & 100.16 & \\
\hline Van7-96-37 & 1 & 4 & 0.16 & 0.02 & 47.74 & 0.87 & 19.88 & 0.61 & 1.81 & 0.48 & 12.45 & 0.28 & 0.14 & 0.03 & 17.58 & 0.24 & 0.22 & 0.02 & 0.00 & 0.00 & 99.99 & \\
\hline Van7-96-38 & 1 & 6 & 0.28 & 0.50 & 56.04 & 0.87 & 10.85 & 0.85 & 1.58 & 0.81 & 11.20 & 0.46 & 0.08 & 0.02 & 19.20 & 0.25 & 0.33 & 0.03 & 0.18 & 0.04 & 99.74 & \\
\hline Van7-96-66B & 1 & 5 & 0.06 & 0.02 & 61.60 & 0.38 & 5.26 & 0.37 & 1.66 & 0.19 & 10.67 & 0.13 & 0.10 & 0.01 & 19.87 & 0.08 & 0.58 & 0.05 & 0.00 & 0.00 & 99.80 & OpxVn \\
\hline
\end{tabular}

${ }^{a}$ Grain number; L preceding a grain number indicates Lee (1997) data for dredge RC27-9-6 samples.

${ }^{b}$ Abbreviations for lithologies (blank indicates residual peridotite): Dep, Trans and Enr are depleted, transitional and enriched zones in cryptically metasomatized samples; GbVn refers to a gabbroic vein, PyxVn to a pyroxenite vein, $\mathrm{CpxVn}$ to a clinopyroxenite vein, and OpxVn to an orthopyroxenite vein; AdjVn is adjacent to a vein, NrMat is $<5 \mathrm{~cm}$ from a vein and FarMat is $>5$ $\mathrm{cm}$ from a vein. 
Table 5.8: Major element composition of plagioclase, in wt $\%$.

\begin{tabular}{|c|c|c|c|c|c|c|c|c|c|c|c|c|c|c|c|}
\hline Analysis & $\operatorname{Grn}^{a}$ & Pts & $\mathrm{SiO}_{2}$ & \pm & $\mathrm{Al}_{2} \mathrm{O}_{3}$ & \pm & $\mathrm{FeO}$ & \pm & $\mathrm{CaO}$ & \pm & $\mathrm{Na}_{2} \mathrm{O}$ & \pm & Total & An & Notes $^{b}$ \\
\hline $6 \mathrm{~K}-465-2$ & $1 \mathrm{I}$ & 6 & 45.34 & 0.32 & 35.20 & 0.38 & 0.11 & 0.02 & 18.00 & 0.35 & 1.02 & 0.19 & 99.72 & 90.7 & Dep \\
\hline $6 \mathrm{~K}-465-2$ & $2 \mathrm{I}$ & 6 & 44.75 & 0.14 & 35.35 & 0.15 & 0.13 & 0.04 & 18.42 & 0.11 & 0.74 & 0.04 & 99.44 & 93.2 & Dep \\
\hline $6 \mathrm{~K}-465-2$ & $3 \mathrm{I}$ & 7 & 45.29 & 0.36 & 35.02 & 0.35 & 0.15 & 0.04 & 18.04 & 0.21 & 1.06 & 0.07 & 99.60 & 90.4 & Dep \\
\hline $6 \mathrm{~K}-465-3$ & 1aI & 3 & 55.36 & 0.29 & 29.34 & 0.45 & 0.16 & 0.07 & 11.17 & 0.32 & 5.09 & 0.31 & 101.21 & 54.5 & NrMat \\
\hline $6 \mathrm{~K}-465-3$ & $3 \mathrm{I}$ & 3 & 57.69 & 0.69 & 27.80 & 0.27 & 0.26 & 0.04 & 8.91 & 0.68 & 6.31 & 0.15 & 101.05 & 43.7 & GbVn \\
\hline $6 \mathrm{~K}-465-3$ & $4 \mathrm{aI}$ & 26 & 55.11 & 0.72 & 28.38 & 0.51 & 0.05 & 0.03 & 10.38 & 0.51 & 5.43 & 0.26 & 99.44 & 51.2 & NrMat \\
\hline $6 \mathrm{~K}-465-3$ & $4 \mathrm{bI}$ & 8 & 55.25 & 0.32 & 28.20 & 0.23 & 0.06 & 0.02 & 10.22 & 0.23 & 5.55 & 0.23 & 99.34 & 50.3 & NrMat \\
\hline RC27-9-6-2 & L1I & 1 & 54.7 & 0.0 & 29.33 & 0.01 & 0.09 & 0.26 & 11.30 & 0.01 & 5.23 & 0.02 & 101.34 & 54.1 & FarMat \\
\hline RC27-9-6-2 & L2I & 1 & 53.6 & 0.0 & 30.25 & 0.01 & 0.19 & 0.20 & 12.43 & 0.01 & 4.83 & 0.02 & 101.62 & 58.5 & NrMat \\
\hline RC27-9-6-2 & L3I & 6 & 49.8 & 0.8 & 32.60 & 0.33 & 0.12 & 0.03 & 15.24 & 0.63 & 3.00 & 0.38 & 103.05 & 73.7 & $\mathrm{CpxVn}$ \\
\hline RC27-9-6-5 & L1I & 6 & 47.2 & 0.4 & 33.62 & 0.28 & 0.10 & 0.03 & 17.02 & 0.18 & 1.84 & 0.19 & 101.03 & 83.6 & \\
\hline RC27-9-6-5 & 1I & 6 & 47.19 & 0.32 & 34.64 & 0.40 & 0.11 & 0.04 & 16.75 & 0.30 & 1.74 & 0.21 & 100.44 & 84.1 & \\
\hline Van7-78-25 & 1I & 6 & 47.88 & 0.25 & 34.05 & 0.17 & 0.13 & 0.03 & 16.25 & 0.14 & 1.98 & 0.14 & 100.32 & 81.9 & \\
\hline Van7-78-31 & 1I & 6 & 48.93 & 0.14 & 32.94 & 0.10 & 0.17 & 0.01 & 15.41 & 0.11 & 2.55 & 0.11 & 100.06 & 76.8 & NrMat \\
\hline $\operatorname{Van} 7-78-31$ & $2 \mathrm{I}$ & 6 & 50.38 & 0.36 & 31.96 & 0.31 & 0.13 & 0.01 & 14.19 & 0.29 & 3.34 & 0.29 & 100.05 & 69.9 & GbVn \\
\hline Van7-78-36 & $11 \mathrm{I}$ & 6 & 47.29 & 0.27 & 34.33 & 0.25 & 0.13 & 0.04 & 17.09 & 0.31 & 1.67 & 0.21 & 100.53 & 84.8 & FarMat \\
\hline $\operatorname{Van} 7-78-36$ & $1 \mathrm{C}$ & 4 & 52.61 & 0.41 & 30.74 & 0.29 & 0.09 & 0.01 & 12.80 & 0.27 & 4.38 & 0.16 & 100.72 & 61.5 & GbVn \\
\hline Van7-78-36 & $2 \mathrm{I}$ & 6 & 53.10 & 0.28 & 30.53 & 0.22 & 0.11 & 0.02 & 12.49 & 0.24 & 4.56 & 0.35 & 100.89 & 59.9 & GbVn \\
\hline $\operatorname{Van} 7-78-40$ & 1I & 6 & 47.94 & 0.43 & 33.26 & 0.75 & 0.19 & 0.04 & 16.17 & 0.51 & 2.03 & 0.14 & 100.04 & 81.3 & \\
\hline Van7-78-41 & 1I & 5 & 46.03 & 0.18 & 35.16 & 0.10 & 0.18 & 0.02 & 18.16 & 0.13 & 1.09 & 0.13 & 100.63 & 90.2 & \\
\hline Van7-96-09 & 1I & 5 & 49.75 & 0.25 & 31.91 & 0.22 & 0.11 & 0.02 & 14.29 & 0.19 & 3.11 & 0.12 & 99.18 & 71.7 & PyxVn \\
\hline Van7-96-09 & $2 \mathrm{I}$ & 6 & 46.15 & 0.53 & 34.77 & 0.48 & 0.13 & 0.01 & 17.27 & 0.20 & 1.46 & 0.15 & 99.79 & 86.7 & PyxVn \\
\hline Van7-96-14 & 1I & 6 & 47.79 & 0.46 & 33.96 & 0.39 & 0.04 & 0.02 & 16.14 & 0.14 & 2.17 & 0.09 & 100.10 & 80.5 & PyxVn \\
\hline Van7-96-14 & $3 \mathrm{C}$ & 3 & 46.92 & 0.13 & 34.09 & 0.07 & 0.05 & 0.01 & 16.77 & 0.02 & 1.87 & 0.07 & 99.70 & 83.2 & PyxVn \\
\hline Van7-96-14 & $3 R$ & 3 & 46.10 & 0.61 & 34.82 & 0.42 & 0.06 & 0.03 & 17.31 & 0.47 & 1.57 & 0.30 & 99.87 & 85.9 & PyxVn \\
\hline Van7-96-14 & $4 \mathrm{C}$ & 4 & 47.62 & 0.38 & 33.64 & 0.17 & 0.08 & 0.01 & 16.01 & 0.12 & 2.25 & 0.10 & 99.62 & 79.7 & PyxVn \\
\hline Van7-96-14 & $4 \mathrm{R}$ & 2 & 47.52 & 0.08 & 33.60 & 0.02 & 0.08 & 0.02 & 16.04 & 0.13 & 2.13 & 0.03 & 99.40 & 80.5 & PyxVn \\
\hline Van7-96-14 & 7 & 4 & 45.85 & 0.25 & 34.82 & 0.33 & 0.12 & 0.01 & 17.49 & 0.28 & 1.40 & 0.14 & 99.72 & 87.3 & PyxVn \\
\hline $\operatorname{Van} 7-96-15$ & $2 \mathrm{I}$ & 6 & 47.94 & 0.36 & 33.66 & 0.19 & 0.11 & 0.04 & 16.46 & 0.29 & 2.13 & 0.12 & 100.32 & 81.0 & PyxVn \\
\hline Van7-96-15 & $3 \mathrm{I}$ & 6 & 46.74 & 0.31 & 34.62 & 0.31 & 0.13 & 0.03 & 17.52 & 0.19 & 1.50 & 0.12 & 100.51 & 86.5 & PyxVn \\
\hline Van7-96-15 & $4 \mathrm{I}$ & 4 & 46.95 & 0.36 & 35.47 & 0.08 & 0.13 & 0.04 & 17.44 & 0.20 & 1.54 & 0.15 & 101.53 & 86.2 & PyxVn \\
\hline Van7-96-16 & 1I & 6 & 47.07 & 0.17 & 34.41 & 0.19 & 0.12 & 0.03 & 17.14 & 0.03 & 1.66 & 0.12 & 100.41 & 85.1 & PyxVn \\
\hline Van7-96-16 & $3 \mathrm{I}$ & 6 & 45.72 & 0.28 & 35.35 & 0.13 & 0.16 & 0.04 & 18.28 & 0.17 & 1.00 & 0.09 & 100.53 & 91.0 & PyxVn \\
\hline Van7-96-18 & 1I & 6 & 49.54 & 0.47 & 32.95 & 0.24 & 0.16 & 0.03 & 14.88 & 0.26 & 2.94 & 0.16 & 100.47 & 73.7 & PyxVn \\
\hline Van7-96-19 & 1I & 5 & 51.23 & 0.29 & 30.37 & 0.35 & 0.12 & 0.05 & 12.87 & 0.36 & 4.24 & 0.15 & 99.20 & 62.6 & NrMat \\
\hline Van7-96-19 & $3 \mathrm{I}$ & 5 & 51.86 & 0.37 & 30.27 & 0.26 & 0.11 & 0.02 & 12.53 & 0.24 & 4.57 & 0.14 & 99.34 & 60.2 & PyxVn \\
\hline Van7-96-21 & 1I & 5 & 50.16 & 2.06 & 32.21 & 1.19 & 0.09 & 0.03 & 14.17 & 1.41 & 3.23 & 0.86 & 99.86 & 70.8 & PyxVn \\
\hline Van7-96-21 & $2 \mathrm{I}$ & 5 & 51.94 & 1.72 & 31.00 & 0.70 & 0.09 & 0.02 & 12.90 & 1.07 & 4.00 & 0.70 & 99.94 & 64.1 & PyxVn \\
\hline $\operatorname{Van} 7-96-21$ & $3 \mathrm{I}$ & 5 & 52.50 & 2.15 & 31.00 & 1.09 & 0.13 & 0.05 & 12.64 & 1.47 & 4.08 & 0.71 & 100.37 & 63.1 & PyxVn \\
\hline
\end{tabular}


Table 5.9: Major element compositions of amphiboles, in wt\%.

\begin{tabular}{|c|c|c|c|c|c|c|c|c|c|c|c|c|c|c|c|c|c|c|c|c|c|c|}
\hline Analysis & $\mathrm{Grn}^{a}$ & Pts & $\mathrm{SiO}_{2}$ & \pm & $\mathrm{TiO}_{2}$ & \pm & $\mathrm{Al}_{2} \mathrm{O}_{3}$ & \pm & $\mathrm{Cr}_{2} \mathrm{O}_{3}$ & $3 \pm$ & $\mathrm{FeO}$ & \pm & $\mathrm{MgO}$ & \pm & $\mathrm{CaO}$ & \pm & $\mathrm{Na}_{2} \mathrm{O}$ & \pm & $\mathrm{K}_{2} \mathrm{O}$ & \pm & Total & Notes $^{b}$ \\
\hline $6 \mathrm{~K}-465-3$ & $\mathrm{~A} 2 \mathrm{C}$ & 4 & 54.84 & 1.20 & 0.35 & 0.15 & 2.27 & 0.83 & 0.02 & 0.02 & 5.93 & 0.49 & 20.47 & 0.51 & 12.07 & 0.12 & 0.62 & 0.17 & 0.05 & & 96.73 & GbVn \\
\hline $6 \mathrm{~K}-465-3$ & $\mathrm{~A} 3 \mathrm{C}$ & 2 & 56.67 & 0.09 & 0.17 & 0.02 & 1.02 & 0.02 & 0.02 & 0.02 & 5.17 & 0.04 & 21.40 & 0.04 & 12.35 & 0.02 & 0.37 & 0.01 & 0.03 & & 97.32 & GbVn \\
\hline $6 \mathrm{~K}-465-3$ & A5C & 7 & 55.56 & 0.80 & 0.16 & 0.08 & 1.58 & 0.54 & 0.01 & 0.01 & 6.51 & 0.29 & 20.22 & 0.33 & 12.27 & 0.15 & 0.54 & 0.15 & 0.03 & 0.01 & 97.04 & GbVn \\
\hline $6 \mathrm{~K}-465-3$ & $\mathrm{~A} 8 \mathrm{C}$ & 10 & 52.22 & 0.87 & 0.16 & 0.13 & 6.13 & 1.07 & 0.51 & 0.14 & 3.94 & 0.27 & 21.12 & 1.39 & 10.86 & 2.30 & 1.23 & 0.18 & & & 96.29 & NrMat \\
\hline RC27-9-6-2 & PL1I & 1 & 45.1 & 0.0 & 2.03 & 0.02 & 12.69 & 0.01 & 1.01 & 0.08 & 3.75 & 0.03 & 18.28 & 0.01 & 12.20 & 0.01 & 2.94 & 0.02 & 0.59 & 0.04 & 98.63 & FarMat \\
\hline RC27-9-6-2 & PL2I & 1 & 44.8 & 0.0 & 2.12 & 0.02 & 13.61 & 0.01 & 1.47 & 0.06 & 4.13 & 0.03 & 18.18 & 0.01 & 12.30 & 0.01 & 3.19 & 0.02 & 0.50 & 0.05 & 100.34 & FarMat \\
\hline RC27-9-6-2 & PL3I & 1 & 45.0 & 0.0 & 2.26 & 0.02 & 12.74 & 0.01 & 1.04 & 0.07 & 3.71 & 0.03 & 18.28 & 0.01 & 12.53 & 0.01 & 3.09 & 0.02 & 0.47 & 0.04 & 99.19 & FarMat \\
\hline RC27-9-6-2 & PL4I & 1 & 44.8 & 0.0 & 1.75 & 0.02 & 12.68 & 0.01 & 0.97 & 0.08 & 3.73 & 0.03 & 18.60 & 0.01 & 12.52 & 0.01 & 3.11 & 0.02 & 0.44 & 0.05 & 98.68 & FarMat \\
\hline RC27-9-6-2 & PL5I & 1 & 44.8 & 0.0 & 1.85 & 0.02 & 12.56 & 0.01 & 0.95 & 0.08 & 4.08 & 0.03 & 18.40 & 0.01 & 12.44 & 0.01 & 3.13 & 0.02 & 0.46 & 0.05 & 98.75 & FarMat \\
\hline RC27-9-6-2 & PL6I & 1 & 44.4 & 0.0 & 1.59 & 0.02 & 12.33 & 0.01 & 1.46 & 0.06 & 3.82 & 0.03 & 18.15 & 0.01 & 12.59 & 0.01 & 2.99 & 0.02 & 0.46 & 0.05 & 97.81 & FarMat \\
\hline
\end{tabular}

${ }^{a}$ Amphibole type, grain number and core (C) or interstitial (I) analysis. Low temperature metamorphic amphiboles are actinolite (A) and high temperature igneous amphiboles are pargasite

(P). L indicates data from Lee $(1997$

${ }^{b}$ Abbreviations for lithologies: GbVn indicates a gabbroic vein and FarMat indicates $>5 \mathrm{~cm}$ from a clinopyroxenite vein 
Table 5.10: Trace element concentrations in $\mathrm{Cpx}$ by ion probe, in ppm.

\begin{tabular}{|c|c|c|c|c|c|c|c|c|c|c|c|c|c|c|c|c|c|}
\hline Sample & Grain $^{a}$ & Type $^{b}$ & $\mathrm{La}$ & $\mathrm{Ce}$ & $\mathrm{Nd}$ & $\mathrm{Sm}$ & $\mathrm{Eu}$ & Dy & $\mathrm{Er}$ & $\mathrm{Yb}$ & $\mathrm{Na}_{2} \mathrm{O}$ & $\mathrm{Ti}$ & $\mathrm{Cr}$ & $\mathrm{Sr}$ & $\mathrm{Y}$ & $\mathrm{Zr}$ & Notes $^{c}$ \\
\hline $\mathrm{KH} 1^{d}$ & Cpx & & 1.22 & 5.39 & 5.56 & 2.12 & 0.75 & 2.30 & 1.12 & 0.99 & & & & & & & \\
\hline $\mathrm{KL} 2 \mathrm{G}^{e}$ & Basalt & & & & & & & & & & 2.27 & 15200 & 290 & 362.00 & 27 & 160.00 & \\
\hline KLB1, Ave, n=21 & Cpx & & 0.22 & 1.86 & 3.29 & 1.70 & 0.70 & 2.83 & 1.67 & 1.49 & & & & & & & \\
\hline KLB1, Std Dev & Cpx & & 0.04 & 0.21 & 0.38 & 0.25 & 0.07 & 0.25 & 0.18 & 0.18 & & & & & & & \\
\hline KLB1, \% Error & $\mathrm{Cpx}$ & & 17 & 11 & 11 & 15 & 10 & 8.9 & 11 & 12 & & & & & & & \\
\hline Count $\%$ Error $^{f}$ & Cpx & & 21 & 13 & 10 & 10 & 8.2 & 4.9 & 6.2 & 5.5 & 0.3 & 0.6 & 0.2 & 5.9 & 2.2 & 7.0 & \\
\hline Duplicate $\%$ Error $^{g}$ & $\mathrm{Cpx}$ & & 32 & 37 & 16 & 17 & 17 & 15 & 18 & 19 & 7.6 & 11 & 6.8 & 14 & 9.4 & 17 & \\
\hline $6 \mathrm{~K}-458-1$ & Cpx 1 & Core & 0.59 & 1.86 & 1.51 & 1.28 & 0.38 & 2.18 & 1.24 & 1.21 & 0.56 & 1470 & 7430 & 3.05 & 18.36 & 5.39 & \\
\hline $6 \mathrm{~K}-458-1$ & Cpx1 & Rim & 0.73 & 3.55 & 3.35 & 1.78 & 0.47 & 3.83 & 2.16 & 1.85 & 0.48 & 2122 & 8246 & 1.72 & 22.13 & 23.22 & \\
\hline $6 \mathrm{~K}-458-1$ & $\mathrm{Cpx} 2$ & Ints & 0.66 & 3.33 & 3.22 & 1.95 & 0.39 & 4.10 & 2.06 & 1.86 & 0.44 & 1979 & 6520 & 3.11 & 21.82 & 26.93 & \\
\hline $6 \mathrm{~K}-458-1$ & Cpx3 & Ints & 0.79 & 3.28 & 3.01 & 1.46 & 0.48 & 3.09 & 1.58 & 1.53 & 0.57 & 2274 & 8182 & 3.08 & 27.37 & 21.43 & \\
\hline $6 \mathrm{~K}-458-3$ & Cpx2 & Ints & 0.33 & 0.69 & 1.41 & 1.25 & 0.46 & 2.82 & 1.43 & 1.26 & 0.40 & 1908 & 5112 & 1.84 & 19.67 & 3.90 & \\
\hline $6 \mathrm{~K}-458-3$ & Cpx3 & Core & 0.09 & 0.22 & 1.66 & 1.72 & 0.55 & 3.89 & 1.35 & 1.88 & 0.39 & 2514 & 6894 & 3.81 & 21.41 & 4.96 & \\
\hline $6 \mathrm{~K}-458-3$ & Cpx3 & Rim & 0.05 & 0.25 & 1.83 & 1.25 & 0.45 & 3.72 & 1.56 & 1.77 & 0.37 & 2316 & 5660 & 4.76 & 23.93 & 5.28 & \\
\hline $6 \mathrm{~K}-458-3$ & Cpx4 & Core & 0.03 & 0.15 & 0.71 & 0.78 & 0.31 & 1.82 & 1.06 & 0.96 & 0.44 & 1374 & 6040 & 3.66 & 13.97 & 1.83 & \\
\hline $6 \mathrm{~K}-458-3$ & Cpx4 & $\operatorname{Rim}$ & 0.11 & 0.28 & 1.05 & 0.61 & 0.33 & 2.04 & 1.47 & 1.16 & 0.49 & 1541 & 5624 & 2.75 & 15.64 & 3.11 & \\
\hline $6 \mathrm{~K}-458-3$ & Cpx 5 & Ints & 0.06 & 0.10 & 0.78 & 0.63 & 0.27 & 1.93 & 1.62 & 1.09 & 0.45 & 1934 & 5006 & 4.10 & 16.11 & 3.98 & \\
\hline $6 \mathrm{~K}-458-3$ & Сpx6 & Ints & 0.43 & 1.60 & 1.51 & 1.01 & 0.35 & 3.18 & 2.03 & 1.88 & & & & & & & \\
\hline $6 \mathrm{~K}-465-2$ & Cpx1 & Core1 & 0.01 & 0.04 & 0.47 & 0.70 & 0.33 & 2.60 & 1.53 & 1.60 & 0.33 & 1312 & 5485 & 3.90 & 15.78 & 1.83 & Dep \\
\hline $6 \mathrm{~K}-465-2$ & Cpx1 & Core2 & 0.04 & 0.18 & 0.67 & 0.85 & 0.36 & 2.68 & 1.83 & 1.59 & & & & & & & Dep \\
\hline $6 \mathrm{~K}-465-2$ & Cpx 1 & Rim1 & 0.01 & 0.05 & 0.71 & 0.90 & 0.30 & 3.31 & 1.82 & 1.72 & 0.31 & 1858 & 5802 & 2.81 & 20.02 & 2.69 & Dep \\
\hline $6 \mathrm{~K}-465-2$ & Cpx1 & Rim2 & 0.03 & 0.04 & 0.53 & 0.73 & 0.21 & 1.82 & 1.23 & 0.89 & & & & & & & Dep \\
\hline $6 \mathrm{~K}-465-2$ & Cpx2 & Core 1 & 0.00 & 0.03 & 0.37 & 0.47 & 0.20 & 1.64 & 1.13 & 1.10 & 0.22 & 1003 & 4291 & 1.16 & 6.63 & 0.80 & Dep \\
\hline $6 \mathrm{~K}-465-2$ & Cpx2 & Core2 & 0.00 & 0.03 & 0.31 & 0.44 & 0.20 & 1.29 & 0.84 & 0.90 & 0.28 & 1169 & & 1.59 & 12.22 & 1.66 & Dep \\
\hline $6 \mathrm{~K}-465-2$ & Cpx2 & Core3 & 0.00 & 0.05 & 0.40 & 0.44 & 0.22 & 1.44 & 0.71 & 0.77 & 0.27 & 1183 & & 1.08 & 11.40 & 1.30 & Dep \\
\hline $6 \mathrm{~K}-465-2$ & $\mathrm{Cpx} 2$ & Core4 & 0.00 & 0.03 & 0.32 & 0.57 & 0.22 & 1.51 & 0.83 & 1.00 & & & & & & & Dep \\
\hline $6 \mathrm{~K}-465-2$ & Cpx2 & Core5 & 0.01 & 0.02 & 0.30 & 0.49 & 0.27 & 1.77 & 1.09 & 1.07 & & & & & & & Dep \\
\hline $6 \mathrm{~K}-465-2$ & Cpx2 & Rim & 0.00 & 0.04 & 0.47 & 0.65 & 0.17 & 2.16 & 1.17 & 1.26 & 0.26 & 1584 & & 6.17 & 16.97 & 2.19 & Dep \\
\hline $6 \mathrm{~K}-465-2$ & Cpx3 & Core & 0.02 & 0.04 & 0.41 & 0.48 & 0.24 & 1.97 & 1.01 & 1.19 & 0.22 & 1073 & 4669 & 1.32 & 10.13 & 1.33 & Dep \\
\hline $6 \mathrm{~K}-465-2$ & Cpx3 & Rim & 0.02 & 0.04 & 0.50 & 0.75 & 0.26 & 2.64 & 1.60 & 1.57 & 0.24 & 1774 & 4506 & 1.33 & 14.95 & 1.61 & Dep \\
\hline $6 \mathrm{~K}-465-2$ & Cpx4 & Core & 0.01 & 0.03 & 0.40 & 0.56 & 0.29 & 2.54 & 1.63 & 1.73 & 0.29 & 1681 & 6007 & 1.47 & 23.18 & 2.93 & Dep \\
\hline $6 \mathrm{~K}-465-2$ & Cpx4 & $\operatorname{Rim}$ & 0.01 & 0.05 & 0.45 & 0.41 & 0.16 & 1.68 & 0.98 & 1.11 & 0.30 & 1825 & 6264 & 3.42 & 21.05 & 2.88 & Dep \\
\hline $6 \mathrm{~K}-465-2$ & Сpx5 & Core1 & 0.86 & 3.77 & 2.48 & 1.10 & 0.38 & 2.69 & 1.92 & 1.98 & 0.52 & 1437 & 5768 & 2.27 & 27.20 & 7.13 & Enr \\
\hline $6 \mathrm{~K}-465-2$ & Cpx5 & Core2 & 0.97 & 4.29 & 2.86 & 1.41 & 0.53 & 3.59 & 2.78 & 2.87 & 0.36 & 1283 & & 1.27 & 22.06 & 2.92 & Enr \\
\hline $6 \mathrm{~K}-465-2$ & Cpx 5 & Rim & 0.47 & 2.09 & 1.82 & 1.27 & 0.38 & 3.17 & 2.65 & 2.42 & 0.17 & 1877 & & 1.17 & 38.52 & 11.86 & Enr \\
\hline $6 \mathrm{~K}-465-2$ & Сpx6 & Core1 & 0.12 & 0.32 & 0.47 & 0.50 & 0.22 & 1.63 & 1.08 & 0.97 & 0.29 & 1069 & & 1.02 & 13.14 & 1.19 & Trans \\
\hline $6 \mathrm{~K}-465-2$ & Сpx6 & Mdpt2 & 0.05 & 0.14 & 0.45 & 0.52 & 0.26 & 1.69 & 1.02 & 1.09 & 0.37 & 1143 & & 1.28 & 13.21 & 1.21 & Trans \\
\hline $6 \mathrm{~K}-465-2$ & Сpx6 & Mdpt3 & 0.16 & 0.62 & 0.73 & 0.69 & 0.26 & 2.34 & 1.53 & 1.83 & 0.37 & 1442 & 5376 & 3.21 & 22.45 & 3.49 & Trans \\
\hline $6 \mathrm{~K}-465-2$ & Сpx6 & Mdpt4 & 0.06 & 0.11 & 0.35 & 0.56 & 0.26 & 1.64 & 1.02 & 0.86 & 0.30 & 1001 & & 0.98 & 11.30 & 1.12 & Trans \\
\hline
\end{tabular}


Table 5.10: Cpx trace elements, Cont.

\begin{tabular}{|c|c|c|c|c|c|c|c|c|c|c|c|c|c|c|c|c|c|}
\hline Sample & Grain $^{a}$ & Type $^{b}$ & $\mathrm{La}$ & $\mathrm{Ce}$ & $\mathrm{Nd}$ & $\mathrm{Sm}$ & $\mathrm{Eu}$ & Dy & $\mathrm{Er}$ & $\mathrm{Yb}$ & $\mathrm{Na}_{2} \mathrm{O}$ & $\mathrm{Ti}$ & $\mathrm{Cr}$ & $\mathrm{Sr}$ & $\mathrm{Y}$ & $\mathrm{Zr}$ & Notes $^{c}$ \\
\hline $6 \mathrm{~K}-465-2$ & Сpx6 & Mdpt5 & 0.10 & 0.23 & 0.47 & 0.52 & 0.28 & 1.54 & 1.09 & 0.91 & 0.30 & 1053 & & 1.01 & 13.07 & 1.27 & Trans \\
\hline $6 \mathrm{~K}-465-2$ & Сpx6 & Mdpt6 & 0.18 & 0.71 & 0.67 & 0.64 & 0.25 & 1.83 & 1.34 & 1.42 & 0.29 & 1108 & & 1.13 & 14.55 & 1.45 & Trans \\
\hline $6 \mathrm{~K}-465-2$ & Сpx6 & Mdpt7 & 0.38 & 1.34 & 1.14 & 0.72 & 0.25 & 2.39 & 1.63 & 2.24 & 0.41 & 1426 & 5305 & 1.72 & 26.16 & 3.58 & Trans \\
\hline $6 \mathrm{~K}-465-2$ & Сpx6 & Rim8 & 0.38 & 1.73 & 2.17 & 1.10 & 0.32 & 2.71 & 1.77 & 1.97 & 0.27 & 1233 & & 0.93 & 21.25 & 4.69 & Trans \\
\hline $6 \mathrm{~K}-465-2$ & Сpx6 & Rim9 & 0.41 & 2.05 & 1.77 & 0.99 & 0.30 & 3.12 & 2.21 & 2.78 & 0.48 & 1774 & 6731 & 3.06 & 30.18 & 7.65 & Trans \\
\hline $6 \mathrm{~K}-465-2$ & Cpx7 & Core & 0.17 & 0.60 & 0.81 & 0.73 & 0.35 & 2.40 & 1.93 & 1.70 & & & & & & & Enr \\
\hline $6 \mathrm{~K}-465-2$ & $\mathrm{Cpx} 7$ & Rim & 0.16 & 0.65 & 0.77 & 0.48 & 0.29 & 2.06 & 1.55 & 1.40 & & & & & & & Enr \\
\hline $6 \mathrm{~K}-465-2$ & Cpx8 & Core1 & 0.02 & 0.08 & 0.50 & 0.69 & 0.33 & 2.05 & 1.28 & 1.19 & 0.43 & 1222 & & 0.92 & 14.25 & 1.24 & Dep \\
\hline $6 \mathrm{~K}-465-2$ & Cpx 8 & Core2 & 0.02 & 0.06 & 0.48 & 0.52 & 0.18 & 1.30 & 0.92 & 0.64 & 0.42 & 1186 & & 1.26 & 13.19 & 1.37 & Dep \\
\hline $6 \mathrm{~K}-465-2$ & Cpx8 & Core3 & 0.02 & 0.06 & 0.39 & 0.49 & 0.26 & 1.48 & 1.02 & 0.92 & & & & & & & Dep \\
\hline $6 \mathrm{~K}-465-2$ & Cpx8 & Rim1 & 0.07 & 0.22 & 0.44 & 0.45 & 0.20 & 1.50 & 1.10 & 0.87 & & & & & & & Dep \\
\hline $6 \mathrm{~K}-465-2$ & Cpx 8 & Rim2 & 0.07 & 0.33 & 0.75 & 0.58 & 0.28 & 2.23 & 1.70 & 1.29 & 0.38 & 1528 & & 0.83 & 18.63 & 1.76 & Dep \\
\hline $6 \mathrm{~K}-465-2$ & Cpx8 & Rim3 & 0.09 & 0.34 & 0.76 & 0.72 & 0.30 & 2.41 & 1.71 & 1.67 & 0.40 & 1597 & & 0.80 & 18.87 & 1.75 & Dep \\
\hline $6 \mathrm{~K}-465-2$ & Cpx9 & Rim1 & 0.60 & 2.98 & 2.72 & 1.24 & 0.28 & 3.15 & 2.11 & 1.95 & 0.40 & 1396 & 5186 & 2.69 & 28.75 & 10.15 & Enr \\
\hline $6 \mathrm{~K}-465-2$ & Cpx9 & Rim2 & 0.94 & 5.33 & 4.84 & 2.23 & 0.51 & 5.31 & 4.17 & 3.76 & 0.33 & 1398 & & 1.03 & 31.12 & 9.39 & Enr \\
\hline $6 \mathrm{~K}-465-2$ & Сpx9 & Rim3 & 1.34 & 7.99 & 7.57 & 3.83 & 0.79 & 7.78 & 5.58 & 5.46 & 0.37 & 2075 & & 1.41 & 42.81 & 16.63 & Enr \\
\hline $6 \mathrm{~K}-465-2$ & Cpx 10 & Ints & 0.01 & 0.04 & 0.49 & 0.78 & 0.24 & 3.08 & 1.82 & 1.50 & 0.34 & 1705 & 4662 & 3.45 & 9.89 & 1.32 & Dep \\
\hline $6 \mathrm{~K}-465-2$ & Cpx11 & Core1 & 0.01 & 0.06 & 0.54 & 0.81 & 0.29 & 2.05 & 1.31 & 1.35 & & & & & & & Dep \\
\hline $6 \mathrm{~K}-465-2$ & Cpx11 & Core2 & 0.01 & 0.05 & 0.50 & 0.66 & 0.23 & 2.21 & 1.31 & 1.24 & & & & & & & Dep \\
\hline $6 \mathrm{~K}-465-2$ & Cpx11 & $\operatorname{Rim}$ & 0.01 & 0.05 & 0.44 & 0.57 & 0.19 & 1.95 & 1.16 & 1.12 & & & & & & & Dep \\
\hline $6 \mathrm{~K}-465-2$ & Cpx12 & Ints & 0.01 & 0.04 & 0.42 & 0.52 & 0.23 & 1.94 & 1.24 & 1.29 & & & & & & & Dep \\
\hline $6 \mathrm{~K}-465-3$ & Cpx4 & Ints & 6.54 & 42.87 & 63.93 & 33.37 & 7.93 & 52.70 & 24.87 & 28.87 & 0.58 & 3955 & 290 & 19.87 & 232.07 & 242.43 & GbVn \\
\hline $6 \mathrm{~K}-465-3$ & Cpx 5 & Rim & 2.68 & 18.53 & 30.67 & 16.08 & 3.05 & 25.63 & 13.34 & 12.42 & 0.72 & 3291 & 246 & 14.75 & 420.08 & 257.52 & GbVn \\
\hline $6 \mathrm{~K}-465-3$ & Сpx6 & Core & 5.43 & 34.90 & 49.02 & 23.04 & 5.50 & 36.59 & 19.51 & 20.54 & 0.47 & 3390 & 66 & 17.11 & 225.33 & 181.01 & GbVn \\
\hline $6 \mathrm{~K}-465-3$ & Cpx7 & Core & 3.97 & 21.72 & 23.82 & 9.14 & 2.10 & 9.52 & 4.07 & 1.78 & 1.09 & 2464 & 4608 & 11.83 & 72.03 & 125.56 & NrMat \\
\hline $6 \mathrm{~K}-465-3$ & Cpx7 & Rim2 & 4.10 & 23.02 & 28.08 & 12.62 & 2.97 & 14.74 & 7.79 & 9.07 & 0.49 & 2316 & 3416 & 3.96 & 95.91 & 119.51 & NrMat \\
\hline $6 \mathrm{~K}-465-3$ & Cpx8 & Ints & 7.02 & 41.01 & 48.90 & 20.53 & 2.94 & 22.43 & 10.57 & 8.65 & 0.47 & 3925 & 4741 & 4.01 & 154.29 & 444.41 & NrMat \\
\hline $6 \mathrm{~K}-465-3$ & Cpx9 & Ints & 9.67 & 58.39 & 74.46 & 29.17 & 3.89 & 32.42 & 16.40 & 11.78 & 0.50 & 3371 & 4720 & 3.80 & 161.97 & 431.24 & NrMat \\
\hline $6 \mathrm{~K}-465-3$ & Cpx 10 & Core & 4.44 & 23.40 & 18.79 & 7.05 & 0.71 & 8.57 & 4.45 & 3.85 & 0.49 & 2480 & 5873 & 3.71 & 50.80 & 83.98 & NrMat \\
\hline $6 \mathrm{~K}-465-3$ & Cpx 10 & Rim & 4.02 & 22.33 & 19.68 & 7.75 & 0.90 & 8.64 & 4.02 & 3.97 & 0.49 & 2047 & 5306 & 1.31 & 47.56 & 75.40 & NrMat \\
\hline $6 \mathrm{~K}-465-3$ & Cpx12 & Core1 & 5.08 & 22.81 & 18.57 & 6.58 & 1.40 & 7.40 & 4.82 & 4.18 & 0.56 & 2185 & 4739 & 2.73 & 69.58 & 124.38 & NrMat \\
\hline $6 \mathrm{~K}-465-3$ & Cpx12 & $\operatorname{Rim}$ & 4.87 & 26.78 & 22.62 & 9.49 & 1.44 & 9.09 & 6.08 & 5.32 & & & & & & & NrMat \\
\hline $6 \mathrm{~K}-466-1$ & Cpx1 & Core & 0.01 & 0.06 & 0.41 & 0.49 & 0.20 & 1.57 & 0.70 & 0.91 & 0.46 & 1294 & 9529 & 1.22 & 10.77 & 2.31 & \\
\hline $6 \mathrm{~K}-466-1$ & Cpx1 & $\operatorname{Rim}$ & 0.01 & 0.05 & 0.52 & 0.39 & 0.17 & 1.75 & 0.89 & 0.75 & 0.41 & 1400 & 8847 & 1.61 & 12.37 & 2.53 & \\
\hline $6 \mathrm{~K}-466-1$ & Сpx3 & Ints & 0.06 & 0.07 & 0.47 & 0.38 & 0.20 & 1.50 & 0.85 & 0.79 & 0.40 & 1480 & 8195 & 1.77 & 11.77 & 2.89 & \\
\hline $6 \mathrm{~K}-466-1$ & Cpx3D & Ints & & & & & & & & & 0.39 & 1628 & 8259 & 2.38 & 12.75 & 3.59 & \\
\hline $6 \mathrm{~K}-643-01$ & Cpx1 & Ints & 0.02 & 0.04 & 0.23 & 0.29 & 0.15 & 1.74 & 0.93 & 1.30 & 0.20 & 913 & 6261 & 1.15 & 9.90 & 0.94 & \\
\hline $6 \mathrm{~K}-643-01$ & Cpx1D & Ints & 0.02 & 0.02 & 0.25 & 0.32 & 0.26 & 2.36 & 1.26 & 1.60 & 0.18 & 1032 & 6518 & 1.41 & 10.39 & 0.90 & \\
\hline $6 \mathrm{~K}-643-01$ & Сpх2 & Core & 0.02 & 0.04 & 0.26 & 0.25 & 0.18 & 1.37 & 0.94 & 0.85 & 0.21 & 579 & 5425 & 1.27 & 5.30 & 0.66 & \\
\hline 6K-643-01 & Cpx2 & $\operatorname{Rim}$ & 0.02 & 0.04 & 0.20 & 0.25 & 0.12 & 0.83 & 0.61 & 0.54 & 0.34 & 918 & 5538 & 1.39 & 8.98 & 1.00 & \\
\hline $6 \mathrm{~K}-643-01$ & Cpx4 & Core & 0.03 & 0.04 & 0.25 & 0.33 & 0.15 & 0.92 & 0.65 & 0.65 & 0.42 & 809 & 5284 & 1.33 & 9.26 & 1.87 & \\
\hline
\end{tabular}


Table 5.10: Cpx trace elements, Cont.

\begin{tabular}{|c|c|c|c|c|c|c|c|c|c|c|c|c|c|c|c|c|c|}
\hline Sample & Grain $^{a}$ & Type $^{b}$ & $\mathrm{La}$ & $\mathrm{Ce}$ & $\mathrm{Nd}$ & $\mathrm{Sm}$ & $\mathrm{Eu}$ & Dy & $\mathrm{Er}$ & $\mathrm{Yb}$ & $\mathrm{Na}_{2} \mathrm{O}$ & $\mathrm{Ti}$ & $\mathrm{Cr}$ & $\mathrm{Sr}$ & $\mathrm{Y}$ & $\mathrm{Zr}$ & Notes $^{c}$ \\
\hline 6K-643-01 & Cpx4 & Rim & 0.02 & 0.04 & 0.39 & 0.39 & 0.19 & 1.35 & 0.95 & 0.81 & 0.35 & 714 & 4664 & 1.63 & 7.01 & 1.31 & \\
\hline 6K-643-01 & Cpx8 & Symp & 0.02 & 0.06 & 0.31 & 0.45 & 0.16 & 1.34 & 0.71 & 0.80 & 0.29 & 905 & 5245 & 1.41 & 8.71 & 1.71 & \\
\hline 6K-643-01 & Cpx8D & Symp & 0.02 & 0.06 & 0.28 & 0.54 & 0.17 & 1.49 & 0.83 & 0.92 & 0.31 & 1261 & 4916 & 1.78 & 12.00 & 1.12 & \\
\hline 6K-643-06 & Cpx5 & Ints & 0.03 & 0.05 & 0.20 & 0.25 & 0.13 & 0.86 & 0.54 & 0.51 & 0.44 & 1233 & 9453 & 2.39 & 8.26 & 1.69 & \\
\hline 6K-643-06 & Сpx6 & Ints & 0.02 & 0.05 & 0.15 & 0.32 & 0.12 & 0.92 & 0.58 & 0.55 & 0.48 & 1223 & 10072 & 1.81 & 8.37 & 6.04 & \\
\hline $6 \mathrm{~K}-643-13$ & Cpx 1 & Ints & 0.01 & 0.01 & 0.10 & 0.30 & 0.10 & 0.97 & 0.71 & 0.63 & 0.30 & 961 & 5195 & 1.90 & 9.95 & 0.73 & \\
\hline $6 \mathrm{~K}-643-13$ & $\mathrm{Cpx} 2$ & Core & 0.02 & 0.02 & 0.17 & 0.31 & 0.23 & 1.42 & 0.82 & 0.88 & 0.13 & 602 & 5945 & 1.25 & 5.23 & 0.66 & \\
\hline 6K-643-13 & $\mathrm{Cpx} 2$ & Rim & & 0.02 & 0.09 & 0.28 & 0.09 & 1.33 & 0.89 & 0.75 & 0.24 & 877 & 6416 & 1.60 & 9.60 & 0.73 & \\
\hline 6K-643-13 & Cpx3 & Ints & 0.00 & 0.03 & 0.11 & 0.15 & 0.08 & 0.87 & 0.63 & 0.46 & 0.28 & 1047 & 3633 & 1.68 & 8.53 & 0.76 & \\
\hline $6 \mathrm{~K}-643-15$ & Cpx1 & Core & 9.62 & 67.80 & 86.11 & 37.97 & 7.55 & 84.70 & 36.23 & 35.82 & 0.55 & 8375 & 5575 & 20.85 & 428.80 & 318.73 & $\mathrm{GbVn}$ \\
\hline 6K-643-15 & Cpx 1 & $\operatorname{Rim}$ & 9.12 & 59.61 & 77.20 & 33.49 & 7.86 & 80.46 & 35.36 & 38.06 & 0.57 & 7132 & 5853 & 25.66 & 342.46 & 273.51 & $\mathrm{GbVn}$ \\
\hline 6K-643-15 & $\mathrm{Cpx} 2$ & Symp & 4.87 & 35.34 & 53.63 & 24.10 & 4.70 & 54.37 & 25.09 & 21.68 & 0.46 & 4393 & 7116 & 9.41 & 291.10 & 276.88 & GbVn \\
\hline 6K-643-15 & $\mathrm{Cpx} 2 \mathrm{D}$ & Symp & 4.58 & 37.56 & 54.23 & 24.24 & 4.87 & 61.34 & 26.05 & 25.41 & 0.48 & 4194 & 7275 & 11.85 & 286.94 & 306.50 & GbVn \\
\hline $6 \mathrm{~K}-643-15$ & Cpx3 & Symp & 2.22 & 14.48 & 15.77 & 6.98 & 1.37 & 19.53 & 9.62 & 11.05 & 0.50 & 1899 & 7709 & 2.90 & 202.00 & 219.88 & NrMat \\
\hline 6K-643-15 & $\mathrm{Cpx} 4$ & Symp & 2.85 & 17.44 & 16.75 & 6.41 & 1.27 & 14.30 & 6.82 & 4.68 & 0.47 & 1316 & 7317 & 2.12 & 90.97 & 72.18 & NrMat \\
\hline 6K-643-15 & $\mathrm{Cpx} 4 \mathrm{D}$ & Symp & & & & & & & & & 0.44 & 1229 & 6696 & 2.41 & 83.05 & 64.57 & NrMat \\
\hline $6 \mathrm{~K}-643-15$ & Cpx5 & Symp & 2.28 & 14.57 & 20.97 & 9.33 & 2.22 & 29.86 & 14.34 & 16.91 & 0.41 & 1535 & 6811 & 5.39 & 202.21 & 195.06 & NrMat \\
\hline $6 \mathrm{~K}-643-15$ & Сpх6 & Core & 0.05 & 0.07 & 0.17 & 0.33 & 0.14 & 0.94 & 0.55 & 0.69 & 0.48 & 760 & 6496 & 1.06 & 7.47 & 1.05 & FarMat \\
\hline $6 \mathrm{~K}-643-15$ & Cpx6 & Rim & 0.14 & 0.48 & 0.56 & 0.42 & 0.19 & 1.42 & 0.94 & 1.15 & 0.52 & 1116 & 6228 & 6.48 & 11.04 & 1.91 & FarMat \\
\hline $6 \mathrm{~K}-643-15$ & Cpx7 & Core & 0.03 & 0.06 & 0.17 & 0.38 & 0.17 & 1.13 & 0.70 & 0.71 & 0.42 & 912 & 7277 & 1.38 & 8.72 & 1.26 & FarMat \\
\hline 6K-643-15 & Cpx7 & Rim & 0.12 & 0.37 & 0.31 & 0.39 & 0.20 & 1.34 & 0.85 & 1.01 & 0.44 & 1003 & 6380 & 6.62 & 9.95 & 1.71 & FarMat \\
\hline $6 \mathrm{~K}-643-15$ & Cpx8 & Ints & 0.06 & 0.10 & 0.15 & 0.37 & 0.14 & 0.95 & 0.57 & 0.70 & 0.61 & 946 & 6623 & 5.61 & 8.42 & 1.27 & FarMat \\
\hline 6K-643-15 & Cpx8D & Ints & & & & & & & & & 0.52 & 1001 & 6890 & 4.93 & 8.63 & 2.25 & FarMat \\
\hline 6K-643-15 & $\mathrm{Cpx} 9$ & Core & 0.07 & 0.17 & 0.20 & 0.31 & 0.12 & 1.00 & 0.62 & 0.55 & 0.54 & 827 & 6428 & 1.08 & 7.34 & 1.75 & FarMat \\
\hline $6 \mathrm{~K}-643-15$ & Cpx 9 & Rim & 0.36 & 1.46 & 1.13 & 0.55 & 0.29 & 1.36 & 0.81 & 0.97 & 0.59 & 896 & 5954 & 26.15 & 9.44 & 2.38 & FarMat \\
\hline 6K-643-15 & Сpx13 & Ints4 & & & & & & & & & 0.59 & 1618 & 6323 & 9.65 & 68.95 & 27.27 & FarMat \\
\hline $6 \mathrm{~K}-643-15$ & Cpx13 & Ints5 & 1.71 & 8.77 & 6.66 & 2.55 & 1.06 & 4.56 & 3.14 & 3.62 & 0.67 & 1124 & 6303 & 8.21 & 37.49 & 11.16 & FarMat \\
\hline 6K-643-15 & Cpx13 & Ints6 & 1.60 & 9.48 & 7.79 & 3.20 & 0.98 & 5.16 & 3.02 & 2.67 & 0.54 & 1296 & 6007 & 9.28 & 39.35 & 17.90 & FarMat \\
\hline 6K-643-15 & Cpx13 & Ints7 & 2.36 & 11.48 & 9.34 & 4.40 & 1.29 & 7.35 & 4.68 & 5.63 & & & & & & & FarMat \\
\hline $6 \mathrm{~K}-643-15$ & Cpx13 & Ints8 & 1.92 & 9.63 & 8.64 & 3.57 & 1.19 & 7.85 & 5.45 & 6.16 & & & & & & & FarMat \\
\hline $6 \mathrm{~K}-649-5$ & Cpx 1 & Core & 0.01 & 0.00 & 0.22 & 0.26 & 0.13 & 1.13 & 0.85 & 0.96 & 0.26 & 683 & 6554 & 2.20 & 9.12 & 0.65 & \\
\hline $6 \mathrm{~K}-649-5$ & $\mathrm{Cpx} 1$ & $\operatorname{Rim}$ & 0.03 & 0.02 & 0.25 & 0.27 & 0.17 & 1.33 & 0.92 & 0.91 & 0.27 & 802 & 5774 & 1.60 & 9.62 & 0.95 & \\
\hline 6K-649-5 & $\mathrm{Cpx} 2$ & Ints & 0.03 & 0.04 & 0.15 & 0.23 & 0.13 & 1.42 & 0.66 & 0.96 & 0.17 & 947 & 11618 & 1.26 & 13.05 & 1.17 & \\
\hline $6 \mathrm{~K}-649-5$ & $\mathrm{Cpx} 4$ & Ints & 0.02 & 0.03 & 0.23 & 0.25 & 0.12 & 1.28 & 0.85 & 1.04 & & & & & & & \\
\hline $6 \mathrm{~K}-649-5$ & Cpx5 & Core & 0.02 & 0.02 & 0.10 & 0.15 & 0.09 & 1.17 & 0.67 & 0.95 & & & & & & & \\
\hline 6K-649-5 & Cpx5 & Rim & 0.02 & 0.02 & 0.22 & 0.17 & 0.13 & 1.40 & 0.77 & 1.06 & & & & & & & \\
\hline $6 \mathrm{~K}-649-5$ & Сpx6 & Ints & 0.01 & 0.02 & 0.16 & 0.12 & 0.07 & 0.94 & 0.53 & 1.04 & 0.30 & 756 & 4771 & 1.28 & 8.10 & 1.17 & \\
\hline $6 \mathrm{~K}-649-5$ & Cpx7 & Ints & 0.02 & 0.01 & 0.11 & 0.08 & 0.06 & 0.87 & 0.49 & 0.76 & & & & & & & \\
\hline 6K-649-5 & Cpx8 & Ints & 0.01 & 0.02 & 0.18 & 0.24 & 0.08 & 1.32 & 0.84 & 1.01 & & & & & & & \\
\hline $6 \mathrm{~K}-649-5$ & Cpx9 & Ints & 0.02 & 0.02 & 0.17 & 0.15 & 0.11 & 1.35 & 0.71 & 1.01 & 0.33 & 748 & 4813 & 3.71 & 8.20 & 2.24 & \\
\hline $6 \mathrm{~K}-651-7$ & $\mathrm{Cpx} 1$ & Ints & 0.02 & 0.13 & 0.48 & 0.53 & 0.33 & 1.70 & 0.85 & 0.61 & 0.35 & 1186 & 5080 & 2.59 & 9.58 & 1.08 & PyxVn \\
\hline
\end{tabular}


Table 5.10: Cpx trace elements, Cont.

\begin{tabular}{|c|c|c|c|c|c|c|c|c|c|c|c|c|c|c|c|c|c|}
\hline Sample & Grain $^{a}$ & Type $^{b}$ & $\mathrm{La}$ & $\mathrm{Ce}$ & $\mathrm{Nd}$ & $\mathrm{Sm}$ & $\mathrm{Eu}$ & Dy & $\mathrm{Er}$ & $\mathrm{Yb}$ & $\mathrm{Na}_{2} \mathrm{O}$ & $\mathrm{Ti}$ & $\mathrm{Cr}$ & $\mathrm{Sr}$ & $\mathrm{Y}$ & $\mathrm{Zr}$ & Notes $^{c}$ \\
\hline $6 \mathrm{~K}-651-7$ & Cpx1D & Ints & 0.03 & 0.12 & 0.55 & 0.41 & 0.31 & 1.77 & 1.18 & 1.13 & & & & & & & PyxVn \\
\hline $6 \mathrm{~K}-651-7$ & $\mathrm{Cp} \times 2$ & Core & 0.04 & 0.06 & 0.29 & 0.50 & 0.21 & 1.11 & 0.73 & 0.55 & 0.33 & 1083 & 5110 & 3.19 & 9.19 & 0.83 & PyxVn \\
\hline $6 \mathrm{~K}-651-7$ & $\mathrm{Cpx} 2$ & Rim & 0.06 & 0.07 & 0.24 & 0.51 & 0.22 & 1.11 & 0.68 & 0.58 & 0.39 & 1416 & 4373 & 2.89 & 9.56 & 1.48 & PyxVn \\
\hline AII107-61-83 & $\mathrm{Cpx} 1$ & Core & 0.02 & 0.03 & 0.38 & 0.38 & 0.20 & 1.56 & 1.19 & 1.01 & 0.64 & 965 & 4207 & 0.74 & 13.59 & 0.99 & \\
\hline AII107-61-83 & $\mathrm{Cpx} 1$ & $\operatorname{Rim}$ & 0.01 & 0.02 & 0.26 & 0.43 & 0.25 & 1.62 & 1.42 & 1.15 & 0.65 & 926 & 4659 & 1.04 & 13.96 & 0.60 & \\
\hline JR31-52-03 & $\mathrm{Cpx} 4$ & Core & 0.01 & 0.03 & 0.27 & 0.38 & 0.19 & 1.36 & 0.77 & 0.78 & 0.53 & 912 & 10956 & 0.96 & 11.03 & 0.87 & \\
\hline JR31-52-03 & $\mathrm{Cpx} 4$ & Rim & 0.01 & 0.06 & 0.26 & 0.43 & 0.17 & 1.61 & 0.77 & 0.79 & 0.51 & 941 & 10004 & 0.86 & 11.15 & 0.91 & \\
\hline JR31-52-03 & Cpx5 & Core & 0.01 & 0.03 & 0.22 & 0.34 & 0.13 & 1.09 & 0.62 & 0.63 & & & & & & & \\
\hline JR31-52-03 & Cpx5 & $\operatorname{Rim}$ & 0.01 & 0.03 & 0.26 & 0.31 & 0.18 & 1.01 & 0.63 & 0.62 & & & & & & & \\
\hline JR31-52-03 & Cpx5D & Rim & 0.01 & 0.05 & 0.29 & 0.39 & 0.17 & 1.18 & 0.65 & 0.63 & & & & & & & \\
\hline JR31-52-03 & Сpx6 & Ints & 0.01 & 0.05 & 0.30 & 0.31 & 0.17 & 1.15 & 0.64 & 0.61 & & & & & & & \\
\hline JR31-52-03 & Cpx7 & Core & 0.00 & 0.03 & 0.35 & 0.47 & 0.16 & 1.19 & 0.74 & 0.71 & 0.50 & 904 & 10097 & 0.93 & 10.13 & 0.90 & \\
\hline JR31-52-03 & Cpx7 & $\operatorname{Rim}$ & 0.03 & 0.04 & 0.34 & 0.36 & 0.20 & 1.41 & 0.83 & 0.84 & 0.49 & 1071 & 8866 & 1.15 & 10.40 & 0.96 & \\
\hline JR31-52-03 & Сpx9 & Ints & 0.00 & 0.03 & 0.26 & 0.30 & 0.19 & 1.43 & 0.80 & 0.81 & 0.48 & 1018 & 8834 & 1.35 & 10.20 & 0.82 & \\
\hline JR31-52-04 & $\mathrm{Cp} \times 3$ & Core & 0.00 & 0.01 & 0.16 & 0.21 & 0.06 & 0.65 & 0.38 & 0.32 & & & & & & & \\
\hline JR31-52-04 & $\mathrm{Cpx} 3$ & Rim & 0.00 & 0.03 & 0.31 & 0.23 & 0.10 & 0.72 & 0.55 & 0.52 & & & & & & & \\
\hline JR31-52-04 & Cpx4 & Core & 0.01 & 0.03 & 0.33 & 0.40 & 0.15 & 1.34 & 0.86 & 0.71 & 0.39 & 1052 & 10374 & 0.89 & 12.14 & 0.81 & \\
\hline JR31-52-04 & $\mathrm{Cpx} 4$ & $\operatorname{Rim}$ & 0.00 & 0.03 & 0.34 & 0.40 & 0.15 & 1.38 & 0.84 & 0.70 & 0.30 & 1426 & 13683 & 1.12 & 16.93 & 1.26 & \\
\hline JR31-52-05 & Cpx1 & Core & 0.01 & 0.02 & 0.30 & 0.49 & 0.20 & 1.43 & 0.77 & 0.76 & 0.43 & 920 & 10969 & 0.59 & 12.06 & 1.04 & \\
\hline JR31-52-05 & Cpx1 & Rim & 0.01 & 0.01 & 0.26 & 0.34 & 0.22 & 1.39 & 0.77 & 0.82 & 0.29 & 1126 & 7950 & 0.64 & 12.58 & 1.36 & \\
\hline JR31-52-05 & Cpx3 & Core & 0.01 & 0.02 & 0.28 & 0.42 & 0.21 & 1.52 & 0.89 & 0.88 & 0.35 & 1126 & 10428 & 1.23 & 14.01 & 0.88 & \\
\hline JR31-52-05 & Cpx5 & Ints & 0.01 & 0.02 & 0.21 & 0.33 & 0.12 & 1.00 & 0.69 & 0.61 & 0.39 & 1002 & 8800 & 0.91 & 11.27 & 0.85 & \\
\hline JR31-52-08 & $\mathrm{Cpx} 1$ & Core & 0.01 & 0.02 & 0.25 & 0.27 & 0.16 & 1.12 & 0.64 & 0.71 & 0.37 & 730 & 10371 & 0.52 & 7.62 & 0.61 & \\
\hline JR31-52-08 & $\mathrm{Cpx} 1$ & Rim & 0.01 & 0.04 & 0.31 & 0.32 & 0.18 & 1.29 & 0.86 & 0.70 & 0.47 & 1097 & 9310 & 0.87 & 10.98 & 0.75 & \\
\hline JR31-52-08 & Cpx1D & Rim & 0.01 & 0.04 & 0.34 & 0.41 & 0.21 & 1.48 & 0.77 & 0.82 & & & & & & & \\
\hline JR31-52-08 & Cpx3 & Ints & 0.01 & 0.04 & 0.41 & 0.44 & 0.17 & 1.39 & 0.79 & 0.72 & 0.50 & 1213 & 11035 & 0.99 & 12.42 & 0.99 & \\
\hline JR31-52-08 & Cpx4 & Rim & 0.01 & 0.04 & 0.30 & 0.40 & 0.16 & 1.36 & 0.83 & 0.92 & 0.42 & 959 & 5842 & 2.02 & 8.68 & 0.78 & \\
\hline JR31-52-08 & Cpx5 & Ints & 0.03 & 0.07 & 0.46 & 0.49 & 0.23 & 1.52 & 0.92 & 0.85 & 0.48 & 1086 & 10099 & 0.91 & 10.48 & 0.83 & \\
\hline Kn162-19-41 & Cpx1 & Core & 0.01 & 0.03 & 0.39 & 0.56 & 0.30 & 2.27 & 1.22 & 1.10 & 0.28 & 1310 & 3637 & 2.07 & 13.25 & 1.80 & PyxVn \\
\hline Kn162-19-41 & Cpx1 & Rim & 0.03 & 0.06 & 0.41 & 0.71 & 0.36 & 2.32 & 1.03 & 1.12 & 0.26 & 1003 & 3251 & 2.76 & 11.32 & 1.89 & PyxVn \\
\hline Kn162-19-41 & $\mathrm{Cpx} 2$ & Ints & 0.01 & 0.04 & 0.31 & 0.40 & 0.28 & 2.09 & 1.47 & 1.41 & 0.20 & 1445 & 3755 & 3.91 & 13.42 & 1.81 & PyxVn \\
\hline Kn162-19-41 & Cpx3 & Ints & 0.01 & 0.02 & 0.21 & 0.46 & 0.31 & 1.82 & 1.27 & 1.01 & 0.24 & 1466 & 4119 & 1.63 & 12.37 & 1.34 & PyxVn \\
\hline Kn162-19-41 & $\mathrm{Cpx} 4$ & Core & 0.01 & 0.03 & 0.23 & 0.48 & 0.26 & 1.92 & 1.41 & 1.31 & 0.24 & 1190 & 3887 & 1.37 & 12.64 & 1.08 & PyxVn \\
\hline Kn162-19-41 & Cpx4D & Core & 0.00 & 0.01 & 0.42 & 0.69 & 0.19 & 1.54 & 1.12 & 0.71 & & & & & & & PyxVn \\
\hline Kn162-19-41 & $\mathrm{Cpx} 4$ & Rim & 0.00 & 0.01 & 0.29 & 0.43 & 0.25 & 1.98 & 1.31 & 1.07 & 0.25 & 1457 & 4197 & 1.66 & 14.26 & 1.38 & PyxVn \\
\hline Kn162-19-41 & Cpx4D & Rim & 0.01 & 0.06 & 0.26 & 0.58 & 0.21 & 1.69 & 0.96 & 0.71 & & & & & & & PyxVn \\
\hline Kn162-19-45 & $\mathrm{Cpx} 1$ & Core & 0.02 & 0.03 & 0.35 & 0.72 & 0.38 & 2.81 & 1.67 & 1.82 & 0.27 & 1338 & 6102 & 1.74 & 12.70 & 0.94 & \\
\hline Kn162-19-45 & Cpx1 & Rim & 0.02 & 0.02 & 0.63 & 0.71 & 0.40 & 3.06 & 1.66 & 1.53 & 0.24 & 1455 & 5215 & 2.53 & 12.17 & 1.80 & \\
\hline Kn162-47-08 & Cpx1 & Ints & 0.01 & 0.04 & 0.34 & 0.47 & 0.28 & 2.10 & 1.32 & 1.04 & 0.67 & 1849 & 4951 & 1.46 & 14.18 & 2.63 & \\
\hline Kn162-47-08 & Cpx2 & Ints & 0.01 & 0.03 & 0.39 & 0.52 & 0.28 & 2.34 & 1.43 & 1.23 & 0.74 & 2456 & 5225 & 1.94 & 16.29 & 3.42 & \\
\hline Kn162-47-08 & $\mathrm{Cp} \times 3$ & Ints & & & & & & & & & 0.52 & 1640 & 3961 & 1.46 & 14.24 & 2.86 & \\
\hline
\end{tabular}


Table 5.10: Cpx trace elements, Cont.

\begin{tabular}{|c|c|c|c|c|c|c|c|c|c|c|c|c|c|c|c|c|c|}
\hline Sample & Grain $^{a}$ & Type $^{b}$ & $\mathrm{La}$ & $\mathrm{Ce}$ & $\mathrm{Nd}$ & $\mathrm{Sm}$ & $\mathrm{Eu}$ & Dy & $\mathrm{Er}$ & $\mathrm{Yb}$ & $\mathrm{Na}_{2} \mathrm{O}$ & $\mathrm{Ti}$ & $\mathrm{Cr}$ & $\mathrm{Sr}$ & $\mathrm{Y}$ & $\mathrm{Zr}$ & Notes $^{c}$ \\
\hline Kn162-47-08 & Cpx4 & Ints & 0.02 & 0.06 & 0.45 & 0.41 & 0.26 & 1.85 & 1.40 & 1.25 & & & & & & & \\
\hline Kn162-47-08 & Cpx 5 & Ints & 0.02 & 0.06 & 0.42 & 0.64 & 0.30 & 1.84 & 1.38 & 1.05 & 0.45 & 1970 & 3788 & 1.60 & 15.48 & 2.67 & \\
\hline Kn162-47-08 & Cpx5D & Ints & & & & & & & & & 0.49 & 1740 & 3548 & 1.41 & 14.11 & 3.02 & \\
\hline Kn162-47-09 & Сpx2 & Ints & 0.62 & 2.81 & 3.10 & 0.76 & 0.22 & 0.50 & 0.24 & 0.21 & 0.80 & 556 & 6931 & 34.37 & 2.93 & 7.28 & \\
\hline Kn162-47-09 & Cpx3 & Core & 0.56 & 2.65 & 2.75 & 0.82 & 0.22 & 0.47 & 0.23 & 0.27 & 0.80 & 594 & 8034 & 36.92 & 3.33 & 8.54 & \\
\hline Kn162-47-09 & Cpx3 & Rim & 0.51 & 2.66 & 2.70 & 0.81 & 0.21 & 0.44 & 0.19 & 0.26 & 0.76 & 594 & 7411 & 36.35 & 3.06 & 8.19 & \\
\hline Kn162-47-10 & Cpx 1 & Core & 0.00 & 0.05 & 0.66 & 0.86 & 0.30 & 1.84 & 1.21 & 1.02 & 0.38 & 1216 & 4203 & 1.92 & 13.58 & 2.91 & PyxVn \\
\hline Kn162-47-10 & Cpx 1 & Rim & 0.04 & 0.12 & 0.88 & 0.85 & 0.37 & 2.09 & 1.22 & 1.09 & 0.36 & 1869 & 3750 & 2.02 & 15.64 & 3.35 & PyxVn \\
\hline Kn162-47-10 & Cpx2 & Ints & 0.03 & 0.15 & 1.08 & 0.96 & 0.38 & 2.24 & 1.53 & 1.18 & 0.30 & 1280 & 2807 & 2.19 & 12.71 & 2.98 & PyxVn \\
\hline Kn162-47-10 & Cpx 5 & Ints & 0.03 & 0.10 & 0.68 & 0.82 & 0.31 & 2.13 & 1.32 & 1.07 & 0.36 & 1169 & 3616 & 2.33 & 13.04 & 2.50 & NrMat \\
\hline Kn162-47-10 & Сpх6 & Core & 0.04 & 0.10 & 0.44 & 0.69 & 0.24 & 1.42 & 0.87 & 0.63 & 0.46 & 1472 & 5328 & 1.70 & 12.69 & 2.10 & FarMat \\
\hline Kn162-47-10 & Сpx6 & Rim & 0.03 & 0.03 & 0.51 & 0.57 & 0.18 & 1.36 & 0.86 & 0.66 & 0.46 & 1471 & 4772 & 1.90 & 12.98 & 2.15 & FarMat \\
\hline Kn162-47-12 & Cpx1 & Ints & 0.03 & 0.10 & 0.55 & 0.44 & 0.21 & 1.71 & 0.85 & 0.97 & 0.45 & 1498 & 4459 & 3.06 & 14.43 & 3.53 & PyxVn \\
\hline Kn162-47-12 & $\mathrm{Cpx} 2$ & Core & 0.02 & 0.13 & 0.61 & 0.69 & 0.29 & 1.79 & 0.83 & 0.78 & 0.45 & 1293 & 4837 & 3.57 & 13.91 & 2.81 & PyxVn \\
\hline Kn162-47-12 & Cpx2 & Rim & 0.02 & 0.21 & 0.78 & 0.64 & 0.28 & 2.10 & 1.16 & 0.78 & 0.37 & 1403 & 3953 & 3.07 & 14.89 & 3.42 & PyxVn \\
\hline Kn162-47-22 & Cpx1 & Core & 0.01 & 0.12 & 0.89 & 0.94 & 0.34 & 2.32 & 1.32 & 1.16 & 0.51 & 1530 & 4996 & 1.72 & 14.83 & 2.19 & AdjVn \\
\hline Kn162-47-22 & Cpx 1 & Rim & 0.00 & 0.10 & 0.84 & 0.87 & 0.38 & 2.30 & 1.37 & 1.22 & 0.46 & 1718 & 4593 & 3.02 & 14.35 & 2.40 & AdjVn \\
\hline Kn162-47-22 & Cpx2 & Core & 0.01 & 0.09 & 1.11 & 0.76 & 0.41 & 2.14 & 1.31 & 1.16 & 0.50 & 1651 & 5173 & 1.89 & 14.14 & 2.40 & PyxVn \\
\hline Kn162-47-22 & Cpx2 & Rim & 0.01 & 0.10 & 1.00 & 1.01 & 0.38 & 2.32 & 1.53 & 1.25 & 0.46 & 1820 & 5217 & 1.71 & 15.85 & 2.80 & PyxVn \\
\hline Kn162-47-22 & Cpx2D & Rim & & & & & & & & & 0.52 & 1969 & 5660 & 1.92 & 15.99 & 2.47 & PyxVn \\
\hline Kn162-47-22 & Cpx3 & Core & 0.00 & 0.09 & 0.65 & 0.76 & 0.37 & 1.77 & 1.16 & 1.03 & 0.51 & 1509 & 5277 & 1.56 & 13.48 & 1.99 & PyxVn \\
\hline Kn162-47-22 & Cpx3 & Rim & 0.01 & 0.09 & 0.92 & 0.91 & 0.35 & 2.28 & 1.30 & 1.24 & 0.48 & 1738 & 4912 & 2.23 & 14.73 & 2.12 & PyxVn \\
\hline Kn162-47-22 & Cpx4 & Ints & & & & & & & & & 0.53 & 1612 & 5572 & 2.29 & 14.90 & 2.10 & PyxVn \\
\hline Kn162-47-24 & Cpx 1 & Core & 0.02 & 0.04 & 0.35 & 0.43 & 0.16 & 1.55 & 1.25 & 0.95 & 0.38 & 1174 & 5766 & 1.20 & 12.23 & 1.56 & \\
\hline Kn162-47-24 & Cpx1 & $\operatorname{Rim}$ & 0.01 & 0.03 & 0.37 & 0.57 & 0.20 & 1.34 & 1.14 & 0.87 & 0.42 & 1371 & 5107 & 1.55 & 13.45 & 1.66 & \\
\hline Kn162-47-24 & Сpx2 & Core & 0.01 & 0.03 & 0.44 & 0.47 & 0.23 & 1.81 & 1.13 & 1.07 & 0.38 & 1163 & 5765 & 1.53 & 12.66 & 1.25 & \\
\hline Kn162-47-24 & Cpx2 & Rim & 0.02 & 0.06 & 0.35 & 0.48 & 0.20 & 1.72 & 1.18 & 1.01 & 0.39 & 1382 & 5132 & 1.81 & 14.09 & 1.60 & \\
\hline Kn162-47-24 & Cpx3 & Symp & 0.01 & 0.03 & 0.22 & 0.34 & 0.23 & 1.54 & 1.25 & 1.04 & 0.32 & 1201 & 4659 & 1.41 & 12.53 & 1.02 & \\
\hline Kn162-47-25 & Cpx1 & Ints & 0.02 & 0.18 & 1.25 & 0.87 & 0.40 & 1.65 & 0.93 & 0.87 & 0.67 & 2498 & 5883 & 2.76 & 15.06 & 9.09 & NrMat \\
\hline Kn162-47-25 & $\mathrm{Cpx} 2$ & Ints & 0.01 & 0.10 & 0.55 & 0.67 & 0.29 & 1.11 & 0.72 & 0.49 & 0.77 & 2480 & 5837 & 2.25 & 12.98 & 7.76 & NrMat \\
\hline Kn162-47-25 & Cpx11 & Core & 0.02 & 0.28 & 1.07 & 0.93 & 0.25 & 1.24 & 0.58 & 0.41 & 0.47 & 2227 & 5144 & 3.38 & 12.10 & 4.02 & PyxVn \\
\hline Kn162-47-25 & Cpx11 & $\operatorname{Rim}$ & 0.02 & 0.26 & 1.22 & 0.74 & 0.35 & 1.60 & 0.77 & 0.84 & 0.34 & 2800 & 5928 & 3.81 & 13.86 & 4.78 & PyxVn \\
\hline Kn162-47-25 & Cpx13 & Ints & 0.01 & 0.18 & 0.74 & 0.72 & 0.15 & 0.93 & 0.53 & 0.50 & 0.49 & 2400 & 5356 & 3.16 & 12.69 & 3.83 & PyxVn \\
\hline Kn162-47-25 & Cpx14 & Ints & 0.04 & 0.35 & 1.06 & 0.88 & 0.28 & 1.44 & 0.70 & 0.68 & 0.36 & 2563 & 6003 & 3.90 & 15.00 & 5.56 & PyxVn \\
\hline Kn162-47-26 & Cpx 1 & Core & 0.02 & 0.21 & 1.13 & 0.72 & 0.27 & 1.42 & 0.92 & 1.04 & 0.63 & 1220 & 4072 & 5.49 & 9.89 & 2.81 & \\
\hline Kn162-47-26 & Cpx 1 & Rim & 0.02 & 0.20 & 0.84 & 0.61 & 0.24 & 1.68 & 0.83 & 0.87 & 0.64 & 1307 & 4157 & 4.92 & 9.56 & 2.31 & \\
\hline Kn162-47-26 & Cpx2 & Ints & & & & & & & & & 0.56 & 1389 & 4077 & 5.12 & 10.08 & 2.12 & \\
\hline Kn162-47-26 & Сpx3 & Ints & 0.03 & 0.18 & 0.89 & 0.53 & 0.21 & 1.35 & 0.72 & 0.93 & 0.47 & 1386 & 3935 & 5.70 & 11.28 & 2.34 & \\
\hline Kn162-47-29 & Cpx1 & Core & 0.00 & 0.04 & 0.41 & 0.31 & 0.15 & 1.10 & 0.71 & 0.72 & 0.46 & 1819 & 6489 & 2.54 & 16.57 & 3.14 & \\
\hline Kn162-47-29 & Cpx 1 & Rim & 0.00 & 0.05 & 0.25 & 0.35 & 0.17 & 1.05 & 0.61 & 0.67 & 0.36 & 1923 & 5591 & 2.87 & 19.02 & 3.70 & \\
\hline Kn162-47-29 & Cpx2 & Core & 0.00 & 0.04 & 0.42 & 0.37 & 0.13 & 1.13 & 0.73 & 0.60 & 0.37 & 1548 & 5815 & 2.42 & 15.88 & 3.90 & \\
\hline
\end{tabular}


Table 5.10: Cpx trace elements, Cont.

\begin{tabular}{|c|c|c|c|c|c|c|c|c|c|c|c|c|c|c|c|c|c|}
\hline Sample & Grain $^{a}$ & Type $^{b}$ & $\mathrm{La}$ & $\mathrm{Ce}$ & $\mathrm{Nd}$ & $\mathrm{Sm}$ & $\mathrm{Eu}$ & Dy & $\mathrm{Er}$ & $\mathrm{Yb}$ & $\mathrm{Na}_{2} \mathrm{O}$ & $\mathrm{Ti}$ & $\mathrm{Cr}$ & $\mathrm{Sr}$ & $\mathrm{Y}$ & $\mathrm{Zr}$ & Notes $^{c}$ \\
\hline Kn162-47-29 & Cpx2 & Rim & 0.03 & 0.15 & 1.01 & 1.02 & 0.37 & 1.78 & 0.97 & 0.92 & 0.34 & 1714 & 5106 & 2.24 & 18.39 & 3.62 & \\
\hline $\mathrm{Kn} 162-47-29$ & $\mathrm{Cp} \times 3$ & Ints & 0.01 & 0.18 & 1.05 & 0.85 & 0.41 & 1.86 & 1.15 & 0.99 & 0.33 & 2108 & 5556 & 2.64 & 18.16 & 3.72 & \\
\hline Kn162-47-36 & Cpx 1 & Core & 0.01 & 0.04 & 0.45 & 0.70 & 0.34 & 1.82 & 1.24 & 1.21 & 0.45 & 1237 & 4350 & 1.57 & 13.87 & 1.79 & \\
\hline Kn162-47-36 & Cpx1 & Rim & & & & & & & & & 0.40 & 1419 & 3108 & 2.36 & 14.82 & 1.73 & \\
\hline Kn162-47-36 & $\mathrm{Cpx} 2$ & Core & 0.02 & 0.05 & 0.55 & 0.80 & 0.30 & 1.78 & 1.21 & 1.27 & 0.47 & 1157 & 4760 & 1.62 & 13.52 & 1.31 & \\
\hline Kn162-47-36 & Cpx2 & Rim & & 0.02 & 0.59 & 0.70 & 0.20 & 2.28 & 1.15 & 1.35 & 0.48 & 1550 & 3835 & 1.96 & 15.85 & 2.33 & \\
\hline Kn162-47-36 & Cpx3 & Ints & 0.01 & 0.03 & 0.47 & 1.11 & 0.32 & 2.12 & 1.43 & 1.10 & 0.54 & 1565 & 3685 & 2.07 & 14.15 & 2.63 & \\
\hline Kn162-47-49 & Cpx1 & Ints & 0.09 & 0.21 & 0.45 & 0.43 & 0.21 & 1.58 & 1.06 & 0.89 & 0.26 & 1665 & 5020 & 2.43 & 13.31 & 2.48 & \\
\hline Kn162-47-49 & Cpx2 & Core & 0.04 & 0.04 & 0.38 & 0.43 & 0.21 & 1.34 & 0.97 & 0.72 & 0.71 & 1384 & 6436 & 4.52 & 13.64 & 2.16 & \\
\hline Kn162-47-49 & $\mathrm{Cpx2}$ & Rim & 0.03 & 0.06 & 0.57 & 0.47 & 0.24 & 1.46 & 0.97 & 0.89 & 0.35 & 1279 & 3367 & 3.89 & 9.08 & 2.25 & \\
\hline Kn162-47-49 & Cpx3 & Ints & 0.02 & 0.05 & 0.49 & 0.45 & 0.20 & 1.31 & 0.81 & 0.80 & 0.39 & 1409 & 5924 & 2.36 & 13.65 & 1.86 & \\
\hline PS86-6-26 & $\mathrm{Cpx} 1$ & Core & 0.06 & 0.41 & 1.76 & 1.37 & 0.55 & 1.81 & 1.41 & 1.13 & 0.97 & 2500 & 4619 & 5.86 & 19.04 & 7.18 & \\
\hline PS86-6-26 & $\mathrm{Cpx} 1$ & $\operatorname{Rim}$ & 0.03 & 0.39 & 1.77 & 1.22 & 0.54 & 2.54 & 1.03 & 1.36 & 0.83 & 2526 & 4006 & 5.10 & 15.92 & 6.50 & \\
\hline PS86-6-26 & Cpx2 & Ints & 0.02 & 0.36 & 1.29 & 1.00 & 0.36 & 1.67 & 1.10 & 0.98 & 0.81 & 2315 & 4217 & 5.42 & 15.77 & 6.27 & \\
\hline PS86-6-38 & $\mathrm{Cpx} 1$ & Core & 0.04 & 0.58 & 2.37 & 1.16 & 0.59 & 2.32 & 1.25 & 1.28 & 0.69 & 1741 & 4361 & 5.00 & 12.45 & 6.44 & \\
\hline PS86-6-38 & $\mathrm{Cpx} 1$ & Rim & 0.06 & 0.60 & 2.43 & 1.19 & 0.59 & 2.80 & 1.31 & 1.36 & 0.91 & 2505 & 4641 & 6.20 & 17.87 & 10.44 & \\
\hline PS86-6-38 & Cpx2 & Ints & 0.08 & 0.72 & 2.98 & 1.64 & 0.71 & 2.67 & 1.47 & 1.56 & 0.79 & 2093 & 4666 & 5.95 & 15.68 & 7.91 & \\
\hline PS86-6-38 & Cpx3 & Core & 0.03 & 0.59 & 2.04 & 1.33 & 0.51 & 2.11 & 1.22 & 0.93 & 1.00 & 2823 & 4720 & 8.48 & 22.72 & 11.09 & \\
\hline PS86-6-38 & Cpx3 & Rim & 0.03 & 0.66 & 2.53 & 1.58 & 0.61 & 2.48 & 1.19 & 1.33 & 0.96 & 2898 & 4520 & 7.83 & 21.06 & 11.17 & \\
\hline PS86-6-39 & Cpx 1 & Core & 0.05 & 0.76 & 2.21 & 0.92 & 0.46 & 2.16 & 1.20 & 1.32 & 1.02 & 1764 & 7291 & 11.98 & 14.82 & 10.21 & \\
\hline PS86-6-39 & $\mathrm{Cpx} 1$ & Rim & 0.08 & 0.92 & 2.87 & 1.55 & 0.64 & 2.61 & 1.53 & 1.42 & 1.11 & 1933 & 6746 & 13.28 & 15.60 & 11.22 & \\
\hline PS86-6-39 & Cpx2 & Ints & 0.09 & 0.88 & 2.18 & 1.51 & 0.54 & 2.40 & 1.22 & 1.34 & 1.08 & 1949 & 6689 & 13.22 & 15.36 & 12.77 & \\
\hline PS86-6-39 & $\mathrm{Cp} \times 3$ & Core & 0.09 & 0.98 & 2.54 & 1.70 & 0.50 & 1.96 & 1.03 & 0.92 & 1.01 & 1770 & 7042 & 13.60 & 15.41 & 10.72 & \\
\hline PS86-6-39 & Cpx3 & Rim & 0.08 & 0.81 & 2.67 & 1.24 & 0.52 & 2.18 & 1.31 & 0.99 & 1.03 & 2088 & 5874 & 15.19 & 16.25 & 12.86 & \\
\hline PS86-6-39 & $\mathrm{Cpx} 4$ & Ints & 0.12 & 0.94 & 2.67 & 1.78 & 0.65 & 2.18 & 1.18 & 1.12 & 1.16 & 2198 & 7165 & 15.19 & 16.79 & 13.33 & \\
\hline PS86-6-40 & $\mathrm{Cpx} 1$ & Ints & 0.02 & 0.35 & 1.63 & 0.91 & 0.40 & 2.74 & 1.78 & 1.95 & 1.00 & 2324 & 4327 & 11.18 & 17.46 & 9.29 & \\
\hline PS86-6-40 & Cpx1D & Ints & & & & & & & & & 0.89 & 2281 & 4285 & 8.11 & 17.58 & 8.95 & \\
\hline PS86-6-40 & Cpx2 & Core & 0.02 & 0.53 & 2.10 & 1.32 & 0.58 & 2.83 & 1.69 & 1.51 & 0.82 & 2195 & 6089 & 13.18 & 17.84 & 9.27 & \\
\hline PS86-6-40 & Cpx2 & Rim & 0.02 & 0.49 & 1.50 & 1.19 & 0.48 & 2.97 & 1.67 & 1.72 & 0.78 & 2436 & 3504 & 19.44 & 17.40 & 11.15 & \\
\hline PS86-6-40 & Cpx3 & Core & 0.04 & 0.58 & 2.05 & 1.37 & 0.59 & 2.67 & 1.42 & 1.46 & 0.97 & 2300 & 4761 & 13.10 & 18.86 & 10.19 & \\
\hline PS86-6-40 & $\mathrm{Cp} \times 3$ & Rim & 0.02 & 0.62 & 2.09 & 1.55 & 0.64 & 3.03 & 1.80 & 1.51 & 0.95 & 2424 & 4325 & 11.24 & 17.95 & 10.31 & \\
\hline RC27-6-9-2 & CpxL1 & Core & 0.10 & 0.57 & 0.57 & 0.31 & 0.07 & 0.44 & 0.27 & 0.27 & 0.45 & 543 & 11399 & 24.39 & 4.00 & 2.06 & FarMat \\
\hline RC27-6-9-2 & CpxL1D & Core & & & & & & & & & 0.48 & 663 & 12280 & 24.88 & 4.37 & 2.89 & FarMat \\
\hline RC27-6-9-2 & CpxL1 & Rim & 0.17 & 1.25 & 1.67 & 0.80 & 0.17 & 1.36 & 0.80 & 0.68 & 0.46 & 1090 & 10234 & 12.59 & 11.56 & 15.80 & FarMat \\
\hline RC27-6-9-2 & CpxL1D & Rim & & & & & & & & & 0.52 & 1062 & 11640 & 14.37 & 12.21 & 15.84 & FarMat \\
\hline RC27-6-9-2 & CpxL2 & Core & 0.04 & 0.27 & 0.31 & 0.17 & 0.05 & 0.32 & 0.22 & 0.16 & 0.49 & 689 & 10333 & 21.12 & 3.18 & 4.30 & FarMat \\
\hline RC27-6-9-2 & CpxL2 & Rim & 0.28 & 1.21 & 0.75 & 0.31 & 0.09 & 0.54 & 0.42 & 0.36 & 0.99 & 796 & 11316 & 27.59 & 4.19 & 2.02 & FarMat \\
\hline RC27-9-6-2 & CpxL3 & Rim & & & & & & & & & 0.43 & 1196 & 13293 & 9.99 & 7.55 & 4.12 & $\mathrm{CpxVn}$ \\
\hline $\mathrm{RC} 27-9-6-2$ & CpxL4 & Ints & & & & & & & & & 0.59 & 1217 & 11804 & 8.13 & 6.67 & 3.76 & $\mathrm{CpxVn}$ \\
\hline RC27-9-6-2 & CpxL6 & Core & 0.03 & 0.24 & 0.41 & 0.29 & 0.10 & 0.61 & 0.38 & 0.35 & 0.64 & 911 & 12342 & 33.74 & 6.34 & 3.61 & NrMat \\
\hline RC27-9-6-2 & CpxL6D & Core & 0.04 & 0.19 & 0.39 & 0.24 & 0.09 & 0.56 & 0.36 & 0.34 & 0.56 & 918 & 11505 & 33.12 & 7.11 & 3.97 & NrMat \\
\hline
\end{tabular}


Table 5.10: Cpx trace elements, Cont.

\begin{tabular}{|c|c|c|c|c|c|c|c|c|c|c|c|c|c|c|c|c|c|}
\hline Sample & Grain $^{a}$ & Type $^{b}$ & $\mathrm{La}$ & $\mathrm{Ce}$ & $\mathrm{Nd}$ & $\mathrm{Sm}$ & $\mathrm{Eu}$ & Dy & $\mathrm{Er}$ & $\mathrm{Yb}$ & $\mathrm{Na}_{2} \mathrm{O}$ & $\mathrm{Ti}$ & $\mathrm{Cr}$ & $\mathrm{Sr}$ & $\mathrm{Y}$ & $\mathrm{Zr}$ & Notes $^{c}$ \\
\hline RC27-9-6-2 & CpxL6 & Rim & 0.03 & 0.23 & 0.48 & 0.27 & 0.09 & 0.70 & 0.41 & 0.36 & 0.54 & 976 & 10439 & 34.19 & 6.61 & 3.58 & NrMat \\
\hline RC27-9-6-2 & CpxL7 & Core & 0.03 & 0.20 & 0.47 & 0.26 & 0.11 & 0.72 & 0.37 & 0.39 & & & & & & & NrMat \\
\hline RC27-9-6-2 & CpxL7 & Rim & 0.03 & 0.19 & 0.50 & 0.26 & 0.09 & 0.71 & 0.46 & 0.41 & 0.50 & 1191 & 8951 & 30.72 & 6.73 & 4.04 & NrMat \\
\hline RC27-9-6-2 & CpxL7D & Rim & & & & & & & & & 0.46 & 1068 & 8796 & 28.59 & 6.66 & 3.63 & NrMat \\
\hline RC27-9-6-2 & Cpx12 & Core & 0.55 & 2.41 & 1.87 & 0.51 & 0.22 & 0.95 & 0.55 & 0.47 & 0.60 & 700 & 8101 & 59.83 & 6.00 & 3.55 & FarMat \\
\hline RC27-9-6-2 & Cpx12 & Rim & 0.49 & 2.21 & 1.52 & 0.50 & 0.23 & 1.04 & 0.60 & 0.55 & 0.50 & 906 & 6002 & 53.15 & 6.94 & 4.75 & FarMat \\
\hline RC27-9-6-2 & Cpx13 & Ints & 0.49 & 2.06 & 1.64 & 0.54 & 0.19 & 1.04 & 0.56 & 0.54 & 0.52 & 790 & 5507 & 47.13 & 6.27 & 4.00 & FarMat \\
\hline RC27-9-6-2 & Cpx14 & Ints & 0.43 & 2.10 & 1.40 & 0.55 & 0.24 & 0.86 & 0.47 & 0.49 & 0.42 & 842 & 7618 & 47.72 & 6.93 & 4.23 & FarMat \\
\hline RC27-9-6-2 & Cpx 15 & Ints & 0.43 & 2.10 & 1.74 & 0.59 & 0.18 & 0.73 & 0.58 & 0.38 & 0.43 & 837 & 5418 & 53.95 & 7.18 & 4.03 & FarMat \\
\hline RC27-9-6-2 & Cpx21 & Core & 0.15 & 0.83 & 1.24 & 0.60 & 0.21 & 1.38 & 0.79 & 0.60 & 0.65 & 1202 & 7961 & 26.76 & 9.40 & 4.62 & CpxVn \\
\hline RC27-9-6-2 & Cpx21 & $\operatorname{Rim}$ & 0.32 & 1.10 & 1.25 & 0.57 & 0.28 & 1.29 & 0.70 & 0.60 & 0.63 & 1177 & 8264 & 23.32 & 9.12 & 5.77 & $\mathrm{CpxVn}$ \\
\hline RC27-9-6-2 & Cpx22 & Core & 0.20 & 1.10 & 1.51 & 0.72 & 0.24 & 1.34 & 0.65 & 0.59 & 0.48 & 1226 & 7351 & 26.11 & 8.93 & 4.46 & CpxVn \\
\hline $\mathrm{RC} 27-9-6-2$ & Cpx23 & Ints & 0.20 & 0.92 & 1.19 & 0.61 & 0.17 & 1.13 & 0.58 & 0.50 & 0.53 & 1198 & 6508 & 24.68 & 8.84 & 4.76 & CpxVn \\
\hline RC27-9-6-5 & Cpx 1 & Core1 & 0.86 & 2.77 & 1.54 & 0.64 & 0.36 & 1.77 & 1.17 & 1.23 & 0.29 & 1273 & 5768 & 1.63 & 18.74 & 4.23 & Enr \\
\hline RC27-9-6-5 & $\mathrm{Cpx} 1$ & Core2 & 0.86 & 2.29 & 1.45 & 0.66 & 0.36 & 2.04 & 0.98 & 1.36 & 0.48 & 1194 & 6389 & 2.26 & 14.35 & 1.05 & Enr \\
\hline RC27-9-6-5 & $\mathrm{Cpx} 1$ & Rim & 1.12 & 6.93 & 9.11 & 4.01 & 0.98 & 5.65 & 2.75 & 2.00 & 0.24 & 3659 & 4979 & 3.15 & 42.21 & 82.90 & Enr \\
\hline RC27-9-6-5 & Cpx2 & Core1 & 0.02 & 0.05 & 0.25 & 0.30 & 0.16 & 1.12 & 0.64 & 0.73 & 0.36 & 1007 & 5579 & 0.83 & 11.61 & 1.08 & Trans \\
\hline RC27-9-6-5 & Cpx2 & Mdpt2 & & & & & & & & & 0.30 & 1070 & 6809 & 1.73 & 13.86 & 1.14 & Trans \\
\hline RC27-9-6-5 & Cpx2 & Mdpt3 & 0.06 & 0.13 & 0.20 & 0.36 & 0.17 & 1.43 & 0.84 & 0.76 & 0.39 & 1121 & 5698 & 1.28 & 13.07 & 1.17 & Trans \\
\hline RC27-9-6-5 & Cpx2 & Mdpt4 & 0.19 & 0.37 & 0.42 & 0.38 & 0.18 & 1.66 & 0.88 & 0.90 & 0.36 & 1270 & 7237 & 1.91 & 16.11 & 1.30 & Trans \\
\hline RC27-9-6-5 & $\mathrm{Cpx} 2$ & Mdpt5 & 0.88 & 3.74 & 2.35 & 1.27 & 0.45 & 2.59 & 1.67 & 1.63 & 0.39 & 1544 & 6811 & 2.40 & 26.81 & 13.06 & Trans \\
\hline RC27-9-6-5 & Cpx2 & Mdpt6 & 1.00 & 4.40 & 3.51 & 1.35 & 0.48 & 3.06 & 1.76 & 1.66 & 0.41 & 1873 & 6857 & 2.16 & 29.80 & 18.35 & Trans \\
\hline RC27-9-6-5 & $\mathrm{Cpx} 2$ & $\operatorname{Rim} 7$ & 1.00 & 5.21 & 5.37 & 2.20 & 0.62 & 4.57 & 2.32 & 1.98 & 0.31 & 2792 & 4956 & 1.92 & 31.24 & 45.18 & Trans \\
\hline RC27-9-6-5 & Cpx3 & Ints & 1.00 & 7.00 & 9.36 & 4.96 & 0.99 & 6.44 & 2.78 & 2.43 & 1.19 & 7912 & 6282 & 9.01 & 58.17 & 150.43 & Enr \\
\hline RC27-9-6-5 & $\mathrm{Cpx} 4$ & Core & 1.31 & 6.33 & 4.68 & 1.74 & 0.62 & 3.24 & 1.56 & 1.51 & 0.55 & 1471 & 5683 & 2.26 & 23.67 & 16.90 & Enr \\
\hline RC27-9-6-5 & $\mathrm{Cpx} 4$ & Rim & 1.00 & 4.58 & 5.23 & 1.97 & 0.61 & 3.69 & 1.83 & 1.53 & 0.35 & 2646 & 5562 & 2.97 & 30.66 & 51.25 & Enr \\
\hline RC27-9-6-5 & Cpx5 & Core & 1.45 & 6.11 & 3.30 & 0.96 & 0.51 & 2.35 & 1.41 & 1.49 & 0.77 & 1632 & 6555 & 3.24 & 25.19 & 21.34 & Enr \\
\hline RC27-9-6-5 & Cpx5 & Rim & 1.14 & 5.69 & 5.93 & 2.65 & 0.65 & 4.16 & 2.32 & 2.12 & 0.50 & 2776 & 8399 & 2.38 & 37.76 & 53.11 & Enr \\
\hline RC27-9-6-7 & Cpx1 & Core & 0.01 & 0.05 & 0.21 & 0.49 & 0.20 & 1.04 & 0.52 & 0.48 & 0.12 & 387 & 4695 & 1.31 & 3.37 & 0.72 & \\
\hline RC27-9-6-7 & Cpx1 & Rim & 0.00 & 0.05 & 0.52 & 0.72 & 0.24 & 1.59 & 0.96 & 0.72 & 0.31 & 1235 & 4952 & 1.82 & 12.74 & 1.52 & \\
\hline RC27-9-6-7 & $\mathrm{Cpx} 3$ & Ints & 0.01 & 0.04 & 0.22 & 0.52 & 0.22 & 1.65 & 0.73 & 0.83 & 0.29 & 1196 & 4220 & 1.39 & 11.13 & 1.26 & \\
\hline RC27-9-6-7 & Cpx5 & Ints & 0.01 & 0.04 & 0.44 & 0.73 & 0.32 & 2.18 & 1.06 & 0.87 & 0.43 & 1515 & 4490 & 1.63 & 12.59 & 1.70 & \\
\hline Van7-78-25 & Cpx1 & Core & 0.16 & 1.06 & 1.77 & 0.98 & 0.40 & 1.96 & 1.16 & 1.12 & 0.31 & 1599 & 5585 & 4.12 & 12.05 & 7.16 & GbVn \\
\hline Van7-78-25 & Cpx1 & Rim & 0.16 & 1.14 & 1.87 & 1.01 & 0.44 & 2.13 & 1.42 & 1.37 & 0.35 & 2199 & 6357 & 4.87 & 16.85 & 12.08 & GbVn \\
\hline Van7-78-25 & Cpx2 & Core & 0.13 & 1.03 & 1.92 & 1.04 & 0.37 & 1.97 & 1.22 & 1.00 & 0.21 & 1791 & 7086 & 6.03 & 17.38 & 8.88 & GbVn \\
\hline Van7-78-25 & Cpx2 & Rim & 0.12 & 0.88 & 1.54 & 1.06 & 0.36 & 2.00 & 1.13 & 0.99 & 0.21 & 2563 & 7061 & 4.80 & 15.91 & 13.93 & GbVn \\
\hline $\operatorname{Van} 7-78-25$ & Cpx3 & Core & 0.14 & 1.05 & 1.88 & 0.98 & 0.49 & 2.03 & 1.59 & 1.24 & 0.14 & 2618 & 9659 & 10.40 & 19.87 & 11.55 & GbVn \\
\hline Van7-78-25 & Cpx3 & Rim & 0.14 & 0.97 & 1.88 & 1.05 & 0.36 & 2.33 & 1.31 & 1.22 & 0.18 & 2256 & 8181 & 5.15 & 14.57 & 10.54 & GbVn \\
\hline Van7-78-31 & $\mathrm{Cpx} 1$ & Ints & 0.36 & 2.15 & 2.26 & 1.06 & 0.32 & 2.30 & 1.21 & 1.21 & 0.43 & 2700 & 6479 & 3.49 & 22.09 & 30.03 & NrMat \\
\hline Van7-78-31 & Cpx2 & Core & 0.46 & 2.34 & 3.10 & 1.57 & 0.49 & 2.27 & 1.15 & 1.18 & 0.34 & 3885 & 686 & 18.22 & 21.57 & 19.63 & $\mathrm{GbVn}$ \\
\hline Van7-78-31 & $\mathrm{Cpx} 2$ & Rim & 0.53 & 3.09 & 4.44 & 2.14 & 0.66 & 3.30 & 1.72 & 1.61 & 0.34 & 4690 & 754 & 14.73 & 26.16 & 25.38 & GbVn \\
\hline
\end{tabular}


Table 5.10: Cpx trace elements, Cont.

\begin{tabular}{|c|c|c|c|c|c|c|c|c|c|c|c|c|c|c|c|c|c|}
\hline Sample & Grain $^{a}$ & Type $^{b}$ & $\mathrm{La}$ & $\mathrm{Ce}$ & $\mathrm{Nd}$ & $\mathrm{Sm}$ & $\mathrm{Eu}$ & Dy & $\mathrm{Er}$ & $\mathrm{Yb}$ & $\mathrm{Na}_{2} \mathrm{O}$ & $\mathrm{Ti}$ & $\mathrm{Cr}$ & $\mathrm{Sr}$ & $\mathrm{Y}$ & $\mathrm{Zr}$ & Notes $^{c}$ \\
\hline Van7-78-31 & Cpx3 & Rim & 0.53 & 3.02 & 3.95 & 2.00 & 0.52 & 3.02 & 1.69 & 1.29 & 0.36 & 4366 & 837 & 16.66 & 25.25 & 24.44 & $\mathrm{GbVn}$ \\
\hline Van7-78-31 & Cpx4 & Ints & 0.46 & 2.99 & 4.17 & 1.93 & 0.60 & 3.24 & 1.52 & 1.49 & 0.40 & 4460 & 847 & 17.46 & 23.82 & 22.13 & GbVn \\
\hline Van7-78-36 & Cpx 1 & Core & 0.55 & 3.08 & 3.31 & 1.48 & 0.59 & 2.44 & 1.53 & 1.41 & 0.49 & 3418 & 1056 & 11.49 & 20.80 & 19.12 & GbVn \\
\hline Van7-78-36 & Cpx1 & $\operatorname{Rim}$ & 0.53 & 2.99 & 4.09 & 2.01 & 0.61 & 3.49 & 1.97 & 1.78 & 0.25 & 3388 & 1417 & 12.65 & 20.74 & 21.55 & GbVn \\
\hline $\operatorname{Van} 7-78-36$ & Cpx3 & Ints & 0.80 & 4.06 & 5.75 & 2.46 & 0.68 & 3.84 & 2.25 & 2.06 & 0.31 & 3813 & 4763 & 11.79 & 26.90 & 39.85 & $\operatorname{AdjVn}$ \\
\hline Van7-78-36 & Cpx3D & Ints & 0.78 & 4.14 & 4.84 & 2.53 & 0.55 & 3.59 & 1.91 & 1.73 & & & & & & & AdjVn \\
\hline $\operatorname{Van} 7-78-36$ & Cpx4 & Ints & 0.42 & 2.39 & 4.13 & 1.97 & 0.65 & 3.26 & 1.94 & 1.72 & 0.26 & 3777 & 1419 & 13.47 & 29.70 & 19.07 & GbVn \\
\hline $\operatorname{Van} 7-78-36$ & Cpx4D & Ints & 0.37 & 2.37 & 3.89 & 1.73 & 0.62 & 3.13 & 1.75 & 1.55 & 0.24 & 3412 & 1419 & 12.14 & 19.61 & 19.29 & GbVn \\
\hline Van7-78-36 & Cpx 10 & Ints & 0.81 & 3.74 & 4.23 & 1.86 & 0.46 & 3.21 & 1.66 & 1.73 & 0.36 & 2397 & 6696 & 2.73 & 25.15 & 33.03 & FarMat \\
\hline $\operatorname{Van} 7-78-36$ & Cpx10D & Ints & 0.71 & 3.57 & 3.99 & 1.88 & 0.44 & 3.54 & 2.00 & 1.66 & 0.33 & 2493 & 5438 & 2.50 & 24.37 & 33.89 & FarMat \\
\hline Van7-78-36 & Cpx11 & Ints & 0.78 & 3.67 & 3.46 & 1.64 & 0.37 & 2.98 & 1.80 & 1.39 & 0.36 & 2122 & 4895 & 2.32 & 20.36 & 24.57 & FarMat \\
\hline Van7-78-36 & Cpx12 & Core & 0.87 & 4.21 & 4.28 & 2.18 & 0.48 & 3.67 & 2.31 & 1.88 & 0.37 & 2757 & 6612 & 2.60 & 26.54 & 47.12 & FarMat \\
\hline $\operatorname{Van} 7-78-36$ & $\mathrm{Cpx} 12$ & $\operatorname{Rim}$ & 0.60 & 3.13 & 3.44 & 1.52 & 0.36 & 2.61 & 1.63 & 1.44 & 0.29 & 2267 & 3880 & 2.48 & 22.03 & 35.18 & FarMat \\
\hline Van7-78-40 & Cpx1 & Core & 1.49 & 5.33 & 2.77 & 0.95 & 0.33 & 1.82 & 1.11 & 1.08 & 0.35 & 1374 & 6095 & 3.96 & 15.88 & 8.95 & \\
\hline $\operatorname{Van} 7-78-40$ & Cpx1D & Core & 1.59 & 6.30 & 3.06 & 0.85 & 0.37 & 1.85 & 1.01 & 1.08 & & & & & & & \\
\hline $\operatorname{Van} 7-78-40$ & $\mathrm{Cpx} 1$ & $\operatorname{Rim}$ & 1.12 & 4.90 & 4.19 & 1.65 & 0.50 & 3.11 & 1.48 & 1.38 & 0.31 & 2554 & 4806 & 3.28 & 20.49 & 30.45 & \\
\hline Van7-78-40 & Cpx2 & Ints & 1.18 & 5.10 & 4.59 & 1.69 & 0.42 & 3.04 & 1.50 & 1.34 & 0.33 & 2556 & 6012 & 3.40 & 20.52 & 32.52 & \\
\hline Van7-78-40 & Cpx3 & Ints & 1.06 & 4.87 & 3.96 & 1.73 & 0.37 & 3.01 & 1.45 & 1.25 & 0.28 & 2197 & 4050 & 1.97 & 18.51 & 19.58 & \\
\hline Van7-78-41 & Cpx1 & Core & 0.37 & 1.55 & 1.18 & 0.76 & 0.25 & 2.40 & 1.22 & 1.48 & 0.28 & 1307 & 7225 & 1.11 & 20.85 & 6.79 & \\
\hline $\operatorname{Van} 7-78-41$ & Cpx1D & Core & 0.47 & 1.79 & 1.38 & 1.04 & 0.31 & 2.72 & 1.66 & 1.57 & & & & & & & \\
\hline $\operatorname{Van} 7-78-41$ & Cpx1 & Rim & 0.24 & 0.99 & 0.92 & 0.60 & 0.16 & 1.83 & 1.04 & 0.90 & 0.21 & 1159 & 3505 & 0.65 & 16.88 & 6.61 & \\
\hline Van7-78-41 & Cpx2 & Core & 0.25 & 1.02 & 1.03 & 0.57 & 0.22 & 1.98 & 1.01 & 1.13 & 0.25 & 1293 & 6406 & 1.07 & 16.05 & 6.47 & \\
\hline Van7-78-41 & Cpx2 & $\operatorname{Rim}$ & 0.24 & 1.03 & 0.90 & 0.49 & 0.23 & 1.82 & 1.19 & 1.05 & 0.26 & 1192 & 4507 & 1.04 & 14.97 & 6.24 & \\
\hline Van7-85-05 & $\mathrm{Cpx} 1$ & Ints & 1.98 & 8.57 & 9.57 & 3.13 & 1.20 & 4.67 & 2.78 & 2.01 & 0.36 & 7380 & 3913 & 25.86 & 27.80 & 52.09 & \\
\hline Van7-85-24 & Cpx1 & Core & 0.00 & 0.01 & 0.27 & 0.37 & 0.22 & 1.80 & 1.17 & 1.03 & 0.35 & 1197 & 5728 & 1.73 & 14.99 & 1.02 & \\
\hline $\operatorname{Van} 7-85-24$ & $\mathrm{Cpx} 1$ & Rim & 0.00 & 0.01 & 0.22 & 0.47 & 0.24 & 1.83 & 1.22 & 1.17 & 0.27 & 1110 & 4326 & 1.63 & 12.86 & 1.21 & \\
\hline Van7-85-24 & Cpx2 & Core & 0.00 & 0.01 & 0.19 & 0.38 & 0.16 & 1.34 & 0.85 & 0.92 & 0.31 & 1012 & 5290 & 1.40 & 12.47 & 0.84 & \\
\hline $\operatorname{Van} 7-85-24$ & Cpx2 & Rim & 0.01 & 0.01 & 0.23 & 0.44 & 0.17 & 1.73 & 1.06 & 0.95 & 0.31 & 1208 & 5047 & 1.55 & 14.24 & 1.03 & \\
\hline $\operatorname{Van} 7-85-24$ & Cpx3 & Core & 0.01 & 0.01 & 0.27 & 0.45 & 0.17 & 1.49 & 1.04 & 0.94 & 0.31 & 1091 & 5528 & 1.26 & 12.03 & 0.88 & \\
\hline Van7-85-24 & Cpx3 & Rim & 0.01 & 0.02 & 0.28 & 0.53 & 0.21 & 1.65 & 1.05 & 1.02 & 0.97 & 1302 & 5062 & 2.99 & 11.96 & 1.13 & \\
\hline Van7-85-24 & $\mathrm{Cpx} 4$ & Ints & 0.00 & 0.01 & 0.33 & 0.52 & 0.25 & 1.74 & 1.17 & 1.08 & 0.34 & 1272 & 5959 & 1.12 & 13.96 & 0.97 & \\
\hline $\operatorname{Van} 7-85-27$ & $\mathrm{Cpx} 1$ & Core & 0.01 & 0.06 & 0.34 & 0.44 & 0.19 & 1.52 & 0.86 & 0.85 & 0.47 & 1024 & 5549 & 0.94 & 9.48 & 1.27 & \\
\hline Van7-85-27 & Cpx1 & Rim & 0.01 & 0.07 & 0.37 & 0.36 & 0.20 & 1.65 & 0.88 & 0.84 & 0.56 & 1120 & 5275 & 1.16 & 11.48 & 2.08 & \\
\hline Van7-85-27 & Cpx2 & Core & 0.00 & 0.08 & 0.27 & 0.51 & 0.16 & 1.38 & 0.79 & 0.74 & 0.30 & 851 & 6215 & 0.91 & 9.26 & 1.10 & \\
\hline Van7-85-27 & Cpx2 & Rim & 0.00 & 0.05 & 0.44 & 0.44 & 0.17 & 1.52 & 0.93 & 0.81 & 0.50 & 957 & 5608 & 1.33 & 10.18 & 1.34 & \\
\hline Van7-85-30 & Cpx1 & Core & 0.04 & 0.03 & 0.36 & 0.32 & 0.18 & 1.39 & 0.97 & 0.74 & 0.22 & 898 & 5663 & 1.03 & 10.49 & 1.01 & \\
\hline $\operatorname{Van} 7-85-30$ & Cpx1 & $\operatorname{Rim}$ & 0.02 & 0.03 & 0.31 & 0.34 & 0.22 & 1.38 & 0.91 & 0.81 & 0.32 & 1274 & 4910 & 0.94 & 14.19 & 1.60 & \\
\hline Van7-85-30 & Cpx3 & Ints & 0.04 & 0.07 & 0.29 & 0.47 & 0.22 & 1.59 & 0.89 & 0.84 & 0.35 & 1514 & 6295 & 1.15 & 15.20 & 1.66 & \\
\hline Van7-85-30 & Cpx4 & Core & 0.03 & 0.06 & 0.36 & 0.36 & 0.25 & 1.46 & 0.88 & 0.75 & 0.28 & 1366 & 8097 & 1.50 & 17.92 & 1.24 & \\
\hline Van7-85-30 & Cpx4 & Rim & 0.03 & 0.08 & 0.36 & 0.48 & 0.27 & 1.45 & 0.85 & 0.87 & 0.27 & 1400 & 6452 & 1.35 & 16.95 & 1.42 & \\
\hline $\operatorname{Van} 7-85-32$ & Cpx3 & Core & 0.01 & 0.03 & 0.23 & 0.40 & 0.13 & 1.20 & 0.76 & 0.58 & 0.22 & 918 & 4706 & 0.92 & 9.78 & 0.64 & \\
\hline
\end{tabular}


Table 5.10: Cpx trace elements, Cont.

\begin{tabular}{|c|c|c|c|c|c|c|c|c|c|c|c|c|c|c|c|c|c|}
\hline Sample & Grain $^{a}$ & Type $^{b}$ & $\mathrm{La}$ & $\mathrm{Ce}$ & $\mathrm{Nd}$ & $\mathrm{Sm}$ & $\mathrm{Eu}$ & Dy & $\mathrm{Er}$ & $\mathrm{Yb}$ & $\mathrm{Na}_{2} \mathrm{O}$ & $\mathrm{Ti}$ & $\mathrm{Cr}$ & $\mathrm{Sr}$ & $\mathrm{Y}$ & $\mathrm{Zr}$ & Notes $^{c}$ \\
\hline Van7-85-32 & Cpx3 & Rim & & 0.02 & 0.13 & 0.37 & 0.19 & 1.19 & 0.78 & 0.51 & 0.25 & 1051 & 4809 & 0.60 & 11.66 & 0.61 & \\
\hline Van7-85-39 & Cpx 1 & Core & 0.01 & 0.02 & 0.32 & 0.50 & 0.27 & 1.49 & 0.93 & 1.05 & 0.43 & 1276 & 5391 & 1.30 & 12.56 & 1.78 & \\
\hline Van7-85-39 & Cpx1D & Core & 0.01 & 0.02 & 0.25 & 0.50 & 0.23 & 1.63 & 1.11 & 1.15 & 0.44 & 1195 & 5064 & 1.37 & 13.03 & 1.59 & \\
\hline Van7-85-39 & Cpx1 & $\operatorname{Rim}$ & & & & & & & & & 0.45 & 1313 & 5039 & 0.95 & 12.89 & 1.48 & \\
\hline Van7-85-39 & Cpx3 & Core & 0.01 & 0.02 & 0.39 & 0.47 & 0.16 & 1.59 & 1.00 & 1.15 & 0.38 & 1091 & 4668 & 1.14 & 12.99 & 0.95 & \\
\hline Van7-85-39 & Cpx3 & $\operatorname{Rim}$ & & 0.01 & 0.32 & 0.38 & 0.20 & 1.71 & 1.31 & 1.01 & 0.31 & 1078 & 4001 & 1.40 & 12.46 & 0.96 & \\
\hline $\operatorname{Van} 7-85-39$ & Cpx4 & Ints & 0.08 & 0.02 & 0.30 & 0.43 & 0.27 & 1.67 & 0.80 & 0.76 & 0.41 & 1224 & 4247 & 1.75 & 11.62 & 1.19 & \\
\hline Van7-85-42 & Cpx 1 & Core & 0.03 & 0.06 & 0.28 & 0.50 & 0.23 & 1.44 & 1.05 & 0.96 & 0.30 & 1155 & 7085 & 1.44 & 13.91 & 1.94 & \\
\hline Van7-85-42 & Cpx 1 & $\operatorname{Rim}$ & 0.01 & 0.02 & 0.22 & 0.46 & 0.23 & 1.64 & 1.01 & 1.00 & 0.38 & 1616 & 7389 & 1.80 & 15.48 & 1.65 & \\
\hline Van7-85-42 & Cpx2 & Core & 0.02 & 0.03 & 0.24 & 0.38 & 0.21 & 1.55 & 0.96 & 0.80 & 0.33 & 1003 & 4641 & 1.56 & 10.59 & 1.32 & \\
\hline Van7-85-42 & Cpx2 & $\operatorname{Rim}$ & 0.02 & 0.04 & 0.25 & 0.42 & 0.20 & 1.67 & 1.11 & 0.90 & 0.27 & 1077 & 3888 & 0.77 & 10.35 & 1.37 & \\
\hline Van7-85-42 & Cpx3 & Ints & 0.01 & 0.05 & 0.32 & 0.40 & 0.24 & 1.42 & 0.93 & 0.82 & 0.31 & 1251 & 6314 & 1.31 & 13.13 & 1.21 & \\
\hline Van7-85-47 & $\mathrm{Cpx} 2$ & Core & 0.01 & 0.02 & 0.25 & 0.33 & 0.18 & 1.46 & 0.91 & 0.89 & 0.34 & 998 & 5182 & 0.61 & 12.53 & 0.56 & \\
\hline Van7-85-47 & Cpx2 & $\operatorname{Rim}$ & 0.01 & 0.03 & 0.37 & 0.49 & 0.20 & 2.25 & 1.37 & 1.16 & 0.32 & 1053 & 4084 & 0.65 & 12.84 & 0.81 & \\
\hline $\operatorname{Van} 7-85-47$ & Cpx3 & Core & 0.01 & 0.03 & 0.32 & 0.49 & 0.18 & 1.37 & 0.90 & 0.89 & 0.34 & 942 & 5793 & 0.51 & 11.64 & 0.64 & \\
\hline Van7-85-47 & Cpx3 & $\operatorname{Rim}$ & 0.01 & 0.02 & 0.19 & 0.37 & 0.17 & 1.41 & 1.10 & 0.93 & 0.37 & 1051 & 4728 & 0.73 & 12.17 & 0.74 & \\
\hline Van7-85-49 & Cpx 1 & Core & 0.01 & 0.02 & 0.15 & 0.23 & 0.14 & 1.17 & 0.71 & 0.86 & 0.37 & 1119 & 5775 & 2.50 & 12.42 & 1.45 & \\
\hline Van7-85-49 & Cpx1 & $\operatorname{Rim}$ & 0.01 & 0.02 & 0.20 & 0.20 & 0.13 & 1.15 & 0.68 & 0.75 & 0.38 & 951 & 5271 & 2.22 & 11.11 & 1.49 & \\
\hline Van7-85-49 & Cpx3 & Ints & 0.02 & 0.06 & 0.36 & 0.63 & 0.30 & 1.66 & 1.04 & 0.88 & 0.42 & 1062 & 5227 & 2.44 & 11.86 & 1.90 & \\
\hline $\operatorname{Van} 7-85-49$ & Cpx4 & Core & 0.01 & 0.03 & 0.31 & 0.44 & 0.22 & 1.45 & 0.80 & 0.80 & 0.37 & 892 & 5445 & 3.17 & 11.48 & 1.19 & \\
\hline Van7-85-49 & $\mathrm{Cpx} 4$ & $\operatorname{Rim}$ & 0.01 & 0.03 & 0.36 & 0.72 & 0.25 & 1.47 & 0.87 & 0.75 & 0.35 & 982 & 4037 & 1.97 & 11.84 & 1.41 & \\
\hline Van7-86-25 & Cpx 1 & Core & 0.02 & 0.01 & 0.14 & 0.36 & 0.20 & 1.51 & 0.82 & 0.84 & 0.33 & 767 & 6545 & 2.47 & 10.00 & 1.37 & \\
\hline Van7-86-25 & Cpx1 & Rim & 0.02 & 0.01 & 0.18 & 0.24 & 0.15 & 0.79 & 0.58 & 0.48 & 0.36 & 900 & 6101 & 2.29 & 9.84 & 3.18 & \\
\hline Van7-86-25 & $\mathrm{Cpx} 2$ & Ints & & 0.02 & 0.10 & 0.30 & 0.12 & 1.05 & 0.65 & 0.59 & 0.40 & 872 & 4932 & 2.37 & 8.76 & 1.17 & \\
\hline Van7-86-25 & Cpx2D & Ints & 0.01 & 0.02 & 0.11 & 0.35 & 0.12 & 1.28 & 0.86 & 0.75 & & & & & & & \\
\hline Van7-86-25 & Cpx3 & Ints & 0.03 & 0.03 & 0.18 & 0.35 & 0.15 & 1.00 & 0.63 & 0.54 & 0.34 & 811 & 4990 & 2.45 & 8.34 & 1.28 & \\
\hline Van7-86-25 & Cpx4 & Core & 0.00 & 0.04 & 0.10 & 0.27 & 0.14 & 1.04 & 0.76 & 0.63 & 0.30 & 696 & 6037 & 3.33 & 8.36 & 1.08 & \\
\hline $\operatorname{Van} 7-86-25$ & $\mathrm{Cpx} 4$ & Rim & 0.00 & 0.01 & 0.13 & 0.33 & 0.17 & 1.35 & 0.89 & 0.89 & 0.34 & 918 & 5803 & 2.81 & 9.87 & 1.42 & \\
\hline Van7-86-27 & Cpx 1 & Core & 0.01 & 0.01 & 0.21 & 0.29 & 0.15 & 1.34 & 0.83 & 1.02 & 0.16 & 745 & 4897 & 0.50 & 7.55 & 0.55 & \\
\hline Van7-86-27 & Cpx 1 & Rim & 0.00 & 0.02 & 0.22 & 0.35 & 0.17 & 1.33 & 0.82 & 0.74 & 0.21 & 1056 & 3495 & 0.80 & 8.88 & 0.45 & \\
\hline $\operatorname{Van} 7-86-27$ & Cpx1D & Rim & 0.01 & 0.02 & 0.21 & 0.37 & 0.15 & 1.42 & 0.98 & 0.86 & & & & & & & \\
\hline Van7-86-27 & $\mathrm{Cpx} 2$ & Ints & 0.03 & 0.02 & 0.20 & 0.28 & 0.17 & 1.57 & 0.89 & 0.79 & 0.35 & 984 & 4230 & 0.50 & 9.25 & 0.51 & \\
\hline Van7-86-27 & Cpx2D & Ints & 0.01 & 0.02 & 0.18 & 0.38 & 0.17 & 1.45 & 0.93 & 0.97 & & & & & & & \\
\hline Van7-86-27 & Cpx3 & Core & 0.00 & & 0.17 & 0.37 & 0.15 & 1.46 & 0.82 & 0.80 & 0.24 & 880 & 4780 & 0.46 & 8.38 & 0.42 & \\
\hline Van7-86-27 & Cpx3 & Rim & 0.00 & 0.01 & 0.10 & 0.37 & 0.13 & 1.43 & 0.92 & 0.90 & 0.12 & 729 & 2600 & 0.66 & 4.83 & 0.45 & \\
\hline $\operatorname{Van} 7-86-28$ & Cpx1 & Core & 0.01 & 0.03 & 0.11 & 0.29 & 0.10 & 1.22 & 0.79 & 0.67 & 0.27 & 899 & 5018 & 2.77 & 8.30 & 0.91 & \\
\hline Van7-86-28 & Cpx1 & Rim & 0.01 & 0.02 & 0.15 & 0.33 & 0.10 & 1.09 & 0.61 & 0.59 & 0.23 & 858 & 2485 & 2.46 & 8.25 & 1.25 & \\
\hline Van7-86-28 & Cpx2 & Ints & 0.00 & 0.02 & 0.08 & 0.33 & 0.10 & 1.22 & 0.87 & 0.81 & 0.21 & 1158 & 4698 & 2.41 & 10.92 & 1.26 & \\
\hline $\operatorname{Van} 7-86-28$ & Cpx3 & Core & 0.01 & 0.03 & 0.20 & 0.25 & 0.13 & 1.10 & 0.73 & 0.66 & 0.24 & 990 & 5315 & 3.00 & 9.31 & 1.36 & \\
\hline Van7-86-28 & Cpx3 & Rim & 0.00 & 0.02 & 0.20 & 0.28 & 0.10 & 1.15 & 0.77 & 0.69 & 0.24 & 1061 & 5124 & 2.82 & 9.40 & 1.53 & \\
\hline $\operatorname{Van} 7-86-28$ & Cpx4 & Ints & 0.00 & 0.03 & 0.17 & 0.19 & 0.13 & 1.10 & 0.67 & 0.65 & & & & & & & \\
\hline
\end{tabular}


Table 5.10: Cpx trace elements, Cont.

\begin{tabular}{|c|c|c|c|c|c|c|c|c|c|c|c|c|c|c|c|c|c|}
\hline Sample & Grain $^{a}$ & Type $^{b}$ & $\mathrm{La}$ & $\mathrm{Ce}$ & $\mathrm{Nd}$ & $\mathrm{Sm}$ & $\mathrm{Eu}$ & Dy & $\mathrm{Er}$ & $\mathrm{Yb}$ & $\mathrm{Na}_{2} \mathrm{O}$ & $\mathrm{Ti}$ & $\mathrm{Cr}$ & $\mathrm{Sr}$ & $\mathrm{Y}$ & $\mathrm{Zr}$ & Notes $^{c}$ \\
\hline Van7-86-30 & Cpx 1 & Core & 0.00 & 0.01 & 0.13 & 0.20 & 0.10 & 0.97 & 0.57 & 0.49 & 0.26 & 887 & 5579 & 1.98 & 9.89 & 1.90 & \\
\hline Van7-86-30 & Cpx 1 & Rim & 0.01 & 0.01 & 0.26 & 0.25 & 0.15 & 1.29 & 0.89 & 0.71 & 0.31 & 898 & 4946 & 2.06 & 8.71 & 1.55 & \\
\hline $\operatorname{Van} 7-86-30$ & Cpx2 & Ints & 0.01 & 0.01 & 0.21 & 0.39 & 0.12 & 1.13 & 0.88 & 0.68 & 0.28 & 1090 & 4923 & 1.82 & 10.22 & 1.66 & \\
\hline $\operatorname{Van} 7-86-30$ & Cpx3 & Ints & 0.01 & 0.01 & 0.22 & 0.30 & 0.13 & 1.46 & 0.85 & 0.73 & 0.29 & 1147 & 4601 & 2.51 & 11.20 & 2.84 & \\
\hline Van7-86-37 & Cpx1 & Core & 0.04 & 0.28 & 0.54 & 0.40 & 0.15 & 1.17 & 0.66 & 0.47 & 0.41 & 895 & 7107 & 5.72 & 8.58 & 3.76 & \\
\hline Van7-86-37 & Cpx 1 & $\operatorname{Rim}$ & 0.02 & 0.26 & 0.62 & 0.41 & 0.15 & 1.10 & 0.77 & 0.51 & 0.43 & 1109 & 6938 & 7.41 & 10.28 & 5.20 & \\
\hline Van7-86-37 & $\mathrm{Cpx} 2$ & Ints & 0.04 & 0.30 & 0.56 & 0.46 & 0.14 & 1.30 & 0.75 & 0.55 & 0.55 & 1195 & 7206 & 8.78 & 10.19 & 5.15 & \\
\hline Van 7-96-09 & Cpx1 & Core & 0.21 & 1.55 & 3.16 & 1.31 & 0.60 & 2.91 & 2.05 & 1.83 & 0.39 & 2098 & 1919 & 6.31 & 24.02 & 14.43 & PyxVn \\
\hline Van7-96-09 & Cpx 1 & $\operatorname{Rim}$ & 0.19 & 1.15 & 2.47 & 1.33 & 0.56 & 2.31 & 1.76 & 1.50 & 0.38 & 2292 & 2030 & 5.72 & 22.39 & 14.37 & PyxVn \\
\hline Van7-96-09 & Cpx2 & Core & 0.19 & 1.43 & 2.61 & 1.20 & 0.52 & 2.55 & 1.65 & 1.58 & 0.52 & 2212 & 1972 & 8.44 & 22.91 & 15.38 & PyxVn \\
\hline Van7-96-09 & Cpx2 & $\operatorname{Rim}$ & 0.17 & 1.55 & 3.65 & 1.87 & 0.77 & 3.99 & 3.16 & 2.18 & 0.46 & 2759 & 2311 & 4.39 & 27.80 & 19.63 & PyxVn \\
\hline Van7-96-09 & Cpx3 & Core & 0.18 & 1.55 & 2.96 & 1.10 & 0.58 & 2.13 & 1.33 & 1.09 & 0.47 & 1957 & 4322 & 10.78 & 13.65 & 16.21 & PyxVn \\
\hline Van7-96-09 & Cpx3 & $\operatorname{Rim}$ & 0.20 & 1.41 & 3.17 & 1.40 & 0.62 & 2.91 & 1.69 & 1.40 & 0.52 & 2511 & 4570 & 5.56 & 17.22 & 19.75 & PyxVn \\
\hline Van7-96-09 & Cpx4 & Ints & 0.26 & 1.67 & 3.96 & 1.77 & 0.75 & 3.62 & 2.30 & 2.17 & 0.44 & 3931 & 2988 & 7.29 & 35.52 & 30.78 & PyxVn \\
\hline Van7-96-09 & Cpx5 & Ints & 0.22 & 1.46 & 3.75 & 1.98 & 0.83 & 3.58 & 2.06 & 1.89 & 0.46 & 2822 & 2809 & 5.82 & 27.26 & 20.40 & PyxVn \\
\hline $\operatorname{Van} 7-96-14$ & Cpx1 & Core & 0.07 & 0.75 & 3.92 & 1.94 & 0.60 & 4.06 & 2.73 & 2.11 & 0.45 & 3881 & 1948 & 2.01 & 31.53 & 21.41 & PyxVn \\
\hline Van7-96-14 & Cpx1 & $\operatorname{Rim}$ & 0.04 & 0.87 & 3.42 & 2.23 & 0.65 & 4.51 & 2.64 & 2.13 & 0.37 & 3876 & 2326 & 3.76 & 27.11 & 18.79 & PyxVn \\
\hline Van7-96-14 & Cpx2 & Core & 0.08 & 0.86 & 3.12 & 1.57 & 0.63 & 3.53 & 2.53 & 2.43 & 0.47 & 3040 & 1259 & 3.06 & 32.49 & 18.71 & PyxVn \\
\hline Van7-96-14 & Cpx2 & Rim & 0.08 & 1.17 & 3.99 & 2.04 & 0.76 & 4.74 & 3.24 & 2.72 & 0.41 & 4461 & 1626 & 1.93 & 39.44 & 25.88 & PyxVn \\
\hline $\operatorname{Van} 7-96-14$ & Cpx 5 & Core & 0.09 & 1.21 & 3.56 & 2.25 & 0.70 & 5.29 & 4.09 & 3.92 & 0.35 & 3245 & 2016 & 1.84 & 42.68 & 25.77 & PyxVn \\
\hline Van7-96-14 & Cpx5 & $\operatorname{Rim}$ & 0.07 & 1.34 & 5.20 & 3.39 & 0.58 & 7.97 & 5.32 & 4.43 & 0.54 & 2026 & 1731 & 3.87 & 16.08 & 15.06 & PyxVn \\
\hline Van7-96-14 & Сpx6 & Core & 0.05 & 1.04 & 3.01 & 1.49 & 0.69 & 3.09 & 2.33 & 2.30 & 0.34 & 2655 & 1451 & 2.88 & 27.44 & 18.19 & PyxVn \\
\hline $\operatorname{Van} 7-96-14$ & Сpx6 & $\operatorname{Rim}$ & 0.08 & 1.41 & 4.75 & 2.48 & 0.88 & 5.53 & 4.10 & 2.90 & 0.39 & 4578 & 1704 & 1.96 & 40.21 & 31.85 & PyxVn \\
\hline Van7-96-14 & Cpx7 & Core & 0.10 & 1.04 & 3.55 & 1.76 & 0.83 & 3.57 & 2.48 & 2.41 & 0.36 & 2584 & 1590 & 2.90 & 27.33 & 19.85 & PyxVn \\
\hline Van7-96-14 & Cpx7 & Rim & 0.08 & 1.20 & 5.32 & 2.67 & 0.76 & 5.37 & 3.42 & 2.84 & 0.54 & 3749 & 1741 & 2.72 & 45.21 & 33.79 & PyxVn \\
\hline $\operatorname{Van} 7-96-15$ & Cpx1 & Ints & 0.12 & 1.73 & 7.08 & 4.36 & 0.81 & 8.07 & 4.09 & 4.08 & 0.53 & 7894 & 5528 & 4.14 & 79.65 & 77.00 & PyxVn \\
\hline Van7-96-15 & Cpx2 & Ints & 0.10 & 1.70 & 5.28 & 2.71 & 0.74 & 5.51 & 3.30 & 2.60 & 0.46 & 5317 & 3640 & 3.72 & 62.35 & 46.14 & PyxVn \\
\hline Van7-96-15 & Cpx3 & Core & 0.05 & 1.10 & 3.04 & 1.59 & 0.63 & 2.92 & 1.97 & 1.96 & 0.43 & 3413 & 2011 & 5.65 & 50.39 & 30.74 & PyxVn \\
\hline Van7-96-15 & Cpx3 & $\operatorname{Rim}$ & 0.09 & 1.65 & 4.21 & 2.42 & 0.84 & 4.62 & 2.71 & 2.56 & 0.42 & 3847 & 2174 & 3.98 & 50.42 & 35.74 & PyxVn \\
\hline Van7-96-15 & Cpx4 & Core & 0.10 & 1.03 & 2.78 & 1.45 & 0.51 & 3.19 & 2.23 & 1.88 & 0.28 & 1731 & 1018 & 7.74 & 19.08 & 11.59 & PyxVn \\
\hline Van7-96-15 & $\mathrm{Cpx} 4$ & Rim & 0.08 & 1.18 & 3.39 & 2.15 & 0.63 & 4.31 & 2.62 & 1.95 & 0.38 & 4254 & 2365 & 4.05 & 44.05 & 31.68 & PyxVn \\
\hline Van7-96-15 & $\mathrm{Cpx} 4 \mathrm{D}$ & Rim & & & & & & & & & 0.41 & 3948 & 1928 & 4.19 & 41.14 & 31.03 & PyxVn \\
\hline Van7-96-16 & Cpx1 & Core & 0.08 & 1.02 & 2.90 & 1.35 & 0.55 & 2.77 & 1.85 & 1.56 & 0.50 & 3281 & 3427 & 7.39 & 37.03 & 28.17 & PyxVn \\
\hline Van7-96-16 & Cpx 1 & Rim & 0.07 & 1.58 & 5.52 & 2.98 & 0.74 & 5.97 & 3.49 & 2.88 & 0.46 & 4351 & 3904 & 3.81 & 53.97 & 45.49 & PyxVn \\
\hline Van7-96-16 & Cpx2 & Ints & 0.10 & 1.53 & 6.12 & 2.95 & 0.71 & 5.52 & 3.36 & 2.46 & 0.43 & 4357 & 3833 & 2.83 & 55.74 & 47.82 & PyxVn \\
\hline Van7-96-16 & Cpx3 & Ints & 0.11 & 1.94 & 6.24 & 3.20 & 0.96 & 5.74 & 4.00 & 2.92 & 0.55 & 4077 & 2458 & 6.02 & 52.16 & 38.18 & PyxVn \\
\hline $\operatorname{Van} 7-96-16$ & $\mathrm{Cpx} 4$ & Core & 0.10 & 1.48 & 3.73 & 1.75 & 0.61 & 3.42 & 2.18 & 1.86 & 0.42 & 3437 & 2261 & 10.06 & 38.25 & 27.10 & PyxVn \\
\hline Van7-96-16 & Cpx4 & $\operatorname{Rim}$ & 0.11 & 1.72 & 4.08 & 2.11 & 0.57 & 3.89 & 2.50 & 1.59 & 0.32 & 5045 & 3015 & 4.51 & 53.17 & 45.16 & PyxVn \\
\hline Van7-96-18 & Cpx1 & Core & 0.22 & 2.11 & 3.60 & 1.61 & 0.59 & 2.40 & 1.55 & 1.41 & 1.11 & 3078 & 4985 & 16.28 & 28.89 & 24.08 & NrMat \\
\hline Van7-96-18 & Cpx1 & Rim & 0.26 & 2.11 & 2.26 & 1.40 & 0.69 & 3.25 & 2.01 & 1.91 & 0.99 & 3047 & 4629 & 14.56 & 24.49 & 21.55 & NrMat \\
\hline Van7-96-18 & Cpx2 & Ints & 0.23 & 1.78 & 2.69 & 1.52 & 0.64 & 2.78 & 1.77 & 1.65 & 1.02 & 3342 & 4104 & 11.27 & 23.81 & 22.06 & NrMat \\
\hline
\end{tabular}


Table 5.10: Cpx trace elements, Cont.

\begin{tabular}{|c|c|c|c|c|c|c|c|c|c|c|c|c|c|c|c|c|c|}
\hline Sample & Grain $^{a}$ & Type $^{b}$ & $\mathrm{La}$ & $\mathrm{Ce}$ & $\mathrm{Nd}$ & $\mathrm{Sm}$ & $\mathrm{Eu}$ & Dy & $\mathrm{Er}$ & $\mathrm{Yb}$ & $\mathrm{Na}_{2} \mathrm{O}$ & $\mathrm{Ti}$ & $\mathrm{Cr}$ & $\mathrm{Sr}$ & $\mathrm{Y}$ & $\mathrm{Zr}$ & Notes $^{c}$ \\
\hline Van7-96-18 & Cpx3 & Ints & 0.22 & 1.69 & 2.65 & 1.19 & 0.49 & 2.60 & 1.66 & 1.53 & 0.87 & 2312 & 3659 & 8.68 & 17.80 & 15.80 & NrMat \\
\hline Van7-96-18 & Cpx3D & Ints & & & & & & & & & 0.86 & 2923 & 3380 & 9.48 & 21.17 & 20.97 & NrMat \\
\hline Van7-96-18 & $\mathrm{Cpx} 4$ & Ints & 0.21 & 1.66 & 2.95 & 1.35 & 0.56 & 3.06 & 1.76 & 1.48 & 1.11 & 2980 & 4186 & 12.16 & 22.90 & 19.66 & NrMat \\
\hline Van7-96-18 & Cpx6 & Core & 0.13 & 1.39 & 2.26 & 1.31 & 0.42 & 2.94 & 2.22 & 1.97 & 0.50 & 1977 & 2047 & 4.82 & 20.95 & 11.19 & PyxVn \\
\hline Van7-96-18 & Сpx6 & $\operatorname{Rim}$ & 0.14 & 1.30 & 2.56 & 1.36 & 0.53 & 3.75 & 2.46 & 2.41 & 0.60 & 2975 & 2989 & 3.66 & 28.58 & 20.29 & PyxVn \\
\hline Van7-96-18 & Cpx7 & Core & 0.18 & 1.55 & 3.03 & 1.59 & 0.65 & 3.65 & 2.81 & 2.49 & 0.50 & 2272 & 2336 & 3.75 & 22.64 & 17.16 & PyxVn \\
\hline Van7-96-18 & Cpx7 & Rim & 0.16 & 1.98 & 3.55 & 2.06 & 0.70 & 5.07 & 2.77 & 2.78 & 0.54 & 3367 & 2978 & 2.41 & 28.46 & 23.99 & PyxVn \\
\hline Van7-96-18 & Cpx8 & Ints & 0.14 & 1.25 & 2.39 & 1.26 & 0.51 & 3.67 & 2.20 & 1.90 & 0.47 & 2910 & 3704 & 2.39 & 29.62 & 21.86 & PyxVn \\
\hline Van7-96-19 & Cpx 1 & Core & 0.22 & 2.18 & 3.79 & 2.12 & 0.59 & 2.83 & 1.49 & 1.53 & 0.54 & 2905 & 5532 & 10.54 & 17.28 & 26.75 & NrMat \\
\hline Van7-96-19 & Cpx1 & Rim & 0.19 & 1.68 & 4.09 & 1.76 & 0.70 & 3.78 & 2.07 & 1.74 & 0.58 & 3941 & 6070 & 6.74 & 22.70 & 38.56 & NrMat \\
\hline Van7-96-19 & Cpx2 & Core & 0.23 & 1.35 & 2.85 & 1.25 & 0.60 & 3.47 & 1.79 & 1.66 & 0.73 & 3493 & 4998 & 9.33 & 25.89 & 33.00 & NrMat \\
\hline Van7-96-19 & $\mathrm{Cp \times 2}$ & Rim & 0.33 & 3.15 & 6.12 & 3.32 & 0.86 & 4.75 & 1.92 & 2.23 & 0.49 & 4479 & 5371 & 5.57 & 31.13 & 43.86 & NrMat \\
\hline Van7-96-19 & Cpx3 & Ints & 0.22 & 2.10 & 4.27 & 2.19 & 0.81 & 3.97 & 1.83 & 1.81 & 0.51 & 3716 & 5721 & 6.20 & 18.12 & 56.53 & NrMat \\
\hline Van7-96-19 & Cpx4 & Ints & 0.21 & 2.54 & 4.90 & 2.66 & 0.67 & 3.76 & 2.05 & 1.86 & 0.47 & 3588 & 5837 & 4.63 & 23.80 & 37.75 & NrMat \\
\hline Van7-96-19 & Cpx5 & Core & 0.62 & 4.13 & 5.62 & 3.06 & 0.86 & 3.72 & 2.20 & 1.92 & 0.47 & 3989 & 5974 & 5.73 & 33.23 & 49.67 & PyxVn \\
\hline Van7-96-19 & Cpx5 & Rim & 0.58 & 4.99 & 7.45 & 3.02 & 0.94 & 5.17 & 2.92 & 2.30 & 0.51 & 4526 & 6200 & 5.41 & 34.21 & 55.80 & PyxVn \\
\hline Van7-96-19 & Сpx6 & Ints & 0.41 & 3.33 & 4.71 & 2.19 & 0.81 & 3.38 & 1.73 & 1.54 & 0.46 & 2997 & 6183 & 7.04 & 19.49 & 32.35 & PyxVn \\
\hline Van7-96-19 & Cpx8 & Core & 0.46 & 2.89 & 3.82 & 1.81 & 0.68 & 2.61 & 1.40 & 1.51 & 0.46 & 2774 & 5648 & 14.56 & 21.44 & 31.64 & PyxVn \\
\hline Van7-96-19 & Cpx8D & Core & 0.57 & 4.08 & 5.57 & 2.06 & 0.91 & 3.45 & 1.80 & 1.72 & & & & & & & PyxVn \\
\hline Van7-96-19 & Cpx8 & Rim & 0.53 & 4.17 & 5.12 & 2.35 & 0.78 & 3.33 & 1.69 & 1.50 & 0.53 & 3380 & 6941 & 6.27 & 21.08 & 35.55 & PyxVn \\
\hline Van7-96-19 & $\mathrm{Cpx} 9$ & Rim & 0.52 & 4.27 & 5.71 & 2.16 & 0.81 & 3.60 & 1.44 & 1.56 & 0.56 & 3489 & 7218 & 15.83 & 16.35 & 38.33 & AdjVn \\
\hline Van7-96-21 & Cpx1 & Core & 0.92 & 4.60 & 4.64 & 1.65 & 0.57 & 1.96 & 1.15 & 1.07 & 1.00 & 3204 & 4756 & 47.27 & 17.32 & 33.22 & PyxVn \\
\hline Van7-96-21 & Cpx1D & Core & 1.36 & 3.42 & 4.87 & 1.96 & 0.84 & 2.79 & 1.45 & 1.31 & & & & & & & PyxVn \\
\hline Van7-96-21 & $\mathrm{Cpx} 1$ & Rim & 1.32 & 8.19 & 8.76 & 3.14 & 1.14 & 3.54 & 2.14 & 2.02 & 0.60 & 3195 & 4319 & 23.71 & 19.61 & 33.01 & PyxVn \\
\hline Van7-96-21 & $\mathrm{Cpx} 4$ & Core & 0.84 & 4.45 & 5.46 & 2.03 & 0.74 & 2.27 & 1.37 & 1.20 & 0.48 & 2500 & 4455 & 27.98 & 12.76 & 23.09 & AdjVn \\
\hline Van7-96-21 & $\mathrm{Cpx} 4$ & Rim & 1.29 & 7.74 & 10.33 & 3.29 & 1.18 & 3.94 & 2.58 & 1.89 & 0.63 & 4884 & 4597 & 10.40 & 27.49 & 55.82 & AdjVn \\
\hline Van7-96-21 & Cpx5 & Core & 1.01 & 5.09 & 5.34 & 1.75 & 0.73 & 2.21 & 1.40 & 1.09 & 0.53 & 2504 & 4460 & 24.44 & 14.19 & 25.32 & AdjVn \\
\hline Van7-96-21 & Cpx5 & Rim & 1.26 & 6.99 & 6.48 & 2.14 & 0.89 & 2.92 & 1.66 & 1.52 & 0.68 & 3534 & 4424 & 37.47 & 23.09 & 38.24 & AdjVn \\
\hline Van7-96-21 & Сpx6 & Ints & 1.10 & 4.58 & 5.31 & 1.81 & 0.69 & 2.20 & 1.16 & 1.08 & 0.47 & 3780 & 4264 & 8.89 & 21.50 & 43.21 & PyxVn \\
\hline Van7-96-21 & Cpx7 & Core & 1.04 & 6.45 & 7.41 & 2.68 & 0.84 & 3.28 & 1.68 & 1.62 & 0.50 & 3122 & 4555 & 18.48 & 21.21 & 33.64 & PyxVn \\
\hline Van7-96-21 & Cpx7 & Rim & 1.01 & 7.07 & 10.19 & 3.98 & 1.15 & 5.11 & 2.95 & 2.39 & 0.81 & 6902 & 4580 & 17.96 & 35.84 & 85.62 & PyxVn \\
\hline Van7-96-21 & Cpx7D & Rim & 1.06 & 8.23 & 11.90 & 4.20 & 1.16 & 5.93 & 2.97 & 2.67 & & & & & & & PyxVn \\
\hline Van7-96-21 & Cpx 8 & Ints & 1.15 & 5.50 & 5.37 & 2.48 & 0.72 & 2.79 & 1.47 & 1.50 & & & & & & & PyxVn \\
\hline Van7-96-25 & Cpx1 & Core & 0.15 & 1.22 & 1.79 & 0.95 & 0.48 & 1.94 & 1.05 & 1.20 & 1.18 & 2272 & 5938 & 13.29 & 18.38 & 15.35 & \\
\hline Van7-96-25 & Cpx1 & Rim & 0.17 & 1.70 & 2.43 & 1.25 & 0.51 & 2.21 & 1.49 & 1.24 & 1.10 & 2692 & 5397 & 13.06 & 19.38 & 19.36 & \\
\hline Van7-96-25 & $\mathrm{Cpx} 2$ & Ints & 0.13 & 1.54 & 2.26 & 1.11 & 0.56 & 2.03 & 1.45 & 1.25 & 1.28 & 2463 & 4974 & 13.83 & 17.19 & 17.21 & \\
\hline Van7-96-25 & Cpx3 & Ints & 0.18 & 1.68 & 2.28 & 1.38 & 0.50 & 2.13 & 1.44 & 1.22 & 1.24 & 2393 & 5464 & 12.87 & 17.19 & 16.10 & \\
\hline Van7-96-25 & $\mathrm{Cpx} 4$ & Ints & 0.20 & 1.28 & 2.29 & 1.12 & 0.51 & 2.05 & 1.18 & 1.13 & 0.93 & 2576 & 5538 & 9.76 & 14.38 & 16.41 & \\
\hline Van7-96-25 & Cpx5 & Core & 0.19 & 1.71 & 2.56 & 1.24 & 0.62 & 2.14 & 1.33 & 1.33 & 1.08 & 2693 & 5919 & 13.39 & 18.43 & 18.09 & \\
\hline Van7-96-25 & Cpx5 & Rim & 0.17 & 1.45 & 2.71 & 1.19 & 0.47 & 2.29 & 1.27 & 1.20 & 1.10 & 2680 & 5785 & 11.67 & 17.34 & 17.70 & \\
\hline Van7-96-28 & $\mathrm{Cpx} 1$ & Core & 1.32 & 4.94 & 3.66 & 1.31 & 0.51 & 1.60 & 0.86 & 0.76 & 1.79 & 2805 & 6171 & 112.95 & 12.32 & 19.69 & \\
\hline
\end{tabular}


Table 5.10: Cpx trace elements, Cont.

\begin{tabular}{|c|c|c|c|c|c|c|c|c|c|c|c|c|c|c|c|c|c|}
\hline Sample & Grain $^{a}$ & Type $^{b}$ & $\mathrm{La}$ & $\mathrm{Ce}$ & $\mathrm{Nd}$ & $\mathrm{Sm}$ & $\mathrm{Eu}$ & Dy & $\mathrm{Er}$ & $\mathrm{Yb}$ & $\mathrm{Na}_{2} \mathrm{O}$ & $\mathrm{Ti}$ & $\mathrm{Cr}$ & $\mathrm{Sr}$ & $\mathrm{Y}$ & $\mathrm{Zr}$ & Notes $^{c}$ \\
\hline Van7-96-28 & Cpx 1 & Rim & 0.85 & 4.53 & 3.24 & 1.28 & 0.48 & 1.46 & 0.78 & 0.74 & 1.68 & 2308 & 5863 & 108.53 & 11.51 & 16.39 & \\
\hline Van7-96-28 & Cpx2 & Core & 1.48 & 5.71 & 3.66 & 1.49 & 0.47 & 1.57 & 0.83 & 0.73 & & & & & & & \\
\hline Van7-96-28 & Cpx3 & Core & 0.97 & 3.99 & 3.15 & 1.08 & 0.45 & 1.31 & 0.57 & 0.70 & 0.75 & 1812 & 6802 & 65.88 & 7.98 & 14.69 & \\
\hline Van7-96-28 & Cpx3 & $\operatorname{Rim}$ & 0.98 & 4.64 & 3.74 & 1.42 & 0.47 & 1.39 & 0.84 & 0.70 & 0.86 & 2769 & 7288 & 55.97 & 14.61 & 22.52 & \\
\hline Van7-96-28 & $\mathrm{Cpx} 4$ & Ints & 1.10 & 5.46 & 4.04 & 1.32 & 0.65 & 1.76 & 0.72 & 0.84 & 0.66 & 2416 & 5887 & 38.54 & 13.63 & 22.25 & \\
\hline Van7-96-28 & Cpx5 & Core & 0.95 & 3.68 & 3.80 & 1.24 & 0.53 & 1.62 & 0.81 & 0.99 & 0.92 & 1785 & 6960 & 70.83 & 8.89 & 14.12 & \\
\hline Van7-96-28 & Cpx5 & Rim & 1.32 & 5.48 & 4.76 & 1.57 & 0.54 & 1.99 & 1.06 & 1.15 & & & & & & & \\
\hline Van7-96-28 & Cpx5D & Rim & 1.10 & 4.24 & 3.75 & 1.21 & 0.62 & 1.74 & 0.97 & 0.91 & & & & & & & \\
\hline Van7-96-28 & Сpx6 & Ints & 1.05 & 4.03 & 2.97 & 1.03 & 0.39 & 1.23 & 0.68 & 0.67 & 1.13 & 2129 & 6734 & 89.19 & 9.82 & 16.90 & \\
\hline Van7-96-35 & Cpx1 & Core & & & & & & & & & 1.43 & 1584 & 8281 & 42.31 & 11.75 & 18.43 & \\
\hline Van7-96-35 & Cpx 1 & $\operatorname{Rim}$ & 0.20 & 1.43 & 2.61 & 1.34 & 0.49 & 1.46 & 0.72 & 0.76 & 1.33 & 1604 & 7836 & 41.40 & 11.26 & 19.28 & \\
\hline Van7-96-35 & Cpx2 & Ints & & & & & & & & & 1.67 & 1841 & 8344 & 34.33 & 12.55 & 22.17 & \\
\hline Van7-96-35 & Cpx3 & Core & 0.40 & 2.44 & 3.35 & 1.29 & 0.48 & 1.62 & 0.95 & 1.04 & 1.14 & 1915 & 7862 & 36.54 & 13.77 & 23.11 & \\
\hline Van7-96-35 & Cpx3 & $\operatorname{Rim}$ & 0.38 & 2.28 & 2.36 & 1.23 & 0.49 & 1.89 & 0.80 & 0.98 & 1.24 & 2047 & 7892 & 33.12 & 13.84 & 26.06 & \\
\hline Van7-96-35 & Cpx4 & Ints & 0.32 & 2.09 & 2.76 & 1.37 & 0.55 & 1.90 & 0.83 & 1.04 & 1.17 & 1903 & 7800 & 32.39 & 12.55 & 23.25 & \\
\hline Van7-96-35 & Cpx5 & Ints & 0.38 & 2.18 & 2.97 & 1.62 & 0.55 & 1.56 & 0.96 & 0.85 & 1.21 & 1822 & 8156 & 39.99 & 12.79 & 23.16 & \\
\hline Van7-96-35 & Сpx6 & Core & 0.49 & 2.60 & 3.24 & 1.68 & 0.56 & 1.93 & 0.72 & 0.96 & 1.16 & 1506 & 8777 & 35.62 & 12.10 & 17.46 & \\
\hline Van7-96-35 & Cpx6 & Rim & 0.39 & 2.62 & 3.46 & 1.69 & 0.62 & 2.16 & 1.13 & 1.35 & 1.31 & 1958 & 7801 & 36.44 & 13.30 & 22.63 & \\
\hline Van7-96-37 & Cpx 1 & Core & 0.88 & 3.84 & 3.51 & 1.36 & 0.53 & 1.59 & 0.82 & 0.79 & 1.20 & 1915 & 8046 & 99.97 & 10.74 & 18.50 & \\
\hline Van7-96-37 & Cpx1 & Rim & 1.21 & 4.41 & 3.55 & 1.21 & 0.62 & 1.97 & 1.19 & 0.98 & 1.08 & 1951 & 7398 & 79.00 & 10.72 & 19.68 & \\
\hline Van7-96-37 & Cpx2 & Ints & 1.23 & 4.68 & 3.37 & 1.52 & 0.67 & 1.67 & 0.91 & 1.05 & 1.07 & 2045 & 8006 & 85.14 & 10.84 & 20.80 & \\
\hline Van7-96-37 & Cpx4 & Ints & 1.00 & 3.73 & 3.38 & 1.32 & 0.60 & 1.61 & 0.65 & 0.93 & 1.30 & 2183 & 7616 & 97.75 & 10.37 & 20.05 & \\
\hline Van7-96-37 & Cpx5 & Core & 1.06 & 3.97 & 3.21 & 1.17 & 0.50 & 1.50 & 0.76 & 0.86 & 1.53 & 1776 & 8350 & 108.54 & 10.94 & 18.63 & \\
\hline Van7-96-37 & Cpx5 & Rim & 1.01 & 4.30 & 3.31 & 1.41 & 0.55 & 1.71 & 0.80 & 0.97 & 1.10 & 1748 & 7605 & 89.47 & 9.94 & 17.67 & \\
\hline Van7-96-38 & Cpx 1 & Core & 0.09 & 1.01 & 2.56 & 1.34 & 0.53 & 2.12 & 1.34 & 1.34 & 1.08 & 2372 & 4230 & 13.52 & 17.93 & 14.32 & \\
\hline Van7-96-38 & Cpx 1 & Rim & 0.10 & 1.16 & 2.56 & 1.34 & 0.60 & 2.57 & 1.82 & 1.35 & 1.09 & 2775 & 3961 & 13.21 & 18.84 & 16.40 & \\
\hline Van7-96-38 & Cpx2 & Core & 0.11 & 0.74 & 3.21 & 1.74 & 0.82 & 3.44 & 2.44 & 1.49 & 1.01 & 2663 & 3989 & 13.17 & 20.10 & 15.57 & \\
\hline Van7-96-38 & Cpx2 & Rim & 0.09 & 1.20 & 3.31 & 1.72 & 0.80 & 3.13 & 2.01 & 1.90 & 0.86 & 2985 & 3613 & 13.29 & 20.72 & 18.62 & \\
\hline Van7-96-66B & Cpx 1 & Ints & 0.22 & 2.20 & 3.45 & 1.41 & 0.61 & 2.67 & 1.06 & 1.05 & 0.53 & 4853 & 3370 & 4.84 & 18.08 & 37.13 & OpxVn \\
\hline Van7-96-66B & Cpx2 & Ints & 0.21 & 2.03 & 2.80 & 1.18 & 0.51 & 2.35 & 1.06 & 0.84 & 0.61 & 4292 & 3310 & 3.96 & 17.85 & 29.83 & OpxVn \\
\hline Van7-96-66B & Cpx3 & Ints & 0.41 & 2.97 & 4.64 & 2.47 & 0.77 & 3.49 & 1.57 & 1.51 & 0.56 & 4944 & 3765 & 7.19 & 23.30 & 39.50 & OpxVn \\
\hline Van7-96-66B & Cpx 5 & Core & 0.22 & 0.68 & 1.13 & 0.39 & 0.22 & 1.08 & 0.53 & 0.63 & 0.68 & 1074 & 575 & 19.64 & 8.31 & 4.45 & Breccia \\
\hline Van7-96-66B & Cpx5 & $\operatorname{Rim}$ & 0.10 & 0.46 & 0.59 & 0.32 & 0.15 & 0.81 & 0.37 & 0.38 & 0.52 & 1045 & 546 & 12.09 & 7.72 & 4.22 & Breccia \\
\hline
\end{tabular}

${ }^{a} \mathrm{D}$ following a grain number indicates duplicate analysis; $\mathrm{L}$ preceding a grain number indicates reprocessed data for sample RC27-9-6-2, from Lee (1997).

${ }^{b}$ Ints refers to interstitial grain, $<1 \mathrm{~mm}$ diameter; Symp refers to symplectite of $\mathrm{Cpx}$ with $\mathrm{Sp} \pm \mathrm{Opx}$; Numbered analyses and Mdpt (midpoint between core and rim) refer to multiple analyses of grains in cryptically metasomatized samples.

${ }^{c}$ Abbreviations for lithologies: Dep, Trans and Enr are depleted, transitional and enriched zones in cryptically metasomatized samples; GbVn refers to a gabbroic vein, PyxVn to a pyroxenite vein, $\mathrm{CpxVn}$ to a clinopyroxenite vein, and $\mathrm{OpxVn}$ to an orthopyroxenite vein; AdjVn is adjacent to a vein, NrMat is $<5 \mathrm{~cm}$ from a vein and FarMat is $>5 \mathrm{~cm}$ from a vein .

Frey, 1984), used as a standard for REEs.

${ }^{e}$ Kilauea tholeiitic basalt glass (Jochum et al., 2000), used as a standard for the other trace elements.

${ }^{f}$ Percent error based on average counting error among all analyses. ${ }^{g}$ Percent error based on average difference among duplicate analyses. 
Table 5.11: Trace element concentrations in plagioclase by ion probe, in ppm.

\begin{tabular}{|c|c|c|c|c|c|c|c|c|c|c|c|c|c|c|c|c|c|}
\hline Sample & Grain & Type $^{a}$ & $\overline{\mathrm{La}}$ & $\mathrm{Ce}$ & $\mathrm{Nd}$ & $\mathrm{Sm}$ & $\mathrm{Eu}$ & Dy & $\mathrm{Er}$ & $\mathrm{Yb}$ & $\mathrm{Na}_{2} \mathrm{O}$ & $\overline{\mathrm{Ti}}$ & $\mathrm{Cr}$ & $\mathrm{Sr}$ & $\bar{Y}$ & $\mathrm{Zr}$ & Notes $^{b}$ \\
\hline Count \% Error & Plag & & 8 & 5 & 10 & 23 & 7 & 28 & 22 & 31 & 0 & 3 & 12 & 3 & 14 & 21 & \\
\hline $6 \mathrm{~K}-465-2$ & Plag1 & Ints & & & & & & & & & 1.33 & 13033 & & 57.8 & 0.95 & 2.18 & Dep \\
\hline $6 \mathrm{~K}-465-2$ & Plag2 & Ints & & & & & & & & & 0.24 & 2419 & & 38.6 & 0.35 & 1.36 & Dep \\
\hline $6 \mathrm{~K}-465-2$ & Plag3 & Ints & & & & & & & & & 0.94 & 52 & & 2.5 & 0.33 & 0.41 & Dep \\
\hline $6 \mathrm{~K}-465-2$ & Plag4 & Ints & & & & & & & & & 1.02 & 52 & & 1.4 & 0.18 & 0.33 & Dep \\
\hline $6 \mathrm{~K}-465-2$ & Plag5 & Ints & & & & & & & & & 1.02 & 60 & & 31.8 & 0.29 & 0.37 & Dep \\
\hline $6 \mathrm{~K}-465-2$ & Plag6 & Ints & & & & & & & & & 0.96 & 52 & & 1.3 & 0.34 & 0.46 & Dep \\
\hline $6 \mathrm{~K}-465-3$ & Plag1a & Ints & & & & & & & & & 7.60 & 49 & 11.70 & 17.3 & 5.15 & 8.31 & NrMat \\
\hline $6 \mathrm{~K}-465-3$ & Plag1b & Ints & 3.29 & 8.53 & 2.74 & 0.65 & 0.56 & 0.36 & 0.43 & 0.09 & 7.44 & 95 & 6.84 & 22.3 & 6.48 & 9.72 & NrMat \\
\hline $6 \mathrm{~K}-465-3$ & Plag3 & Ints & 3.18 & 7.43 & 2.13 & 0.52 & 2.28 & 0.17 & 0.36 & 0.09 & 4.34 & 245 & 4.11 & 325.5 & 1.26 & 0.71 & $\mathrm{GbVn}$ \\
\hline $6 \mathrm{~K}-465-3$ & Plag4a & Ints & 11.65 & 27.07 & 8.26 & 1.39 & 2.46 & 0.47 & 0.43 & 0.18 & 4.07 & 250 & 1.61 & 50.5 & 1.23 & 0.25 & NrMat \\
\hline $6 \mathrm{~K}-465-3$ & Plag4b & Ints & 10.69 & 24.47 & 8.26 & 1.38 & 2.33 & 0.41 & 0.47 & 0.21 & 3.49 & 247 & 1.51 & 54.1 & 1.40 & 0.36 & NrMat \\
\hline RC27-9-6-5 & Plag1 & Ints & 1.23 & 1.73 & 0.27 & 0.02 & 0.23 & 0.01 & 0.08 & 0.02 & 1.59 & 36 & 2.58 & 6.5 & 0.06 & 0.12 & Dep \\
\hline Van7-78-31 & Plag1 & Ints & & & & & & & & & 2.32 & 87 & 1.49 & 81.5 & 0.48 & 0.10 & NrMat \\
\hline Van7-78-31 & Plag2 & Ints & 0.52 & 1.15 & 0.38 & 0.09 & 0.27 & 0.03 & 0.04 & 0.01 & 2.82 & 174 & 1.82 & 371.1 & 0.49 & 0.30 & GbVn \\
\hline Van7-78-36 & Plag11 & Ints & 0.98 & 1.56 & 0.47 & 0.08 & 0.23 & 0.04 & 0.03 & 0.01 & 1.51 & 69 & 2.79 & 47.4 & 0.21 & 0.33 & FarMat \\
\hline Van7-78-36 & Plag1 & Core & 0.42 & 0.93 & 0.30 & 0.05 & 0.26 & 0.03 & 0.04 & 0.01 & 3.06 & 184 & 2.97 & 260.7 & 0.31 & 0.36 & GbVn \\
\hline Van7-78-36 & Plag2 & Ints & 0.38 & 0.85 & 0.32 & 0.08 & 0.28 & 0.02 & 0.04 & 0.01 & 2.67 & 205 & 0.49 & 297.9 & 0.39 & 0.64 & $\mathrm{GbVn}$ \\
\hline Van7-78-36 & Plag2 & IntsR & & & & & & & & & 2.94 & 201 & 0.91 & 286.9 & 0.21 & 0.11 & $\mathrm{GbVn}$ \\
\hline Van7-78-41 & Plag1 & Ints & & & & & & & & & 0.85 & 29 & 1.45 & 9.9 & 0.20 & 0.62 & \\
\hline Van7-96-09 & Plag1 & Ints & 0.17 & 0.52 & 0.38 & 0.15 & 0.34 & 0.07 & 0.07 & 0.06 & 2.58 & 121 & 2.45 & 58.4 & 0.37 & 0.42 & PyxVn \\
\hline Van7-96-09 & Plag2 & Ints & 0.19 & 0.55 & 0.34 & 0.08 & 0.17 & 0.01 & 0.03 & 0.01 & 0.88 & 62 & 1.20 & 70.9 & 0.28 & 0.49 & PyxVn \\
\hline Van7-96-14 & Plag1 & Ints & 0.08 & 0.30 & 0.45 & 0.16 & 0.34 & 0.25 & 0.10 & 0.07 & 1.83 & 121 & 1.58 & 31.0 & 0.25 & 0.41 & PyxVn \\
\hline Van7-96-14 & Plag3 & Core & 0.06 & 0.38 & 0.59 & 0.15 & 0.41 & 0.09 & 0.08 & 0.04 & 1.64 & 162 & 1.05 & 22.1 & 0.56 & 0.36 & PyxVn \\
\hline Van7-96-14 & Plag3 & Rim & 0.05 & 0.38 & 0.52 & 0.27 & 0.38 & 0.10 & 0.08 & 0.12 & 1.33 & 112 & 1.40 & 146.3 & 0.46 & 0.50 & PyxVn \\
\hline Van7-96-14 & Plag4 & Core & 0.11 & 0.61 & 0.55 & 0.21 & 0.38 & 0.17 & 0.11 & 0.13 & 2.01 & 244 & 1.33 & 22.2 & 0.56 & 0.30 & PyxVn \\
\hline Van7-96-14 & Plag4 & Rim & 0.07 & 0.49 & 0.44 & 0.21 & 0.31 & 0.14 & 0.16 & 0.04 & 1.74 & 207 & 1.53 & 15.7 & 0.57 & 0.30 & PyxVn \\
\hline Van7-96-14 & Plag7 & Ints & 0.06 & 0.36 & 0.52 & 0.14 & 0.38 & 0.07 & 0.08 & 0.03 & & & & & & & PyxVn \\
\hline Van7-96-15 & Plag2 & Ints & 0.08 & 0.57 & 0.54 & 0.09 & 0.41 & 0.05 & 0.09 & 0.04 & 2.19 & 215 & 1.66 & 33.0 & 0.75 & 0.39 & PyxVn \\
\hline Van7-96-15 & Plag3 & Ints & 0.07 & 0.36 & 0.31 & 0.09 & 0.27 & 0.05 & 0.10 & 0.03 & 1.51 & 99 & 1.77 & 24.5 & 0.53 & 0.36 & PyxVn \\
\hline Van7-96-15 & Plag4 & Ints & 0.06 & 0.39 & 0.67 & 0.27 & 0.26 & 0.44 & 0.29 & 0.14 & & & & & & & PyxVn \\
\hline Van7-96-16 & Plag1 & Ints & 0.04 & 0.37 & 0.63 & 0.27 & 0.24 & 0.07 & 0.08 & 0.15 & 1.71 & 128 & 1.49 & 150.9 & 0.65 & 0.29 & PyxVn \\
\hline Van7-96-16 & Plag3 & Ints & 0.07 & 0.53 & 0.48 & 0.06 & 0.23 & 0.04 & 0.06 & 0.02 & 0.95 & 59 & 1.15 & 36.7 & 0.24 & 0.22 & PyxVn \\
\hline Van7-96-18 & Plag1 & Ints & 0.12 & 0.41 & 0.35 & 0.11 & 0.21 & 0.08 & 0.08 & 0.02 & 2.36 & 170 & 6.39 & 30.9 & 0.45 & 0.88 & PyxVn \\
\hline Van7-96-19 & Plag1 & Ints & 0.12 & 0.42 & 0.36 & 0.13 & 0.35 & 0.13 & 0.10 & 0.03 & 2.63 & 173 & 7.58 & 29.9 & 0.33 & 0.64 & NrMat \\
\hline Van7-96-19 & Plag3 & Ints & 0.33 & 1.03 & 0.31 & 0.13 & 0.42 & 0.02 & 0.07 & 0.04 & 2.69 & 141 & 4.54 & 145.6 & 0.25 & 0.48 & PyxVn \\
\hline Van7-96-21 & Plag1 & Ints & 0.55 & 1.68 & 0.91 & 0.13 & 0.31 & 0.14 & 0.05 & 0.09 & 2.53 & 194 & 0.93 & 106.2 & 0.49 & 0.27 & PyxVn \\
\hline Van7-96-21 & Plag2 & Ints & 0.58 & 1.66 & 0.86 & 0.13 & 0.28 & 0.04 & 0.29 & 0.06 & 2.36 & 188 & 1.06 & 84.4 & 0.45 & 0.48 & PyxVn \\
\hline Van7-96-21 & Plag3 & Ints & 0.69 & 1.75 & 0.78 & 0.20 & 0.32 & 0.04 & 0.07 & 0.02 & 1.36 & 176 & 0.77 & 75.6 & 0.25 & 0.21 & PyxVn \\
\hline
\end{tabular}


Table 5.11: Plagioclase trace elements Cont.

\begin{tabular}{|c|c|c|c|c|c|c|c|c|c|c|c|c|c|c|c|c|c|}
\hline Sample & Grain & Type $^{a}$ & $\mathrm{La}$ & $\mathrm{Ce}$ & $\mathrm{Nd}$ & $\mathrm{Sm}$ & $\mathrm{Eu}$ & Dy & $\mathrm{Er}$ & $\mathrm{Yb}$ & $\mathrm{Na}_{2} \mathrm{O}$ & $\mathrm{Ti}$ & $\mathrm{Cr}$ & $\mathrm{Sr}$ & $\mathrm{Y}$ & $\mathrm{Zr}$ & Notes $^{b}$ \\
\hline Van7-96-21 & Plag4 & Ints & 0.46 & 1.61 & 0.92 & 0.26 & 0.22 & 0.10 & 0.07 & 0.04 & & & & & & & PyxVn \\
\hline Van7-96-21 & Plag5 & Ints & 0.47 & 1.81 & 1.00 & 0.22 & 0.26 & 0.07 & 0.06 & 0.01 & & & & & & & PyxVn \\
\hline Van7-96-21 & Plag6 & Symp & 0.30 & 1.24 & 0.63 & 0.20 & 0.26 & 0.02 & 0.16 & 0.08 & & & & & & & PyxVn \\
\hline
\end{tabular}


Table 5.12: Trace element concentrations in Opx by ion probe, in ppm.

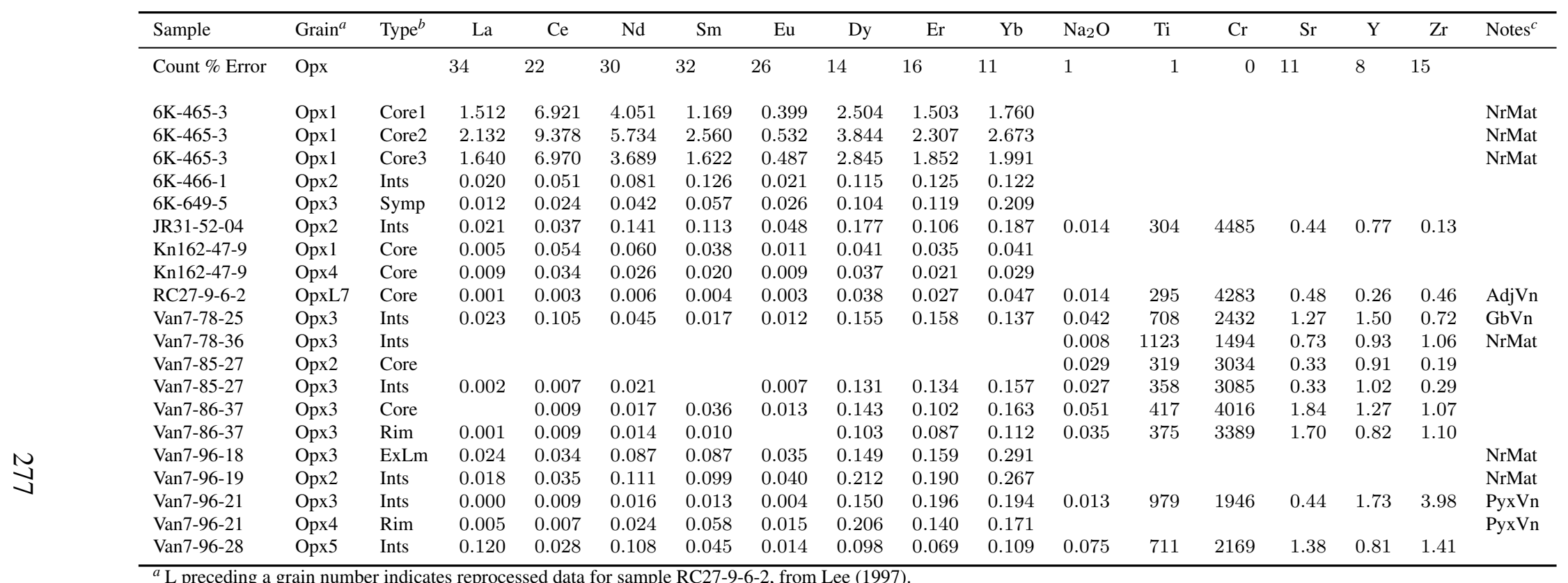

${ }^{b}$ Ints refers to interstitial grain, $<1 \mathrm{~mm}$ diameter; Symp refers to symplectite of Cpx with Sp and Opx; ExLm refers to exsolution lamellae in Cpx.

${ }^{c}$ Dep, Trans and Enr are depleted, transitional and enriched zones in cryptically metasomatized samples; GbVn refers to a gabbroic vein, PyxVn to a pyroxenite vein, CpxVn to a clinopyroxenite vein, and $\mathrm{OpxVn}$ to an orthopyroxenite vein; $\mathrm{Adj} \mathrm{Vn}$ is adjacent to a vein, NrMat is $<5 \mathrm{~cm}$ from a vein and FarMat is $>5 \mathrm{~cm}$ from vein. 
Table 5.13: Ion probe trace element concentrations in alteration phases, in ppm.

\begin{tabular}{|c|c|c|c|c|c|c|c|c|c|c|c|c|c|c|c|c|c|}
\hline Sample & Grain $^{a}$ & Type & $\mathrm{La}$ & $\mathrm{Ce}$ & $\mathrm{Nd}$ & $\mathrm{Sm}$ & $\mathrm{Eu}$ & Dy & $\mathrm{Er}$ & $\mathrm{Yb}$ & $\mathrm{Na}_{2} \mathrm{O}$ & $\mathrm{Ti}$ & $\mathrm{Cr}$ & $\mathrm{Sr}$ & $\bar{Y}$ & $\mathrm{Zr}$ & Notes $^{b}$ \\
\hline $6 \mathrm{~K}-465-3$ & Actin2 & Core & 1.18 & 9.80 & 19.69 & 10.56 & 2.13 & 17.30 & 8.79 & 8.17 & 0.58 & 5024 & 214 & 10.88 & 371.31 & 311.60 & $\mathrm{GbVn}$ \\
\hline $6 \mathrm{~K}-465-3$ & Actin2 & Rim & 2.73 & 20.13 & 40.84 & 23.06 & 4.33 & 39.15 & 20.49 & 18.47 & 0.60 & 2084 & 222 & 8.83 & 313.77 & 177.35 & GbVn \\
\hline $6 \mathrm{~K}-465-3$ & Actin3 & Core & 2.28 & 19.01 & 35.00 & 20.24 & 4.50 & 33.41 & 17.84 & 16.71 & 0.34 & 1261 & 193 & 6.53 & 160.52 & 80.15 & $\mathrm{GbVn}$ \\
\hline $6 \mathrm{~K}-465-3$ & Actin3 & Rim & 2.10 & 17.44 & 31.42 & 16.48 & 3.76 & 29.78 & 15.43 & 14.81 & 0.76 & 2496 & 196 & 9.98 & 369.62 & 235.58 & GbVn \\
\hline $6 \mathrm{~K}-465-3$ & Actin4 & Core & 1.12 & 9.85 & 18.89 & 11.09 & 1.98 & 19.26 & 9.45 & 9.56 & 0.30 & 1588 & 204 & 6.14 & 155.43 & 82.48 & GbVn \\
\hline $6 \mathrm{~K}-465-3$ & Actin4 & Rim & 2.06 & 14.90 & 28.78 & 16.44 & 3.21 & 29.35 & 14.70 & 14.82 & 0.79 & 2759 & 208 & 11.01 & 373.55 & 262.25 & GbVn \\
\hline $6 \mathrm{~K}-465-3$ & Actin5 & Core & 5.01 & 38.69 & 69.99 & 35.72 & 7.94 & 52.37 & 24.78 & 26.41 & 0.75 & 1532 & 135 & 6.21 & 326.75 & 298.62 & GbVn \\
\hline $6 \mathrm{~K}-465-3$ & Actin8 & Core & 4.79 & 23.94 & 21.79 & 7.34 & 2.73 & 8.45 & 5.05 & 5.38 & 0.85 & 751 & 2350 & 4.53 & 39.02 & 49.69 & NrMat \\
\hline JR31-52-04 & Amph5 & Core & 0.27 & 0.26 & 0.49 & 0.77 & 0.20 & 1.40 & 1.05 & 0.96 & 0.54 & 921 & 7545 & 2.20 & 4.46 & 0.24 & \\
\hline JR31-52-04 & Amph5 & Rim & 0.08 & 0.08 & 0.37 & 0.39 & 0.12 & 0.93 & 0.59 & 0.61 & & & & & & & \\
\hline Van7-85-32 & Amph1 & Rim & 0.18 & 0.40 & 0.24 & 0.25 & 0.14 & 1.30 & 0.78 & 0.84 & 1.78 & 1235 & 6063 & 8.32 & 11.01 & 1.28 & \\
\hline Van7-85-32 & Amph2 & Core & 0.62 & 1.79 & 0.72 & 0.43 & 0.23 & 1.67 & 1.15 & 1.00 & 1.36 & 1004 & 5179 & 8.40 & 12.66 & 0.98 & \\
\hline Van7-85-32 & Amph2 & $\operatorname{Rim}$ & 0.31 & 0.88 & 0.34 & 0.34 & 0.14 & 1.52 & 1.01 & 0.88 & 1.41 & 1251 & 4916 & 8.01 & 8.34 & 0.91 & \\
\hline RC27-9-6-2 & SerpL1 & & 0.01 & 0.05 & 0.12 & 0.08 & 0.02 & 0.15 & 0.08 & 0.09 & & & & & & & InCpxL6 \\
\hline RC27-9-6-2 & SerpL2 & & 0.01 & 0.03 & 0.10 & 0.05 & 0.02 & 0.12 & 0.06 & 0.07 & & & & & & & InCpxL6 \\
\hline RC27-9-6-2 & SerpL3 & & 0.001 & 0.005 & 0.013 & 0.013 & 0.001 & 0.010 & 0.007 & 0.010 & & & & & & & AfterOliv \\
\hline RC27-9-6-2 & SerpL4 & & 0.002 & 0.004 & 0.007 & 0.005 & 0.003 & 0.007 & 0.013 & 0.006 & & & & & & & AfterOliv \\
\hline RC27-9-6-2 & SerpL5 & & 0.003 & 0.007 & 0.011 & 0.012 & 0.005 & 0.010 & 0.011 & 0.009 & & & & & & & AfterOpx \\
\hline
\end{tabular}

${ }^{b} \mathrm{GbVn}$ is a gabbroic vein; NrMat is $<5 \mathrm{~cm}$ from a vein. 
Table 5.14: Percent deviation among repeat measurements of the KH1 standard

\begin{tabular}{|c|c|c|c|c|c|c|c|c|c|}
\hline Date (ymd) & $\mathrm{n}^{a}$ & $\mathrm{La}$ & $\mathrm{Ce}$ & $\mathrm{Nd}$ & $\mathrm{Sm}$ & $\overline{\mathrm{Eu}}$ & Dy & $\mathrm{Er}$ & $\mathrm{Yb}$ \\
\hline $2001 / 08 / 21$ & 2 & 6 & 8 & 12 & 3 & 5 & 11 & 3 & 14 \\
\hline $2001 / 08 / 30$ & 0 & 2 & 1 & & 2 & 2 & & ( & 0 \\
\hline $2002 / 01 / 15$ & 2 & 6 & 2 & & 7 & 4 & 0 & 18 & 4 \\
\hline $2002 / 01 / 22$ & 2 & 3 & 3 & 2 & 9 & 4 & 5 & 4 & 3 \\
\hline $2002 / 01 / 24$ & 2 & ? & 3 & & 6 & 1 & 3 & 2 & 6 \\
\hline $2004 / 01 / 27$ & 2 & 4 & 3 & 1 & 5 & 7 & 4 & 13 & 4 \\
\hline $2003 / 0$ & 4 & 30 & 11 & 10 & 12 & 12 & 14 & 12 & 13 \\
\hline 2003/1 & 2 & 1 & 7 & 4 & 18 & & 14 & 3 & 6 \\
\hline 2004/( & 2 & 3 & 2 & 4 & 5 & 8 & 6 & 13 & 5 \\
\hline 2004/ & 2 & 6 & 10 & ? & 1 & 2 & & 1 & 8 \\
\hline 2004 & 2 & ? & 7 & 1 & $?$ & 2 & 12 & 2 & 2 \\
\hline 2004/ & 4 & 7 & 4 & 6 & 10 & 2 & & 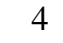 & 6 \\
\hline 2004/ & 2 & 4 & 1 & & 10 & 9 & 11 & 13 & 6 \\
\hline $2004 / 08 / 14$ & 3 & ? & 1 & 2 & 8 & 3 & 9 & 11 & 16 \\
\hline $2005 / 01 / 29$ & 2 & 3 & 3 & 10 & 5 & 3 & 2 & 0 & 2 \\
\hline $2005 / 02 / 07$ & $J$ & 2 & 4 & 2 & 5 & 3 & & 5 & 3 \\
\hline $2005 / 02 / 08$ & ? & 14 & 4 & 0 & 1 & 2 & 2 & 9 & 9 \\
\hline $2005 / 03 / 30$ & 3 & 7 & 4 & 5 & 8 & 4 & 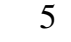 & 12 & 14 \\
\hline $2005 / 05 / 31$ & 4 & 11 & 10 & 8 & 6 & 17 & 10 & 9 & 24 \\
\hline $2005 / 06 / 01$ & 2 & 5 & 9 & 17 & 14 & 3 & 15 & 12 & 1 \\
\hline $2005 / 06 / 02$ & 4 & 7 & 7 & 3 & 3 & 5 & 6 & 9 & 9 \\
\hline $2005 / 06 / 28$ & 2 & 4 & 2 & 7 & 6 & . & 1 & 5 & 7 \\
\hline $2005 / 06 / 29$ & 3 & 26 & 15 & 3 & 20 & 15 & 22 & 22 & 14 \\
\hline $2005 / 06 / 30$ & 3 & 8 & 2 & 4 & 5 & 11 & . & 6 & 6 \\
\hline $2006 / 01 / 10$ & 6 & 3 & 6 & 9 & 10 & 9 & 14 & 20 & 16 \\
\hline 2006/01/11 & 8 & 10 & 8 & 6 & 9 & 10 & 15 & 16 & 13 \\
\hline 2006/01/12 & 8 & 7 & 7 & 8 & 10 & 11 & 15 & 11 & 18 \\
\hline $2006 / 01 / 13$ & 7 & 11 & 9 & 6 & 10 & 5 & 10 & 13 & 7 \\
\hline $2006 / 02 / 17$ & 2 & 30 & 1 & 10 & 3 & 16 & 13 & 2 & 0 \\
\hline $2006 / 06 / 21$ & 8 & 7 & 10 & 12 & 8 & 12 & 6 & 13 & 17 \\
\hline $2006 / 09 / 25$ & 9 & 9 & 7 & 9 & 10 & 10 & 14 & 16 & 14 \\
\hline $2006 / 09 / 26$ & 6 & 12 & 9 & 10 & 15 & 10 & 12 & 14 & 10 \\
\hline $2006 / 09 / 27$ & 4 & 14 & 4 & 11 & 4 & 10 & 9 & 26 & 19 \\
\hline $2006 / 09 / 29$ & 10 & 12 & 7 & 10 & 25 & 20 & 11 & 23 & 18 \\
\hline Average & & 8 & 6 & 6 & 8 & 7 & 9 & 10 & 0 \\
\hline
\end{tabular}

${ }^{a}$ Number of analysis. 
Table 5.15: Percent deviation among daily repeat analyses of the KL2G standard

\begin{tabular}{lrrrrrrr}
\hline Date (ymd) & $\mathrm{n}^{a}$ & $\mathrm{Na} 2 \mathrm{O}$ & $\mathrm{Ti}$ & $\mathrm{Cr}$ & $\mathrm{Sr}$ & $\mathrm{Y}$ & $\mathrm{Zr}$ \\
\hline $2001 / 08 / 22$ & 2 & 12 & 7 & 7 & 8 & 4 & 3 \\
$2002 / 01 / 28$ & 2 & 4 & 2 & & 3 & 1 & 0 \\
$2002 / 01 / 29$ & 2 & 2 & 2 & & 2 & 3 & 2 \\
$2003 / 12 / 13$ & 2 & 1 & 0 & 1 & 1 & 2 & 2 \\
$2004 / 02 / 12$ & 4 & 17 & 9 & 11 & 10 & 11 & 10 \\
$2004 / 02 / 17$ & 2 & 7 & 6 & 7 & 7 & 4 & 7 \\
$2004 / 04 / 14$ & 2 & 1 & 0 & 0 & 1 & 3 & 2 \\
$2004 / 05 / 07$ & 3 & 5 & 5 & 4 & 5 & 4 & 5 \\
$2004 / 09 / 17$ & 3 & 6 & 2 & 5 & 4 & 5 & 6 \\
$2004 / 11 / 26$ & 2 & 4 & 0 & 1 & 0 & 1 & 0 \\
$2005 / 01 / 29$ & 2 & 2 & 2 & 1 & 3 & 0 & 2 \\
$2005 / 02 / 09$ & 3 & 2 & 1 & 3 & 2 & 2 & 3 \\
$2005 / 03 / 28$ & 4 & 6 & 3 & 5 & 6 & 5 & 4 \\
$2005 / 03 / 29$ & 3 & 1 & 4 & 2 & 3 & 4 & 5 \\
$2005 / 07 / 01$ & 4 & 6 & 0 & 2 & 1 & 3 & 3 \\
$2005 / 07 / 29$ & 5 & 9 & 4 & 9 & 7 & 8 & 5 \\
$2006 / 01 / 09$ & 4 & 2 & 3 & 1 & 3 & 5 & 3 \\
$2006 / 02 / 16$ & 6 & 7 & 3 & 7 & 9 & 6 & 7 \\
$2006 / 02 / 17$ & 4 & 3 & 1 & 1 & 2 & 3 & 3 \\
$2006 / 09 / 28$ & 4 & 9 & 4 & 8 & 7 & 8 & 8 \\
Average & & 5 & 3 & 4 & 4 & 4 & 4 \\
\hline
\end{tabular}

${ }^{a}$ Number of analysis. 
Table 5.D1: Major and trace element compositions of unusual phases in Sample 6K-465-3.

\begin{tabular}{|c|c|c|c|c|c|c|c|c|c|c|}
\hline $\begin{array}{l}\text { Grain }^{a} \\
\text { Type }^{b} \\
\text { Notes }^{c}\end{array}$ & $\begin{array}{l}\text { Ilm1 } \\
\text { Core } \\
\text { GbVn }\end{array}$ & $\begin{array}{l}\mathrm{Ilm} 1 \\
\mathrm{Rim} \\
\mathrm{GbVn}\end{array}$ & $\begin{array}{l}\text { Apat2 } \\
\text { Ints } \\
\text { GbVn }\end{array}$ & $\begin{array}{l}\text { Kaer1 } \\
\text { Ints } \\
\text { KtVn }\end{array}$ & $\begin{array}{c}\text { PlagK1A } \\
\text { Ints } \\
\text { KtVn }\end{array}$ & $\begin{array}{c}\text { PlagK1B } \\
\text { Ints } \\
\text { KtVn }\end{array}$ & $\begin{array}{l}\text { RutK1 } \\
\text { Ints } \\
\text { KtVn }\end{array}$ & $\begin{array}{c}\text { ApatK1 } \\
\text { Ints } \\
\text { KtVn }\end{array}$ & $\begin{array}{c}\text { Cpx7 } \\
\text { Rim1 } \\
\text { NrMat }\end{array}$ & $\begin{array}{l}\mathrm{P} \\
\mathrm{E}\end{array}$ \\
\hline \multicolumn{11}{|c|}{ Major element oxides (Wt\%) } \\
\hline Pts & 2 & 3 & 2 & 6 & 8 & 8 & 6 & 5 & & \\
\hline $\mathrm{SiO} 2$ & 0.00 & 0.00 & 0.18 & 42.97 & 56.65 & 56.33 & 0.00 & 0.11 & & \\
\hline $\mathrm{TiO} 2$ & 53.79 & 53.90 & & 5.27 & & & 98.09 & & & \\
\hline $\mathrm{A} 12 \mathrm{O} 3$ & 0.00 & 0.00 & 0.00 & 11.78 & 26.97 & 27.26 & 0.01 & 0.01 & & \\
\hline $\mathrm{Cr} 2 \mathrm{O} 3$ & 0.10 & 0.08 & & 0.71 & & & 0.74 & & & \\
\hline $\mathrm{Fe} 2 \mathrm{O} 3$ & 0.00 & 0.00 & & & & & 0.00 & & & \\
\hline $\mathrm{FeO}$ & 40.53 & 41.34 & 0.13 & 4.20 & 0.07 & 0.09 & 0.09 & 0.08 & & \\
\hline $\mathrm{MnO}$ & 0.68 & 1.34 & 0.06 & 0.05 & & & 0.01 & 0.02 & & \\
\hline $\mathrm{MgO}$ & 3.82 & 2.07 & 0.04 & 16.62 & 0.00 & 0.35 & 0.00 & 0.11 & & \\
\hline $\mathrm{NiO}$ & 0.05 & 0.02 & & & & & 0.03 & & & \\
\hline \multicolumn{11}{|l|}{$\mathrm{ZnO}$} \\
\hline $\mathrm{CaO}$ & 0.00 & 0.00 & 56.01 & 11.77 & 8.87 & 9.16 & 0.06 & 55.99 & & \\
\hline $\mathrm{Na} 2 \mathrm{O}$ & & & 0.01 & 2.97 & 6.34 & 6.08 & & 0.00 & & \\
\hline $\mathrm{K} 2 \mathrm{O}$ & & & 0.00 & 0.51 & 0.16 & 0.06 & & 0.00 & & \\
\hline P2O5 & & & 42.14 & & & & & 42.14 & & \\
\hline $\mathrm{Cl}$ & & & 0.44 & & & & & 0.71 & & \\
\hline $\mathrm{F}$ & & & 1.94 & & & & & 1.41 & & \\
\hline Total & 98.97 & 98.76 & 100.95 & 96.84 & 99.07 & 99.33 & 99.05 & 100.57 & & \\
\hline Plag An $\%$ & & & & & 43.21 & 45.29 & & & & \\
\hline \multicolumn{11}{|c|}{ Trace elements (ppm) } \\
\hline $\mathrm{La}$ & & & 57051 & 6.91 & 2.64 & 2.29 & 246 & 93224 & 4.33 & 3.85 \\
\hline $\mathrm{Ce}$ & & & 225756 & 40.99 & 5.20 & 4.76 & 633 & 299119 & 25.52 & 8.16 \\
\hline $\mathrm{Nd}$ & & & 196323 & 49.06 & 1.15 & 1.58 & 78 & 199727 & 28.28 & 2.64 \\
\hline $\mathrm{Sm}$ & & & 67559 & 19.16 & 0.14 & 0.12 & & 56328 & 9.57 & 0.72 \\
\hline $\mathrm{Eu}$ & & & 17484 & 4.51 & 1.15 & 0.95 & 12 & 10851 & 2.62 & 1.63 \\
\hline Dy & & & 60326 & 26.35 & 0.08 & 0.07 & 15 & 46743 & 12.38 & 0.36 \\
\hline $\mathrm{Er}$ & & & 26201 & 13.80 & 0.09 & 0.10 & 10 & 19338 & 7.10 & 0.49 \\
\hline $\mathrm{Yb}$ & & & 23713 & 10.61 & 0.03 & 0.03 & 58 & 16184 & 7.50 & 0.28 \\
\hline $\mathrm{Na} 2 \mathrm{O}$ & & & & 3.35 & 4.83 & 4.45 & & & 0.47 & 4.37 \\
\hline $\mathrm{Ti}$ & & & & 36269 & 256 & 229 & & & 2067 & 428 \\
\hline $\mathrm{Cr}$ & & & 204 & 5730 & 1.25 & 1.29 & & 575 & 3501 & 5100 \\
\hline $\mathrm{Sr}$ & & & 83355 & 31.02 & 89.29 & 76.86 & 3210 & 86244 & 4.60 & 68.32 \\
\hline $\mathrm{Y}$ & & & 485488 & 156 & 0.27 & 0.60 & 1049 & 362111 & 70.91 & 1.64 \\
\hline $\mathrm{Zr}$ & & & 11675 & 270 & 0.14 & 0.75 & & 9155 & 94.31 & 1.79 \\
\hline
\end{tabular}


Table 5.D1: 6K-465-3 Cont.

\begin{tabular}{|c|c|c|c|c|c|c|c|c|c|c|}
\hline $\begin{array}{l}\text { Grain } \\
\text { Type } \\
\text { Notes }\end{array}$ & $\begin{array}{l}\text { Cpx12 } \\
\text { Core2 } \\
\text { NrMat }\end{array}$ & $\begin{array}{l}\text { Plag12 } \\
\text { ExLm } \\
\text { NrMat }\end{array}$ & $\begin{array}{l}\text { Oliv12 } \\
\text { ExLm } \\
\text { NrMat }\end{array}$ & $\begin{array}{l}\text { Spin12 } \\
\text { ExLm } \\
\text { NrMat }\end{array}$ & $\begin{array}{c}\text { Cpx14 } \\
\text { Core } \\
\text { NrMat }\end{array}$ & $\begin{array}{c}\text { Plag14C } \\
\text { ExLm } \\
\text { NrMat }\end{array}$ & $\begin{array}{c}\text { Cpx14 } \\
\text { Rim } \\
\text { NrMat }\end{array}$ & $\begin{array}{c}\text { Plag14R } \\
\text { ExLm } \\
\text { NrMat }\end{array}$ & $\begin{array}{c}\text { Cpx15 } \\
\text { Core } \\
\text { NrMat }\end{array}$ & $\begin{array}{l}\text { Plag15 } \\
\text { ExLm } \\
\text { NrMat }\end{array}$ \\
\hline \multicolumn{11}{|c|}{ Major element oxides (Wt\%) } \\
\hline Pts & 19 & 6 & 7 & 1 & 17 & 1 & 8 & 1 & 18 & 2 \\
\hline $\mathrm{SiO} 2$ & 53.10 & 55.27 & 40.78 & 0.04 & 51.89 & 55.21 & 53.44 & 55.33 & 53.16 & 53.26 \\
\hline $\mathrm{TiO} 2$ & 0.42 & & & 0.63 & 0.42 & & 0.37 & & 0.33 & \\
\hline $\mathrm{A} 12 \mathrm{O} 3$ & 2.86 & 27.71 & 0.00 & 21.26 & 3.26 & 27.20 & 2.11 & 27.91 & 2.78 & 29.29 \\
\hline $\mathrm{Cr} 2 \mathrm{O} 3$ & 1.04 & & & 42.17 & 2.18 & & 0.98 & & 1.01 & \\
\hline $\mathrm{Fe} 2 \mathrm{O} 3$ & & & & 1.97 & & & & & & \\
\hline $\mathrm{FeO}$ & 2.72 & 0.16 & 11.42 & 26.52 & 3.10 & 0.13 & 2.63 & 0.10 & 2.64 & 0.17 \\
\hline $\mathrm{MnO}$ & 0.08 & & & 0.39 & 0.08 & & 0.07 & & 0.07 & \\
\hline $\mathrm{MgO}$ & 16.56 & 0.04 & 46.77 & 5.36 & 16.35 & 0.86 & 16.54 & 0.02 & 16.52 & 0.01 \\
\hline $\mathrm{NiO}$ & & & & 0.12 & & & & & & \\
\hline $\mathrm{ZnO}$ & & & & 0.43 & & & & & & \\
\hline $\mathrm{CaO}$ & 22.24 & 10.10 & 0.06 & 0.33 & 21.59 & 9.65 & 22.78 & 9.94 & 22.72 & 11.82 \\
\hline $\mathrm{Na} 2 \mathrm{O}$ & 0.63 & 5.86 & & & 0.59 & 5.68 & 0.49 & 5.92 & 0.49 & 4.80 \\
\hline \multicolumn{11}{|l|}{$\mathrm{K} 2 \mathrm{O}$} \\
\hline \multicolumn{11}{|l|}{$\mathrm{P} 2 \mathrm{O} 5$} \\
\hline \multirow{2}{*}{\multicolumn{11}{|c|}{$\begin{array}{l}\mathrm{Cl} \\
\mathrm{F}\end{array}$}} \\
\hline & & & & & & & & & & \\
\hline Total & 99.66 & 99.16 & 99.04 & 99.21 & 99.47 & 98.73 & 99.41 & 99.22 & 99.73 & 99.35 \\
\hline Plag An\% & & 48.80 & & & & 48.42 & & 48.13 & & 57.67 \\
\hline \multicolumn{11}{|c|}{ Trace elements (ppm) } \\
\hline $\mathrm{La}$ & 3.92 & 4.96 & & & & & & & & \\
\hline $\mathrm{Ce}$ & 18.87 & 9.76 & & & & & & & & \\
\hline $\mathrm{Nd}$ & 15.68 & 2.71 & & & & & & & & \\
\hline Sm & 5.81 & 0.78 & & & & & & & & \\
\hline $\mathrm{Eu}$ & 0.92 & 1.03 & & & & & & & & \\
\hline Dy & 6.16 & 0.56 & & & & & & & & \\
\hline $\mathrm{Er}$ & 4.37 & 0.46 & & & & & & & & \\
\hline $\mathrm{Yb}$ & 3.84 & 0.33 & & & & & & & & \\
\hline $\mathrm{Na} 2 \mathrm{O}$ & 0.53 & 3.77 & 0.12 & & & & & & & \\
\hline $\mathrm{Ti}$ & 2194 & 343 & 54 & & & & & & & \\
\hline $\mathrm{Cr}$ & 5235 & 413 & 220 & & & & & & & \\
\hline $\mathrm{Sr}$ & 1.51 & 34.38 & 1.83 & & & & & & & \\
\hline Y & 58.05 & 5.29 & 0.16 & & & & & & & \\
\hline $\mathrm{Zr}$ & 103 & 8.82 & 0.32 & & & & & & & \\
\hline
\end{tabular}

